Tese apresentada à Escola Politécnica da Universidade de São Paulo para obtenção do título de Doutor em Ciências - Programa de Engenharia Metalúrgica e de Materiais 


\section{ANÁLISE NUMÉRICA E EXPERIMENTAL DE UM AÇO TRIP SUBMETIDO AOS PROCESSOS DE ESTAMPAGEM A QUENTE E TÊMPERA E PARTIÇÃO (Q\&P)}

Tese apresentada à Escola Politécnica da Universidade de São Paulo para obtenção do título de Doutor em Ciências - Programa de Engenharia Metalúrgica e de Materiais

Área de Concentração:

Engenharia Metalúrgica e de Materiais

Orientador:

Prof. Dr. André Paulo Tschiptschin

SÃo PAULO 


\section{FICHA CATALOGRÁFICA}

Este exemplar foi revisado e corrigido em relação à versão original, sob responsabilidade única do autor e com anuência de seu orientador.

São Paulo, de de

Assinatura do autor:

Assinatura do orientador:

Ariza Echeverri, Edwan Anderson

Análise numérica e experimental de um aço TRIP submetido aos processos de estampagem a quente e têmpera e partição (Q\&P) / E.A. Ariza Echeverri.--versão corr.--São Paulo, 2017.

218 p.

Tese (Doutorado) - Escola Politécnica da Universidade de São Paulo. Departamento de Engenharia Metalúrgica e de Materiais.

1. Têmpera e partição 2. Estampagem a quente 3. Simulação física e numérica 4. Aço TRIP. Universidade de São

Paulo. Escola Politécnica. Departamento de Engenharia Metalúrgica e de Materiais II. t. 


\section{DEDICATÓRIA}

A:

Isaac Ariza Arango

Juliana Gómez Mejía

María Emma Echeverri L. 


\section{AGRADECIMENTOS}

Meu agradecimento ao Professor André Paulo Tschiptschin é imensurável. Os conhecimentos transmitidos, a paciência, entusiasmo, o apoio e a confiança depositada em mim e em meu trabalho desde o início deste processo foram indispensáveis para a realização desta pesquisa. Um sincero “MUITÍSSIMO OBRIGADO!” prezado Professor André.

Da mesma forma estou muito agradecido com o Professor Hélio Goldenstein por me transmitir seu amor pelo conhecimento, por me fazer perguntas que eu não tinha considerado nos resultados obtidos, por me empolgar a fazer novas descobertas e análises, tudo sempre em meio de papos descontraídos. Professor Hélio, admiro muito sua simplicidade, o grande amor pelo conhecimento e, o respeito e bom trato a seus alunos e demais pessoas que te rodeiam.

Ao meu grande amigo e colega Arthur Seiji Nishikawa. Muito obrigado pelas discussões constantes dos resultados e toda a contribuição, suporte e apoio durante a realização desta pesquisa. Sua empolgação, alegria, paixão pelo aprendizado, simplicidade e gentileza são motivo de admiração e profundo agradecimento.

Aos professores do Departamento de Engenharia Metalúrgica e de Materiais - PMT - USP: Dr. Cesar Roberto Farias Azevedo e Dr. Marcelo Aquino Martorano, por seus ensinamentos, conselhos e amizade.

Aos companheiros e amigos do laboratório e do PMT: Leidy Hernández Buitrago, Alan Barros de Almeida, Adriano Alex Almeida, Daniel Rodrigues Jr., Danny Centeno, Mario González, André Kraszczuk, Guilherme Faria, Luis Varela, Marcelo Rojas, Wilmar Calderón, Duberney Hincapie e Rafael Rocha. Obrigado pela ajuda, cooperação, as discussões acadêmicas e por fazer do espaço do laboratório um ambiente tão agradável.

A Luis Felipe Perilla López e Felipe Jaime Dávila pela ajuda na parte experimental e análise dos resultados.

Ao Laboratório Nacional de Nanotecnologia - LNNano - pelo apoio técnico e por permitir o uso da linha XTMS acoplada ao síncrotron, em especial ao Leonardo Wu pelo apoio durante as análises.

Ao Laboratório de Fenômenos de Superfície - LFS - por facilitar o uso do triboindentador, em especial ao Manuel Alberteris pelo suporte nas medições.

Ao Verissimo Silva dos Santos pela ajuda com as análises por MEV-FEG.

À CAPES, à CNPq (Projeto: 235297/2014-3 PVE) e à FAPESP (Processo: 2014/11793-4). 
Special thanks to Dr. Edgar Lara-Curzio for facilitating the triboindenter and SEM and to Dr. Kinga A. Unocic for the STEM measurements at Oak Ridge National Laboratory (ORNL). I would like to thanks Prof. Suresh Surdasam Babu for his patience and teachings during my stay at the University of Tennessee and at ORNL. It was a real challenge and a great experience to share with his research group.

To Dorothy W. Coffey for her assistance with the FIB (Focus Ion Milling) specimen preparation.

My sincerest thanks to Dr. Jonathan D. Poplawsky and Dr. Wei Guo for many valuable inputs towards operating 3D - LEAP effectively for the best results.

A la preciosa: Juliana Gómez Mejía. Las palabras, los besos y los abrazos no son suficientes para expresar mi profundo agradecimiento. Por el apoyo incondicional, la fuerza, las palabras de ánimo, nuestros momentos juntos, los viajes, las conversas amenas y por todo el amor que me has brindado durante todo este tiempo, GRACIAS TOTALES. 


\section{RESUMO}

O desenvolvimento de métodos de simulação física e numérica tem criado novas possibilidades de otimização dos processos relacionados à estampagem com inclusão de processos industriais reais. Portanto, recorrendo à aplicação destes métodos de análise, é possível avaliar a transformação mecânica e as transformações de fase que ocorrem no material e prever as interações entre as propriedades dos materiais no processo de conformação, o comportamento constitutivo do material, as variáveis de otimização do processo, bem como a previsão das tensões e deformações a fim de estabelecer a melhor relação material-processo-desempenho. A introdução e crescente utilização de aços avançados de alta resistência (AHSS) em aplicações automotivas exige uma maior compreensão dos fenômenos físicos envolvidos no processamento termomecânico a fim de otimizar a performance da peça final fabricada. $\mathrm{O}$ presente trabalho teve como objetivo avaliar experimentalmente o processo de estampagem a quente, com posterior tratamento térmico de têmpera e partição e analisar as microestruturas formadas e suas propriedades mecânicas. A formação de microestruturas durante o processo de estampagem a quente e de têmpera e partição foi avaliada neste trabalho por simulação física em simulador termomecânico Gleeble, acoplado à uma linha de difração de raios X (XTMS) de feixe de luz síncrotron no Laboratório Nacional de Nanotecnologia (LNNano). Foram avaliadas a partição do carbono, a estabilidade térmica da austenita retida e a formação de microconstituintes resultantes da transformação da austenita durante resfriamento forçado (têmpera), seguido de partição de carbono em patamares isotérmicos. Foram utilizadas técnicas de caracterização com apoio de microscopia eletrônica (MEV-FEG e STEM), EBSD, tomografia de sonda atômica (APT) e avaliação de propriedades mecânicas por ensaios de tração e indentação instrumentada. A análise numérica foi realizada por meio do método dos elementos finitos (MEF) e por elementos finitos orientada a objetos (OOF, Object Oriented Finite Element Analysis) visando estabelecer correlações entre microestrutura e propriedades mecânicas, comparando com resultados experimentais. Os resultados e conclusões obtidos no projeto, além de possibilitarem a identificação dos mecanismos fundamentais de geração de microestruturas durante o processo, auxiliam no projeto de aços AHSS estampados a quente, usados principalmente na indústria automobilística, na busca pela redução do consumo de combustível, através da redução do peso, e pelo aumento da segurança dos passageiros.

Palavras-chave: Têmpera e partição, Estampagem a quente, Simulação física, Simulação numérica. 


\begin{abstract}
The development of numerical and physical simulation methods has created new possibilities regarding the optimization of metal forming processes, taking into account real industrial forming processes. Therefore, by applying such methods of analysis it is now possible to assess the material phase transformations and predict the interactions between material properties and the forming process, the constitutive behavior of the material, and optimize process variables as well as predicting the best material-process-performance relationship. The increasing usage of Advanced High Strength Steels (AHSS) in automotive applications demands a better insight of the physical phenomena involved in the thermomechanical processing in order to optimize the performance of the final manufactured part. Thermomechanical simulation of the hot stamping, quenching and partitioning process was carried out in a Gleeble machine coupled to the XTMS Synchrotron X-ray diffraction line at the National Nanotechnology Laboratory (LNNano). Carbon partitioning, carbon contents, and amount of retained austenite, martensite, bainite and ferrite was assessed online during the experiments. In addition, characterization techniques by optical, electron microscopy (FEG-SEM and STEM), EBSD, and Atom Probe Tomography (APT) were applied. Mechanical testing of subsize specimens of the processed steels was performed by means of tensile tests and macro and nanoindentation tests. The numerical analysis was performed using the finite element method (FEM) and object-oriented finite element technique (OOF). The results were compared with the experimental results of mechanical testing of specimens used in the thermomechanical simulations and with hot stamped sheets, where quenching and partitioning were carried out. The results and conclusions obtained in this project allow the identification of the fundamental mechanisms of the process, helping the design of the hot stamping process for AHSS steels used primarily in the automotive industry, seeking weight reduction to improve fuel economy and increased passenger safety.
\end{abstract}

Keywords: Quenching and partitioning, Hot stamping, Physical simulation, Numerical simulation. 


\section{LISTA DE ABREVIATURAS E SÍMBOLOS}

$\mathrm{Ac}_{1} \quad$ Temperatura de início de formação de austenita no aquecimento

$\mathrm{Ac}_{3}$

Temperatura em que a transformação de ferrita para austenita se completa durante aquecimento

$\mathrm{Ae}_{1} \quad$ Temperaturas de equilíbrio de início da austenitização

$\mathrm{Ae}_{3}$ Temperaturas de equilíbrio de fim da austenitização

AHSS Aços avançados de alta resistência

APT Tomografia de Sonda Atômica

A-R Como recebido

at.\% Porcentagem atômica

BC Band Contrast

$\mathrm{BH} \quad$ Bake Hardening

C Carbono

$C_{\gamma} \quad$ Teor de carbono na austenita

$C_{\alpha^{\prime}} \quad$ Teor de carbono na martensita

CPS3 Elemento bidimensional triangular linear de quatro nós com deslocamento e temperatura bi-linear

CCC Cúbica de Corpo Centrado

CCE Constrained Carbon Equilibrium - Equilíbrio constrito ou restringido de carbono

CFC Cúbica de Face Centrada

CP Complex Phase

CS Cold Stamping - Estampagem na temperatura ambiente

DIC Digital Image Correlation - Correlação de imagem digital

DIFT Deformation Induced Ferrite Transformation - Transformação ferrítica induzida por deformação

DP Dual Phase

DRX Difração de raios $\mathrm{X}$

$d_{h k l} \quad$ Distância interplanar

$d_{0} \quad$ Distância interplanar padrão

$e \quad$ Carga elétrica fundamental

E $\quad$ Módulo de elasticidade 


\begin{tabular}{|c|c|}
\hline$E^{*}$ & Módulo de elasticidade reduzido \\
\hline$E_{\varepsilon}$ & Energia de deformação armazenada \\
\hline EBSD & Difração de elétrons retroespalhados \\
\hline EDS & $\begin{array}{l}\text { Energy Dispersive X-ray Spectroscopy - Espectroscopia de raios X por } \\
\text { energia dispersive }\end{array}$ \\
\hline$F$ & Fator de estrutura / Força \\
\hline FIB & Focused Ion Beam - Feixe de íons focalizados \\
\hline FVM & Fração volumétrica de martensita \\
\hline$G$ & Energia livre de Gibbs \\
\hline $\mathrm{H}$ & Dureza \\
\hline $\mathrm{h}$ & Profundidade de penetração do indentador \\
\hline$h k l$ & Índices de Miller \\
\hline HS & Hot Stamping - Estampagem a quente \\
\hline HSQ\&P & Hot Stamping and Quenching and Partitioning \\
\hline HSS & Aços convencionais de alta resistência \\
\hline HV & Dureza Vickers \\
\hline IPF & Figura de Polo Inverso \\
\hline IQ & Qualidade de Imagem \\
\hline$I_{R}$ & Intensidade relativa \\
\hline IT & Temperatura de austenitização intercrítica \\
\hline KAM & Kernel Average Misorientation - Desorientação média de kernel \\
\hline$L$ & Comprimento \\
\hline LNLS & Laboratório Nacional de Luz Síncrotron \\
\hline LNNano & Laboratório Nacional de Nanotecnologia \\
\hline$l_{0}$ & Comprimento inicial \\
\hline LR & Limite de Resistência à tração \\
\hline M & Mega \\
\hline MEF & Método dos Elementos Finitos \\
\hline $\mathrm{MEV}$ & Microscópio eletrônico de varredura \\
\hline$M_{S}$ & Temperatura de início da transformação martensítica \\
\hline$M_{f}$ & Temperatura de final da transformação martensítica \\
\hline$n$ & Taxa de encruamento / estado de ionização \\
\hline OIM & Orientation Imaging Map \\
\hline
\end{tabular}




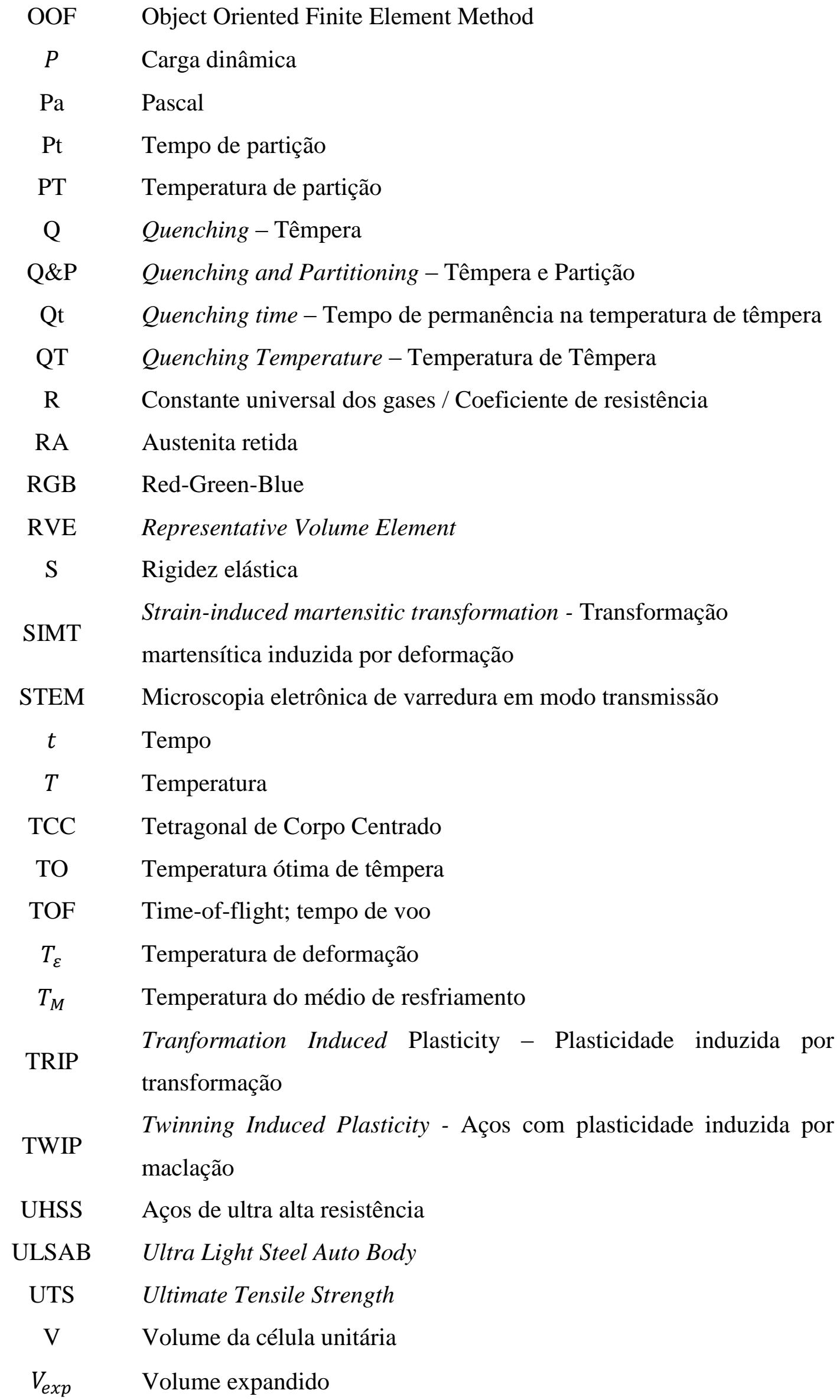




\begin{tabular}{|c|c|}
\hline$V_{\gamma}$ & Fração volumétrica da austenita \\
\hline$V_{\alpha^{\prime}}$ & Fração volumétrica da martensita \\
\hline$X$ & Fração de volume transformado \\
\hline XTMS & $X$-ray Scattering and Thermo-Mechanical Simulation \\
\hline wt.\% & Porcentagem em peso \\
\hline$\alpha$ & Ferrita \\
\hline$\alpha^{\prime}$ & Martensita \\
\hline$\alpha_{f}^{\prime}$ & Martensita fresca, nova ou secundária \\
\hline$\alpha_{b}$ & Ferrita bainítica \\
\hline$\alpha_{D R X}$ & Recristalização dinâmica da ferrita \\
\hline$\alpha_{D I F T}$ & Ferrita DIFT \\
\hline$\alpha_{E}$ & Ferrita epitaxial \\
\hline$\alpha_{I C}$ & Ferrita intercrítica \\
\hline$a_{\gamma}$ & Parâmetro de rede da austenita \\
\hline$\gamma$ & Austenita \\
\hline$\gamma_{b}$ & Austenita na forma de bloco \\
\hline$\gamma^{\varepsilon}$ & Austenita deformada \\
\hline$\gamma_{f}$ & Austenita na forma de filme \\
\hline$\delta$ & Energia absorvida durante deformação \\
\hline$\Delta G_{Q}$ & Variação da energia livre química \\
\hline$\Delta G_{M}$ & Variação da energia livre mecânica \\
\hline$\Delta T$ & Variação da temperatura \\
\hline$\Delta u$ & Variação do deslocamento \\
\hline$\varepsilon$ & Deformação / Carboneto \\
\hline$\dot{\varepsilon}$ & Taxa de deformação \\
\hline$\varepsilon^{*}$ & Taxa de transformação isotrópica para a reação martensítica \\
\hline$\varepsilon_{u}$ & Alongamento uniforme \\
\hline$\varepsilon_{T}$ & Alongamento total \\
\hline$\theta$ & Cementita / ângulo \\
\hline$\theta_{h k l}$ & Semi-ângulo de difração \\
\hline$\lambda$ & Comprimento de onda \\
\hline$\mu_{c}$ & Potencial químico do carbono \\
\hline
\end{tabular}




$\begin{array}{cl}\mu_{F e} & \text { Potencial químico do ferro } \\ \mu_{c}^{\gamma} & \text { Potencial químico do carbono na austenita } \\ \mu_{c}^{\alpha} & \text { Potencial químico do carbono na martensita } \\ \phi, \zeta \text { e } \psi & \text { Ângulos } \\ v & \text { Coeficiente de Poisson } \\ \sigma & \text { Tensão } \\ \sigma_{r} & \text { Tensão de escoamento real representativa } \\ \sigma_{y} & \text { Limite de escoamento } \\ \sigma_{y}^{\gamma} & \text { Limite de escoamento da austenita } \\ \sigma_{y}^{\alpha} & \text { Limite de escoamento da bainita } \\ \sigma_{y}^{\alpha^{\prime}} & \text { Limite de escoamento da martensita } \\ \tau & \text { Tensão de cisalhamento crítica projetada } \\ \chi_{E q} & \text { Composição química da fase em equilíbrio } \\ \approx & \text { Aproximadamente igual }\end{array}$




\section{SUMÁRIO}

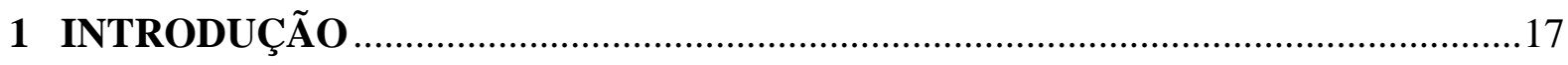

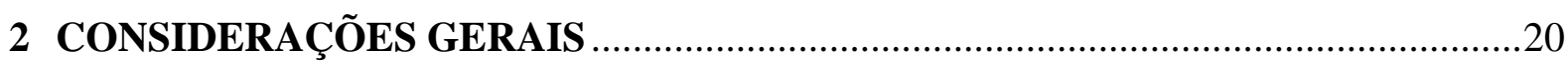

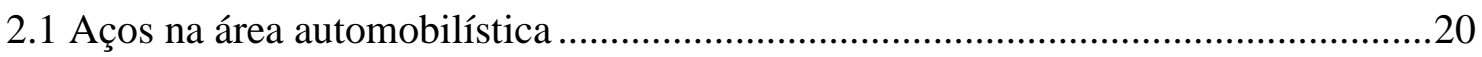

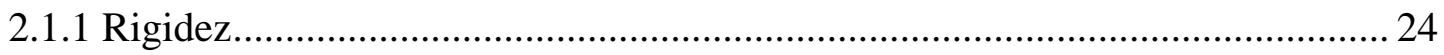

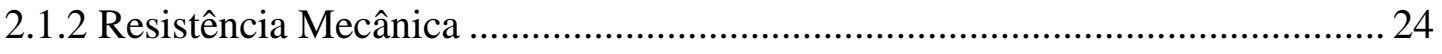

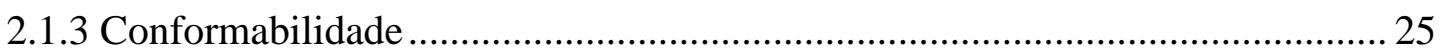

2.1.4 Proteção contra colisão (Crashworthiness) ................................................ 25

2.2 Importância, justificativa e desafios para o desenvolvimento dos AHSS ................25

2.3 Aços com plasticidade induzida por transformação e estabilidade da austenita .......30

2.4 Têmpera e Partição ............................................................................................. 36

2.4.1 Equilíbrio Constrito ou Restringido de Carbono ..................................................39

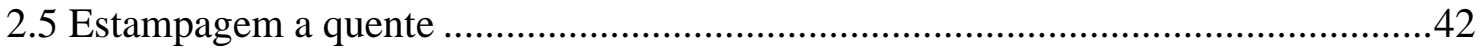

2.5.1 Método direto de estampagem a quente ........................................................ 44

2.5.2 Método indireto de estampagem a quente ................................................... 45

2.6 Importância e justificativa da aplicação dos processos de estampagem a quente e de têmpera e partição.................................................................................................45

2.7 Efeitos da deformação plástica em alta temperatura ..........................................4

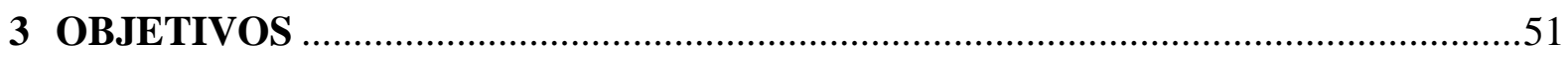

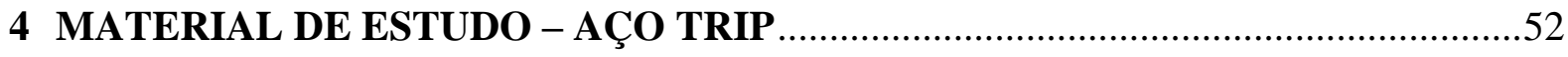

5 TÉCNICAS E PROCEDIMENTOS EXPERIMENTAIS ...........................................55

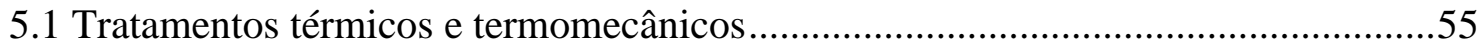

5.2 Difração de raios X síncrotron in situ em alta temperatura .....................................56

5.3 Difração de raios X e determinação da fração de austenita retida ............................61

5.4 Cálculo das frações volumétricas de austenita e ferrita ..........................................61

5.5 Variação do parâmetro de rede da austenita ..........................................................63

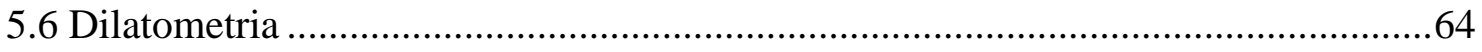

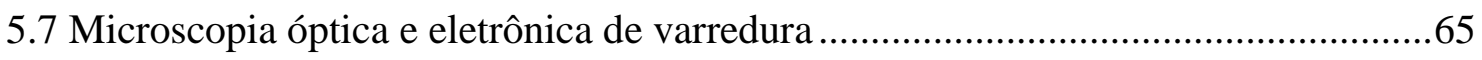

5.8 Difração de elétrons retroespalhados (EBSD) …..................................................65

5.9 Microscopia eletrônica de varredura em modo transmissão (STEM) ......................69

5.10 Tomografia por sonda atômica (APT) .......................................................... 70 
5.11 Estereologia quantitativa .74

5.12 Nanoindentação .75

5.13 Algoritmo de conversão das curvas de nanoindentação em curvas tensãodeformação 79

5.14 Microdureza .83

5.15 Ensaios mecânicos tensão-deformação em corpos de prova reduzidos. . .84

5.16 Modelamento por elementos finitos orientado a objetos (OOF2) . .86

6 CARACTERIZAÇÃO E METODOLOGIA PARA CALCULAR AS PROPRIEDADES MECÂNICAS DE UM AÇO TRIP SUBMETIDO A ESTAMPAGEM A QUENTE E

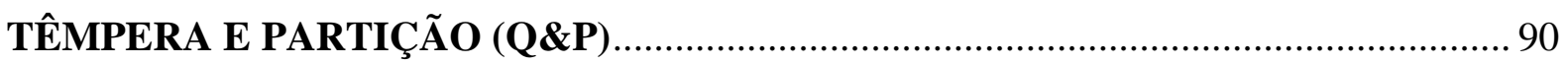

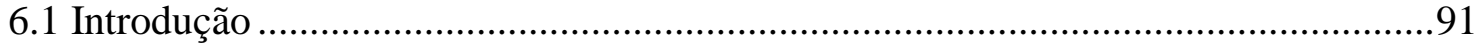

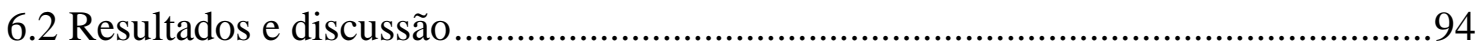

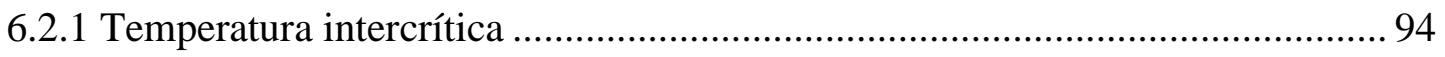

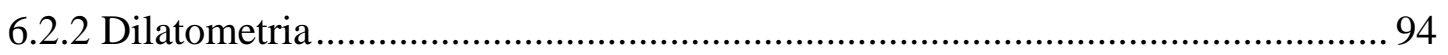

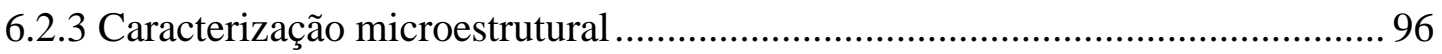

6.2.4. Difração de raios X e avaliação in situ usando radiação síncrotron.................. 99

6.2.5 Nanodureza e algoritmo de conversão ……............................................... 100

6.2.6 Quantificação volumétrica das fases e microdureza ...................................... 105

6.2.7. Simulações baseadas na microestrutura e ensaios micromecânicos............... 106

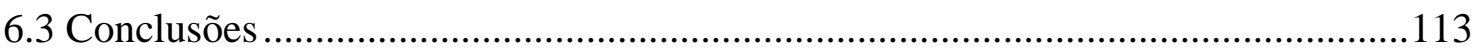

7 COMBINAÇÕES DE DUCTILIDADE E RESISTÊNCIA MECÂNICA PARA DIVERSAS FRAÇÕES VOLUMÉTRICAS DE FERRITA, MARTENSITA E

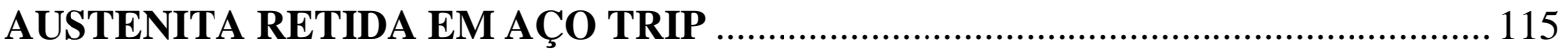

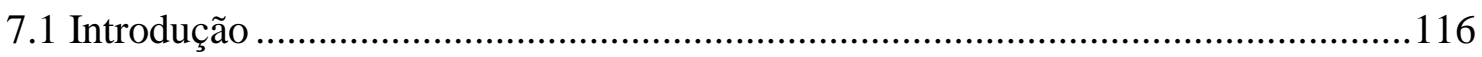

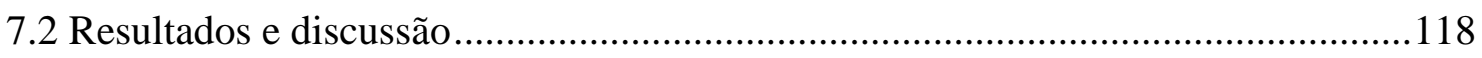

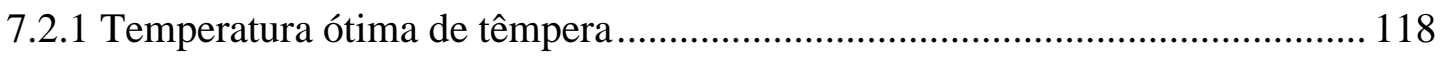

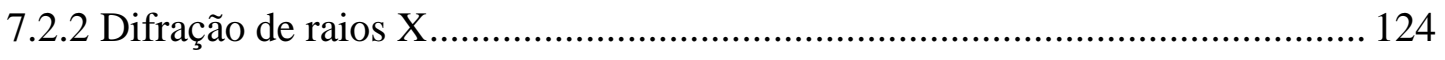

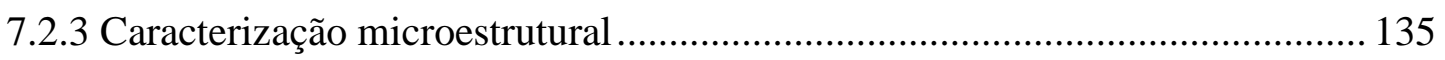

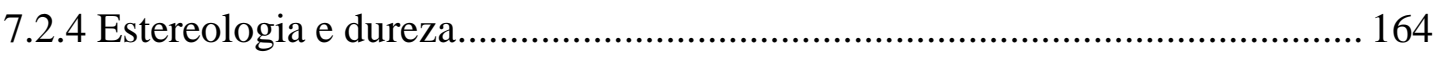

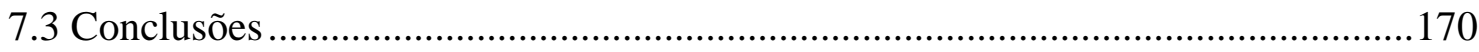


8 AVALIAÇÃO DA PARTIÇÃO DO CARBONO NA NOVA GERAÇÃO DE AÇOS DE

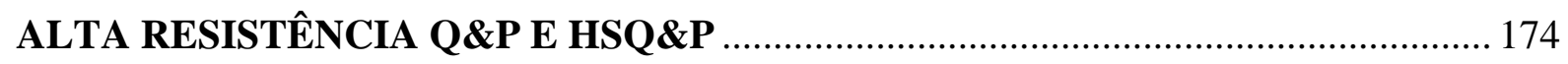

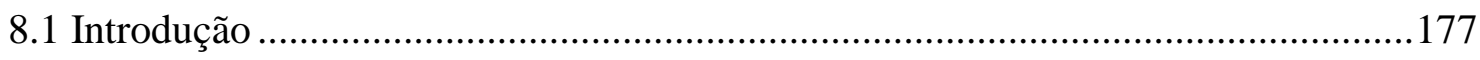

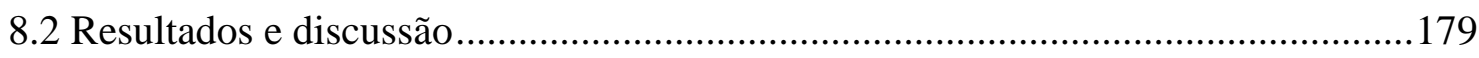

8.2.1 Caracterização da amostra Q\&P ............................................................. 179

8.2.2 Caracterização da amostra HSQ\&P deformada a $750{ }^{\circ} \mathrm{C}$.............................. 183

8.2.3 Caracterização da amostra HSQ\&P deformada a $800{ }^{\circ} \mathrm{C}$.............................. 190

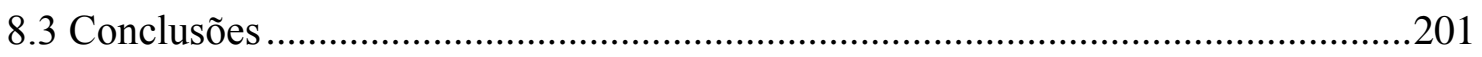

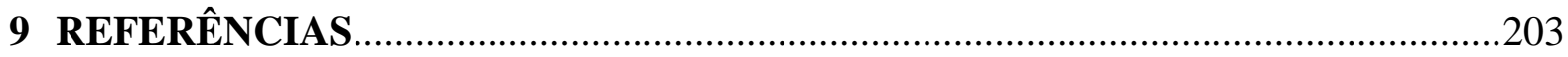




\section{INTRODUÇÃO}

Desenvolver um conjunto completo de produção e de tecnologias para aplicação dos aços de elevada resistência por meio do estudo e controle do processo de estampagem é um foco de pesquisa atualmente necessário. O desafio a ser enfrentado para otimizar o peso da estrutura do veículo é o desenvolvimento de aços com elevada resistência mecânica sem comprometimento de sua conformabilidade. Nesse contexto, uma das soluções recentemente encontrada foi o desenvolvimento de uma nova geração de aços de alta resistência, os chamados aços avançados de alta resistência (AHSS). O aumento do nível de resistência mecânica conseguido com esses aços leva quase inevitavelmente à redução de seu alongamento total e, portanto, também à redução de sua estampabilidade. Contudo, o uso de microestruturas adequadas permite minimizar a perda de ductilidade. Desta maneira, os AHSS são uma classe de aços que oferecem uma relação resistência/conformabilidade superior, sem afetar a ductilidade e o aumento da absorção de energia, o que melhora a resistência ao impacto.

Embora os limites de conformação a frio dos aços AHSS ainda não tenham sido devidamente alcançados, atualmente a estampagem a quente é a única rota de processo que permite a fabricação de componentes com formatos complexos e alta resistência mecânica. A austenitização do aço, além de facilitar o processo de conformação em função da menor resistência mecânica e maior ductilidade do material sob processamento, também permite aproveitar os fenômenos metalúrgicos decorrentes da transformação metalúrgica posterior para obter perfis de propriedades mecânicas que permitam reduzir o peso das peças e melhorar seu desempenho. É notável que ainda há muito trabalho no sentido de se aperfeiçoar o processo de estampagem a quente (HS, do inglês Hot Stamping ou Press hardening) e determinar como utilizar plenamente seu potencial metalúrgico para produzir peças que cumpram suas funções da forma mais eficiente e econômica possível.

Uma outra abordagem inovadora para produzir aços avançados de alta resistência, chamada de têmpera e partição (Q\&P, do inglês Quenching and Partitioning), foi proposta por Speer et al., [1]. O objetivo do processo é produzir microestruturas mistas compostas por martensita, ferrita e frações controladas de austenita retida. Nesse processo a supersaturação de carbono da martensita resultante da têmpera é utilizada, durante a etapa de partição, para estabilizar a austenita não transformada, o que acontece pela migração de carbono da martensita para a austenita retida [1]. O tratamento de Q\&P é caracterizado pelo aquecimento da peça até uma temperatura ligeiramente superior à temperatura crítica $A_{c 3}$ (austenitização plena), ou na região intercrítica (entre $A_{c 1}$ e $A_{c 3}$ ), manutenção nesta temperatura por certo tempo e em seguida 
resfriamento (a uma alta velocidade para garantir que não ocorram transformações difusionais) até uma temperatura predeterminada entre as temperaturas de início $\left(M_{s}\right)$ e fim $\left(M_{f}\right)$ da transformação martensítica. $\mathrm{O}$ objetivo é produzir uma microestrutura parcialmente martensítica, seguido de uma etapa de tratamento térmico de partição, para que ocorra a redistribuição do carbono da martensita para a austenita. Desse modo, a austenita estabilizada pelo enriquecimento em carbono é retida na microestrutura após a têmpera final à temperatura ambiente.

$\mathrm{O}$ processo de Q\&P difere dos processos existentes para produzir microestruturas nos AHSS, tais como formação de bainita (TRIP), e têmpera e revenido. A supressão da precipitação de carbonetos é a grande diferença quando comparado com tratamentos térmicos convencionais de têmpera e revenido, onde se espera que o carbono forme carbonetos (de transição) durante a etapa do revenido. Assim, enquanto a microestrutura de um aço temperado e revenido consiste de martensita revenida e carbonetos precipitados, a microestrutura Q\&P é projetada para obter martensita revenida e austenita retida. Por outro lado, a possibilidade de estabilizar a austenita pela partição de carbono proveniente da martensita durante o processo de partição, distingue o processo de Q\&P dos tratamentos tradicionais de transformação bainítica aplicados em aços TRIP.

A têmpera e partição é, portanto, um problema complexo que envolve o acoplamento entre fenômenos térmicos, de transformação de fase e mecânicos, no qual existe uma grande dificuldade de controlar a microestrutura para obter as propriedades mecânicas desejadas. Essas condições transientes tornam, por conseguinte, difícil investigar experimentalmente a sequência de acontecimentos que ocorrem durante o processo, como, por exemplo, a evolução das fases e o estado de tensões e deformações internas dos componentes, razão pela qual simulações físicas e numéricas têm se mostrado alternativas viáveis para descrever e prever os processos que ocorrem nas peças durante tratamento. Uma vez que o controle efetivo das transformações de fase pode conduzir à produção de peças de aço com melhores propriedades mecânicas através das microestruturas requeridas, a simulação acurada dessas transformações é a chave para predizer as condições cinéticas e mecânicas durante o tratamento térmico.

O processo de têmpera e partição tem despertado um grande interesse na indústria automobilística e nas pesquisas recentes pela obtenção de chapas de aço com alta resistência com aumento na sua conformabilidade, a fim de economizar no consumo de combustível e obter maior resistência ao impacto. No entanto, há necessidade de estudos adicionais [2] para entender melhor as contribuições da microestrutura nos níveis de resistência e ductilidade observados, incluindo uma melhor compreensão da influência das discordâncias, dos 
carbonetos precipitados, da distribuição de solutos (empobrecimento de carbono), da fração de austenita e da estabilidade da austenita retida.

Assim, neste trabalho procura-se a identificação dos mecanismos fundamentais da estampagem a quente (HS) e de têmpera e partição (Q\&P) para um aço TRIP, a partir de diferentes temperaturas e tempos de tratamento. Além de contribuir no entendimento destes mecanismos, espera-se que os resultados auxiliem no projeto de aços comerciais utilizados principalmente na indústria automobilística. Em vista disso, a partir deste trabalho pretende-se encontrar as rotas de Q\&P apropriadas para aços estampados a quente, com diversas frações volumétricas de austenita retida estabilizada, ferrita intercrítica e ripas de martensita. Com estes objetivos, ciclos de Q\&P foram desenvolvidos de forma a obter a máxima fração de austenita retida, ao final do processo. Com esta microestrutura, é possível obter uma boa combinação de resistência e ductilidade. Através da combinação do processo de estampagem a quente e de têmpera e partição (denominado na presente pesquisa de HSQ\&P), o alongamento do aço pode ser melhorado sem diminuir a resistência à tração. Desta maneira, o processo combinado (HSQ\&P) mostra que é possível atingir uma boa associação de propriedades para a nova geração de aços de alta resistência pela transformação da austenita retida metaestável em martensita induzida por deformação (efeito TRIP), contribuindo na absorção de energia durante impacto. Nas operações de estampagem a quente uma avaliação precisa da influência dos parâmetros do processo nas propriedades finais dos componentes estampados é fundamental para o desenho e otimização dos processos de conformação. 


\section{CONSIDERAÇÕES GERAIS}

\subsection{Aços na área automobilística}

A indústria automobilística tem incentivado nas últimas décadas o desenvolvimento de novos aços do tipo estrutural para fabricação de componentes de carroceria que confiram aumento na segurança dos passageiros, redução do peso e alto desempenho. Do ponto de vista metalúrgico, pode-se classificar os aços estruturais para aplicações automotivas em [3, 4]:

- Aços de baixa resistência: aços de baixo carbono (mild steels, macios de elevada ductilidade devido à sua microestrutura principalmente ferrítica e usualmente contendo baixos teores de carbono e elementos de liga) e aços livres de intersticiais (IF- InterstitialFree), os quais, por possuírem teores muito baixos de elementos intersticiais em solução sólida $(\mathrm{C}<$ 0,003\% ou 30 ppm; $\mathrm{N}<0,004 \%$ ou 40 ppm), e devido à adição de elementos microligantes formadores de carbonetos e nitretos ( $\mathrm{Ti}$ e/ou $\mathrm{Nb}$ ), criam uma matriz ferrítica livre de elementos intersticiais. Dessa forma, esses aços apresentam alta plasticidade, baixa resistência mecânica e excelentes propriedades de conformação e estampabilidade (isto é, valores altos do coeficiente de anisotropia e de ductilidade).

- Aços convencionais de alta resistência: aços carbono-manganês (CMn), com precipitados de $\mathrm{Nb}$ e/ou Ti; aços refosforados (endurecidos por solução sólida pela adição de $\mathrm{P}$ ); aços Bake Hardening (BH, endurecimento por cozimento, conseguido após a estampagem e a pintura da peça, durante a secagem em estufa da pintura aplicada); isotrópicos (mesmo alongamento independente da direção $-0^{\circ}, 45^{\circ}$ ou $90^{\circ}$ da chapa), em que existe controle dos precipitados $(\mathrm{Ti} / \mathrm{N})$, das temperaturas de acabamento $\left(\approx 800{ }^{\circ} \mathrm{C}\right)$, bobinamento $\left(\approx 500{ }^{\circ} \mathrm{C}\right) \mathrm{e}$ recozimento e da porcentagem de deformação no laminador das tiras a frio (50 a $80 \%)$ para formar a textura de recristalização desejada; aços microligados ou de alta resistência e baixa liga (HSLA - High Strength Low Alloy) com microestrutura ferrítica-perlítica ultra-refinada, contendo microadições de $\mathrm{Nb}$, Ti e/ou V.

- Aços avançados de alta resistência (AHSS) e de ultra alta resistência (UHSS): aços bifásicos (DP - Dual Phase), contendo fina dispersão de martensita e/ou bainita em uma matriz de baixa resistência mecânica constituída de ferrita poligonal. A alta resistência mecânica é produzida através da alta geração de discordâncias pelo encruamento da matriz ferrítica; aço multifásico com fases complexas ( $\mathrm{CP}$ - Complex Phase), com microestrutura constituída por uma matriz refinada constituída de pequenos grãos de ferrita, frações volumétricas entre 80 e $90 \%$ de bainita e martensita, isenta de austenita retida, contendo adicionalmente precipitados 
de $\mathrm{Nb}$, Ti ou $\mathrm{V}$; aços martensíticos (MART ou MS) de baixo carbono $(<0,2 \%)$ com microestrutura predominantemente martensítica na forma de ripas. Esses aços podem, no entanto, conter outros constituintes como martensita auto-revenida, bainita, ferrita acicular e/ou austenita retida, o que lhes confere altos níveis de resistência mecânica; aços com plasticidade induzida por transformação (TRIP, Transformation Induced Plasticity) em que a intensificação do encruamento é produzida pela transformação da austenita retida em martensita induzida pelas tensões de conformação; aços ao boro (entre 0,0015 e 0,005\% de B) de alta temperabilidade, usados principalmente nos processos de estampagem a quente. O boro, quando presente na forma de solução sólida, segrega para os contornos de grão austeníticos e impede a nucleação de ferrita [5].

Outra classificação, tem sido proposta para esses aços, de acordo com sua resistência mecânica (LR - Limite de resistência à tração):

- Aços de baixa resistência: LR < $270 \mathrm{MPa}$.

- Aços convencionais de alta resistência (HSS): LR entre 270 e $700 \mathrm{MPa}$, dentre os quais se encontram os HSLA, aços de alta resistência baixa liga (ou microligados).

- Aços avançados de alta resistência (AHSS): LR entre 550 e $700 \mathrm{MPa}$.

- Aços avançados de ultra alta resistência (UHSS): LR > $700 \mathrm{MPa}$.

A principal diferença entre os HSS e AHSS está na microestrutura. Enquanto as características dos HSS são determinadas por sua microestrutura ferrítica, os AHSS são multifásicos com ferrita, martensita, bainita e/ou austenita retida (e, eventualmente, carbonetos e nitretos precipitados) em quantidades suficientes para produzir limites de escoamento e de resistência mecânica maiores. Desse modo, alguns tipos de aços AHSS têm uma maior capacidade de endurecimento por deformação, resultando em um melhor compromisso entre resistência e ductilidade, quando comparados aos HSS convencionais. A classificação desses aços foi atribuída por iniciativa do projeto liderado pela Porsche Engineeering conhecido como ULSAB-AVC (Ultra Light Steel Auto Body - Advanced Vehicle Concept [6]), que deu continuidade ao projeto ULSAB (Ultra Light Steel Auto Body), finalizado em 1999, que contou com a parceria de 35 companhias siderúrgicas de 18 países [7]. Um dos benefícios oriundos dessa iniciativa $(U L S A B)$ foi a introdução dos HSS nas estruturas automobilísticas, destacandose entre esses os aços BH e os HSLA. O projeto ULSAB explorou novas oportunidades para redução de peso em componentes automotivos, resultando no desenvolvimento de uma carroceria automotiva com $90 \%$ de aços HSS, reduzindo aproximadamente $25 \%$ da massa, e melhorando os níveis de rigidez à torção (em até 80\%) e à flexão (em até 52\%) [8]. Já com o 
projeto ULSAB-AVC, finalizado em 2002, houve um aumento significativo na eficiência do consumo de combustível devido à redução em peso do veículo $(\approx 17 \%)$, com níveis superiores de resistência em componentes que precisam de operações de conformação em sua fabricação [6]. A partir desse projeto foi proposta a aplicação de novos tipos de aços AHSS nos componentes automobilísticos, entre os quais se encontram os DP, TRIP, CP e MART.

Na Figura 2-1 é apresentada, esquematicamente, a relação entre resistência mecânica e o alongamento total para diferentes tipos de aços. De acordo com a figura, fica evidente que os AHSS possuem valores superiores de resistência mecânica e de relação ductilidade/resistência mecânica, em comparação aos HSS. Também se observa como o aumento do nível de resistência mecânica leva, quase que inevitavelmente, à redução de seu alongamento total, que pode ser associado à estampabilidade. Na parte inferior dessa figura são encontrados os aços AHSS, comumente chamados de alta resistência da primeira geração, que incluem os DP, CP TRIP e MS. Esses aços foram desenvolvidos com o objetivo de aumentar o limite de resistência dos HSS para valores superiores aos $700 \mathrm{MPa}$. No entanto o aumento da resistência mecânica levou à perda de ductilidade, principalmente no aços MS, onde o alongamento caiu para $\approx 5 \%$. A preocupação em aumentar o desempenho no alongamento dos aços da primeira geração levou ao desenvolvimento dos aços conhecidos como aços de alta resistência da segunda geração. Esse grupo de aços é representado na porção superior-direita da Figura 2-1, no qual se incluem os aços com plasticidade induzida por maclação (TWIP - Twinning Induced Plasticity), L-IP (Lightweight steels with Induced Plasticity) e AUST-SS (Austenitic Stainless Steel). Esses aços são atraentes devido à sua excelente conformabilidade e resistência mecânica. No entanto, apresentam grandes problemas de processamento (por exemplo, a necessidade de um maior tempo para o refino do aço líquido [9]), quando comparados com as chapas de aço de baixo carbono; além disso, seu custo inviabiliza sua maior utilização devido ao elevado teor de elementos de liga (como, por exemplo, o teor de manganês entre 15 e $25 \%$ e do Si de 2 a 4\%), necessários para produzir uma microestrutura austenítica [10]. Adicionalmente, Nanda et al. [11] mencionam que esses aços apresentam difícil soldabilidade pelo próprio fato de serem altamente ligados e tenderem a apresentar trincamento após a peça ser conformada e armazenada (delayed cracking).

Em vista disso, para expandir o espectro dos AHSS, de tal forma que seja possível conseguir aços mais resistentes e dúcteis, existem dois caminhos: ou reduzir a quantidade de manganês e outros elementos de liga para reduzir os custos do aço TWIP ou dos aços inoxidáveis austeníticos (AUST-SS), ou modificar os parâmetros de processamento termomecânico dos aços da primeira geração [12]. Para a segunda opção, entre algumas das estratégias que podem 
ser abordadas estão [11, 13]: modificar as rotas de processamento tradicionais dos aços DP ou TRIP para aumentar suas propriedades; desenvolver aços de alta resistência com microestrutura bainítica ultra-refinada (nanobainita); aplicar novas rotas de fabricação ou pós-processamento térmico como a têmpera e partição [1] e o processamento de microestruturas flash [14], aplicando rápido aquecimento, tempo curto de manutenção na temperatura de austenitização (para evitar a completa dissolução de carbonetos e a homogeneização do carbono na austenita) seguido de rápido resfriamento; ou desenvolver novos aços TRIP com teores maiores de $\mathrm{Mn}$, os chamados aços HMS-TRIP (High Manganese TRIP Steels) [15].

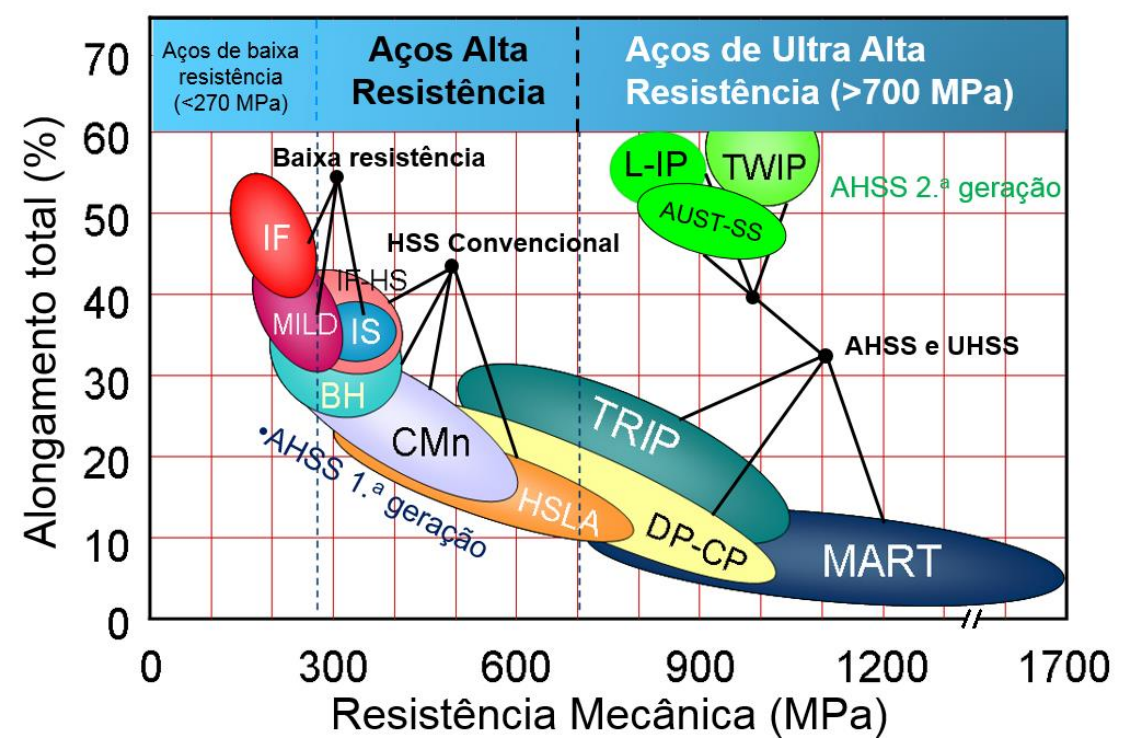

Figura 2-1. Relação entre resistência mecânica e alongamento total (ductilidade) para diversas famílias de aços [4].

A indústria automobilística vem empregando materiais com índices de mérito (LR/peso) cada vez maiores, visando diminuir o consumo de combustível e a emissão de gases que contribuem para o efeito estufa. Nessa linha de atuação vem sendo desenvolvida uma nova geração de aços com elevada resistência mecânica e ductilidade, sem que represente um aumento significativo nos custos de produção, os assim chamados aços avançados de alta resistência da terceira geração. Entretanto, o desafio que se coloca no desenvolvimento desses aços está em alcançar níveis de resistência elevados sem comprometer sua conformabilidade a frio [16].

Uma boa combinação de alta resistência e ductilidade dos AHSS permite a fabricação de componentes estruturais com menor espessura, melhorando a segurança dos passageiros devido a sua elevada capacidade de absorção de energia durante impacto. Essa combinação pode ser atingida pelo balanço na diferença das propriedades mecânicas de microconstituintes duros e macios, baseado no pressuposto que cada constituinte contribui na resistência e na ductilidade 
formando uma microestrutura composta, e/ou controlando os mecanismos de deformação, pela imposição de barreiras à movimentação das discordâncias através do controle dos mecanismos de deslizamento e maclação, por exemplo, pela distribuição de pequenos precipitados e/ou pelo efeito do tamanho dos grãos [17]. Além disso, a melhor conformabilidade dos AHSS, em relação aos aços de alta resistência convencionais, com a mesma resistência mecânica, fornecem ao projetista do automóvel maior flexibilidade na otimização e geometria dos componentes.

A seguir são descritas algumas das características das propriedades mecânicas dos AHSS aplicados na indústria automobilística.

\subsubsection{Rigidez}

A rigidez de um componente é afetada tanto pelo módulo de elasticidade como pela geometria do material. Nos aços de baixa liga, o módulo de elasticidade praticamente independe da composição química e do processamento termomecânico. Portanto, se a finalidade do projeto é melhorar a rigidez, deve-se mudar a geometria do componente. Os AHSS oferecem uma maior flexibilidade na otimização da rigidez devido à sua melhor conformabilidade. Assim, a diminuição da espessura do perfil estrutural pode ser contrabalançada pela mudança em sua geometria ou usando técnicas de união contínuas, tais como a soldagem a laser ou de adesão com substância aglutinante [18].

\subsubsection{Resistência Mecânica}

Por outro lado, a resistência mecânica de um componente depende da sua geometria e dos seus limites de escoamento e/ou de resistência à tração. Os AHSS proporcionam uma vantagem na flexibilidade do design sobre os aços convencionais de alta resistência, devido à sua maior conformabilidade e características de endurecimento por deformação. Além disso, os AHSS possuem uma melhor capacidade de aumentar o limite de escoamento por bake hardening ${ }^{1}$.

A possibilidade de obtenção de perfis estruturais de elevada resistência mecânica após estampagem, sem necessidade de tratamento térmico para endurecimento, é hoje um objetivo maior na engenharia de materiais e nos departamentos de projeto de veículos automotores. Nesse sentido os aços AHSS vêm se mostrando apropriados, já que permitem estampagem a quente e têmpera na própria matriz, exigindo baixos esforços de conformação e apresentando

\footnotetext{
${ }^{1} \mathrm{O}$ aumento do limite de escoamento pode ser proporcionado por dois mecanismos: o encruamento e o efeito do envelhecimento após deformação. O primeiro causado pela deformação plástica e o segundo resulta de um tratamento térmico de baixa temperatura que produz a movimentação de átomos intersticiais (principalmente carbono e/ou nitrogênio) para discordâncias produzidas durante as operações prévias de conformação.
} 
elevada resistência mecânica após resfriamento na matriz, com formação de estruturas martensíticas.

\subsubsection{Conformabilidade}

Os aços AHSS têm muitas características vantajosas ligadas à conformabilidade em comparação aos aços HSLA com limite de resistência similar. Os AHSS em geral, têm uma maior taxa de encruamento inicial, maior limite de resistência à ruptura e, especialmente nos aços DP (Dual Phase), têm-se uma menor relação entre o limite de escoamento e o limite de resistência à tração (menor razão elástica). Todas essas vantagens combinadas com o maior alongamento mostram que os AHSS combinam alta resistência com boa conformabilidade. Uma vantagem importante dos aços DP é que um valor muito alto de $n$ (taxa de encruamento) em baixas deformações, que limita o aparecimento de deformações localizadas e o desenvolvimento de gradientes acentuados de deformação. Entre os AHSS, essa propriedade, relacionada com a plasticidade ou a ductilidade, tem se mostrado especialmente superior nos aços assistidos pelo efeito TRIP, sendo que a austenita retida desempenha um papel muito relevante na conformabilidade.

\subsubsection{Proteção contra colisão (Crashworthiness)}

A capacidade de resistência às colisões é uma característica que está ganhando cada vez maior importância. As especificações de componentes estruturais mais recentes exigem dos componentes veiculares maior capacidade de absorver energia durante os acidentes. Esse potencial de absorção de energia pode ser avaliado com base na integral da função que define as curvas de tensão-deformação. O melhor desempenho nas colisões dos aços AHSS, quando comparados aos aços de alta resistência convencionais, está associado com as maiores taxas de encruamento e de deformação plástica. Assim, tanto o encruamento como o bake hardening melhoram significativamente as características de absorção de energia devido ao aumento da tensão de escoamento.

\subsection{Importância, justificativa e desafios para o desenvolvimento dos AHSS}

As atividades de pesquisa sobre os aços AHSS têm se expandido rapidamente, levando à utilização crescente desses aços na indústria automobilística, como observado na Figura 2-2 [16], onde para 2020 se projeta um aumento de $\approx 15 \%$ no peso dos veículos pelo uso de $\approx 250$ $\mathrm{kg}$ em componentes estruturais de aços AHSS. Essa porcentagem poderia ser muito superior se fossem utilizados outros tipos de aços. Por outro lado, o projeto FSV (Future Steel Vehicle), 
concluído em 2011, que deu continuidade aos projetos ULSAB e ULSAB-AVC, demonstrou que usando $97 \%$ de aços HSS e AHSS na estrutura de um veículo de teste, permite obter até $\approx$ $35 \%$ de redução em massa [8].

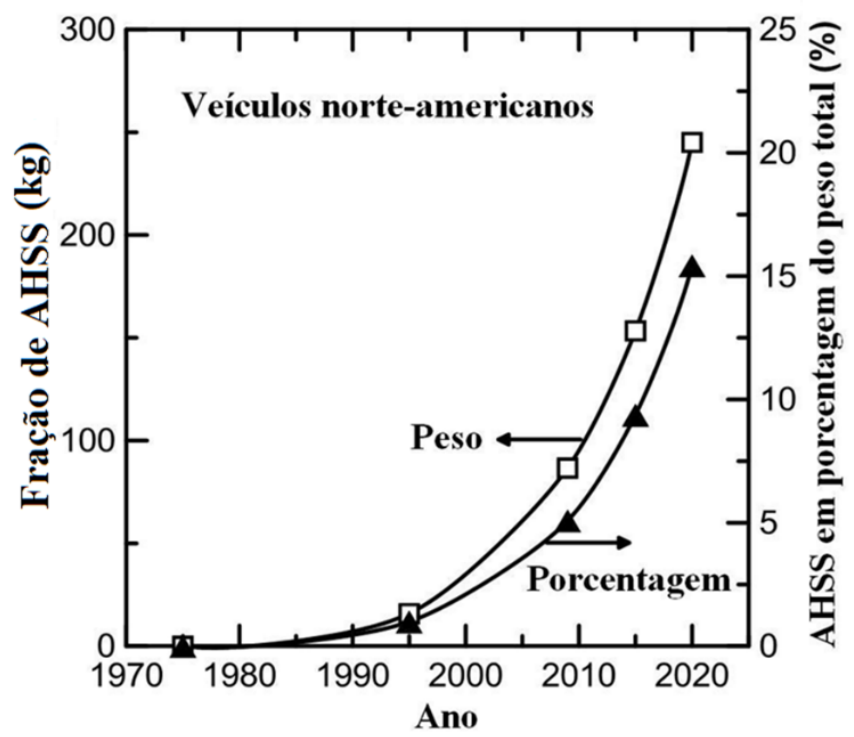

Figura 2-2. Histórico e projeção das mudanças das frações de AHSS (em kg) e da porcentagem em peso de veículos norte-americanos, para o período entre 1970 e 2020 [16].

Além disso, existem normas reguladoras cada vez mais rígidas para fabricação de automóveis, como são a europeia NCAP (New Car Assessment Program) e as americanas NHTSA (National Highway Traffic Safety Administration) e CAFE (Corporate Average Fuel Economy). O programa europeu para as alterações climáticas (European Climate Change Programme), o Parlamento Europeu e a Comissão Europeia (Europe Comission) estabeleceram a criação de estratégias para a produção de veículos leves, a fim de reduzir as emissões de $\mathrm{CO}_{2}$ com vistas a alcançar os objetivos da UE de $95 \mathrm{~g}$ de $\mathrm{CO}_{2} / \mathrm{km}$ até 2020. Dessa forma, por exemplo, um Volkswagen Golf, o carro mais vendido na Europa nos anos de 2014 e 2015, que emite em média $125 \mathrm{~g}$ de $\mathrm{CO}_{2} / \mathrm{km}$, estaria cerca de $25 \%$ acima das exigências da norma aprovada pelo Parlamento Europeu [19]. Já o carro mais vendido no mundo no ano de 2015 (1,33 milhão de unidades), o Toyota Corolla, tem uma emissão média de $167,9 \mathrm{~g}$ de $\mathrm{CO}_{2} / \mathrm{km}$ [20]. Adicionalmente, a relação entre a emissão de $\mathrm{CO}_{2}$ e a economia no consumo de combustível também representa um aspecto importante, já que, segundo a Agencia de Energia Internacional (IEA, International Energy Agency) [21], o setor de transportes é responsável por mais da metade do consumo de petróleo no mundo, representando 64,5\% em 2014. Utilizando os valores descritos por Fonstein [7] para essa relação, a redução da emissão atual de $\mathrm{CO}_{2}$ do Toyota Corolla para a exigida pela UE para 2020 é equivalente a uma economia no consumo (em $\mathrm{m} / \mathrm{l})$ de combustível de $\approx 79 \%$. Devido à variação nos preços do petróleo e por ser um 
recurso não renovável, os fabricantes de automóveis sabem que o consumo de combustível é um dos indicadores críticos para competir no mercado.

No Brasil, $4^{\circ}$ maior mercado global de veículos e o $7^{\circ}$ fabricante, existe estímulo do governo para adesão aos programas de eficiência energética por meio das regras do novo regime automotivo. O lançamento no ano de 2012 do Inovar-Auto, nome da nova política industrial, deu ênfase ao tema de eficiência energética e emissão de gás carbônico, e de maior competitividade, tecnologia e segurança para os carros produzidos e vendidos no Brasil. A exigência mínima de eficiência energética passará a ser, em 2017, 12\% superior à média atual de consumo. Montadoras e importadoras terão de atingir uma média entre os seus modelos de 17,26 km por litro de gasolina e de 11,96 km por litro de etanol para conseguir uma redução de imposto $^{2}$. Individualmente, hoje nenhum carro atinge o patamar proposto, sendo que o consumo médio dos carros nacionais é de $14 \mathrm{~km}$ por litro de gasolina e 9,71 km por litro de etanol. Adicionalmente, o Brasil se comprometeu no Acordo de Paris a reduzir $43 \%$ das emissões até 2030. Um compromisso altamente necessário, tendo em vista que, segundo os dados do Instituto de Energia e Meio Ambiente (IEMA) [22], entre 1994 e 2014 houve no Brasil um crescimento de $192 \%$ nas emissões de gases de efeito estufa de carros e motos. Para atingir a meta de redução de consumo, as empresas terão necessariamente de investir em tecnologias mais modernas de produção, como motores mais eficientes, menos poluentes, peças mais leves, elevando o padrão nacional $^{3}$. Portanto, os principais objetivos do programa Inovar-Auto, perante esses desafios, se baseiam no desenvolvimento de soluções inovadoras que tornem competitivos os automóveis produzidos localmente por meio do aumento da pesquisa e desenvolvimento local, focados no aumento da eficiência energética e da segurança dos veículos nacionais e na redução da emissão de poluentes. Segundo Lora et al. [23], para o setor automobilístico do Brasil enfrentar esses desafios, o uso da estampagem a quente para a produção de aços de alta resistência é a tecnologia mais promissora

Por conseguinte, centros de pesquisa industriais e de diversas universidade no mundo todo, atualmente estão na busca de estratégias que consigam reduzir o peso dos veículos, sem afetar a segurança dos passageiros, que é o principal fator para diminuição do consumo de combustível. Pesquisas apontam que a redução de $10 \%$ de peso nos veículos reduz o consumo de combustível de 6 a $10 \%$ e em $\approx 4 \%$ a emissão de $\mathrm{CO}_{2}[7,24]$. Portanto, para satisfazer as

\footnotetext{
2 A partir de 2017, carros que alcançarem redução de $15,46 \%$ ou maior que $18,84 \%$ no consumo de combustível, terão direito a um acréscimo de 1 e 2 pontos percentuais, respectivamente, na redução no IPI (Imposto sobre Produtos Industrializados). Fonte: www.inovarauto.com.br. Acesso em: 02 dez. 2016

${ }^{3}$ Fonte: Ministério do Desenvolvimento, Indústria e Comércio Exterior (MDIC).
} 
exigências em termos de segurança, resistência ao impacto e de redução do consumo de combustível, a alternativa mais viável para criação de componentes estruturais de menor espessura é o desenvolvimento de aços de alta e ultra alta resistência com uma adequada conformabilidade [7].

Dessa maneira, a pesquisa atual pretende continuar estudando a expansão do amplo espectro dos HSS, com particular interesse em aços de uma "terceira geração" dos aços convencionais e AHSS (Figura 2-3), que melhorem o compromisso entre resistência mecânica e alongamento total em relação aos aços da primeira geração, mas que sejam de menor custo que os aços da segunda geração, com o objetivo de reduzir o peso da estrutura do veículo sem comprometer aspectos de segurança dos passageiros, como a capacidade de absorção de impacto em colisão.

No entanto, é necessário atingir alguns requisitos e desafios para viabilizar a produção dos aços da terceira geração, como [11, 13, 25]: a) alta fração volumétrica de austenita estabilizada na temperatura ambiente, de forma que seja possível transformá-la em martensita com o a avanço progressivo da deformação plástica do aço; b) baixos teores de carbono de tal forma que a soldabilidade não seja comprometida; c) baixos níveis de elementos de liga para não aumentar os custos do material; e (d) rotas de processamento viáveis com os sistemas de produção de chapas de aço existentes.

Adicionalmente, existem desafios devidos à alta resistência e baixa conformabilidade dos AHSS [26], uma vez que são observadas fraturas prematuras em várias operações de conformação, exigindo maiores pesquisas sobre a mecânica da fratura. Além disso, esses aços requerem maiores pressões de conformação, causam desgaste mais rápido das ferramentas, requerem lubrificantes especiais e revestimentos especialmente projetados, bem como são necessários maiores estudos do efeito mola (springback) resultante da recuperação elástica devida a tensões residuais induzidas durante o processo de estampagem, afetando a precisão dimensional dos componentes. Segundo Placidi et al. [27] o efeito mola representa uma das maiores preocupações para a produção em massa de componentes estruturais automotivos usando aços AHSS. Por outro lado, devido à estrutura multifásica e aos processos de fabricação complexos desses aços, são necessários novos métodos de ensaio para a determinação precisa das propriedades mecânicas e físicas dos materiais utilizados durante o processo. 


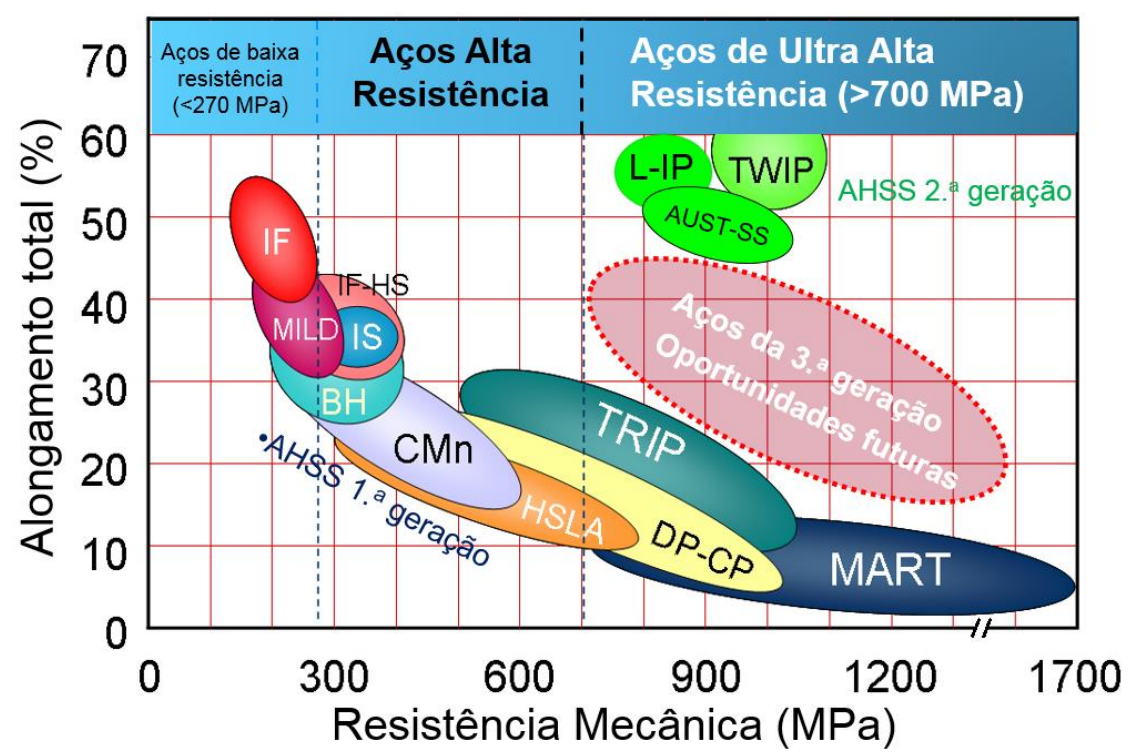

Figura 2-3. Área de interesse para geração de uma terceira geração de novos aços de alta resistência. Adaptado de [16].

$\mathrm{Na}$ Figura 2-4 são apresentadas as curvas comparativas dos AHSS, obtidas por modelamento numérico [28] que correlacionam microestruturas e propriedades de resistência e ductilidade para misturas hipotéticas de ferrita-martensita (linha vermelha), a qual se ajusta bem ao comportamento dos AHSS da primeira geração à base de ferrita, e a curva com misturas hipotéticas de austenita-martensita (em cor azul), correspondente aos aços da terceira geração. Essa curva sugere que as propriedades mecânicas intermediárias entre os aços da primeira e segunda geração sejam preenchidos por combinações microestruturais complexas entre fases de alta resistência (nesse caso martensita, mas poderiam também ser incluídas bainita e/ou ferrita com grãos refinados) e fases endurecíveis por deformação (como a austenita retida). Matlock e Speer [25, 28] sugerem que essas frações sejam obtidas através de uma recente abordagem metalúrgica conhecida como têmpera e partição. Como se observa nessa figura, o aumento da resistência em ambas as curvas aumenta com o aumento da fração volumétrica de martensita (FVM). Essa previsão também sugere que a fração volumétrica de austenita tem maior influência na ductilidade do que a ferrita, de forma tal que uma microestrutura contendo austenita e martensita tem maior energia de deformação que aquela consistindo de ferrita e martensita, nas mesmas proporções. Isso demonstra porque a primeira combinação apresenta melhor desempenho em termos de ductilidade e que são necessárias certas frações volumétricas de austenita na microestrutura se o objetivo é preencher a lacuna dos aços da terceira geração. Com essa finalidade, torna-se essencial o controle das condições de processamento na etapa de produção e/ou de tratamento térmico posterior, a fim de otimizar a microestrutura e, por conseguinte, a relação entre a resistência mecânica e a ductilidade. 


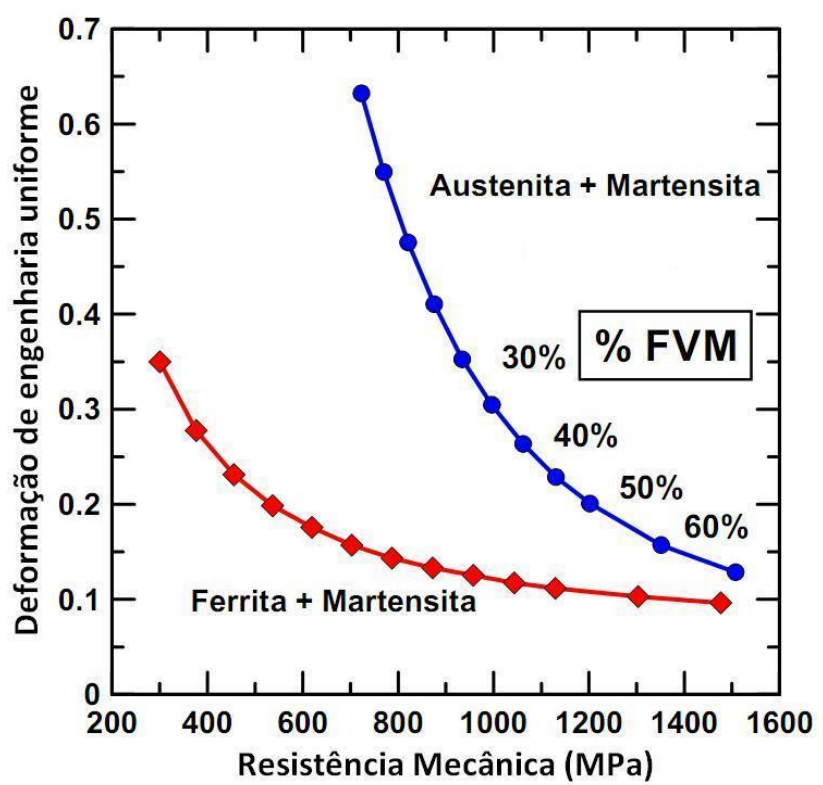

Figura 2-4. Combinações de ductilidade e resistência mecânica para misturas hipotéticas de ferrita + martensita (linha vermelha) e austenita + martensita (linha azul) [28]. FVM representa fração volumétrica da martensita.

\subsection{Aços com plasticidade induzida por transformação e estabilidade da austenita}

O aumento significativo da plasticidade durante uma transformação de fase é conhecido como efeito TRIP - Transformation Induced Plasticity. Esse efeito foi descrito e investigado pela primeira vez em 1967 por Zackay et al [29], embora já houvesse sido utilizado anteriormente nos aços Hadfield de alto teor de manganês [30]. Esse efeito é observado em aços multifásicos em que a austenita retida se transforma em martensita durante a aplicação de uma deformação, fenômeno conhecido como transformação martensítica induzida por deformação (SIMT, do inglês strain-induced martensitic tranformation) [31], aumentando a taxa de encruamento e possibilitando um alongamento maior. A produção desse tipo de aços pode ser realizada a partir de duas rotas de processamento: recozimento contínuo ou laminação a quente. O primeiro pode ser realizado por meio de austenitização plena ou parcial (recozimento intercrítico) de chapas de aço com microestrutura ferrítica-perlítica, previamente laminadas a frio. Nesse caso, o aço multifásico é inicialmente aquecido até a temperatura de austenitização plena ou intercrítica (entre $\mathrm{Ac}_{1}$ e $\mathrm{Ac}_{3} \approx 700$ e $900{ }^{\circ} \mathrm{C}$ ), permitindo a dissolução da perlita e a recristalização da microestrutura deformada, e mantido nessa temperatura por certo tempo (3 a 5 minutos) para formar uma microestrutura $100 \%$ austenítica, ou frações volumétricas controladas de austenita e ferrita (no caso intercrítico). No caso da austenitização plena, a formação de ferrita desejada é controlada durante o resfriamento, enquanto no recozimento intercrítico, a fração volumétrica de ferrita é determinada pela temperatura de aquecimento. Após austenitização plena ou parcial o aço é resfriado até a temperatura de transformação 
bainítica $\left(350-500{ }^{\circ} \mathrm{C}\right)$. No caso da austenitização intercrítica o resfriamento é rápido (> 20 ${ }^{\circ} \mathrm{C} / \mathrm{s}$ ), a fim de evitar as transformações ferrítica ou perlítica. Em ambos os casos, o aço é mantido novamente na temperatura de transformação bainítica (austêmpera) por certo tempo (200 - 600 s) para que parte da austenita formada na temperatura intercrítica ou durante a austenitização plena se transforme em bainita. A quantidade de austenita transformada em bainita dependerá da temperatura e do tempo de manutenção no patamar isotérmico de transformação bainítica. Nas etapas de recozimento intercrítico, transformação ferrítica e de transformação bainítica, a austenita é enriquecida em carbono, o que causa uma redução da temperatura $M_{S}$ (temperatura de início da transformação martensítica) para abaixo da temperatura ambiente, aumentando sua estabilidade. Finalmente, o aço é temperado à temperatura ambiente, formando-se uma microestrutura constituída por ferrita, bainita, austenita retida e, eventualmente, uma pequena porcentagem de martensita.

Como mencionado, o segundo procedimento para produzir aços com efeito TRIP é por laminação a quente. Nesse caso, o aço é laminado em alta temperatura (região austenítica) e subsequentemente mantido no campo intercrítico para formar uma quantidade controlada de ferrita e enriquecer a austenita em carbono. Posteriormente, o material é resfriado rapidamente até a temperatura de transformação bainítica e bobinado nessa temperatura, para que a austenita se transforme parcialmente em bainita. Nesse procedimento também se evita a formação de perlita durante o resfriamento e a precipitação de cementita na etapa de transformação bainítica. De forma semelhante ao que acontece no recozimento intercrítico, no processo de laminação a quente também ocorre enriquecimento em carbono da austenita, tanto na temperatura intercrítica como na etapa de transformação bainítica, diminuindo-se a temperatura $M_{s}$ para obter austenita retida estável na temperatura ambiente. Estimativas avaliam que na região ferrítica o teor de carbono na austenita aumenta de $0,2 \%$ para $0,3-0,4 \%$, enquanto na região de transformação bainítica esse teor aumenta para 1,0 - 1,5\%. Isto significa que o primeiro estágio não é suficiente para evitar a transformação martensítica durante a têmpera final, sendo, portanto, necessário o estágio de transformação bainítica para garantir a estabilidade da austenita.

Para realizar esses procedimentos, os elementos de liga desempenham um papel importante, principalmente no posicionamento das curvas no diagrama de resfriamento contínuo e no enriquecimento em carbono da austenita. Dessa forma, os aços assistidos pelo efeito TRIP contêm principalmente carbono (para enriquecer e estabilizar a austenita) e manganês (que é um elemento estabilizador da austenita e, adicionalmente aumenta a resistência por solução sólida), com certas adições de silício ou alumínio para favorecer a formação de ferrita e suprimir 
a formação de carbonetos (cementita) no patamar isotérmico da transformação bainítica, o que facilita a rejeição do carbono para a austenita. No entanto, altos teores de silício podem ser deletérios para a qualidade superficial dos aços laminados a quente. Adicionalmente, outros elementos como titânio, níquel e vanádio também são adicionados para controlar o comportamento da transformação em aços TRIP e melhorar sua resistência.

A vantagem dos aços assistidos pelo efeito TRIP é que eles têm uma maior ductilidade que outros aços com resistência mecânica similar. Essa característica permite a produção de peças mais complexas para aplicações automotivas. Além disso, como a transformação martensítica não envolve difusão, a sua formação ocorre instantaneamente (independentemente do tempo), o que permite que o efeito TRIP ocorra em altas taxas de deformação. Dessa forma, esse fenômeno favorece a absorção de energia em caso de impacto [32]. Nos aços assistidos pelo efeito TRIP, a energia absorvida (calculada pela área total em baixo da curva tensãodeformação), em função da resistência à tração, tem se mostrado superior à apresentada por aços DP, bainíticos, de baixo carbono e outros aços de alta resistência, como CP e MART [32, 33]. A absorção de energia, associado ao balanço entre resistência e ductilidade (tenacidade), e, por conseguinte, a conformabilidade, são controladas principalmente pela porcentagem e estabilidade da austenita retida.

A austenita retida pode-se transformar em martensita pelo resfriamento até temperaturas suficientemente baixas ou pela aplicação de uma carga externa. No segundo caso, isso pode ocorrer durante a deformação elástica, definida como transformação induzida ou assistida por tensão (stress-assisted), ou após o início do escoamento plástico da austenita $\left(\sigma_{y}^{\gamma}\right)$, definido como transformação induzida por deformação (strain-induced) [34]. Por conseguinte, durante a transformação induzida por deformação vários mecanismos atuam simultaneamente: escoamento plástico, subdivisão das tensões e deformações entre os microconstituintes, pela falta de homogeneidade da deformação plástica entre fases duras e macias, e transformação de fase de austenita para martensita [35]. A mudança do modo de transformação da austenita retida $(\gamma)$ em martensita $\left(\alpha^{\prime}\right)$, de assistida por tensão para induzida por deformação ocorre em uma temperatura definida como $M_{S}^{\sigma}$ [34], como representado na Figura 2-5. Para temperaturas inferiores a $M_{S}$, a transformação martensítica ocorre espontaneamente durante resfriamento nos sítios de nucleação pré-existentes, sem precisar de energia mecânica adicional, devido à suficiente força motriz (dada pela diferença na energia livre química entre as duas fases [36], $\left.\Delta G_{Q}=\Delta G_{Q}^{\alpha^{\prime}}-\Delta G_{Q}^{\gamma}\right)$. Por sua vez, acima da $M_{S}$ a austenita pode se transformar em martensita sob efeito de deformação. Entre $M_{S}$ e $M_{S}^{\sigma}$ a nucleação de martensita se origina apenas por 
esforços elásticos, em sítios de nucleação pré-existentes, como subestruturas de deformação e configurações de discordâncias, e entre $M_{S}^{\sigma}$ e $M_{d}$ a nucleação é induzida por deformação plástica, pela criação de novos sítios de nucleação heterogêneos causados pelas interações (ou interseções) entre discordâncias e/ou bandas de cisalhamento formadas por deslizamento, que podem se apresentar como maclas mecânicas, grupos de defeitos de falhas de empilhamento $[34,37]$. Por conseguinte, a temperatura $M_{s}^{\sigma}$ define uma fronteira aproximada entre os regimes de temperatura em que os dois modos de nucleação operam, sendo que para temperaturas próximas à $M_{s}^{\sigma}$ ambos mecanismos podem operar [38]. Para temperaturas acima de $M_{d}$ não há mais formação de martensita porque em altas temperaturas a energia de falha (ou defeito) de empilhamento da austenita é maior e há menor força motriz para que ocorra transformação martensítica induzida por deformação [33].

A Figura 2-5(b) mostra a relação entre a energia livre de Gibbs e a temperatura (estabilidade termodinâmica) da martensita e a austenita, e descreve o efeito da força motriz mecânica no processo de transformação martensítica. Na temperatura $T_{0}$ a martensita e a austenita, da mesma composição química, têm a mesma energia livre $\left(G_{\gamma}=G_{\alpha^{\prime}}\right)$. Acima de $T_{0}$ a austenita é mais estável, enquanto abaixo de $T_{0}$ a martensita é mais estável devido a sua menor energia livre. Abaixo da temperatura $M_{S}$ a força motriz química $\left(\Delta G_{M S}^{\gamma \rightarrow \alpha^{\prime}}\right)$, produzida pelo super-resfriamento em relação à $T_{0}$, é suficiente para causar a transformação de austenita para martensita, sem ser necessário o aporte de energia mecânica adicional. Observa-se que entre $M_{s}$ e $T_{0}$, na medida em que a temperatura aumenta, a diferença entre as energias livres químicas da austenita e da martensita $\left(\Delta G_{Q(T 1)}^{\gamma \rightarrow \alpha^{\prime}}\right)$ diminui, de modo que austenita já não se transforma espontaneamente em martensita porque a $\Delta G_{Q(T 1)}^{\gamma \rightarrow \alpha^{\prime}}$ não é suficiente. No entanto, a deformação aplicada produz uma força motriz mecânica adicional $\left(\Delta G_{M}\right)^{4}$, suprindo a energia necessária para desencadear a reação. Desse modo, nessa faixa de temperaturas, como as forças motrizes mecânica e química possuem o mesmo sinal (-), com o aumento da temperatura, ambas as forças se adicionam e causam aumento na diferença da energia livre total $\left(\Delta G_{M S}^{\gamma \rightarrow \alpha^{\prime}}=\Delta G_{Q(T 1)}^{\gamma \rightarrow \alpha^{\prime}}+\Delta G_{M}\right)$. Acima da $T_{0}$, os sinais de ambas as energias são opostos e a força motriz química se opõe à transformação de

\footnotetext{
${ }^{4} \mathrm{O}$ componente de energia mecânico na região de nucleação assistida por tensão é dado por: $\Delta G_{M}=\tau_{s} \gamma_{0}+\sigma_{n} \varepsilon_{n}$, onde $\tau_{s}$ é a tensão de cisalhamento projetada (ou resolvida) ao longo do plano de hábito da interface da $\gamma / \alpha^{\prime} ; \gamma_{0}$ é a magnitude da deformação da transformação; $\sigma_{n}$ é a tensão normal projetada no plano de hábito e $\varepsilon_{n}$ é o componente normal de dilatação [293]. Por sua vez, o componente de energia mecânico na região de nucleação induzida por deformação é dado por: $\Delta G_{M}=\frac{1}{8 \pi(1-v)} G b^{\frac{1}{2}} \tau_{s} \gamma_{0}\left(\frac{\varepsilon_{c}}{L}\right)^{1 / 2}+\tau_{s}$, onde $b$ é o vetor de Burgers; $G$ o modulo de cisalhamento, $L$ um parâmetro relacionado com o tamanho de grão da $\gamma, v$ é o coeficiente de Poisson e $\varepsilon_{c}$ e a deformação crítica [38].
} 
fase martensítica [39]. Como consequência, o componente de energia mecânico $\left(\Delta G_{M}\right)$ tem que ser maior que a força motriz química na temperatura $M_{S}\left(\Delta G_{M S}^{\gamma \rightarrow \alpha^{\prime}}\right)$ para induzir a transformação martensítica por deformação. Contudo, com o aumento adicional da temperatura $\left(T>M_{d}\right)$ ocorre um aumento ainda maior da força motriz química, de forma que a força motriz mecânica precisa ser maior e, portanto a transformação induzida mecanicamente se torna impossível [40]. Dessa forma, em altas temperaturas, visto que a tensão de escoamento da austenita $\left(\sigma_{y}^{\gamma}\right)$ é menor (Figura 2-5(a)), independentemente da taxa de deformação, o aumento da tensão causa unicamente deformação plástica convencional ou maclação, ao invés de transformação. Portanto, em aços contendo austenita retida estabilizada na faixa de temperaturas entre $M_{S} \mathrm{e}$ $M_{d}$, a formação de martensita produzida pela deformação plástica ajuda a manter o encruamento, atrasando o início da estricção e criando um maior alongamento uniforme. Essa é a grande vantagem dos aços TRIP [38]. Segundo Jung et al. [35] a estabilidade da austenita retida nos aços TRIP deve ser ajustada de forma que a temperatura em serviço seja ligeiramente superior à temperatura $M_{S}^{\sigma}$. Todavia, a temperatura de utilização do material deve ser menor que a temperatura $M_{d}$ para favorecer o efeito TRIP.

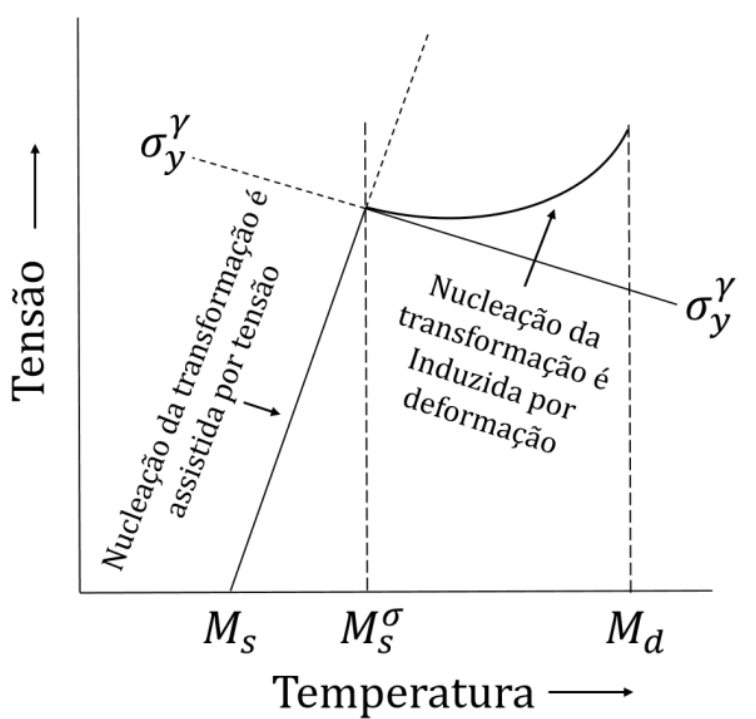

(a)

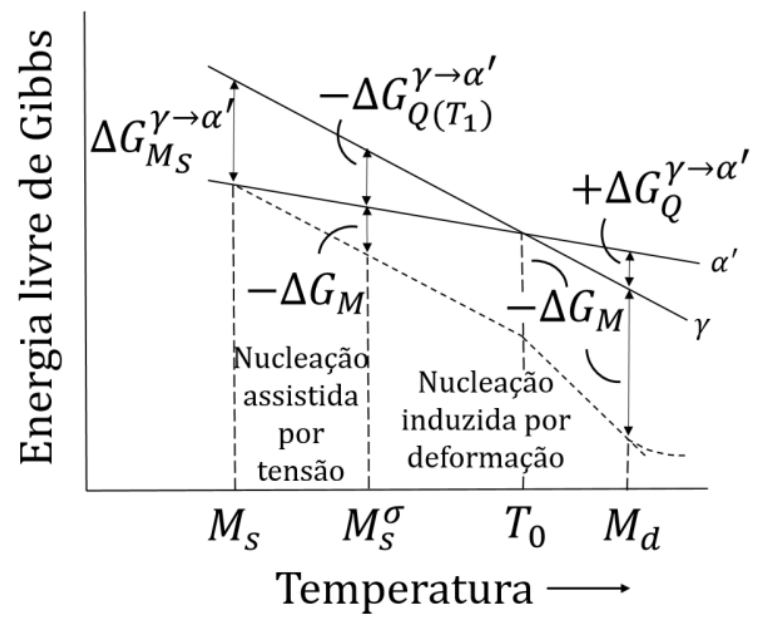

(b)

Figura 2-5. (a) Diagrama esquemático do início da transformação martensítica $\left(\boldsymbol{M}_{\boldsymbol{s}}\right)$ induzida por tensão, deformação e temperatura; (b) variação da energia livre de Gibbs $(\boldsymbol{\Delta} \boldsymbol{G})$ da martensita $\left(\boldsymbol{\alpha}^{\prime}\right)$ e da austenita $(\boldsymbol{\gamma})$ em função da temperatura. $\boldsymbol{\sigma}_{\boldsymbol{y}}^{\gamma}$ e $\boldsymbol{\gamma}^{\varepsilon}$ representam o limite de escoamento da austenita e austenita deformada, e $\Delta \boldsymbol{G}_{\boldsymbol{Q}} \mathrm{e}$ $\Delta \boldsymbol{G}_{\boldsymbol{M}}$ representam as energias livres química e mecânica, respectivamente. $\Delta \boldsymbol{G}_{\boldsymbol{M} \boldsymbol{s}}^{\gamma \rightarrow \boldsymbol{\alpha}^{\prime}}$ e $\Delta \boldsymbol{G}_{\boldsymbol{Q}\left(\boldsymbol{T}_{\mathbf{1}}\right)}^{\gamma \rightarrow \boldsymbol{\alpha}^{\prime}}$ são as mudanças de energia livre químicas devido à transformação $\boldsymbol{\alpha}^{\prime} \rightarrow \boldsymbol{\gamma}$, na temperatura $\boldsymbol{M}_{\boldsymbol{s}}$ e em uma certa temperatura $\boldsymbol{T}_{\mathbf{1}}$, respectivamente. Adaptado de [41].

A plasticidade induzida pela transformação martensítica sob a ação de tensões aplicadas proporciona uma alteração substancial nas propriedades mecânicas do material. Essa 
possibilidade permite projetar materiais e processos que aproveitem a própria transformação de fase em si, e não unicamente as propriedades produzidas ao final da transformação. Essa noção de explorar as propriedades durante as mudanças microestruturais é relativamente recente em relação à visão clássica das relações entre microestrutura e propriedades [42].

Dessa forma, a estabilidade da austenita é hoje discutida em termos de sua estabilidade térmica e mecânica. A primeira avaliada em termos da temperatura $M_{S}$ e a segunda definida pela transformação induzida mecanicamente pela deformação e determinada principalmente pela temperatura $M_{d}$, que representa a máxima temperatura na qual a martensita se forma sob a influência de uma tensão [39]. No primeiro caso essa estabilidade, como tem sido comentado, é garantida, principalmente, pelo teor de carbono, que é um dos elementos fundamentais para estabilização da austenita [43]. No entanto, outros fatores também influenciam a estabilidade da austenita, como seu tamanho de grão, morfologia e orientação, propriedades das fases que a circundam e a temperatura e taxa de deformação [44-48]. Contudo, entre todos os fatores que estabilizam a austenita, o teor de carbono e o tamanho de grão são os dois mecanismos principais $[35,48]$.

Como comentado, o processo de deformação de um aço multifásico é complexo. No caso de uma tensão aplicada, quando a ferrita é a fase circundante da austenita, a ferrita se deforma primeiro, transferindo a carga para austenita, deformando-a e, subsequentemente, causando sua transformação (efeito TRIP), endurecendo o material. Quando a austenita está contornada por fases mais duras, como bainita ou martensita, dificulta-se a transferência da deformação para austenita, de modo que ela se transforma mais lentamente ou não se transforma $[49,50]$. Nesse caso, a austenita, mesmo tendo menor teor de carbono, pode apresentar maior estabilidade durante a deformação. No caso do tamanho do grão, sua redução aumenta a estabilidade da austenita retida pela redução na densidade de sítios de nucleação para que ocorra a transformação martensítica $[47,48]$. Em relação à dependência da morfologia do grão na estabilidade da austenita retida, vários autores propõem [51-55] que frente a uma deformação mecânica a austenita retida na forma de filmes é mais estável do que na forma de blocos, mesmo apresentando um menor teor de carbono. Este comportamento é associado principalmente ao maior número de defeitos, como falhas de empilhamento ou discordâncias, presentes na austenita na forma de blocos [52], que atuam como sítios nucleadores da martensita [56] mesmo em baixas deformações. Além disso, filmes de austenita retida estão geralmente circundados por microconstituintes com maior dureza e resistência ao escoamento plástico, como martensita e bainita. Dessa forma, a austenita é estabilizada pela alta pressão hidrostática exercida por essas fases, que restringe a expansão volumétrica e a deformação cisalhante associada à 
transformação martensítica $[52,57]$. Essa pressão hidrostática $\left(\sigma_{p}\right)$ pode ser determinada pela expressão $[58,59]$ :

$$
\sigma_{p}=\frac{2}{3}\left(\sigma_{y}+2 n \varepsilon^{*}\right)+\frac{2}{3} \sigma_{y} \ln \left[\frac{E \varepsilon^{*}}{(1-v) \sigma_{y}}\right]
$$

em que $\sigma_{y}, n, E$ e $v$ são o limite de escoamento, a taxa de encruamento, o módulo de elasticidade e o coeficiente de Poisson da fase que circunda a austenita (martensita ou bainita), respectivamente, e, $\varepsilon^{*}$ é a taxa de transformação isotrópica para a reação martensítica, determinada de forma aproximada por:

$$
\varepsilon^{*}=0,0058+0,0045 \% C
$$

em que $\mathrm{C}$ representa a porcentagem de carbono (em massa) da fase circundante.

Dessa forma, a pressão hidrostática pode ter uma influência significativa na transformação martensítica em aços com efeito TRIP. De fato, Pyshmintsev et al. [60] mostraram experimentalmente, usando um gerador especial de pressão hidráulica e a técnica de saturação magnética para medir a quantidade de austenita (paramagnética) em amostras de aço TRIP deformadas em tração, que com o aumento da pressão hidrostática houve diminuição da taxa de transformação da austenita em martensita e, em consequência, aumento do alongamento uniforme, sendo que, por exemplo, uma pressão $\sigma_{p}$ de $100 \mathrm{MPa}$ causou diminuição da $M_{s}$ entre 20 e $25{ }^{\circ} \mathrm{C}$. No entanto, os autores também mencionam que o excesso de estabilidade da austenita causada por uma alta pressão hidrostática pode não ser necessariamente favorável à taxa de encruamento durante a deformação.

\subsection{Têmpera e Partição}

$\mathrm{O}$ processo de têmpera e partição (Q\&P) foi desenvolvido com o intuito de gerar microestruturas mistas compostas por martensita, ferrita e frações controladas de austenita retida, principalmente em aços TRIP. Nesse processo a supersaturação de carbono da martensita resultante da têmpera é utilizada, durante a etapa de partição, para estabilizar a austenita não transformada pela migração de carbono da martensita para a austenita [1], em razão da solubilidade do carbono ser muito maior na austenita. A difusão do carbono é possível porque a precipitação de carbonetos é suprimida ou retardada pela adição de elementos de liga, em particular Si, Al e P. A supressão da precipitação de carbonetos, que consomem parte do carbono da austenita, e a estabilização da austenita pelo particionamento do carbono são as grandes diferenças quando comparado com tratamentos térmicos convencionais como de 
têmpera e revenido, onde se espera que o carbono forme carbonetos durante o revenimento da martensita. Segundo Speer et al. [1] quando a precipitação de carbonetos é suprimida, o particionamento do carbono desde a martensita supersaturada para austenita pode ocorrer mesmo em altas temperaturas. Por outro lado, a possibilidade de estabilizar a austenita pelo controle do enriquecimento de carbono durante o processo de partição e a possibilidade de aumentar a resistência do material pela presença de quantidades substanciais de martensita distingue o processo de $\mathrm{Q} \& \mathrm{P}$ dos tratamentos tradicionais de transformação bainítica aplicados em aços TRIP. Adicionalmente, a austenita retida formada no processo de Q\&P é mais refinada quando comparada com a da bainita isenta de carbonetos, que contém geralmente regiões de austenita na forma de blocos, com menores concentrações de carbono, sendo, portanto, menos estável, e apresentando maior potencial para se transformar em martensita de alto teor de carbono, causando diminuição da tenacidade [61].

No processo Q\&P (Figura 2-6), o material é inicialmente austenitizado e nesse estágio o teor de carbono inicial da liga, $\mathrm{C}_{\mathrm{i}}$, é igual ao teor de carbono na austenita, $\mathrm{C}_{\gamma}$ (teor de carbono homogêneo no material). Posteriormente o aço é temperado a uma temperatura específica de têmpera QT entre $M_{s}$ e $M_{f}$ para formar frações volumétricas controladas de martensita e austenita durante o resfriamento. Nessa etapa $C_{i}$ é igual a $C_{\gamma}$ e ao teor de carbono na martensita, $\mathrm{C}_{\alpha^{\prime}}$. Após a têmpera, é feito o tratamento isotérmico de partição que tem como finalidade viabilizar a difusão de carbono da martensita para a austenita. Esse patamar isotérmico pode ser igual à temperatura QT (Q\&P em uma etapa) ou a uma temperatura mais elevada (Q\&P de duas etapas). Nesse estágio, devido à migração do carbono da martensita para austenita, $\mathrm{C}_{\gamma}$ torna-se maior que $\mathrm{C}_{\mathrm{i}}$ e $\mathrm{C}_{\alpha^{\prime}}$. Finalmente o aço é temperado até a temperatura ambiente. Desse modo, como discutido anteriormente, o excesso de carbono em solução sólida na austenita diminui sua temperatura $M_{S}$ e a estabiliza. Uma variação do processo ilustrado na Figura 2-6 consiste em utilizar um tratamento intercrítico em vez da austenitização completa, trazendo como vantagem a produção de austenita com uma concentração inicial de carbono ainda maior, portanto mais estável. A microestrutura resultante consiste principalmente de martensita revenida, ou particionada, e austenita retida e, no caso do tratamento com austenitização intercrítica a microestrutura final contém também ferrita. Dessa forma, no produto final a martensita confere resistência mecânica semelhante à obtida durante o tratamento de revenimento, enquanto a austenita (e a ferrita intercrítica) conferem ductilidade e tenacidade em virtude da ocorrência do efeito TRIP [62]. 


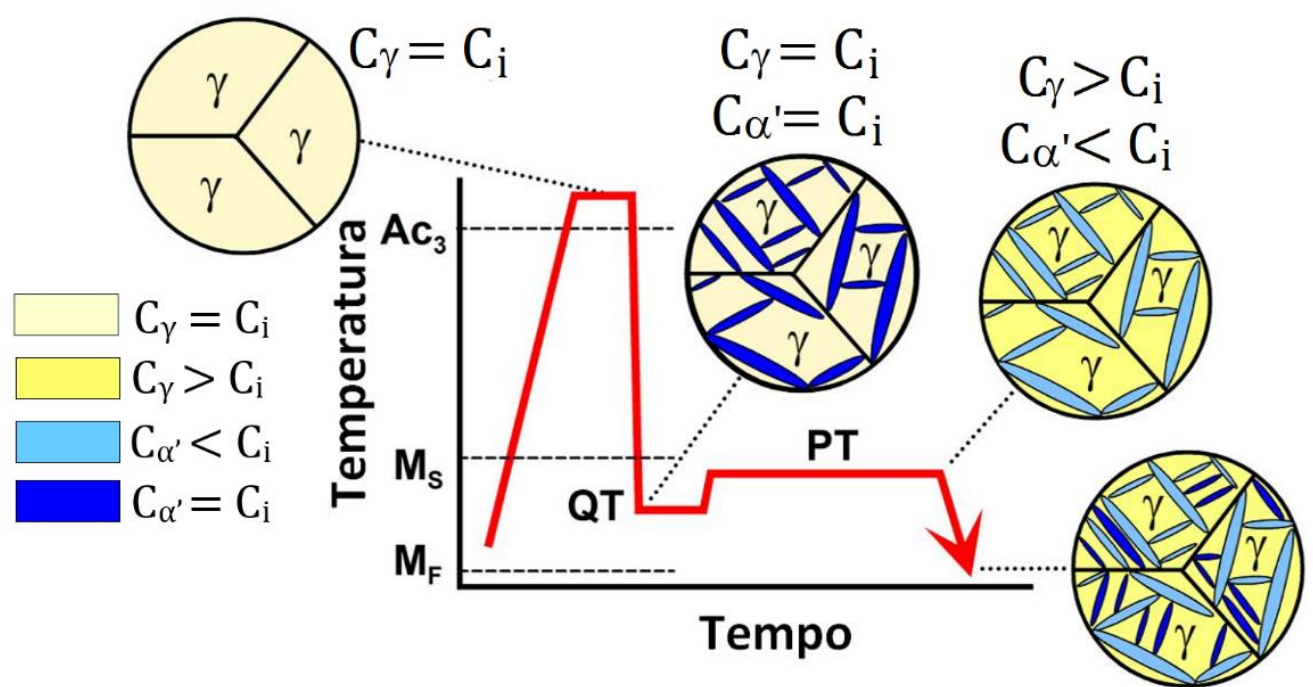

Figura 2-6. Desenho esquemático do processo de Têmpera e Partição (Q\&P). Ci, C $\gamma$ e $C_{\alpha^{\prime}}$ representam a concentração de carbono inicial, na austenita e na martensita, respectivamente. QT e PT representam a temperatura de têmpera de partição, respectivamente [1].

Nos tratamentos térmicos convencionais, a subsequente partição de carbono entre a martensita e a austenita retida é geralmente ignorada, uma vez que as temperaturas usadas são normalmente muito baixas para permitir a difusão significativa após a têmpera e principalmente devido à supersaturação ser geralmente eliminada por processos competitivos, sendo o mais comum deles a precipitação de carbonetos durante a etapa de revenimento [1, 63]. No processo de Q\&P a possiblidade de controlar a fração de austenita e seu teor de carbono representam uma vantagem fundamental no projeto de produção e otimização de microestruturas dos AHSS da terceira geração. A otimização das frações volumétricas de austenita retida é possível pelo controle da fração volumétrica de martensita formada durante a têmpera, por meio da definição da temperatura de têmpera (QT). A temperatura QT não só vai determinar a fração volumétrica de martensita presente nessa temperatura, mas também determina o máximo teor de carbono disponível para estabilizar a austenita sob condições ideais de partição. Assumindo que todo o carbono da martensita se difunde para a austenita, e aplicando o balanço de massa para o carbono, pode-se determinar a fração estável de austenita à temperatura ambiente [1]. Uma implicação dessa consideração é a existência de um compromisso entre a fração de austenita e o grau de enriquecimento possível para um dado material. A termodinâmica desse particionamento ideal do carbono da martensita para austenita é descrito pelo modelo de equilíbrio constrito ou restringido de carbono (CCE, Constrained Carbon Equilibrium), que é caracterizado pela igualdade do potencial químico na austenita e na martensita apenas para o carbono [28, 63-65]. 


\subsubsection{Equilíbrio Constrito ou Restringido de Carbono}

Como discutido anteriormente, fica claro que o mecanismo determinante do processo de Q\&P é a transferência de carbono da martensita supersaturada para a austenita, causado a fim de reduzir a diferença entre o potencial químico de carbono na austenita e na martensita. Alguns autores [1, 65-67] têm afirmado que o "equilíbrio constrito de carbono" (CCE) é a condição que governa esse fluxo de carbono.

O CCE tem origem no conceito de paraequilíbrio proposto por Hultgren [68] e, por isso, essa condição foi inicialmente chamada de paraequilíbrio constrito (Constrained Paraquilibrium) [1]. Após discussão entre Hillert e Ägren [65, 67] e Speer et al. [66] o termo equilíbrio constrito de carbono foi adotado e vem sendo mais comumente utilizado. $\mathrm{O}$ paraequilíbrio é uma condição termodinâmica que considera que o equilíbrio é estabelecido apenas em relação à espécie com maior mobilidade, ou seja, é representado em situações em que a difusividade dos elementos substitucionais é desprezível (isto é, quando a fração de sítios do elemento de baixa mobilidade permanece a mesma na fase produto e na fase matriz), quando comparado com a rápida difusão de elementos intersticiais como o carbono. Para a condição de paraequilíbrio ser atingida é necessário que os percentuais das fases sejam ajustados, que pode ser alcançado sob a condição cinética de migração da interface de transformação [69]. Essa migração envolve, mesmo que em curta escala, movimentação de Fe e outros átomos substitucionais [37]. Na condição de equilíbrio constrito de carbono (CCE) os átomos de ferro e substitucionais permanecem completamente imóveis, mas o carbono pode ser redistribuído (particionado) em larga escala entre as fases sob a restrição (constraint) de uma interface fixa ou estacionária [70]. Como a interface é considerada fixa, a difusão de elementos substitucionais não ocorre, nem mesmo em curta escala, de modo que o paraequilíbrio entre martensita (ferrita) e austenita não pode ser atingido em um sistema multicomponente (ou de ortoequilíbrio no diagrama $\mathrm{Fe}-\mathrm{C}$ ). Essas condições dão origem ao conceito de paraequilíbrio constrito (constrained paraequilibrium), posteriormente chamado de CCE.

Desta forma, o conceito CCE considera que tanto os átomos de ferro como os substitucionais são imóveis em temperaturas onde ocorre a difusão do carbono, de forma que a difusão em baixas temperaturas fica limitada aos átomos intersticiais e que a interface martensita-austenita pode ser assumida imóvel ou estacionária. Assumindo a interface estacionária, a condição básica de equilíbrio define que a partição de carbono finaliza quando o potencial químico do carbono $\left(\mu_{c}\right)$ na interface for igual em ambas as fases $\left(\mu_{c}^{\gamma}=\mu_{c}^{\alpha}\right)$. Portanto, o modelo não 
considera a expansão volumétrica frequentemente observada na etapa de partição [71-74], nem a formação de carbonetos ou a segregação de carbono para as discordâncias da martensita.

A Figura 2-7 mostra esquematicamente o diagrama de Energia livre de Gibbs (G) vs. composição $(\mathrm{Fe}-\mathrm{C})$ para a ferrita $(\alpha)$ e austenita $(\gamma)$ para uma dada temperatura e considerando a pressão constante. Nessa figura observa-se que o potencial químico dos elementos nas diferentes fases pode ser deduzido a partir de uma tangente comum às curvas da energia livre de Gibbs. Na Figura 2-7(a) se observa que a tangente comum para as respectivas composições químicas das fases em equilíbrio $\left(\chi_{E q}\right)$ satisfaz a condição de igual potencial químico para o carbono $\left(\mu_{c}^{\gamma}=\mu_{c}^{\alpha}\right)$ e o ferro $\left(\mu_{F e}^{\gamma}=\mu_{F e}^{\alpha}\right)$. Isso significa que as composições de $\alpha$ e $\gamma$ são únicas no ortoequilíbrio (condição de mínima energia livre). Assim, a condição termodinâmica em que o potencial químico do carbono é igual em ambas as fases se satisfaz quando as tangentes às curvas de energia livre da $\alpha$ e da $\gamma$ interceptam o eixo do carbono (eixo à direita das ordenadas) em um único ponto. Desse modo, a Figura 2-7(b) ilustra dois exemplos de composição química para $\alpha$ (em azul) e $\gamma$ (vermelho) com o mesmo potencial químico para o carbono na $\alpha$ e $\gamma$ $\left(\mu_{c}^{\gamma(I-I I)}=\mu_{c}^{\alpha(I-I I)}\right)$ e diferente potencial químico para o ferro na $\alpha$ e $\gamma\left(\mu_{F e}^{\gamma(I-I I)} \neq \mu_{F e}^{\alpha(I-I I)}\right)$, em ambas as composições. Como cada ponto de carbono pode ser usado para projetar uma tangente às curvas de energia livre de $\alpha$ e $\gamma$, infere-se que existem infinitas composições $(\chi)$ possíveis para $\alpha$ e $\gamma$ que satisfazem a condição $\mu_{c}^{\gamma}=\mu_{c}^{\alpha}$ [1]. Isso significa que sob condições de CCE não há uma composição fixa de cada fase que satisfaça a condição termodinâmica geral. No entanto, embora existam infinitos pares de composições obedecendo à relação $\mu_{c}^{\gamma}=\mu_{c}^{\alpha}$, a restrição devido ao balanço de massa permite definir uma composição única a ser alcançada para cada situação.

A partir das atividades do carbono nas fases $\alpha$ e $\gamma[75,76]$, no sistema Fe-C, é possível obter uma relação entre as composições em $\alpha$ e $\gamma$, que obedecem à igualdade do potencial de carbono em ambas as fases:

$$
\chi_{C}^{\gamma}=\chi_{C}^{\alpha} \exp \left[\frac{76789-43,8 T-(169105-120,4 T) \chi_{C}^{\gamma}}{R T}\right]
$$

em que $\chi_{C}^{\gamma}$ e $\chi_{C}^{\alpha}$ são as frações molares de carbono na austenita e na ferrita, respectivamente e $T$ e $R$ são a temperatura (em $\mathrm{K}$ ) e a constante universal dos gases.

A restrição imposta pelo CCE da interface estacionária pressupõe que o número de átomos de ferro e substitucionais permanece inalterada em ambos os lados da interface durante a partição. Esse balanço de massa para os átomos de ferro (ou outro átomo substitucional) entre 
a austenita inicialmente não transformada e a austenita na condição de equilíbrio constrito de carbono (CCE) pode ser formulado como:

$$
f_{C C E}^{\gamma}\left(1-\chi_{C C E}^{\gamma}\right)=f_{i}^{\gamma}\left(1-\chi_{C}^{\text {liga }}\right)
$$

em que $\chi_{C}^{\text {liga }}$ é o teor de carbono total da liga (em fração atômica), $f_{i}^{\gamma}$ é a fração molar de austenita retida antes da etapa partição e $f_{C C E}^{\gamma}$ e $\chi_{C C E}^{\gamma}$ são a fração de austenita e sua concentração de carbono, na condição de CCE quando a partição de carbono finaliza. Note-se que para um sistema binário $\mathrm{Fe}-\mathrm{C}$ :

$$
1-\chi_{C}=\chi_{F e}
$$

O balanço de massa para o carbono, obtido pela soma dos teores de carbono em ambas as fases, pode ser expresso como:

$$
f_{C C E}^{\alpha} \chi_{C C E}^{\alpha}+f_{C C E}^{\gamma} \chi_{C C E}^{\gamma}=\chi_{C}^{l i g a}
$$

em que $f_{C C E}^{\alpha}$ e $\chi_{C C E}^{\alpha}$ são a fração molar de martensita particionada e o teor de carbono na martensita, ambas na condição de CCE. Dessa forma, a relação entre as frações de fase pode ser obtida a partir da equação 2.5 :

$$
f_{C C E}^{\alpha}+f_{C C E}^{\gamma}=1
$$

Portanto, o CCE pode ser determinado pela solução (obtida por processo numérico iterativo, solução numérica) simultânea das equações 2.3 a 2.5. A descrição feita para o sistema $\mathrm{Fe}-\mathrm{C}$, pode ser utilizada igualmente em aços de baixa liga [1], modificando as atividades do carbono (equação 2.3) em função dos parâmetros de interação do carbono com os demais substitucionais. Cálculos mostram que embora a aplicação das equações acima seja relativamente simples, é possível estimar a composição da austenita, no CCE com razoável precisão assumindo que todo o $\mathrm{C}$ da $\alpha^{\prime}$ se difunde para $\gamma$ durante a partição e aplicando-se um balanço de massa para o $\mathrm{C}$ baseado na quantidade de $\gamma$ após o tratamento de têmpera [37]. 


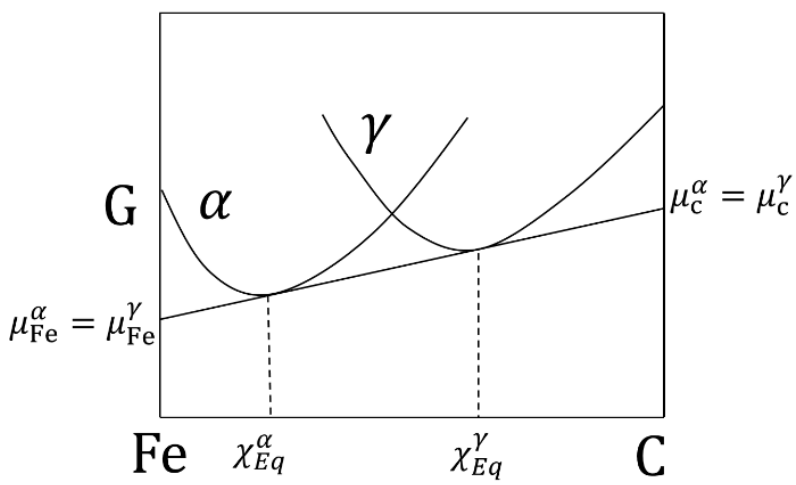

(a)

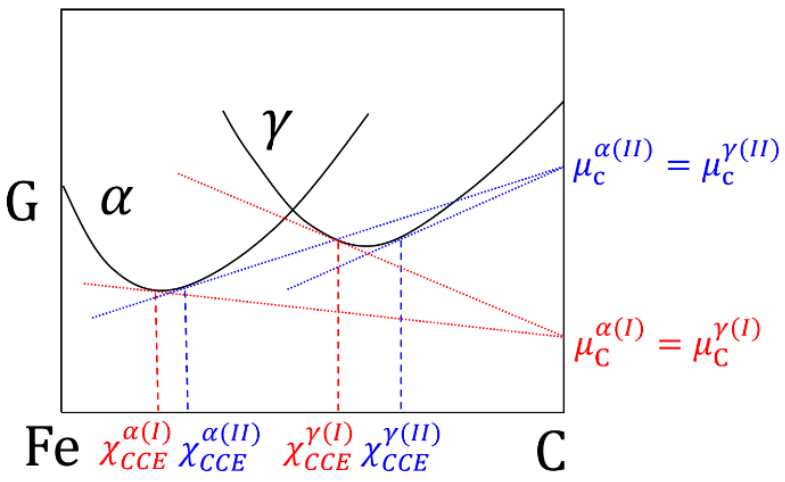

(b)

Figura 2-7. Diagrama esquemático da energia livre de Gibbs $(G)$ vs. composição (para uma dada temperatura e considerando pressão constante) entre ferrita $(\boldsymbol{\alpha})$ e austenita $(\boldsymbol{\gamma})$ para um sistema Fe-C, indicando: (a) a tangente

comum para as respectivas composições químicas de equilíbrio $\left(\chi_{E q}\right)$ que satisfazem a condição de igual potencial químico para o carbono $\left(\boldsymbol{\mu}_{c}^{\gamma}=\boldsymbol{\mu}_{c}^{\alpha}\right)$ e o ferro $\left(\boldsymbol{\mu}_{\boldsymbol{F} \boldsymbol{e}}^{\gamma}=\boldsymbol{\mu}_{\boldsymbol{F} \boldsymbol{e}}^{\alpha}\right)$; (b) condições possíveis de Equilíbrio Constrito de Carbono (CCE), ilustrando dois exemplos (I e II) de composição química para $\boldsymbol{\alpha}$ (em azul) e $\boldsymbol{\gamma}$ (vermelho) com o mesmo potencial químico para o carbono e diferente potencial químico para o ferro na $\boldsymbol{\alpha}$ e $\boldsymbol{\gamma}$ em ambas as composições.

\subsection{Estampagem a quente}

Existe uma grande dificuldade na produção de chapas de elevada resistência com o processo comum de estampagem a frio devido à baixa conformabilidade, elevado efeito mola e susceptibilidade à ruptura, além de causar desgaste nas ferramentas de conformação e requerer maiores forças durante a conformação, de forma que o processo de estampagem a quente (Hot Stamping) foi proposto como uma alternativa no processamento de componentes estruturais.

O processo de estampagem a quente é uma tecnologia relativamente recente que combina o método tradicional de tratamento térmico de têmpera com a tecnologia da conformação (Figura 2-8). As propriedades e qualidade final das peças estampadas por este processo são fortemente afetadas pelo material e pelos parâmetros do ciclo termomecânico utilizado, tais como tempo e temperatura de austenitização, caminhos da deformação, taxa de resfriamento, temperatura e evolução da microestrutura, os quais interagem entre si durante a conformação e os estágios do resfriamento.

Esse processo foi desenvolvido e patenteado em 1977 por uma companhia sueca (Plannja Hard Tech), a qual usou o processo para lâminas de serra e lâminas cortadoras de grama [77]. Em 1984, a companhia $S A A B$ Automobile $A B$ foi a primeira fabricante de veículos que adotou o processo em um componente de aço avançado de alta resistência (o aço 22MnB5) para o automóvel $S A A B 9000$ [78]. No entanto, até o final dos anos noventa, devido às excelentes vantagens industriais observadas, muitas indústrias e instituições do mundo todo começaram a contribuir para o desenvolvimento do processo [79]. O rápido crescimento da produção de automóveis gerou uma intensa competição entre os fabricantes, levando à redução dos preços 
nos diversos modelos oferecidos. Somado a isto, o crescimento da demanda por redução de peso nos veículos (a qual reduz o consumo de combustível) e peças de maior qualidade e maior nível de segurança para os passageiros forçaram o avanço da tecnologia de estampagem. Atualmente, estima-se que os componentes estampados a quente contribuem com aproximadamente $25 \%$ da redução do peso dos veículos sem afetar seu rendimento [23].

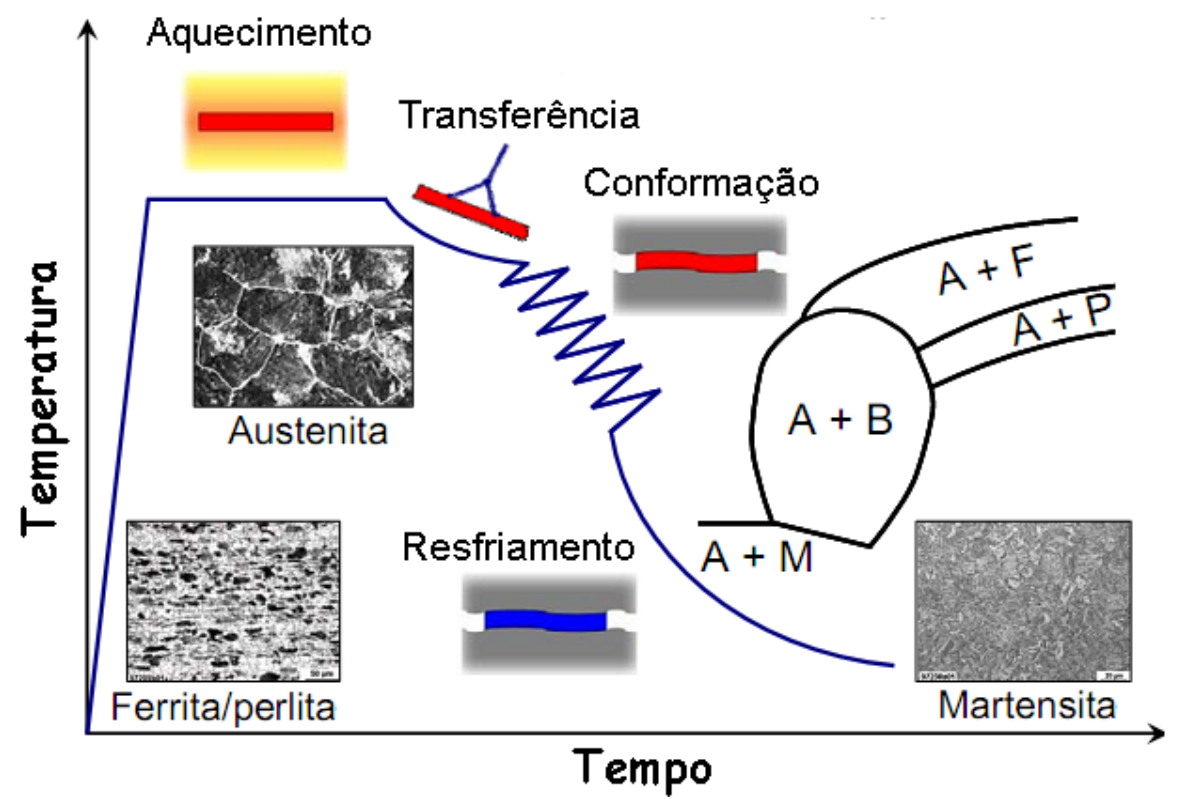

Figura 2-8. Processo de estampagem a quente [80].

O processo de estampagem a quente (particularmente desenvolvido para aços ao boro) é caracterizado pelo aquecimento da peça até uma temperatura ligeiramente superior à temperatura crítica (austenitização), manutenção nesta temperatura por certo tempo, e em seguida, resfriamento até a temperatura de conformação, que varia entre 800 e $600{ }^{\circ} \mathrm{C}$, para logo ser resfriada a uma velocidade suficientemente alta para garantir a transformação martensítica. A conformação plástica a temperaturas elevadas permite obter geometrias complexas devido à elevada conformabilidade a quente do material, proporcionada pela fase austenítica [81]. Em consequência, a principal vantagem de aplicar o processo de estampagem a quente está na excelente precisão nas formas dos componentes tratados e na possibilidade de produzir peças AHSS sem nenhum efeito mola [79].

Portanto, pesquisas experimentais sobre a estampagem a quente de aços de alta resistência requerem o desenvolvimento de novos métodos de ensaio e de técnicas experimentais que permitam avaliar a influência dos parâmetros e das condições típicas do processo sobre as propriedades de chapas de aço de alta resistência, bem como os fenômenos térmicos, mecânicos e microestruturais envolvidos no processo. 


\subsubsection{Método direto de estampagem a quente}

No método direto de estampagem a quente (Figura 2-9), os componentes são austenitizados em temperaturas entre 900 e $950^{\circ} \mathrm{C}$, com manutenção nesta temperatura durante 4 a 10 minutos, dependendo da espessura da chapa, sendo subsequentemente transferidos, o mais rápido possível, para uma matriz de conformação. A transferência geralmente leva de 3 a 6 s. Em altas temperaturas $\left(650\right.$ a $\left.850{ }^{\circ} \mathrm{C}\right)$, o material tem alta conformabilidade, devido a sua microestrutura nesta temperatura (austenita + bainita e/ou ferrita), que permite criar mais facilmente formas complexas a partir de um único golpe. Os componentes são estampados e logo resfriados dentro da ferramenta por um período de tempo $(\approx 10 \mathrm{~s})$ especificado de acordo com a espessura da chapa até a profundidade almejada ser atingida. Durante esse período a peça conformada é temperada em um conjunto de matriz fechada, que é resfriada internamente por meio de canais de circulação de água, a uma taxa de 50 a $100{ }^{\circ} \mathrm{C} / \mathrm{s}$, garantindo a têmpera plena (transformação martensítica) do componente. Uma vantagem do processo é a possibilidade de controlar a velocidade de resfriamento para obter as microestruturas desejadas. $\mathrm{O}$ tempo total do ciclo de transferência, estampagem, e resfriamento na matriz é de 15 a 25 s. A peça sai da linha de estampagem a quente a aproximadamente $100^{\circ} \mathrm{C}$, de forma a evitar grandes distorções térmicas após o resfriamento ao ar. O produto final possui limites de resistência entre 1400 e $1600 \mathrm{MPa}$ e limite de escoamento entre 1000 e $1200 \mathrm{MPa}$ [82]. Depois desse processo, as peças são geralmente perfuradas e cortadas a laser ou por meios convencionais de corte sob pressão na matriz.

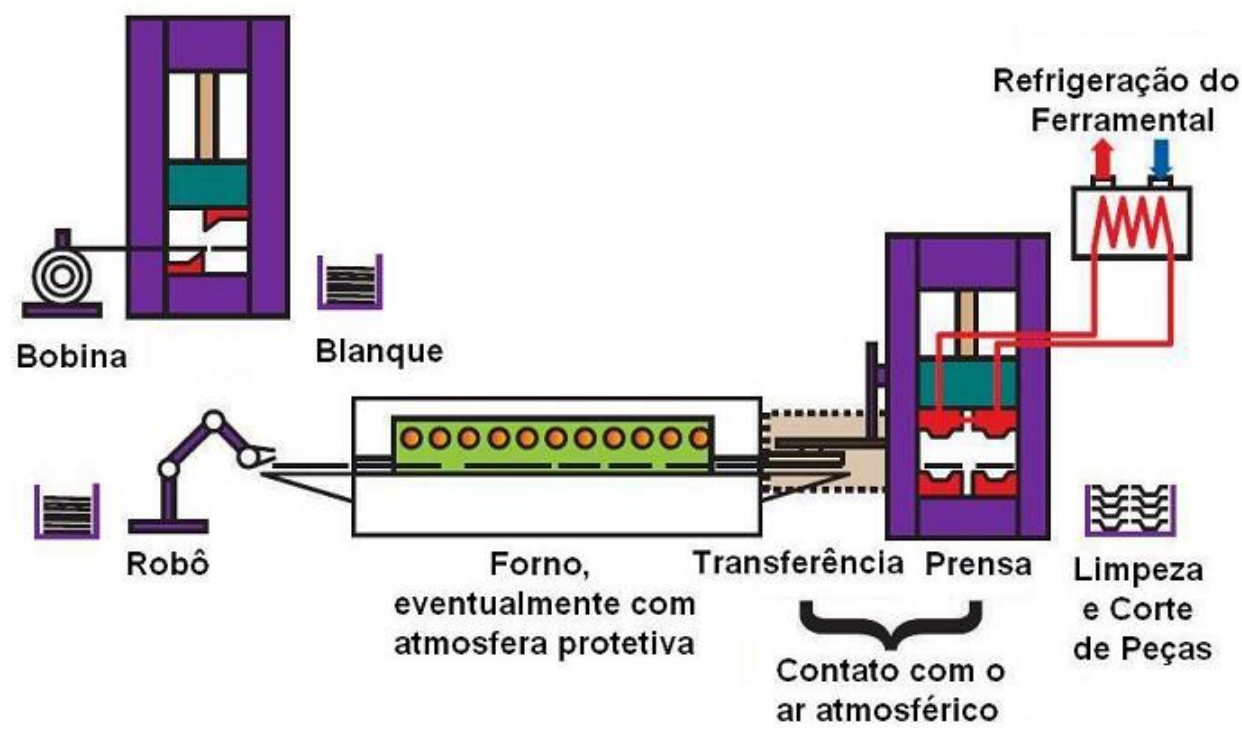

Figura 2-9. Método direto de estampagem a quente [83]. 


\subsubsection{Método indireto de estampagem a quente}

No processo indireto (Figura 2-10), ao contrário do método direto de estampagem a quente, a peça é estampada até aproximadamente 80 a $90 \%$ de sua forma final em uma matriz convencional, sem aquecimento, seguida por uma operação de rebarbação parcial, que depende da tolerância da borda. Em seguida, os blanques (pré-deformados) são aquecidos no forno até a temperatura de austenitização e são subsequentemente temperados na matriz, com os mesmos princípios descritos no processo de estampagem direto. A razão para o passo adicional é aumentar os limites de conformação para peças com formas muito mais complexas e reduzir o desgaste nas ferramentas e peças conformadas. No entanto, este método é mais raramente usado em aplicações industriais.

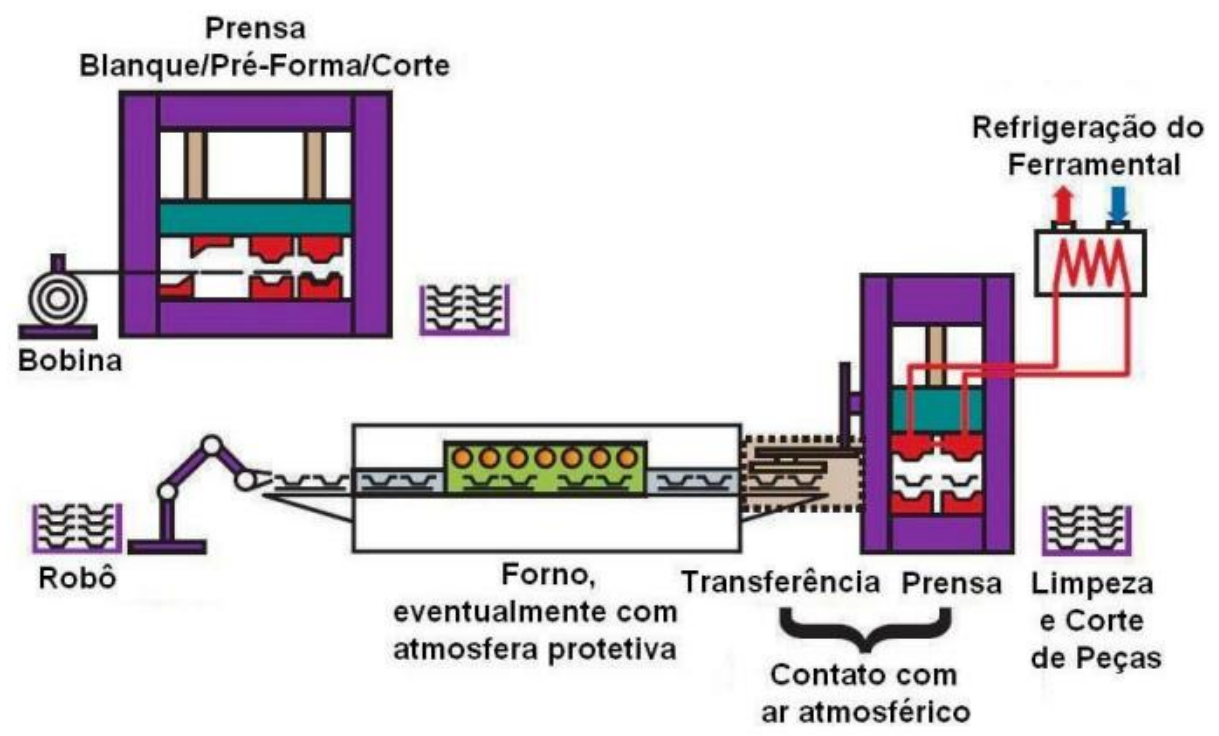

Figura 2-10. Método indireto de estampagem a quente [83].

\subsection{Importância e justificativa da aplicação dos processos de estampagem a quente e de têmpera e partição}

Em resposta às demandas da indústria automobilística por materiais com melhor relação entre resistência mecânica e ductilidade, as pesquisas na indústria siderúrgica continuam exigindo o desenvolvendo de novos tipos de aços avançados de alta resistência. Esses aços podem ser usados em várias peças do chassi, a fim de melhorar a segurança do passageiro e a redução do peso do automóvel pela utilização de chapas com espessura mais fina. No entanto, é sabido que a alta resistência desses aços, a qual é relativamente maior do que as chapas de aço de baixo carbono, leva à perda da sua conformabilidade e ao aparecimento do efeito mola (springback) nas peças deformadas. 
Atualmente, a estampagem a quente dos aços de alta resistência está se mostrando como uma tecnologia que permite atingir as estritas exigências tecnológicas da fabricação de automóveis. A alta conformabilidade e a redução do efeito mola exibido durante a deformação em altas temperaturas, junto à evolução microestrutural, controlada durante a têmpera, são as principais questões que fazem deste um processo de interesse na produção de peças complexas com espessura reduzida (devido à relação melhorada entre massa e resistência). Portanto, o processo de estampagem a quente continua ganhando atenção internacional dos círculos industriais e das equipes acadêmicas, focando sua implementação principalmente na indústria automotiva, embora se espere que esta tecnologia possa ser estendida a outros usos industriais, especialmente na construção de pontes, trens de alta velocidade e construção civil [84].

Um dos principais objetivos no desenvolvimento e aplicação dos aços avançados de alta resistência para a diminuição do peso do automóvel, é que estes não só levam a uma redução significativa das emissões de $\mathrm{CO}_{2}$ e de redução do consumo de energia, senão que também possuem vantagens no aumento da segurança dos passageiros devido à maior absorção de energia durante as colisões, bem como, na reciclagem e reutilização dos materiais. Portanto, a redução do peso e dos custos, a partir de novas tecnologias de estampagem de chapas de aço, são os principais objetivos dos estudos atuais de conformação de peças para indústria automotiva.

Como discutido anteriormente, entre todos os fatores que estabilizam a austenita, há indícios de que o teor de carbono e o tamanho de grão são os dois mecanismos principais [35, 48]. A estabilidade mecânica da austenita produzida pelo enriquecimento em carbono e a redução do tamanho de grão causada pela deformação em alta temperatura são as principais abordagens e interesses de estudo na presente pesquisa. A primeira abordagem é feita pelo tratamento de Q\&P, enquanto a segunda pelo processamento termomecânico de deformação em alta temperatura (hot stamping). A combinação da deformação em alta temperatura e do Q\&P é realizada com a intenção de reduzir o tamanho de grão e aumentar a resistência mecânica sem afetar significativamente o alongamento e a tenacidade do material sem a necessidade de se usar elementos de liga adicionais que possam encarecer os custos do material.

Desta forma, pesquisas experimentais sobre a estampagem a quente de aços de alta resistência em temperaturas elevadas e do processo de Q\&P requerem o desenvolvimento de novos métodos de ensaio e de técnicas experimentais que permitam avaliar a influência dos parâmetros e das condições típicas dos processos (temperaturas e tempos de manutenção, quantidades e temperaturas de deformação, entre outros) sobre as microestruturas e as propriedades mecânicas de chapas de aço TRIP, sendo necessárias técnicas aprimoradas do 
monitoramento dos fenômenos térmicos, mecânicos e microestruturais envolvidas nos tratamentos termomecânicos.

\subsection{Efeitos da deformação plástica em alta temperatura}

Desde o final dos anos 1950 resultados de pesquisa sobre a influência da conformação a quente nas transformações de fase mostraram que a deformação poderia ter influência na subsequente transformação da austenita. Entretanto, somente a partir dos anos 1980 constatouse que em aços de baixo carbono a transformação $\gamma \rightarrow \alpha$ podia ser dinamicamente induzida pela deformação e que o tamanho de grão da ferrita produzido por essa transformação era muito mais refinado do que o produzido pela laminação a quente convencional $[85,86]$. Esse tipo de transformação tem sido descrita como transformação ferrítica induzida pela deformação (DIFT, Deformation Induced Ferrite Transformation) [86]. A literatura técnica inglesa, se refere também a esse mecanismo como: Deformation Induced Transformation (DIT) [87, 88], Strain Induced Transformation to Ferrite (SITF) [89], Strain induced transformation (SIT) [90][91], Strain Induced Dynamic Transformation (SIDT) [92], ou Dynamic Strain Induced Transformation [93]. Independente da denominação adotada, todos os estudos concordam em que esse tipo de transformação é determinado por duas características comuns: a transformação ocorre durante a deformação aplicada, dentro de uma determinada faixa de temperaturas, e o refinamento dos grãos de ferrita pode ser obtido através dessa transformação. A transformação é induzida tanto pelo aumento da energia livre da austenita (devido ao aumento da densidade de defeitos como discordâncias e por acúmulo de tensões internas [94]), como pelo aumento da densidade de sítios de nucleação [86]. Não só a quantidade, taxa e temperatura de deformação aplicados nos processos termomecânicos podem ter efeitos significativos na transformação, mas também, a composição química do aço e o tamanho do grão da austenita apresentam influencias significativas no efeito DIFT. Hoje, por exemplo, é consenso que a diminuição da temperatura de deformação, o aumento da quantidade de deformação e um grão austenítico refinado favorecem a formação de ferrita por efeito DIFT [91, 93, 95, 96].

Termodinamicamente, no efeito DIFT a energia de deformação armazenada na austenita aumenta a força motriz para que ocorra a transformação de fase [97]. Sob condições de deformação, a força motriz depende de duas componentes de energia: uma é a energia livre química $\Delta G_{Q}$ e a outra é a energia de deformação armazenada $\left(\Delta G_{\varepsilon}\right)$. Esse excesso de energia pode induzir ou acelerar a transformação $\gamma \rightarrow \alpha$ em temperaturas acima das temperaturas $\mathrm{Ae}_{1}$ ou $\mathrm{Ae}_{3}$ (temperaturas de equilíbrio de início e fim da austenitização) [94]. Isso significa que 
depois da deformação da austenita, a uma certa temperatura, a energia livre de Gibbs da austenita aumenta por causa da energia de deformação armazenada, como ilustrado na Figura 2-11(a). Nessa figura se observa que a deformação plástica aumenta as concentrações do elemento $i$ (p. ex. o carbono em um diagrama Fe-C) na austenita e na ferrita. A Figura 2-11(b) ilustra a influência da energia de deformação armazenada, $E_{\varepsilon}$, na força motriz para que ocorra a transformação $\gamma \rightarrow \alpha$ [98]. Segundo esse resultado, existe uma energia de deformação armazenada $\left(E_{\varepsilon}\right)$ de $\approx 90 \mathrm{~J} / \mathrm{mol}$ causada pela deformação da austenita a $780{ }^{\circ} \mathrm{C}$. Li et al. [99] mostraram que para um ensaio de compressão uniaxial uma deformação de $36 \%$ cria uma $E_{\varepsilon}$ de $20 \mathrm{~J} / \mathrm{mol}$, causando um aumento na temperatura $\mathrm{Ae}_{3} \mathrm{de} \approx 10^{\circ} \mathrm{C}$.

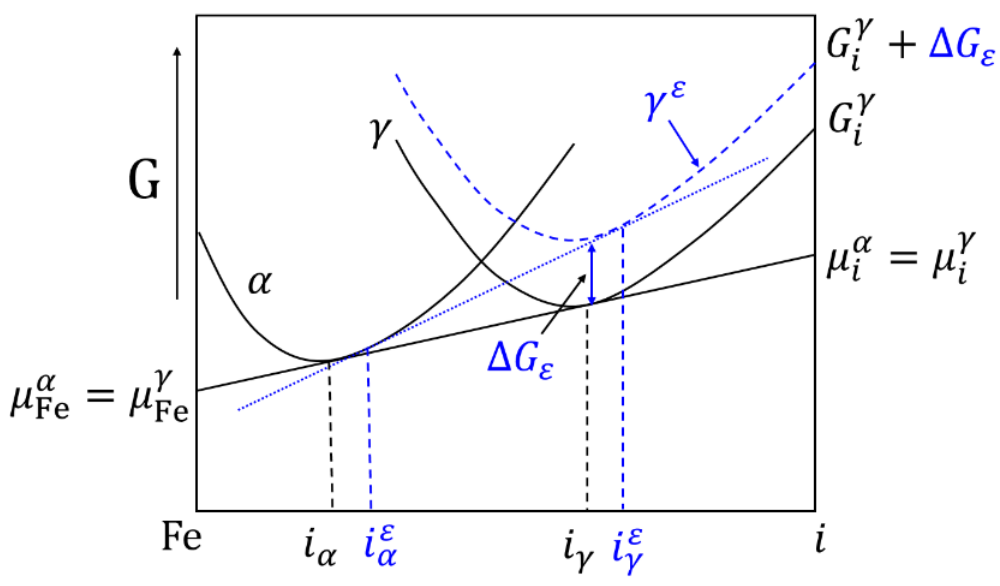

(a)

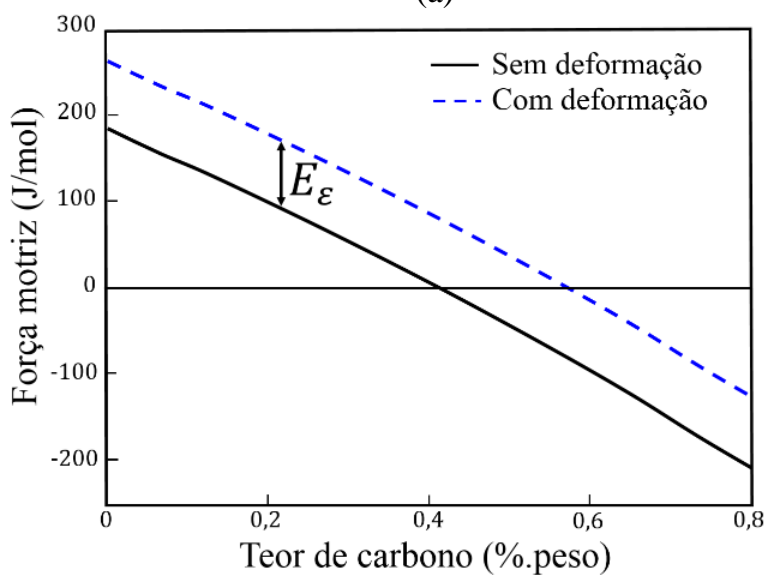

(b)

Figura 2-11. Representação esquemática da variação da energia livre de Gibbs $(\mathrm{G})$ com e sem energia de deformação armazenada $\Delta \boldsymbol{G}_{\boldsymbol{\varepsilon}}$ na austenita $(\gamma)$ para um sistema binário Fe-i (i, é um elemento puro). $\alpha$ e $\boldsymbol{G}_{\boldsymbol{i}}^{\boldsymbol{\gamma}}$ representam ferrita e a energia livre de Gibbs molar de um elemento i [99]. (b) Força motriz para transformação $\gamma \rightarrow \alpha$ em função do teor de carbono a $780{ }^{\circ} \mathrm{C}$, para um aço de baixo carbono [98].

Como durante a deformação a quente, parte da energia de deformação é armazenada principalmente na forma de discordâncias, essa relação pode ser determinada de acordo com a expressão:

$$
\Delta G_{\varepsilon}=k \mu \rho b^{2} V_{\gamma}
$$


em que $\rho$ é a densidade de discordâncias, $\mu$ e $b$ representam o modulo de cisalhamento e o vetor de Burgers da austenita, ambos em função da temperatura; $V_{\gamma}$ é a fração molar de austenita, dependente da temperatura e do teor de carbono, e $k$ é uma constante igual a $0,5[98,99]$. Usando simulação pelo método de Monte Carlo, Tong et al. [100] mostraram que os valores críticos da densidade de discordâncias e da energia de deformação armazenada para desencadear o início do efeito DIFT durante uma deformação de $10 \%$ a $860{ }^{\circ} \mathrm{C}$ (sistema binário Fe-C com $0,13 \%$ ) são $3,8 \times 10^{13} \mathrm{~m}^{-2}$ e $21,1 \mathrm{~J} / \mathrm{mol}$, respectivamente. Outros autores [101] estimaram valores de energias de deformação armazenada de 21,6 J/mol e 63,4 J/mol para densidades de discordâncias de $1,2 \times 10^{15} \mathrm{~m}^{-2}$ e $3,5 \times 10^{15} \mathrm{~m}^{-2}$, respectivamente.

No efeito DIFT, devido à deformação local, a ferrita nucleia de forma heterogênea (devido à distribuição da energia armazenada) nas áreas de maior distorção, principalmente nos contornos de $\alpha / \gamma$. Com o aumento da deformação formam-se continuamente núcleos dentro dos grãos, em sítios de maior distorção como: bandas de deformação, bandas de deslizamento, regiões macladas, contornos de sub-grãos e interfaces. Diferentemente do mecanismo de nucleação por saturação de sítios, proposto por Cahn [102], no efeito DIFT o processo de nucleação é um processo insaturado. Dessa forma, o modelo cinético desenvolvido por Jonhson-Mehl-Avrami-Kolmogorov (JMAK), comumente utilizado para descrever o mecanismo homogêneo de nucleação e crescimento do processo de transformação de $\gamma \rightarrow \alpha$, não pode ser aplicado para descrever a cinética do efeito DIFT [96, 103]. Além disso, é difícil distinguir as frações volumétricas formadas por DIFT das frações geradas durante o posterior resfriamento [96].

Adicionalmente, por causa da deformação a quente, a densidade de discordâncias aumenta continuamente e como a difusão do carbono ocorre preferencialmente através de caminhos como contornos de grão e discordâncias, o efeito DIFT ocorre por difusão de curto alcance do carbono [103], dominada pelo potencial químico na interface $\alpha / \gamma$. Dessa forma, o enriquecimento em carbono supersatura a ferrita DIFT, que em consequência possui maior concentração em carbono do que a ferrita "estática" [96][104] (i.e. a formada após a deformação). Além disso, a deformação da austenita reduz significativamente o tempo de incubação para nucleação da ferrita, e o efeito DIFT pode ocorrer em um curto período de tempo $(\approx 0,08 \mathrm{~s})$ [96]. Em aços de baixo carbono, o tempo de incubação para o efeito DIFT é de aproximadamente duas ordens de grandeza menor que para a transformação da ferrita isotérmica [96]. Como mostrado por Essadiqi e Jonas [105], mesmo quando a taxa de deformação da austenita é baixa $\left(7,4 \times 10^{-4} \mathrm{~s}^{-1}\right)$ o tempo de incubação é reduzido. Já a cinética 
do crescimento da ferrita DIFT é determinada tanto pela difusão do carbono na austenita como pela mobilidade da interface $\alpha / \gamma$ [98].

Por outro lado, o efeito DIFT é acompanhado pela recristalização dinâmica da ferrita $\left(\alpha_{D R X}\right)$. Através dessa recristalização se formam grãos equiaxiais de ferrita finos e ultra-finos [101]. Esse fenômeno é importante, uma vez que se sabe que o refinamento do tamanho de grão é o único caminho para aumentar simultaneamente a resistência e a tenacidade dos aços [106]. Dessa forma, durante a deformação em alta temperatura ${ }^{5}$, acontecem de forma consecutiva o efeito DIFT e $\alpha_{D R X}$. Por simulação de Monte Carlo, Tong et al. [100] não observaram a ocorrência simultânea de recuperação dinâmica da austenita e efeito DIFT durante a deformação. No entanto, espera-se que em aços microligados, em concomitância com o efeito DIFT ocorra principalmente a recuperação dinâmica da ferrita em vez de recristalização dinâmica [94].

O mecanismo exato responsável pelo refinamento de grão de uma microestrutura deformada ainda é assunto de debate. No entanto, a visão geral é de que esse refinamento resulta de uma distribuição não uniforme de discordâncias, que tendem a se organizar em configurações de baixa energia para formar estruturas de células dentro dos grãos grosseiros originais. Portanto, durante o processo de recristalização há um aumento de energia associado ao acúmulo de discordâncias no contorno de grão. Essa energia é o agente para o processo de recristalização e esse é o fenômeno metalúrgico que permite o crescimento de novos grãos na matriz deformada [107]. Contudo, outras opiniões são enfáticas no papel das bandas de deformação no refinamento do grão [108].

Dessa forma, o efeito DIFT é um mecanismo complexo que envolve vários fenômenos físico-químicos que incluem a difusão dos átomos de soluto, evolução da distribuição de discordâncias, movimentação de contornos de grão, transformação de fase, recristalização dinâmica e suas interações (energia livre química, energia armazenada, energia nos contornos de grão) $[98,100]$. Portanto, apesar de o efeito DIFT ser um fenômeno amplamente estudado, devido a sua complexidade, ainda não há uma visão unificada sobre o mecanismo que rege a transformação de fase por DIFT [96], de forma que alguns autores [98, 103] afirmam que ainda são necessárias maior número de pesquisas e análises de observações experimentais a fim de compreender em profundidade a essência dos mecanismos e da cinética que envolvem o fenômeno DIFT.

\footnotetext{
${ }^{5}$ Cabe ressaltar que não é fácil estabelecer a temperatura exata em que a transformação por efeito DIFT acontece uma vez que a temperatura de equilíbrio se desloca quando a deformação é aplicada e. além disso, o tamanho de grão da austenita prévio também afeta as temperaturas de início de transformação [92].
} 


\section{OBJETIVOS}

O objetivo da presente pesquisa é caracterizar a microestrutura e as propriedades mecânicas de um aço TRIP submetido ao processo combinado de estampagem a quente (HS) com posterior tratamento de têmpera e partição (Q\&P) usando técnicas experimentais e modelos de simulação numérica. Os interesses do trabalho focaram-se em:

- Compreender a cinética das transformações de fase durante o processo de Q\&P, com e sem deformação em altas temperaturas.

- Desenvolver e aplicar métodos de análise metalográfica e micromecânica para caracterizar e quantificar as microestruturas dos componentes após têmpera $(\mathrm{Q})$, estampagem a quente (HS), têmpera e partição (Q\&P), e o processo combinado de deformação a quente e de têmpera e partição (HSQ\&P).

- Desenvolver e validar um novo modelo numérico para prever propriedades mecânicas a partir das microestruturas obtidas, após processos de Q, HS, Q\&P e HSQ\&P.

- Comparar as propriedades mecânicas associadas às diversas microestruturas obtidas após os processos de Q, HS, Q\&P e HSQ\&P usando um algoritmo reverso aplicado às curvas obtidas por nanoindentação instrumentada, ensaios mecânicos de tração em corpos de prova de tamanho reduzido, e análise por elementos finitos usando a combinação de OOF e programa Abaqus.

- Estudar diversas rotas de tratamentos Q\&P apropriadas para aços estampados a quente, a fim de se obter diversas frações volumétricas de austenita retida estabilizada, ferrita intercrítica e pacotes de martensita.

- Abrir o espectro de informações sobre o comportamento das propriedades mecânicas e térmicas de aços de alta resistência, disponíveis no mercado brasileiro. 


\section{MATERIAL DE ESTUDO - AÇO TRIP}

Para esse trabalho foi selecionado um aço TRIP de alto teor de silício que, devido a essa característica, é visado por grupos de pesquisa em têmpera e partição (Q\&P). A escolha desse material baseia-se no objetivo da pesquisa em testar o processo combinado de estampagem a quente seguido do processo Q\&P, chamado nesta pesquisa de HSQ\&P. Sabe-se que a resistência e a ductilidade são duas propriedades mecânicas fundamentais dos materiais que, entretanto, apresentam características opostas. Isto é, um material pode ser altamente resistente ou dúctil, mas dificilmente apresenta ambas características ao mesmo tempo. Portanto, o processo combinado de HSQ\&P proposto pretende enfrentar o paradigma mais básico da ciência dos materiais em que o aumento da resistência mecânica leva à perda de ductilidade e um aumento da ductilidade só pode ser alcançado sacrificando a resistência. A razão dessa dicotomia se deve à natureza fundamental do mecanismo de deformação plástica dos metais associado com a geração e movimentação das discordâncias, enquanto os mecanismos de dureza e resistência mecânica estão associados com a possibilidade de restringir a movimentação de discordâncias.

A proposta foi produzir microestruturas complexas com o processo combinado e avaliar o que acontece quando materiais que têm demonstrado boas propriedades após o tratamento Q\&P são previamente deformados a quente.

A composição química da liga estudada é dada na Tabela 4-1 e o processo esquemático do tratamento térmico de recozimento contínuo aplicado ao material é mostrado na Figura 4-1. Como se observa na tabela os principais elementos de liga presentes no aço TRIP são o C, Si e Mn. Desses elementos, C e Mn são gamagênicos, uma vez que retardam a transformação de austenita $(\gamma)$ para ferrita $(\alpha)$. Por sua vez o Si é estabilizador da fase $\alpha$ e está presente para inibir a precipitação da cementita durante a reação bainítica. Na presença do Si, durante a reação bainítica ocorre rejeição do carbono para a austenita, aumentando sua estabilidade. Não obstante, elevados teores de Si podem levar à formação de cores de revenido (óxido colorido sobre a chapa, o que pode afetar a pintura do material) e de uma carepa aderente durante a deformação a quente, o que pode ser problemático para qualidade superficial da peça estampada a quente [109].

De acordo com o ciclo térmico apresentado na Figura 4-1, o aço TRIP, após laminação à frio, é aquecido até o campo intercrítico $(\alpha+\gamma)$ e resfriado rapidamente até uma temperatura acima da transformação martensítica, seguido de manutenção nessa temperatura por um certo período a fim de induzir a transformação bainítica. Ao final do período de manutenção no 
patamar isotérmico é aplicado um novo resfriamento acelerado até a temperatura ambiente, produzindo ao final do tratamento uma microestrutura constituída de ferrita, bainita e austenita retida (também pode ser formada uma pequena porção de martensita). Como a transformação bainítica que ocorre durante o patamar isotérmico é incompleta, a microestrutura apresenta austenita retida ao final do tratamento. A presença de bainita e de austenita retida enriquecida em carbono são características típicas dos aços TRIP.

Tabela 4-1. Composição química do aço TRIP do presente estudo.

\begin{tabular}{cccccc}
\hline Elemento & $\mathbf{C}$ & $\mathbf{S i}$ & $\mathbf{M n}$ & $\mathbf{C r}$ & $\mathbf{B}$ \\
\hline$\%$ em massa & 0,23 & 1,23 & 1,50 & 0,02 & 0,0001 \\
\hline
\end{tabular}

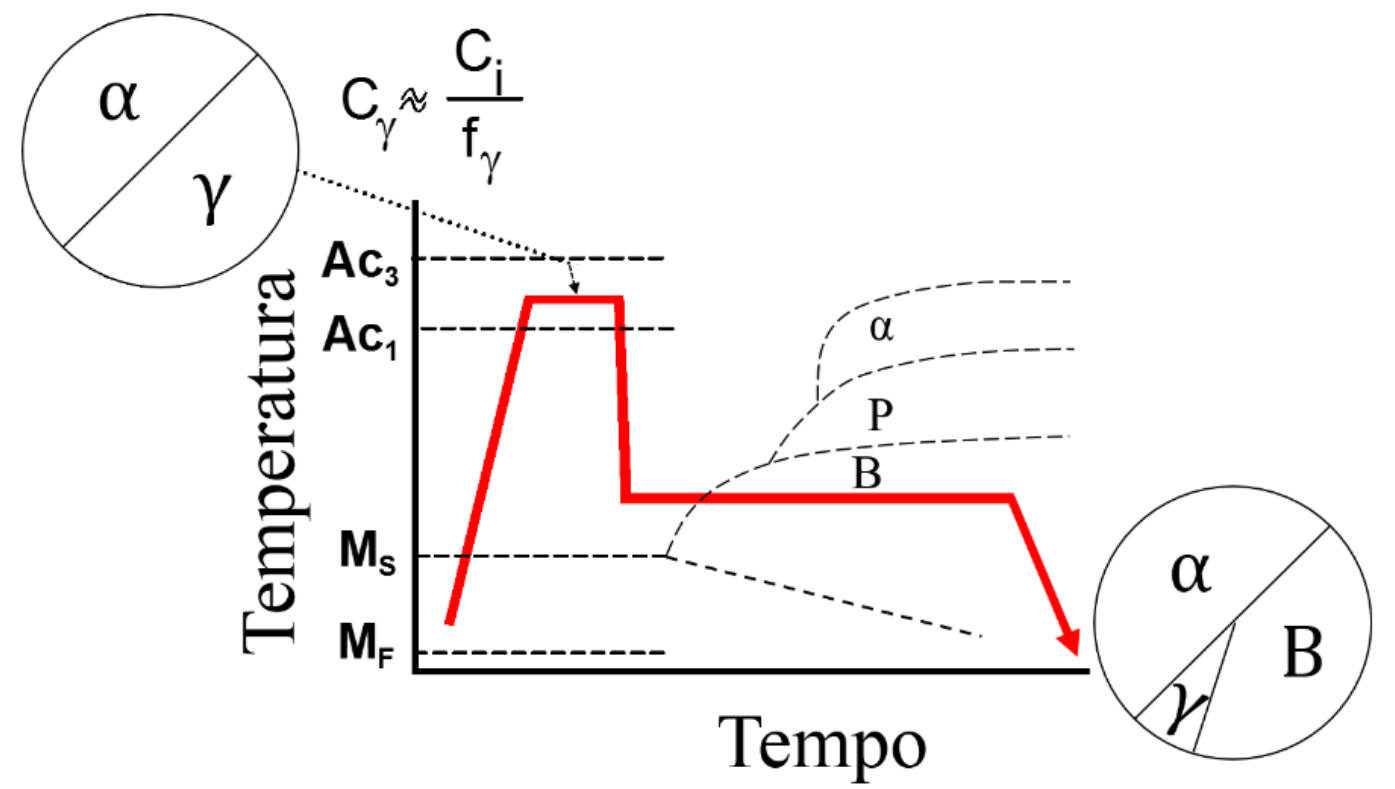

Figura 4-1. Processo esquemático do processo de recozimento contínuo aplicado ao aço TRIP após laminação a frio. $\gamma, \alpha$ e B representam austenita, ferrita e bainita, respectivamente. $\mathrm{F} \gamma, \mathrm{C} \gamma$ e $\mathrm{C}$ i são fração volumétrica de austenita e carbono na austenita e inicial, respectivamente.

A Figura 4-2 apresenta a microestrutura da amostra como recebida obtida usando difração de elétrons retroespalhados (EBSD). Como se observa, a distribuição dos microconstituintes é condizente com o tratamento térmico aplicado. O tratamento térmico aplicado gera um material com limites de escoamento e de resistência de $504 \mathrm{MPa}$ e $778 \mathrm{MPa}$, respectivamente, com um alongamento total de $\approx 35 \%$. 


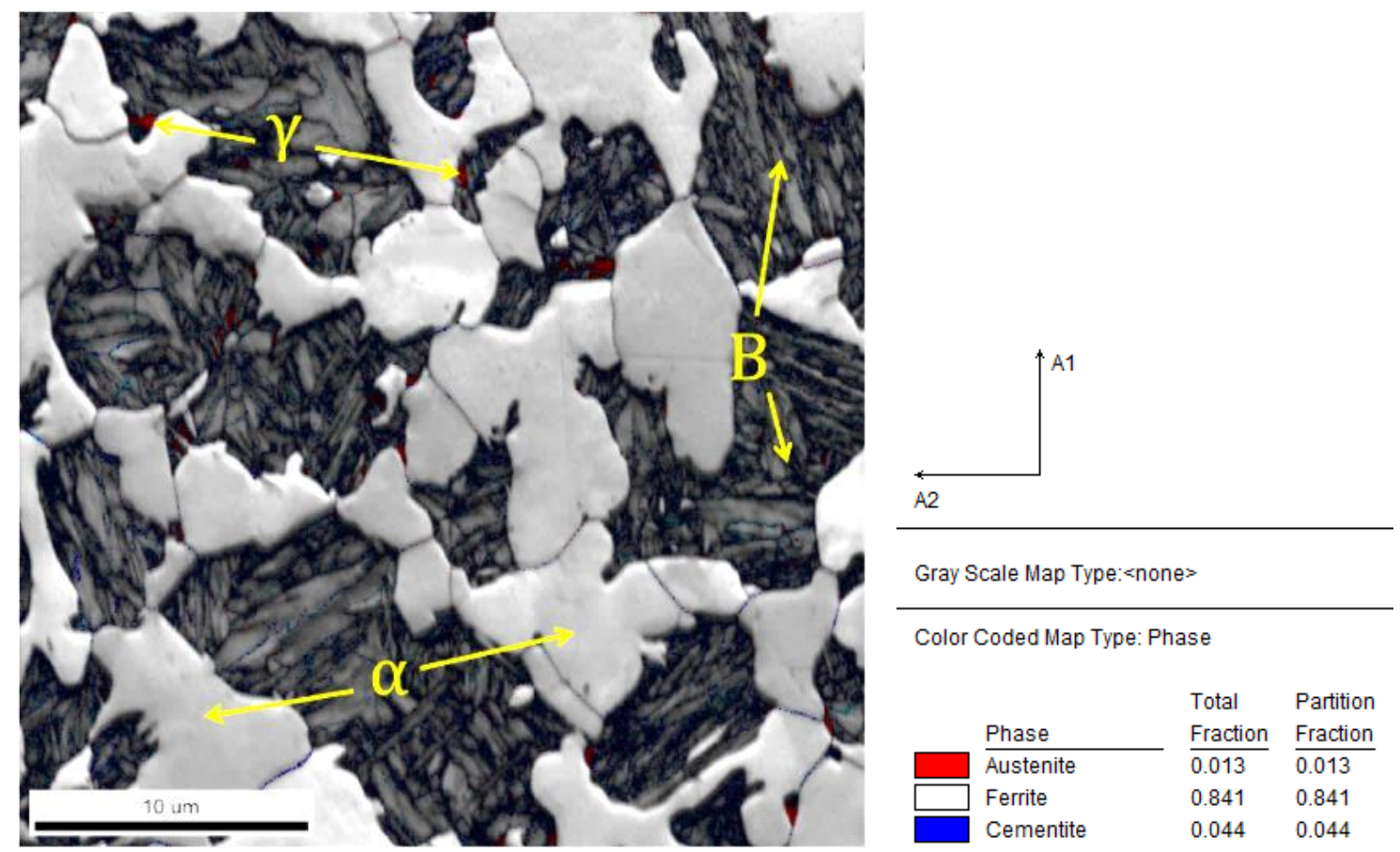

Figura 4-2. Microestrutura obtida por difração de elétrons retroespalhados do aço TRIP do presente estudo. $\gamma, \alpha$ e B representam austenita, ferrita e bainita, respectivamente. 


\section{TÉCNICAS E PROCEDIMENTOS EXPERIMENTAIS}

\subsection{Tratamentos térmicos e termomecânicos}

Os tratamentos térmicos e termomecânicos foram realizados no simulador termo-mecânico Gleeble 3S50® na estação experimental XTMS (X-ray Scattering and Thermo-Mechanical Simulation), operada pelo Laboratório Nacional de Nanotecnologia (LNNano) com suporte do Laboratório Nacional de Luz Síncrotron (LNLS).

Chapas de aço TRIP foram submetidas aos processos de têmpera (Q), têmpera e partição (Q\&P), estampagem a quente (HS) e ao processo combinado de estampagem a quente com posterior processo de Q\&P (chamado aqui de HSQ\&P). Foi usado o simulador termomecânico Gleeble ${ }^{\circledR} 3550$ operado sob vácuo $\left(\approx 6 \times 10^{-3}\right.$ torr $)$ para reproduzir as condições dos processos em termos da taxa de aquecimento e de resfriamento, da deformação e das temperaturas de têmpera e de partição avaliadas. Os processos termomecânicos realizados são esquematicamente representados e detalhados no início de cada capítulo de resultados. De forma geral, em todos os casos as amostras na condição como recebida foram solubilizadas por 5 minutos a $1000{ }^{\circ} \mathrm{C}$ com aquecimento a uma taxa de $15^{\circ} \mathrm{C} / \mathrm{s}$. Após solubilização as amostras foram austenitizadas intercriticamente a $820{ }^{\circ} \mathrm{C}$ ou $800{ }^{\circ} \mathrm{C}$ com tempo de permanência de 5 minutos. O objetivo da austenitização intercrítica foi obter ferrita intercrítica e austenita com teores altos de carbono (> $2 \%$ em peso) e de maior temperabilidade, de tal forma que o processo de têmpera possa ser aplicado sem precipitação de ferrita durante o resfriamento. Diferentes temperaturas intercríticas foram avaliadas de modo a estudar sua influência no enriquecimento em carbono e na porcentagem final de austenita retida. $\mathrm{O}$ equilíbrio termodinâmico (i.e., proporção de fases e respectivas composições) na temperatura intercrítica foi calculado usando o programa Thermo-Calc ${ }^{\circledR}$ com a base de dados TCFE, otimizada para ligas ferrosas e amplamente utilizada para análise de aços em geral. O propósito foi determinar o limite de solubilidade do carbono na ferrita e na austenita, a composição química das fases em função da temperatura e a fração volumétrica das fases na temperatura intercrítica. Após austenitização intercrítica, um conjunto de amostras foi resfriado (em todos os casos a taxa de resfriamento na têmpera foi de $60{ }^{\circ} \mathrm{C} / \mathrm{s}$, sendo esta a maior taxa de resfriamento atingida pelo sistema para o formato do corpo de prova estudado) e deformado a quente durante o resfriamento a temperaturas de deformação inicial e final de $750{ }^{\circ} \mathrm{C}$ e $714^{\circ} \mathrm{C}$, enquanto outro conjunto de amostras foi deformado isotermicamente a $800{ }^{\circ} \mathrm{C}$. No caso das amostras deformadas (HS ou HSQ\&P) a quantidade de deformação foi de 10, 30 ou 50\% e a taxa nominal de deformação foi 
em todos os casos de $0,5 \mathrm{~s}^{-1}$, condizente com a faixa de taxas de deformação encontradas durante estampagem a quente convencional [110]. A deformação foi controlada usando um extensômetro a laser acoplado ao sistema Gleeble, que fornece medições em tempo real das variações na largura da amostra. O mesmo dispositivo foi usado para monitorar as respostas nas mudanças do volume específico durante todo o ciclo de tratamento. A deformação real foi calculada em função do valor do deslocamento medido pelo extensômetro $(\Delta \mathrm{d})$ e da leitura inicial do dilatômetro $\left(d_{o}\right)$, de acordo com a equação:

$$
\varepsilon=2 \ln \left(\frac{d_{o}}{d_{o}+\Delta d}\right)
$$

No caso dos aços temperados e particionados a temperatura de têmpera (QT) é um parâmetro importante, já que determina a fração volumétrica de martensita que particionará o carbono para estabilizar a austenita durante a etapa de partição e, consequentemente, também determina a máxima fração volumétrica de austenita retida na temperatura ambiente. $\mathrm{Na}$ presente pesquisa foram estudadas diferentes temperaturas QT a fim de explorar as condições em que se obtém as maiores frações volumétricas de austenita retida na temperatura ambiente. Nos primeiros tratamentos térmicos e termomecânicos realizados foi utilizada a temperatura ótima de têmpera $\left(250^{\circ} \mathrm{C}\right)$, determinada experimentalmente no trabalho de Clarke et al. [111], cujo aço estudado possui uma composição similar ao do presente estudo. Os resultados atribuindo a QT proposta por Clarke et al. [111] são apresentados no capítulo 6. Posteriormente, foi calculada a temperatura ótima de têmpera para as condições do aço TRIP do presente estudo, considerando o modelo de equilíbrio constrito de carbono proposto por Speer et al. [1]. A metodologia e comentários adicionais da estimativa dessa temperatura ótima de têmpera são apresentados no capítulo 7. Os resultados usando a QT calculada para o aço TRIP do presente estudo são apresentados nos capítulos 7 e 8.

\subsection{Difração de raios $X$ síncrotron in situ em alta temperatura}

Os ensaios de simulação física com análise de difração de raios $\mathrm{X}$ in situ usando radiação síncrotron, além de permitirem a avaliação posterior das propriedades mecânicas, possibilitam o estudo detalhado dos mecanismos de partição, enriquecimento e estabilidade da austenita e, acompanhar a evolução das fases em tempo real.

O acompanhamento da evolução dos microconstituintes durante tratamento termomecânico em temperaturas elevadas foi feito em simulador termomecânico Gleeble3S50®, acoplado a 
uma fonte de radiação síncrotron, na instalação XTMS pertencente ao LNNano. A instalação e montagem experimental são mostradas na Figura 5-1. Microestruturas resultantes de têmpera e partição (Q\&P) são extremamente difíceis de caracterizar por métodos metalográficos tradicionais, pois seus microconstituintes são de dimensões nanométricas. Por outro lado, o uso de simulador termomecânico junto à linha de difração de raios X é uma das poucas técnicas que permitem o acompanhamento da evolução da formação dos microconstituintes em elevadas temperaturas, durante tratamentos termomecânicos.

A instalação XTMS conta com um goniômetro Heavy Duty Huber de alta resolução montado ao redor do simulador termomecânico (Figura 5-1b). O goniômetro é montado sobre uma mesa de alinhamento que permite o posicionamento do plano de difração sobre a superfície da amostra. Nas diferentes séries de experimentos foram utilizadas duas configurações de detectores. A primeira consiste de um par de detectores Mythen $1 \mathrm{~K}$ instalados sobre o goniômetro, possuindo 1280 canais de aquisição (píxeis) de $50 \mu \mathrm{m}$ de largura, que podem ser posicionados em ângulos entre 0 e $150^{\circ}$, a uma distância mínima da superfície da amostra de $365 \mathrm{~mm}$. Na distância mínima de trabalho cada detector cobre uma faixa de ângulos de aproximadamente $10^{\circ}$, totalizando um ângulo de cobertura de cerca de $20^{\circ}$ e resolução angular de $0,05^{\circ}$. O uso do detector Mythen permite rápida aquisição de dados de difração dentro da faixa limitada de ângulos, possibilitando medições em tempo real (in situ). Na segunda configuração foi utilizado um detector 2D Rayonix SX165 com tamanho de píxel de $39 \times 39$ $\mu \mathrm{m}^{2}$ cobrindo uma área circular de $165 \mathrm{~mm}$ diâmetro. Para as aquisições o detector foi posicionado na distância mínima de trabalho de $285 \mathrm{~mm}$, dessa forma minimizando a perda de intensidade do feixe difratado devido à interação com o ar. Binning de $2 \times 2$ foi utilizado de modo a reduzir o tempo de leitura $(\approx 3 \mathrm{~s})$ em relação à configuração $1 \times 1(\approx 5 \mathrm{~s})$. Nessas condições o detector cobre cerca de $30^{\circ}$ ao longo do ângulo de Bragg $2 \theta$ e aproximadamente $40^{\circ}$ ao longo do ângulo azimutal.

No interior da câmara (Figura 5-1c) do simulador Gleeble os corpos de prova são presos por garras de cobre, por meio das quais é conduzida corrente elétrica para aquecimento das amostras por efeito Joule (Figura 5-1d). O controle da potência é feito por algoritmo proporcional integral derivativo (PID), sendo que a resposta de temperatura é obtida por meio de termopares soldados às amostras. 


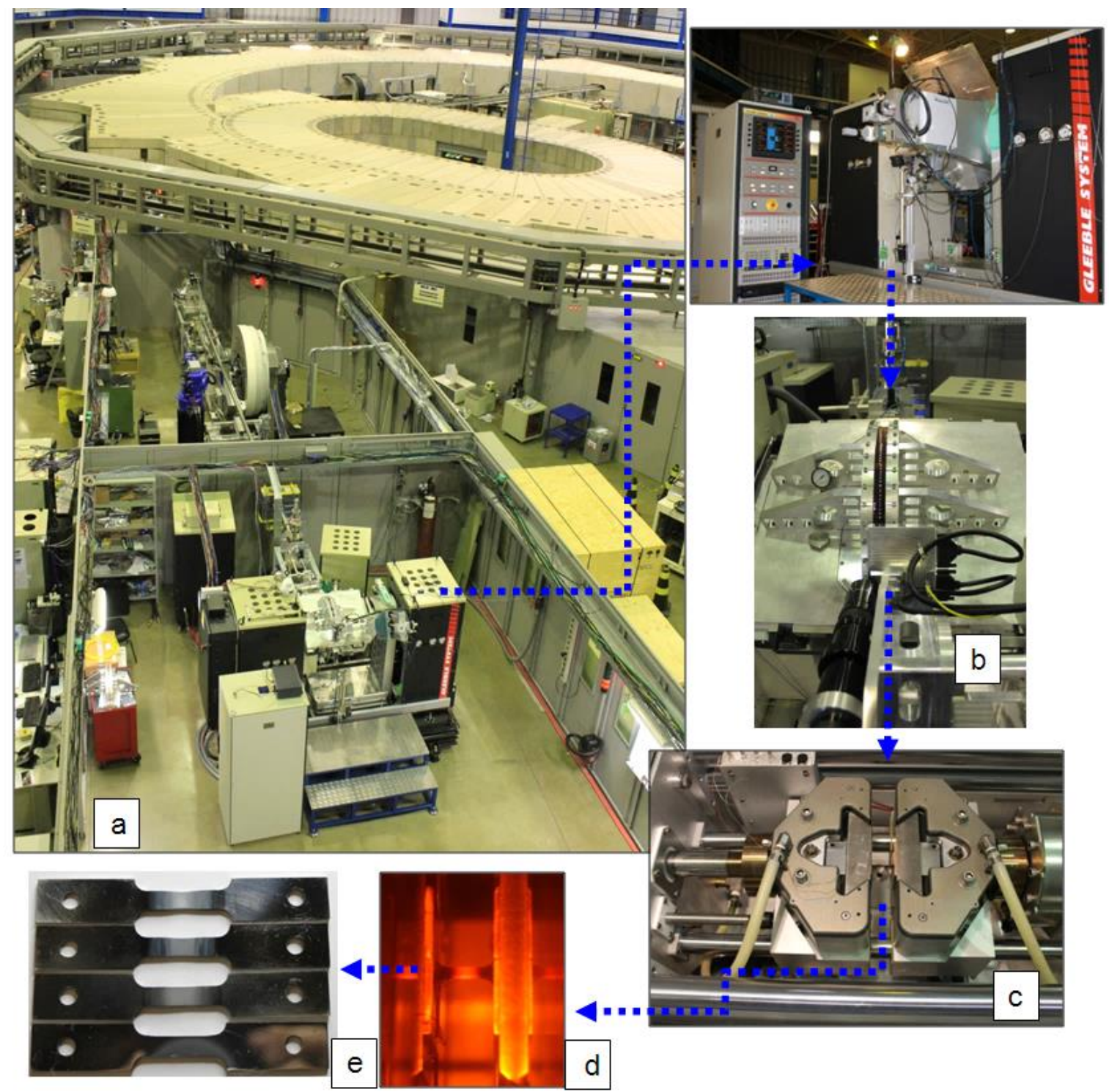

Figura 5-1. Simulador termomecânico acoplado a uma fonte de radiação síncrotron na instalação XTMS do LNLS, usada para as análises in situ das transformações de fase. (a) Instalação XTMS integrado à linha de difração de raios X XRD1; (b) simulador termomecânico Gleeble; (c) sistema de garras para a montagem da amostra dentro da câmara; (d) amostra aquecida durante tratamento; (e) amostras sem e com deformação a 0,10 , 30 e $50 \%$.

O uso do equipamento Gleeble 3S50® permitiu programar os ciclos termomecânicos de interesse (Q, HS, Q\&P e HSQ\&P), incluindo a taxa e quantidade de deformação projetadas. As amostras foram tratadas termicamente usando o método de aquecimento por resistividade, controlado por termopares tipo K (cromel-alumel). Foram usadas amostras planas com $10 \mathrm{~mm}$ de comprimento efetivo e 1,5 mm de espessura, como mostrado na Figura 5-2. Esse método causa um gradiente de temperatura em torno da área testada, no entanto, o estudo foi feito dentro da região central de $\approx 3 \mathrm{~mm}$, onde o gradiente térmico é desprezível. A energia do feixe foi estabelecida em $12 \mathrm{keV}$, equivalente ao comprimento de onda $(\lambda)$ de 1,033 $\AA$, utilizando monocromadores de $\mathrm{Si}(111)$, e o tamanho do feixe foi controlado por fendas verticais e 
horizontais, o que aumenta o grau de colimação. As fendas de limitação de fluxo de fótons foram ajustadas para permitirem que apenas uma região de $2 \times 0,5 \mathrm{~mm}^{2}$ do feixe incidisse sobre a superfície da amostra.

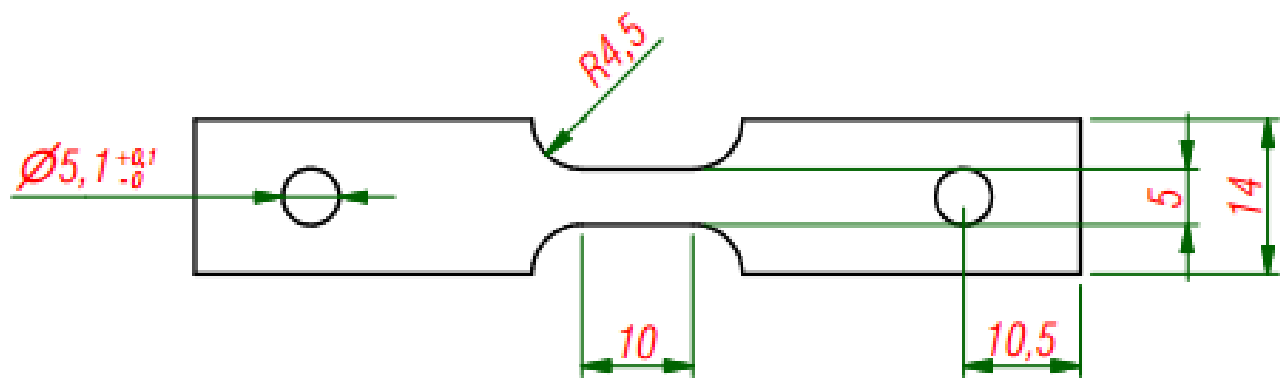

Figura 5-2. Desenho do corpo de prova utilizado nos ensaios termomecânicos realizados na Gleeble junto à linha de difração. Espessura 1,5 mm. Dimensões em mm.

Para reduzir a oxidação das amostras durante os testes in situ, a câmara do simulador foi evacuada até a pressão de $\approx 10^{-3}$ torr usando bombas mecânica e difusora. Entretanto, nos primeiros testes foi constatado que esse nível de vácuo não foi suficiente para evitar a descarbonetação das amostras. A descarbonetação (i.e., perda de carbono do material) acontece devido à presença de teores residuais de oxigênio na câmara, que causam a oxidação do carbono. Esse problema não pôde ser contornado nem mesmo após a adoção da prática de purga na câmara utilizando um gás inerte (argônio). A solução encontrada para esse problema foi a aplicação de uma camada fina de graxa de alto vácuo sobre a superfície das amostras antes do início dos tratamentos. A graxa agiu como uma barreira físico-química reduzindo a interação entre o oxigênio e a amostra. Entretanto, a graxa pode ser considerada transparente para a passagem de raios- $\mathrm{X}$ de alta energia.

Todos os estudos in situ foram feitos acompanhando, especificamente, as mudanças da área integrada dos picos difratados pelos planos da austenita e da ferrita/martensita. Os difratogramas obtidos nesta etapa foram integrados a fim de observar a evolução microestrutural durante o tratamento térmico e a posição teórica dos picos foi calculada para identificar as correspondentes fases e os planos da estrutura difratados. Cabe destacar que a imprecisão no posicionamento da amostra (em consequência de que o centro de difração não se situa de forma precisa no centro do goniômetro), as irregularidades superficiais da amostra e variações na profundidade de penetração de raios $\mathrm{X}$ causam imprecisões na medição dos parâmetros de rede [112]. Dessa forma, a montagem da amostra nas garras e o alinhamento do feixe foram procedimentos realizados de forma minuciosa para garantir a maior precisão da montagem experimental. Durante o posicionamento das amostras no interior da câmara do simulador procurou-se estabelecer o ângulo $\omega$ de $15^{\circ}$ entre a superfície da amostra e o feixe 
incidente de raios X. Adicionalmente para as análises in situ do enriquecimento em carbono, usando o detector Mythen $1 \mathrm{~K}$, o goniômetro foi posicionado a $45^{\circ}$ o que permite realizar aquisições entre $39^{\circ}$ e $64^{\circ}$ e, portanto, analisar os picos (220) e (311) da austenita. Esse procedimento foi adotado uma vez que as aquisições incluindo ângulos menores registram os picos da austenita (111) e (200). Nesse caso, o pico (111) da austenita pode apresentar superposição com o pico (110) da ferrita o que dificulta a posterior análise da variação em $2 \theta$ do pico de difração da austenita. Adicionalmente, os dois primeiros picos da austenita são mais sensíveis às tensões residuais, produzindo efeitos no seu deslocamento e superpõe-se ao fenômeno do enriquecimento em carbono. Além disso, como picos maiores também apresentam influência da tensão residual, antes dos testes foi aplicada uma fina dispersão de $\mathrm{Al}_{2} \mathrm{O}_{3}$ para calibração da posição dos picos durante as análises da mudança de $2 \theta$.

Antes dos ensaios todas as superfícies das amostras foram polidas até $1 \mu \mathrm{m}$, para minimizar os efeitos das irregularidades da superfície e foi aplicada a camada fina de graxa, como comentado anteriormente, para controlar a descarbonetação da superfície da amostra.

Dependendo da etapa do tratamento térmico, foram utilizados diferentes tempos e frequências de aquisição de dados, como esquematizado na Figura 5-3, para uma representação de um tratamento de HSQ\&P com deformação não isotérmica. Durante a etapa isotérmica de partição, cuja análise é enfatizada neste trabalho, aquisições foram feitas usando tempo de exposição de 3 segundos, com intervalos de 0,5 segundos. No início do tratamento térmico e ao final da etapa de partição e do tratamento térmico foram feitas varreduras do ângulo de difração entre 40 e $120^{\circ}$ com 10 segundos de exposição por passo, de modo a obter um número de picos de difração substantivo para quantificação das fases. O uso de ângulos maiores na varredura, evita a superposição dos dois primeiros picos de austenita e ferrita, o que dificulta a quantificação precisa das fases. 


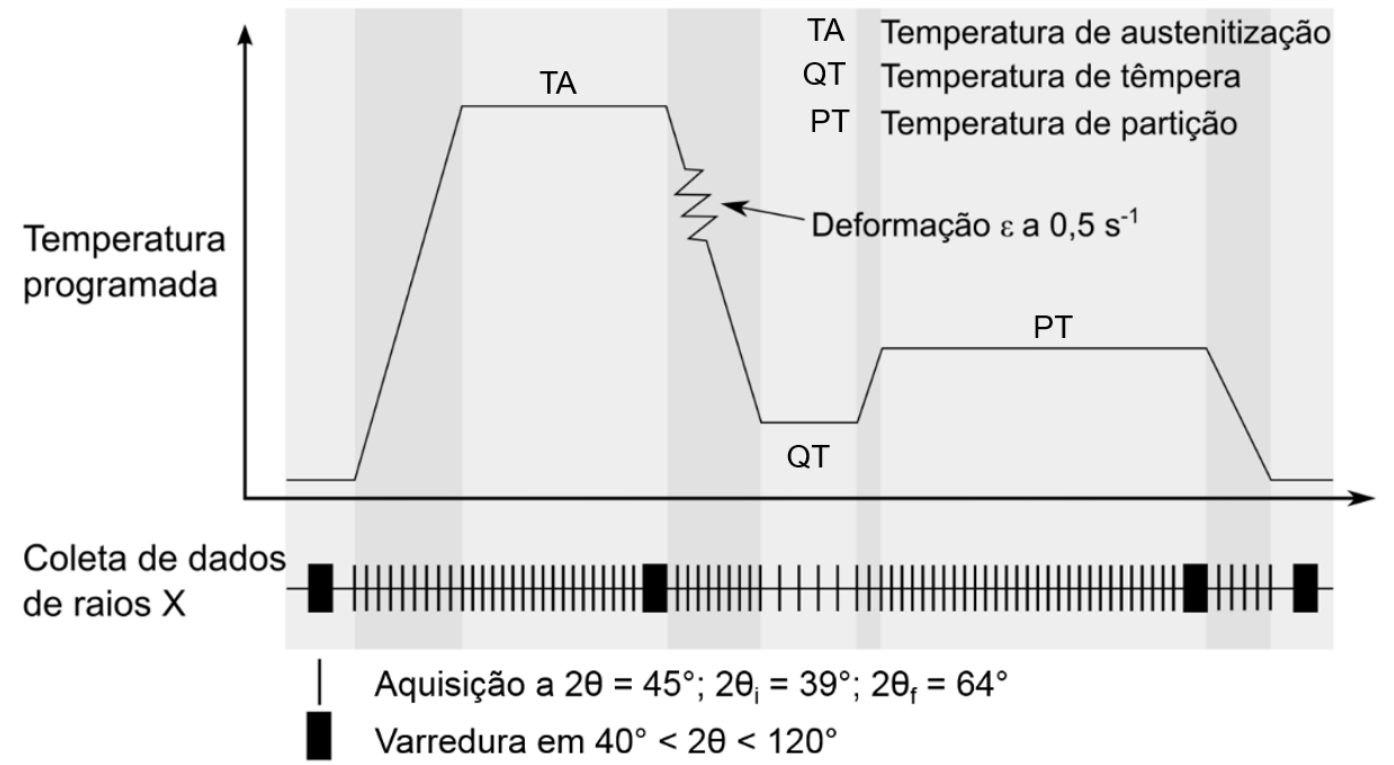

Figura 5-3. Ilustração esquemática da coleta de dados de um ciclo de tratamento termomecânico HSQ\&P com deformação não isotérmica programada para as amostras tratadas na estação experimental XTMS.

\subsection{Difração de raios $X$ e determinação da fração de austenita retida}

Para os primeiros ensaios realizados (resultados correspondentes ao capítulo 6), devido à influência da descarbonetação na aquisição precisa dos picos de difração, foram realizadas análises complementares de difração de raios X ex-situ, nas amostras tratadas na Gleeble. Para isto, a superfície da amostra foi preparada por lixamento e polimento até $1 \mu \mathrm{m}$, de modo a remover a camada descarbonetada e de se reduzir as irregularidades superficiais. As amostras foram analisadas por difração de raios $\mathrm{X}$ após polimento, sem ataque, e as frações volumétricas das fases foram calculadas por método de comparação direta das intensidades dos picos. Foi utilizado um equipamento da marca Rigaku, pertencente ao Centro de Ciência e Tecnologia de Materiais (CCTM) do Instituto de Pesquisas Energéticas e Nucleares (IPEN), modelo D/MAX. Foram usadas fendas de $\mathrm{Cu}$, com $0,5^{\circ}$ na posição de divergência e $0,3 \mathrm{~mm}$ na posição de recepção. As varreduras foram realizadas no intervalo $2 \theta=40-102^{\circ}$, com passo angular de $0,04^{\circ}$, tempo de contagem de 10 segundos e radiação de $\mathrm{Cu} \mathrm{K} \alpha(\lambda=1,5405 \AA ̊$ ). A potência utilizada foi de $20 \mathrm{kV}$ e $20 \mathrm{~mA}$.

\subsection{Cálculo das frações volumétricas de austenita e ferrita}

A fração volumétrica de austenita retida foi calculada a partir dos difratogramas obtidos por difração de raios X, em concordância com as especificações descritas na norma ASTM E 975- 
03 [113] e também seguindo o trabalho de Gnäupel-Herold e Creuziger [114], que discute os parâmetros envolvidos na determinação do teor da austenita retida em aços TRIP. Se para os cálculos são consideradas unicamente as fases austenítica e ferrítica, as frações volumétricas relativas podem ser convertidas em frações volumétricas absolutas, de acordo com a identidade $\mathrm{V}_{\gamma}+\mathrm{V}_{\alpha}=1$. Esse método é chamado de método de comparação direta [115]. Como nos aços estudados a quantidade de carbonetos é desprezível, este método pode ser aplicado. As intensidades integradas dos picos (200), (211) e (220) da ferrita/martensita e, os picos (220), (311) e (331) da austenita foram usados para calcular a fração volumétrica de austenita retida. As intensidades integradas calculadas foram determinadas pelo ajuste de uma distribuição gaussiana para cada pico de difração, segundo:

$$
I=I_{0} \exp \left[-\left(\frac{2 \theta-2 \theta_{0}}{w}\right)^{2}\right]+b c k
$$

em que $I$ corresponde à intensidade de difração observada em função do ângulo $2 \theta, I_{0}$ é a intensidade máxima medida no ângulo de difração $2 \theta_{0}$, w é a largura do pico gaussiano e $b c k$ contabiliza o sinal de fundo (background), que tem seu valor assumido como constante nas proximidades do pico considerado. As áreas integradas sob os picos foram calculadas pela integração da curva Gaussiana, conforme:

$$
A=\int_{-\infty}^{\infty} I_{0} \exp \left[-\left(\frac{2 \theta-2 \theta_{0}}{w}\right)^{2}\right] d \theta=I_{0}|w| \sqrt{\pi}
$$

Considerando que as áreas integradas das intensidades dos picos são proporcionais às frações volumétricas de cada fase no volume observado, as frações volumétricas de fases podem ser calculadas, segundo:

$$
V_{\gamma}=1-V_{\alpha}=\frac{\sum\left(A^{\gamma} / R^{\gamma}\right)}{\sum\left(A^{\alpha} / R^{\alpha}\right)+\sum\left(A^{\gamma} / R^{\gamma}\right)}
$$

onde $A^{\gamma}$ e $A^{\alpha}$, representam a área do pico de austenita e de ferrita, respectivamente, e os valores de $R$ (intensidades relativas teóricas) são determinados para cada fase de acordo com a reflexão de Bragg e o comprimento de onda do feixe incidente:

$$
R=\left(\frac{1}{V^{2}}\right)\left[F F^{*} p\left(\frac{1+\cos ^{2} 2 \theta}{\operatorname{sen}^{2} \theta \cos \theta}\right)\right] \exp [-2 M]
$$


em que $V$ é o volume da célula unitária, $F$ é o fator de estrutura, $F^{*}$ seu conjugado complexo, $p$ é a multiplicidade de planos da reflexão, $\theta$ é o ângulo de Bragg e $\exp [-2 M]$ é o fator térmico de Debye-Waller. Usando as técnicas e tabelas descritas em [113, 115] e a partir do programa PowderCell, foram calculados os valores de $R$ para as radiações de $\mathrm{Cu} \mathrm{K} \alpha(\lambda=1,5405 \AA)$ e síncrotron $(\lambda=1,03302 \AA)$ como mostrado na Tabela 5-1:

Tabela 5-1. Valores dos parâmetros $R$ para ferrita $(\alpha)$ e austenita $(\gamma)$.

\begin{tabular}{|c|c|c|c|c|c|}
\hline \multirow[t]{2}{*}{$\alpha_{\mathrm{hkl}}$} & \multicolumn{2}{|c|}{$R_{h k l}^{\alpha}$} & \multirow[t]{2}{*}{$\gamma_{\mathrm{hkl}}$} & \multicolumn{2}{|c|}{$R_{h k l}^{\gamma}$} \\
\hline & $\mathrm{Cu} \mathrm{K} \alpha$ & Síncrotron & & $\mathrm{Cu} \mathrm{K} \alpha$ & Síncrotron \\
\hline (110) & 250 & 1840 & (111) & 184 & 1351 \\
\hline (200) & 36 & 288,6 & (200) & 83 & 644,3 \\
\hline (211) & 71 & 530,0 & $(220)$ & 47 & 376,7 \\
\hline (220) & 25 & 142,5 & (311) & 58 & 390,0 \\
\hline
\end{tabular}

\subsection{Variação do parâmetro de rede da austenita}

A variação do parâmetro de rede da austenita ao longo do tratamento isotérmico também foi avaliada pelos resultados de difração de raios X. A partir do cálculo da distância interplanar $\left(d_{h k l}\right)$ pela lei de Bragg (equação 5.6), o parâmetro de rede da austenita $\left(a_{\gamma}\right)$ foi determinado pela equação 5.7, que, para sistemas cristalinos cúbicos, estabelece a relação entre $a_{\gamma}$ e a $d_{h k l}$ entre planos de índices de Miller $h k l$.

$$
\begin{gathered}
n \lambda=2 d_{h k l} \operatorname{sen}\left(\theta_{0}\right) \\
a_{\gamma}=d_{h k l}^{\gamma} \sqrt{h^{2}+k^{2}+l^{2}}
\end{gathered}
$$

A variação do parâmetro de rede foi interpretada em decorrência do enriquecimento em carbono da austenita durante a etapa de partição do tratamento Q\&P. Dessa forma, a variação do teor de carbono foi estimada por meio da equação de Dyson e Holmes [116], que leva em conta a variação do parâmetro de rede da austenita em função dos elementos em solução sólida na austenita:

$$
\begin{gathered}
a_{\gamma}=3,5780+3,30 \times 10^{-2} \% w_{C}^{\gamma}+9,5 \times 10^{-4} \% w_{M n}^{\gamma}-2 \times 10^{-4} \% w_{C r}^{\gamma}+5,6 \times \\
10^{-3} \% w_{A l}^{\gamma}+3,1 \times 10^{-3} \% w_{M o}^{\gamma}+1,8 \times 10^{-4} \% w_{V}^{\gamma}
\end{gathered}
$$


em que $\% w_{i}^{\gamma}$ é a porcentagem em massa do elemento químico $i$ dissolvido na austenita. Uma vez que as aquisições foram feitas em alta temperatura, para que os valores de $a_{\gamma}$ pudessem ser interpretados na temperatura ambiente pelo método descrito acima, previamente à aplicação da equação 5.8, o efeito da expansão térmica no parâmetro de rede da austenita foi corrigido utilizando a equação proposta por Bohemen [117]:

$$
\frac{\Delta L^{\gamma}}{L_{0}^{\gamma}}=B_{\gamma} T+B_{\gamma} \Theta_{D}^{\gamma}\left[\exp \left(-\frac{T}{\Theta_{D}^{\gamma}}\right)-1\right]
$$

em que $\Delta L^{\gamma}$ descreve a variação de comprimento da amostra completamente austenítica na temperatura absoluta $T$ em relação a seu comprimento $L_{0}^{\gamma}$ extrapolado para o estado de referência a $0 \mathrm{~K} . B_{\gamma}$ e $\Theta_{D}^{\gamma}$ são constantes de ajuste determinadas pela regressão linear de dados disponíveis na literatura com valores iguais a $24,8 \times 10^{-6} \mathrm{~K}^{-1} \mathrm{e} 280 \mathrm{~K}$, respectivamente. Por outro lado, levando em conta que as transformações ocorreram em temperaturas na faixa dos $400{ }^{\circ} \mathrm{C}$. considerou-se o efeito das tensões residuais desprezíveis.

\subsection{Dilatometria}

A dilatometria é uma ferramenta útil para estudar as transformações de fases em aços devido ao fato de que as mudanças volumétricas (dilatações resultantes da mudança da densidade) produzidas pela grande maioria das transformações em função da temperatura são facilmente detectadas. Portanto, ensaios de dilatometria, prévios aos ensaios realizados no LNLS, foram realizados usando dilatômetro Bähr DIL805A (Figura 5-4), disponível no Departamento de Engenharia Metalúrgica e de Materiais da EPUSP (PMT-USP). Esses ensaios permitiram simular os ciclos térmicos dos processos de têmpera e de têmpera e partição, de modo a determinar as temperaturas $A_{c 1}, A_{c 3}$ e $M_{s}$ e realizar as análises microestruturais posteriores. Não foi possível realizar os experimentos que incluem as etapas de deformação nesse equipamento, uma vez que o dilatômetro não possui o módulo necessário. Os experimentos foram feitos sob vácuo $\left(10^{-4} \mathrm{mbar}\right)$ de forma a evitar alterações químicas do material durante o experimento (i.e., oxidação e descarbonetação). O aquecimento das amostras é feito por indução eletromagnética utilizando uma bobina de cobre refrigerada a água e o controle da temperatura é feito por meio de termopares tipo $\mathrm{S}$ soldados às superfícies das amostras. Esse aquecimento por indução eletromagnética permite o controle da taxa de aquecimento $\left(15^{\circ} \mathrm{C} / \mathrm{s}\right)$ até as temperaturas de homogeneização $\left(1000^{\circ} \mathrm{C}\right)$ e de austenitização $\left(820\right.$ ou $\left.800^{\circ} \mathrm{C}\right)$ e a manutenção 
nessas temperaturas por um determinado tempo (300 s). A têmpera foi realizada com gás He para reproduzir uma alta taxa de resfriamento, a fim de evitar a formação de ferrita, perlita, ou bainita durante o resfriamento.

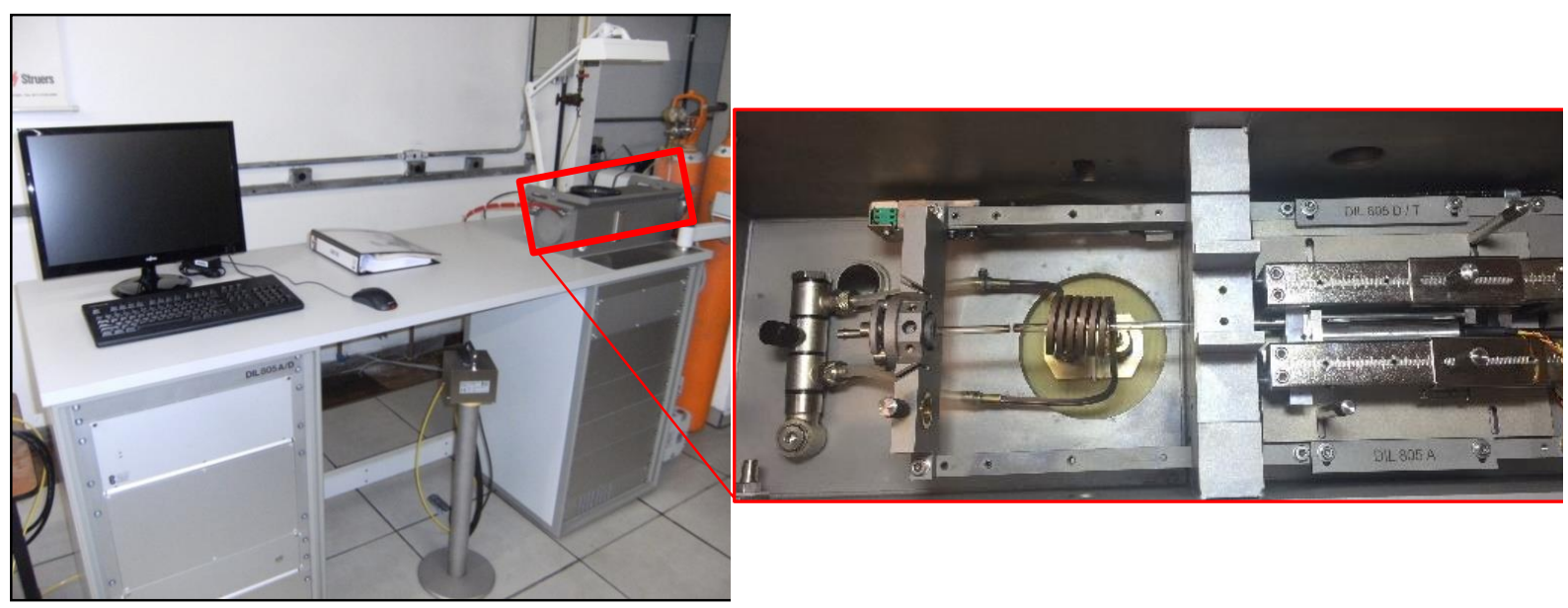

Figura 5-4. Dilatômetro Bähr DIL805A.

\subsection{Microscopia óptica e eletrônica de varredura}

As análises metalográficas foram feitas seguindo os procedimentos de corte e lixamento até a grana 1000 para o desbaste mais grosseiro e polimento final com suspensões com alumina de granulometria 1 e $0,3 \mu \mathrm{m}$, de acordo com o procedimento metalográfico padrão [118]. Para revelação da microestrutura do aço foi empregado o reagente químico Nital 2\% (2 ml de HNO3 em $98 \mathrm{ml}$ de álcool etílico, 95\%), usualmente aplicado na revelação de aços carbono; o tempo de imersão foi de $\approx 10 \mathrm{~s}$. Após ataque metalográfico as amostras foram lavadas com água fria e álcool etílico, sendo posteriormente secas com ar quente forçado e submetidas ao exame em microscópio óptico Philips modelo XL30, tendo sido obtidas as micrografias apresentadas nos resultados.

Para ter um melhor detalhamento da microestrutura e diferenciar aspectos em maior escala das fases presentes, foram feitas, após observação metalográfica por microscopia óptica, análises em microscópio eletrônico de varredura (MEV) FEI Inspect F50, equipado com canhão de emissão de campo (FEG) para observação de partículas menores.

\subsection{Difração de elétrons retroespalhados (EBSD)}

Para as análises por EBSD, as amostras tratadas por Q\&P e HSQ\&P foram preparadas com polimento final com pasta de diamante e sílica coloidal $(0,05 \mu \mathrm{m})$. O EBSD foi desenvolvido usando microscópio eletrônico de varredura operado a $20 \mathrm{kV}$, com um ângulo de inclinação da amostra de $70^{\circ}$, com distâncias de operação variando entre 16 e 19 mm e com tamanho do passo 
de 0,1 $\mu \mathrm{m}$. O software TSL-OIM (TexSEM Laboratories - Orientation Imaging Microscopy) foi utilizado para analisar os dados e criar os mapas de identificação das fases, imagem de qualidade, orientação cristalográfica, fator de Schmid e desorientação média resultantes dos processos termomecânicos.

O software TSL-OIM contém várias funções automatizadas para caracterização local nos mapas de EBSD. Na presente pesquisa foram utilizadas principalmente:

a) Qualidade de Imagem (IQ), que descreve a qualidade do padrão de difração dos elétrons retroespalhados [119]. A IQ é afetada pela presença de defeitos cristalinos, como contornos de grão, a alta densidade de discordâncias, precipitados e deformações, ou por fatores superficiais, como rugosidade e contaminação. Portanto, se o padrão da intensidade dos picos (da transformada de Hough, a partir das linhas de Kikuchi) é claro e bem definido, significa que o cristal tem baixa distorção e apresenta um valor alto de IQ.

b) Figura de polo inverso (IPF, por suas siglas em inglês Inverse Pole Figure) que mostra a distribuição de determinadas direções cristalográficas de um determinado plano em relação a um cristal de referência (sistema de eixos relativo à amostra), de modo que é possível, com base na projeção estereográfica ${ }^{6}$, construir um mapa de orientações de grãos (OIM, Orientation Image Map). No software, o usuário indica a direção cristalina a ser considerada, inserindo os índices que definem o vetor de componentes (geralmente os eixos normais à superfície). Desse modo, uma figura de polo inverso mostra qual direção cristalina do sistema de orientação da amostra está alinhada (é paralela) à direção normal de determinado plano cristalográfico na amostra, e os pontos do mapa são coloridos com base no triângulo unitário de referência. Portanto, a IPF indica a distribuição das normais a muitos planos cristalográficos diferentes, com referência a uma direção cristalográfica específica.

c) Desorientação média de kernel (KAM, por suas siglas em inglês Kernel Average Misorientation), que indica a desorientação média (ângulo) entre um ponto no centro de um kernel (núcleo) predeterminado, e os pontos no perímetro desse kernel, como mostrado na Figura 5-5(a). O valor da desorientação média desse ponto (grão no centro de kernel) em relação a seus vizinhos é calculado sob a condição que desorientações superiores ao valor

\footnotetext{
${ }^{6}$ Mapeamento de planos e direções bidimensionais, em que a célula unitária é colocada no centro (origem do sistema de coordenadas) de uma esfera de referência de raio arbitrário e o plano, que pode ser representado por seu "polo", é projetado ou estendido até cortar a esfera. Nessa representação o "polo" é a intercepção da perpendicular do plano com a superfície da esfera. Portanto, a projeção estereográfica permite representar de forma precisa as relações angulares entre os planos do cristal. Já que é independente da distorção da área, estas se mantêm constantes.
} 
de tolerância (desorientação máxima) são excluídos do cálculo do valor médio (Figura 5-5b). Na Figura 5-6 são observados mapas de kernel para várias combinações de vizinhos mais próximos e de desorientação máxima. No presente estudo a desorientação média de Kernel foi calculada usando o quinto vizinho mais próximo e uma desorientação máxima de dez graus. Dessa forma, no presente estudo, foram utilizados mapas da distribuição de KAM para avaliar os gradientes de deformação locais ou a distribuição da deformação plástica localizada, entre os diferentes grãos.

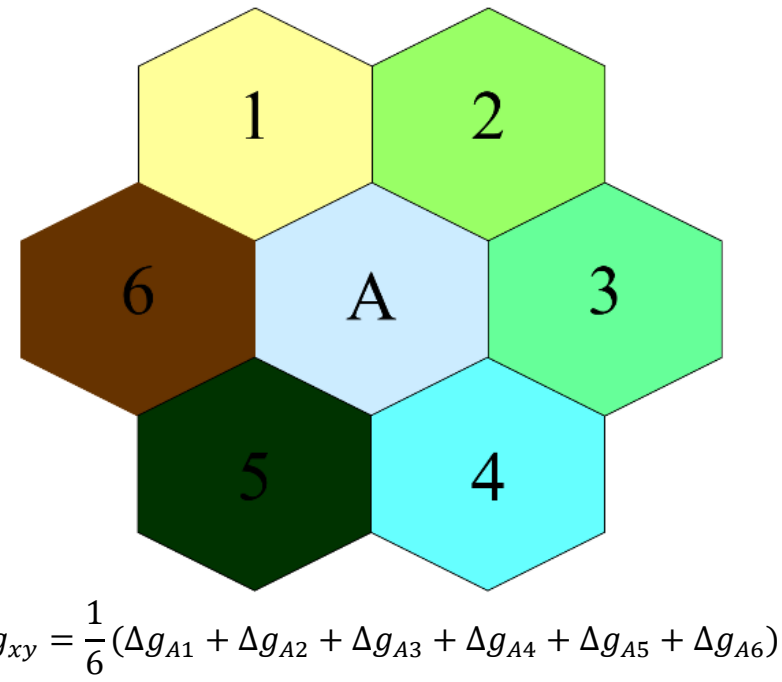

(a)

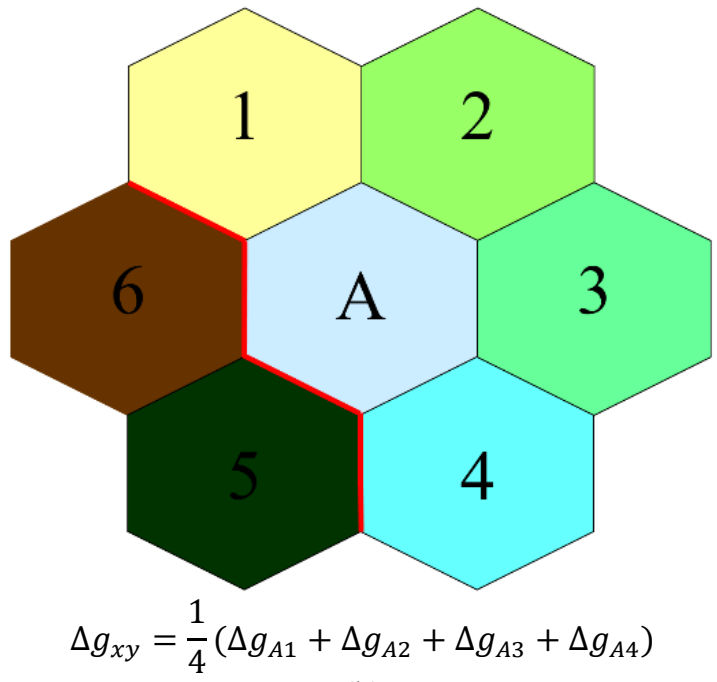

(b)

Figura 5-5. (a) Definição da desorientação média de Kernel (KAM). Cada hexágono representa um píxel na varredura do EBSD. O valor da desorientação local atribuído ao ponto central corresponde à média das desorientações, portanto, $\Delta \boldsymbol{g}_{x y}$ representa a desorientação média entre um píxel x e um píxel y; (b) representação da exclusão de $\Delta \boldsymbol{g}_{\boldsymbol{A 5}}$ e $\Delta \boldsymbol{g}_{\boldsymbol{A 6}}$ do cálculo do valor médio ao exceder o valor superior de tolerância (desorientação máxima). Usando KAM cada pixel no mapa é colorido em função da mudança de orientação do grão em relação a seus vizinhos [119]. 


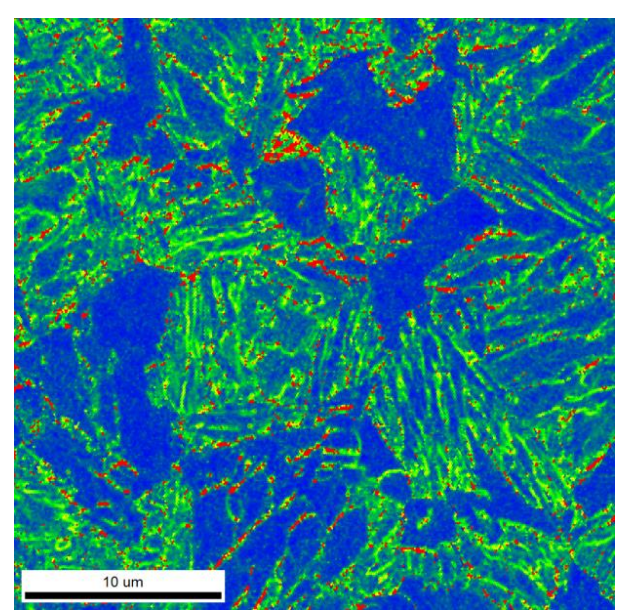

(a)

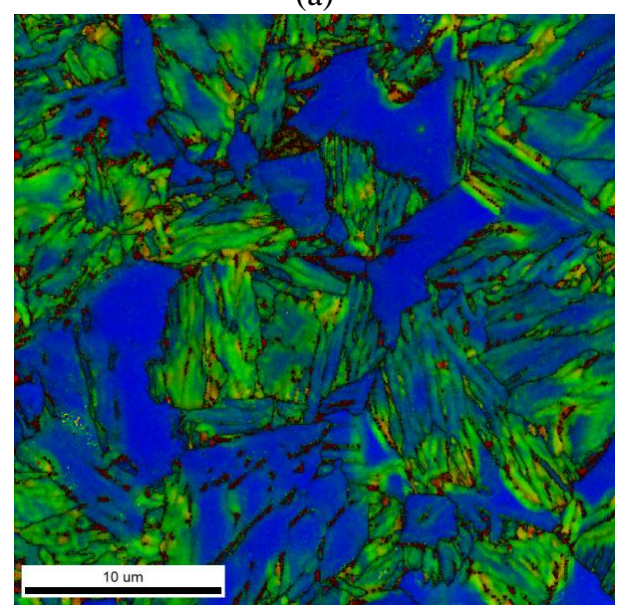

(c)

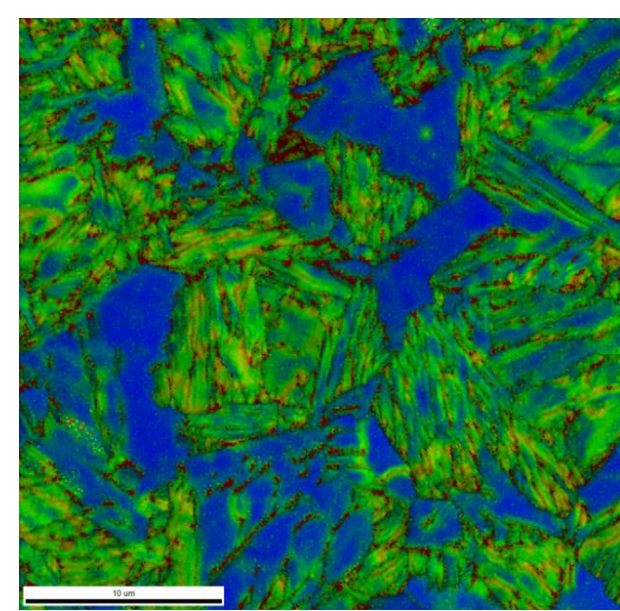

(b)

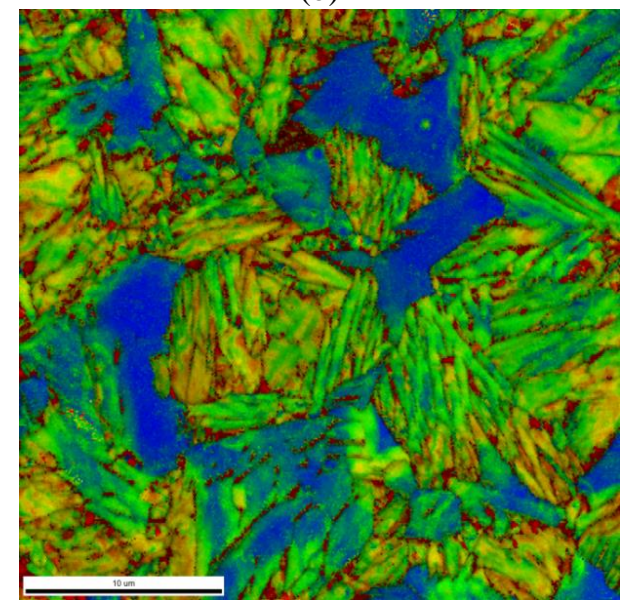

(d)

Figura 5-6. Desorientação média de Kernel combinando o vizinho mais próximo e a máxima desorientação. (a) $1 .^{\circ}$ vizinho e $3^{\circ}$ de desorientação máxima; (b) $3 .^{\circ}$ vizinho e $5^{\circ}$ de desorientação máxima; (c) $5 .^{\circ}$ vizinho e $10^{\circ}$ de desorientação máxima; (d) $8 .^{\circ}$ vizinho e $10^{\circ}$ de desorientação máxima.

d) Mapas dos fatores de Schmid [120] foram calculados, uma vez que esse critério oferece uma indicação da resistência à deformação de uma região particular para um certo estado de tensões. Para isto, a relação entre a tensão de cisalhamento critica projetada $(\tau)$ e a tensão de tração aplicada $(\sigma)$, definida como fator de Schmid ou fator de orientação $(m)$, matematicamente pode ser descrito como:

$$
\tau=m \sigma=[\cos (\zeta) \cdot \cos (\phi)]\left(F / A_{0}\right)
$$

em que $A_{0}$ é a área do plano de deslizamento e $\zeta$ e $\phi$ são os ângulos entre a orientação da força externa à tração aplicada $(F)$ e o plano normal de deslizamento $(\{111\} \gamma$ ou $\{110\} \alpha)$,

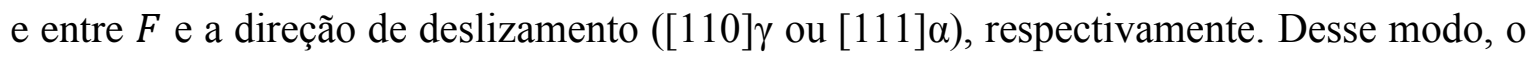
fator de Schmid pode ser definido como a razão entre a tensão de cisalhamento projetada no plano e na direção do sistema de deslizamento correspondentes, e a tensão uniaxial 
aplicada. Portanto, uma diminuição do fator de Schmid resulta na redução da tensão de cisalhamento crítica projetada para que ocorra, por exemplo, a transformação martensítica. Para as estruturas CCC o sistema de deslizamento predominante consiste na família de planos $\{110\}$ e direções $\langle 111\rangle^{7}$, e para as estruturas CFC trata-se do par $\left.\{111\} /<110\right\rangle$. Em outras palavras, em estruturas CFC, sabe-se que o movimento das discordâncias ocorre em quatro planos de deslizamento $\{111\}$ com três possíveis direções de deslizamento $\langle 110\rangle$, de forma que existem 12 sistemas de deslizamento possíveis para a austenita. Já no caso das estruturas CCC há seis planos de deslizamento do tipo $\{110\}$ e duas direções de deslizamento $<110>$ em cada plano $\{110\}$, de forma que existem igualmente 12 sistemas de deslizamento que podem ser ativados. Para o reticulado cristalino CCC, outros sistemas de escorregamento podem também ser ativados $(211) /<-111>$ e $(321) /<-111>$, resultando em 48 sistemas de escorregamento potencialmente ativos para deformação. Nos resultados obtidos, os grãos tendo os maiores fatores de Schmid foram indicados em vermelho, enquanto os menores fatores de Schmid foram indicados em azul, usando um sistema de coloração irisada (cores do arco-iris).

Os resultados dos fatores de Schmid obtidos por meio do software TSL/OIM podem ser obtidos em forma de uma tabela numérica, em função das coordenadas de cada ponto varrido dentro da área analisada, ou na forma de mapas, onde a cada grão corresponde uma cor em função da intensidade da tensão atuante nele e de sua orientação cristalográfica.

\subsection{Microscopia eletrônica de varredura em modo transmissão (STEM)}

Microscopia eletrônica de varredura em modo transmissão (STEM, Scanning Transmission Electron Microscopy) e análises por espectroscopia de raios X por energia dispersiva (EDS, Energy Dispersive X-ray Spectroscopy) foram utilizadas para caracterização microestrutural e de composição química das amostras tratadas por Q\&P e HSQ\&P. As amostras para as análises por STEM foram preparadas via feixe de íons focalizados (FIB, Focused Ion Beam) usando um microscópio MEV-FIB Hitachi NB5000 pertencente ao Center for Nanophase Materials Sciences em Oak Ridge National Laboratory na cidade de Oak Ridge nos Estados Unidos. A preparação por FIB é necessária porque para se extrair informações da seção transversal da amostra, ela deve passar por uma sequência de passos para afinamento até atingir uma espessura que seja transparente à transmissão dos elétrons. Por FIB esse afinamento é feito por meio de um feixe de íons de $\mathrm{Ga}^{+}$. As amostras foram examinadas no microscópio eletrônico de

\footnotetext{
${ }^{7}$ No entanto, nos reticulados cristalinos CCC o deslizamento também pode ocorrer nas famílias de planos $\{112\}$ e $\{123\}$ sob certas condições.
} 
varredura/transmissão FEI Talos F200X (pertencente à Materials Science and Technology Division em Oak Ridge National Laboratory na cidade de Oak Ridge nos Estados Unidos) operado a $200 \mathrm{kV}$, equipado com fonte de elétrons com emissão de campo de brilho aumentado (X-FEG) e sistema Super-X de EDS com 4 detectores de deriva de silício (comumente denominados SDD, do inglês Silicon-Drift Detectors) de raios X para análise química.

\subsection{Tomografia por sonda atômica (APT)}

A tomografia de sonda atômica (APT, do inglês Atom Probe Tomography) permite identificar quimicamente, e de forma individual, os átomos do material. Assim, essa técnica possibilita avaliar a distribuição atômica local pela reconstrução de estruturas atômicas tridimensionais de fases, precipitados ou interfaces. O princípio fundamental da técnica é baseado na evaporação de íons pela aplicação de um campo elétrico (FIE, Field Ion Evaporation), e combinação da técnica de espectrometria de massa de tempo de voo com a microscopia de projeção de ponto, usando o número atômico e os isótopos comuns para identificar o tipo de átomo e criar as imagens 3D em escala atômica. Para remover os átomos da ponta da amostra são aplicadas sequências de pulsos de alto voltagem (DC $\approx 2-11 \mathrm{kV}$ ) e/ou pulsos de laser focalizados. A preparação de amostras por FIB comentada anteriormente para preparação das amostras para análise por STEM, também é necessária nas análises por APT. No entanto, enquanto para STEM são preparadas lâminas finas, para a técnica de APT são necessárias peças em formato de agulha afiada. A sequência de passos na preparação da agulha por FIB é mostrada na Figura 5-7. Como se observa nessa figura as amostras devem ser suficientemente pontiagudas (<100 nm), para que seja possível gerar a evaporação por campo, e não devem apresentar protuberâncias desde a ponta até a base.

A Figura 5-8 mostra de forma esquemática a configuração do funcionamento de um sistema

de APT. A amostra é colocada dentro de uma câmara de ultra alto vácuo $\left(<10^{-8} \mathrm{~Pa}\right.$ ou $10^{-10}$ mbar) e resfriada até temperaturas criogênicas (30 a $80 \mathrm{~K}$ ), a fim de reduzir a oscilação térmica dos átomos, que pode produzir erros de posição (conhecido como background espectral) dos átomos coletados. A eliminação da energia térmica maximiza a sensibilidade da estrutura atômica, permitindo taxas de evaporação similares entre átomos e aumentando a precisão na determinação da posição dos átomos. Adicionalmente, nessas condições (de vácuo e temperatura) se limita a evaporação preferencial, minimiza-se a difusão preferencial e serve como parte de um sistema adicional de bombeamento assistido por geração de vácuo [121]. No entanto, com a redução da temperatura a agulha fica fragilizada e rompe facilmente durante a 
evaporação, o que leva à perda de um número considerável de amostras durante a etapa de análise no tomógrafo. A aplicação de uma sequência de altas voltagens positivas ou de pulsações de laser na ponta da agulha, criam um elevado campo elétrico $\left(\approx 10^{10} \mathrm{~V} / \mathrm{m}\right)$ que rompe as ligações atômicas na superfície da amostra (desorção) e causa a ionização. Esse campo elétrico é proporcional à voltagem aplicada e inversamente proporcional ao raio de curvatura da ponta da amostra. Por essa razão, o formato da agulha possui um raio menor que $100 \mathrm{~nm}$ com a finalidade de produzir o campo elétrico necessário para induzir a evaporação. Devido à elevada diferença de potencial, os átomos evaporados, na forma de íons (cátions), são lançados para o detector $2 \mathrm{D}$, localizado $\mathrm{a} \approx 100 \mathrm{~nm}$ do eletrodo local e acelerados por força eletrostática. A partir dos tempos de voo (TOF, do inglês time-of-flight) de cada íon desde a ponta da amostra ( $\mathrm{t}_{1}$, na Figura 5-8, correspondente ao momento da desorção) até o detector ( $\mathrm{t}_{2}$, na Figura 5-8), é calculada a relação massa/carga e se identifica a natureza química do íon. Essa relação é obtida ao igualar as energias produzidas pelo campo elétrico (energia potencial para o íon escapar da ponta) e a cinética:

$$
n e V_{0}=\frac{1}{2} m\left(\frac{d^{2}}{t^{2}}\right)
$$

em que $n, e$ e $V_{0}$ representam o estado de ionização, a carga elétrica fundamental e a voltagem aplicada e $m, d$ e $t$ representam a massa do íon, a distância entre a ponta da amostra e o eletrodo local e o tempo de voo entre a ponta da amostra e o detector $(\approx 500 \mathrm{~ns})$, determinado com um conversor de tempo digital. Como comentado, a partir da igualdade das energias, é possível obter a relação massa/carga que permite identificar o tipo de íon, de acordo com:

$$
\frac{m}{n}=2 e V_{0}\left(\frac{t^{2}}{d^{2}}\right) \rightarrow T O F=d \frac{\sqrt{m / n}}{2 e V_{0}}
$$

A trajetória dos íons até o detector segue as linhas do campo elétrico aplicado e é independente da massa ou da carga, já que depende apenas da distribuição das linhas. A posição original dos átomos na ponta da amostra é determinada a partir da posição $(x, y)$ do impacto dos íons no detector (aproximando trajetórias retilíneas), enquanto a sequência de eventos detectados na evaporação é utilizada para obter a informação da profundidade (posição em $z$ ), o que permite fazer, usando um algoritmo de reconstrução de projeção inversa, a reconstrução em 3D da distribuição atômica no interior do material, como mostrado à direita da Figura 5-8. Mas para isto, deve-se manter o fluxo de evaporação de átomos constante durante o 
experimento. Como observado no estágio final da Figura 5-7 a amostra apresenta um formato no qual o diâmetro varia ao longo do comprimento. Portanto, para manter o fluxo de íons constante, a amplitude da voltagem do pulso aplicada precisa ser gradualmente incrementada conforme avança a evaporação (como se observa no balanço de energias, quanto maior é $V$, maior a rapidez dos íons e menor $T O F$ ). No entanto, valores muito altos de voltagem ou incrementos muito rápidos podem causar fratura da agulha durante o experimento, o que apresenta outra causa de perda de amostras durante a etapa de análise por APT.

(1) Extração

(2) Montagem

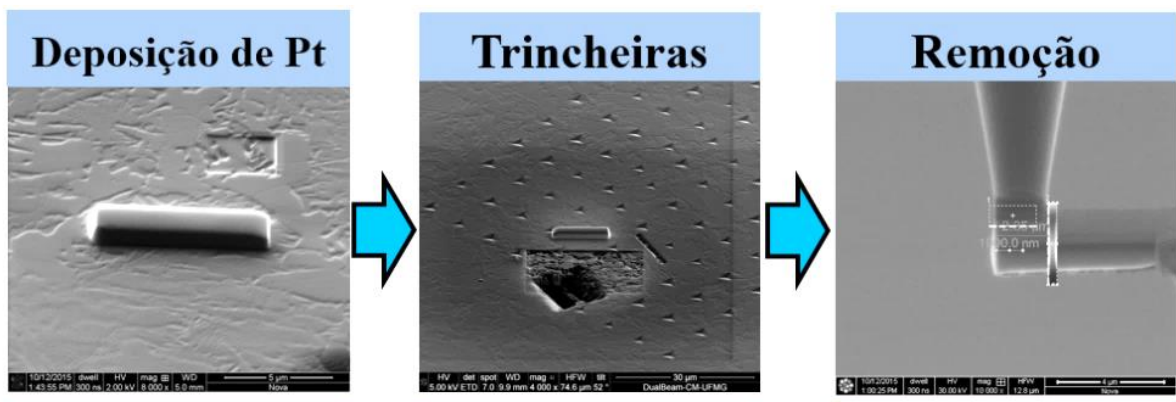

(3) Polimento da ponta
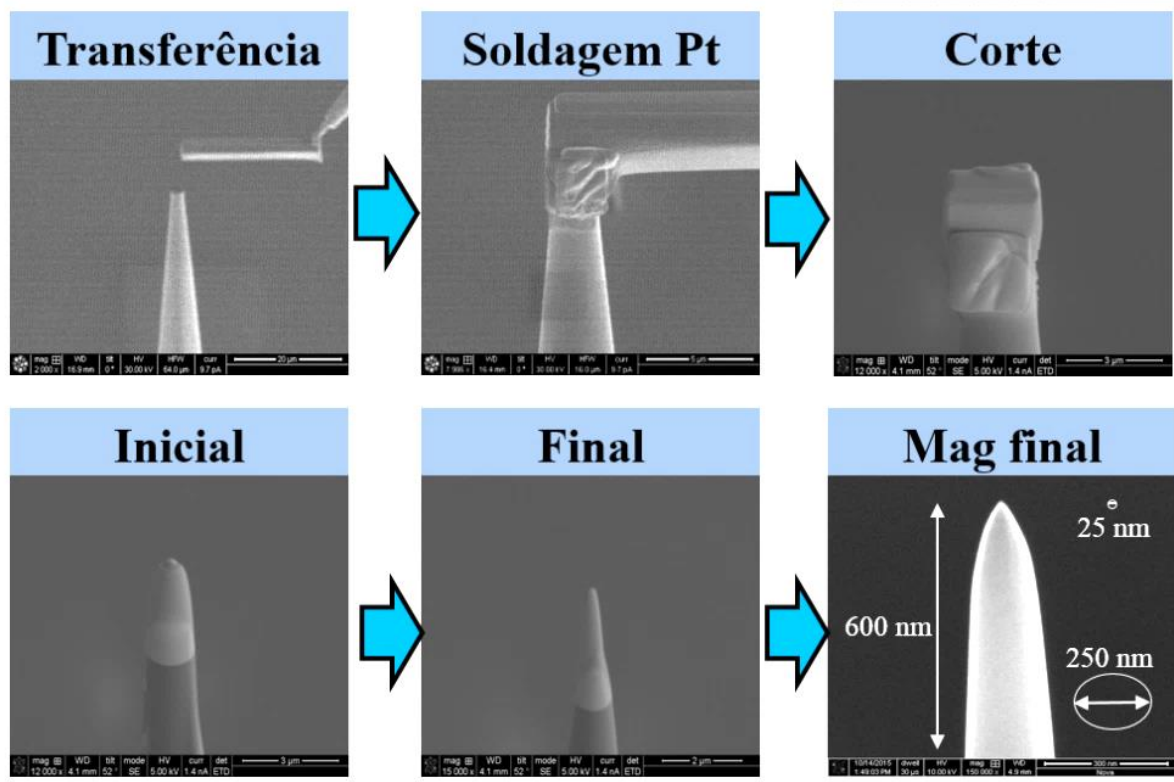

Figura 5-7. Sequência de passos para preparação por íons focalizados (FIB) de uma agulha para ser evaporada por APT. Os três estágios principais incluem a remoção da amostra usando íons de Ga+ para criar as trincheiras na superfície da amostra, mas antes precisa ser feita uma deposição de uma camada de $\mathrm{Pt}$ de $\approx 200 \mathrm{~nm}$ para delimitar a região e proteger a superfície de implantação iônica. Uma vez a amostra está livre se transfere e se solda no manipulador via deposição de Pt o que permite realizar o polimento final na forma de nanoagulha para posterior evaporação no APT. 


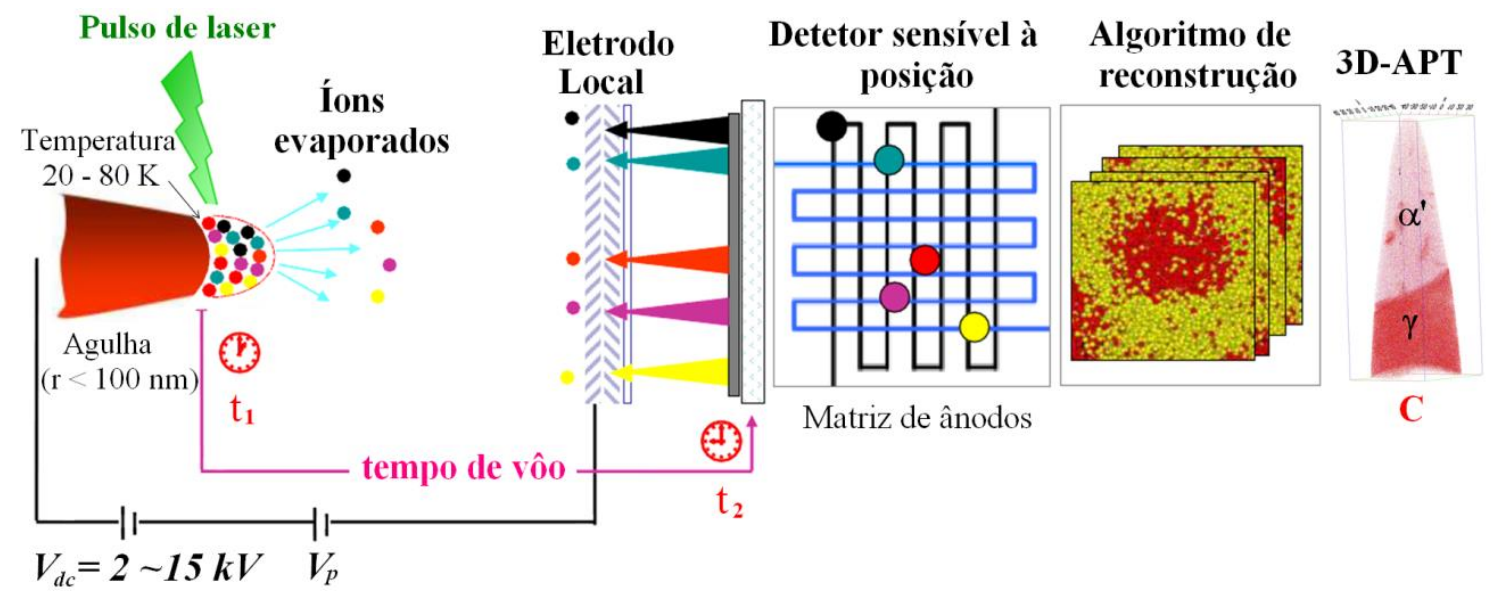

Figura 5-8. Diagrama esquemático do funcionamento de um sistema de tomografia por sonda atômica (APT). Adaptado de [121].

A técnica de análise de alta resolução por APT foi utilizada na presente pesquisa a fim de estudar as características e perfis de distribuição de carbono, manganês e silício nos microconstituintes, nos precipitados e nas interfaces, e de analisar a influência da deformação em alta temperatura no enriquecimento em carbono da austenita.

Como comentado, amostras em formato de agulha ultrafinas foram preparadas para os experimentos de APT usando um feixe de íons de gálio focalizado (FIB) instalado em um microscópio FEI Nova 200 de feixe duplo. As amostras foram evaporadas, no modo laser, em um equipamento LEAP® 4000X HR (pertencente ao Center for Nanophase Materials Sciences -CNMS - em Oak Ridge National Laboratory na cidade de Oak Ridge, nos Estados Unidos). O tomógrafo por sonda atômica utilizado é apresentado na Figura 5-9. As configurações de evaporação adotadas foram: temperatura $30 \mathrm{~K}$, potência do laser $50 \mathrm{pJ}$ a uma taxa de repetição de $200 \mathrm{kHz}$ e uma taxa de detecção íon/pulso de 0,5-1,0\%. As posições de cada íon evaporado nas direções $x$ e $y$ foram determinadas pelo detector primário e o tempo de voo de cada átomo foi registrado a fim de gerar o espectro de massa e posteriormente determinar o tipo de elemento. A reconstrução tridimensional das diferentes camadas ao longo do eixo $z$ e a análise dos dados foram realizadas com auxílio do software CAMECA IVAS (Integrated Visualization \& Analysis Software). Foram usados três métodos de quantificação: iso-superfícies, proxigramas, volumes isolados (a fim de quantificar apenas a matriz sem a influência de misturas de carbonetos ou precipitados) e perfis de linhas de composição normais às interfaces. 

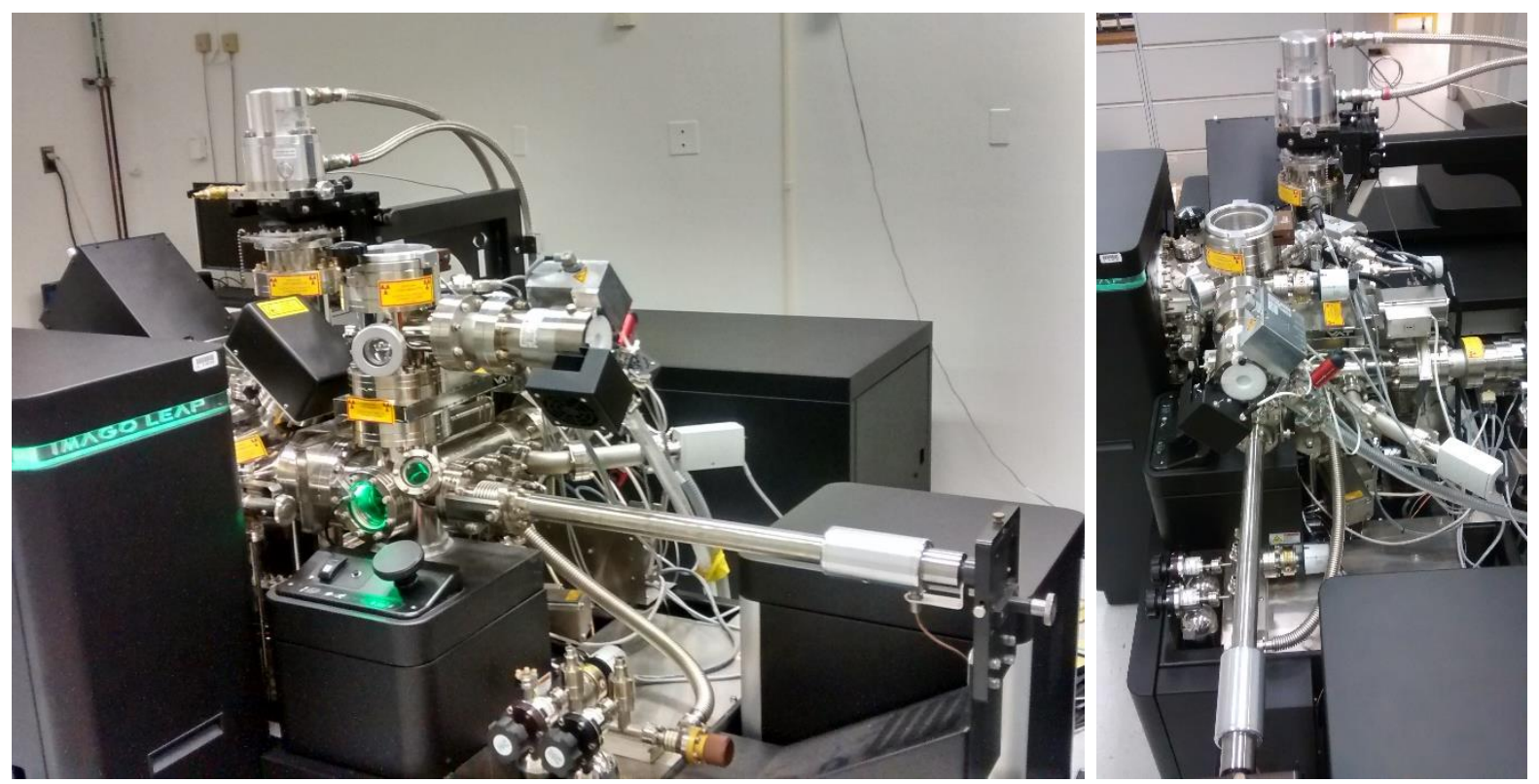

Figura 5-9. Equipamento LEAP (Local Electrode Atom Probe) 4000X HR®.

\subsection{Estereologia quantitativa}

Foram utilizadas as especificações da norma [122], de determinação da fração volumétrica pela contagem sistemática manual de pontos. Este método consiste em sobrepor uma rede de pontos sobre a imagem obtida por MEV. O número de pontos que caem dentro da fase de interesse, dividido pelo número total de pontos da rede, dá a relação numericamente igual à fração volumétrica do aspecto selecionado. Para quantificar a proporção das fases, foram utilizadas malhas de até 391 pontos (Figura 5-10) sobrepostas em pelo menos três imagens obtidas por MEV.

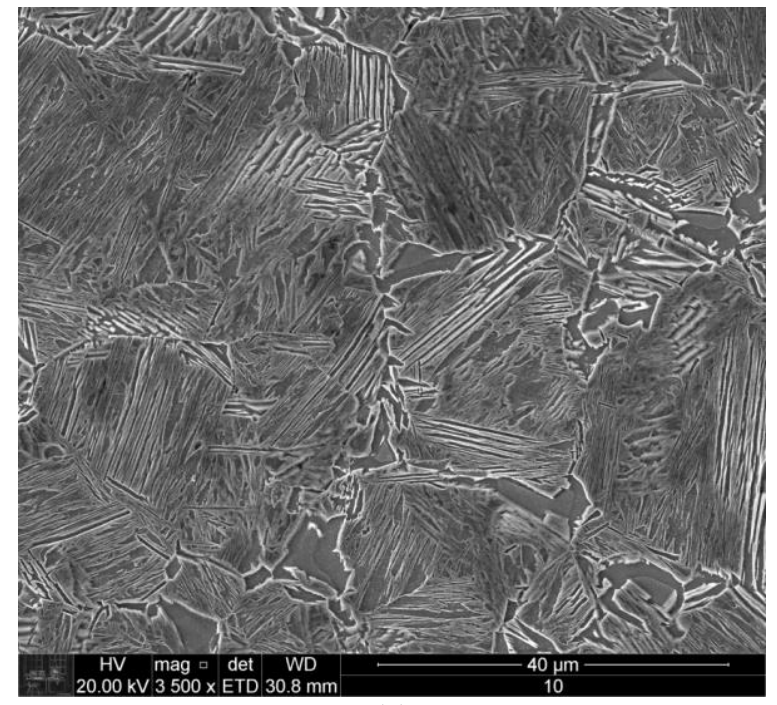

(a)

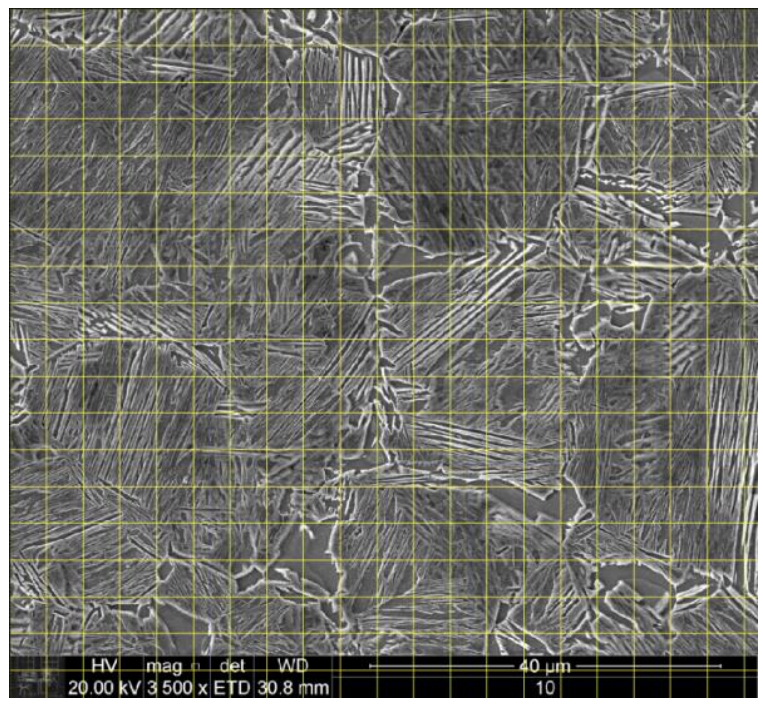

(b)

Figura 5-10. Rede para determinação da fração volumétrica. (a) MEV da região analisada, (b) malha superposta na micrografia. 


\subsection{Nanoindentação}

Esta técnica permite a caracterização simultânea da dureza e do modulo de Young na superfície dos materiais, para profundidades que variam de uns poucos nanômetros até vários micrômetros. Ao contrário dos ensaios de macrodureza em que se aplica uma carga fixa, na nanoindentação se utiliza uma carga dinâmica $(P)$ que aumenta linearmente com o tempo, o que permite acompanhar a penetração do indentador $(h)$ durante as etapas de carregamento e descarregamento, realizar testes para pequenas penetrações e automatizar (instrumentar) o processo de medição. Devido ao fato de que a marca de indentação é extremamente pequena e as medições são automatizadas, é possível realizar um grande número de medições, avaliar regiões específicas e criar mapas das propriedades mecânicas.

Os nanoindentadores utilizam penetradores (geralmente de diamante) piramidais de base quadrada tipo Vickers (Figura 5-11a) ou, mais comumente o indentador de pirâmide triangular tipo Berkovich (Figura 5-11b).

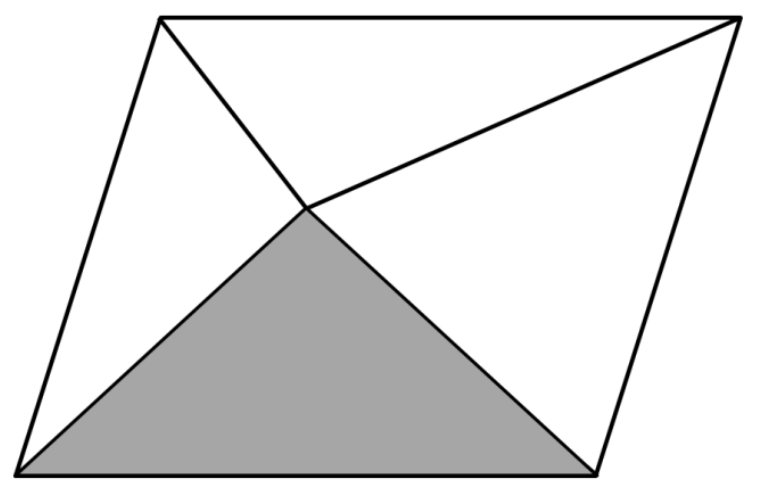

(a)

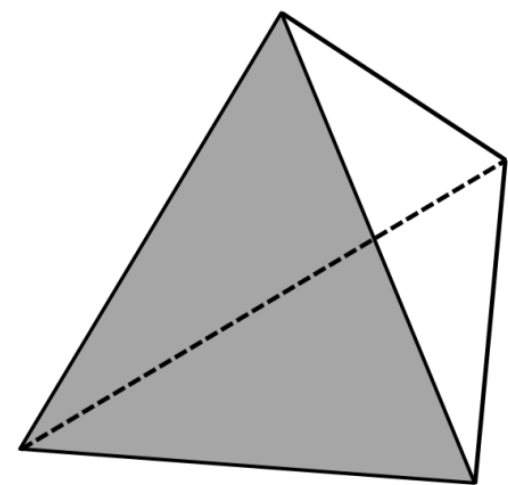

(b)

Figura 5-11. Penetradores utilizados em ensaios de nanoindentação: (a) tipo Vickers; (b) tipo Berkovich.

Uma vez colocada a amostra sobre uma base móvel do indentador, ela pode se movimentar nos planos $x, y$ e $z$ de forma controlada, o que permite, usando o microscópio óptico acoplado, localizar a região de interesse a ser analisada (Figura 5-12) e se obter a correspondente curva força-deslocamento (Figura 5-13). 


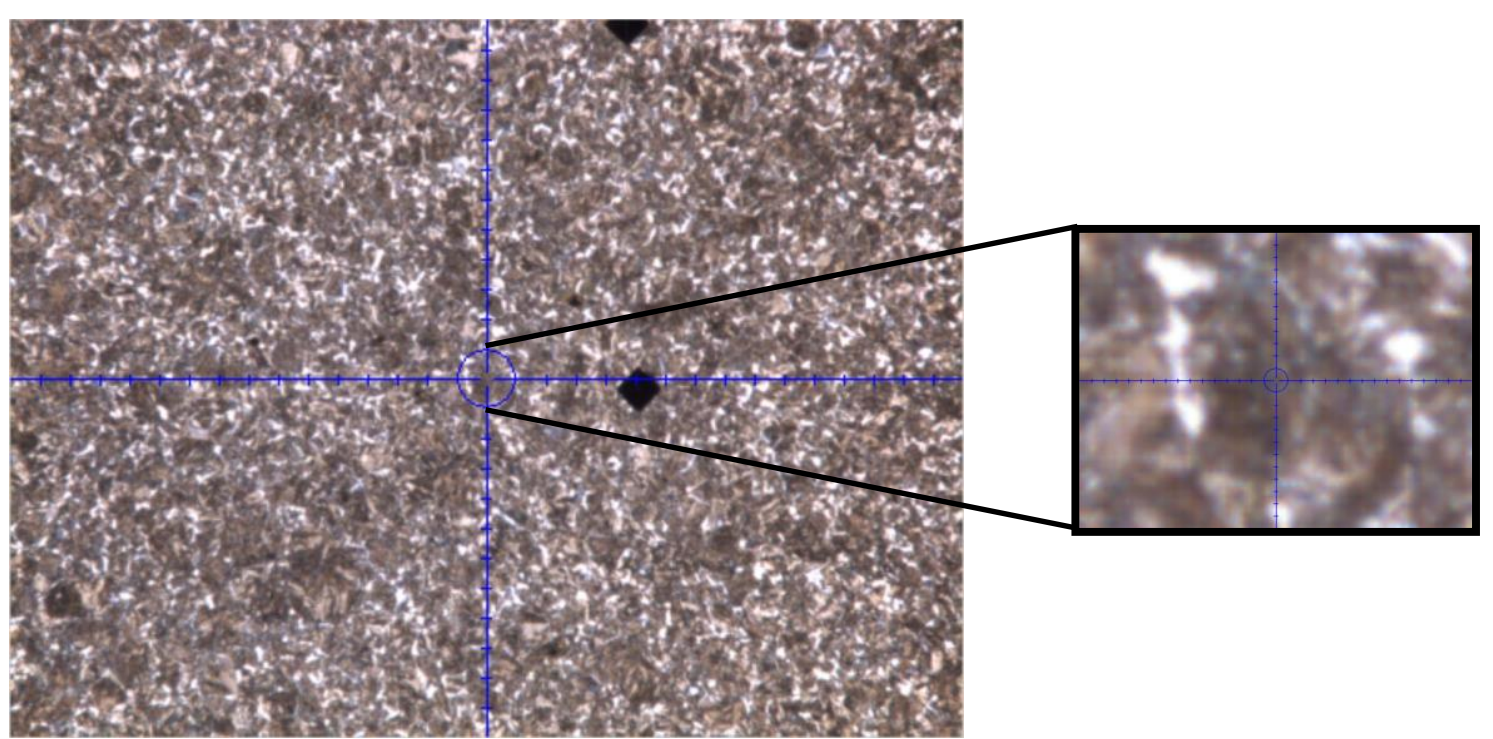

Figura 5-12. Localização da região selecionada para realizar a nanoindentação usando o microscópio óptico acoplado ao triboindentador.

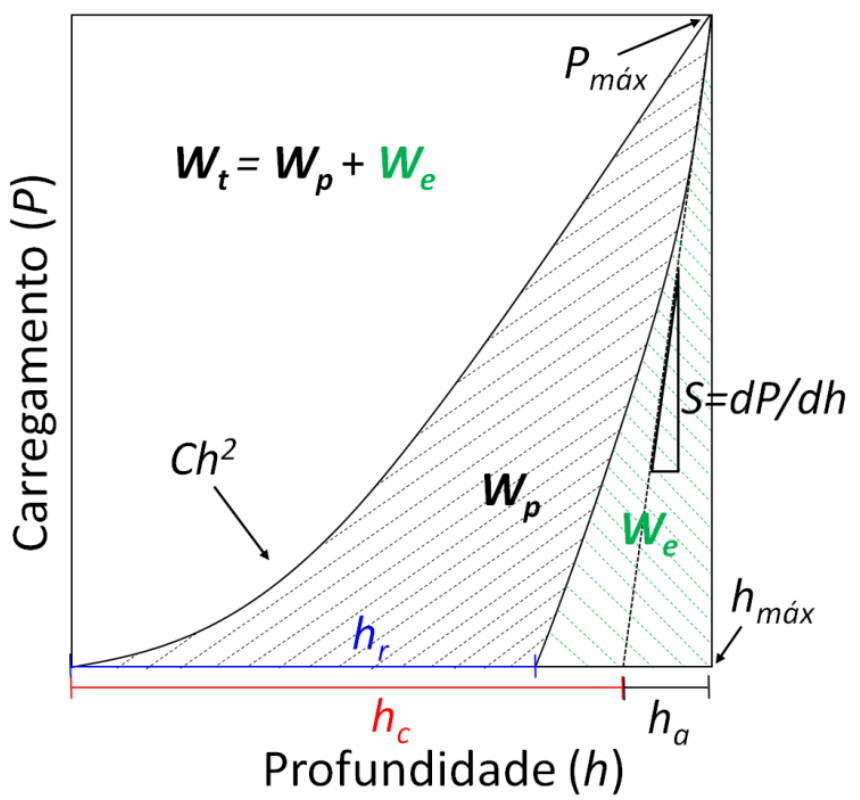

(a)

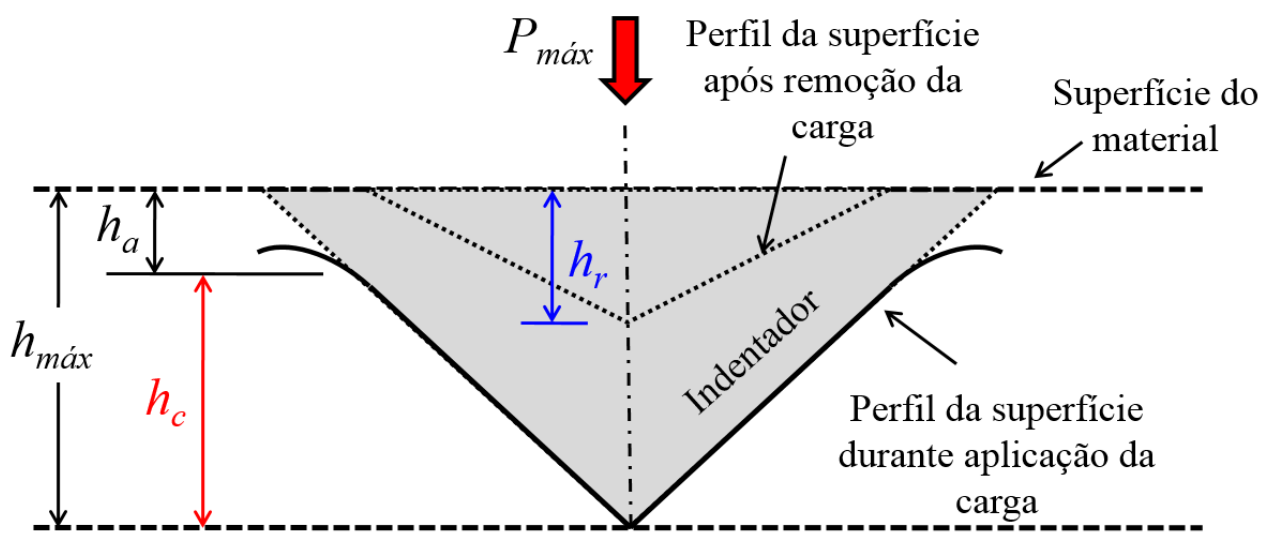

(b)

Figura 5-13. (a) Curva carregamento-profundidade de penetração num ensaio de nanoindentação; (b) detalhamento da relação da curva carregamento-profundidade no perfil da impressão de uma indentação. $h_{m a ́ x}$ indica o deslocamento máximo do indentador quando uma carga máxima $(P)$ é aplicada. 
Os testes de nanoindentação instrumentada foram realizados em dois nanoindentadores Hysitron modelo Triboindenter TI 950 equipados com ponta de diamante tipo Berkovich, um pertencente ao Laboratório de Fenômenos de Superfícies do Departamento de Engenharia Mecânica da Universidade de São Paulo e o outro ao CNMS no Laboratório Nacional de Oak Ridge nos Estados Unidos. Os nanoindentadores podem realizar os testes utilizando o controle tanto da força aplicada pela ponta sobre a amostra, como do deslocamento da ponta durante o processo de indentação. As amostras foram testadas na temperatura ambiente, após polimento em solução diamantada até $1 \mu \mathrm{m}$ para posterior analise por MEV, ou em pasta de diamante e sílica coloidal $(0,05 \mu \mathrm{m})$ para as análises complementares por EBSD. Foi utilizado o modo de controle de força com cargas constantes de $15 \mathrm{mN}$ ou $1,5 \mathrm{mN}$ (para identificação de fases menores) em matrizes de indentação de $10 \times 10$ (mapa de 100 nanoindentações) ou $15 \times 15$ (em total 225 indentações) com espaçamentos de $10 \mu \mathrm{m}$ nas direções vertical e horizontal. Para a realização das indentações, a força foi controlada em função do tempo enquanto foi medido o deslocamento da ponta sobre o material. O equipamento foi previamente calibrado em uma amostra padrão de cristal de quartzo para verificação dos valores do módulo de Young $(E)$ e do coeficiente de Poisson ( $v$ ) desse material, para o qual $E$ e $v$ deviam estar próximos a 72 GPa e 0,18, respectivamente. A análise estatística dos valores obtidos com a sequência de nanoindentações permitiu obter os valores da dureza $(H), E$ e do módulo elástico reduzido $\left(E^{*}\right)$ do material, através do método de Oliver e Pharr [123]. O método de Oliver e Pharr é o mais amplamente aceito e, portanto, utilizado para determinação de $H, E^{*}$ e $E$ e para análise dos dados de nanoindentação. Além disso, o método desenvolvido por Oliver e Pharr permite uma estimativa da projeção da área deformada plasticamente quando o indentador atinge a força máxima do teste. Como observado na Figura 5-13(b), essa área difere da área observada da impressão residual deixada após o teste de indentação, uma vez que a segunda é menor devido à recuperação elástica do material. Por este método, a dureza é calculada como a razão entre a força aplicada e a área projetada da deformação plástica do material para essa força (equação 5.13), sendo essa última extraída da curva de indentação (Figura 5-13(a)). Esse método permite a determinação da razão força-área deformada, tanto no regime de deformação elástico como no plástico. Essa razão quando calculada nas curvas de indentação no regime elástico é chamada de pressão média de contato, e, quando calculada para o regime plástico, é chamada de dureza.

$$
H=\frac{P_{\max }}{A\left(h_{c}\right)}
$$


Na equação $5.13 P_{\text {máx }}$ (em Newtons) indica a carga máxima aplicada e $A\left(h_{c}\right)$ a área de contato projetada do indentador para a máxima carga aplicada, expressa pela função de área aplicada para a máxima profundidade de penetração [123].

A partir da função de área obtém-se a área da secção transversal do indentador para diferentes profundidades de penetração, que é a forma de descrever a geometria do indentador. No caso do indentador Berkovich (assumindo geometria perfeita, com um ângulo de indentador na ponta de $65,27^{\circ}$ ), a área A calculada a partir da função contato projetada é dada por:

$$
A\left(h_{c}\right)=3 \sqrt{3} h_{c}{ }^{2} \tan ^{2} \theta=24.49 h_{c}{ }^{2}
$$

onde $h_{c}$ está relacionado com o comprimento da deformação e a forma do indentador. De fato, com base nas Figura 5-13 é possível observar que:

$$
h_{c}=h_{m a ́ x}-h_{a}
$$

em que $h_{a}$ representa o deslocamento elástico (penetração elástica) da superfície no perímetro de contato, que pode ser calculado usando a expressão:

$$
h_{a}=\vartheta \frac{P_{m a ́ x}}{S}
$$

em que $\vartheta$ é um parâmetro que depende da geometria do indentador $(\vartheta=0,75$, para indentadores Berkovich). A determinação de $S$ apartir da curva de descarregamento, permite calcular $h_{a}$ usando a equação 5.16 e, portanto estimar $h_{c}$. Durante a retirada do penetrador, ele permanece em contato com a superfície durante um periodo correspondente a sua recuperação elástica e a profundidade de penetração plástica $\left(h_{c}\right)$ é obtida mediante a extrapolação da porção inicial da curva de descarregamento. Esse comportamento se observa na secção linear da curva de descarregamento na Figura 5-13(a). A inclinação (ou coeficiente angular) dessa linha, dada pela derivada $d P / d h$, representa a rigidez elástica da superfície e pode ser expressa, para o indentador Berkovich, como:

$$
S=\frac{d P}{d h}=\frac{2 \beta}{\sqrt{\pi}} E^{*} \sqrt{A\left(h_{c}\right)}
$$

em que $\beta$ é um fator de correção da geometria do indentador $(\beta=1,05$; para indentadores axisimétricos) e $E^{*}$ (em GPa) é o módulo elástico reduzido do material, expressado como: 


$$
\frac{1}{E^{*}}=\frac{1-v_{b}^{2}}{E_{b}}+\frac{1-v_{i}^{2}}{E_{i}}
$$

em que $v_{b}, E_{i}$ e $v_{i}$, são respectivamente, o coeficiente de Poisson do material estudado $(0,33)$, o módulo de elasticidade do indentador (1140 GPa) e o coeficiente de Poisson do indentador $(0,07)$. Dessa forma, das curvas de carga-deslocamento analisadas, os dados do módulo de elasticidade reduzido ( $E^{*}$, em GPa) são calculados, segundo:

$$
E^{*}=\frac{\sqrt{\pi}}{2 \beta \sqrt{A\left(h_{c}\right)}} \times S=\frac{\sqrt{\pi}}{2 \beta \sqrt{A\left(h_{c}\right)}} \times \frac{d P}{d h}
$$

Portanto, calculando o valor do módulo elástico reduzido e, sabendo as propriedades mecânicas do indentador $\left(E_{i}\right.$ e $\left.v_{i}\right)$, é possível determinar o valor da relação $\left(1-v_{b}^{2}\right) / E_{b}$, e, usando as equações descritas, é possível determinar o módulo de elasticidade e a nanodureza para cada indentação.

\subsection{Algoritmo de conversão das curvas de nanoindentação em curvas tensão-deformação}

Um grande número de trabalhos têm desenvolvido métodos e algoritmos para extrair as propriedades mecânicas dos materiais a partir de curvas de carregamento-profundidade de penetração $(P \times h)$ obtidas em equipamentos de indentação instrumentada [124-128]. Dentre todos esses métodos, Dao et al. [127] desenvolveram o esquema de análise reverso mais completo para determinar as propriedades elasto-plásticas usando as curvas $P \times h$ de ensaios de nanoindentação para ligas metálicas. Por essa razão, na presente pesquisa foi adotado o algoritmo proposto por Dao et al. [127] para determinar o limite de escoamento $\left(\sigma_{y}\right)$ e o coeficiente de encruamento $(n)$ de aços tratados por Q\&P e HSQ\&P. Para atingir esse objetivo, foram utilizadas malhas de $140 \times 140 \mu \mathrm{m}^{2}$ com 225 pontos de nanoindentação. Assumiu-se que o comportamento plástico do material segue a lei de potência de encruamento (equação 5.20). O limite de resistência à tração pôde ser estimado por meio do cálculo da tensão de escoamento no ponto em que a deformação real obedece a relação de Considère para determinação do início de instabilidades plásticas (isto é, a estricção ocorre quando se satisfaz a equação 5.21).

$$
\sigma=\left\{\begin{array}{c}
E \varepsilon, \text { para } \sigma \leq \sigma_{y} \\
R \varepsilon^{n}, \text { para } \sigma \geq \sigma_{y}
\end{array}\right.
$$




$$
\sigma=\frac{d \sigma}{d \varepsilon} \text { ou } \varepsilon=n
$$

em que $\sigma$ e $\varepsilon$ são, respectivamente, a tensão real de escoamento e a deformação real, $E$ é o módulo Young e $R$ é um coeficiente de resistência. Alternativamente, a equação 5.20 para o regime plástico de deformação ( $\sigma \geq \sigma_{y}$ ) pode ser reescrita em função do limite de escoamento, do módulo de Young e da deformação plástica, $\varepsilon_{p}$ :

$$
\sigma=\sigma_{y}\left(1+\frac{E}{\sigma_{y}} \varepsilon_{p}\right)^{n}
$$

A equação 5.22 é muito útil, pois permite expressar a tensão de escoamento em função das propriedades elasto-plásticas do material, eliminando a necessidade do uso do coeficiente $R$. De acordo com a curva típica de $P \times h$ em um ensaio de indentação instrumentada (e.g., Figura 5-13(a)), durante o carregamento, a resposta geralmente segue a lei de Kick [129]:

$$
P=C h^{2}
$$

em que $C$ é uma constante que determina a curvatura do carregamento e é dependente da geometria do indentador e das propriedades elasto-plásticas da amostra indentada. A pressão média de contato, $P_{a v e}$, é associada como a propriedade de dureza na região de indentação e é definida por:

$$
P_{\text {ave }}=\frac{P_{m}}{A_{m}}
$$

em que $A_{m}$ é a área projetada da indentação medida na força máxima $P_{m}$ aplicada. A máxima profundidade de penetração, $h_{m}$, ocorre na aplicação de $P_{m}$ e a inclinação inicial da curva durante o descarregamento é definida como:

$$
\left.\frac{d P_{u}}{d h}\right|_{h_{m}}
$$

em que $P_{u}$ é a força de descarregamento. Por sua vez, $A_{m}$ pode ser estimado, em função de $h_{m}$, desprezando os efeitos de pile up e sink in, pela relação:

$$
A_{m}=c^{*} h_{m}^{2}
$$


na qual a constante $c^{*}$ assume o valor de 24,56 para o indentador Berkovich, utilizado neste trabalho. A profundidade residual da indentação durante o descarregamento é denotada por $h_{r}$, enquanto $W_{t}, W_{p}$ e $W_{e}$ são, os trabalhos de deformação total, plástico e elástico, respectivamente. Note-se que as três propriedades, como mostrado na Figura 5-13, relacionamse entre si pela relação:

$$
W_{p}=W_{t}-W_{e}
$$

Como discutido pelos autores na referência [127], $C,\left.\frac{d P_{u}}{d h}\right|_{h_{m}}$ e $\frac{h_{r}}{h_{m}}$ são três quantidades independentes que podem ser obtidas a partir da curva $P \times h$. O mérito do algoritmo reverso de Dao et al. [127] foi o de fazer uso de funções adimensionais que estabelecem a correlação unívoca entre estas quantidades e as propriedades mecânicas macroscópicas do material. Como ponto de partida, Dao et al. expressaram o carregamento durante o ensaio de indentação em função de quatro variáveis, $h, E^{*}, \sigma_{r}$ e $n$, ou seja:

$$
P=P\left(h, E^{*}, \sigma_{r}, n\right)
$$

em que $\sigma_{r}$ é a tensão de escoamento real representativa, correspondente a uma deformação arbitrária, e $E^{*}$ é o módulo elástico reduzido, expresso, como mostrado na equação 5.18 , em função das propriedades elásticas do material e do indentador.

$\mathrm{Na}$ sequência, os autores determinaram uma série de funções adimensionais correlacionando as três variáveis independentes obtidas da curva de carregamento (i.e., $C$, $\left.\left.\frac{d P_{u}}{d h}\right|_{h_{m}} \mathrm{e} \frac{h_{r}}{h_{m}}\right)$ com as propriedades mecânicas que caracterizam a curva tensão-deformação do material $\left(E^{*}, \sigma_{0,033}, n\right.$ e $\left.p_{\text {ave }}\right)$. O conjunto de equações adimensionais utilizadas neste trabalho, é mostrado nas equações 5.29 a 5.32. A tensão representativa calculada para a deformação de $0,033, \sigma_{0,033}$, foi utilizada por Dao et al. [127] de forma conveniente para tornar a equação 5.22 dependente apenas de $\frac{E^{*}}{\sigma_{0,033}}$. 


$$
\begin{aligned}
\Pi_{1}\left(\frac{E^{*}}{\sigma_{0,033}}\right)= & \frac{C}{\sigma_{0,033}} \\
& =-1,131\left[\ln \left(\frac{E^{*}}{\sigma_{0,033}}\right)\right]^{3}+13,635\left[\ln \left(\frac{E^{*}}{\sigma_{0,033}}\right)\right]^{2} \\
& -30,594\left[\ln \left(\frac{E^{*}}{\sigma_{0,033}}\right)\right]+29,267 \\
\Pi_{2}\left(\frac{E^{*}}{\sigma_{0,033}}, n\right) & =\left.\frac{1}{E^{*} h_{m}} \frac{d P_{u}}{d h}\right|_{h_{m}} \\
& =\left(-1,40557 n^{3}+0,77526 n^{2}+0,15830 n\right. \\
& -0,06831)\left[\ln \left(\frac{E^{*}}{\sigma_{0,033}}\right)\right]^{3} \\
& +\left(17,93006 n^{3}-9,22091 n^{2}-2,37733 n\right. \\
& +0,86295)\left[\ln \left(\frac{E^{*}}{\sigma_{0,033}}\right)\right]^{2} \\
& +\left(-79,99715 n^{3}+40,55620 n^{2}+9,00157 n\right. \\
& -2,54543)\left[\ln \left(\frac{E^{*}}{\sigma_{0,033}}\right)\right]^{2}+\left(122,65069 n^{3}-63,88418 n^{2}\right. \\
& -9,58936 n+6,20045)
\end{aligned}
$$

$$
\left.-0,075187\left(\frac{h_{r}}{h_{m}}\right)^{1,135826}\right\}
$$

O fluxograma mostrado na Figura 5-14 apresenta a sequência de etapas necessária para determinação das propriedades mecânicas do material por meio do algoritmo reverso. Note-se que, uma vez determinadas as propriedades do material, o limite de escoamento $\sigma_{y}$, pode ser determinado a partir da equação 5.22. 
Problema reverso: $C, h_{r}\left(\right.$ ou $\left.\frac{W_{p}}{W_{t}}\right), h_{m}\left(\right.$ ou $\left.P_{m}\right),\left.\frac{d P_{u}}{d h}\right|_{h_{m}} \longrightarrow E^{*}, A_{m}, P_{\text {ave }}, \sigma_{0,033}, \sigma_{y}, n$

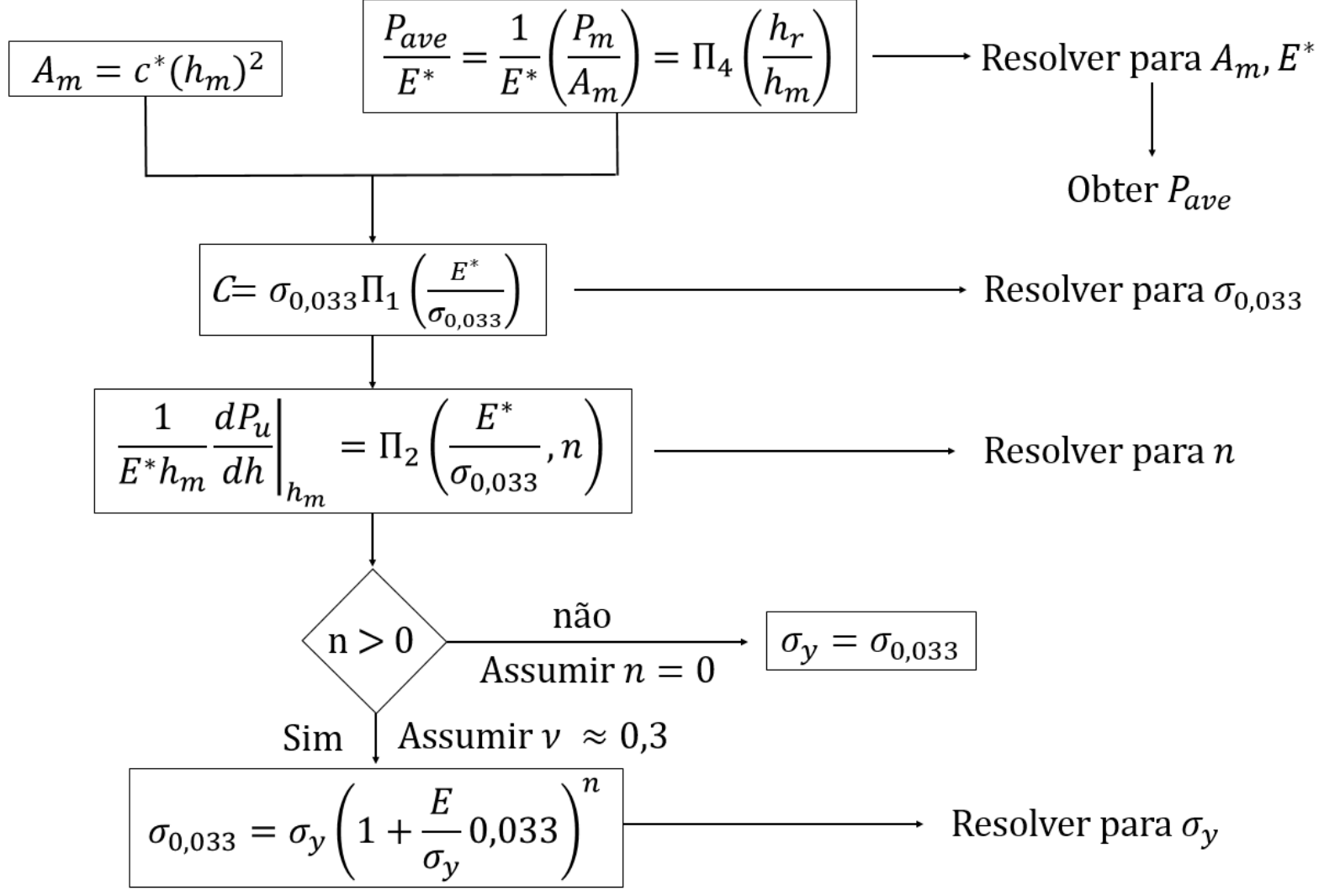

Figura 5-14. Fluxograma do algoritmo de análise reversa proposto por Dao et al., [127] e utilizado na presente pesquisa para determinar as propriedades mecânicas de limite de escoamento e coeficiente de encruamento.

A resolução das equações não-lineares mostradas na sequência de etapas não pode ser feita analiticamente. Desta forma, uma rotina programada em R-script foi escrita e interpretada para geração dos resultados. Foram descartados os pontos de indentação que forneceram resultados sem significado físico, ou seja, valores negativos das propriedades calculadas, e cuja regressão para determinação da constante $C$ apresentou valores de coeficiente de determinação $\mathrm{R}^{2}$ inferiores ao limiar de 0,99 .

\subsection{Microdureza}

Nos testes de microdureza foi usado o microdurômetro FUTURE TECH, utilizando penetrador Vickers com carga de 0,5 kg e um tempo de penetração de $10 \mathrm{~s}$. Foram realizadas pelo menos 25 medidas na parte intermediária da amostra. A partir dessas medidas, foram realizados os cálculos do valor médio e desvio padrão das durezas nas amostras tratadas no simulador termomecânico Gleeble. 


\subsection{Ensaios mecânicos tensão-deformação em corpos de prova reduzidos}

Ensaios de tração foram conduzidos em corpos de prova de tamanho reduzido (sub-size) extraídos da parte central das amostras previamente tratadas no simulador termomecânico Gleeble, como mostrado na Figura 5-15(a). A usinagem dos corpos de prova sub-size foi realizada por eletro-erosão a fio a temperaturas que não superaram os $70{ }^{\circ} \mathrm{C}$ durante o corte, utilizando um fluido dielétrico a fim de evitar alterações dimensionais ou danos na amostra, que pudessem alterar a microestrutura antes do ensaio mecânico. As dimensões da amostra subsize são mostradas na Figura 5-15(a) e estão baseados no trabalho recentemente publicado por De Knijf et al. [130] de aços Q\&P tratados em um simulador Gleeble. Para evitar o escorregamento das amostras durante os testes de tração, foi construído um sistema de garras como mostrado na Figura 5-15(b). Os ensaios foram conduzidos em máquinas de ensaios mecânicos Kratos, disponível no Departamento de Engenharia Metalúrgica e de Materiais da USP, e Instron modelo 3369, pertencente ao Grupo de Mecânica dos Sólidos e Impacto Estrutural do Departamento de Engenharia Mecânica da USP, ambas com célula de carga de $500 \mathrm{~N}$.

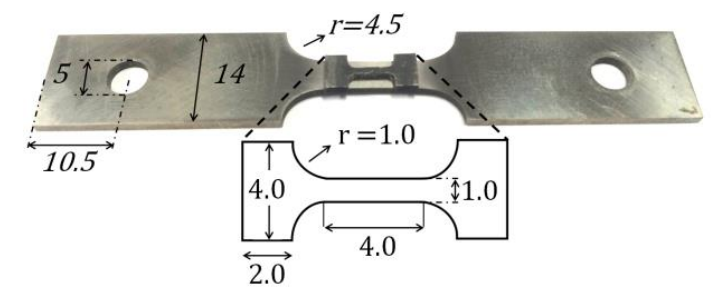

(a)

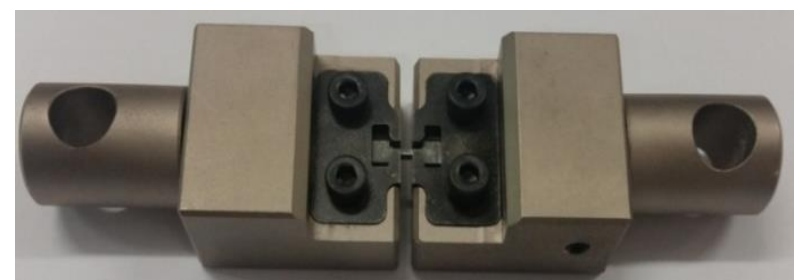

(b)

Figura 5-15. (a) Região de extração dos corpos de prova das amostras tratadas em simulador termomecânico Gleeble e representação esquemática da geometria das amostras para ensaios de micromecânicos de tração. Espessura igual a 1,5 mm. Dimensões em mm; (b) Sistema de garras projetado para os testes micromecânicos de tração.

As medidas da deformação foram conduzidas sem uso de extensômetro devido à dificuldade da instalação do dispositivo nos corpos de prova com as dimensões da presente pesquisa. Para o acompanhamento da deformação e determinação do alongamento total, em um conjunto de amostras (resultados apresentados no capítulo 6) foram feitas marcas de microdureza na superfície da amostra. A medição da variação do comprimento antes e depois do ensaio foi realizada usando microscópio óptico e micrômetro acoplados ao microdurômetro FUTURE TECH e a deformação durante o ensaio foi registrada por meio de vídeo, o que auxiliou no acompanhamento do distanciamento das marcas, até o instante da fratura. As curvas forçadeslocamento do ensaio de tração obtidas pela máquina foram convertidas em curvas tensãodeformação dividindo o valor de força $(F)$ pela área da seção inicial do corpo de prova $\left(A_{o}\right)$ 
para se obter a tensão $(\sigma)$ e dividindo o valor da variação do deslocamento $(\Delta l)$ na direção da deformação pelo comprimento inicial (antes da aplicação da carga) do corpo de prova $\left(l_{o}\right)$ para se obter a deformação $(\varepsilon)$.

Em outro conjunto de amostras (resultados apresentados no capítulo 8) as medidas de deformação durante o ensaio foram feitas usando a técnica de correlação de imagem digital (DIC, Digital Image Correlation). Nesta técnica é usada uma análise de correlação matemática para calcular a deformação na superfície da amostra a partir de uma série consecutiva de imagens. Os detalhes do algoritmo matemático utilizado para calcular os campos de deformação pelo DIC estão apresentados no trabalho de Blaber et al. [131]. O método DIC consiste na medição da deformação da amostra durante o ensaio por comparação, píxel por píxel, da sequência de imagens obtidas antes e depois do alongamento [132]. Para isto, foi necessário limpar a superfície da amostra e aplicar, usando aerossóis, uma fina camada de tinta branca, seguida pela dispersão aleatória de gotículas pretas, criando uma dispersão de pontos pretos no centro da amostra que atuam como pontos de referência para comparação no pós-processamento pelo algoritmo DIC. As imagens durante o ensaio mecânico foram registradas usando uma câmara de 5 mega-píxeis montada em um tripé e alinhada e focalizada ao centro da amostra. As fotos foram tomadas a cada $0,3 \mathrm{~s}$, correspondente a uma velocidade de fotogramas de 3,33 quadros/s. As imagens foram registradas até a fratura do material e as deformações foram calculadas a partir dos deslocamentos usando o programa de acesso livre n-corr [133].

A distorção da amostra durante o ensaio de tração é influenciada pela distorção (elasticidade) do sistema deformante, sendo o sistema deformante toda a região fora do comprimento útil da amostra $\left(l_{o}\right)$, compreendendo parte do corpo de prova, garras, travessão de aplicação de carga, etc. O módulo de elasticidade obtido de uma curva registrada diretamente pela máquina de tração é bem diferente daquele característico do material, de forma que se faz necessária a realização da correção da curva tensão $\times$ deformação de engenharia obtida diretamente da máquina. A influência da elasticidade do sistema $(K S)$ será tanto maior quanto menor for sua rigidez (resistência à deformação elástica). Para a correção dos valores do módulo de Young das curvas tensão-deformação foi usada a equação de correção proposta por HajyAkbary et al. [134], originalmente aplicada para corrigir a rigidez da máquina de ensaios mecânicos em corpos de prova de tração com dimensão reduzida.

$$
\frac{1}{K s}=\frac{1}{K m}+\frac{1}{K c p}
$$


em que $K s, K m$ e $K c p$ representam a rigidez do sistema, da máquina e do corpo de prova, respectivamente, $\operatorname{com} K=E . A / l$ e $E=\sigma_{e} / \varepsilon$. Sabendo que o deslocamento total é a somatória do deslocamento da máquina mais o deslocamento do corpo de prova e que pela lei de Hooke temos $l=F / K$, com $F=\sigma . A$, podemos obter uma expressão que relaciona as deformações com a rigidez da máquina:

$$
\varepsilon_{c p}=\varepsilon+\frac{\sigma \cdot A}{K m \cdot l}
$$

Na Figura 5-16, são apresentadas as curvas corrigida e não corrigida do ensaio tensãodeformação na amostra como recebida, usando corpos de prova sub-size. A curva não corrigida inclui as informações elasto-plásticas tanto da amostra quanto do sistema deformante. Já a curva corrigida leva em conta somente os valores práticos.

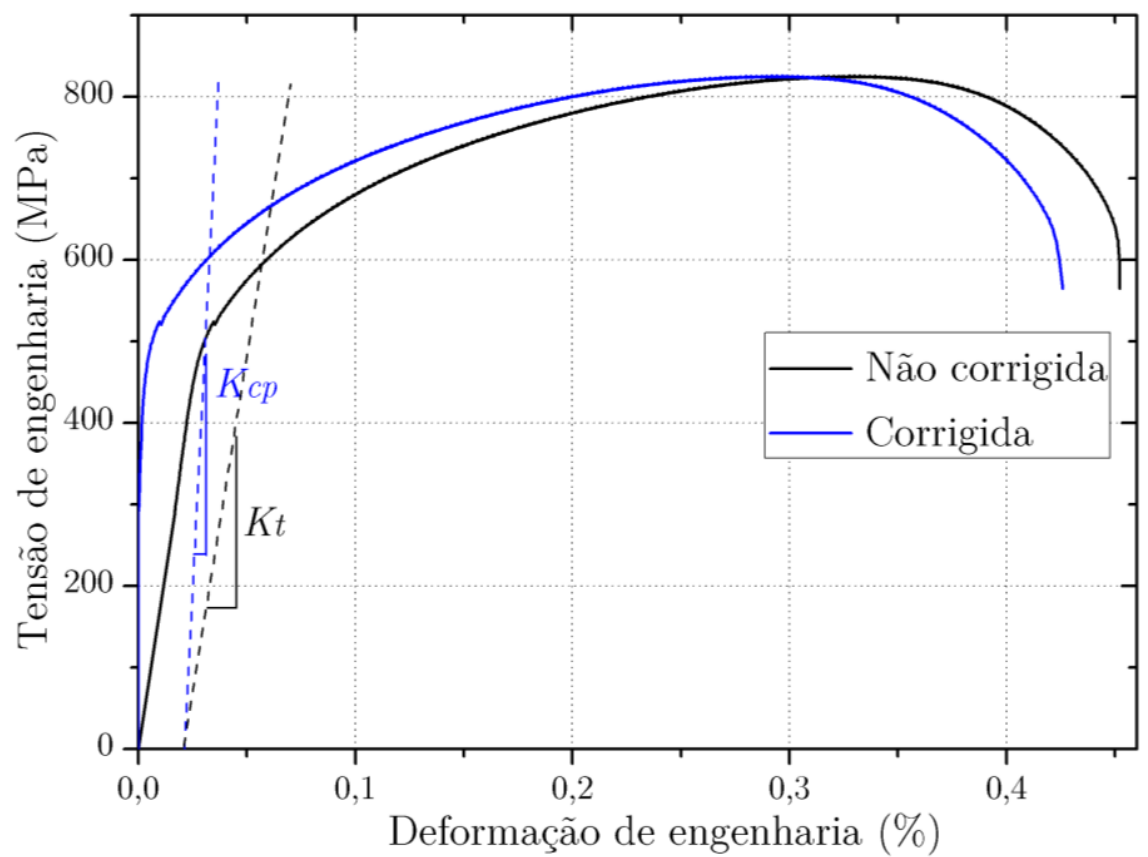

Figura 5-16. Curvas tensão-deformação aparente (direita) obtida pela influência da deformação da máquina de ensaios mecânicos e a respectiva curva real corrigida.

\subsection{Modelamento por elementos finitos orientado a objetos (OOF2)}

Tendo em vista o método dos elementos finitos (MEF), o programa OOF2® [135] foi criado por um grupo de pesquisadores do NIST (do inglês, National Institute of Standards and Technology) para calcular as propriedades mecânicas, incluindo o estado de tensões e deformações, de microestruturas sob a ação de condições de contorno impostas. Em lugar de usar o modelo de célula unitária empregado convencionalmente no MEF, o OOF2@ analisa microestruturas reais através da discretização da microestrutura, identifica características 
(agrupando os pixels), permite a geração de malhas e a atribuição de propriedades mecânicas às diferentes fases associadas aos grupos de pixels que as identificam. Esse procedimento permite avaliar as respostas mecânicas ou térmicas para as condições de contorno atribuídas ao modelo [136, 137].

O programa OOF2 contém um gerador de malha e um sistema de módulos para realizar análise por elementos finitos. Na presente pesquisa, foi utilizado apenas o gerador de malha do OOF2 (versão 2.1.12), e a análise por MEF foi realizada em código comercial Abaqus®, importando a malha (arquivo de malha .inp) gerada previamente em OOF2. O uso do Abaqus para a solução do modelo MEF é justificado por sua tecnologia robusta (em termos de convergência e eficiência computacional) para a solução numérica das equações não-lineares e do problema elasto-plástico, incluindo o uso de elementos planos de deformação, para as análises micromecânicas subsequentes. Dessa forma, o gerador de malha de OOF2 foi utilizado para criar a malha que define e agrupa os microconstituintes e a malha foi exportada para o Abaqus, para conduzir as análises micromecânicas sob carregamento uniaxial na microestrutura "virtual", que incorpora as morfologias reais das fases.

O primeiro passo para a criação da malha no OOF2 foi importar uma imagem obtida por MEV-FEG da superfície do aço TRIP após o tratamento termomecânico (Figura 5-17(a)). Essa imagem foi processada usando as ferramentas de processamento de imagem RGB e de contraste incorporadas no software Adobe Photoshop ${ }^{\circledR}$ para identificar as diferentes características da micrografia (Figura 5-17(b)). Cores similares, ou píxeis com níveis de cinza similares, nas imagens RGB foram isoladas no OOF2 e foram atribuídas a uma fase ou microconstituinte específico para cada conjunto de píxeis. A Figura 5-17(c) mostra as regiões identificadas como ferrita; o mesmo tratamento de imagem foi realizado para os outros microconstituintes. Malhas de elementos finitos foram geradas e refinadas como mostrado na Figura 5-17(d). Elementos individuais foram também selecionados com base em sua homogeneidade e modificados criando um refino de malha nos contornos. A geração das malhas em OOF2 usa uma abordagem virtual baseada na energia - virtual energy-based approach - [136]. O refinamento da malha em OOF2 permite a divisão dos elementos e a movimentação dos nós para se adaptar à forma da microestrutura e desta maneira minimizar o parâmetro funcional da energia virtual, $\beta$ [136, 137]:

$$
\beta=\varphi \beta_{\text {hom }}+(1-\varphi) \beta_{\text {forma }}
$$


em que $\varphi$ é um parâmetro entre 0 e 1 , com 0 correspondendo à forma de um triângulo ou quadrilátero ideal e 1 correspondendo a um elemento completamente homogêneo (contendo apenas um grupo de pixels da mesma cor) [137]. O funcional de energia considera as energias dependendo da quantificação das qualidades da forma $\left(\beta_{\text {forma }}\right)$ e da homogeneidade $\left(\beta_{\text {hom }}\right)$ de cada elemento da malha.

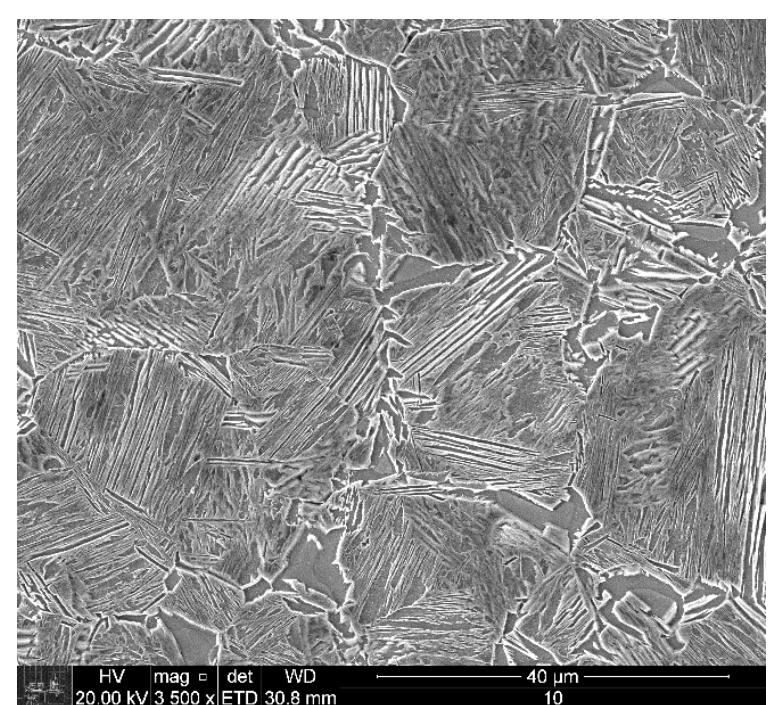

(a)

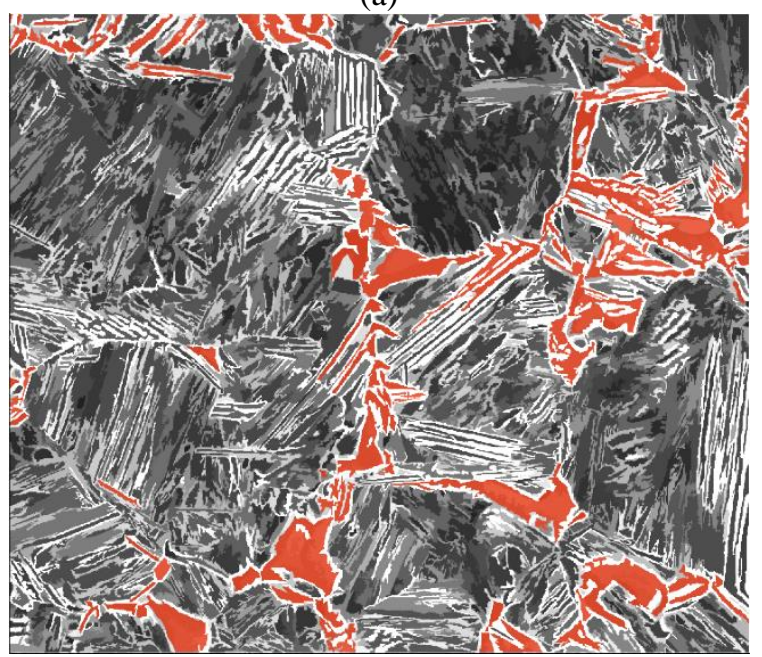

(c)

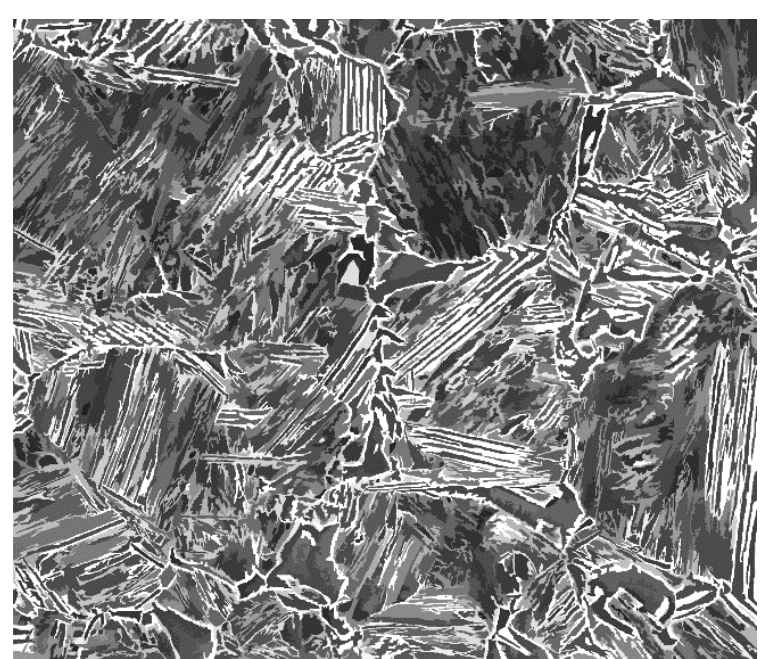

(b)

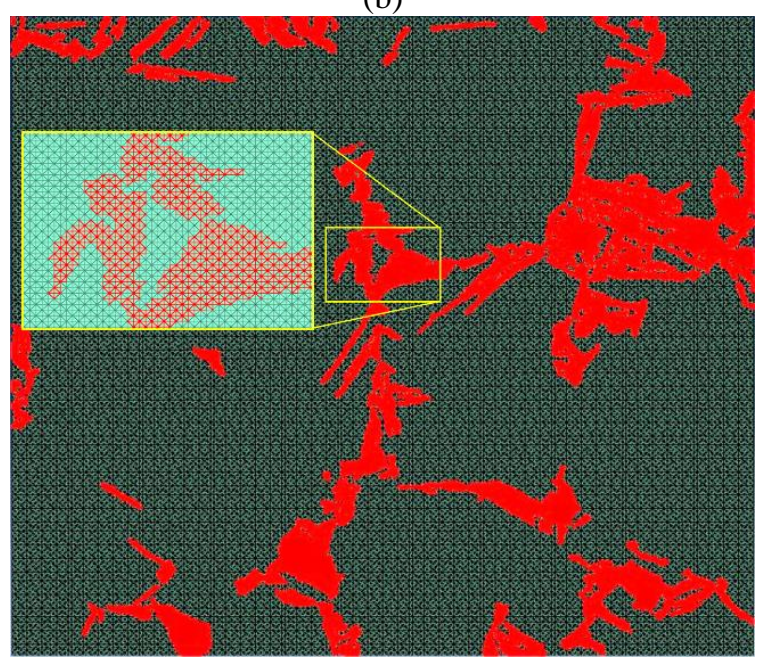

(d)

Figura 5-17. Passos envolvidos na criação de uma malha usando OOF2. Neste caso é uma ilustração para uma única fase (ferrita) (a) imagem MEV-FEG (b) realce dos contornos e do contraste (c) escolha da fase de interesse (d) criação da malha e importação para Abaqus.

Um dos propósitos da modelagem micromecânica é considerar apenas uma pequena parte do material. Isto é possível se o modelo é um elemento de volume representativo (conhecido como RVE, do inglês Representative Volume Element) [138]. Elementos bidimensionais triangulares lineares, tipo CPS3, foram adotados no modelo de elementos finitos para simular o comportamento no plano de uma chapa de aço TRIP sob tração. No modelo MEF elastoplástico foram assumidos o critério de von Mises, a regra do fluxo associativo e a condição de 
endurecimento isotrópico para cada fase. A regra de fluxo prescreve a direção de ocorrência da deformação plástica quando a condição de escoamento é superada. O carregamento uniaxial foi simulado pela fixação dos deslocamentos ao longo do eixo $x$ e aplicando condições de contorno de deslocamento ao longo do eixo $y$. Cabe ressaltar que na literatura têm sido reportados vários modelos de simulação numérica baseados na microestrutura [139-141]. No entanto, a maioria deles tem assumido partículas simples idealizadas, microestruturas simples (bifásicas ou grandes tamanhos de grão) ou características de forma simples como esferas e elipsóides. Portanto, é interessante o desenvolvimento de técnicas para simulação de microestruturas que incorporem as características das formas complexas de microestruturas reais como proposto na presente pesquisa, onde imagens de MEV foram usadas como entrada no código computacional.

Quando o objetivo está baseado em tentar calcular da forma mais precisa possível, os campos de tensão e deformação dentro do RVE, a morfologia deve ser a mais realista possível. No caso da análise baseada na microestrutura, esta deve ser representada por uma estrutura de grãos. Pelo fato de os grãos serem estruturas tridimensionais (3D), modelos de simulação 3D deverão ser preferidos; p. ex. o algoritmo Voronoi [138] ou a técnica de montagem serial consecutiva de micrografias [142], que permitem estimativas mais precisas. Entretanto, o uso de modelos 3D pode incrementar a complexidade da malha, o que acontece também nas reconstruções microestruturais (no caso de secções metalográficas ao longo do plano xy), e a definição das condições de contorno no modelo. Além disso, a quantidade de dados (número de elementos e de equações a serem resolvidas) pode aumentar consideravelmente os tempos de simulação, exigindo clusters mais robustos para o desempenho da simulação. Choi et al. [143] e Sodjit et al. [144] mencionam que modelos 2D são capazes de capturar as características essenciais dos comportamentos no plano da deformação de aços TRIP, e, consequentemente, aproximações usando modelos numéricos $2 \mathrm{D}$ podem ser realizadas para diversas aplicações a fim de esclarecer as respostas mecânicas baseadas na microestrutura.

Desta maneira, baseado na combinação de OOF2® e Abaqus ${ }^{\circledR}$, ambos programas sendo projetados para modelagem por elementos finitos, foram calculadas as propriedades mecânicas de tração, incluindo nos modelos numéricos as microestruturas complexas obtidas por microscopia eletrônica de varredura obtidas da região central dos corpos de prova tratados por simulação física usando simulador termomecânico Gleeble. 


\section{CARACTERIZAÇÃO E METODOLOGIA PARA CALCULAR AS PROPRIEDADES MECÂNICAS DE UM AÇO TRIP SUBMETIDO A ESTAMPAGEM A QUENTE E TÊMPERA E PARTIÇÃO (Q\&P)}

\section{Resumo}

Foram realizadas simulações termomecânicas dos processos de têmpera, estampagem a quente, e têmpera e partição em simulador termomecânico Gleeble®3S50 acoplado a uma linha de difração de raios $\mathrm{X}$ gerados por fonte de luz síncrotron. As microestruturas e as propriedades mecânicas foram analisadas usando microscópio eletrônico de varredura por emissão de campo (FEG-SEM), difração de raios X e nanoindentação. As microestruturas das amostras tratadas termomecanicamente foram modeladas usando o método dos elementos finitos orientado a objetos (OOF). As microestruturas modeladas por OOF foram integradas a um modelo elastoplástico de elementos finitos para predizer o comportamento mecânico. Usando o método de algoritmo reverso, foram determinadas as propriedades mecânicas elasto-plásticas de diferentes microconstituintes. Isto foi feito por meio da análise de curvas força-profundidade de penetração obtidas por nanoindentação instrumentada. Ensaios de tração dos aços tratados termomecanicamente foram realizados usando corpos de prova de tamanho reduzido (sub-size) extraídos da região central das amostras tratadas em simulador termomecânico Gleeble ${ }^{\circledR} 3 \mathrm{~S} 50$. A comparação entre os resultados experimentais, do algoritmo reverso e das microestruturas modeladas por OOF mostraram uma boa concordância. 


\subsection{Introdução}

O aumento das exigências da indústria automobilística para diminuir o consumo de combustível e aumentar a segurança dos passageiros e pedestres tem estimulado o desenvolvimento da nova geração de aços de alta resistência. Para reduzir o consumo de combustível é necessário reduzir o peso do veículo usando chapas finas que apresentem uma boa relação entre resistência mecânica e ductilidade. Um caminho promissor para obter um balanço favorável entre resistência ductilidade é por meio do tratamento térmico de têmpera e partição (Q\&P) [1]. O tratamento de Q\&P pode produzir uma microestrutura martensítica com consideráveis quantidades de austenita retida (RA). Nesse processo, o aço é austenitizado total ou parcialmente e depois temperado até uma temperatura (QT) entre as temperaturas de início $\left(M_{S}\right)$ e fim $\left(M_{f}\right)$ da transformação martensítica, para criar uma mistura controlada de martensita e austenita. Em adição, uma porcentagem de ferrita intercrítica formada durante a austenitização pode estar presente, dependendo da temperatura de austenitização utilizada. Na sequência, na etapa de partição, o aço é mantido em um patamar isotérmico na mesma temperatura de têmpera (tratamento Q\&P em uma etapa) ou aquecido até uma temperatura de partição (PT) mais elevada (Q\&P em duas etapas) para permitir que o carbono particione da martensita para a austenita. Na etapa de partição, a difusão do carbono ocorre da martensita supersaturada para a austenita não transformada (partição de carbono), estabilizando-a à temperatura ambiente. A austenita enriquecida em carbono, estabilizada na temperatura ambiente, pode contribuir nas propriedades mecânicas de forma semelhante ao que acontece nos aços onde ocorre transformação induzida por plasticidade (TRIP) [145]. A distribuição do carbono, especificamente sua concentração local em fases individuais, contornos de grão ou contornos de interfaces, são parâmetros essenciais para influenciar as transformações de fase e as propriedades mecânicas.

Adicionalmente, a estampagem a quente (HS) é um dos métodos mais eficazes para produzir aços de ultra alta resistência em componentes automotivos. Esse é um processo não isotérmico projetado para chapas metálicas, no qual a conformação e a têmpera acontecem de forma simultânea [146]. Sua principal vantagem está na maior precisão na forma das peças, permitindo o uso de chapas metálicas mais finas. Dessa forma, a redução do peso pode ser alcançado enquanto se mantém a integridade estrutural, permitindo a produção de peças de ultra alta resistência sem que apresentem retorno elástico (springback) [82].

Recentemente, Liu et al. [147] apontaram que embora o processo de Q\&P seja um dos métodos mais promissores para produzir aços avançados de alta resistência (AHSS) com alta 
resistência e ductilidade, os métodos de tratamento térmico não consideram as transformações de fase induzidas pela deformação. Poucos estudos têm investigado o potencial da combinação dos processos de estampagem a quente e de têmpera e partição [147-151]. No entanto, esses estudos foram limitados à deformação isotérmica com austenitização plena e a tratamentos de Q\&P de uma etapa. Uma exceção é o trabalho de Chang et al. [149], que desenvolveram o tratamento de Q\&P em duas etapas com tempo de têmpera de um minuto antes do tratamento de partição. No entanto, De Knijf et al. [152] salientaram que o tempo de manutenção isotérmica na temperatura de têmpera em aços Q\&P precisa ser mantido curto o suficiente (geralmente de cinco a dez segundos), a fim de evitar a precipitação de produtos de transformação isotérmica na temperatura de têmpera. Na presente pesquisa, é proposto um novo processo (designado aqui como: HSQ\&P) aplicado em aço assistido por efeito TRIP, que combina a austenitização intercrítica com deformação não isotérmica, seguido de tratamento Q\&P de duas etapas. Os experimentos foram conduzidos usando equipamento de simulação termomecânica, a fim de comparar a microestrutura e as propriedades mecânicas do aço TRIP submetido a têmpera (Q), HS, Q\&P e HSQ\&P. Várias técnicas de caracterização e modelagem foram usadas: nanoindentação, método dos elementos finitos orientada a objetos e testes micromecânicos. A influência do tempo, a temperatura e a deformação na estabilidade da austenita retida, bem como o papel da plasticidade induzida pela transformação na conformabilidade e a absorção de energia foram estudadas in situ, usando difração de raios $\mathrm{X}$ gerados por fonte de luz síncrotron. Esses experimentos foram realizados na estação experimental brasileira XTMS operada conjuntamente pelo Laboratório Nacional de Nanotecnologia (LNNano) e pelo Laboratório Nacional de Luz Síncrotron (LNLS).

O Simulador termomecânico Gleeble®3S50 foi usado para reproduzir as condições de tratamento termomecânicas (taxas de aquecimento, resfriamento e deformação) esquematizadas na Figura 6-1. Os parâmetros de tempo e temperatura para os processos de Q\&P (temperatura de têmpera, QT, tempo de têmpera, Qt, temperatura de partição, PT, e tempo de partição, Pt) foram baseados no trabalho de Clarke et al. [111], desenvolvido em um aço de composição similar ao do presente estudo. Com base no modelo de partição completa do carbono e assumindo austenitização intercrítica, Clarke et al. [111] indicaram uma temperatura ótima de têmpera (com a qual se obtém a maior fração volumétrica de austenita na temperatura ambiente) de $240{ }^{\circ} \mathrm{C}$. Nos resultados experimentais esses autores mostraram que quando o aço foi temperado a $240{ }^{\circ} \mathrm{C}$ a máxima fração de austenita retida foi para a condição de partição feita em temperatura de $400{ }^{\circ} \mathrm{C}$ com manutenção por $30 \mathrm{~s}$. No entanto, seus resultados também mostraram que a maior porcentagem de austenita retida, considerando todos os resultados 
experimentais, foi obtida para uma temperatura de têmpera de $250^{\circ} \mathrm{C}$ com etapa de partição a $400{ }^{\circ} \mathrm{C}$ por $100 \mathrm{~s}$. Tendo em vista esses resultados, os parâmetros de tratamento escolhidos para este trabalho foram temperatura de têmpera de $250{ }^{\circ} \mathrm{C}$ com etapa de partição a $400{ }^{\circ} \mathrm{C}$ por $30 \mathrm{~s}$.

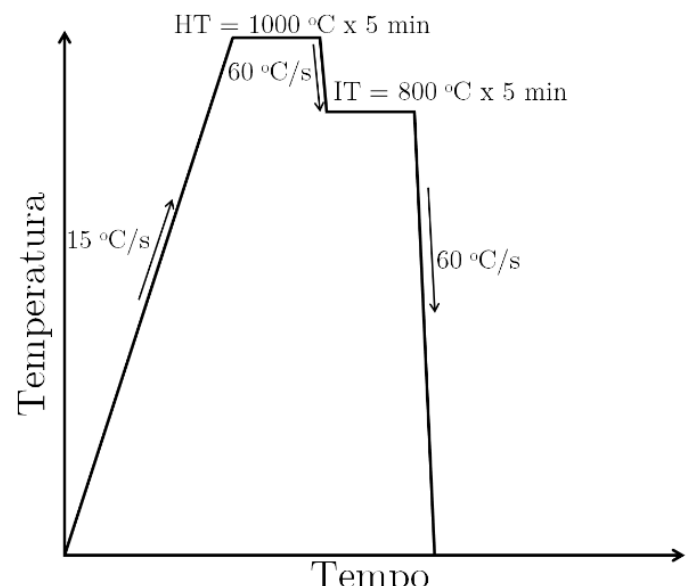

(a)

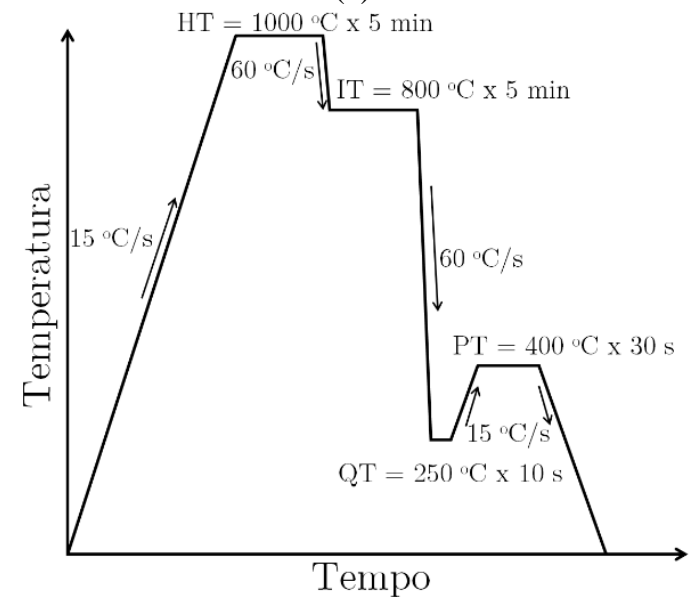

(c)

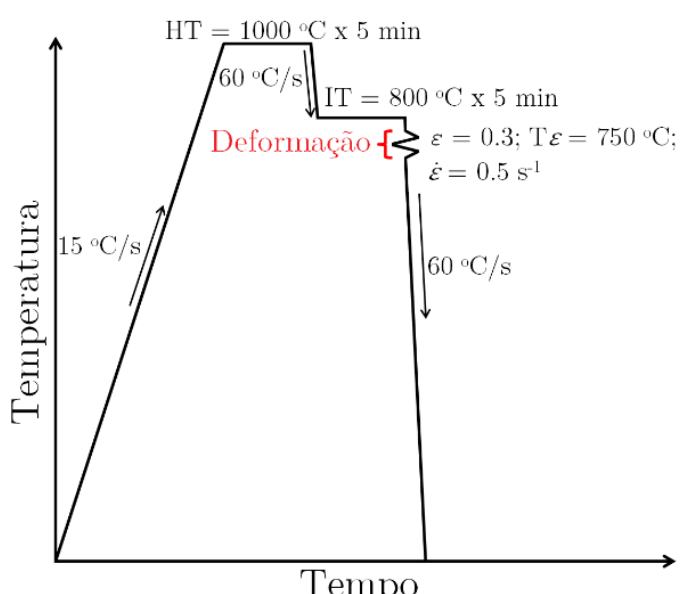

(b)

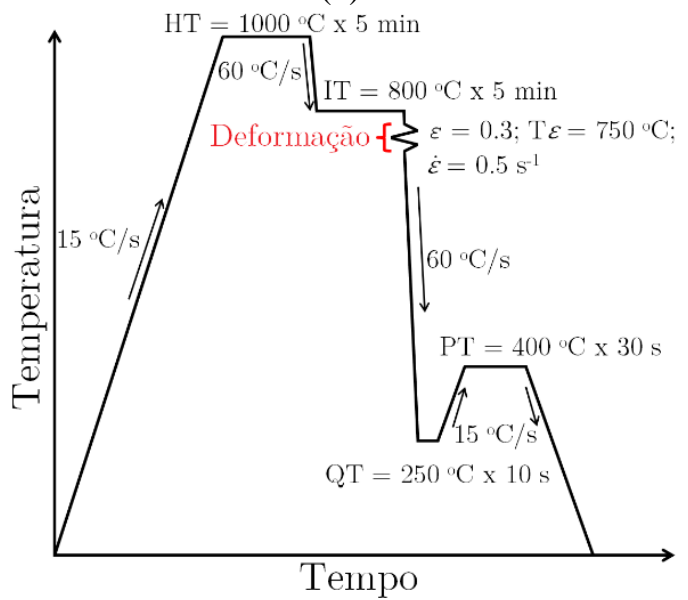

(d)

Figura 6-1. Representação esquemática dos tratamentos termomecânicos: (a) têmpera, (b) estampagem a quente (HS), (c) têmpera e partição (Q\&P) e (d) HS seguido por Q\&P (HSQ\&P). HT, IT, QT e PT representam as temperaturas de homogeneização, intercrítica, têmpera e partição, respectivamente. $T \varepsilon, \varepsilon$ e $\dot{\varepsilon}$ representam a temperatura, quantidade e taxa de deformação, respectivamente.

O procedimento experimental utilizado nas experiências realizadas no presente capítulo inclui as secções de: simulações no software Thermo-Calc ${ }^{\circledR}$ (usando a base de dados TCFE), análise in situ usando radiação síncrotron no simulador termomecânico Gleeble, dilatometria, determinação da austenita retida por difração de raios $\mathrm{X}$, caracterização metalográfica e mecânica usando microscopia eletrônica de varredura (MEV-FEG), EBSD, nanoindentação, estereologia quantitativa, simulação pelo método de elementos finitos orientada a objetos e em programa Abaqus, algoritmo reverso para conversão das curvas de nanodureza em propriedades mecânicas, ensaio mecânico em corpos de prova de tamanho reduzido (sub-size) extraídos de amostras tratadas em Gleeble e microdureza. 


\subsection{Resultados e discussão}

\subsubsection{Temperatura intercrítica}

As frações volumétricas das fases obtidas por meio de simulações termodinâmicas de equilíbrio, utilizando software Thermo-Calc®, são mostrados na Figura 6-2. Nesta figura é possível observar que quando a temperatura é inferior à temperatura $\mathrm{Ae}_{1}\left(\approx 700^{\circ} \mathrm{C}\right)$, o aço contém aproximadamente $98 \%$ de ferrita $(\alpha)$ e $2 \%$ de cementita $(\theta)$. Durante o aquecimento, tanto a cementita como a ferrita iniciam sua transformação para austenita $(\gamma)$ acima da temperatura $\mathrm{Ae}_{1}$. Quando a temperatura $\mathrm{Ae}_{1}{ }_{1}\left(\approx 715^{\circ} \mathrm{C}\right)$ é atingida a cementita é completamente dissolvida. Na faixa de temperaturas entre $\mathrm{Ae}_{1}$ e $\mathrm{Ae}^{\prime}{ }_{1}$ a concentração de carbono na austenita ( $\mathrm{C} \gamma$, em peso) aumenta, com o aumento da temperatura, de $0,59 \%$ a $0,65 \%$. Em temperaturas superiores a $A^{\prime}{ }_{1}$ a ferrita continua sua transformação para austenita e o carbono decresce em função da temperatura até a temperatura $\mathrm{Ae}_{3}\left(840^{\circ} \mathrm{C}\right)$ ser atingida. Uma vez que a fração de austenita em equilíbrio pode ser considerada como o limite superior da fração de austenita durante o tratamento intercrítico, os dados termodinâmicos são úteis para compreender os resultados obtidos por dilatometria.

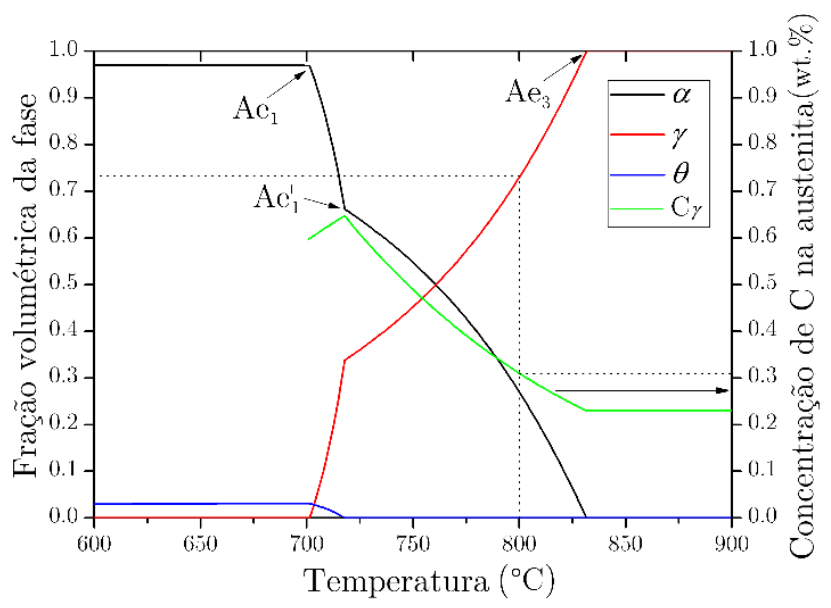

Figura 6-2. Frações volumétricas das fases em equilíbrio e concentração de carbono na austenita em função da temperatura previsto por Thermo-Calc ${ }^{\circledR}$ (TCFE). $\alpha, \gamma$ e $\theta$ são ferrita, austenita e cementita. $C \gamma$ representa a concentração de carbono (em peso) na austenita.

\subsubsection{Dilatometria}

Como mostrado na Figura 6-3, as amostras foram homogeneizadas a $1000{ }^{\circ} \mathrm{C}$ (por 5 minutos), seguido por tratamento de austenitização intercrítica a $800{ }^{\circ} \mathrm{C}$ (por $5 \mathrm{~min}$ ). $\mathrm{O}$ aquecimento a uma taxa constante de $15^{\circ} \mathrm{C} / \mathrm{s}$ teve como objetivo simular a taxa de aquecimento usualmente utilizada em chapas de aço. Em seguida, as amostras foram resfriadas até a 
temperatura ambiente $\left(20^{\circ} \mathrm{C}\right)$ a uma taxa de $60^{\circ} \mathrm{C} / \mathrm{s}$. A curva de dilatometria permitiu identificar as temperaturas $\mathrm{Ac}_{1}$ e $\mathrm{Ac}_{3}$ a $760^{\circ} \mathrm{C}$ e $890^{\circ} \mathrm{C}$, respectivamente. A ausência de inflexões na etapa de resfriamento anteriores à expansão decorrente da formação de martensita indica que não ocorreram transformações de fase difusionais durante esta etapa, após a austenitização intercrítica. A transformação martensítica inicia em $\approx 390^{\circ} \mathrm{C}$ e prossegue até a temperatura de têmpera a $250{ }^{\circ} \mathrm{C}$. Durante a etapa de partição a $400{ }^{\circ} \mathrm{C}$ por $30 \mathrm{~s}$ foi observada uma expansão volumétrica na amostra, sugerindo que: a) parte da austenita transformou-se em ferrita-bainítica $[74,153]$ e/ou; b) houve formação de martensita isotérmica $[73,154]$ e/ou; c) a martensita formada durante a têmpera continua crescendo; e/ou, d) a partição de carbono da martensita para austenita ocorreu envolvendo migração da interface martensita/austenita $[155,156]$.

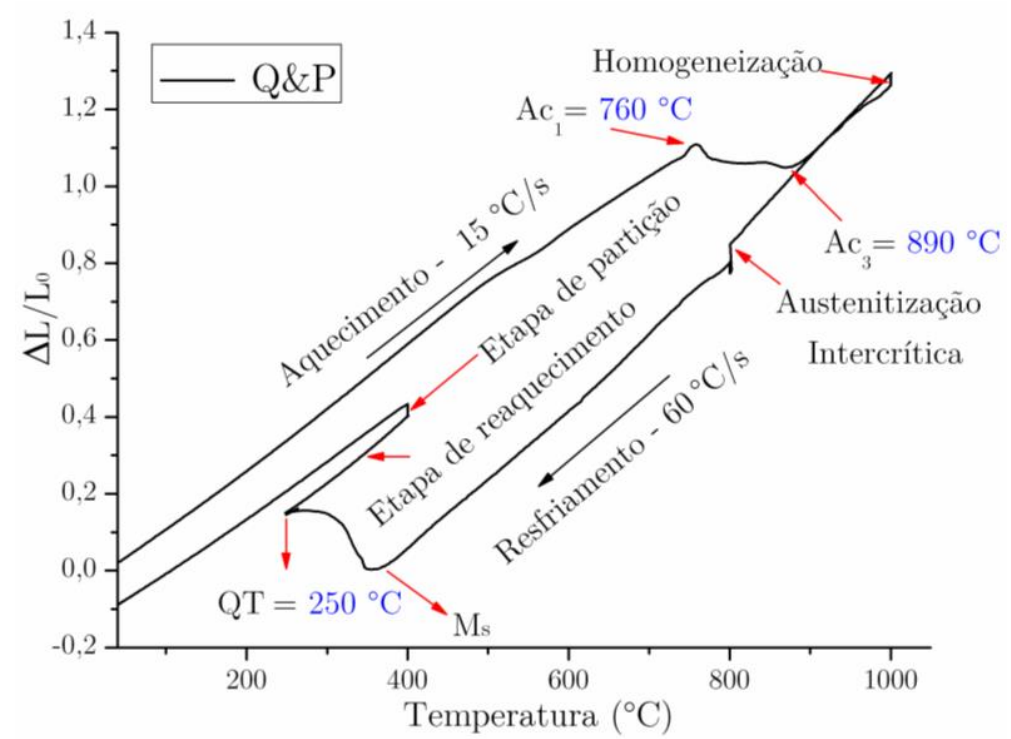

Figura 6-3. Curva obtida por dilatometria do aço TRIP submetido ao processo de têmpera e partição (Q\&P). QT e $\mathbf{M}_{\mathbf{s}}$ indicam a temperatura de têmpera e de início da transformação martensítica.

Embora a formação de cementita possa acontecer durante a etapa de partição, a expansão acima mencionada não se relaciona com a precipitação de cementita, dado que causaria uma contração da amostra $[153,157]$. A expansão também foi observada durante a etapa de partição da amostra tratada por HSQ\&P. A comparação das etapas de partição das amostras Q\&P e HSQ\&P mostraram que a expansão para a condição HSQ\&P é consideravelmente menor do que na condição Q\&P, como se observa na Figura 6-4. Esse resultado indica uma menor cinética para a decomposição da austenita, provavelmente devido à estabilização mecânica da austenita, a qual pode afetar a formação de bainita [158] e/ou retardar a transformação martensítica [159]. No primeiro mecanismo, as florestas de discordâncias formadas durante a deformação da austenita retardam o crescimento da bainita. As discordâncias podem afetar o avanço das interfaces formadas por arranjos de discordâncias que deslizam (glissile), da mesma forma que 
um escorregamento comum é mais difícil dentro de uma floresta de discordâncias [160], o que dificulta a transformação martensítica pelo mecanismo cisalhante [161]. Dessa forma, quando o processo HSQ\&P é aplicado, não ocorrem, ou pelo menos são altamente reduzidas, a formação de bainita ou o crescimento das placas de martensita.

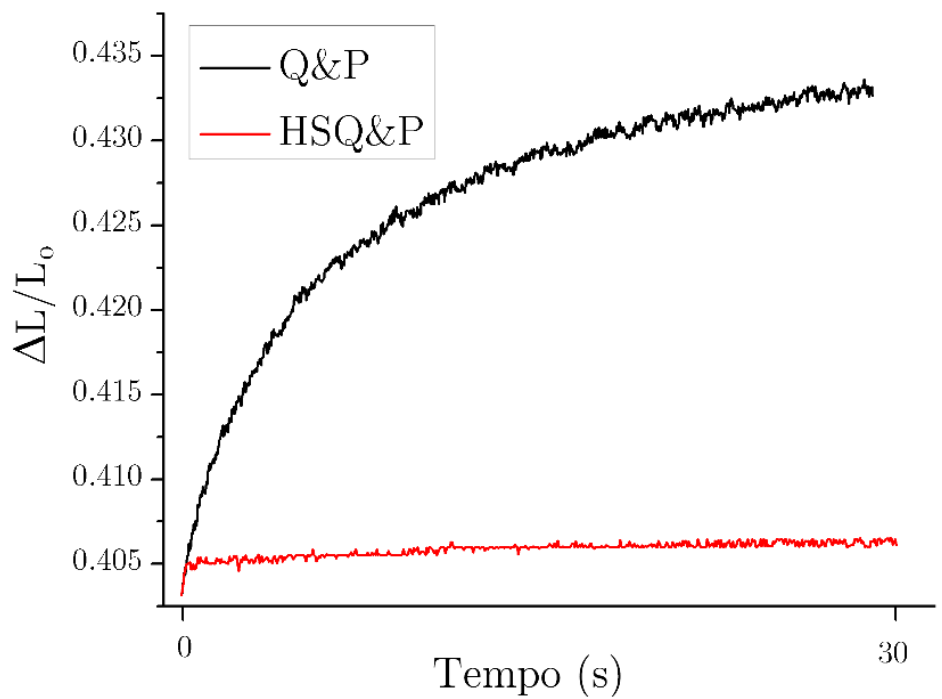

Figura 6-4. Mudança relativa do comprimento da amostra em função do tempo na etapa de partição a $400{ }^{\circ} \mathrm{C}$ para os processos de Q\&P e de HSQ\&P. O tempo de início ( 0 s) corresponde ao momento em que a temperatura de $400^{\circ} \mathrm{C}$ é atingida na etapa de partição. Para facilitar a comparação as curvas foram movimentadas ao longo do eixo das ordenadas.

\subsubsection{Caracterização microestrutural}

Na Figura 6-5 pode-se observar imagens obtidas por MEV-FEG das amostras do aço TRIP tratadas por Q, Q\&P, HS e HSQ\&P. Nessas imagens, a martensita é representada nos grãos maiores, regiões em tons de cinza mais claros, identificadas como exemplo pelo contorno em vermelho, enquanto os grãos menores em tons de cinza mais escuros e em baixo relevo são de ferrita. As microestruturas das amostras tratadas por Q e Q\&P são muito semelhantes, consistindo de ferrita $(\alpha)$, ferrita-bainítica $\left(\alpha_{b}\right)$, martensita $\left(\alpha^{\prime}\right)$ e dois tipos diferentes de austenita retida: na forma de blocos $\left(\gamma_{b}\right)$ e na forma de filmes $\left(\gamma_{f}\right)$. A determinação das diferenças e os detalhes microestruturais foi apenas possível utilizando maiores aumentos, como mostrado no quadro amarelo inserido à esquerda da Figura 6-5(b). A partir dessa imagem é possível observar que a microestrutura contém três diferentes tipos diferentes de ferrita: ferrita intercrítica $\left(\alpha_{I C}\right)$, ferrita epitaxial $\left(\alpha_{E}\right)$ e $\alpha_{b}$. As ferritas intercrítica e epitaxial podem ser facilmente distinguidas devido às diferenças topográficas e à resposta ao ataque metalográfico. Detalhes da formação e a distribuição dos perfis de carbono das microestruturas formadas por esses dois tipos de ferrita foram detalhadas por Santofimia et al. [162]. Visto que a presença de 
ferrita epitaxial aumenta a ductilidade e reduz a fração de austenita formada durante a partição, Santofimia et al. [162] ressaltaram a importância de controlar a formação de ferrita epitaxial durante a etapa da têmpera, a fim de garantir uma adequada fração volumétrica de austenita antes da formação de martensita. As Figura 6-5(c) e 6-5(d), correspondentes às amostras HS e HSQ\&P, parecem indicar que a transformação de bainita foi suprimida pela deformação em alta temperatura e que a deformação não isotérmica induz a formação de ferrita nos contornos de grão da austenita. A quantidade de ferrita nos contornos de grão foi maior nas amostras HS e HSQ\&P quando comparadas com as Q e Q\&P. A nucleação de ferrita durante a deformação pode ocorrer pelo mecanismo conhecido como transformação ferrítica induzida pela deformação (DIFT, Deformation Induced Ferrite Transformation) [86]. A Figura 6-6 mostra que a deformação em alta temperatura também promove a diminuição do tamanho de grão, o que poderia contribuir para um melhor compromisso resistência-ductilidade do aço TRIP estudado. Nessa figura, o tamanho e distribuição das regiões austeníticas (estrutura CFC) estão indicadas pelas regiões em vermelho, enquanto a ferrita e a martensita (estrutura CCC) aparecem em verde. As regiões mais escuras em verde indicam regiões de menor contraste de banda (BC, Band Contrast) devido à maior densidade de discordâncias, o que muito provavelmente corresponde a martensita fresca $\left(\alpha_{f}^{\prime}\right)^{8}$, que é a martensita criada durante a têmpera final até a temperatura ambiente [162]. Essas áreas correspondem a grãos contendo uma maior densidade de defeitos no reticulado cristalino, como discordâncias [163, 164] ou defeitos puntiformes [165], produzindo um baixo contraste devido à distorção dos limites das bandas de Kikuchi e na menor qualidade dos padrões de difração indexados [166]. Além disso, as placas de martensita revenida têm um tamanho maior que a martensita fresca, uma vez que a primeira transforma através do grão total de austenita, enquanto a martensita fresca se transforma a partir das regiões de menor tamanho (e estabilidade) de austenita após a etapa de partição.

\footnotetext{
${ }^{8}$ A martensita criada durante a têmpera final (têmpera após o estágio de partição) também é conhecida como martensita nova, secundária ou não revenida. Na presente pesquisa foi adotado o termo "martensita fresca", devido a denominação comum na literatura inglesa de "fresh martensite".
} 


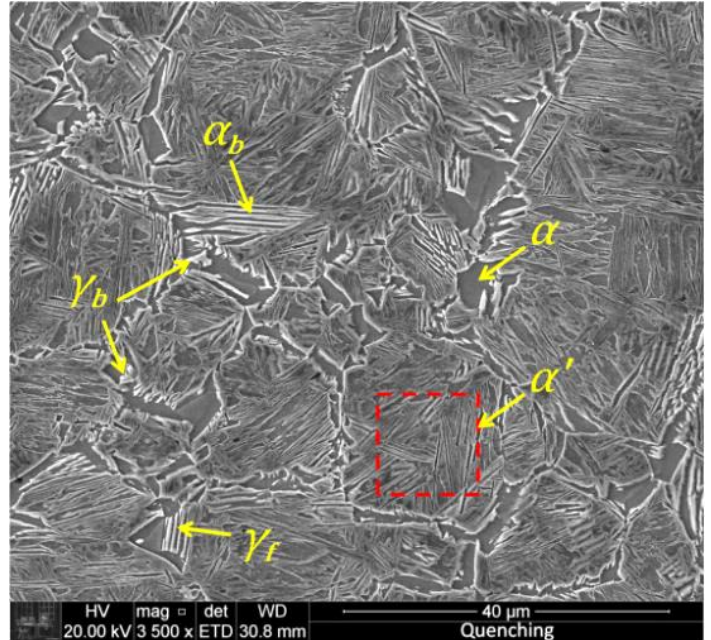

(a)

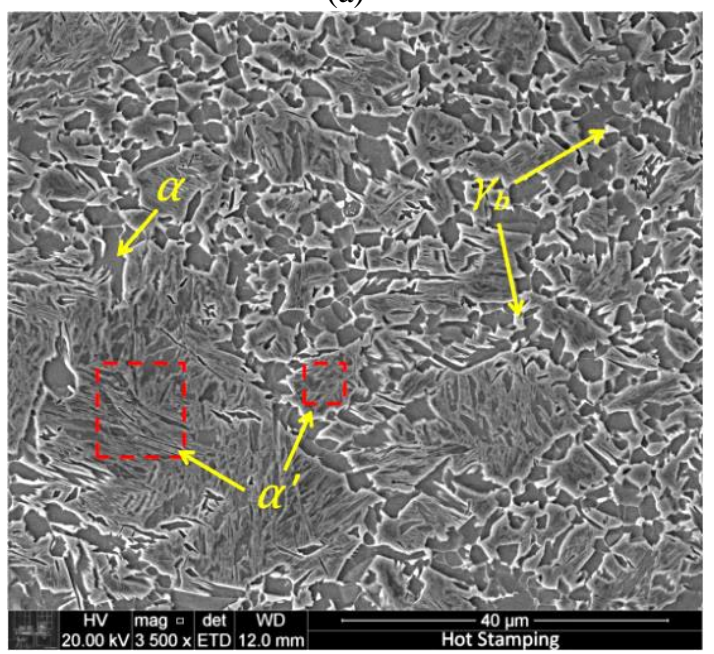

(c)

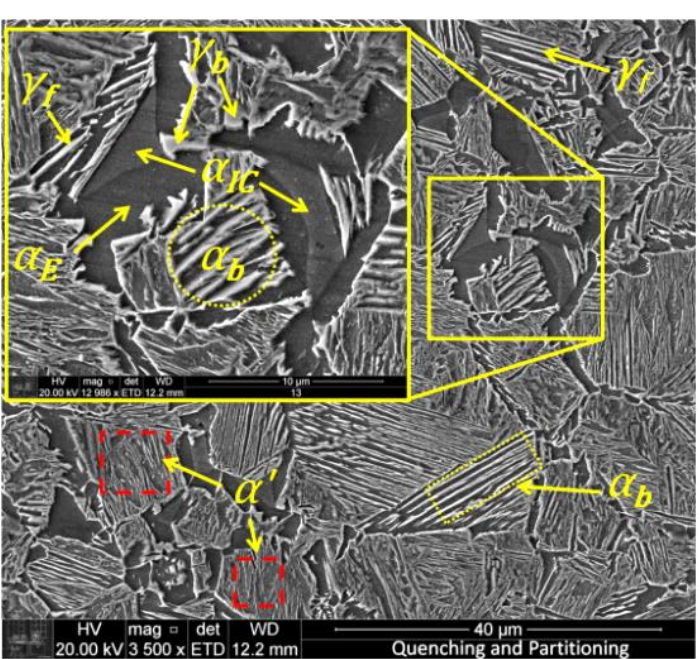

(b)

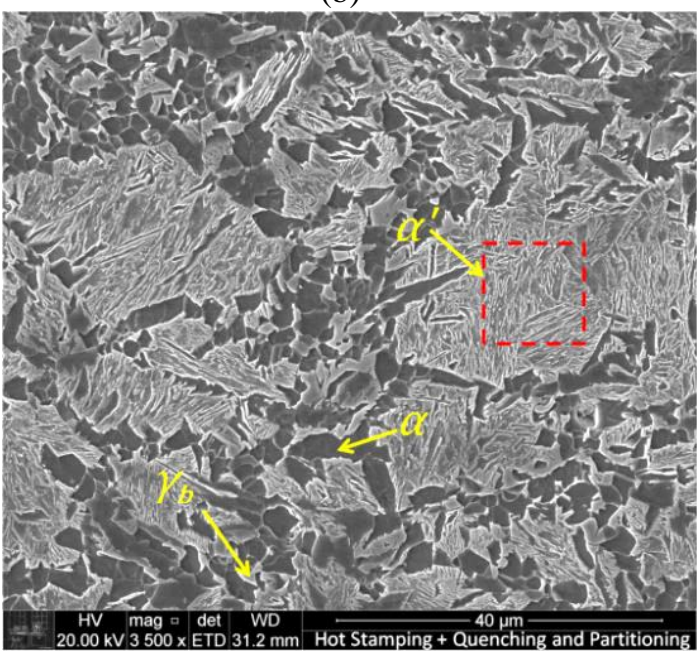

(d)

Figura 6-5. Imagens obtidas por MEV-FEG após os tratamentos de: (a) têmpera; (b) Q\&P; (c) HS; e (d) HSQ\&P. $\boldsymbol{\alpha}^{\prime}, \boldsymbol{\alpha}, \boldsymbol{\alpha}_{\boldsymbol{b}}, \boldsymbol{\alpha}_{\boldsymbol{I}}, \boldsymbol{\alpha}_{\boldsymbol{E}}, \boldsymbol{\gamma}_{\boldsymbol{b}}$, e $\boldsymbol{\gamma}_{\boldsymbol{f}}$ são martensita, ferrita, ferrita-bainítica, ferrita intercrítica, ferrita epitaxial e austenita retida na forma de blocos e de filmes, respectivamente.

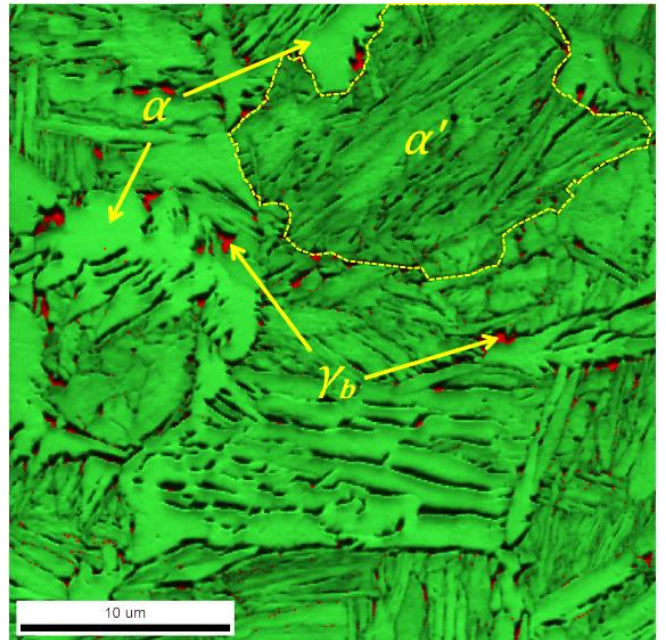

(a)

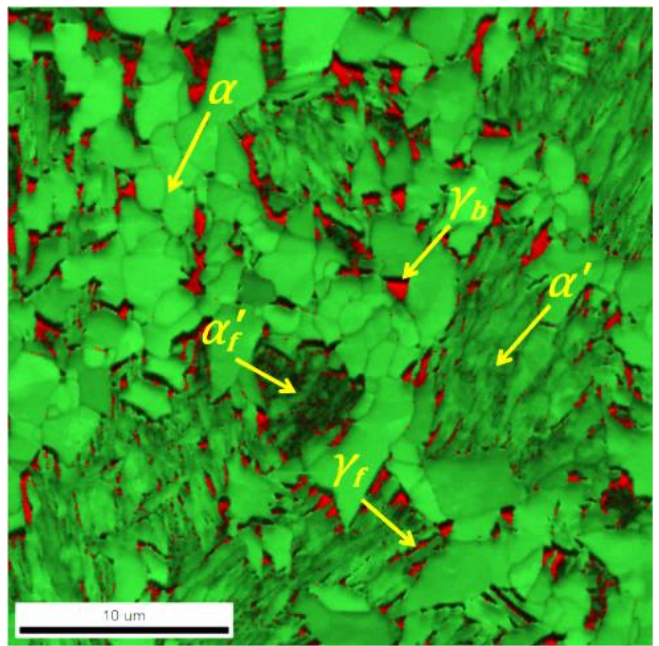

(b)

Figura 6-6. Imagens por EBSD após: (a) Q\&P, com 3\% de austenita retida ( $\gamma$ ); (b) HSQ\&P, com $7 \%$ de $\boldsymbol{\gamma}$. $\boldsymbol{\gamma}_{\boldsymbol{b}}$ e $\boldsymbol{\gamma}_{\boldsymbol{f}}$ são austenita retida na forma bloco e de filme. $\boldsymbol{\alpha}$ é ferrita; $\boldsymbol{\alpha}^{\prime}$ é martensita (a região delimitada no contorno amarelo na imagem (a) pode conter alguns filmes finos de $\boldsymbol{\gamma}$ entre as ripas de martensita, mas elas estão abaixo da resolução do sistema EBSD); e $\boldsymbol{\alpha}_{\boldsymbol{f}}^{\prime}$ é martensita fresca. 


\subsubsection{Difração de raios $X$ e avaliação in situ usando radiação síncrotron}

A Figura 6-7(a) mostra os padrões de difração e as intensidades calculadas para as quatro diferentes rotas de processamento aplicadas ao aço TRIP. Os resultados evidenciam que os tratamentos térmicos envolvendo a etapa de partição (Q\&P e HSQ\&P) resultam em maiores quantidades de austenita retida (entre 6,7 e 8,0\%). A amostra HSQ\&P mostrou um leve aumento da fração volumétrica de austenita, muito provavelmente devido à rejeição do carbono a partir da ferrita formada durante a deformação em alta temperatura (efeito DIFT), levando ao enriquecimento da austenita residual e a sua estabilização. Embora parte da austenita retida tenha sido consumida pela formação de ferrita durante a deformação pelo efeito DIFT, o aumento da fração volumétrica de austenita foi confirmada tanto pelos resultados de difração de raios X como pelos de EBSD. A partir desses resultados, espera-se que os tratamentos em que é aplicada deformação em alta temperatura, antes do processo de Q\&P, contribuam refinar a microestrutura multifásica, melhorando a resistência e a ductilidade, esta última devido à ocorrência do efeito TRIP, devido ao aumento da fração volumétrica de austenita retida.

Os resultados dos experimentos de difração síncrotron in-situ mostrados na Figura 6-7(b) indicam um aumento no teor de carbono da austenita com o aumento do tempo de partição, tanto para o tratamento Q\&P quanto para o HSQ\&P. O enriquecimento em carbono da austenita em decorrência da partição do carbono, rejeitado pela martensita causa o aumento de seu parâmetro de rede. A partir da equação de Dyson e Holmes [116] a concentração de carbono após ambos os tratamentos foi de aproximadamente 1,2 $\pm 0,03 \%$ em peso. Zhang et al. [167] têm destacado que são necessários teores de carbono superiores a 1\% (em peso) para estabilizar a austenita. Por outro lado, apenas valores abaixo de 1,5\% (em peso) contribuem para o efeito TRIP [168]. Note-se que embora os resultados da equação de Dyson e Holmes tenham mostrado um enriquecimento similar da austenita para ambos os tratamentos, o enriquecimento durante a etapa de partição foi menor na amostra HSQ\&P, quando comparada com a amostra Q\&P. Isto pode ser explicado pelo agrupamento ('clustering') e segregação dos átomos de carbono para os defeitos do reticulado, ou seja, a deformação em alta temperatura pode levar à segregação dos átomos de carbono para regiões com alta densidade de discordâncias formando atmosferas de Cottrell. No entanto, a ferrita formada pelo efeito DIFT poderia contribuir com o maior teor de carbono na austenita na temperatura ambiente. Consequentemente, quando são comparados os dois efeitos descritos (partição de carbono por Q\&P e efeito DIFT), parece ser que o efeito DIFT tem uma maior contribuição para o enriquecimento em carbono na austenita e a estabilização da austenita na temperatura ambiente. Adicionalmente, a estabilização mecânica 
da austenita por florestas de discordâncias podem, também, contribuir para o aumento da fração volumétrica de austenita retida na temperatura ambiente, como observado nos resultados de EBSD e difração de raios $X$.

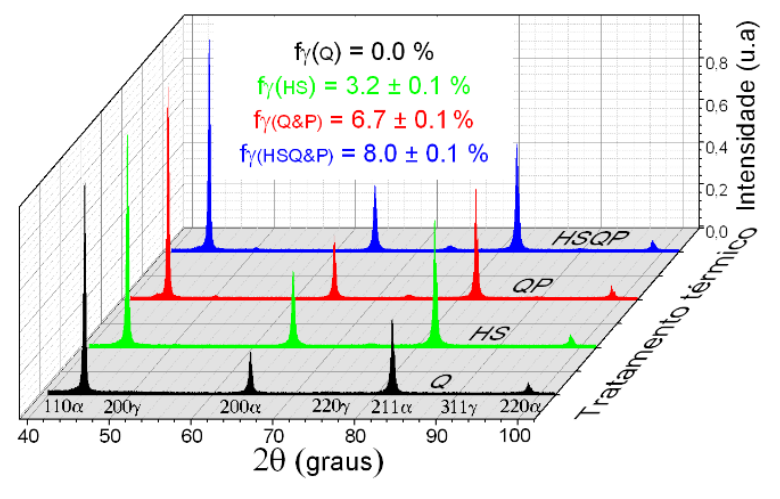

(a)

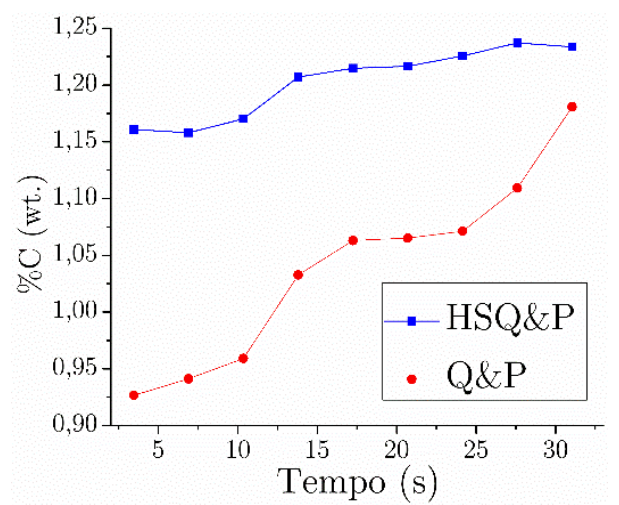

(b)

Figura 6-7. (a) Padrões de difração de raios X com intensidades normalizadas para $\boldsymbol{\alpha}$ e $\boldsymbol{\gamma}$, na temperatura ambiente, adquiridas após os tratamentos de Q, HS, Q\&P e HSQ\&P; (b) evolução dos teores de carbono (\%C) na $\gamma$ em função do tempo (in situ) durante a etapa de partição a $400{ }^{\circ} \mathrm{C}$ para os tratamentos de Q\&P e HSQ\&P.

\subsubsection{Nanodureza e algoritmo de conversão}

A caracterização microestrutural por MEV-FEG, como já foi comentado, foi complementada pela caracterização micromecânica a fim de interpretar adequadamente as microestruturas obtidas. O mapeamento da superfície a partir da nanodureza é uma técnica poderosa para avaliar os microconstituintes, bem como a homogeneidade microestrutural. Cada microconstituinte tem sua própria faixa de dureza e, portanto, os valores de dureza podem ser usados como critério para reconhecer, tanto qualitativa como quantitativamente, a presença de diferentes fases ou microconstituintes na microestrutura. Na Figura 6-8, um mapa de medições de nanodureza foi superposto a uma imagem de microscopia eletrônica de varredura para a amostra Q\&P. A Figura 6-9 apresenta os valores de nanodureza e as curvas carga-deslocamento para as seis nanoindentações, mostradas na Figura 6-8. A dureza pode ser diretamente relacionada à profundidade de penetração; desse modo, as profundidades de penetração menores podem ser associadas com regiões de martensita. As indentações \#1 e \#2 claramente identificam ferrita poligonal (valores de nanodureza de 3,87 e 4,99 GPa), enquanto a indentação \#3 indica uma dureza de 3,77 GPa e pode ser identificada como uma região de ferrita-bainítica (bainita superior isenta de carbonetos com austenita retida entremeada por filmes de austenita). Os resultados correspondentes às indentações \#1 e \#2 mostram que a dureza no centro do grão de ferrita rodeado por regiões de austenita (indentação \#1) foi menor que a ferrita próxima à 
interface ferrita/martensita (indentação \#2). As medições feitas nas proximidades das interfaces ferrita/martensita podem ser influenciadas pelas restrições impostas pela região de maior dureza (resistência mecânica) na fase mais macia [169]. As indentações \#4 e \#5 foram realizadas em uma região de martensita com 8,19 GPa de nanodureza e em uma placa de martensita que apresenta precipitação de carbonetos e 7,19 GPa de nanodureza. As profundidades de penetração das indentações em ambos os casos foram de aproximadamente $300 \mathrm{~nm}$. Os valores de dureza da ferrita obtidos na presente pesquisa foram levemente superiores a alguns reportados na literatura [170-172], mesmo tratando-se de amostras tratadas por Q\&P [173]. Isto se deve, provavelmente, às restrições induzidas nos contornos de grão da ferrita pelos constituintes mais duros ao seu redor. Desse modo, as propriedades locais de alguns microconstituintes individuais podem variar com o grau de homogeneidade da microestrutura, o tamanho de grão, as tensões residuais do material indentado, bem como, com a distribuição heterogênea do carbono associado à partição do carbono da martensita para austenita nos tratamentos de Q\&P, o que leva a variações locais da resistência para o mesmo microconstituinte. Durante os ensaios de nanoindentação o efeito TRIP [174] foi revelado na austenita retida. Esse comportamento é observado especialmente na etapa de carregamento da curva carregamento-profundidade de penetração onde pequenas descontinuidades ou pop-ins $[174,175]$ podem ser observadas. Essas descontinuidades são indicadas por setas vermelhas na curva 6 da Figura 6-9. Os vários pop-ins podem estar associados à estabilidade relativa e a morfologia da austenita retida. Os primeiros pop-ins (inferiores) podem estar associados com a transformação de blocos de austenita retida para placas de martensita, uma vez que esse tipo de transformação acontece sob a ação de menores deformações, quando comparado com a austenita na forma de filmes, que transformam para martensita sob o efeito de uma deformação de maior intensidade [176, 177] e, portanto, apresentam maior estabilidade [174]. Deste modo, pode ser concluído que o uso das técnicas de nanodureza para caracterização e identificação de microconstituintes individuais é um método útil e confiável de caracterização. 


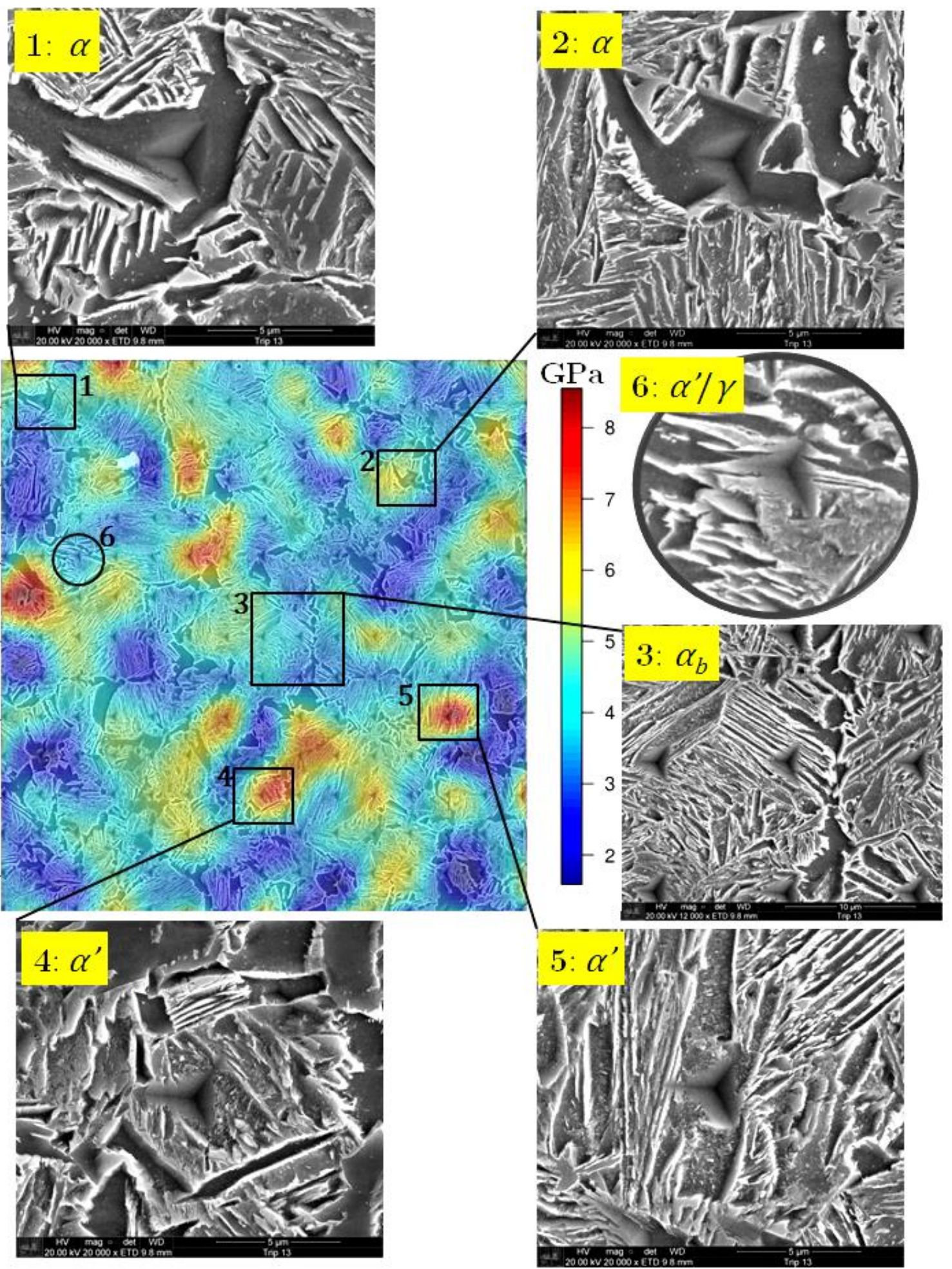

Figura 6-8. Mapa de nanodureza do aço TRIP após o tratamento de Q\&P e imagens MEV-FEG mostrando às impressões das nanoindentações na ferrita $(\alpha)$, ferrita-bainítica $\left(\alpha_{b}\right)$, martensita $\left(\alpha^{\prime}\right)$ e em uma interface martensita/austenita $\left(\alpha^{\prime} / \gamma\right)$. 


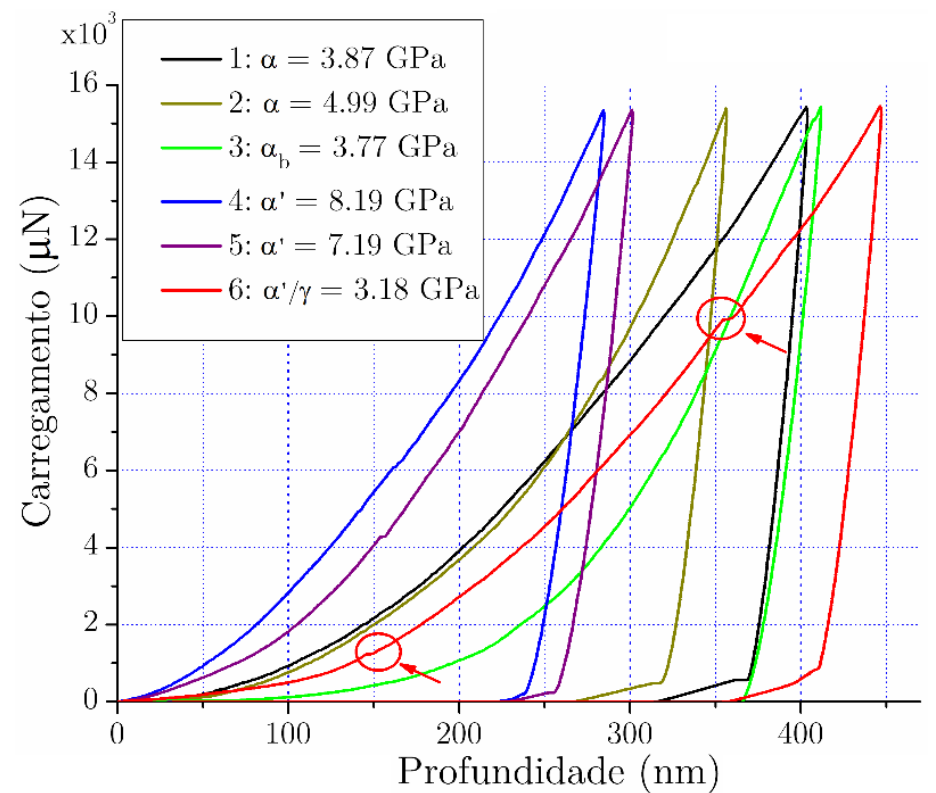

Figura 6-9. Curvas carregamento-profundidade de penetração obtidas por nanoindentação das regiões identificadas na Figura 6-8. O efeito TRIP na etapa de carregamento é observado na forma de pequenas descontinuidades ou pop-ins, indicadas pelas setas em vermelho. As curvas e os resultados de nanodureza correspondem a ferrita $(\alpha)$, ferrita-bainítica $\left(\alpha_{b}\right)$, martensita $\left(\alpha^{\prime}\right)$ e interface martensita/austenita $\left(\alpha^{\prime} / \gamma\right)$.

Ghassemi-Armaki et al. [169] mencionam que o desafio da nanoindentação está na conversão dos dados de carregamento e profundidade de penetração em curvas tensãodeformação, especialmente, para o regime plástico. Com esse objetivo, foi realizada a avaliação das propriedades mecânicas e do comportamento elasto-plástico do material tratado usando os resultados das curvas carregamento-profundidade obtidas por nanoindentação, usando o método de algoritmo reverso proposto por Dao et al. [127]. Essa metodologia é importante, porque ainda não existe um consenso na literatura a respeito do método de obtenção de curvas tensão-deformação de cada fase. Além disso, nanoindentações permitem obter respostas de fases individualmente e com tamanhos entre 1 e $10 \mu \mathrm{m}$ para ligas multifásicas. Esperava-se que as curvas tensão-deformação para distintas ferritas na mesma amostra tivessem diferentes comportamentos, dependendo das variações em escala local da microestrutura (p. ex., teor de carbono, orientação dos grãos, tensões locais e o efeito das fases circundantes). De fato, esse comportamento pode ser observado na Figura 6-10 para as curvas tensão-deformação previstas pelo algoritmo reverso. Portanto, os ensaios nanomecânicos de fases individuais por meio de nanoindentação fornecem informações importantes, que ajudam na identificação dos microconstituintes presentes nas microestruturas dos aços TRIP tratados em simulador termomecânico Gleeble por Q, HS, Q\&P e HSQ\&P. 


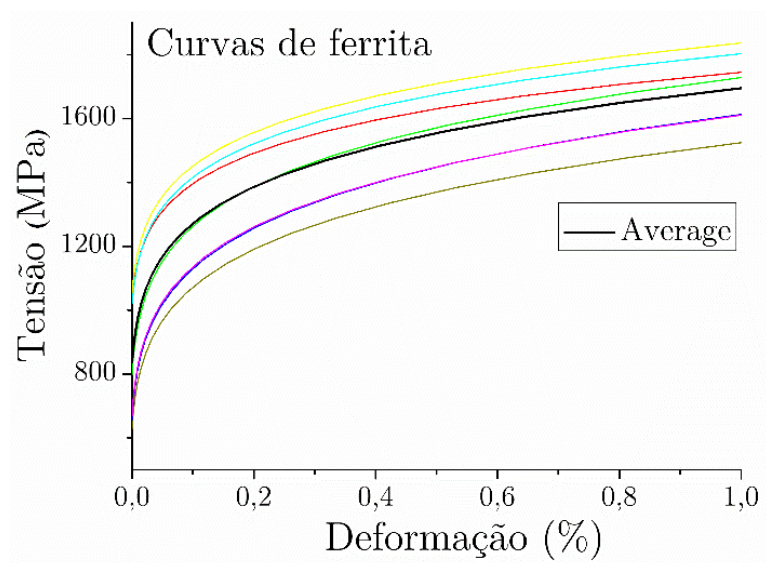

Figura 6-10. Curvas tensão-deformação verdadeiras para várias ferritas indentadas. Essas curvas foram obtidas das análises das curvas carga-profundidade usando o algoritmo reverso [127].

Foi possível calcular o limite de resistência $\left(\sigma_{y}\right)$ e o coeficiente de encruamento $(n)$ a partir das análises das curvas carregamento-profundidade de penetração do aço TRIP tratado por Q, HS, Q\&P e HSQ\&P. Na Figura 6-11 são apresentados os mapas de distribuição de $n$ (variando de 0,001 a 0,25 ) e de $\sigma_{y}$ (de 0,5 a 2,5 GPa) obtidos pela implementação do algoritmo reverso [127] para o tratamento de Q\&P. Os mapas mostrados na Figura 6-11 foram úteis para a avaliação da distribuição espacial de $\sigma_{y}$ e $n$ e para a identificação da resistência e ductilidade das fases presentes na microestrutura multifásica do aço TRIP, após o tratamento. $\mathrm{O}$ processamento dos dados foi realizado usando uma rotina escrita em linguagem de programação $\mathrm{R}$ [178]. Os cálculos realizados, utilizando o código desenvolvido, podem proporcionar indicações úteis para o desenho do processamento experimental dos tratamentos termomecânicos, permitindo prever os efeitos das características microestruturais nas propriedades mecânicas.

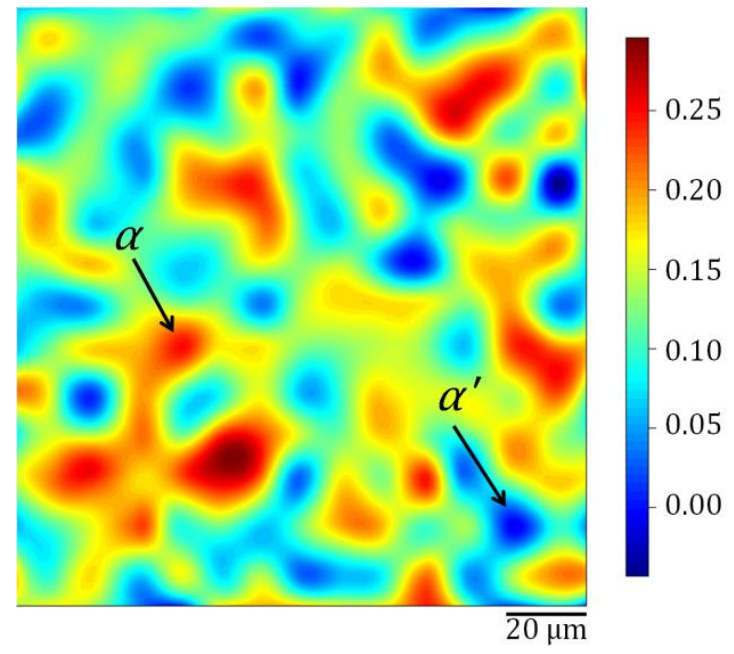

(a)

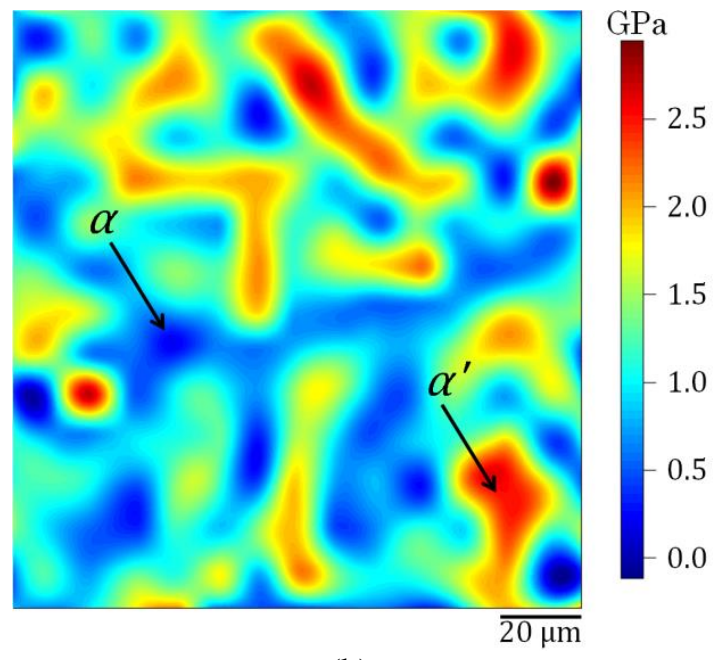

(b)

Figura 6-11. Mapas de distribuição na superfície da amostra TRIP tratada por Q\&P: (a) coeficiente de encruamento; (b) limite de escoamento. $\alpha^{\prime}$ e $\alpha$ indicam martensita e ferrita, respectivamente. 
O cálculo dos valores médios e os desvios padrão da nanodureza (calculado a partir de 225 nanoindentações), o módulo elástico reduzido $\left(E^{*}\right)$ e $n$ (obtidos pela implementação do algoritmo reverso) são listados na Tabela 6-1. Os resultados dos limites de resistência são discutidos na seguinte secção.

Tabela 6-1. Valores médios da nanodureza, o modulo elástico reduzido $\left(E^{*}\right)$ e do coeficiente de endurecimento (n) obtido a partir da implementação do algoritmo reverso, para as amostras de aço TRIP A-R (como recebido), Q, HS, Q\&P e HSQ\&P.

\begin{tabular}{cccc}
\hline Condição & $\begin{array}{c}\text { Nanodureza } \\
(\mathrm{GPa})\end{array}$ & $\begin{array}{c}E^{*} \\
(\mathrm{GPa})\end{array}$ & $n$ \\
\hline A-R & $2,28 \pm 1,0$ & $190,9 \pm 50$ & $0,22 \pm 0,04$ \\
Q & $4,16 \pm 1,0$ & $220,4 \pm 36$ & $0,11 \pm 0,05$ \\
Q\&P & $3,96 \pm 0,9$ & $220,2 \pm 33$ & $0,12 \pm 0,05$ \\
HS & $3,84 \pm 1,1$ & $232,5 \pm 50$ & $0,14 \pm 0,06$ \\
HSQ\&P & $4,11 \pm 1,3$ & $258,7 \pm 65$ & $0,14 \pm 0,05$ \\
\hline
\end{tabular}

\subsubsection{Quantificação volumétrica das fases e microdureza}

Os valores médios da microdureza das amostras estudadas (Q, HS, Q\&P, HSQ\&P e como recebida, A-R), bem como as frações volumétricas de $\alpha, \alpha^{\prime}$ e $\alpha_{b}$ medidos por estereologia quantitativa de acordo com a norma ASTM E562-02 [122], levaram aos resultados apresentados na Tabela 6-2.

Tabela 6-2. Frações volumétricas das fases nas microestruturas A-R (como recebida), Q, HS, Q\&P e HSQ\&P.

\begin{tabular}{cccc}
\hline Condição & $\begin{array}{c}V \alpha \\
(\% \text { em peso })\end{array}$ & $\begin{array}{c}V \alpha^{\prime} \\
(\% \text { em peso })\end{array}$ & $\begin{array}{c}\text { Microdureza, } \mathrm{HV}_{0.5} \\
\left(\mathrm{kgf} / \mathrm{mm}^{2}\right)\end{array}$ \\
\hline A-R & $66,0 \pm 3$ & $34,0 \pm 3$ & $240,6 \pm 6$ \\
Q & $10,4 \pm 2$ & $88,4 \pm 1$ & $402,4 \pm 7$ \\
Q\&P & $21,4 \pm 8$ & $71,9 \pm 1$ & $371,6 \pm 11$ \\
HS & $19,6 \pm 5$ & $77,2 \pm 1$ & $396,0 \pm 26$ \\
HSQ\&P & $33,7 \pm 2$ & $58,9 \pm 2$ & $330,7 \pm 5$ \\
\hline
\end{tabular}

O aumento da fração volumétrica de martensita e a redução da porcentagem de ferrita poderia explicar a maior microdureza da amostra temperada (Q) em relação à amostra HS. Da mesma forma, o aumento da porcentagem de ferrita observado e calculado na amostra HSQ\&P explica a evidente diminuição da microdureza nessa amostra. Não foram observadas diferenças significativas quando comparadas as microestruturas dos aços submetidos a Q e HS; adicionalmente, essas amostras mostraram os valores mais altos de nanodureza, muito provavelmente devido a sua alta densidade de discordâncias e presença de fases duras. Além disso, a fração de ferrita na amostra Q\&P foi similar à fração de ferrita na amostra HS. Isto implica que a deformação tem um efeito aparente na formação de ferrita na amostra HS e a 
etapa de partição tem um efeito na formação de ferrita-bainítica, como foi evidenciado na Figura 6-4. Portanto, a combinação desses dois efeitos leva à maior formação das frações volumétricas de ferrita na amostra HSQ\&P.

É importante ressaltar que os valores de microdureza e de nanodureza mostraram tendências similares nos resultados das amostras Q, Q\&P e A-R. No entanto, para as amostras HS e HSQ\&P, os valores de nanodureza foram superiores aos de microdureza, mostrando que as medições por nanoindentação podem ser mais susceptíveis tanto às heterogeneidades microestruturais, relacionadas, por exemplo, à heterogeneidade no teor de carbono e pela diferença nos diferentes tipos de martensita (fresca e revenida) e austenita retida (filmes e blocos), como ao refinamento no tamanho dos grãos produzido pela deformação (Figura 6-6(b)). Outro possível mecanismo explicando esse comportamento poderia ser a partição de carbono (ou distribuição do soluto) da martensita para austenita e as mudanças do teor de carbono como consequência da formação de ferrita durante a deformação a $750^{\circ} \mathrm{C}$. As medições de nanoindentação também podem ser influenciadas pela forte dependência do tamanho de grão [179], da anisotropia dos grãos, do estado local de tensões e da natureza dos grãos adjacentes. Por outro lado, nos ensaios de microdureza, os valores dos comprimentos das diagonais estiveram na faixa dos 30 a $50 \mu \mathrm{m}$, de modo que vários grãos de ferrita, martensita e austenita retida influenciaram na medida de uma única indentação.

\subsubsection{Simulações baseadas na microestrutura e ensaios micromecânicos}

Para compreender o comportamento mecânico do aço TRIP tratado por Q, HS, Q\&P e HSQ\&P e, em particular, a relação entre o comportamento microscópico e macroscópico sob ensaios tensão-deformação, foram realizadas análises por elementos finitos baseados na microestrutura. Com esse objetivo, OOF e Abaqus foram combinados para modelar microestruturas heterogêneas reais bidimensionais obtidas por MEV-FEG após os tratamentos termomecânicos aplicados. A modelagem micromecânica de microestruturas reais contendo grãos aleatórios foi possível pela implementação de diferentes números de elementos e técnicas de criação de malhas. Por exemplo, utilização de malha adaptativa permitiu a subdivisão dos elementos, a movimentação dos nós de acordo com a microestrutura e a minimização do parâmetro de energia funcional da malha, descrito na metodologia na equação 5.35. O tamanho da malha é um desafio constante na modelagem por elementos finitos de microestruturas, porque malhas muito grosseiras não conseguem se ajustar suficientemente à curvatura dos 
contornos de grão [139]. Portanto, refinamentos adequados das malhas tendem a mostrar melhores convergências e melhor ajuste com os resultados experimentais. No presente estudo, a melhor convergência foi atingida usando uma malha de $180 \mu \mathrm{m} \times 155 \mu \mathrm{m}$ e um valor médio de 120.000 elementos. Nos resultados aqui apresentados são discutidas unicamente as condições mais bem-sucedidas (em termos de discretização, graus de liberdade, tipos de elementos, modelos de endurecimento, etc.) para obter a melhor aderência entre a modelagem por elementos finitos e os resultados experimentais. Desse modo, a discussão da correlação entre a microestrutura e o comportamento mecânico foi unicamente baseada na natureza inerente das microestruturas analisadas.

Geralmente, os artigos com resultados de pesquisas envolvendo simulações baseadas na microestrutura, para calcular as propriedades mecânicas usam como dados de entrada as propriedades constitutivas ou curvas tensão-deformação de cada fase obtidas da literatura [139] ou de experimentos macroscópicos (ensaios mecânicos de tensão-deformação). No entanto, como foi observado nas análises de nanoindentação da ferrita (Figura 6-10), os resultados podem variar quando são comparados com os da literatura, onde a maioria das propriedades mecânicas obtidas por meio de nanoindentação foram avaliadas em aços bifásicos (DP) contendo grãos grandes [139, 169, 180, 181]. Portanto, na presente pesquisa o algoritmo reverso descrito previamente foi utilizado para calcular os valores médios das curvas tensão deformação, para serem usadas como dados de entrada no modelo pelo método de elementos finitos de microestruturas reais, tendo em conta a distribuição e morfologia das fases. Para a simulação do carregamento uniaxial sob as condições de contorno descritas, as imagens de MEV-FEG foram incorporadas em um modelo de elementos finitos para estudar a resposta mecânica dessas microestruturas sob carregamento uniaxial. As curvas tensão-deformação foram obtidas das saídas das forças de reação e dos deslocamentos. Os resultados da distribuição das tensões de von Mises associada com as microestruturas obtidas por MEV são apresentadas na Figura 6-12, mostrando como essas tensões podem se comportar dentro de uma microestrutura heterogênea quando uma tensão de tração uniaxial é aplicada.

Quando uma microestrutura de um aço multifásico é submetida a tensão, se espera que a deformação das fases não seja uniforme. Isto devido ao fato de que existem muitas variações locais na microestrutura que afetam o comportamento da deformação plástica, como são as diferenças das propriedades mecânicas entre as fases, as diferenças nas frações volumétricas, as relações cristalográficas, morfologias, interações e heterogeneidade das tensões. Desse modo, algumas regiões da microestrutura podem sofrer maior deformação em regiões nas quais os elementos apresentam menor resistência. 


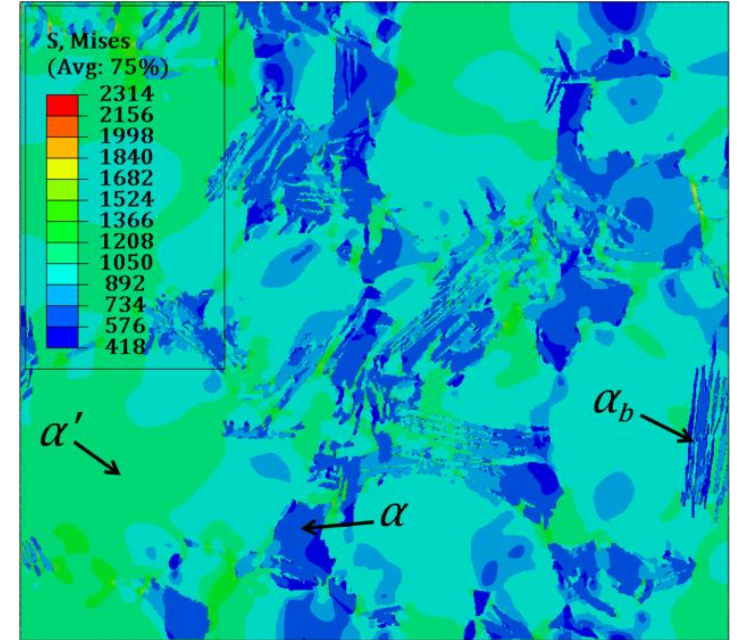

(a)

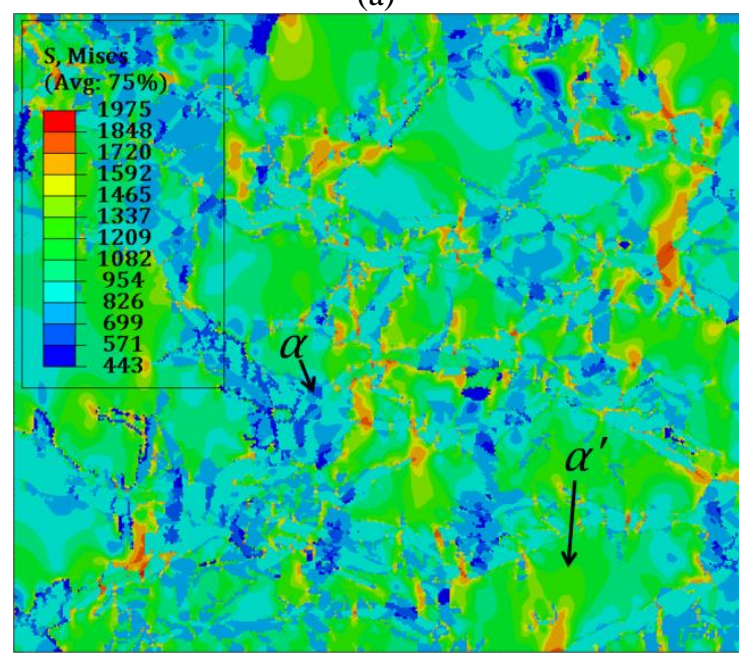

(c)

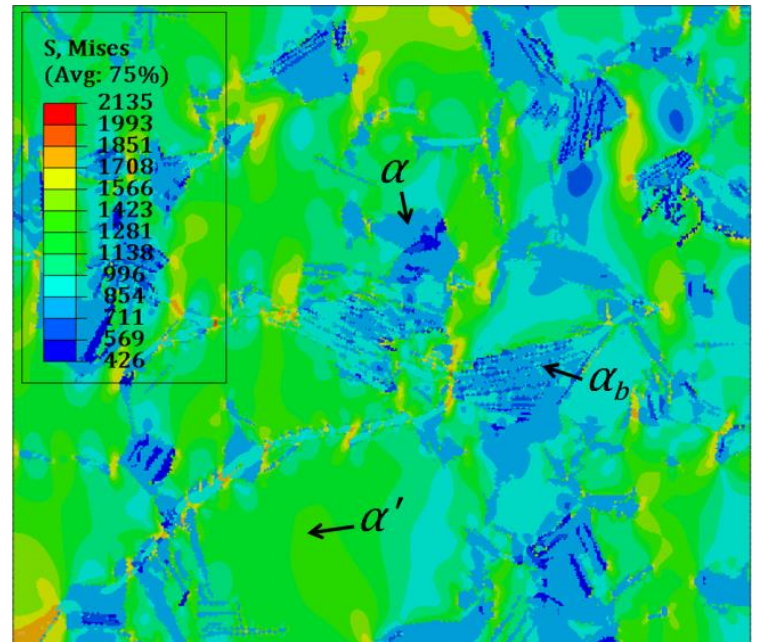

(b)

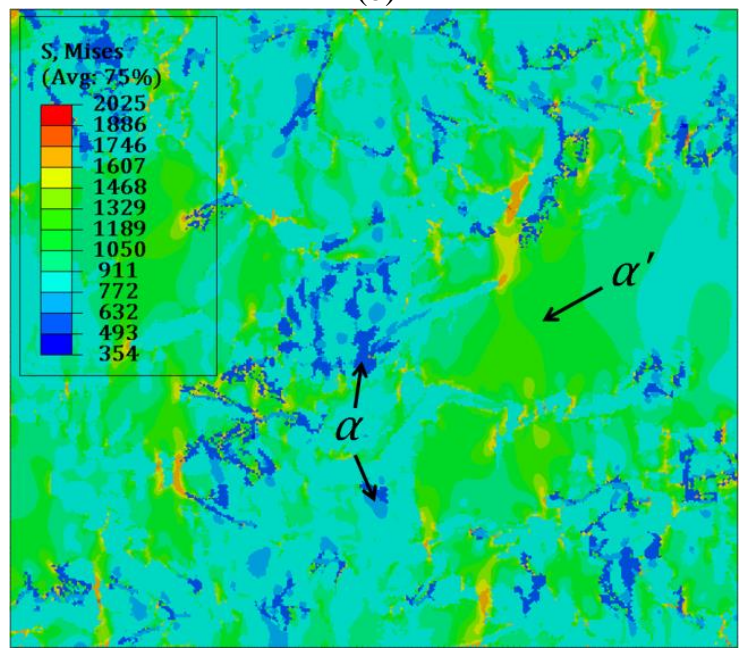

(d)

Figura 6-12. Distribuições das tensões de von Mises sob carregamento uniaxial em tração obtidas pelo método dos elementos finitos para diferentes microestruturas MEV do aço TRIP após tratamentos de: (a) Q; (b) Q\&P; (c) HS; e (d) HSQ\&P. Resultados em MPa. $\alpha^{\prime}, \alpha$ e $\alpha_{b}$ indicam martensita, ferrita e ferrita-bainítica, respectivamente.

A fim de validar os cálculos realizados por elementos finitos e avaliar as propriedades mecânicas das amostras fisicamente simuladas, foram extraídas amostras de tamanho reduzido da região central das amostras tratadas na Gleeble. Os ensaios mecânicos de tração nas amostras de tamanho reduzido foram realizados em três amostras diferentes para garantir a reprodutibilidade. A confiabilidade dos resultados dos ensaios mecânicos a partir de amostras de tamanho reduzido foi garantida pela comparação dos resultados em amostras na condição como recebida, com os resultados obtidos pelo fornecedor do material os quais foram determinados por meio de ensaio mecânico em amostras de tamanho padrão (Figura 6-13 e Tabela 6-3). 


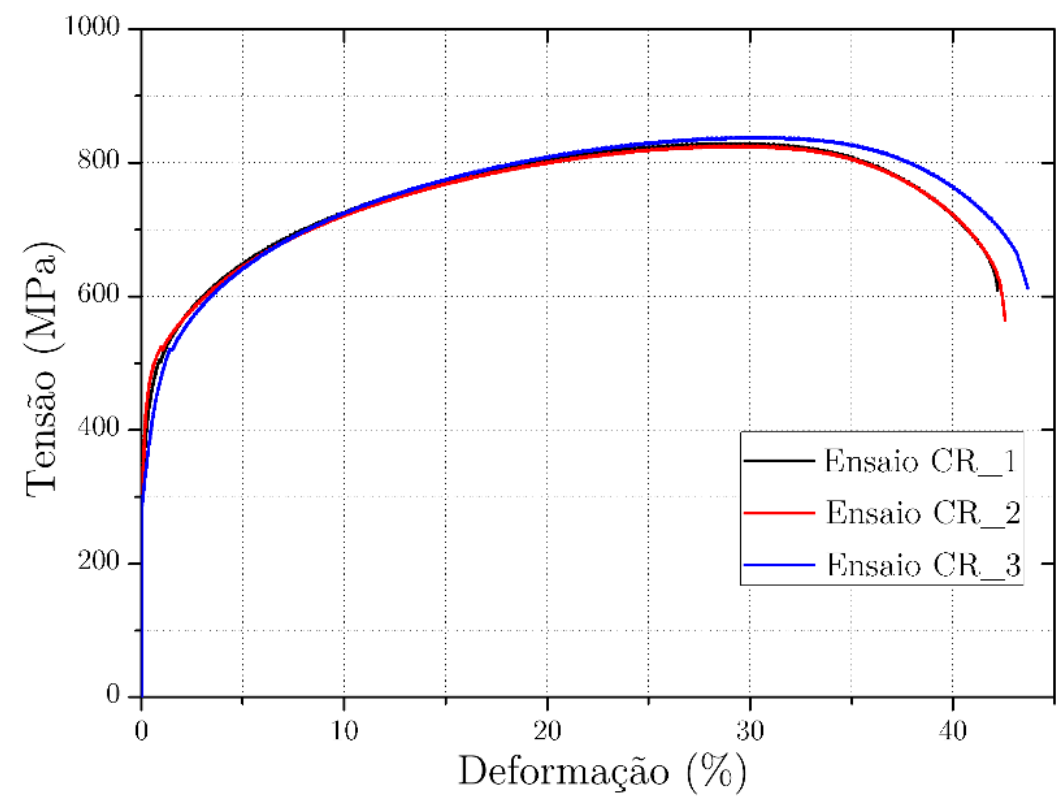

Figura 6-13. Curvas tensão-deformação obtidas no ensaio na amostra na condição como recebida.

Tabela 6-3. Comparação das propriedades mecânicas entre o ensaio mecânico em corpo de prova reduzido e os obtidos por ensaio mecânico em amostras padrão. Amostra TRIP na condição como recebida.

\begin{tabular}{cccccc}
\hline \multirow{2}{*}{$\begin{array}{c}\text { Propriedade } \\
\text { Mecânica }\end{array}$} & $\begin{array}{c}\text { Ensaio } \\
\text { mecânico } \\
\text { padrão }\end{array}$ & Ensaio 1 & Ensaio 2 & Ensaio 3 & Média \\
\cline { 3 - 6 } & $504 \pm 4$ & 492 & 482 & 509 & $494 \pm 14$ \\
$\sigma_{y}(\mathrm{MPa})$ & $778 \pm 2$ & 785 & 770 & 808 & $788 \pm 19$ \\
LR $(\mathrm{MPa})$ & $35.5 \pm 1$ & 33,8 & 33,3 & 34,8 & $33,9 \pm 2$ \\
$\varepsilon_{T}(\%)$ & &
\end{tabular}

$\sigma_{y}$, LR e $\varepsilon_{T}$ são os limites de escoamento e máximo de resistência e o alongamento total, respectivamente.

A Figura 6-14 apresenta a comparação das curvas tensão-deformação sob condição de carregamento uniaxial dos resultados experimentais usando corpo de prova de tamanho reduzido e das simulações por elementos finitos baseadas na microestrutura. É importante mencionar que as curvas simuladas representam os valores médios de três microestruturas simuladas obtidas para a mesma condição de tratamento térmico. Em geral, a predição das curvas tensão-deformação foi aceitável, com exceção do comportamento do limite de resistência dos tratamentos que incluem a etapa de partição. Essa falta de concordância pode estar relacionada com as diferenças no comportamento das frações volumétricas de austenita e/ou na estabilidade da austenita durante o processo de deformação, as quais não puderam ser previstas pela simulação. Não obstante, os resultados da Figura 6-14 indicam que a modelagem por elementos finitos é uma aproximação que pode ser usada para prever, ao menos de forma qualitativa, os comportamentos mecânicos de amostras multifásicas previamente tratadas no sistema Gleeble. As simulações também poderiam ajudar fornecendo informação aprofundada dos mecanismos de deformação e da interação entre as fases presentes nas microestruturas consideradas. Adicionalmente, as análises por elementos finitos combinando OOF e Abaqus 
podem ser ferramentas de aproximação úteis para: a) prever propriedades mecânicas, evitando ensaios destrutivos nas amostras, o que geralmente implica em perda de material e consumo de energia produzido pelo aquecimento e reaquecimento nos tratamentos térmicos em experimentos exploratórios do tipo tentativa e erro; b) comparar modelos idealizados e microestruturas reais; e c) identificar as características microestruturais importantes que permitam projetar microestruturas complexas e atingir as propriedades macroscópicas desejadas.

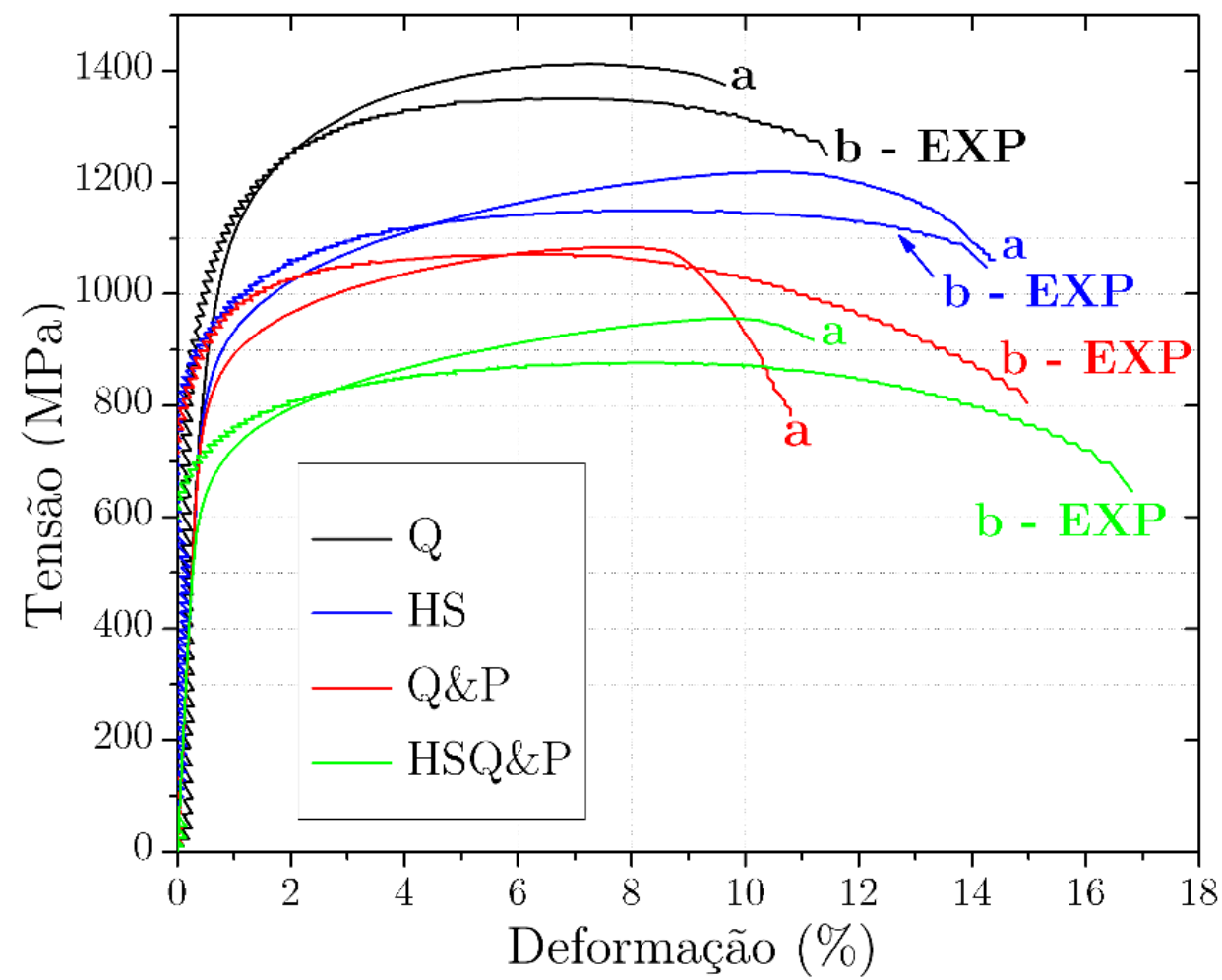

Figura 6-14. Curvas tensão-deformação obtidas pelo método dos elementos finitos e pelo ensaio mecânico em corpo de prova de tamanho reduzido após os ensaios de Q, HS, Q\&P e HSQ\&P. As curvas identificadas com a letra "a" denotam os resultados simulados, enquanto "b-EXP" indicam as curvas experimentais.

Os resultados experimentais e das simulações (Figura 6-14) mostraram uma tendência similar no comportamento do limite de escoamento em função da deformação. No entanto, quando a deformação aumenta, o alongamento total e o limite de resistência parecem ter sido subestimados, especialmente no caso das amostras particionadas. A anisotropia dos grãos causa heterogeneidades nos campos de deformação local quando estruturas policristalinas estão sob carregamento [141] e essa característica não foi considerada no modelo de elementos finitos utilizado. De fato, a própria condição da simulação plana de deformação 2D pode dificultar uma maior adesão dos resultados simulados aos experimentais, pois na direção normal podemse desenvolver tensões locais, não previstas no modelo [144]. Além disso, não foram 
consideradas no modelo condições especiais nas interfaces, como critérios de atrito, adesão ou decoesão, e a interação real poderia ser mais próxima à interação de corpos separados com critérios de contato definidos. Outra explicação pode ser que as tensões residuais não foram incorporadas no modelo de elementos finitos [138]. Além das razões já mencionadas, o presente modelo não é capaz de detectar as mudanças locais na ativação dos sistemas de escorregamento devido à imposição do endurecimento isotrópico [141]. Adicionalmente, os grãos de martensita fresca são muito pequenos e estão espaçadamente distribuídos na microestrutura, e por essa razão sua identificação por meio de nanoindentação foi difícil. Essa limitação na implementação do algoritmo reverso pode também levar à imprecisão nas comparações. Portanto, os mecanismos acima mencionados devem ser considerados em pesquisas futuras para prever comportamentos mais realistas por meio de simulações a partir de microestruturas reais.

Cabe mencionar que a forma serrilhada das curvas tensão-deformação, principalmente observada na região elástica, deriva-se dos poucos dígitos decimais nos dados de saída da célula de carga da máquina de ensaios mecânicos.

Os resultados experimentais das curvas tensão-deformação na Figura 6-14, evidenciam que as variações nas propriedades mecânicas estiveram diretamente relacionadas, e em concordância, com as frações volumétricas de cada fase (Tabela 6-2) para os respectivos tratamentos termomecânicos. Nesses resultados, é possível observar que a amostra Q tem os maiores limites de escoamento $(\approx 1050 \mathrm{MPa})$ e de resistência mecânica $(\approx 1350 \mathrm{MPa})$ e os menores valores de alongamento $(\approx 11 \%)$. Esse comportamento é explicado pela maior porcentagem de martensita $(\approx 88 \%)$ e a menor fração volumétrica de ferrita $(\approx 9 \%)$ na amostra temperada. Como esperado, a ferrita é mais dúctil que a martensita e, portanto, amostras com maiores frações volumétricas de ferrita sofrem maiores deformações. Para as amostras deformadas a $750{ }^{\circ} \mathrm{C}$, a diferença do limite de escoamento entre a amostra particionada (HSQ\&P) e a não particionada (HS) foi de $\approx 200 \mathrm{MPa}$, enquanto a diferença do limite de resistência foi de $\approx 270 \mathrm{MPa}$, em ambos os casos sendo maior para a amostra HS. Deve-se notar que para a amostra HSQ\&P, as respostas dos limites de escoamento e de resistência foram reduzidas, provavelmente pela maior porcentagem de ferrita $(30 \%)$ e pelo menor teor de carbono da martensita, devido à etapa de partição. Em contrapartida, a ductilidade, associada com o maior alongamento $(\approx 16 \%)$ observado nessa amostra, foi maior, provavelmente devido à maior fração de ferrita e à maior estabilidade da austenita causada pelo enriquecimento em carbono ( $\mathrm{C}_{\gamma} \approx 1,23 \%$, em peso), o que favorece o efeito TRIP. Como tem sido comentado por alguns pesquisadores $[167,168]$, austenita com a concentrações de carbono $\left(C_{\gamma}\right)$ na faixa dos 
1,0-1,5\% em peso dão maior contribuição para o melhor desempenho do aço sob efeito TRIP. Adicionalmente, de acordo com a relação de Hall-Petch, o tamanho médio dos grãos de ferrita mais finos $(\approx 15 \mu \mathrm{m})$ pode contribuir com o comportamento plástico do material. Alternativamente, o comportamento do encruamento da martensita com menor teor de carbono pode ser diferente da martensita com teores altos de carbono, o que influencia a ductilidade, exibindo diferenças no encruamento, principalmente nos primeiros estágios da deformação [144]. Por outro lado, embora as amostras particionadas tenham mostrado menores valores de resistência mecânica, elas apresentaram os maiores valores de alongamento total. Sabe-se que a energia absorvida durante deformação $(\delta)$, também chamada de índice de conformabilidade, depende do produto entre a resistência à tração e a alongamento e, dessa forma, as amostras particionadas mostram valores de $\delta$ próximos aos outros tratamentos (15 - $16 \mathrm{GPa} \%)$ e superiores aos processos convencionais de estampagem a quente, que são geralmente menores aos $10 \mathrm{GPa} \%$ [182]. Adicionalmente, os resultados também indicam que a aplicação do tratamento térmico com austenitização intercrítica pode promover maior ductilidade e a redução dos níveis de resistência mecânica devido à presença de uma significativa quantidade de ferrita intercrítica na microestrutura.

A Tabela 6-4 compara os limites de escoamento $\left(\sigma_{y}\right)$ e de resistência (LR) obtidos experimentalmente, usando amostras de tração com tamanho reduzido, a partir da implementação do algoritmo reverso a partir dos resultados de nanoindentação e do modelo numérico, usando o método dos elementos finitos (MEF) para modelar as microestruturas. Nesses resultados se observa que os valores numéricos mostram variação nos valores de $\sigma_{y}$, enquanto os valores de LR são comparáveis com os resultados experimentais. Em geral, o melhor ajuste experimental foi obtido com as análises por elementos finitos, enquanto o algoritmo reverso apresentou a melhor correlação para os tratamentos Q e HS. Conforme mencionado, isto pode ser explicado pelo fato de que o algoritmo reverso pode ser mais susceptível ao avaliar regiões heterogêneas, mais provavelmente relacionadas com a heterogeneidade dos teores de carbono, ou devido a que as medições por nanoindentação são fortemente dependentes do tamanho do grão, da anisotropia, do estado de tensões locais e da natureza dos grãos adjacentes. 
Tabela 6-4. Comparação entre os limites de escoamento $\left(\boldsymbol{\sigma}_{\boldsymbol{y}} \pm 20 \mathrm{MPa}\right)$ e de resistência (LR $\left.\pm 15 \mathrm{MPa}\right)$ obtidos experimentalmente a partir de amostras de tração com tamanho reduzido, pela implementação do algoritmo reverso usando os resultados de nanoindentação e das simulações pelo método dos elementos finitos (MEF) baseadas na microestrutura, após Q, Q\&P, HS e HSQ\&P.

\begin{tabular}{ccccccc}
\hline \multirow{2}{*}{ Condição } & \multicolumn{2}{c}{$\begin{array}{c}\text { Resultados experimentais corpo } \\
\text { de prova reduzido }\end{array}$} & \multicolumn{2}{c}{ Algoritmo reverso } & \multicolumn{2}{c}{$\begin{array}{c}\text { MEF baseado na } \\
\text { microestrutura }\end{array}$} \\
\cline { 2 - 7 } & $\sigma_{y}$ & LR & $\sigma_{y}$ & LR & $\sigma_{y}$ & LR \\
\hline Q & 1044 & 1350 & 1070 & 1327 & 1091 & 1411 \\
Q\&P & 870 & 1070 & 1008 & 1287 & 897 & 1084 \\
HS & 889 & 1149 & 913 & 1250 & 876 & 1199 \\
HSQ\&P & 679 & 878 & 963 & 1343 & 655 & 956 \\
\hline
\end{tabular}

Como foi mencionado, recentemente alguns estudos têm tentado mostrar o potencial da combinação do processo de estampagem a quente com o de têmpera e partição [147-151]. No entanto, nenhum deles está relacionado diretamente com a deformação envolvida no processo de estampagem, uma vez que esses pesquisadores têm simulado fisicamente ensaios de compressão em equipamento Gleeble. Portanto, os resultados de simulação física aqui apresentados representam maior proximidade ao comportamento esperado por componentes tratados pelo tratamento combinado de estampagem a quente e de têmpera e partição.

\subsection{Conclusões}

Um inovador processo (HSQ\&P) aplicado a um aço assistido pelo efeito TRIP foi proposto, que combina a austenitização intercrítica com a deformação a quente (HS) não isotérmica, seguido pelo tratamento de têmpera e partição (Q\&P) em duas etapas. Foram conduzidos experimentos usando simulador termomecânico Gleeble ${ }^{\circledR}$ 3S50, acoplado a uma fonte de radiação síncrotron, a fim de comparar as microestruturas e as propriedades mecânicas do aço TRIP submetido aos tratamentos de têmpera (Q), HS, Q\&P e HSQ\&P. Dos resultados obtidos, as seguintes conclusões podem ser estabelecidas:

- A implementação do algoritmo reverso para avaliar os experimentos de nanoindentação permitiu modelar as curvas tensão-deformação para cada fase, que em seguida puderam ser usadas como dados de entrada para modelar microestruturas reais via modelagem numérica usando o método dos elementos finitos (MEF).

- Os mapas de distribuição obtidos em microescala do limite de escoamento e do coeficiente de encruamento permitem avaliar a distribuição das propriedades mecânicas entre as fases e microconstituintes presentes na microestrutura.

- A formação de bainita não acontece ou é altamente reduzida durante a etapa de partição quando o processo de HSQ\&P é aplicado. 
- Durante o processo de HSQ\&P, a deformação aplicada não só leva à formação de ferrita por efeito DIFT, mas também a uma redução do tamanho dos grãos de $\approx 30 \mu \mathrm{m}$ para as amostras Q\&P para $\approx 15 \mu \mathrm{m}$ para as amostras HSQ\&P, contribuindo no aprimoramento da otimização de propriedades resistência-ductilidade em aços assistidos pelo efeito TRIP.

- A difração de raios $X$ usando radiação síncrotron realizada durante as simulações termomecânicas de Q\&P e HSQ\&P mostraram que os teores de carbono na austenita aumentam em função do tempo durante a etapa de partição a $400{ }^{\circ} \mathrm{C}$. Esse efeito foi mais pronunciado na amostra Q\&P do que na amostra HSQ\&P.

- A deformação em alta temperatura realizada antes do processo de Q\&P contribui no refinamento da microestrutura multifásica, melhorando a resistência e a ductilidade devido ao aumento das frações volumétricas de austenita retida, favorecendo assim o efeito TRIP. 


\section{COMBINAÇÕES DE DUCTILIDADE E RESISTÊNCIA MECÂNICA PARA DIVERSAS FRAÇÕES VOLUMÉTRICAS DE FERRITA, MARTENSITA E AUSTENITA RETIDA EM AÇO TRIP}

\section{Resumo}

As propriedades mecânicas dos novos aços avançados de alta resistência são dependentes de sua composição química e da morfologia e distribuição de seus microconstituintes. A variação desses microconstituintes pode ser obtida por meio de tratamentos térmicos e termomecânicos. Usando simulador termomecânico Gleeble foram realizados, em um aço TRIP, tratamentos térmicos de têmpera e partição $(\mathrm{Q} \& \mathrm{P})$ e termomecânicos, combinando deformação na temperatura ambiente (CS) ou a quente (HS) com o posterior tratamento de Q\&P, a fim de investigar a influência na microestrutura e no comportamento mecânico de parâmetros como: temperaturas de austenitização intercrítica e de têmpera, tempo de permanência na etapa de partição e quantidade e temperatura de deformação. O procedimento experimental inclui: a determinação da temperatura ótima de têmpera de acordo com o modelo termodinâmico de equilíbrio constrito do carbono; análises in situ, usando radiação síncrotron, da variação do parâmetro de rede da austenita durante o estágio de partição; análise de variância da temperatura de início de transformação martensítica $\left(M_{S}\right)$; e a caracterização microestrutural e mecânica. Para a caracterização microestrutural foram utilizadas as técnicas de microscopia óptica, eletrônica de varredura e a difração de elétrons retroespalhados (EBSD). O EBSD permitiu distinguir claramente as diferentes morfologias da austenita retida e analisar a orientação cristalográfica das fases, o tamanho de grão, a deformação local usando mapas do fator de Schmid e os gradientes de desorientação usando análises de kernel (KAM). Adicionalmente o EBSD foi combinado com a técnica de nanodureza a fim de caracterizar microestrutural e mecanicamente (de forma local) os aços tratados por Q\&P e HSQ\&P. Essa combinação permitiu identificar as faixas de nanodureza da martensita, da ferrita e da ferrita-bainítica e a dependência dos resultados de nanodureza da orientação cristalográfica. Por último são analisados e discutidos os resultados das porcentagens de ferrita, obtidos usando estereologia quantitativa, da austenita, obtidos por difração de raios $\mathrm{X}$ e da microdureza para todos os tratamentos realizados. Os resultados mecânicos obtidos são promissores para a ampliação do espectro de aços avançados da terceira geração. 


\subsection{Introdução}

Atualmente existe uma crescente demanda industrial de aços que apresentem ótimas combinações de ductilidade e resistência mecânica, mas que não impliquem em aumentos consideráveis dos custos de produção. No setor automobilístico essa demanda visa a redução do peso dos veículos, a redução das emissões de $\mathrm{CO}_{2}$ e o aumento da segurança dos passageiros e pedestres, em caso de colisão. Os dois primeiros requisitos exigem a redução da massa do veículo, o que requer a produção de chapas mais finas, enquanto o aumento da segurança pode ser atingido com componentes mais resistentes e, portanto, poderia demandar chapas de maior massa. Dessa forma, o aumento da resistência sem perda de ductilidade e as reduções em peso, emissão de $\mathrm{CO}_{2}$ e consumo de combustível pela diminuição das espessuras das chapas, mas sem comprometer a segurança dos passageiros, criam um paradigma para a metalurgia. Para enfrentar esse desafio têm sido propostos diversos tipos de microestruturas e tratamentos térmicos (microestruturas DP refinadas [179, 183, 184], TRIP modificadas [185-188], microestruturas bainítica [189-191] e nanobainítica [192-194], têmpera e partição - Q\&P [1, 195, 196], TWIP com menores teores de Mn [197-199], etc.) que combinam microconstituintes que favorecem ao mesmo tempo a ductilidade, por meio da presença de austenita retida e ferrita, e a resistência mecânica, pela presença de martensita e bainita. A estabilidade da austenita retida é desejada uma vez que ela pode contribuir no efeito TRIP (do inglês, Transformation Induced Plasticity) não só durante a conformação, mas também pela absorção de energia no caso de uma colisão. Portanto, ampliar a compreensão dos parâmetros que controlam as microestruturas e, em consequência, as propriedades mecânicas dos novos aços avançados de alta resistência é uma tarefa em constante evolução.

Este capítulo tem como propósito estudar o tratamento Q\&P (em chapas de 1,5 $\mathrm{mm}$ de espessura de aço de TRIP de alta resistência), incluindo a influência da deformação prévia em alta temperatura e da temperatura de têmpera, na procura de um novo processo tecnológico que garanta tanto o aumento da resistência mecânica quanto da ductilidade. A vantagem industrial da deformação em alta temperatura está na possibilidade de produzir componentes estruturais com geometrias complexas com redução do retorno elástico (springback) e a fabricação de peças mais finas, assim reduzindo o peso dos componentes. A deformação em alta temperatura também viabiliza a produção de ferrita induzida pela deformação (DIFT, Deformation Induced Ferrite Transformation) [86], que contribui para o enriquecimento em carbono da austenita e, portanto, favorece sua estabilização. Além disso, a formação de bainita no estágio de partição é retardada durante o processo de Q\&P pela estabilização mecânica da austenita deformada [72, 
158]. Dessa forma, com o processo de deformação a quente com posterior tratamento de Q\&P, chamado na presente pesquisa de HSQ\&P, obtém-se uma microestrutura multifásica contendo principalmente martensita, ferrita (DIFT e intercrítica) e austenita retida. O aumento das porcentagens de ferrita e austenita podem reduzir consideravelmente os níveis de resistência do aço, mas contribuem no objetivo de aumentar a ductilidade.

Os tratamentos térmicos e termomecânicos foram planejados a fim de gerar uma ampla variedade de microestruturas consistindo de martensita, ferrita, austenita retida e ferritabainítica, de tal forma que consigam preencher parte do espectro dos aços chamados da terceira geração. O procedimento experimental neste capítulo inclui as secções de: análise in situ usando radiação síncrotron no simulador termomecânico Gleeble, caracterização microestrutural usando microscópica óptica, eletrônica de varredura, EBSD, nanoindentação, estereologia quantitativa e microdureza. As análises in situ usando radiação síncrotron visam medir o enriquecimento em carbono na austenita por meio da mudança do parâmetro de rede no estágio de partição, comparando a influência que têm o grau de redução e a temperatura de deformação. Desta forma, usando os procedimentos descritos são analisadas a influência de parâmetros como: porcentagem de deformação, tempo de partição e temperaturas de austenitização intercrítica, deformação e têmpera, na porcentagem de austenita retida, o tamanho de grão, a temperatura de início da transformação martensítica, e na morfologia, porcentagem e distribuição dos microconstituintes formados após os tratamentos. 


\subsection{Resultados e discussão}

Os tratamentos térmicos e termomecânicos avaliados neste capítulo consistiram em têmpera (Q), têmpera e partição (Q\&P), estampagem a quente (HS), e o processo combinado de estampagem a quente com posterior têmpera e partição (HSQ\&P), aplicados ao aço TRIP. Inicialmente as amostras foram homogeneizadas a $1000^{\circ} \mathrm{C}$ por 5 minutos e em seguida foram austenitizadas intercriticamente (a 800 ou $820^{\circ} \mathrm{C}$ ), com tempo de permanência de 5 minutos, taxas de aquecimento de $15^{\circ} \mathrm{C} / \mathrm{s}$, e taxas de resfriamento de $60{ }^{\circ} \mathrm{C} / \mathrm{s}$. Para os aços que incluem deformação em alta temperatura foram estudadas duas temperaturas de deformação (uma isotérmica a $800{ }^{\circ} \mathrm{C}$ e a outra não-isotérmica iniciando em $750{ }^{\circ} \mathrm{C}$ e finalizando em $714{ }^{\circ} \mathrm{C}$ ) e três quantidades de deformação (10, 30 ou 50\%). A taxa de deformação nominal para todos os testes foi de $0,5 \mathrm{~s}^{-1}$, que está dentro da faixa das taxas de deformação encontradas durante ensaios convencionais de estampagem a quente [200].

No caso dos aços particionados, a temperatura de têmpera (QT) é um parâmetro importante, já que determina a fração volumétrica de martensita que poderá rejeitar carbono para estabilizar a austenita, durante o estágio de partição e, portanto, também controla a máxima fração volumétrica de austenita retida à temperatura ambiente. A seguir são descritos o procedimento e os resultados do cálculo da temperatura ótima de têmpera estudada nesta seção.

\subsubsection{Temperatura ótima de têmpera}

Na Figura 7-1 é apresentada a fração volumétrica de austenita não transformada em função da temperatura de têmpera, calculada usando a regra das alavancas a partir das curvas de dilatometria na região de transformação martensítica. Os dados experimentais representados pelos círculos abertos foram ajustados pelo método dos mínimos quadrados ao modelo proposto por Koistinen e Marburger (K\&M) [201]. A partir do ajuste dos resultados experimentais e considerando a austenitização intercrítica (sob essa condição, a concentração inicial de carbono na austenita é controlada pela temperatura intercrítica) foi determinada a equação de $K \& M$ modificada para as condições do presente estudo, que prevê a quantidade de austenita nãotransformada $\left(V_{\gamma}\right)$ em função da temperatura de têmpera durante a transformação martensítica:

$$
V_{\alpha^{\prime}}=1-V_{\gamma}=1-\exp \left[-3,51 \times 10^{-2}(377,2-T)\right]
$$


Observa-se na Figura 7-1 que a equação de K\&M se ajusta bem em baixas temperaturas (elevados super-resfriamentos) aos valores experimentais, embora para altas temperaturas os pontos experimentais desviem-se sensivelmente da equação ajustada, porque o início da transformação martensítica (logo abaixo do $M_{S}$ ) ocorre de forma gradual [202], o que não permite um melhor ajuste dos valores experimentais.

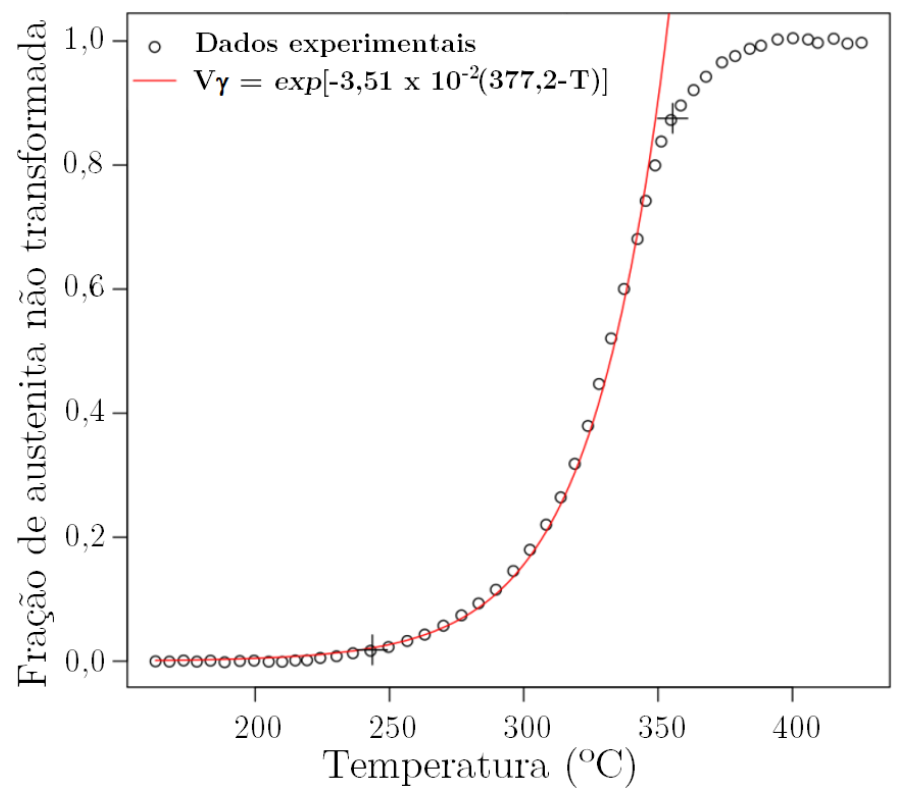

Figura 7-1. Fração não transformada de austenita em função da temperatura de têmpera determinada pelos dados do experimento de dilatometria na amostra TRIP temperada.

Para a determinação da quantidade máxima possível de austenita estável na temperatura ambiente foi desenvolvida uma rotina em linguagem $\mathrm{R}$ [178] para calcular a temperatura "ótima" de têmpera [1]. Os cálculos foram realizados com base na metodologia descrita por Speer et al. [1], que faz uso de equações que preveem o início da transformação martensítica $\left(M_{S}\right)$ (p. ex., equação de Andrews [203]) e a fração de martensita transformada em função do resfriamento a uma temperatura abaixo do $M_{S}$ (equação de $K \& \mathrm{M}$ ). A equação proposta por Koistinen e Marburger é usualmente utilizada com esse propósito. No presente estudo é utilizada a equação de K\&M ajustada para os resultados experimentais, mas no presente estudo foi implementada a equação modificada de acordo com os resultados experimentais (Eq. 7.1). No modelo proposto por Speer et al. [1], as equações 7.1 e de início de transformação martensítica são utilizadas duas vezes. Primeiro, para calcular a temperatura $M_{S}$ da austenita inicial e sua fração volumétrica a uma certa temperatura de têmpera abaixo do $M_{S}$ e, posteriormente para calcular a temperatura $M_{S}$ após o estágio de partição, assumindo partição completa do carbono da martensita para austenita. 
$\mathrm{Na}$ Figura 7-2 as curvas tracejadas mostram as frações volumétricas dos componentes microestruturais e ajudam a explicar a relação entre a quantidade de austenita retida final e a temperatura de têmpera. Esses componentes microestruturais incluem a austenita e a martensita presente na temperatura da têmpera inicial (QT) e a martensita adicional (martensita fresca) que se forma na têmpera final à temperatura ambiente [204]. A curva em preto corresponde à fração volumétrica final de austenita após o tratamento de têmpera e partição em função da temperatura de têmpera. Esses resultados indicam a existência de uma temperatura "ótima" de têmpera $\left(\mathrm{TO} \approx 318^{\circ} \mathrm{C}\right.$ ) que fornece o maior percentual possível de austenita retida $(\approx 21 \%)$ após a têmpera final, assumindo austenitização intercrítica e usando o modelo termodinâmico de equilíbrio constrito (CCE) ou restringido do carbono [63]. No entanto, cabe mencionar que os cálculos realizados sob o modelo de CCE assumem algumas condições idealizadas no estágio da partição, tais como: interfaces estacionárias, partição ideal do carbono da martensita para austenita (i.e., o fluxo de carbono que sai da martensita é igual ao que chega na austenita) e as reações competitivas, como a formação ou precipitação de carbonetos, são completamente suprimidas. Contudo, não há outros métodos mais sofisticados para a determinação da temperatura "ótima" de têmpera para maximizar a estabilização da austenita após o estágio de partição. Clarke et al. [205] propuseram uma nova metodologia de seleção que prevê a fração de austenita incluindo um modelo para a cinética da partição, mas as reações competitivas foram ignoradas e a interface ferrita/austenita foi assumida imóvel. No entanto, Qu et al. [70] recentemente afirmaram que seleção da temperatura de têmpera baseado nesses modelos cinéticos de particionamento de carbono têm baixa previsibilidade.

De acordo com a Figura 7-2, a microestrutura final é composta por austenita, martensita (presentes após a têmpera inicial) e uma possível fração adicional de martensita que pode se formar durante o resfriamento final, caso a austenita não tenha se tornado estável o suficiente durante a etapa de partição. Vale a pena destacar que têmperas realizadas acima da temperatura considerada "ótima", geram uma grande fração de austenita não transformada. No entanto, essa maior quantidade de austenita representa um menor enriquecimento em carbono, tornando-a pouco estável e permitindo que durante o resfriamento final se transforme parcialmente em martensita [64]. No caso da utilização de temperaturas de têmpera inferiores à temperatura considerada ótima, grande parte da austenita é transformada em martensita durante a primeira etapa de têmpera, o que reduz a quantidade de fração volumétrica de austenita antes da partição, mas aumenta a disponibilidade de carbono para ser particionado. Nesse caso, o enriquecimento da austenita durante o processo de partição pode ser muito superior ao necessário para torná-la estável na temperatura ambiente. 
A metodologia descrita permitiu calcular a temperatura ótima de têmpera para o aço TRIP austenitizado intercriticamente, orientando a seleção das temperaturas de têmpera aplicadas durante os tratamentos de Q\&P e de HSQ\&P e visando a obtenção de uma quantidade substancial de austenita após os tratamentos térmicos.

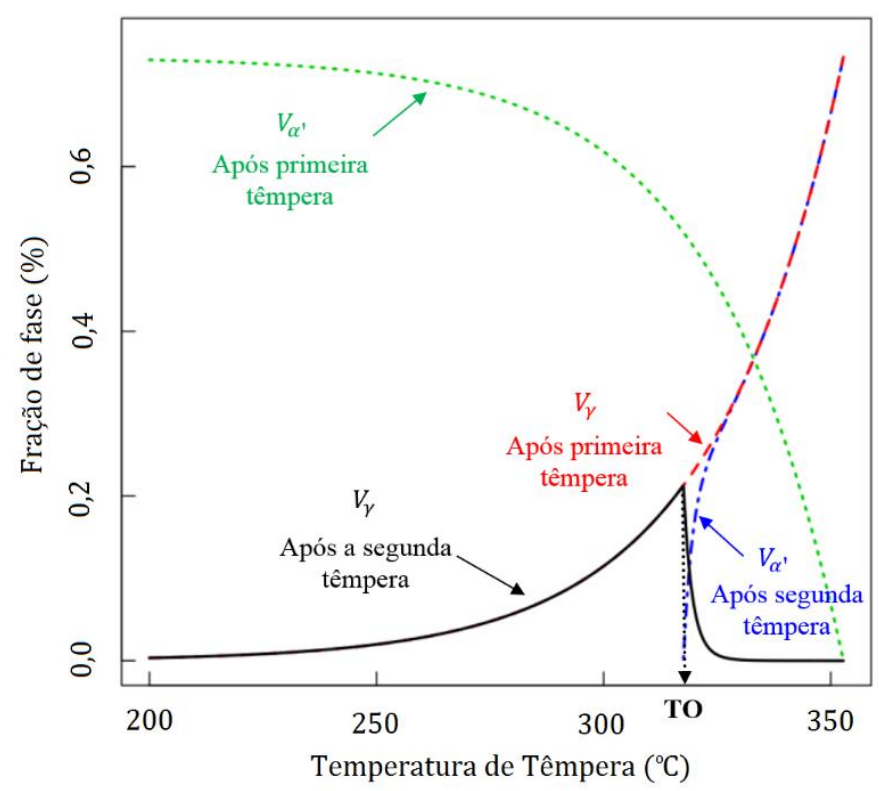

Figura 7-2. Previsão da fração volumétrica de austenita retida após austenitização intercrítica, assumindo partição total do carbono segundo o modelo de Speer et al. [1]. TO, indica a temperatura "ótima" de têmpera.

Com base no cálculo da temperatura ótima de têmpera (TO igual a $318^{\circ} \mathrm{C}$ ) foram planejados e realizados experimentos de têmpera e partição $(\mathrm{Q} \& \mathrm{P})$ e de estampagem a quente seguido de têmpera e partição (HSQ\&P) na estação experimental XTMS, operada em conjunto pelo LNNano e pelo LNLS. A estação consiste em um simulador termomecânico Gleeble $3 \mathrm{~S} 50^{\mathrm{TM}}$ integrado à linha de difração de raios X XRD1 do LNLS. O planejamento experimental usando a radiação síncrotron consistiu em avaliar os processos que incluem etapa de partição com temperatura de têmpera de $318{ }^{\circ} \mathrm{C}$, e duas temperaturas adicionais, com diferença de $\pm 10{ }^{\circ} \mathrm{C}$, isto é, em $308{ }^{\circ} \mathrm{C}$ e $328^{\circ} \mathrm{C}$. A variação da temperatura de têmpera foi adotada com a finalidade de contemplar possíveis mudanças promovidas pela deformação prévia em alta temperatura ou devidas à imprecisão na previsão dessa temperatura pela própria cinética da partição e às restrições adotadas no modelo termodinâmico (p. ex., interface estacionária, todo o carbono da martensita está disponível para estabilizar a austenita ou a supressão das reações competitivas, como a precipitação de carbonetos). Além disso, foram realizados dois conjuntos adicionais de experimentos, um deles visando avaliar a influência da mudança da temperatura de austenitização intercrítica $\left(820^{\circ} \mathrm{C}\right.$, com a qual se obteve uma $\left.\mathrm{TO} \approx 328^{\circ} \mathrm{C}\right)$ e o outro, um novo caminho termomecânico viável industrialmente que inclui a deformação a frio da chapa (em 
$10 \%$ ) com posterior tratamento de Q\&P (com QT em $318^{\circ} \mathrm{C}$ e $328^{\circ} \mathrm{C}$ ), chamado aqui de CSQ\&P. Para a condição da temperatura intercrítica de $820{ }^{\circ} \mathrm{C}$ foram avaliadas duas temperaturas de deformação (10 e 30\%) na mesma temperatura de deformação $\left(750{ }^{\circ} \mathrm{C}\right)$. Em todos os casos, o tempo de permanência na temperatura de têmpera (Qt) foi de $5 \mathrm{~s}$. O tempo de permanência pequeno foi imposto a fim de evitar produtos de transformação isotérmica abaixo da temperatura $M_{S}$ [206]. A etapa de partição foi realizada à temperatura PT de $400{ }^{\circ} \mathrm{C}$ com tempos de permanência de 100 ou 500 s. Tendo em conta as condições descritas, na Figura 7-3 são apresentados esquematicamente os tratamentos avaliados nesta secção. Nas Figuras 7-3(ac) são apresentados os tratamentos Q\&P e CSQ\&P e nas Figuras 7-3(d-f) os correspondentes aos tratamentos termomecânicos de HSQ\&P.

Tempos curtos de partição são geralmente utilizados a fim de evitar que ocorra transformação bainítica ou engrossamento dos carbonetos. No entanto, considerando que tempos de partição curtos poderiam não ser favoráveis em processos industriais para componentes de aço de grande porte pela dificuldade de manutenção e homogeneização da temperatura e, com o objetivo de analisar in situ o comportamento do parâmetro de rede para tempos maiores de partição, foram desenvolvidos e analisados experimentos de Q\&P e HSQ\&P com tempos de partição de 500 s. Adicionalmente, esses experimentos também permitem comparar as mudanças do parâmetro de rede, a formação de martensita fresca e quantificar a austenita retida para tempos maiores de partição.

Cabe ressaltar que além dos experimentos esquematizados na Figura 7-3, também foram realizados os tratamentos que incluem somente a têmpera $(\mathrm{Q})$ e a deformação a quente (HS), sem o posterior tratamento de partição. Dessa forma, as mesmas condições de austenitização e deformação a alta temperatura apresentadas na Figura 7-3 foram aplicadas nessas amostras, seguidas de resfriamento (têmpera) até a temperatura ambiente a $60{ }^{\circ} \mathrm{C} / \mathrm{s}$. 


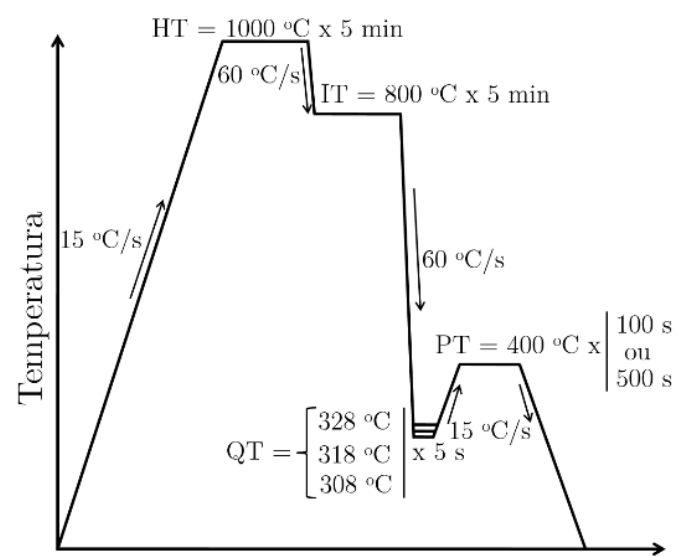

Tempo

(a)

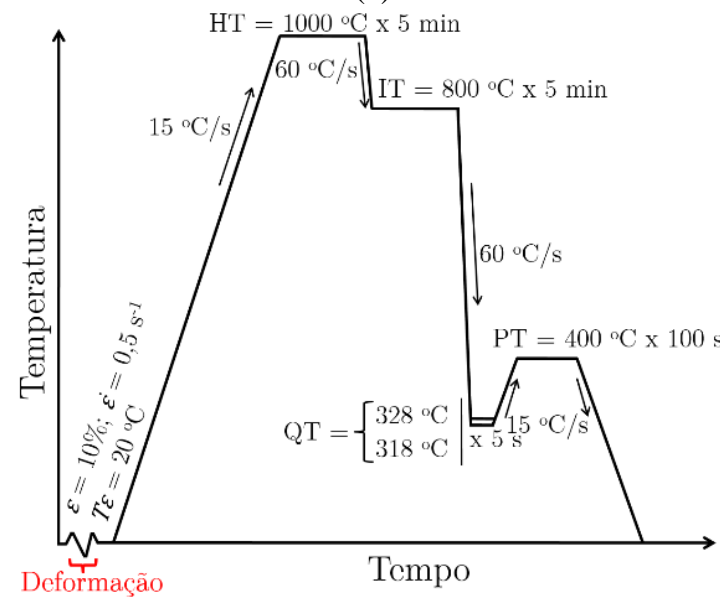

(c)

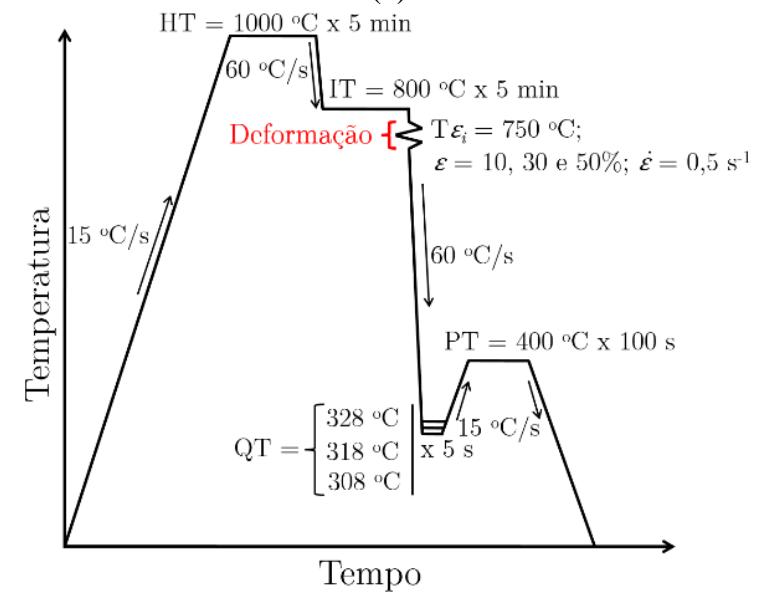

(e)

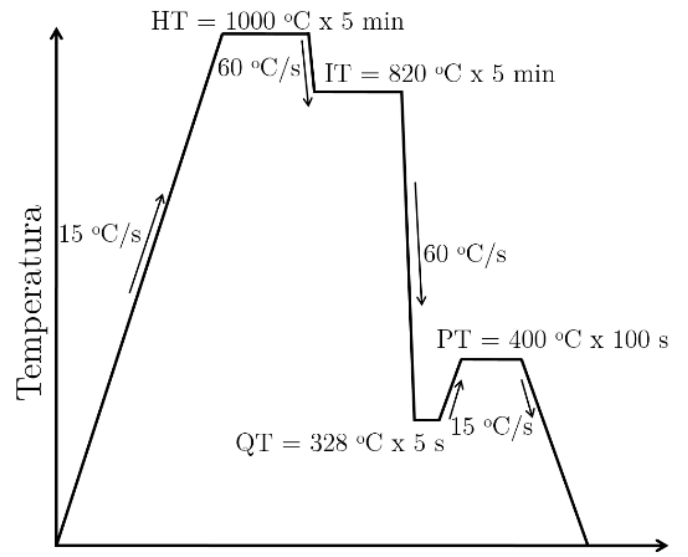

Tempo

(b)

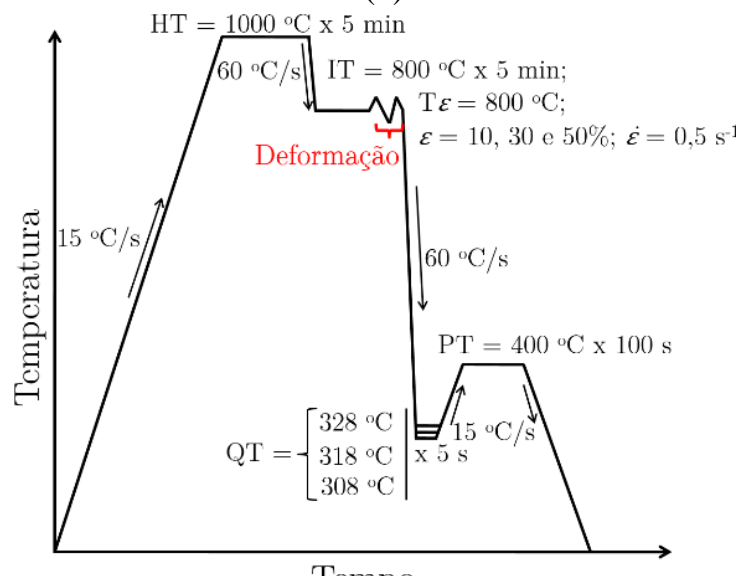

Tempo

(d)

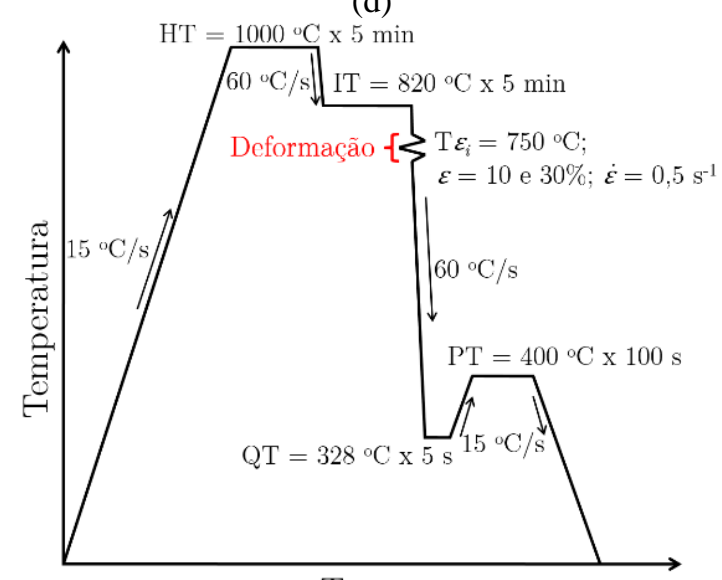

Tempo

(f)

Figura 7-3. Representação esquemática dos tratamentos termomecânicos de têmpera e partição $(\mathrm{Q} \& \mathrm{P})$ e dos tratamentos termomecânicos de deformação a quente seguidos de têmpera e partição (HSQ\&P) aplicados ao aço TRIP. (a) Q\&P, com austenitização intercrítica (IT) a $800^{\circ} \mathrm{C}$ e temperaturas de têmpera (QT) de 328,318 e 308

${ }^{\circ} \mathrm{C}$; (b) Q\&P, com IT a $820^{\circ} \mathrm{C}$ e QT de $328^{\circ} \mathrm{C}$; (c) deformação a frio com posterior tratamento de Q\&P

(CSQ\&P) com IT a $800^{\circ} \mathrm{C}$ e QT de 328 e $318^{\circ} \mathrm{C}$. (d) HSQ\&P, com IT a $800^{\circ} \mathrm{C}$, deformação isotérmica a $800^{\circ} \mathrm{C}$

e QT de 328,318 e $308^{\circ} \mathrm{C}$; (e) HSQ\&P, com IT a $800^{\circ} \mathrm{C}$, deformação não-isotérmica iniciando em $750{ }^{\circ} \mathrm{C}$ seguido de Q\&P, com QT a 328,318 e $308^{\circ} \mathrm{C}$; (f) HSQ\&P, com IT a $820^{\circ} \mathrm{C}$, deformação não-isotérmica iniciando em $750^{\circ} \mathrm{C}$ seguido de Q\&P com QT a $328^{\circ} \mathrm{C}$. HT e PT representam as temperaturas de homogeneização e partição, respectivamente. $T \varepsilon, \varepsilon$ e $\dot{\varepsilon}$ representam a temperatura, quantidade e taxa de deformação, respectivamente. 


\subsubsection{Difração de raios $X$}

Na Figura 7-4 são apresentados os resultados da mudança do parâmetro de rede da austenita em função do tempo (in situ) durante a etapa de partição $\left(400{ }^{\circ} \mathrm{C}\right.$ por $\left.100 \mathrm{~s}\right)$, obtidos usando radiação síncrotron. Para possibilitar a comparação das mudanças das curvas do parâmetro de rede, os resultados foram agrupados de acordo com a temperatura de têmpera (QT) e as figuras foram movimentadas ao longo do eixo das ordenadas. Da comparação entre os tratamentos de Q\&P e HSQ\&P com deformações em 10, 30 e 50\% para as temperaturas de deformação de 750 ${ }^{\circ} \mathrm{C}$ e $800{ }^{\circ} \mathrm{C}$, nas três temperaturas de têmpera utilizadas $\left(308{ }^{\circ} \mathrm{C}, 318{ }^{\circ} \mathrm{C}\right.$ e $\left.328{ }^{\circ} \mathrm{C}\right)$, é possível observar que em todos os casos a deformação promove um menor incremento do parâmetro de rede da austenita no estágio de partição, o que supõe um menor enriquecimento em carbono com o aumento da deformação. Adicionalmente, para as amostras deformadas a $800{ }^{\circ} \mathrm{C}$ (com temperatura de austenitização intercrítica, IT, de $800^{\circ} \mathrm{C}$ ) ocorre um enriquecimento em carbono ligeiramente maior quando comparado com as amostras deformadas a $750{ }^{\circ} \mathrm{C}$.

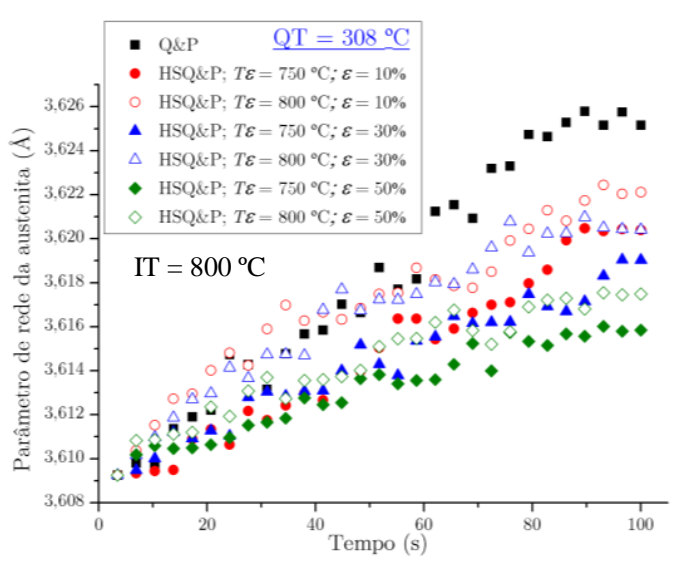

(a)

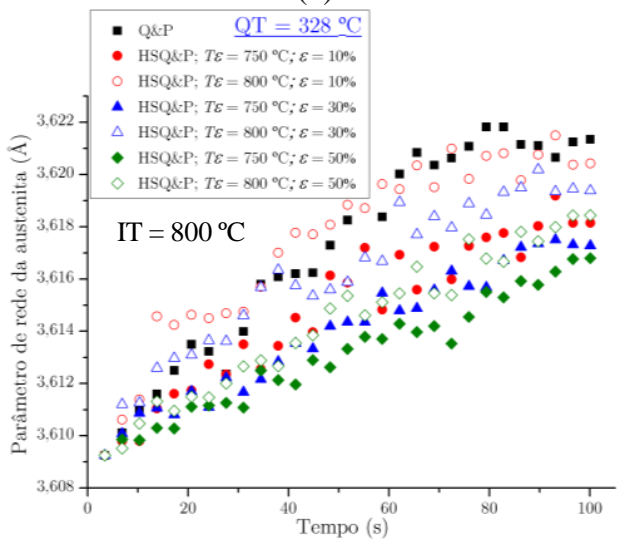

(c)

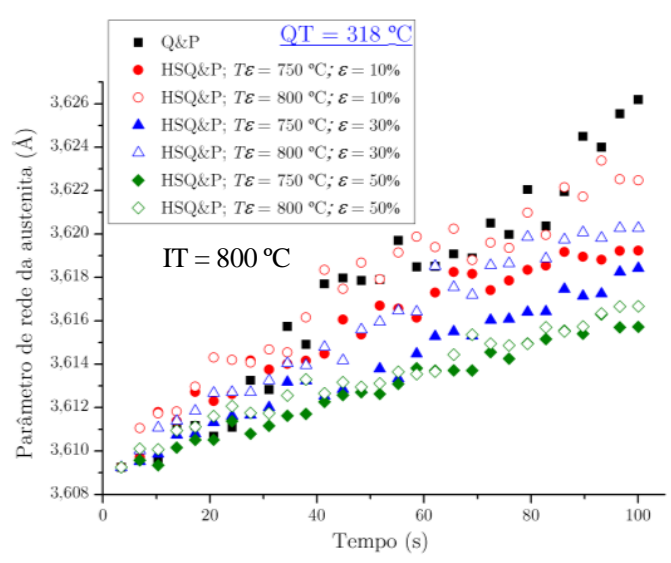

(b)

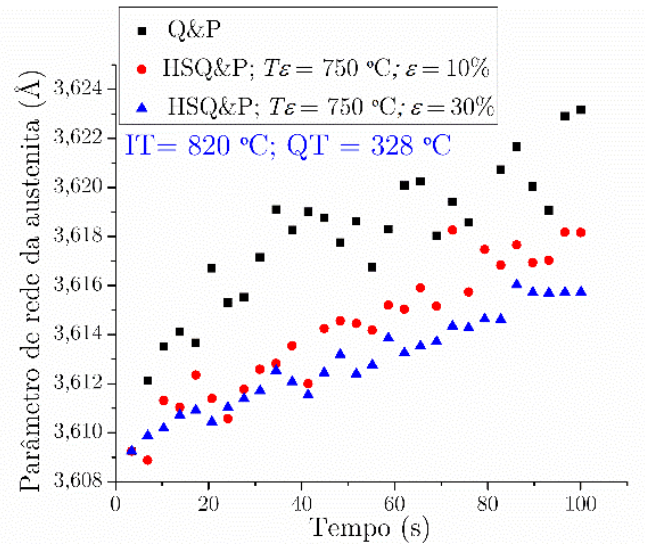

(d)

Figura 7-4. Análise in situ da evolução do parâmetro de rede da austenita durante a etapa de partição. Comparação dos tratamentos de Q\&P e HSQ\&P em função da temperatura de têmpera (QT), da temperatura de deformação $(T \varepsilon)$, e da porcentagem de deformação $(\varepsilon)$. (a) Temperatura e de austenitização intercrítica $($ IT $)=$ $800{ }^{\circ} \mathrm{C}$ e QT $=308^{\circ} \mathrm{C}$; (b) IT $=800^{\circ} \mathrm{C}$ e QT $=318^{\circ} \mathrm{C}$; (c) IT $=800{ }^{\circ} \mathrm{C}$ e QT $=328^{\circ} \mathrm{C}$; (d) IT $=820{ }^{\circ} \mathrm{C}$ e QT $=$ $328^{\circ} \mathrm{C}$. 
Na Figura 7-5 são apresentados os padrões de difração para a amostra na condição como recebida e dos estágios inicial e final durante o processo de partição a $400{ }^{\circ} \mathrm{C}$ por $100 \mathrm{~s}$, da amostra Q\&P austenitizada intercriticamente a $800^{\circ} \mathrm{C}$ e temperada a $328^{\circ} \mathrm{C}$. Os dados foram coletados como imagens 2D usando detector Rayonix e para as análises quantitativas os padrões de difração foram integrados azimutalmente para serem convertidos em valores de intensidade unidimensionais em função do ângulo 20. Dessa forma, as frações volumétricas de austenita no início e no fim do estágio de partição foram calculadas em 17,2\% e 8,4\%, respectivamente.

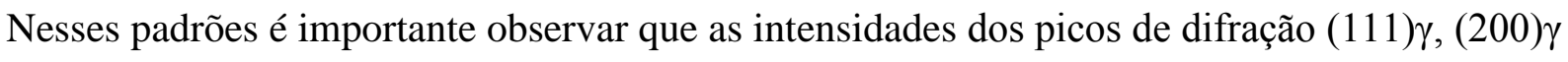
e (220)y correspondentes a austenita são consideravelmente reduzidos durante o estágio de partição. Essa redução indica que embora tenha havido enriquecimento de carbono na austenita, há um consumo dessa fase durante o estágio de partição, produzido, possivelmente, pela formação de bainita.

Adicionalmente, na Figura 7-5 é possível observar que ocorrem variações nas intensidades ao longo dos anéis de difração, principalmente para os correspondentes à fase CCC (ferrita e martensita). Essa variação (regiões do verde ao vermelho nos picos 110 e 200 da $\alpha$ ) é causada pela textura ${ }^{9}$ e pelas deformações plásticas não uniformes presentes no material [35]. Como se observa na Figura 7-5(a) e 7-5(b) a textura está presente desde antes do tratamento térmico (amostra como recebida) e se mantém até o fim do estágio de partição, o que confirma que a textura cristalográfica não surge como consequência do tratamento Q\&P. Em aços avançados de alta resistência, principalmente em aços TRIP, as fases CCC frequentemente apresentam textura cristalográfica após a dupla transformação de $\alpha$ em $\gamma$ e $\gamma$ em $\alpha$ produzida através da recristalização ${ }^{10}$ ou desenvolvida pela deformação da ferrita durante o processo de laminação [207, 208]. Portanto, observa-se que não há uma influência considerável dos parâmetros do processo Q\&P na textura do material. A estimativa da fração volumétrica de austenita, em aços que apresentam textura, exige a utilização de vários picos de difração para minimizar a influência de orientações preferenciais nos resultados [209, 210].

\footnotetext{
${ }^{9}$ A textura pode ser genericamente definida como uma condição na qual a distribuição de orientações não é aleatória [237].

${ }^{10}$ A recristalização pode ser genericamente definida com a eliminação de discordâncias por migração de contornos de alto ângulo, preexistentes na estrutura encruada, ou formados durante o recozimento.
} 


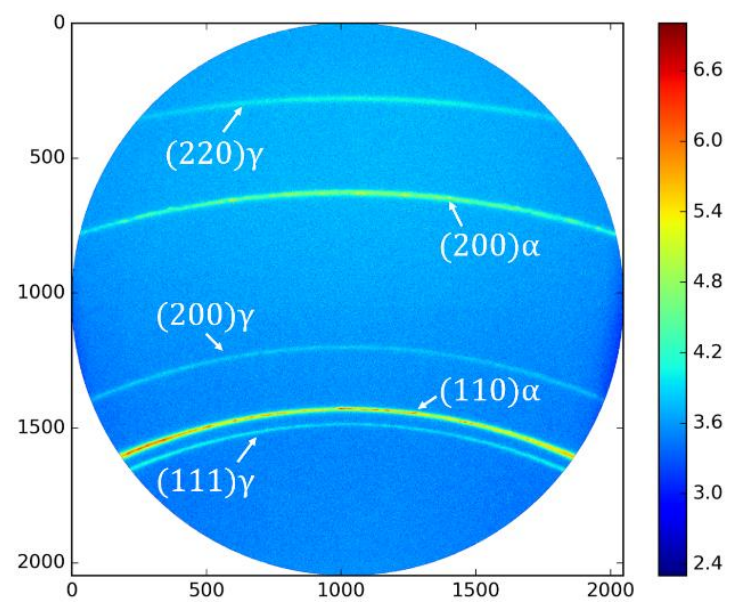

(a)

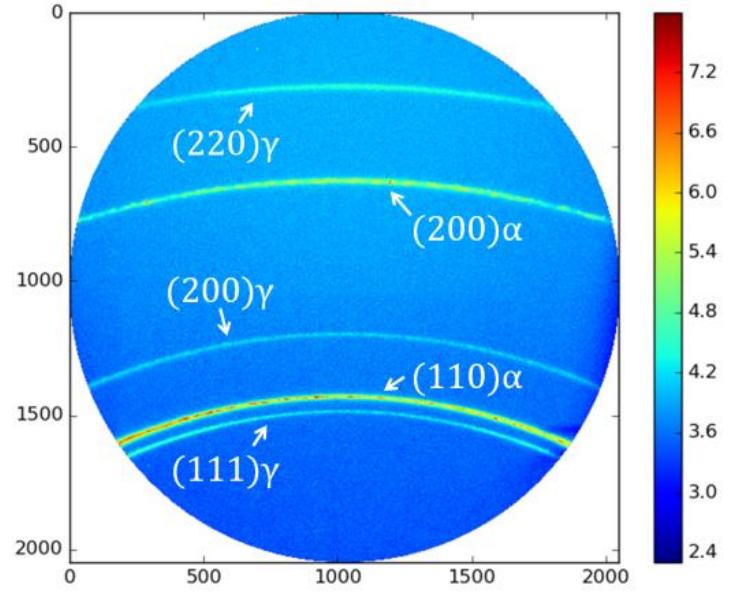

(b)

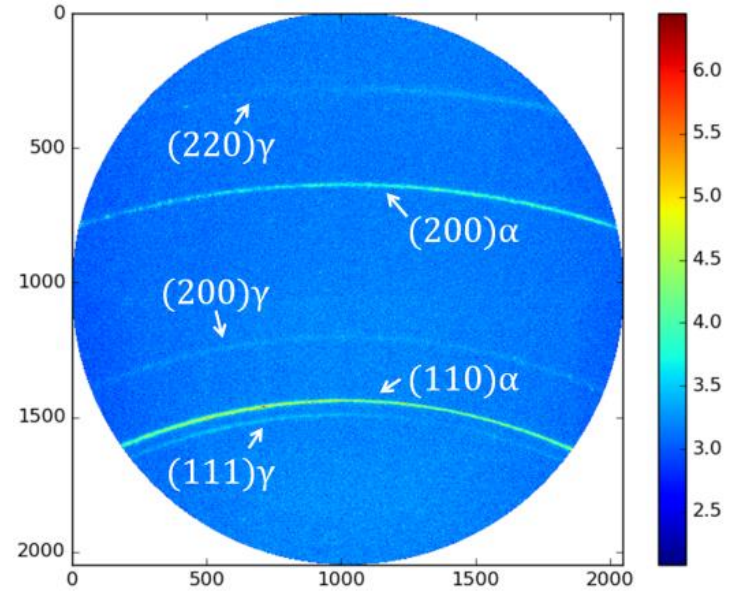

(c)

Figura 7-5. Padrões de difração de raios $\mathrm{X}$ in situ obtidos com detector $2 \mathrm{D}$ mostrando a evolução dos picos de difração da austenita $(\gamma)$ e da ferrita $(\alpha)$, coletados na temperatura ambiente antes do tratamento e a $400{ }^{\circ} \mathrm{C} \mathrm{em}$ função do tempo de partição (100 s). (a) Amostra na condição como recebida; (b) estágio inicial do estágio de partição ( $\mathrm{V} \gamma=17,2 \%)$; (c) estágio final da partição $(\mathrm{V} \gamma=8,4 \%)$. Amostra Q\&P, austenitizada intercriticamente a $800{ }^{\circ} \mathrm{C}$ e temperada a $328^{\circ} \mathrm{C}$.

A Figura 7-6 apresenta a variação do parâmetro de rede da austenita em função do tempo durante o estágio de partição para amostras HSQ\&P deformadas em $30 \%$ e $50 \%$ a $800{ }^{\circ} \mathrm{C}$ e 750 ${ }^{\circ} \mathrm{C}$, temperadas a $318{ }^{\circ} \mathrm{C}$ e $328^{\circ} \mathrm{C}$ e particionadas a $400{ }^{\circ} \mathrm{C}$ por $500 \mathrm{~s}$. Em geral, os resultados para tempos de partição de 500 s mostraram que com o incremento da deformação e a redução da temperatura de deformação o enriquecimento do parâmetro de rede da austenita é reduzido. A difração in situ permite observar com clareza o efeito da deformação no enriquecimento em carbono da austenita. Além disso, os tempos de partição maiores indicam que a maior taxa de variação do parâmetro de rede acontece até aproximadamente $180 \mathrm{~s}$. 


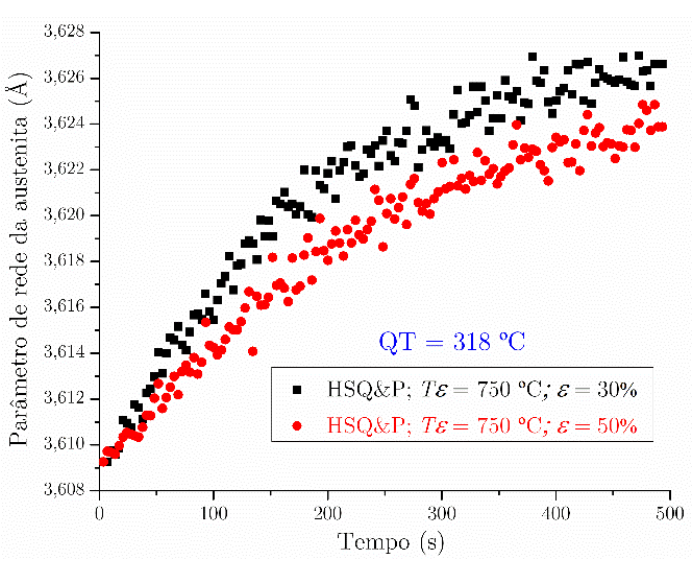

(a)

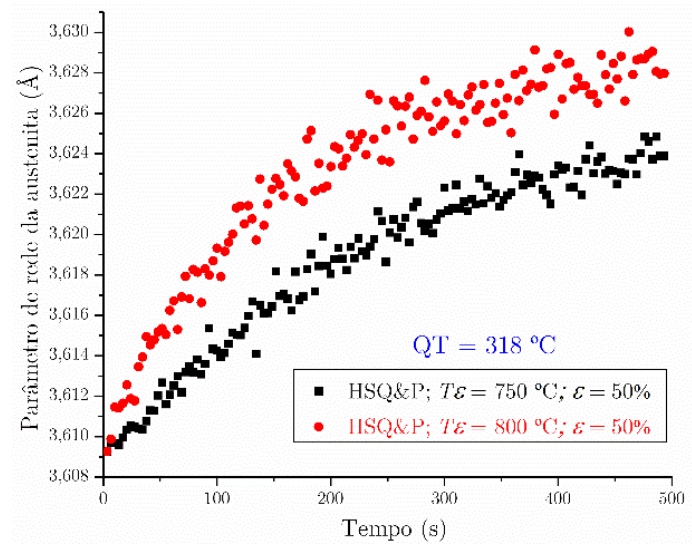

(b)

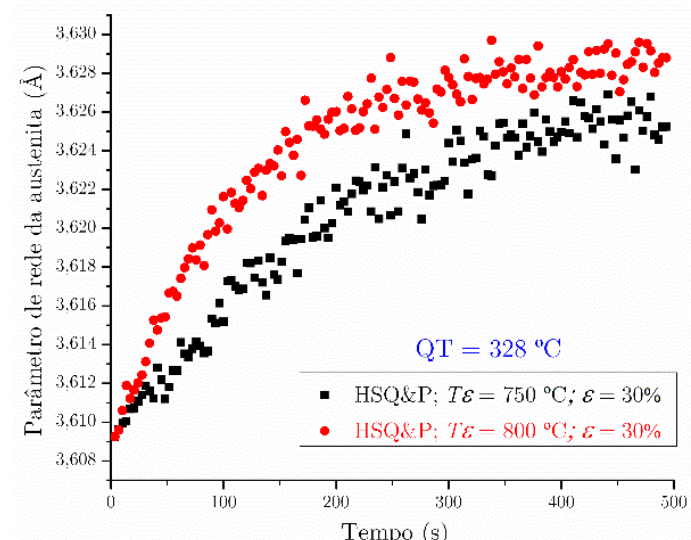

(c)

Figura 7-6. Evolução do teor de carbono dissolvido na austenita em função do tempo de partição (500 s).

Comparação dos tratamentos HSQ\&P em função da temperatura de têmpera (QT), da temperatura de deformação $(T \varepsilon)$, e da porcentagem de deformação $(\varepsilon)$. (a) QT $=318^{\circ} \mathrm{C}$, (b) QT $=318^{\circ} \mathrm{C},(\mathrm{c}) \mathrm{QT}=328^{\circ} \mathrm{C}$. IT $=$ $800^{\circ} \mathrm{C}$.

Pela lei de Bragg sabe-se que a redução dos valores de $2 \theta$ indicam um aumento das distâncias interplanares e, consequentemente, do parâmetro de rede, que, por sua vez, é associado ao enriquecimento em carbono da fase. Esse comportamento é observado na Figura 7-7 onde, usando detector Mythen unidimensional, o deslocamento para valores menores de $2 \theta$ é observado, tanto na amostra Q\&P como na HSQ\&P. Comparando ambas as figuras é importante observar que no processo de Q\&P a intensidade do pico de difração (200) da austenita $(\gamma)$ é consideravelmente reduzido após os $200 \mathrm{~s}$, enquanto no processo HSQ\&P, embora seja igualmente reduzida, conserva uma parcela maior da intensidade até finalizar o processo de partição aos 500 s. Além disso, os resultados da fração volumétrica de austenita na temperatura ambiente dessas amostras foram de 4,3\% para amostra Q\&P e de 10,3\% para amostra HSQ\&P. Esses resultados provam que as amostras deformadas em alta temperatura fornecem maior estabilidade para a austenita, possivelmente em decorrência do maior teor de carbono inicial da austenita por conta da maior quantidade de ferrita, ou pela estabilização mecânica da austenita pela formação de florestas de discordâncias durante a deformação. Ademais, se durante o processo de Q\&P ocorre reação bainítica durante o estágio de partição, 
esse processo se manifesta como um mecanismo adicional no enriquecimento em carbono, embora em contrapartida consuma parte da austenita disponível. A partir dos resultados presume-se que no processo Q\&P a cinética da transferência de átomos de carbono para austenita retida torna-se gradualmente mais lenta na medida em que a quantidade de austenita remanescente é continuamente reduzida pela reação bainítica.

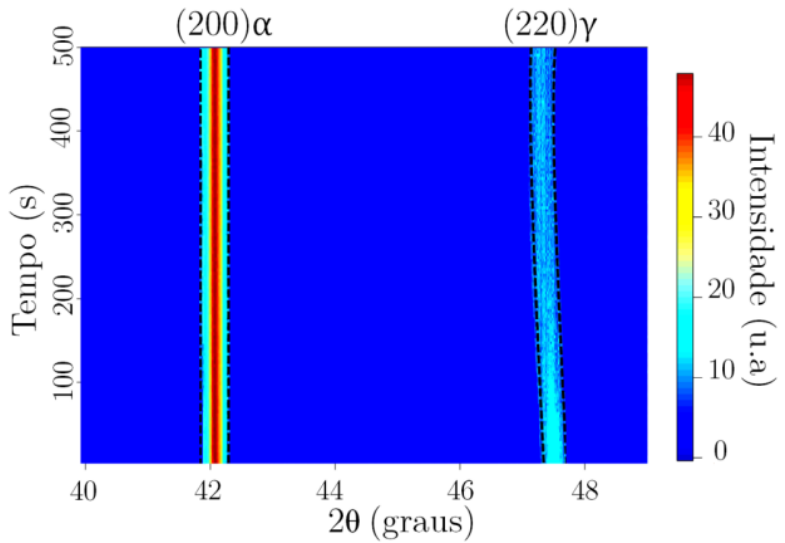

(a)

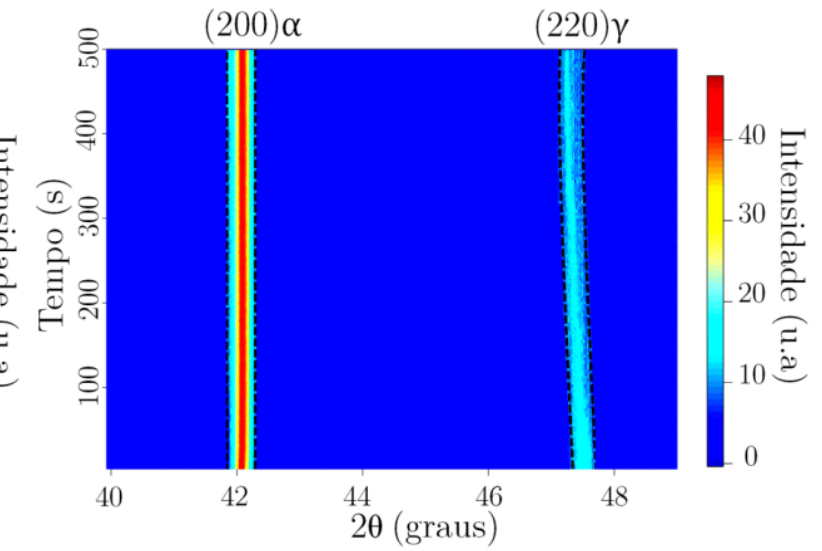

(b)

Figura 7-7. Padrões de difração de raios X in situ mostrando a evolução do picos de difração (200) $\alpha$ e (200) $\gamma$, coletados a $400{ }^{\circ} \mathrm{C}$ em função do tempo de partição (500 s). (a) Q\&P; com temperatura de têmpera de $328^{\circ} \mathrm{C}$; (b) HSQ\&P, deformada a $750{ }^{\circ} \mathrm{C}$ em $30 \%$, e temperada a $328^{\circ} \mathrm{C}$.

Usando a integração das intensidades dos difratogramas (Figura 7-8) obtidas após os diferentes tratamentos térmicos e termomecânicos realizados no aço TRIP e em concordância com as especificações descritas na norma ASTM E 975-03 [113] foram calculadas as frações volumétricas de austenita retida. O cálculo das frações volumétricas de austenita retida é importante para compreender seu efeito no comportamento mecânico do material, principalmente na ductilidade do material favorecida pelo efeito TRIP. 


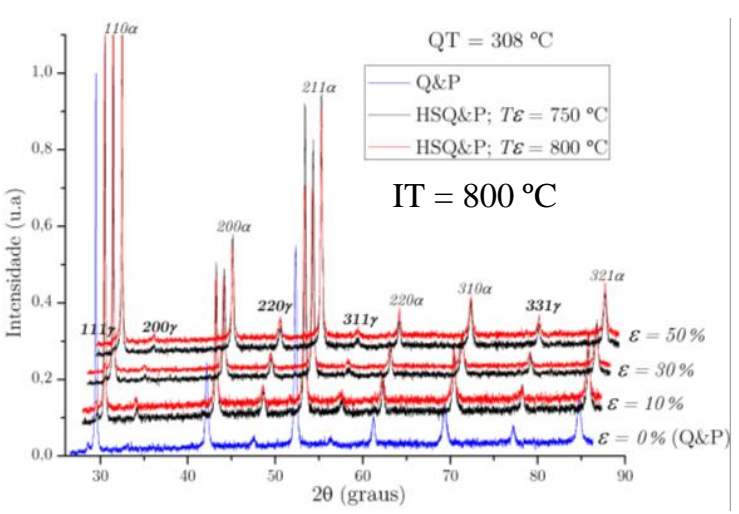

(a)

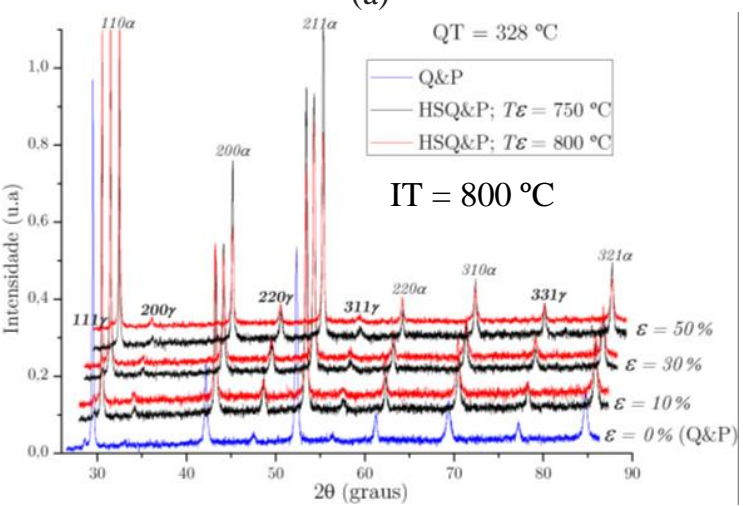

(c)

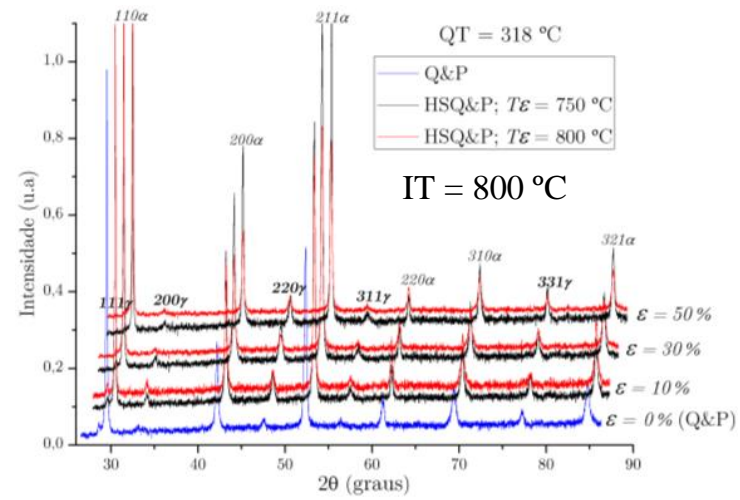

(b)

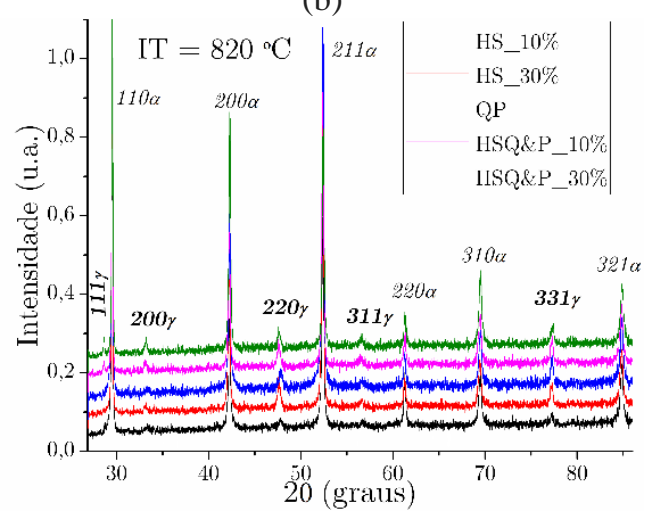

(d)

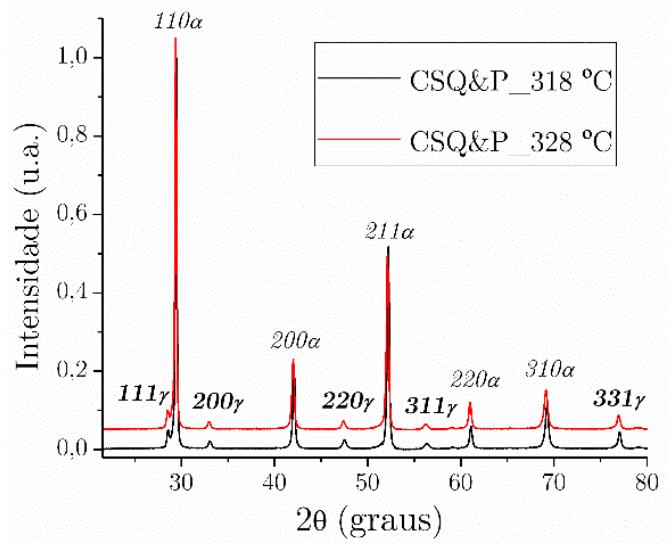

(e)

Figura 7-8. Comparação dos difratogramas de acordo com a temperatura intercrítica de austenitização (IT) e de têmpera (QT) nas amostras tratadas por têmpera e partição (Q\&P), processo de estampagem a quente (HS) ou a frio (CS) e de estampagem a quente seguido de têmpera e partição (HSQ\&P) particionadas a $400{ }^{\circ} \mathrm{C}$ por $100 \mathrm{~s}$.

(a) IT $=800{ }^{\circ} \mathrm{C}$, QT $=308^{\circ} \mathrm{C}$, (b) IT $=800^{\circ} \mathrm{C}$, QT $=318^{\circ} \mathrm{C}$, (c) IT $=800^{\circ} \mathrm{C}$, QT $=328^{\circ} \mathrm{C}$, (d) IT $=820^{\circ} \mathrm{C}$, (e)

CSQ\&P. TE representa a temperatura de início da deformação e $\varepsilon$ a porcentagem de deformação.

Na Figura 7-9 são apresentados os resultados das frações volumétricas de austenita retida, correspondentes aos aços que sofreram tratamentos de Q\&P (incluindo os HSQ\&P), superpostas à fração de austenita retida em função da temperatura de partição (curva preta), prevista pelo modelo de Speer et al. [1]. Os resultados experimentais obtidos por difração de raios X são apresentados em pontos com diversas formas e cores, e superpostos na curva do modelo, a fim de identificar o tratamento realizado e os resultados com maiores e menores frações volumétricas de austenita retida. De forma geral, se observa que os processos que 
incluem a etapa de partição com prévia deformação em alta temperatura (os HSQ\&P) apresentam as maiores porcentagens de austenita retida. Esses resultados sugerem que nas amostras deformadas houve um maior aumento no teor em carbono da austenita, produzido pela formação de ferrita durante a deformação (efeito DIFT), que contribuiu com a estabilização da austenita na temperatura ambiente. Além disso, a porcentagem de austenita retida aumentou gradualmente quando a amostra foi deformada até 30\%, no entanto, houve uma diminuição quando a deformação aumento de $30 \%$ para $50 \%$. A maior porcentagem de austenita retida $(\approx$ $17,5 \%$ ) foi calculada na amostra HSQ\&P austenitizada intercriticamente a $820^{\circ} \mathrm{C}$, deformada a $750^{\circ} \mathrm{C}$ em $30 \%$ e temperada a $328^{\circ} \mathrm{C}$ (temperatura de partição de $400{ }^{\circ} \mathrm{C}$ por $100 \mathrm{~s}$ ), enquanto que a menor porcentagem de austenita retida $(\approx 4,3 \%)$ foi encontrada na amostra $\mathrm{Q} \& \mathrm{P}$, temperada a $308^{\circ} \mathrm{C}$ (com temperatura de partição de $400{ }^{\circ} \mathrm{C}$ por 500 s). Esses resultados podem ser explicados pela maior contribuição em carbono da amostra austenitizada intercriticamente numa temperatura levemente superior $\left(+20^{\circ} \mathrm{C}\right)$ o que poderia estar contribuindo em uma maior estabilidade da austenita. Já no caso da amostra com menor porcentagem de austenita retida, como foi observado nos resultados usando radiação síncrotron, é evidente que há um consumo da fase durante o estágio de partição para tempos prolongados de partição, provavelmente pela formação de bainita. Além disso, a menor temperatura de têmpera implica em uma menor quantidade de austenita não-transformada no início da etapa de partição. Por outro lado, é interessante observar, que de forma geral, os resultados mostram que as maiores porcentagens de austenita retida tanto nas amostras Q\&P como nas HSQ\&P foram obtidas para a temperatura ótima prevista pelo modelo de Speer et al. [1]. 


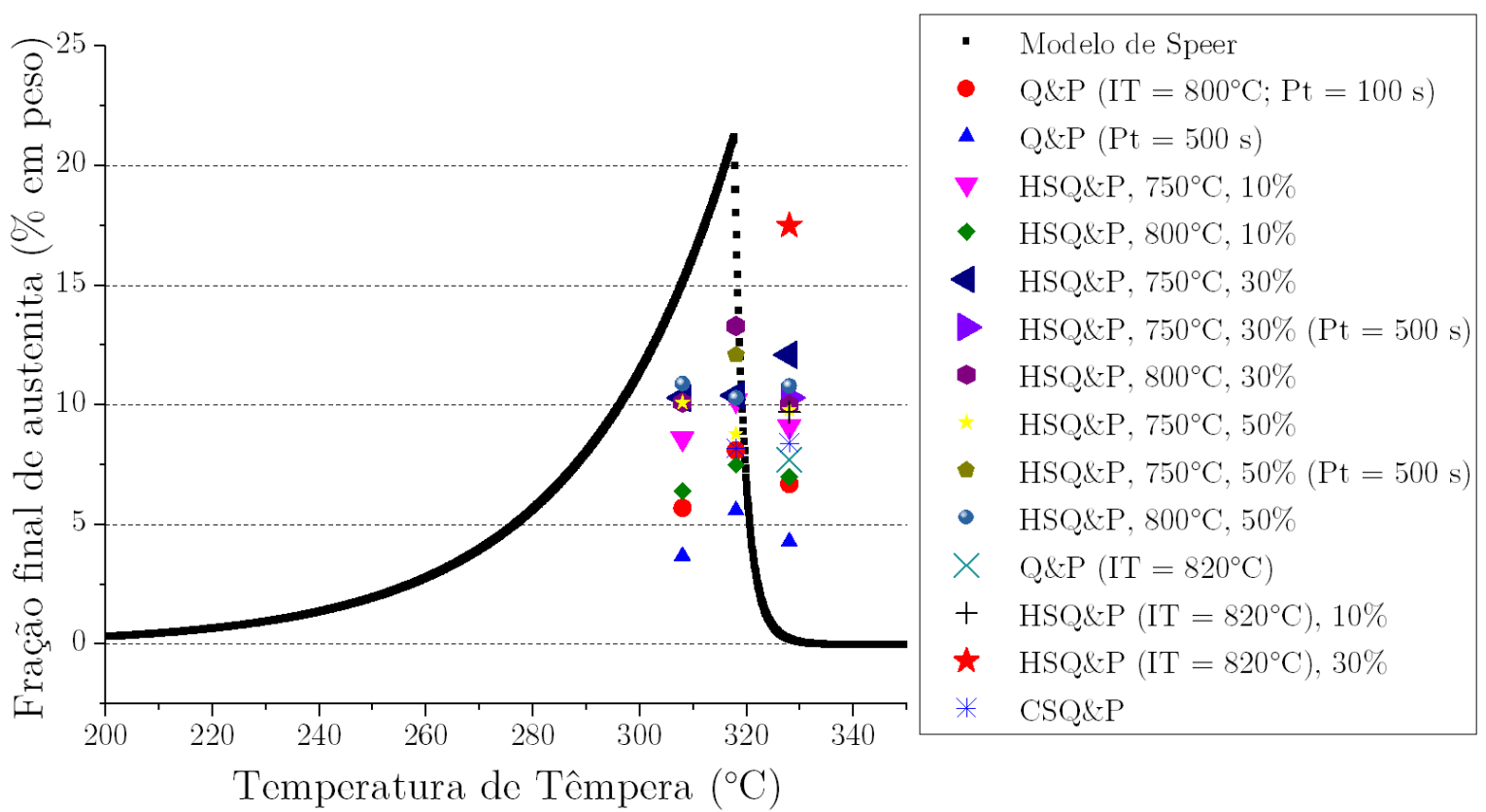

Figura 7-9. Frações volumétricas de austenita retida em função das temperaturas de austenitização intercrítica (IT), de têmpera (QT), das temperaturas e quantidades de deformação e do tempo de partição (Pt), após a aplicação dos processos de têmpera e partição $(\mathrm{Q} \& \mathrm{P})$ e de deformação a quente seguido por têmpera e partição (HSQ\&P). A curva preta representa a fração volumétrica de austenita em função da temperatura de têmpera prevista pelo modelo de Speer et al. [1]

Na Tabela 7-1 são apresentadas as médias das temperaturas de início de transformação martensítica $\left(M_{S}\right)$, determinadas durante o resfriamento a partir das curvas de dilatometria, para cada um dos experimentos térmicos e termomecânicos realizados. Observa-se que com a diminuição da temperatura de deformação e o aumento da deformação ocorre diminuição da temperatura $M_{s}$, principalmente até a deformação de 30\%. A análise de variância (ANOVA, do inglês Analysis of Variance) com dois fatores (two-way) considerou os valores de $M_{s}$ para cada condição de tratamento térmico. A ANOVA considerou como variável-resposta a temperatura $M_{S}$ e como fatores de entrada a temperatura de deformação e a porcentagem de deformação, verificando quais fatores afetam significativamente a variável-resposta através do valor- $p$ (determinado pela área sob a curva da distribuição $\mathrm{F}$ de Snedecor). Constatou-se que para as amostras HSQ\&P a influência da temperatura de deformação é mais significativa no resultado da temperatura $M_{S}$ do que a porcentagem de deformação, visto que o valor- $p$ do fator temperatura de deformação foi de 0,001 , ao passo que o valor- $p$ da porcentagem de deformação foi de 0,280 . Considerando que a confiabilidade adotada foi de $95 \%$, nota-se então que somente a temperatura de deformação afeta significativamente a temperatura $M_{s}$. Como justificativa para os resultados, a deformação da austenita em alta temperatura promove a transformação de fase difusional $\left(\alpha_{D I F T}\right.$, ferrita DIFT), o que resulta em um maior enriquecimento em carbono da austenita na transformada e na redução da temperatura $M_{S}$. 
Tabela 7-1. Temperatura de início da transformação martensítica $\left(M_{S}\right)$, para as amostras Q\&P e HSQ\&P.

\begin{tabular}{|c|c|c|c|c|c|}
\hline \multirow{3}{*}{$\begin{array}{l}\text { Temperatura de } \\
\text { austenitização } \\
\text { intercrítica (IT) }\end{array}$} & \multirow{3}{*}{$\begin{array}{l}M_{s} \text { para o } \\
\text { tratamento de Q\&P }\end{array}$} & \multicolumn{4}{|c|}{$M_{s}$ para os tratamentos incluindo prévia deformação (HSQ\&P) } \\
\hline & & \multirow{2}{*}{$\begin{array}{l}\text { Temperatura de } \\
\text { deformação }\end{array}$} & \multicolumn{3}{|c|}{ Porcentagem de deformação } \\
\hline & & & $10 \%$ & $30 \%$ & $50 \%$ \\
\hline \multirow[b]{2}{*}{$800^{\circ} \mathrm{C}$} & \multirow[b]{2}{*}{$388 \pm 4$} & $800^{\circ} \mathrm{C}$ & $383 \pm 11$ & $375 \pm 6$ & $382 \pm 11$ \\
\hline & & $750^{\circ} \mathrm{C}$ & $375 \pm 8$ & $365 \pm 3$ & $366 \pm 7$ \\
\hline $820^{\circ} \mathrm{C}$ & $379 \pm 1$ & $750^{\circ} \mathrm{C}$ & $372 \pm 3$ & $363 \pm 1$ & - \\
\hline
\end{tabular}

Adicionalmente foi feito uma ANOVA considerando um único fator (\% deformação) e 4 níveis $(0 \%, 10 \%, 30 \%$ e $50 \%)$ para comparar a variável - resposta $\left(M_{S}\right)$ das amostras Q\&P com HSQ\&P. Observou-se que existe uma diferença estatisticamente significativa na variávelresposta $M_{S}$, dado que o valor- $p$ do fator de porcentagem de deformação foi de 0,02 , inferior a 0,050, correspondente ao $\alpha$-erro com confiabilidade de 95\%. Isso sugere que ao alterar a porcentagem de deformação $(0 \%, 10 \%, 30 \%$ e $50 \%)$ a média da temperatura $M_{S}$ não é estatisticamente igual. Foi observado também que a influência na temperatura $M_{S}$ é maior (valor- $p=0,00$ ) quando a amostra é previamente deformada a $750{ }^{\circ} \mathrm{C}$ do que a $800{ }^{\circ} \mathrm{C}$. Isso indica que a deformação a $800{ }^{\circ} \mathrm{C}$ não causa um enriquecimento em carbono da austenita suficiente, para causar mudanças consideráveis na temperatura $M_{S}$.

Como foi comentando, a deformação da austenita promove a formação de ferrita DIFT que resulta no enriquecimento em carbono da austenita e na diminuição da temperatura $M_{S}$. Esse mecanismo explica a diminuição da temperatura $M_{S}$ quando a deformação aumenta de $0(\mathrm{Q} \& \mathrm{P})$ para $10 \%$ e de $10 \%$ para $30 \%$. Por outro lado, é observado um aumento de $\approx 7{ }^{\circ} \mathrm{C}$ na temperatura $M_{S}$ quando a deformação a $800{ }^{\circ} \mathrm{C}$ aumentou de $30 \%$ para $50 \%$. Quando a austenita é deformada uma componente de energia livre mecânica $\left(\Delta G_{M}\right)$ é adicionada à mudança da energia livre química $\left(\Delta G_{Q}\right)$, aumentando a diferença na energia livre total $\left(\Delta G_{T}\right)$ necessária para que aconteça a transformação. Esse aumento na energia livre total na austenita induzida pela deformação implica na elevação da temperatura $M_{S}$, como esquematizado na Figura 7-10. Adicionalmente, como sugerem Nikravesh et al. [211] e Wang et al. [212], o resultado também pode ser explicado pela diminuição da estabilidade da austenita com aumento da recristalização dinâmica causada pelos efeitos da redução do tamanho do grão e da distribuição e densidade de defeitos, especialmente na região dos contornos de grão, produzidos com o aumento da deformação. Por sua vez, Huang et al. [213] propõem que discordâncias acumuladas próximas aos contornos dos grãos de austenita contribuem para o aumento da temperatura $M_{S}$, enquanto as discordâncias intragranulares (as quais podem ser rearranjadas para formar subgrãos no 
interior dos graõs, causando seu refinamento) tem um efeito contrário, diminuição da $M_{s}$. Não obstante, existem outros fatores, além da composição química ou da recristalização dinâmica que podem influenciar na mudança dos valores da temperatura $M_{s}$. Também podem influenciar a temperatura $M_{S}$ as taxas de resfriamento e deformação, o tamanho de grão, as tensões elásticas e plásticas, os defeitos microestruturais e até certos tipos de contornos de grão da austenita [214].

Portanto, a partir dos resultados da temperatura $M_{s}$ obtidos é possível concluir que mesmo podendo coexistir diferentes fenômenos que implicam na mudança dessa temperatura, o enriquecimento em carbono da austenita parece ser o fenômeno predominante para baixas deformações $(\leq 30 \%)$, enquanto o aumento da energia livre total pela criação de uma força motriz mecânica causada pela deformação parece ser preponderante para altas porcentagens de deformação.

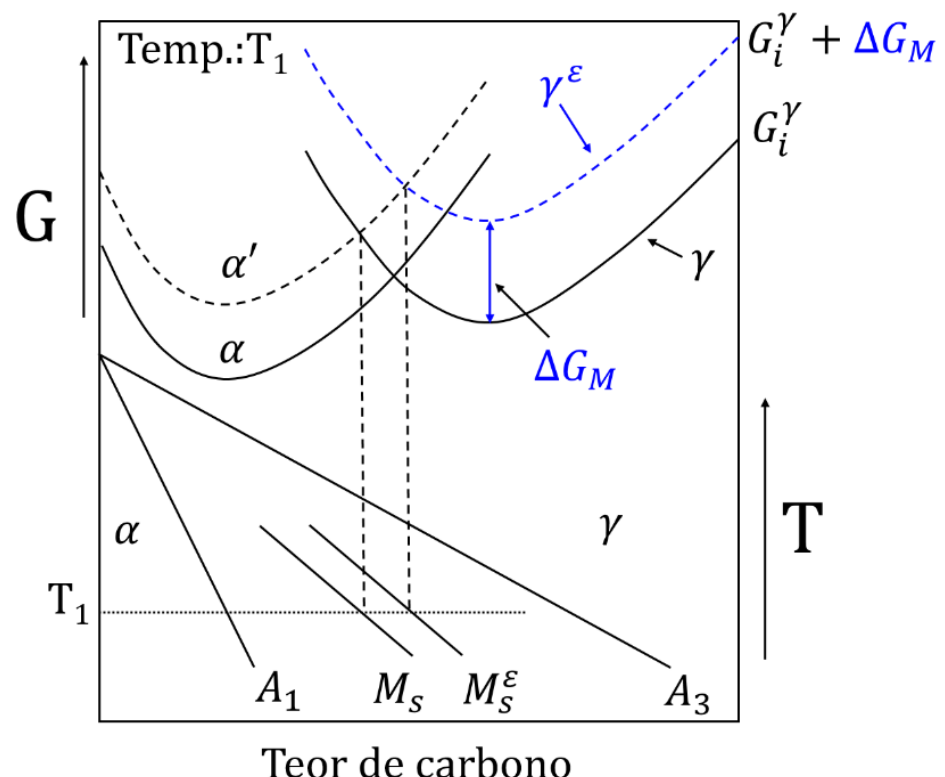

Figura 7-10. Representação esquemática da variação da energia livre de Gibbs $(G)$ e da temperatura $(T)$ para a martensita $\left(\alpha^{\prime}\right)$, ferrita $(\alpha)$ e austenita com deformação $\left(\gamma^{\varepsilon}\right)$ e sem deformação $(\gamma)$, em função do teor de carbono. $M_{S}$ e $M_{S}^{\varepsilon}$ representam as temperaturas de início da transformação martensítica sem deformação e com deformação, respectivamente.

Os resultados de difração de raios $\mathrm{X}$ e do enriquecimento em carbono da austenita são importantes devido à importância que representa a estabilidade mecânica da austenita nos aços TRIP. Essa estabilidade mecânica está relacionada à deformação plástica da austenita que acontece antes de sua transformação, a qual retarda o crescimento da martensita [215,216]. Na estabilização mecânica, o movimento da interface martensita/austenita ou bainita/austenita é bloqueado principalmente pelos emaranhados de discordâncias da austenita deformada [217] ou pela interseção entre as discordâncias de transformação e a alta densidade de discordâncias 
causadas pela deformação da austenita em alta temperatura [218]. De acordo com essa teoria, o início da estabilização mecânica pode ser previsto pelo equilíbrio entre a força que ativa o movimento da interface contra a resistência do emaranhado de discordâncias. Portanto, da mesma forma que o escorregamento de discordâncias é dificultado pelos emaranhados de discordâncias, qualquer obstáculo na trajetória da interface irá impedir o seu movimento. Como se sabe, a transformação martensítica ocorre através da movimentação de uma interface semicoerente, formada por discordâncias que têm seus vetores de Burgers normais ao plano da interface, podendo então se movimentar por escorregamento. A estabilização mecânica tem sido encontrada em fases em forma de placas ou fases criadas por transformações com cisalhamento do tipo "deslocativa" (as vezes chamada "displaciva", pelo neologismo proveniente do termo displacive), como é o caso da martensita ou da ferrita bainítica ou de Widmanstätten. Já no caso das transformações reconstrutivas ou difusivas, como por exemplo, a ferrita alotriomórfica, elas são aceleradas se a fase matriz (austenita) é deformada previamente. Isso pode ser explicado pelo aumento da densidade dos sítios de nucleação e pela destruição dos defeitos introduzidos pela deformação, quando a nova fase cresce, como acontece na recristalização onde a energia armazenada no material é a força motriz, e é, portanto, acelerada quando a energia é grande o suficiente. Enquanto nas transformações reconstrutivas a eliminação dos defeitos gerados pela deformação à frente da interface em movimento contribui na força motriz, nas transformações do tipo deslocativas os defeitos são herdados pelas placas em crescimento e, portanto, não contribuem para a força motriz. Dessa forma, quando a densidade de barreiras presentes na austenita se torna muito grande não há potencial termodinâmico suficiente para que o crescimento da martensita seja possível ou para que ocorra o cisalhamento do volume que causa a transformação martensítica, contribuindo para a estabilidade mecânica dos grãos de austenita $[219,220]$.

A estabilização mecânica e química da austenita também explica a diminuição da temperatura $M_{S}$ (Tabela 7-1), principalmente na temperatura de deformação de $750{ }^{\circ} \mathrm{C}$, na qual, provavelmente, houve um maior enriquecimento em carbono da austenita causado pela transformação difusiva, diminuição do tamanho de grão e um aumento na densidade discordâncias da austenita, o que causaria uma maior resistência ao cisalhamento da rede. Não obstante, esse efeito não é significativo nos processos de deformação isotérmica $\left(800{ }^{\circ} \mathrm{C}\right)$ devido, provavelmente, ao fato de que a quantidade de carbono particionado para austenita durante a deformação não é suficiente para mudar consideravelmente a temperatura $M_{S}$ e a uma menor formação da densidade de discordâncias na austenita em temperaturas mais altas. Em todo caso, a diminuição da temperatura $M_{s}$ com a deformação (principalmente quando a 
deformação aumenta de $0 \% \rightarrow 10 \% \rightarrow 30$ ), apresentada na Tabela 7-1, indica um aumento da estabilidade da austenita causada pela prévia deformação em alta temperatura.

\subsubsection{Caracterização microestrutural}

\subsubsection{Microscopia óptica}

Imagens obtidas por microscopia óptica de alguns dos experimentos realizados são apresentadas nas Figuras 7-11 e 7-12. Na Figura 7-11 são mostradas algumas das micrografias das amostras após os tratamentos de têmpera $(\mathrm{Q})$, têmpera e partição $(\mathrm{Q} \& \mathrm{P})$ e estampagem a quente (HS) e na Figura 7-12 as correspondentes a alguns dos experimentos do processo combinado de estampagem a quente e têmpera e partição (HSQ\&P). Nessas figuras pode-se distinguir principalmente as regiões de martensita, com tonalidade marrom escura, de bainita, na forma de filmes de tonalidade clara, e de ferrita epitaxial (formada na temperatura intercrítica) ou DIFT (produzida pela deformação em alta temperatura) com tonalidade branca em formas poligonais. Nessas micrografias é possível observar que nas amostras que sofreram deformação há um aumento evidente na formação de ferrita. Isso acontece porque a cinética da nucleação de ferrita é acelerada pela deformação da austenita devido: ao aumento da força motriz causada pela energia de deformação armazenada, à aceleração da difusão de carbono na austenita e ao aumento de sítios de nucleação no interior dos grãos do austenita [99]. Esses defeitos aumentam localmente a energia livre de Gibbs, desestabilizando a austenita e acelerando a cinética da transformação ferrítica [101]. Esse aumento da ferrita também ocorre com o aumento da porcentagem da deformação e com a diminuição da temperatura de deformação. Segundo Ghosh et al. [221] com o aumento da temperatura de deformação há diminuição da força motriz química para que ocorra transformação $\gamma \rightarrow \alpha$. Adicionalmente, a temperatura de deformação afeta a natureza e densidade dos defeitos intragranulares [222] e o refino dos grãos de ferrita.

Várias tentativas para identificação de austenita retida usando diversos reagentes metalográficos (LePera, Klemm e Picral com variações de concentração e proporção de seus componentes), tempos de permanência, combinação de ataques e luz polarizada foram realizadas. Todavia, esses ensaios não foram bem sucedidos ou apresentavam dúvida na interpretação. Dessa forma, optou-se por usar microscopia eletrônica de varredura e a difração de elétrons retroespalhados para uma caracterização mais objetiva da austenita retida e para posterior análise das fases por estereologia quantitativa. Assim, embora não tenha sido possível distinguir a austenita na forma de blocos e filmes por meio de microscopia óptica, devido a seu 
menor aumento, a técnica ajudou a visualizar a distribuição e homogeneidade microestrutural após os tratamentos térmicos e termomecânicos realizados.

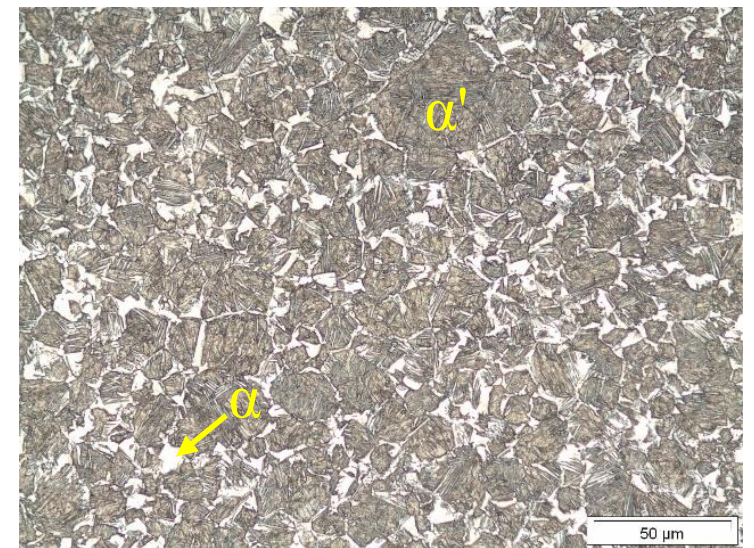

(a)

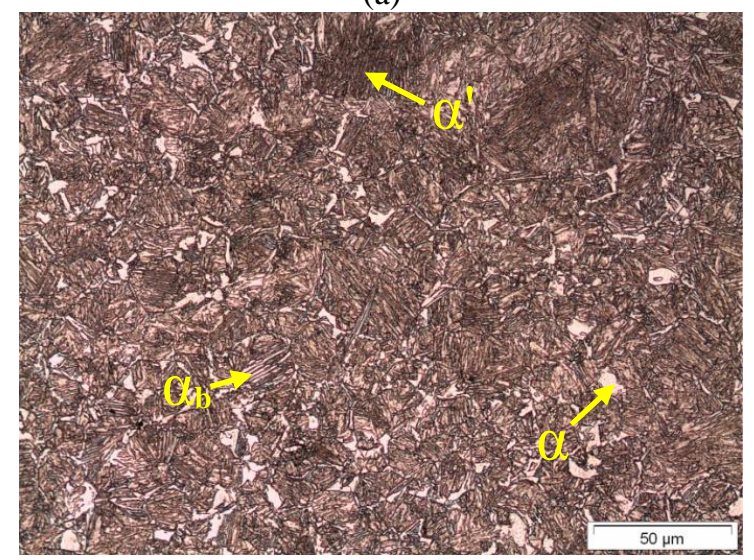

(c)

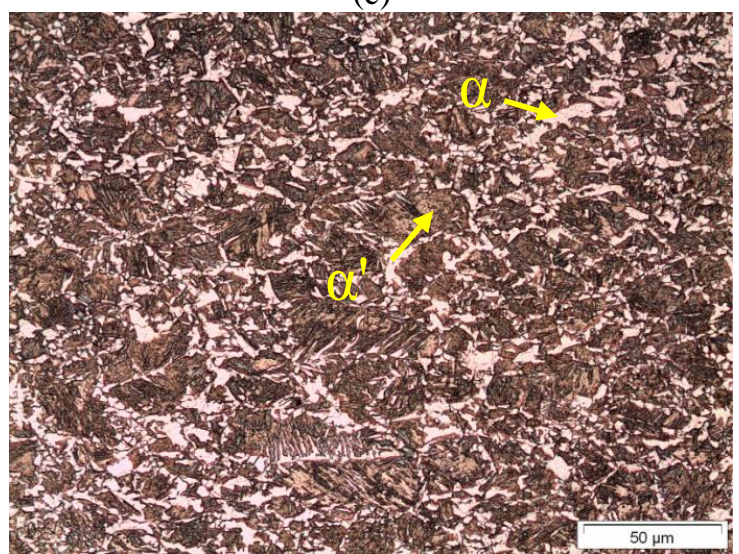

(e)

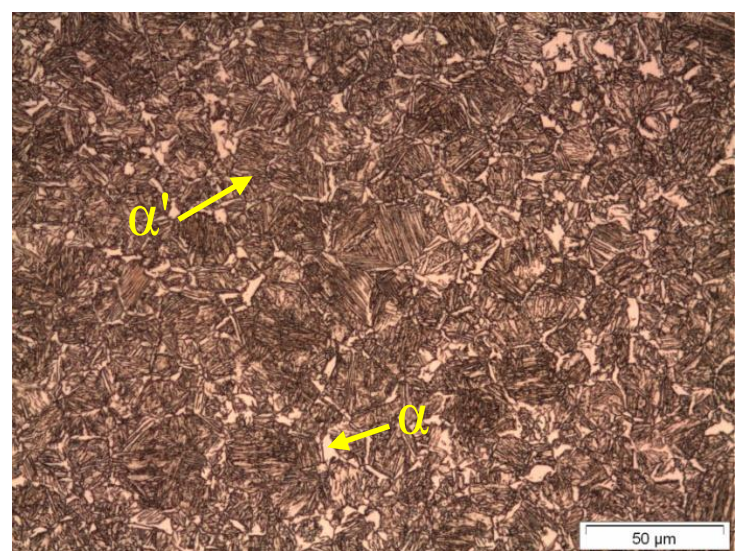

(b)

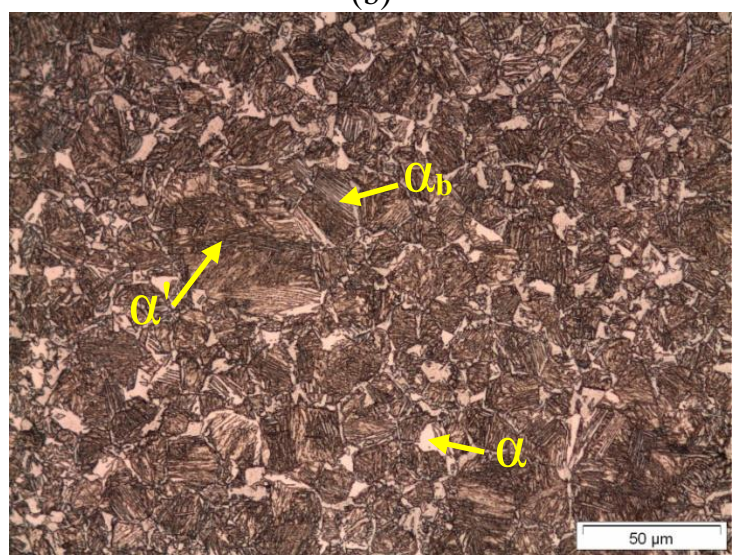

(d)

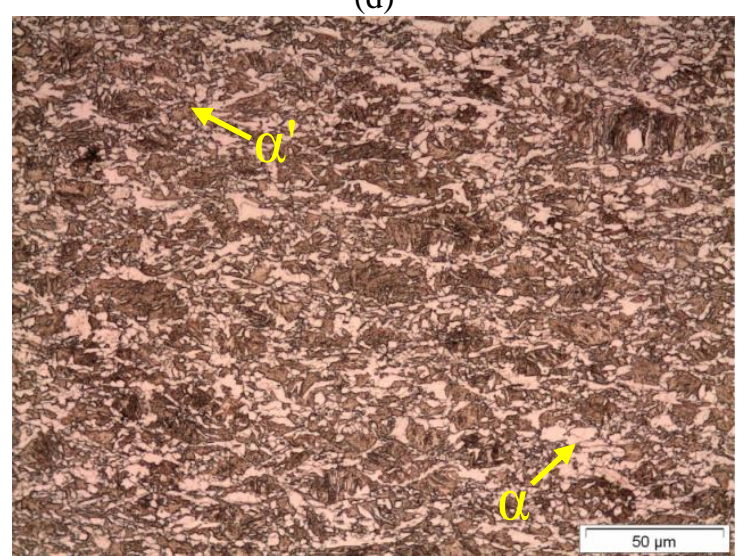

(f)

Figura 7-11. Imagens obtidas por microscopia óptica do aço TRIP, após os tratamentos de têmpera (Q), têmpera e partição (Q\&P) e estampagem a quente (HS), com prévia austenitização intercrítica a $800{ }^{\circ} \mathrm{C}$ : (a) Q; (b) Q\&P, com Q a $308^{\circ} \mathrm{C}$; (c) Q\&P, com Q a $318^{\circ} \mathrm{C}$; (d) Q\&P, com Q a $328^{\circ} \mathrm{C}$; (e) HS, com deformação em $30 \%$ a 750

${ }^{\circ} \mathrm{C}$ e (f) HS, com deformação em $50 \%$ a $750{ }^{\circ} \mathrm{C} . \alpha^{\prime}, \alpha_{\mathrm{b}}, \alpha$ e $\gamma$ indicam martensita, ferrita-bainítica, ferrita e austenita, respectivamente. Ataque: Nital $2 \%$. 


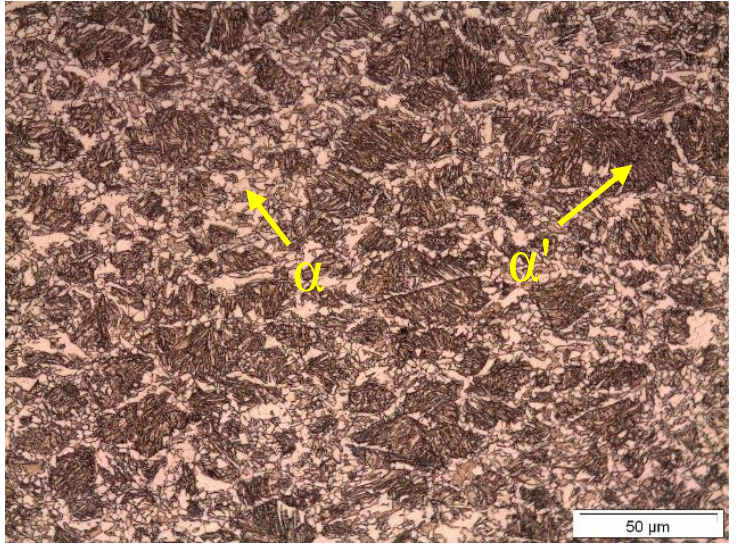

(a)

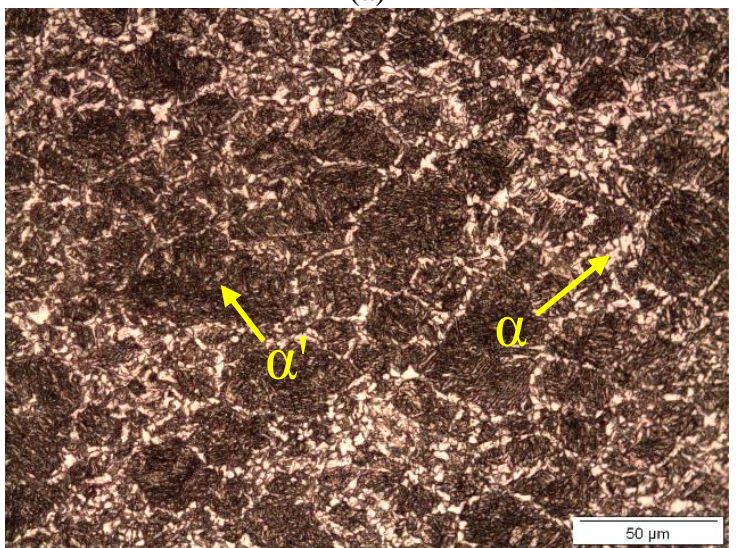

(c)

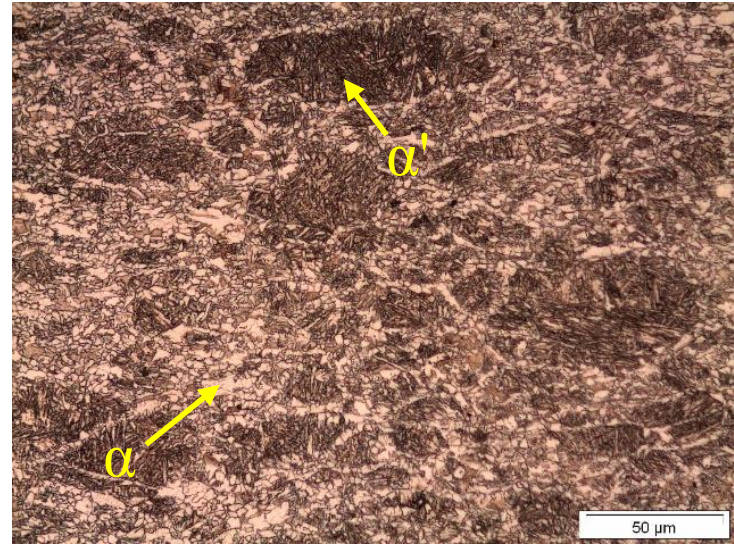

(b)

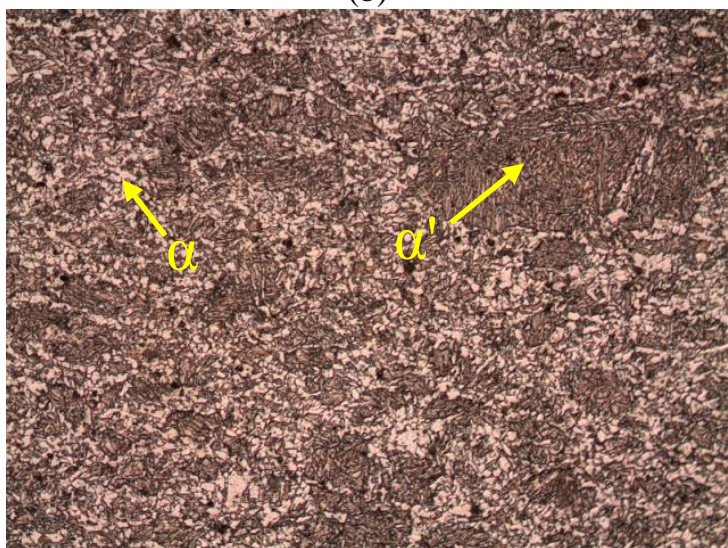

(d)

Figura 7-12. Imagens obtidas por microscopia óptica do aço TRIP, após os tratamentos combinados de estampagem a quente seguido de têmpera e partição (HSQ\&P) com temperatura de têmpera de $318^{\circ} \mathrm{C}$. (a) HSQ\&P, com deformação em $30 \%$ a $750{ }^{\circ} \mathrm{C}$; (b) HSQ\&P, com deformação em $50 \%$ a $750{ }^{\circ} \mathrm{C}$; (c) HSQ\&P, com deformação em $30 \%$ a $800^{\circ} \mathrm{C}$ e (d) HSQ\&P, com deformação em $50 \%$ a $800{ }^{\circ} \mathrm{C}$. $\alpha^{\prime}$ e $\alpha$ indicam martensita e ferrita, respectivamente. Ataque: Nital $2 \%$.

\subsubsection{Microscopia eletrônica de varredura}

Imagens obtidas por microscopia eletrônica de varredura (MEV) de alguns dos experimentos realizados são apresentadas nas Figuras 7-13 a 7-16. Na Figura 7-13 são mostradas algumas das micrografias das amostras após os tratamentos de têmpera (Q) e de têmpera e partição (Q\&P), com prévia austenitização intercrítica a 800 e $820^{\circ} \mathrm{C}$ e tempos de partição de 100 e $500 \mathrm{~s}$. As imagens da Figura 7-14 correspondem às micrografias das amostras submetidas ao tratamento de estampagem a quente (HS) e nas Figuras 7-15 e 7-16 se observam as imagens de alguns dos experimentos do processo combinado de estampagem a frio ou a quente com posterior tratamento de têmpera e partição (CSQ\&P e HSQ\&P). Em geral, nessas imagens se observa a ferrita $(\alpha)$ em baixo relevo e em tonalidade mais escura, localizada nos contornos de grão da martensita $\left(\alpha^{\prime}\right)$. Além disso, é possível distinguir claramente a ferrita bainítica $\left(\alpha_{b}\right)$ caracterizada na forma de ripas alternadas com filmes de austenita retida $\left(\gamma_{f}\right)$ e 
alguns blocos de austenita retida $\left(\gamma_{b}\right)$ adjacentes à ferrita alotriomórfica. De acordo com o tratamento de Q\&P, espera-se que os grãos de martensita possuam austenita retida entre as ripas na forma de filmes. No entanto, a clara identificação desse produto entre as ripas de martensita não foi possível por MEV.

Na Figura 7-13 é possível observar que as amostras Q e Q\&P, apesar de terem sido austenitizadas em temperaturas intercríticas diferentes, não apresentam diferenças consideráveis na distribuição, morfologia e presença de seus microconstituintes, estando principalmente formadas por microestruturas multifásicas constituídas por ripas de martensita que se apresentam em feixes $\left(\alpha^{\prime}\right)$ agrupados em pacotes, $\alpha_{b}$, ferrita primária (proeutetóide) ou intercrítica com morfologia poligonal $(\alpha)$, ferrita epitaxial $\left(\alpha_{E}\right)$, a qual cresceu a partir da ferrita intercrítica $\left(\alpha_{I}\right)$ durante o rápido resfriamento, austenita retida nas formas de blocos $\left(\gamma_{b}\right)$, principalmente localizadas nos contornos da martensita e a ferrita e austenita na forma de filmes $\left(\gamma_{f}\right)$. Na imagem 7.13(e), correspondente à amostra Q\&P austenitizada intercriticamente a 800 ${ }^{\circ} \mathrm{C}$ e particionada a $400{ }^{\circ} \mathrm{C}$ por $500 \mathrm{~s}$, foram ampliadas duas regiões (quadros amarelos), uma ripa de martensita que indica a presença de precipitados alinhados em seu interior e uma região de $\alpha_{b}$. Nessa amostra se observa, qualitativamente, uma maior presença de $\alpha_{b}$ quando comparada com a amostra Q\&P austenitizada intercriticamente a $800{ }^{\circ} \mathrm{C}$ e particionada a 400 ${ }^{\circ} \mathrm{C}$ por $100 \mathrm{~s}$, associado mais provavelmente ao tempo maior de partição, possibilitando a transformação bainítica. Por outro lado, espera-se que nessa amostra a martensita tenha particionado completamente o carbono para austenita, como sugerido pelos resultados de difração de raios $\mathrm{X}$ in situ, que mostraram que durante o estágio de partição para tempos de partição de 500 s após 180 s houve uma aparente estabilização no enriquecimento em carbono da austenita (Figura 7-6). Esse maior enriquecimento poderia estabilizar a austenita, de tal forma que poderia diminuir a presença de martensita fresca na temperatura ambiente. Esse resultado é importante, uma vez que alguns autores [208] têm sugerido que a presença de martensita fresca deteriora as propriedades mecânicas (fragilização) do material. 


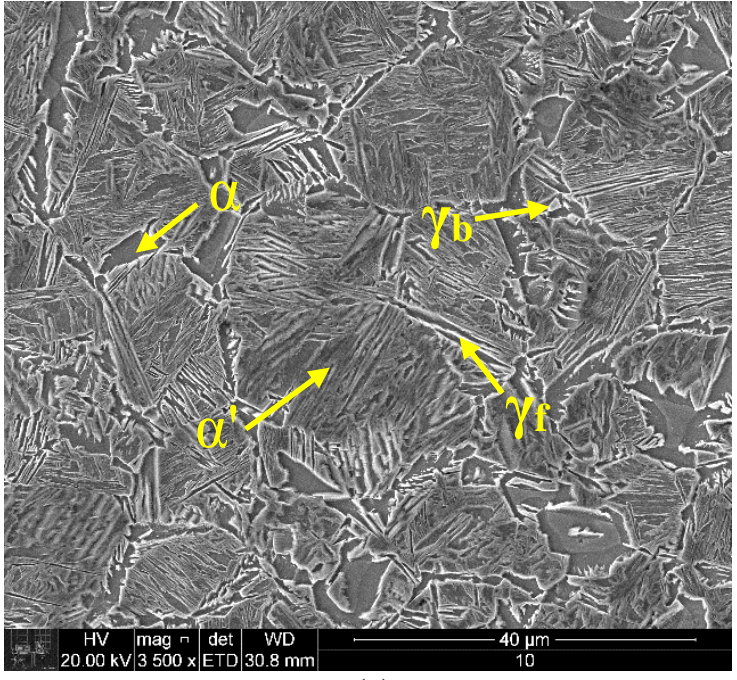

(a)

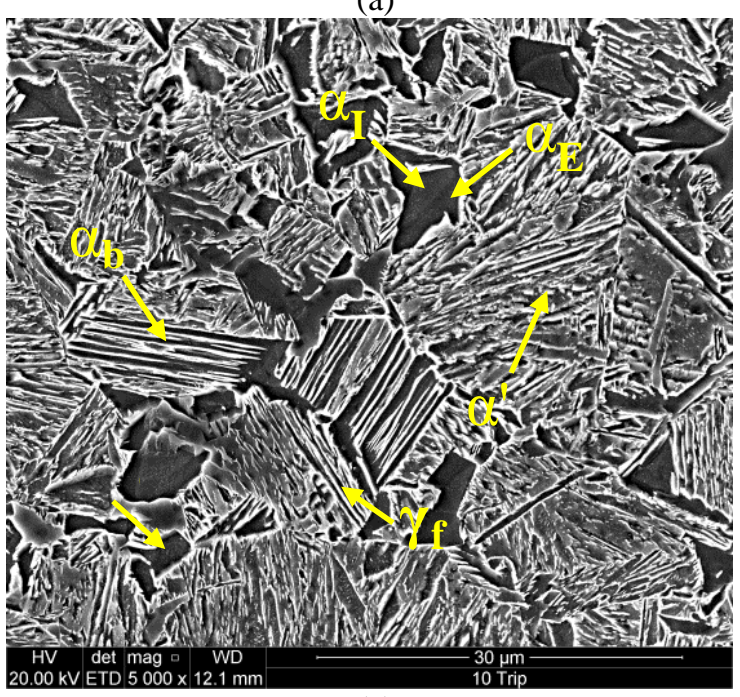

(c)
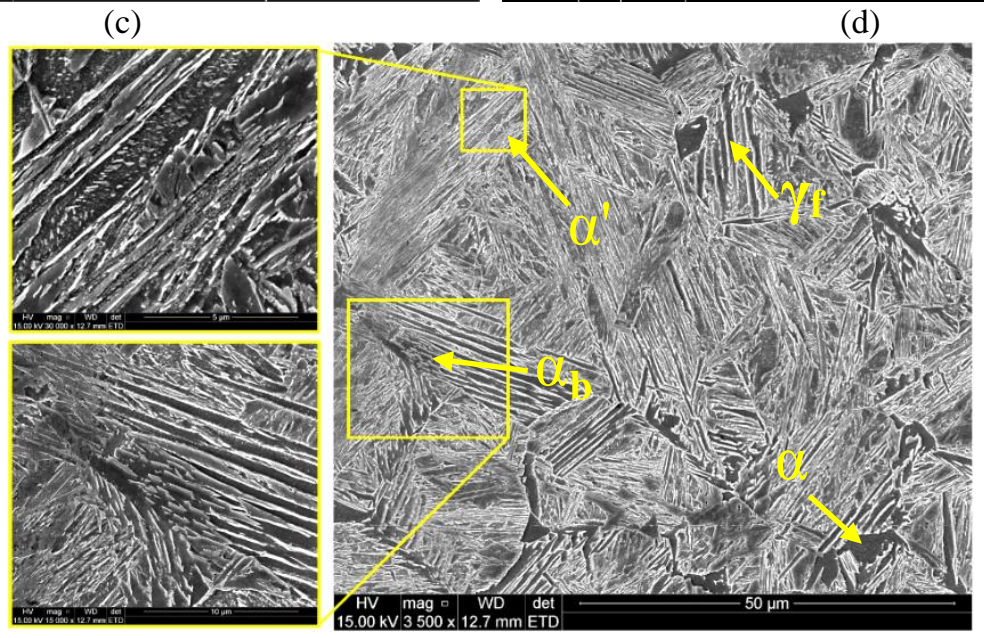

(e)

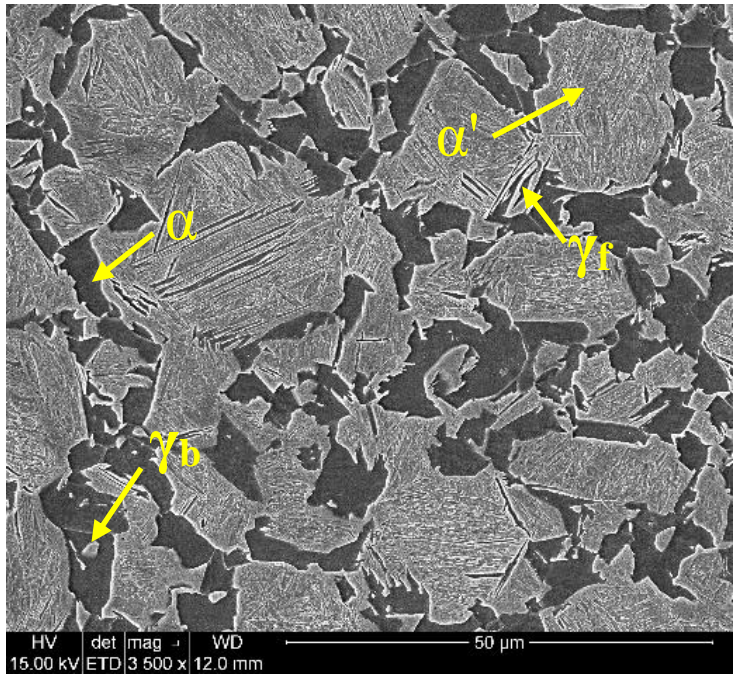

(b)

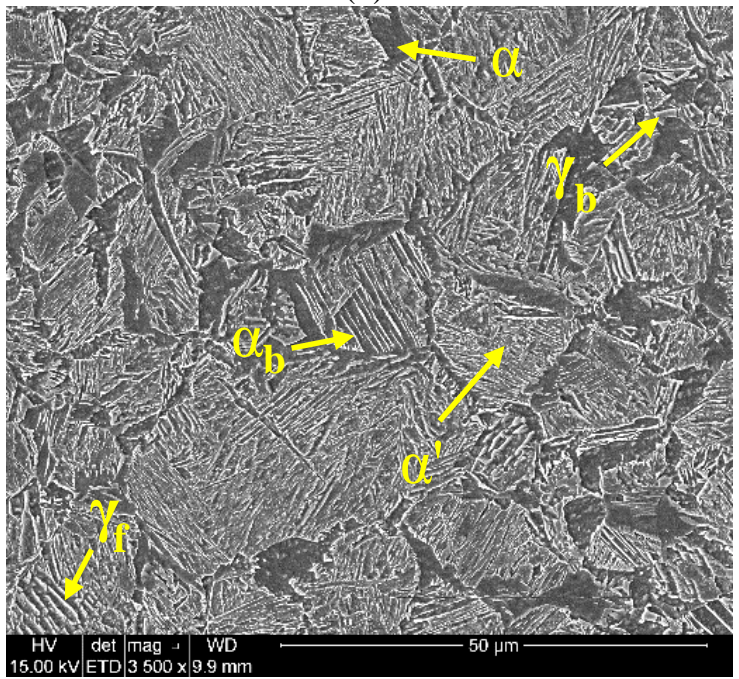

(d)

Figura 7-13. Imagens obtidas por MEV do aço TRIP: (a) têmpera (Q), com austenitização intercrítica (IT) a 800
${ }^{\circ} \mathrm{C}$; (b) Q, com IT $=820^{\circ} \mathrm{C}$; (c) têmpera e partição (Q\&P), com IT $=800{ }^{\circ} \mathrm{C}$, temperatura de têmpera (QT) de $308^{\circ} \mathrm{C}$ e tempo de partição (Pt) de $100 \mathrm{~s}$; (d) Q\&P, com IT $=820^{\circ} \mathrm{C}$, QT $=328^{\circ} \mathrm{C}$ e Pt $=100 \mathrm{~s}$; (e) Q\&P, com IT $=800{ }^{\circ} \mathrm{C}, \mathrm{QT}=328^{\circ} \mathrm{C}, \mathrm{Pt}=500 \mathrm{~s} . \alpha^{\prime}, \alpha_{\mathrm{b}}, \alpha_{\mathrm{I}}, \alpha_{\mathrm{E}}, \gamma_{\mathrm{b}}$ e $\gamma_{\mathrm{f}}$ são martensita, ferrita-bainítica, ferrita intercrítica, ferrita epitaxial, austenita retida na forma de bloco e austenita retida na forma de filme, respectivamente. Nital $2 \%$.

A partir das imagens da Figura 7-14, correspondentes a algumas das amostras submetidas ao tratamento de HS, é possível observar que com o aumento da quantidade de deformação é 
gerada uma maior quantidade de ferrita nos contornos de grão da martensita e uma diminuição nos tamanhos dos grãos tanto da $\alpha$ como da austenita original (transformada em martensita durante a têmpera). Além disso, se observa que as deformações em $10 \%$ realizadas a $750{ }^{\circ} \mathrm{C}$ ou a $800{ }^{\circ} \mathrm{C}$, não apresentam consideráveis mudanças nem na formação de ferrita, nem no refinamento dos grãos.

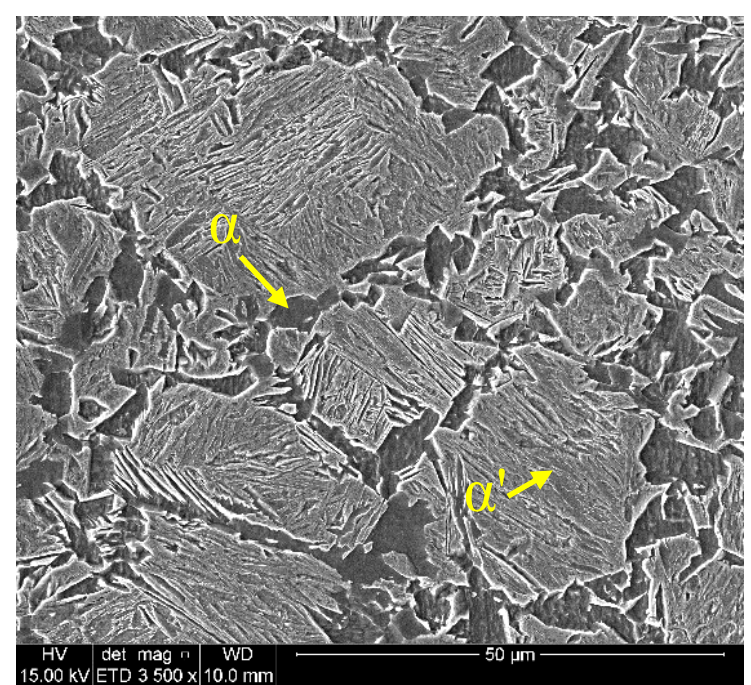

(a)

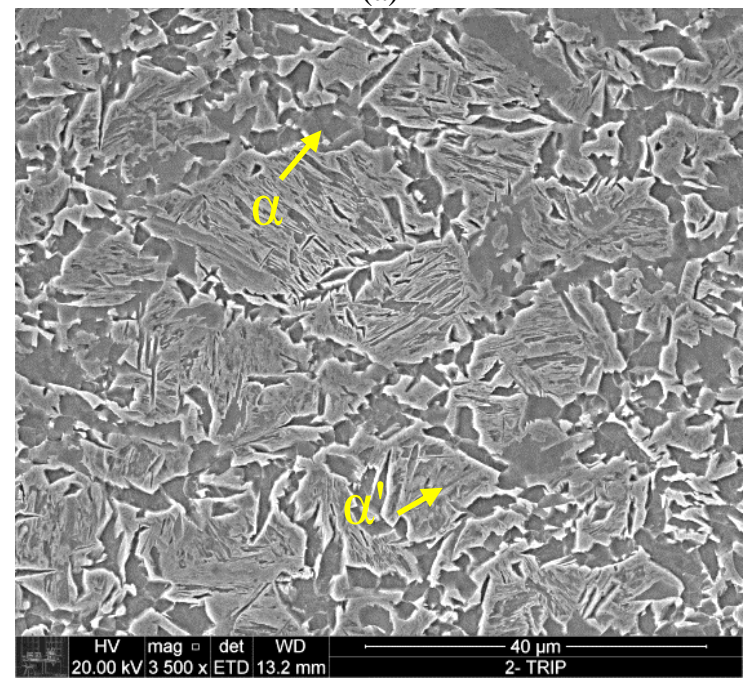

(c)

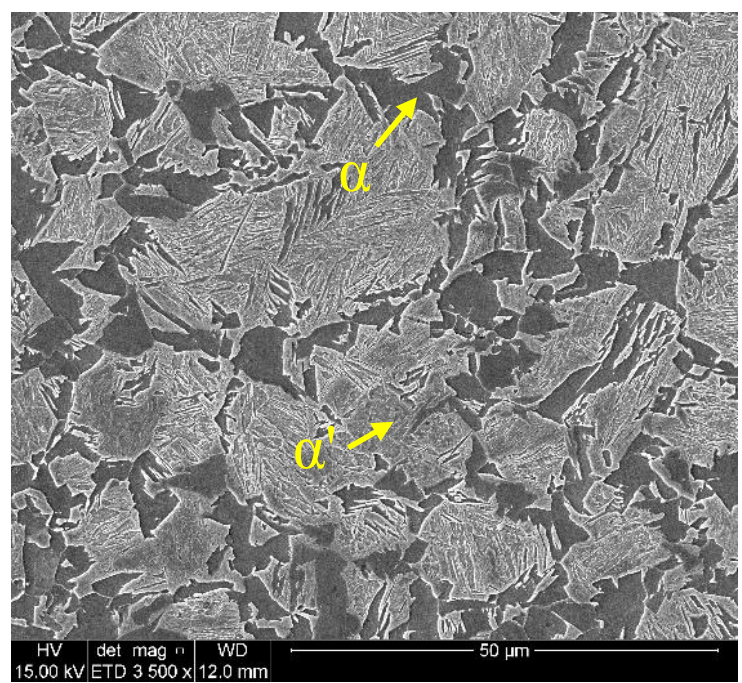

(b)

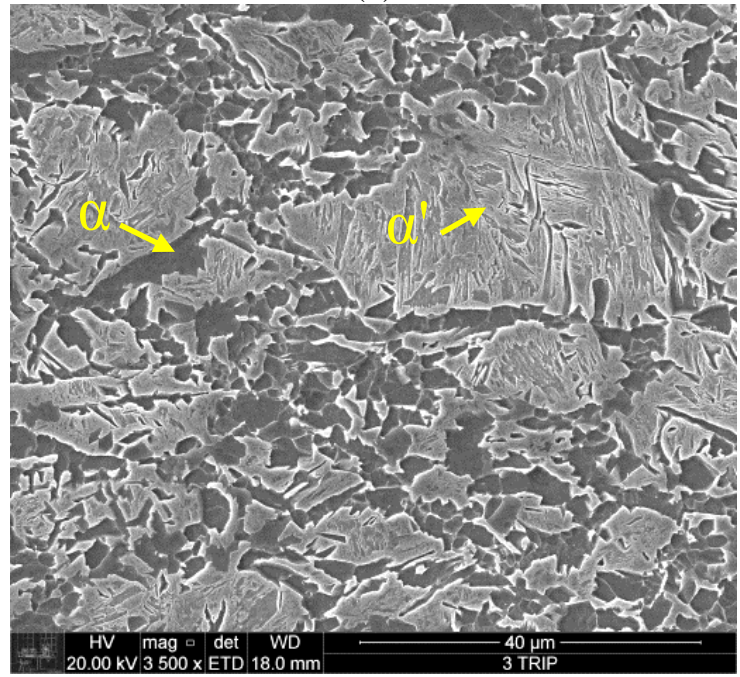

(d)

Figura 7-14. Imagens obtidas por microscopia eletrônica de varredura das amostras de aço TRIP após os processos de estampagem a quente (HS) com prévia austenitização intercrítica a $800{ }^{\circ} \mathrm{C}$. (a) $\mathrm{HS}$ com deformação em $10 \%$ a $750{ }^{\circ} \mathrm{C}$; (b) HS com deformação em $10 \%$ a $800^{\circ} \mathrm{C}$; (c) HS com deformação em $30 \%$ a $750{ }^{\circ} \mathrm{C}$; (d) HS com deformação em $50 \%$ a $750^{\circ} \mathrm{C}$. $\alpha^{\prime}$ e $\alpha$ representam martensita e ferrita, respectivamente. Ataque: Nital $2 \%$.

Nas Figuras 7-15 e 7-16 se observam as imagens de alguns dos experimentos do processo combinado de CSQ\&P e de HSQ\&P, com austenitização intercrítica a 800 e $820{ }^{\circ} \mathrm{C}$, respectivamente, deformações em 10, 30 ou $50 \%$ e temperaturas de têmpera (QT) de 318 ou $328^{\circ} \mathrm{C}$. Comparando as amostras submetidas aos processos de CSQ\&P e HSQ\&P deformadas em $10 \%$, ambas temperadas a $328^{\circ} \mathrm{C}$ e particionadas a $400{ }^{\circ} \mathrm{C}$ por $100 \mathrm{~s}$ (Figuras $7-15$ (a) e 7 - 
15(b)), observa-se que amostra deformada a frio apresenta grãos maiores de ferrita e maior formação de martensita fresca ou não revenida. Isto indica que a deformação em alta temperatura favorece o refinamento do grão (causada possivelmente pela recristalização na temperatura de deformação) e a menor formação de martensita fresca, devido possivelmente, ao favorecimento da segregação do carbono para austenita ou para defeitos do reticulado durante a deformação em alta temperatura.

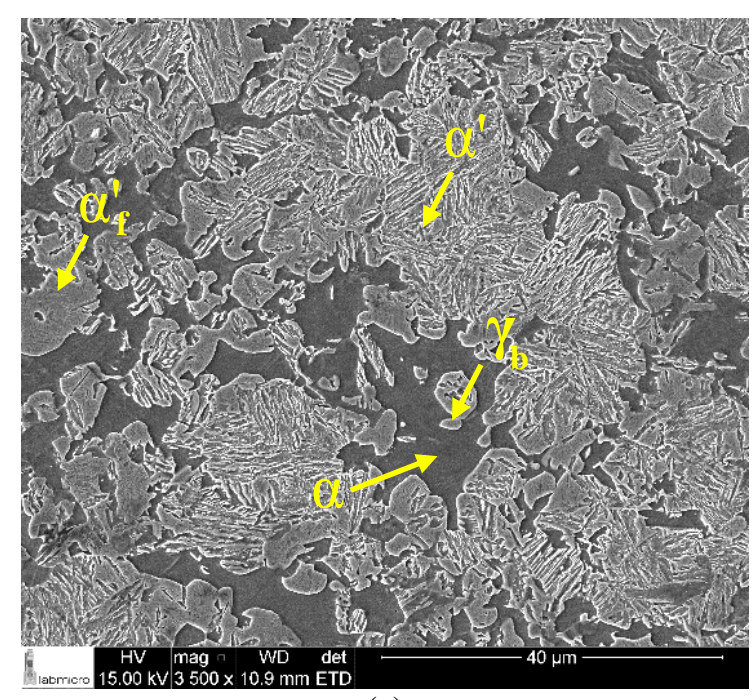

(a)

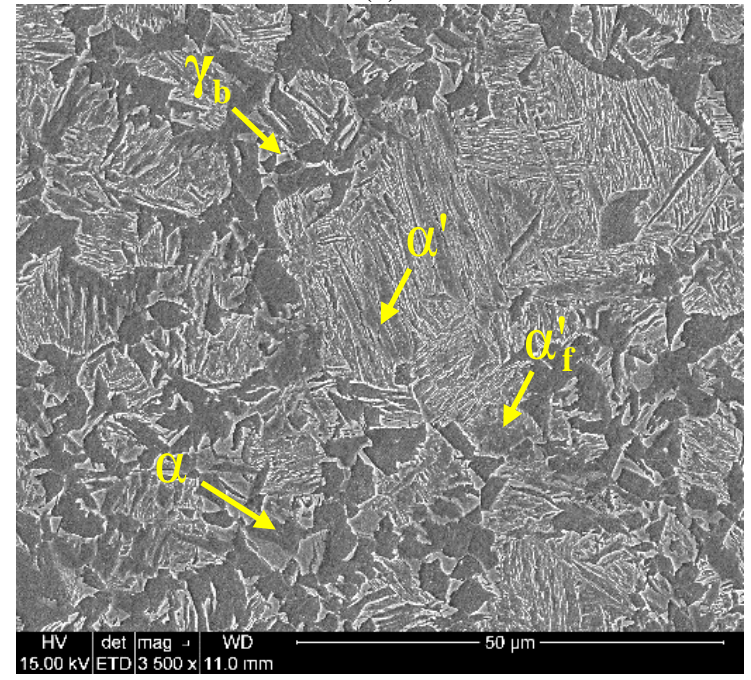

(c)

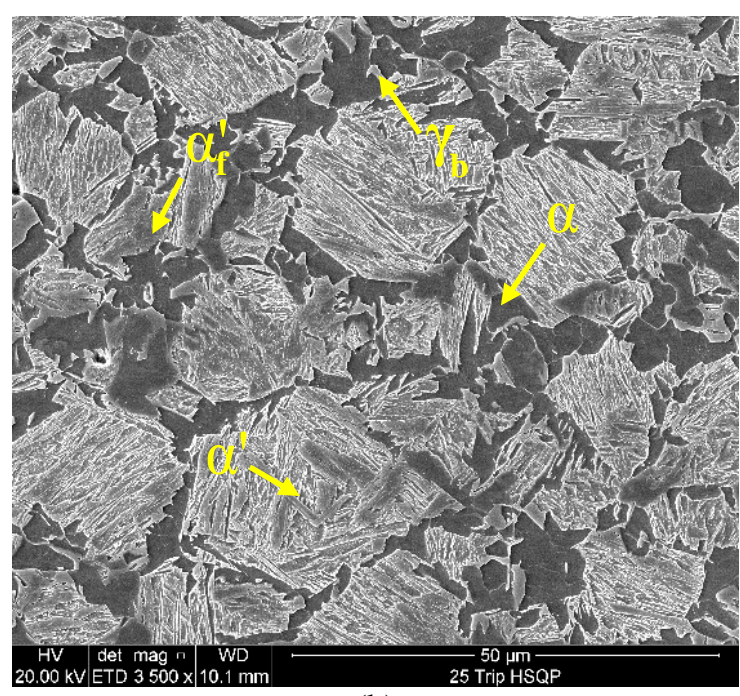

(b)

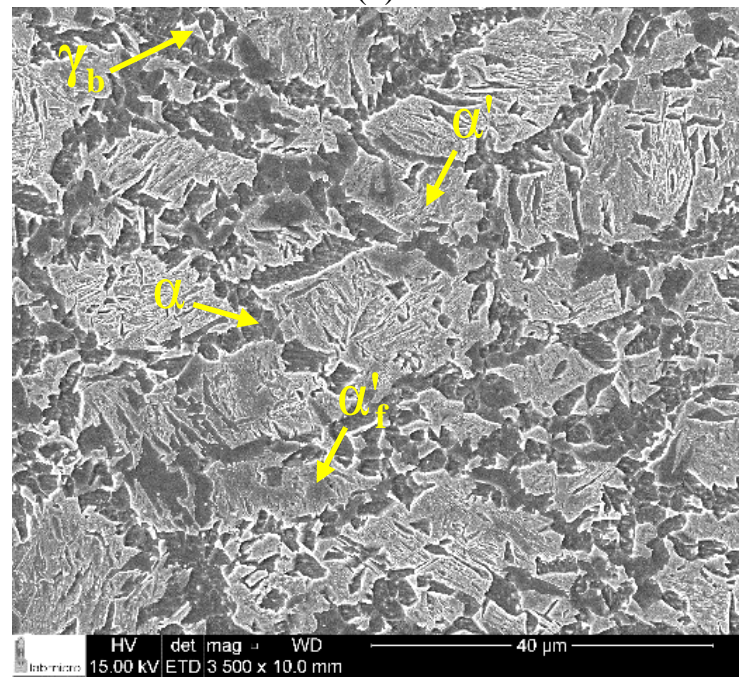

(d)

Figura 7-15. Imagens obtidas por MEV das amostras de aço TRIP após os tratamentos combinados de estampagem a frio (CS) ou a quente (HS), seguidos de têmpera e partição (CSQ\&P ou HSQ\&P). (a) CSQ\&P, com deformação a frio em $10 \%$, austenitização intercrítica (IT) a $800{ }^{\circ} \mathrm{C}$ e temperatura de têmpera (QT) de 328 ${ }^{\circ} \mathrm{C}$; (b) HSQ\&P com IT $=800{ }^{\circ} \mathrm{C}$, deformação em $10 \%$ a $800{ }^{\circ} \mathrm{C}$ e QT $=328^{\circ} \mathrm{C}$; (c) HSQ\&P com IT $=820^{\circ} \mathrm{C}$, deformação em $10 \%$ a $750{ }^{\circ} \mathrm{C}$ e QT $=328^{\circ} \mathrm{C}$; (c) HSQ\&P com IT $=820^{\circ} \mathrm{C}$, deformação em $30 \%$ a $750{ }^{\circ} \mathrm{C}$ e QT $=328{ }^{\circ} \mathrm{C}$. Todas as amostras foram particionadas a $400{ }^{\circ} \mathrm{C}$ por $100 \mathrm{~s} . \alpha^{\prime}, \alpha_{\mathrm{f}}^{\prime}, \alpha_{\mathrm{b}}, \alpha, \gamma_{\mathrm{b}}$ e $\gamma_{\mathrm{f}}$ representam martensita revenida, martensita fresca, ferrita-bainítica, ferrita, austenita retida na forma de bloco e austenita retida na forma de filme, respectivamente. Ataque: Nital $2 \%$.

De forma similar às amostras HS, nas amostras HSQ\&P também é possível observar que com o aumento da quantidade de deformação há uma maior formação de $\alpha$ nos contornos de 
grão da austenita original e uma diminuição nos tamanhos dos grãos, tanto da $\alpha$ como da austenita. Não obstante, ao contrário das microestruturas deformadas a 800 e a $750{ }^{\circ} \mathrm{C}$ em $10 \%$ que não mostraram consideráveis mudanças nas suas microestruturas, as amostras deformadas em 30 e $50 \%$ mostram que a deformação a $800{ }^{\circ} \mathrm{C}$ produz menos $\alpha$ que as amostras deformadas a $750{ }^{\circ} \mathrm{C}$.

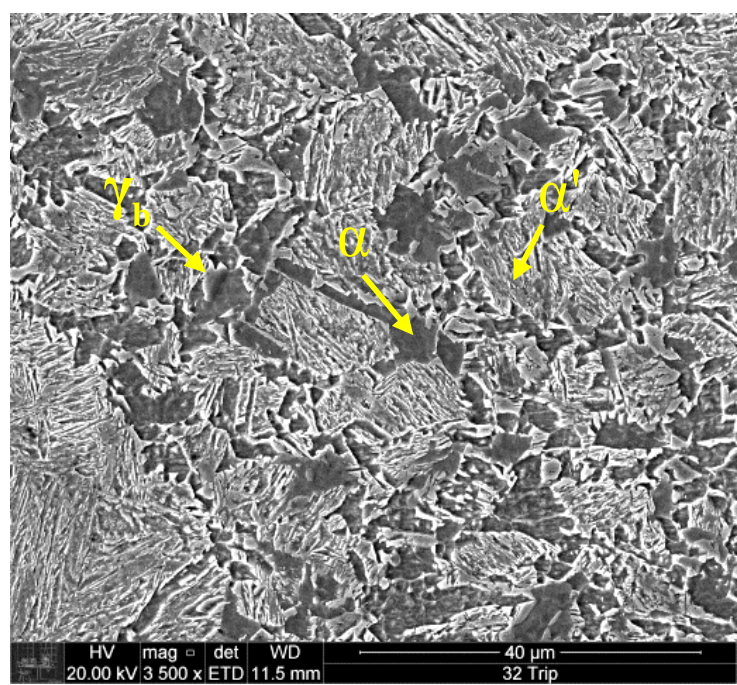

(a)

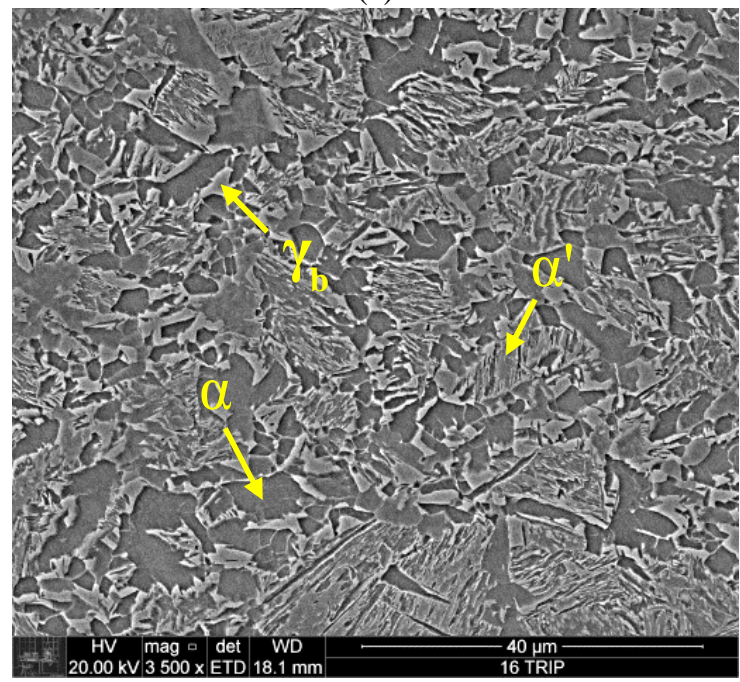

(c)

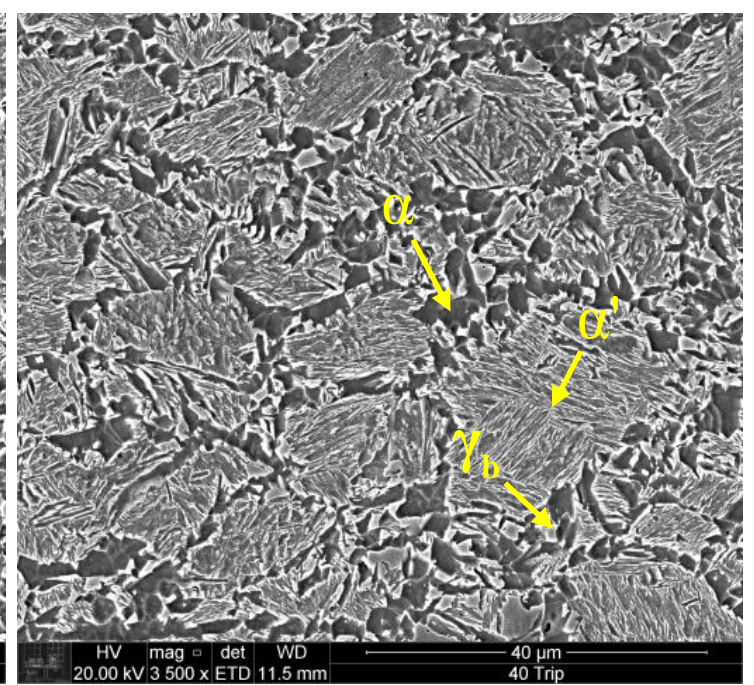

(b)

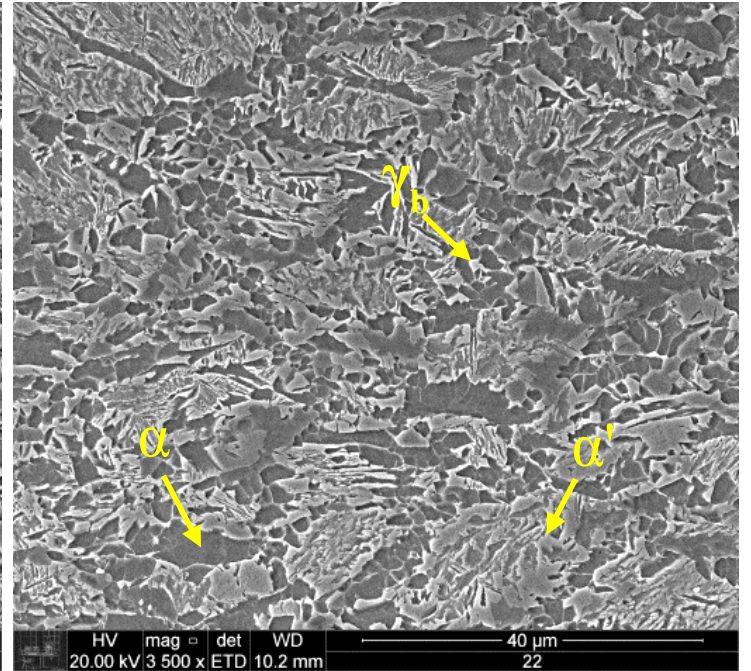

(d)

Figura 7-16. Imagens obtidas por microscopia eletrônica de varredura das amostras de aço TRIP após os tratamentos combinados de estampagem a quente seguido de têmpera e partição (HSQ\&P). (a) HSQ\&P, com deformação em $30 \%$ a $800{ }^{\circ} \mathrm{C}$ e temperatura de têmpera (QT) de $328^{\circ} \mathrm{C}$; (b) HSQ\&P com deformação em $50 \%$ a

$800^{\circ} \mathrm{C}$ e QT $=328^{\circ} \mathrm{C}$; (c) HSQ\&P com deformação em $30 \%$ a $750{ }^{\circ} \mathrm{C}$ e QT $=328^{\circ} \mathrm{C}$; (d) HSQ\&P com deformação em $50 \%$ a $750{ }^{\circ} \mathrm{C}$ e QT $=318{ }^{\circ} \mathrm{C}$. Todas as amostras foram austenitizadas intercriticamente a $800^{\circ} \mathrm{C}$ e particionadas a $400{ }^{\circ} \mathrm{C}$ por $100 \mathrm{~s}$. Ataque: Nital $2 \%$.

Na Figura 7-17 são apresentados os resultados de amostras HSQ\&P, com austenitização intercrítica a $800{ }^{\circ} \mathrm{C}$, deformações em $30 \%$ com temperaturas de têmpera (QT) de 318 e $328^{\circ} \mathrm{C}$ e particionadas a $400{ }^{\circ} \mathrm{C}$ por $500 \mathrm{~s}$. Como se observa nas regiões retangulares coloridas em amarelo, mesmo nas amostras deformadas em alta temperatura é observada ferrita bainítica $\left(\alpha_{b}\right)$ 
nas microestruturas devido ao maior tempo de permanência no estágio de partição, como previsto pelos resultados in situ que mostram o consumo da austenita.

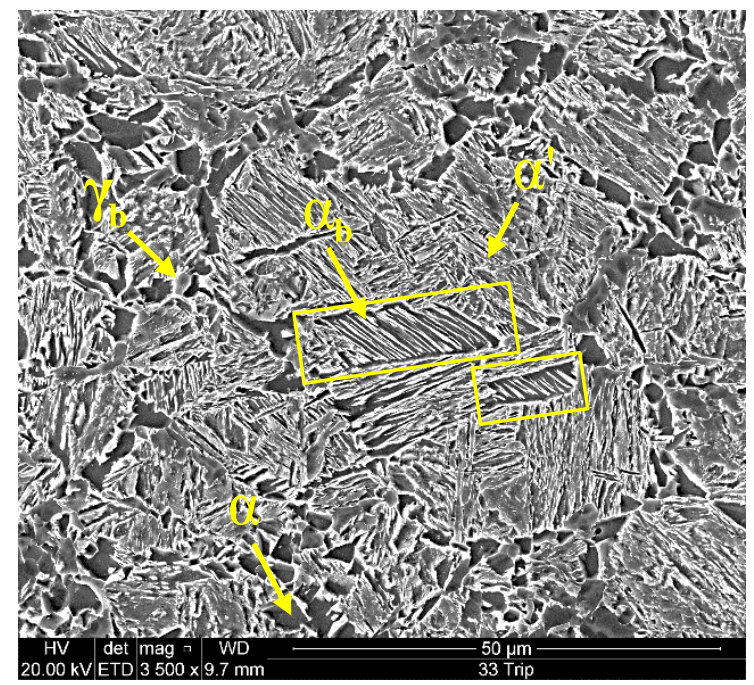

(a)

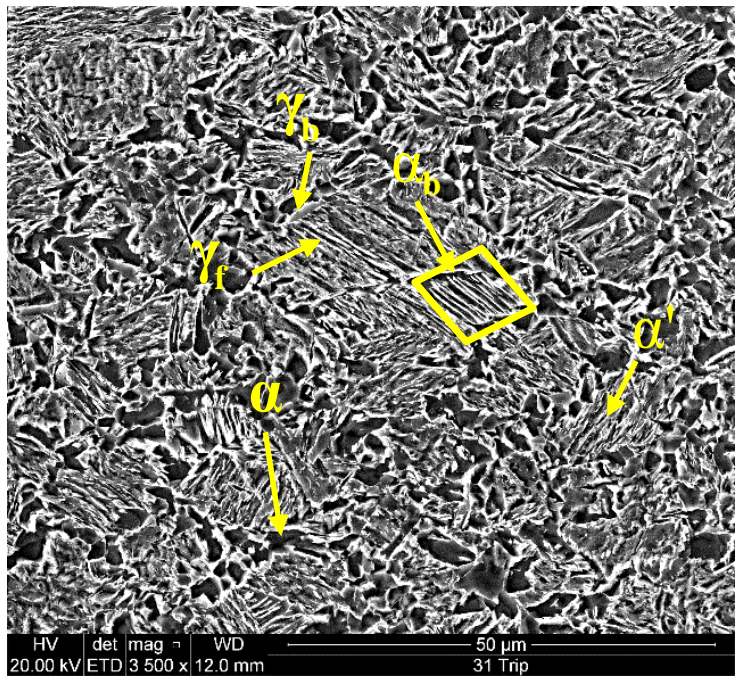

(b)

Figura 7-17. Imagens obtidas por microscopia eletrônica de varredura das amostras de aço TRIP após os tratamentos combinados de estampagem a quente seguido de têmpera e partição (HSQ\&P) das amostras particionadas a $400{ }^{\circ} \mathrm{C}$ por $500 \mathrm{~s}$. (a) $\mathrm{HSQ} \& \mathrm{P}$, com deformação em $30 \%$ a $800^{\circ} \mathrm{C}$ e temperatura de têmpera (QT) de $328^{\circ} \mathrm{C}$; (b) HSQ\&P, com deformação em $30 \%$ a $800^{\circ} \mathrm{C}$ e temperatura de têmpera (QT) de $318^{\circ} \mathrm{C}$.

A partir das análises microestruturais por microscopia óptica e eletrônica de varredura fica evidente que a ferrita poligonal se forma nos contornos dos grãos da austenita metaestável deformada e que sua porcentagem muda dependendo da quantidade e temperatura de deformação, ambas relacionadas diretamente com a energia de deformação armazenada na austenita, que facilita a nucleação da ferrita e reduz o período de incubação [223, 224].

\subsubsection{Difração de elétrons retroespalhados (EBSD)}

O EBSD combinando as ferramentas de identificação de fases e de mapas de orientações de grãos (IPF, Inverse Pole Figure) é uma poderosa ferramenta para a caracterização microestrutural e análise de materiais cristalinos, pelo qual a austenita retida (CFC) e a ferrita (CCC) podem ser facilmente distinguidas. Análises por EBSD foram realizadas a fim de obter informação da microestrutura, morfologia e quantificação das fases após os processos de Q\&P e HSQ\&P. A Figura 7-18 apresenta os resultados das amostras Q\&P e HSQ\&P (deformadas a $750{ }^{\circ} \mathrm{C}$ ou $800{ }^{\circ} \mathrm{C}$ em $30 \%$ ), temperadas a $308^{\circ} \mathrm{C}$ e particionadas a $400{ }^{\circ} \mathrm{C}$ por $100 \mathrm{~s}$. A Figura 7-19 apresenta os resultados de EBSD de identificação de fases e IPF obtidos para amostra Q\&P (Figuras 7-19(a) e 7-19(b)), temperada a $318^{\circ} \mathrm{C}$ e particionada a $400{ }^{\circ} \mathrm{C}$ por $100 \mathrm{~s}$, e das amostras com o mesmo tratamento de Q\&P, mas com prévia deformação em $30 \%$ a $750{ }^{\circ} \mathrm{C}$ (Figuras 7-19(c) e 7-19(d)) e a $800{ }^{\circ} \mathrm{C}$ (Figuras 7-19(e) e 7-19(f)). Nessas figuras é possível 
distinguir claramente as diferentes morfologias da austenita retida ( $\gamma$, em cor vermelho), a qual se apresenta na forma de: blocos equiaxiais (grãos pré-existentes de austenita), distribuídos ao longo dos pacotes de martensita e próximos aos contornos da ferrita; na forma de filmes entre as ripas de martensita $\left(\alpha^{\prime}\right)$ e entre as placas de ferrita bainítica $\left(\alpha_{b}\right)$; e embebida nos grãos de ferrita. A concentração de $\gamma$ nos contornos de grão pode ser explicada devido ao fato de que a nucleação ocorre preferencialmente nas descontinuidades do reticulado, e os contornos de grão representam uma região privilegiada.

Comparando as microestruturas Q\&P e HSQ\&P é possível observar que com a deformação em alta temperatura a ferrita e os blocos de martensita são consideravelmente refinados. Essa microestrutura pode ser favorável devido ao aumento da resistência ao impacto e à fratura produzidos pela dificuldade criada pelo refino do grão para o andamento ou a propagação de trincas [225].

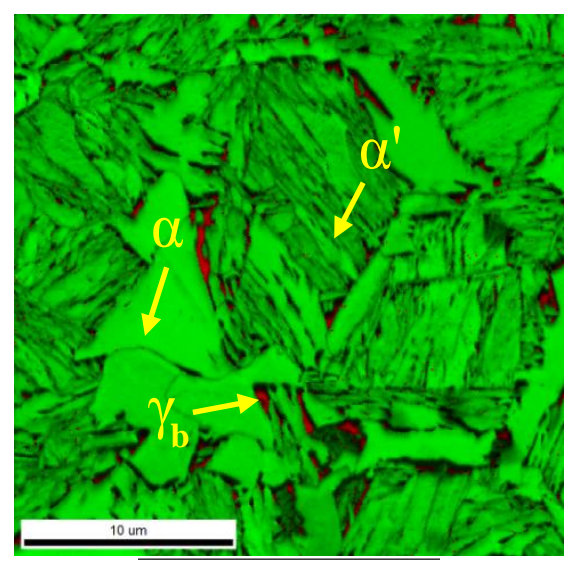

Color Coded Map Type: Phase

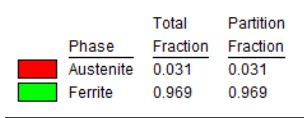

(a)

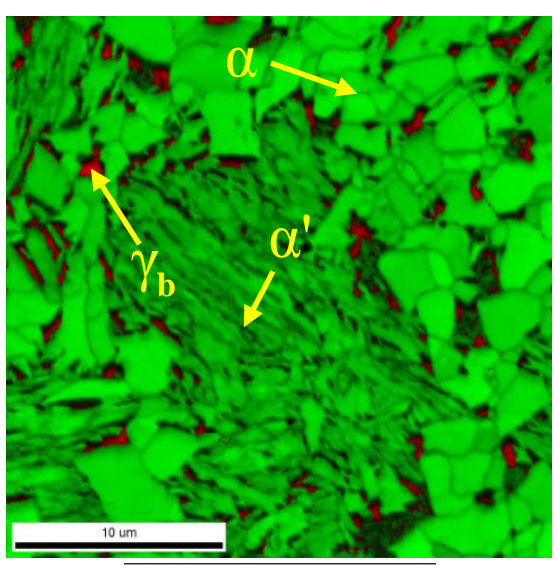

Color Coded Map Type: Phase

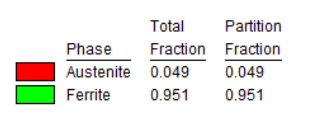

(b)

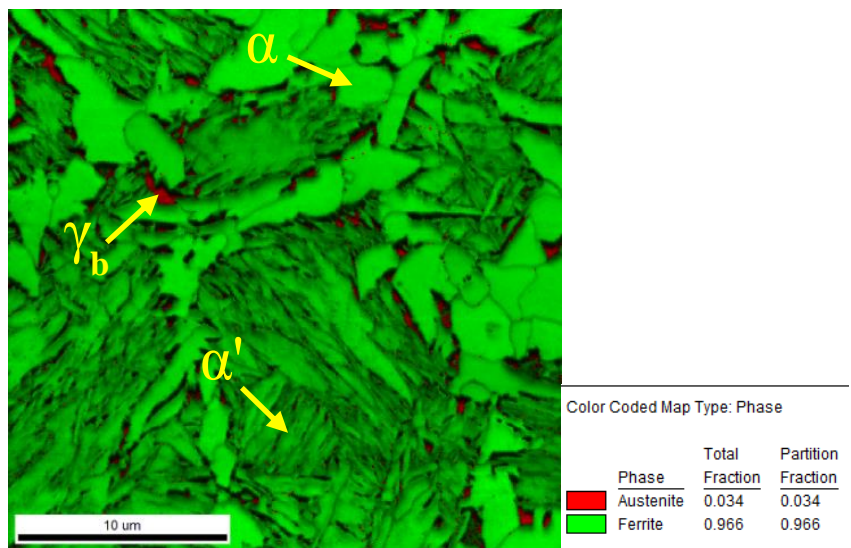

(c)

Figura 7-18. Imagens obtidas por EBSD das amostras de aço TRIP após os tratamentos combinados de têmpera e partição (Q\&P) e de estampagem a quente seguido de têmpera e partição (HSQ\&P) das amostras austenitizadas intercriticamente a $800{ }^{\circ} \mathrm{C}$, temperadas a $308^{\circ} \mathrm{C}$ e particionadas a $400^{\circ} \mathrm{C}$ por $100 \mathrm{~s}$. (a) Q\&P; (b) HSQ\&P com deformação em $30 \%$ a $750{ }^{\circ} \mathrm{C}$; (c) HSQ\&P com deformação em $30 \%$ a $800{ }^{\circ} \mathrm{C}$. 


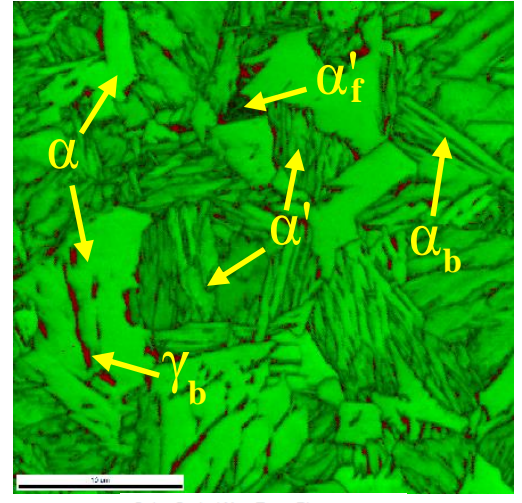

Color Coded Map Type: Phase

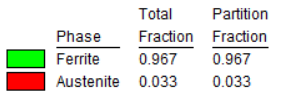

(a)

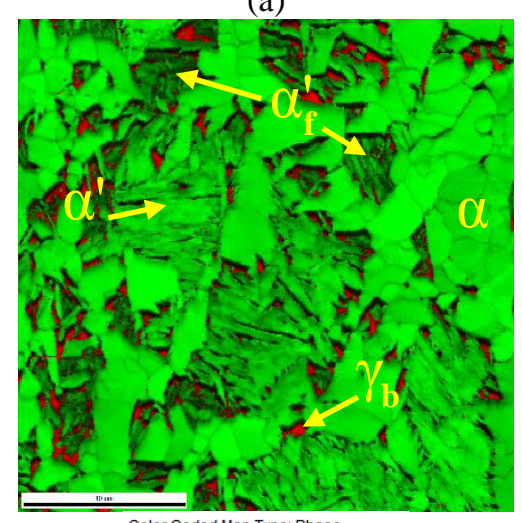

Total Partition

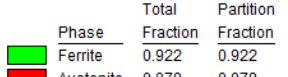

(c)

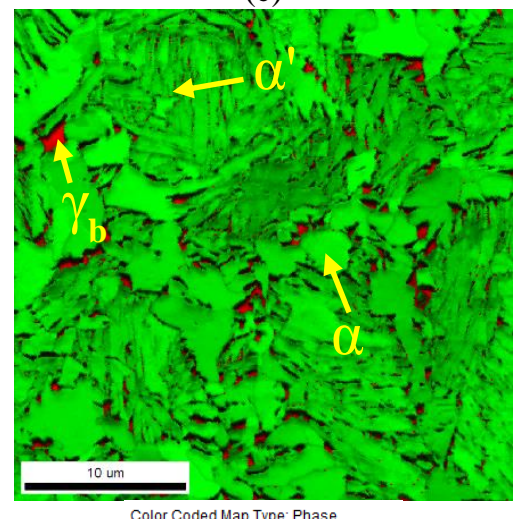

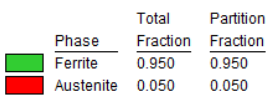

(e)

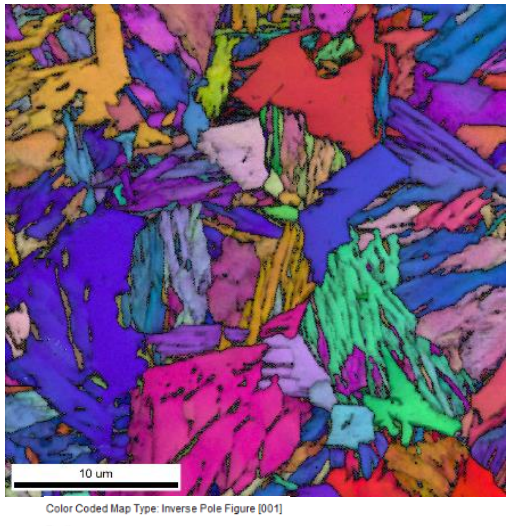

Ferrte
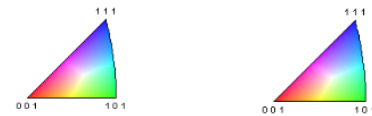

(b)

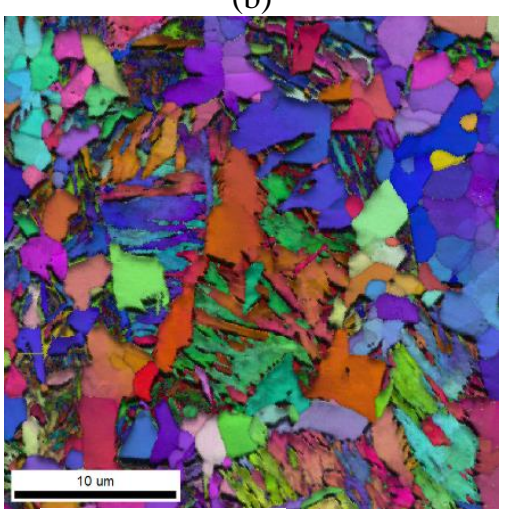

Color
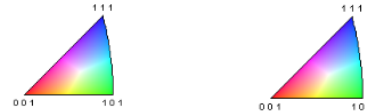

(d)

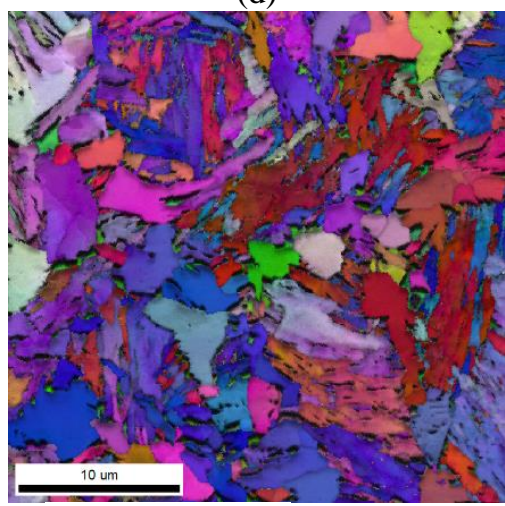

color

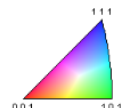

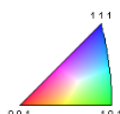

(f)

Figura 7-19. Imagens obtidas por EBSD combinando as ferramentas de identificação de fases e de mapas de orientações de grãos (IPF, imagens b, d e f) das amostras de aço TRIP após os tratamentos de têmpera e partição

(Q\&P) e de estampagem a quente seguido de têmpera e partição (HSQ\&P) das amostras austenitizadas

intercriticamente a $800^{\circ} \mathrm{C}$, temperadas a $318^{\circ} \mathrm{C}$ e particionadas a $400^{\circ} \mathrm{C}$ por 100 s. (a) e (b) Q\&P; (c) e (d) HSQ\&P com deformação em $30 \%$ a $750{ }^{\circ} \mathrm{C}$; (e) e (f) HSQ\&P com deformação em $30 \%$ a $800^{\circ} \mathrm{C} . \alpha^{\prime}, \alpha, \alpha_{b}, \alpha_{\mathrm{f}}^{\prime}$ e $\gamma$ representam martensita, ferrita, ferrita-bainítica, martensita fresca e austenita, respectivamente. 
O uso do EBSD também permitiu a quantificação da austenita retida para cada tratamento, a qual foi de 3,1\% para a amostra Q\&P, 4,9\% para a HSQ\&P deformada a $750{ }^{\circ} \mathrm{C}$ e $3,4 \%$ para a deformada a $800{ }^{\circ} \mathrm{C}$, todas temperadas a $308^{\circ} \mathrm{C}$. Por sua vez, para a amostra temperada a 318 ${ }^{\circ} \mathrm{C}$ as porcentagens de austenita foram de 3,3\% para a amostra Q\&P, de 8,0\% para a HSQ\&P deformada a $750{ }^{\circ} \mathrm{C}$ e de $5,0 \%$ para a deformada a $800{ }^{\circ} \mathrm{C}$. Comparando os resultados da fração volumétrica de austenita obtidos por EBSD e por difração de raios $X$, se observa que com técnica de EBSD se obtém valores menores. Essa discrepância nos resultados da fração de austenita entre as duas técnicas tem sido reportada na literatura [130, 226-228] e tem sido atribuída aos limites de resolução espacial dos sistemas de EBSD, visto que as ripas de menor tamanho de austenita podem não ser detectadas por EBSD, mas sim por difração de raios X [130, 226]; ao pequeno tamanho da região de análise por EBSD e à heterogeneidade da microestrutura, o que torna as análises pouco representativas do volume do material estudado [227]; à possível transformação induzida pela deformação de austenita em martensita durante a preparação mecânica da superfície para posterior análise por EBSD e à maior profundidade de penetração dos raios $X(\approx 15 \mu \mathrm{m})$ em relação à dos elétrons $(0,05 \mu \mathrm{m})$ [228].

Na Figura 7-20 é apresentada a combinação da imagem de qualidade com o mapa de orientações de grãos para austenita da amostra HSQ\&P deformada a $750{ }^{\circ} \mathrm{C}$ e temperada a 318 ${ }^{\circ} \mathrm{C}$. A partir desse mapa é possível observar que as ilhas de austenita pertencentes ao mesmo grão possuem a mesma orientação cristalográfica, como mostrado nas regiões delimitadas pelos contornos em amarelo. Isto indica que essa austenita retida se originou do mesmo grão prévio de austenita [196].

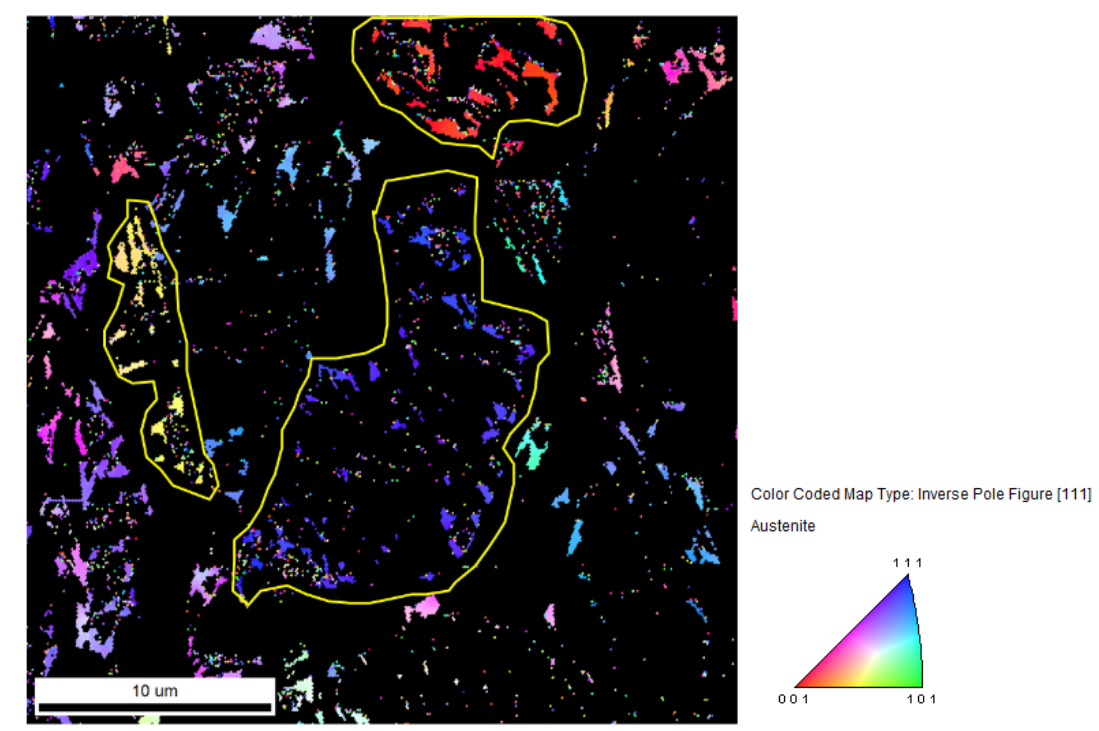

Figura 7-20. Imagem obtida combinando as ferramentas de identificação de fases (para austenita) e de orientações de grãos da amostra HSQ\&P, austenitizada intercriticamente a $800{ }^{\circ} \mathrm{C}$, deformada em $30 \%$ a $750{ }^{\circ} \mathrm{C}$, temperada a $318^{\circ} \mathrm{C}$ e particionada a $400{ }^{\circ} \mathrm{C}$ por $100 \mathrm{~s}$. 
Os resultados da área do tamanho do grão para os tratamentos de Q\&P e HSQ\&P das amostras temperadas a $318^{\circ} \mathrm{C}$ são apresentados na Figura 7-21. Nessa figura se observa como houve um refino considerável do tamanho do grão devido à deformação em alta temperatura, sendo que o valor médio para amostra Q\&P foi de $28 \mu^{2}$, enquanto as amostras HSQ\&P apresentaram valores médios em torno de $16 \mu \mathrm{m}^{2}$. Essa redução do tamanho do grão (observada também nas imagens obtidas por MEV e EBSD) nas amostras HSQ\&P pode ter sido causado pela ocorrência de recristalização dinâmica associada à geração de um número grande de defeitos durante a deformação a quente.

O principal potencial termodinâmico para que a recristalização (migração de contornos de alto ângulo) ocorra é a energia armazenada durante a deformação plástica na forma de defeitos cristalinos $^{11}$. Na grande maioria das condições de deformação a quente, a nucleação da recristalização dinâmica ocorre preferencialmente nos contornos de grão [196], especialmente nos contornos altamente deformados. Esse mecanismo é caracterizado pela formação de colares sucessivos (necklacing), que consiste em nucleação dos novos grãos em etapas, que avançam sequencialmente para o interior do grão [196]. Esse comportamento é mais facilmente observado nos resultados por microscopia óptica da Figura 7-12, onde grãos de ferrita sofreram um intenso refino e contornam alguns dos grãos de martensita na forma de "colares". Os grãos recristalizados dinamicamente param de crescer e permanecem pequenos, porque o potencial termodinâmico é igualado com o restante da matriz deformada através das discordâncias geradas [196]. Isto é, cria-se um balanço energético entre a introdução de novos contornos de grão (aumento da energia livre) e a eliminação dos defeitos cristalinos (diminuição da energia livre). Dessa forma, nas microestruturas em que ocorre recristalização dinâmica, em geral, existe um considerável refinamento dos grãos. Zheng et al. [98] destacam que a recristalização dinâmica de grãos ferrita subdivide os grãos de ferrita previamente formados pela deformação em alta temperatura (efeito DIFT ou DSIT, dynamic strain-induced transformation), mantendo sua morfologia equiaxial. Contudo, durante o efeito DIFT ocorre nucleação de ferrita intragranular de forma rápida e extensiva nas subestruturas de discordâncias, o que causa o refinamento dos grãos de ferrita [222]. Por conseguinte, tanto a transformação de austenita em ferrita que ocorre devido à deformação (efeito DIFT), como a recristalização dinâmica seriam os principais mecanismos que contribuem na formação de grãos refinados de ferrita.

\footnotetext{
${ }^{11}$ As discordâncias são defeitos cristalinos de não-equilíbrio. Um aumento da densidade de discordâncias (causado por exemplo, quando o material é deformado plasticamente) sempre leva a um aumento da energia livre, porque a contribuição para aumento da entropia é desprezível. Como, ademais, a variação de volume quando se criam discordâncias é praticamente nula, a variação de energia livre pode ser igualada à variação de energia interna. Essa variação é o potencial termodinâmico para ocorrência de recristalização [294].
} 


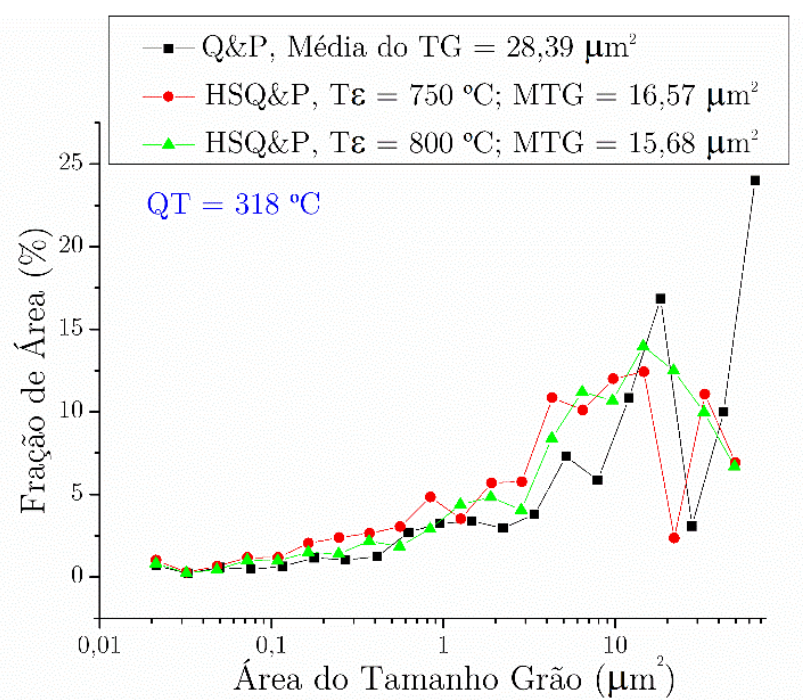

Figura 7-21. Área do tamanho de grão das amostras Q\&P e HSQ\&P temperadas a $318^{\circ} \mathrm{C}$. A deformação das amostras HSQ \&P foi de $30 \%$ a $750{ }^{\circ} \mathrm{C}$ e $800{ }^{\circ} \mathrm{C}$.

Os mapas de orientação obtidos por EBSD podem ser também usados para investigar a distribuição da deformação entre grãos, o que é importante para compreender o comportamento da deformação global do material. A desorientação (mudança da orientação local) entre grãos causada pela deformação plástica pode ser caracterizada usando a aproximação de kernel [229]. Nesta aproximação, cada píxel do mapa é colorido em função da mudança do grau de orientação com relação aos píxeis vizinhos. Para isto, o componente de distribuição local de desorientação calcula a desorientação média entre cada píxel e seus píxeis vizinhos e atribui o valor médio a esse píxel; uma restrição referente às desorientações que excedam o valor da tolerância (valor máximo de desorientação que o usuário define) implica na exclusão desses dados do cálculo da média. Desta forma, mapas de distribuição da desorientação local foram obtidos para avaliar o gradiente de deformação local e a distribuição da deformação plástica localizada, em pequena escala. Assim, a desorientação de kernel, que é uma medida estreitamente relacionada à densidade de discordâncias [230], foi usada para identificar o gradiente de orientações existente entre a martensita, a ferrita-bainítica e a ferrita no aço TRIP tratado por Q\&P ou HSQ\&P. Na Figura 7-22 observa-se a desorientação média de kernel (KAM, do inglês Kernel Average Misorientation) para amostra Q\&P (Figura 7-22(a)) temperada a $318^{\circ} \mathrm{C}$ e particionada a 400 ${ }^{\circ} \mathrm{C}$ por $100 \mathrm{~s}$ e das amostras com o mesmo tratamento de Q\&P, mas com deformação prévia a $750^{\circ} \mathrm{C}$ (Figura 7-22(b)) e $800^{\circ} \mathrm{C}$ (Figura 7-22(c)). A tolerância do ângulo de desorientação para a identificação dos grãos foi de $10^{\circ}$. A cor azul representa desorientações menores que $2^{\circ}$, a cor verde desorientações entre $2^{\circ}$ e $5^{\circ}$, a cor amarela entre $5^{\circ}$ e $7^{\circ}$, a laranja entre $7^{\circ}$ e $8^{\circ}$ e a vermelha desorientações entre $8^{\circ}$ e $10^{\circ}$. Observa-se que a maior parte das áreas em azul, ou seja, com desorientações variando entre $0^{\circ}$ e $3^{\circ}$, correspondem a áreas de ferrita com maior contraste de 
bandas (BC, Band Contrast). Um maior contraste de bandas indica uma maior razão entre o sinal e o ruído, o que facilita o reconhecimento das bandas de Kikuchi pelo software. Áreas em verde correspondem a regiões com menor BC, indicando as regiões de martensita. Desse modo, nas microestruturas analisadas se observa que a martensita apresenta os maiores gradientes de desorientação local devido à maior densidade de discordâncias, originada pelo cisalhamento ou deformação plástica que ocorre durante a mudança do reticulado CFC para tetragonal compacta (TC). Essa tetragonalidade está relacionada ao fato do carbono ser um soluto intersticial e, portanto, é tanto maior quanto mais carbono estiver em solução. Por sua vez, a ferrita contém comparativamente uma menor quantidade de discordâncias e carbono, o que explica também seus menores valores de dureza. Os contornos de grão de alto ângulo (> $15^{\circ}$ ) foram determinados e as interfaces ferrita/martensita foram delineadas por linhas sólidas a fim de correlacionar as deformações locais com as características microestruturais.

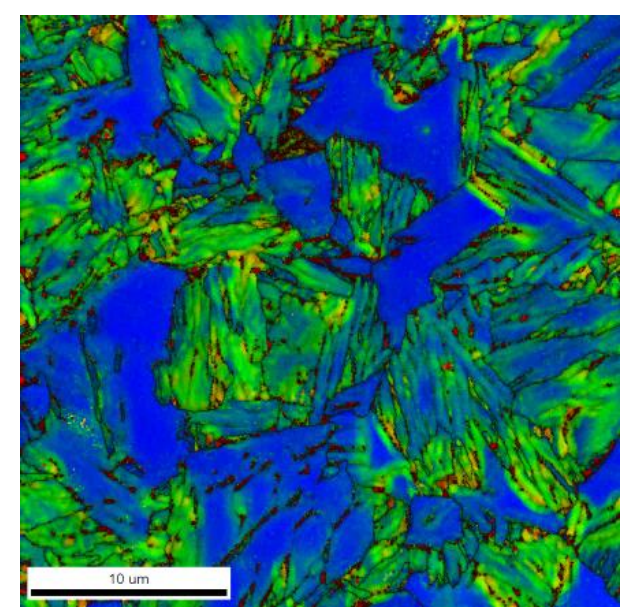

(a)

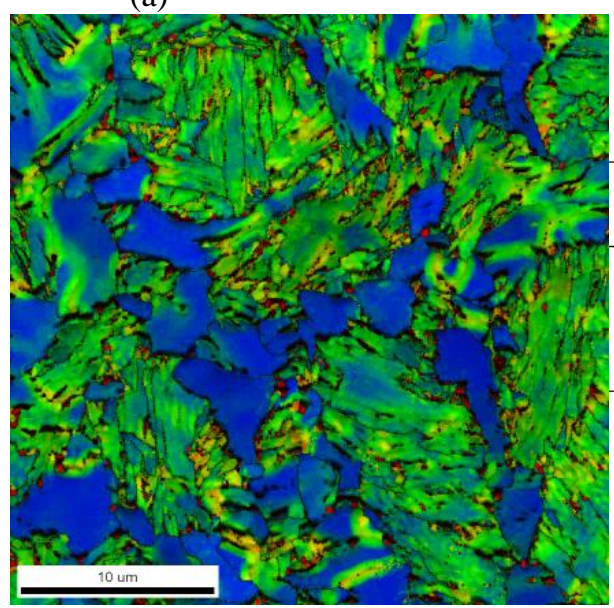

(c)

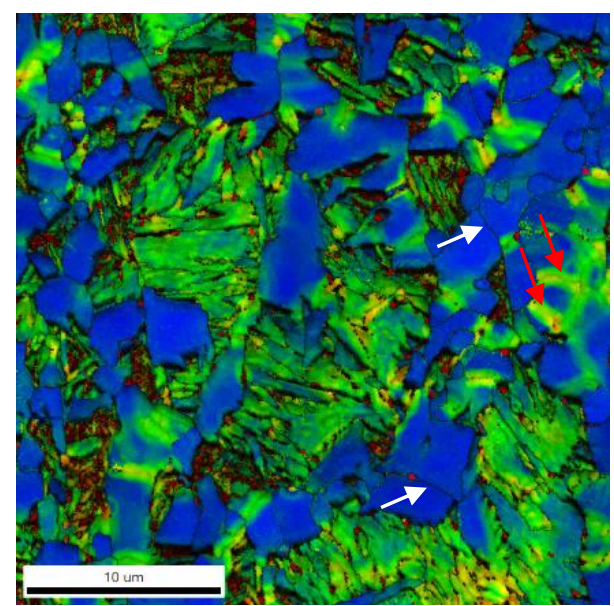

(b)

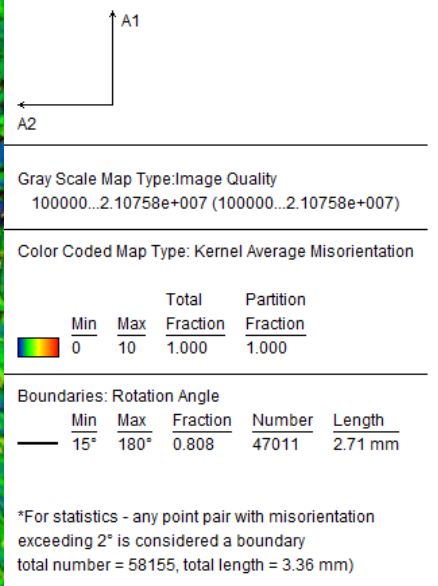

total number $=58155$, total length $=3.36 \mathrm{~mm}$ )

Figura 7-22. Caracterização da desorientação kernel (usando EBSD) do aço TRIP após tratamentos de Q\&P e HSQ\&P. As amostras foram temperadas a $318{ }^{\circ} \mathrm{C}$ e particionadas a $400{ }^{\circ} \mathrm{C}$ por $100 \mathrm{~s}$. (a) Q\&P; (b) HSQ\&P deformada em $30 \%$ a $750^{\circ} \mathrm{C}$; (c) HSQ\&P deformada em $30 \%$ a $800{ }^{\circ} \mathrm{C}$. 
De forma similar ao que acontece nos resultados de difração de raios X, a martensita não é distinguida da ferrita pela indexação dos padrões de difração devido às similaridades entre as estruturas cristalinas das duas fases (a tetragonalidade da martensita é próxima de 1). No entanto, foi possível distinguir a martensita da ferrita pelas regiões de menor índice de qualidade, resultado da alta densidade de discordâncias da martensita. Por meio dos resultados de EBSD e da desorientação foi realizada a distinção das duas martensitas que são geradas durante os processos de têmpera e partição. Uma é a martensita revenida ou particionada durante o estágio de partição, que possui baixo teor de carbono, e a outra é a martensita fresca ou não particionada, gerada no último resfriamento, após o processo de partição, a partir da austenita menos estável e, portanto, de maior teor de carbono e densidade de discordâncias, quando comparada com a martensita revenida. Como a magnitude local da desorientação está relacionada com a densidade das discordâncias e com a deformação plástica, foi possível avaliar a magnitude da distribuição local da desorientação entre as diferentes fases em amostras tratadas por Q\&P e HSQ\&P. Adicionalmente, nas amostras HSQ\&P são observados maiores valores de KAM em algumas interfaces ferrita/ferrita (setas vermelhas). Também são observadas interfaces ferrita/ferrita com baixos valores de KAM (setas brancas), similares às observadas na condição Q\&P. Esses resultados podem ser explicados pela formação de dois tipos de ferrita: a ferrita gerada pelo efeito DIFT, que apresenta menores valores de KAM, e a ferrita formada durante a etapa intercrítica, que foi deformada principalmente nos contornos de grão [231] e apresenta maiores valores de KAM.

A Figura 7-23 apresenta uma região selecionada para avaliação da martensita fresca por desorientação. A alta desorientação local nos blocos da martensita fresca é identificada pelas regiões em verde escurecidas no mapa de qualidade de imagem (IQ) (Figura 7-23(a)). A martensita fresca está localizada nas imediações dos grãos de austenita retida, o que torna confiável a distinção entre as martensitas fresca e revenida por meio da imagem de qualidade [232]. A Figura 7-23(b) apresenta a desorientação ponto-à-origem (point-to-origin) ao longo da seta da micrografia na Figura 7-23(a). Esse caminho permite a análise da relação de orientação dentro dos grãos de uma imagem de qualidade, a qual mostrou uma variação entre $15^{\circ}$ e $55^{\circ}$ de desorientação. Os resultados com graus de desorientação superiores aos $50^{\circ}$ são identificados nesta micrografia como martensita fresca, que é uma desorientação típica entre blocos dentro de um pacote único de martensita [232]. Nesse resultado se observa igualmente que a martensita fresca consiste de blocos com tamanho menor que $0,5 \mu \mathrm{m}$ de largura. 


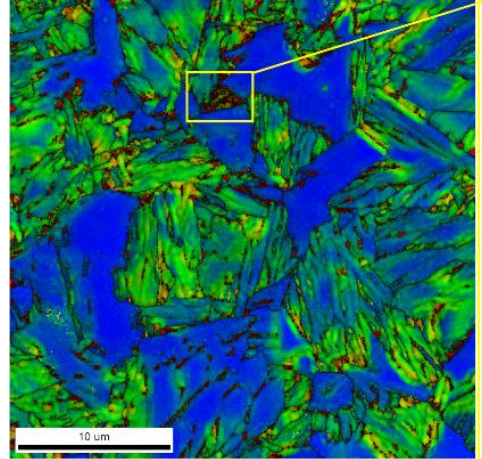

(a)
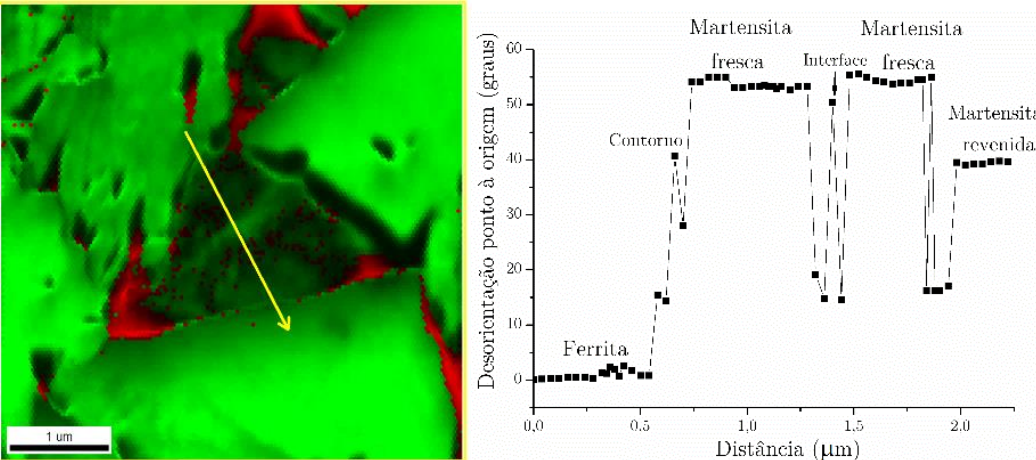

(b)

Figura 7-23. (a) Mapa de desorientação de kernel (KAM) com contornos de grau com desorientações maiores a $15^{\circ}$, foram avaliados os 5 vizinhos (ou fronteiras) mais próximos e o limite máximo de desorientação foi de $10^{\circ} \mathrm{e}$ EBSD combinando a imagem de qualidade e a identificação das fases da região indicada no quadro amarelo da região à esquerda. A seta representa o caminho de desorientação avaliado. (b) Desorientação ponto-à-origem do caminho avaliado na Figura (a) identificados como martensita fresca.

Na Figura 7-24 é observada a análise da desorientação das regiões identificadas por EBSD como ferrita. Na Figura 7-24(a) observam-se os quatro caminhos usados para análise da desorientação, e na Figura 7-24(b) o resultado da média da desorientação dos caminhos avaliados na Figura 7-24(a). Os resultados claramente mostram que para as regiões identificadas como ferrita a desorientação não supera os $2^{\circ}$.

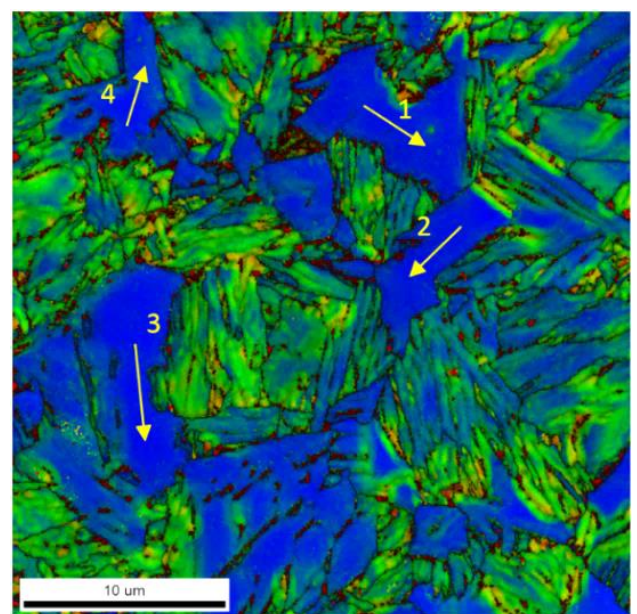

(a)

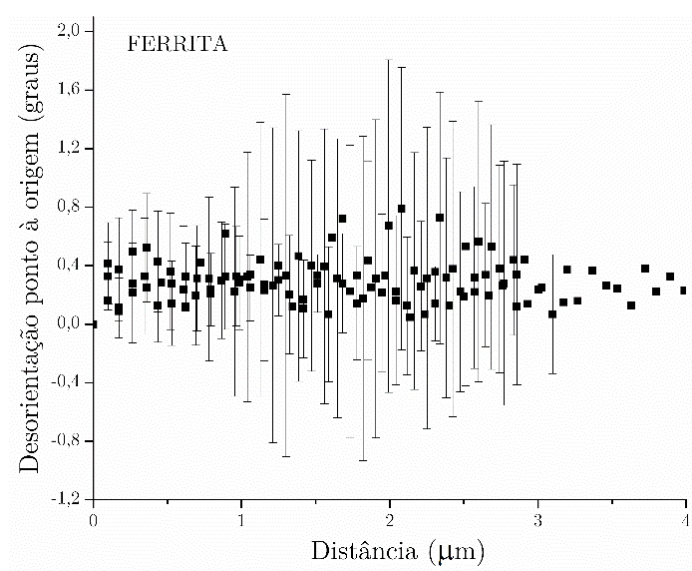

(b)

Figura 7-24. (a) Mapa de desorientação média de kernel com contornos de grau com desorientações maiores a $15^{\circ}$ para identificação de ferrita; (b) valores médios da desorientação ponto-à-origem dos caminhos 1 a 4 identificados como ferrita.

Na Figura 7-25 é observada a análise da desorientação das regiões identificadas por EBSD como martensita revenida e ferrita-bainítica para amostra Q\&P austenitizada intercriticamente a $800{ }^{\circ} \mathrm{C}$, temperada a $318^{\circ} \mathrm{C}$ e particionada a $400{ }^{\circ} \mathrm{C}$ por $100 \mathrm{~s}$. Na Figura 7-25(a) o contorno amarelo delimita a região selecionada para análise da desorientação na martensita revenida. A Figura 7-25(b) corresponde ao mapa de desorientação da região ampliada indicando por meio da seta o caminho usado para análise da desorientação ponto-à-origem e na Figura 7-25(c) o 
resultado da desorientação desse caminho. Nas Figuras 7-25(d) e 7-25(e) observaram-se os mapas de EBSD identificando as fases (CCC em verde e CFC em vermelho) e a região selecionada (contorno em amarelo) para análise da ferrita-bainítica. Na Figura 7-25(e) é indicado, por meio da seta, o caminho usado para análise e obtenção do resultado (Figura 7-25(f)) da desorientação ponto-à-origem. Os resultados dessas análises claramente mostram que para as regiões identificadas como martensita revenida, a desorientação não supera os $50^{\circ}$ e os contornos dos blocos tem uma desorientação que superam $45^{\circ}$, o que leva a considerá-los como contornos de alto-ângulo. Enquanto, para as regiões identificadas como ferrita-bainítica, a desorientação se encontra ao redor dos $20^{\circ}$. Portanto, a partir dos resultados da desorientação ponto-à-origem se observa que a desorientação é menor que $2^{\circ}$ para a ferrita, entre $10^{\circ}$ e $20^{\circ}$ para a ferrita-bainítica e acima dos $20^{\circ}$ para as martensitas revenida e fresca. O que representa uma nova abordagem para identificação dos microconstituintes, usando a desorientação média de Kernel e ponto-à-origem a partir dos resultados de EBSD.

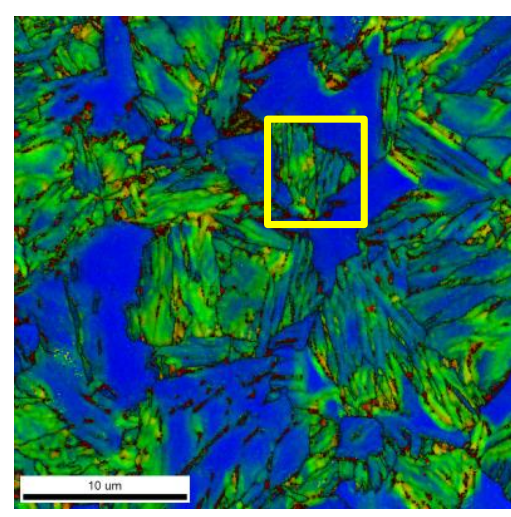

(a)

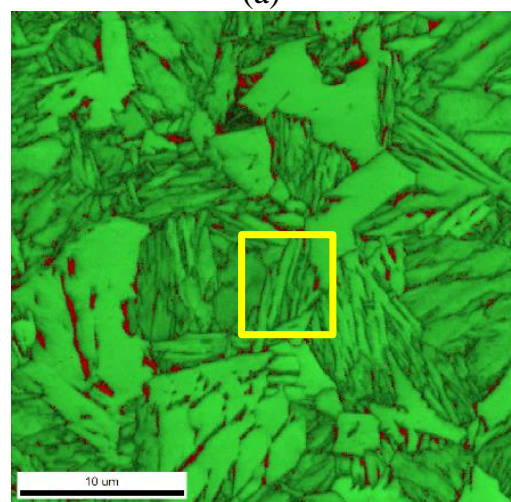

(d)

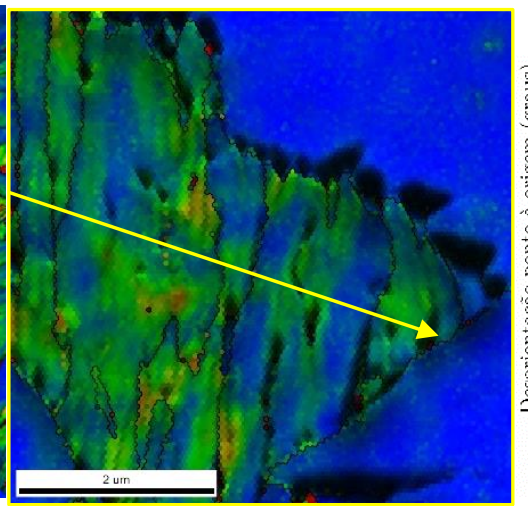

(b)

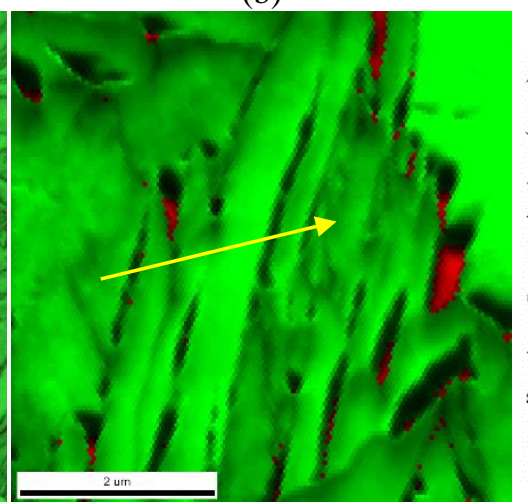

(e)

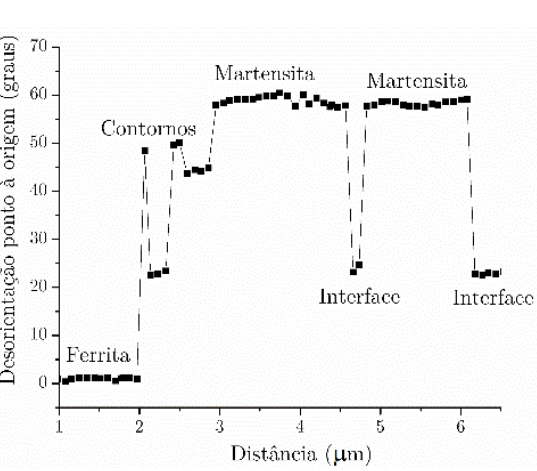

(c)

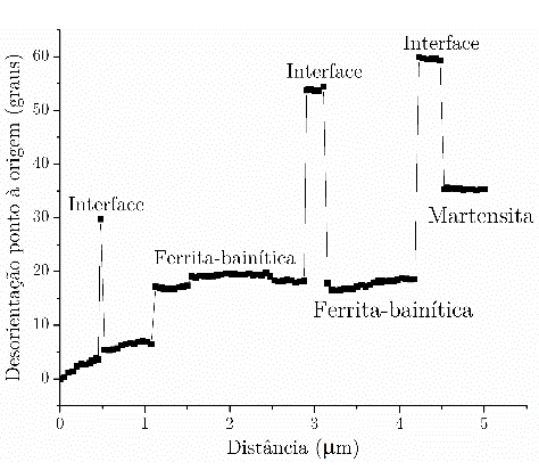

(f)

Figura 7-25. Desorientação média de kernel e identificação de fases por EBSD da amostra Q\&P austenitizada intercriticamente a $800{ }^{\circ} \mathrm{C}$, temperada a $318^{\circ} \mathrm{C}$ e particionada a $400{ }^{\circ} \mathrm{C}$ por $100 \mathrm{~s}$. (a) Mapa de desorientação média de kernel com contornos de grau com desorientações maiores a $15^{\circ}$ para avaliação de uma região de martensita revenida (contorno em amarelo); (b) mapa ampliado da desorientação de kernel de uma região de martensita revenida; (c) valores médios da desorientação ponto-à-origem do caminho indicado pela seta na figura (b); (d) e (e) EBSD do mapa de identificação de fases da região ampliada (quadro amarelo), indicando por meio da seta amarela o caminho usado para análise da desorientação de kernel; (f) valores médios da desorientação ponto-à-origem do caminho indicado pela seta amarela na figura (e). 
Dessa forma, por meio da avaliação do gradiente de desorientação no mapa de componentes de desorientação local, a magnitude da deformação plástica local pode ser analisada. Essa abordagem permite a avaliação qualitativa dos pequenos gradientes de deformação local que estão intrinsecamente ligados aos gradientes de orientação, da mesma forma que a deformação plástica está associada fisicamente com o movimento das discordâncias e com a rotação do reticulado cristalino [233]. A comparação dos resultados mostra que as amostras deformadas apresentam um aumento na rotação da estrutura local e, portanto, um aumento médio da desorientação para um píxel especifico em relação a seus vizinhos o que, por sua vez, permite a identificação dos microconstituintes em microestruturas complexas tratadas pelos processos de Q\&P e HSQ\&P.

\subsubsection{EBSD e Nanoindentação}

Nesta seção é proposta uma abordagem de caracterização microestrutural e mecânica em escala local e global, baseada na combinação das técnicas de EBSD e nanoindentação instrumentada. A ideia principal foi obter informação dos microconstituintes presentes nas microestruturas das amostras tratadas por Q\&P e HSQ\&P e relacionar as fases com as curvas de nanoindentação. Na Figura 7-26 é apresentada uma malha de nanoindentações $10 \times 10 \mu \mathrm{m}^{2}$ separadas por $10 \mu \mathrm{m}$, tanto nas abscissas quanto nas ordenadas, superposta à imagem obtida por EBSD, correspondente à amostra Q\&P, austenitizada intercriticamente a $800^{\circ} \mathrm{C}$, temperada a $318^{\circ} \mathrm{C}$ e particionada a $400{ }^{\circ} \mathrm{C}$ por $100 \mathrm{~s}$. Esse tipo de abordagem pode ser útil para relacionar as fases às nanoindentações e a dependência da nanodureza com a orientação cristalográfica e com a distribuição e tamanho dos grãos.

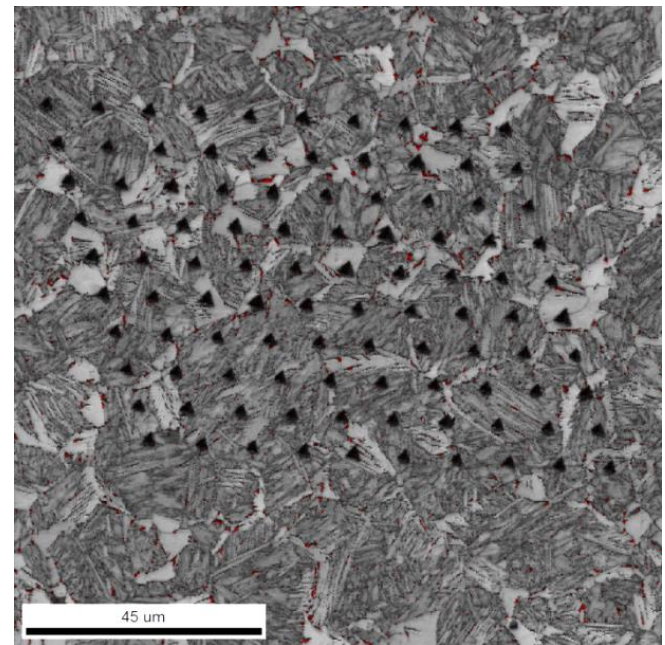

(a)

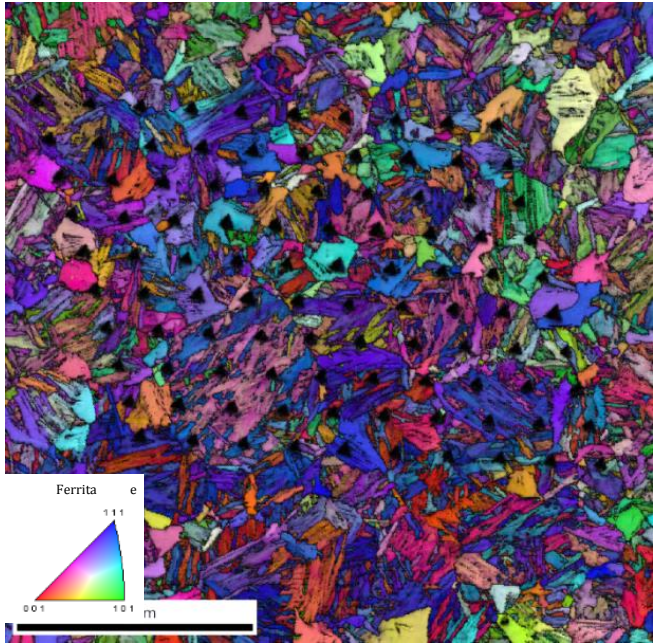

(b)

Figura 7-26. Amostra Q\&P austenitizada intercriticamente a $800{ }^{\circ} \mathrm{C}$, temperada a $318^{\circ} \mathrm{C}$ e particionada a $400{ }^{\circ} \mathrm{C}$ por 100 s. (a) Malha $10 \times 10$ das nanoindentações superpostas a um mapa de identificação de fases (CCC em cinza e CFC em vermelho); (b) mapa de orientações de grãos para a malha de nanoindentações. 
Na Figura 7-27 são mostrados alguns dos microconstituintes identificados pela correlação dos resultados de nanodureza com a identificação de fases em combinação com os mapas de EBSD de índice de qualidade e KAM. Nesta figura os círculos brancos, amarelos e vermelhos representam as regiões de martensita, ferrita-bainítica e ferrita, respectivamente. De acordo com os resultados em várias regiões e em diferentes amostras, as faixas de nanodureza estão entre 5,0 e 5,9 GPa para martensita, entre 2,6 e 4,0 GPa para a ferrita e entre os 3,1 e 5,0 GPa para a ferrita-bainítica. Por sua vez pode-se confirmar, como já mencionado na seção anterior, que a desorientação está acima dos $20^{\circ}$ para martensita, entre $10^{\circ}$ e $20^{\circ}$ para a ferrita-bainítica e menor que $2^{\circ}$ para a ferrita. A redução da nanodureza e da desorientação nas regiões ferríticas pode ser atribuída a uma menor densidade de discordâncias [171].

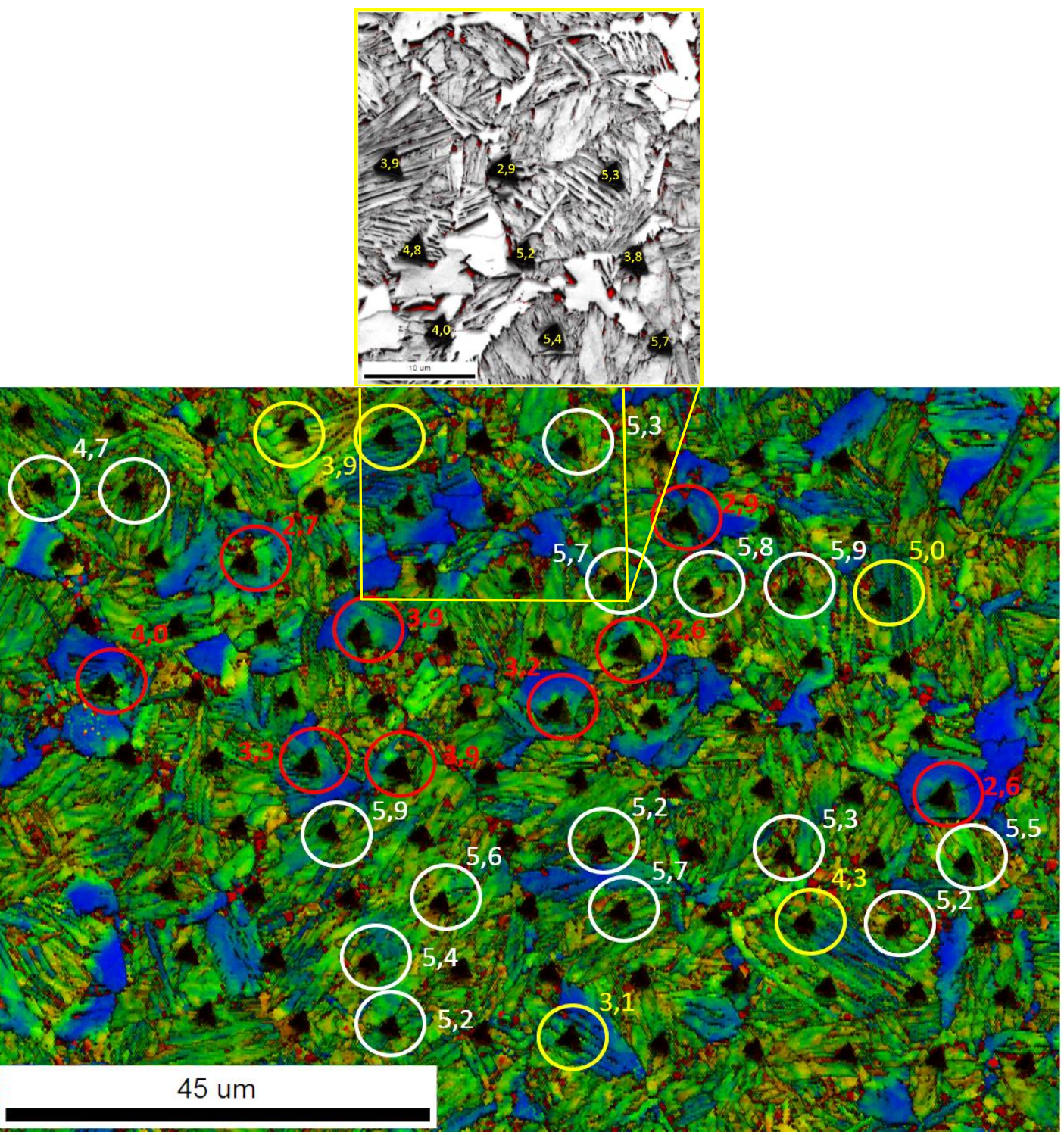

Figura 7-27. Desorientação média de kernel da amostra Q\&P austenitizada a $800{ }^{\circ} \mathrm{C}$, temperada a $318^{\circ} \mathrm{C}$ e particionada a $400^{\circ} \mathrm{C}$ por $100 \mathrm{~s}$. Os círculos brancos, amarelos e vermelhos identificam regiões de martensita, ferrita-bainítica e ferrita, respectivamente. Resultados em GPa. 
Observa-se que existe uma superposição dos valores de nanodureza para a ferrita e a ferritabainítica na faixa de valores entre 3 e $4 \mathrm{GPa}$, o que pode ser atribuído à influência na nanodureza de fatores como: tamanho de grão, orientação cristalográfica, aumento ou diminuição na densidade de discordâncias, tensões geradas pelas fases circundantes, etc. No entanto, a distinção entre os dois constituintes é possível graças as suas diferenças morfológicas observadas pela imagem de qualidade combinada com a desorientação de Kernel. Em relação à martensita, esta apresenta maiores valores de KAM quando comparada com a ferrita-bainítica, o que permite sua distinção.

Cabe destacar que as regiões identificadas como ferrita-bainítica (Figura 7-28(a)) apresentaram variações (mudanças escalonadas) nas curvas de carregamento conhecidos como pop-ins, como apresentado na Figura 7-28(c). Essa região corresponde à ferrita-bainítica identificada na parte inferior da Figura 7-27 com o valor de nanodureza de 3,1 GPa. Na Figura 7-28(b) observa-se que as placas de ferrita (cor verde) contêm filmes de austenita retida (cor vermelha). Esses pop-ins podem estar relacionados à transformação de fase induzida pela deformação da austenita retida para martensita, como reportado na literatura [175, 234]. Outros pesquisadores destacam que os pop-ins têm sido detectados como resultado de um amolecimento geométrico quando uma tensão externa é aplicada e, uma variante específica da martensita é selecionada [235], o que minimiza a energia total durante a transformação de austenita para martensita induzida por deformação [175, 236]. Os múltiplos pop-ins observados podem estar relacionados à transformação gradual da austenita na medida em que a indentação avança, sendo que a austenita menos estável transforma nos primeiros estágios da deformação plástica.

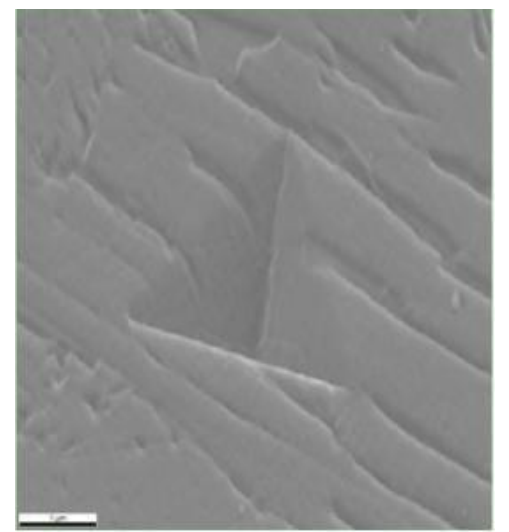

(a)

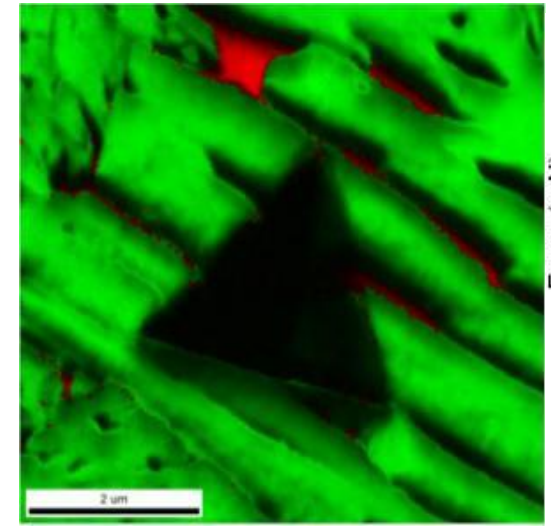

(b)

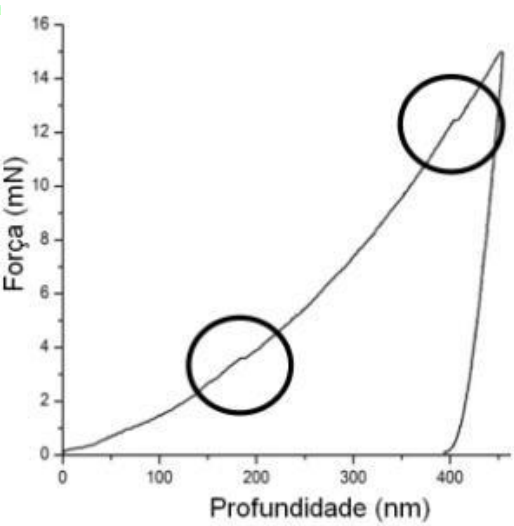

(c)

Figura 7-28. Indentação em uma região identificada por desorientação de kernel como ferrita-bainítica. (a) Imagem por microscopia eletrônica de varredura; (b) identificação de fases por EBSD. As regiões em verde representam a estrutura $\mathrm{CCC}$ e as regiões em vermelho a estrutura $\mathrm{CFC}$, neste caso austenita; (c) curva de carregamento-descarregamento da nanoindentação, os círculos indicam as regiões com os pop-ins. 
As amostras tratadas por HSQ\&P foram igualmente analisadas por EBSD e nanoindentação a fim de relacionar os microconstituintes e suas características (como tamanho e distribuição dos grãos) aos resultados de nanodureza. Na Figura 7-29 são apresentados os resultados para as amostras HSQ\&P austenitizadas intercriticamente a $800^{\circ} \mathrm{C}$, deformadas a $750{ }^{\circ} \mathrm{C}$ (Figura 7-29(a)) e a $800{ }^{\circ} \mathrm{C}$ (Figura 7-29(b)), ambas temperadas a $318^{\circ} \mathrm{C}$ e particionadas a $400{ }^{\circ} \mathrm{C}$ por 100 s. No que lhe concerne, na Figura 7-30 são apresentados os resultados de nanoindentação relacionando por EBSD à imagem de qualidade, à identificação das fases e KAM para as amostras HSQ\&P austenitizadas intercriticamente a $800{ }^{\circ} \mathrm{C}$, temperadas a $328{ }^{\circ} \mathrm{C}$ e particionadas a $400{ }^{\circ} \mathrm{C}$ por $100 \mathrm{~s}$. O tamanho e distribuição da austenita (estrutura CFC) são indicados pelas regiões em vermelho, enquanto as regiões de ferrita e martensita (estrutura CCC) aparecem em verde. As regiões em verde mais escuro indicam regiões com menor banda de contraste ${ }^{12}$ (BC, Band-contrast) devido à alta densidade de discordâncias, o que determina as regiões de martensita, o que pode ser confirmado pelos altos valores de nanodureza nessas regiões. Dessa forma, com a técnica de nanoindentação combinada com EBSD foi possível validar as hipóteses da identificação de fases usando a desorientação média de kernel apresentada na seção anterior (Figuras 7-22 a 7-25).

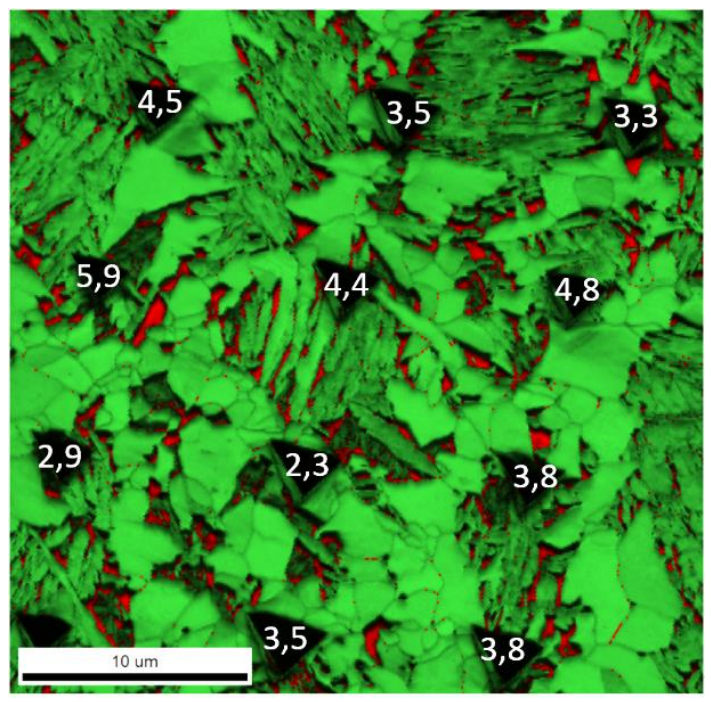

(a)

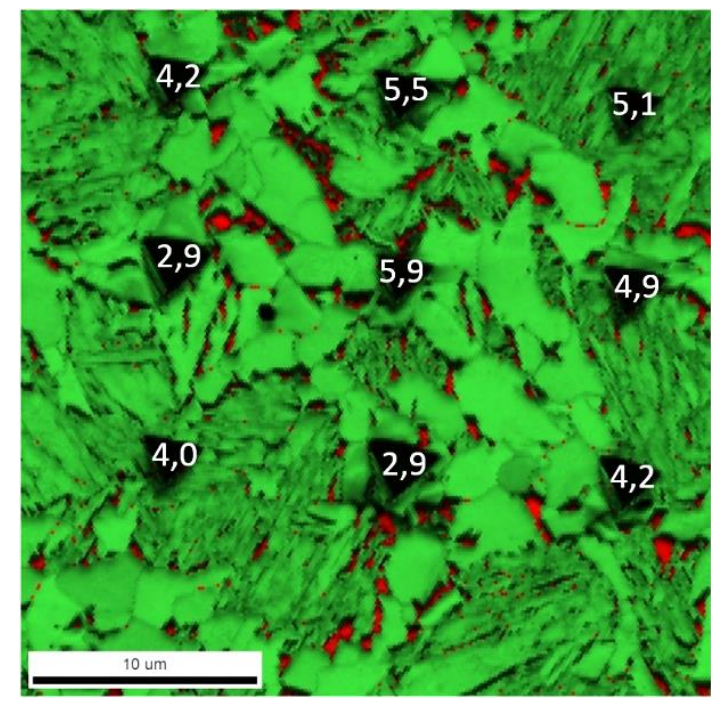

(b)

Figura 7-29. Mapa de EBSD e nanoindentações da amostra HSQ\&P, austenitizada intercriticamente a $800^{\circ} \mathrm{C}$, temperada a $318^{\circ} \mathrm{C}$ e particionada a $400{ }^{\circ} \mathrm{C}$ por $100 \mathrm{~s}$. As amostras foram deformadas em $30 \%$ a: (a) $750{ }^{\circ} \mathrm{C}$, (b) $800^{\circ} \mathrm{C}$. Os resultados das nanodureza em GPa. As regiões em verde indicam as fases CCC (ferrita ou martensita) e as vermelhas a fase CFC (austenita).

\footnotetext{
$12 \mathrm{O}$ contraste de banda $(\mathrm{BC})$ é um fator de qualidade dos padrões de elétrons retroespalhados (EBSP, do inglês, electron backscatter patterns) derivado da transformada de Hough que descreve a intensidade média das bandas de Kikuchi (a banda de Kikuchi representa um certo plano atômico que pode ser descrito por seu vetor normal) em relação à intensidade global dentro do EBSP [295].
} 
Na Figura 7-30 são apresentados os resultados da identificação das fases, a desorientação kernel e o mapa de orientações de grãos de uma região com uma malha de nanoindentações de $4 \times 4$ da amostra HSQ\&P austenitizada intercriticamente a $800{ }^{\circ} \mathrm{C}$, deformada a $750{ }^{\circ} \mathrm{C} \mathrm{em}$ $30 \%$, temperada a $328^{\circ} \mathrm{C}$ e particionada a $400^{\circ} \mathrm{C}$ por $100 \mathrm{~s}$. Na Figura 7-30(a) as regiões em vermelho indicam a fase CFC (austenita) e as regiões em cinza as fases CCC (ferrita ou martensita). Nas regiões CCC pode se distinguir claramente a ferrita da martensita pela morfologia dos grãos. Enquanto a ferrita apresenta grãos com forma equiaxial em tons de cinza mais claros, as regiões de martensita, constituídas principalmente de ripas que se apresentam na forma de feixes, apresentam tons de cinza mais escuros, provavelmente causado pela grande densidade de discordâncias. A distinção da ferrita e a martensita a partir da comparação entre a forma dos grãos e os tons de cinza é validada pelos resultados de nanodureza e KAM (Figura 7-30(b)) nessas regiões. Como se observa, os feixes de martensita agrupados em pacotes possuem maiores valores de KAM (representados pela tonalidade verde) e estão contornados pelos grãos de ferrita (grãos em azul, devido à menor desorientação kernel dentro do grão) formados na temperatura intercrítica e durante a deformação. Devido à diferença nos valores de dureza, observa-se que nas regiões de martensita o tamanho das indentações é levemente menor que na ferrita. $\mathrm{Na}$ amostra HSQ \&P, deformada a $800{ }^{\circ} \mathrm{C}$ em $30 \%$, enquanto a martensita apresenta resultados de nanodureza entre 4,9 e 6,8 GPa, os grãos de ferrita têm valores de nanodureza entre 2,8 e 3,9 GPa. O teor de carbono da martensita é o principal responsável pela sua alta dureza e resistência mecânica. Comparando esses resultados (valor médio) com os da amostra Q\&P se observa um incremento de $\approx 15 \%$ na nanodureza da martensita. Esse aumento pode estar relacionado ao aumento na densidade de defeitos, como discordâncias ou maclas, ou à diminuição do tamanho dos grãos pela deformação em alta temperatura. Portanto, do ponto de vista microestrutural, a martensita possui dureza e resistência mecânica superiores à da ferrita, mesmo tratando-se de uma martensita com teores de carbono muito baixos [237].

Comparando os resultados de nanodureza no mapa de orientações de grãos (Figura 7-30(c)) à primeira vista se observa que a nanodureza é levemente maior nos grãos com tendência à orientação [111], que nos grãos que tendem a estar orientados nas direções [001] e [101], o que poderia estar associado a um maior esforço requerido para ativar e deslizar as discordâncias na direção [111]. A discussão desse comportamento será feita mais adiante. 


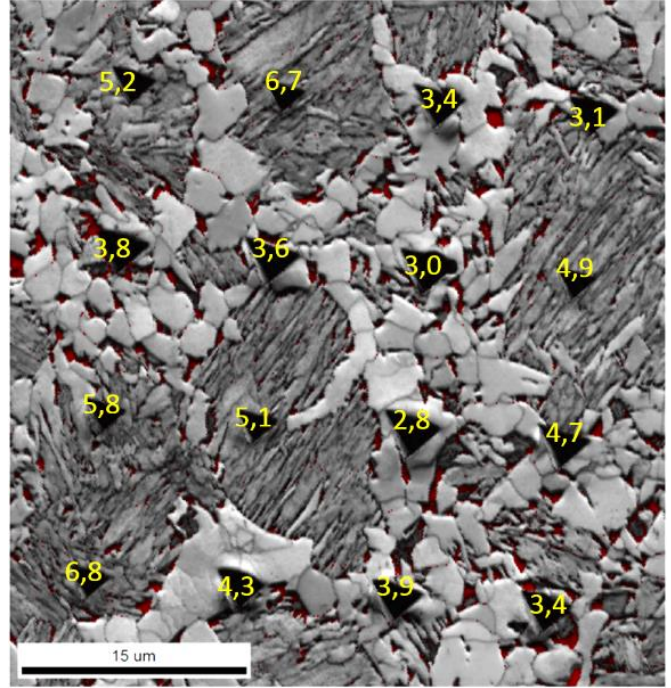

(a)

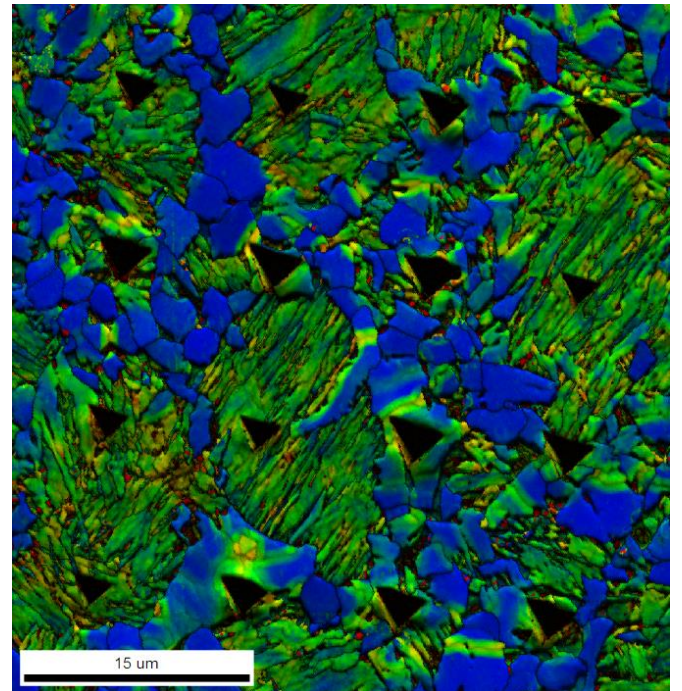

(b)

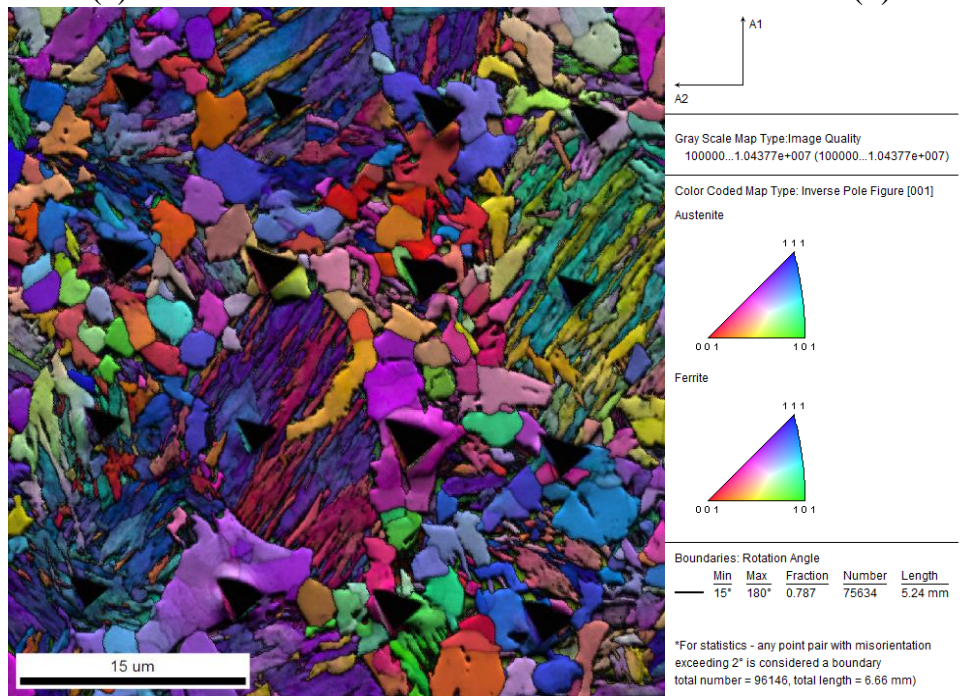

(c)

Figura 7-30. Superposição das marcas de nanoindentação no: (a) mapa de identificação de fases (em vermelho a austenita); (b) desorientação de kernel, e (c) mapa de orientações de grãos. Amostra HSQ\&P, austenitizada intercriticamente a $800{ }^{\circ} \mathrm{C}$, deformada a $800{ }^{\circ} \mathrm{C}$ em $30 \%$, temperada a $328^{\circ} \mathrm{C}$ e particionada a $400{ }^{\circ} \mathrm{C}$ por $100 \mathrm{~s}$.

Por causa do pequeno tamanho dos grãos, existe dificuldade para identificar e caracterizar claramente por meio de nanoindentação o comportamento mecânico tanto da austenita retida como da martensita fresca. Dessa forma, com o intuito de avaliar a nanodureza da martensita fresca e correlacionar o comportamento da austenita retida sob o efeito da deformação (efeito TRIP) com a orientação cristalográfica, os tamanhos das indentações foram reduzidos, diminuindo a força aplicada $(1,5 \mathrm{mN})$ durante a indentação, como mostrado na Figura 7-31. 


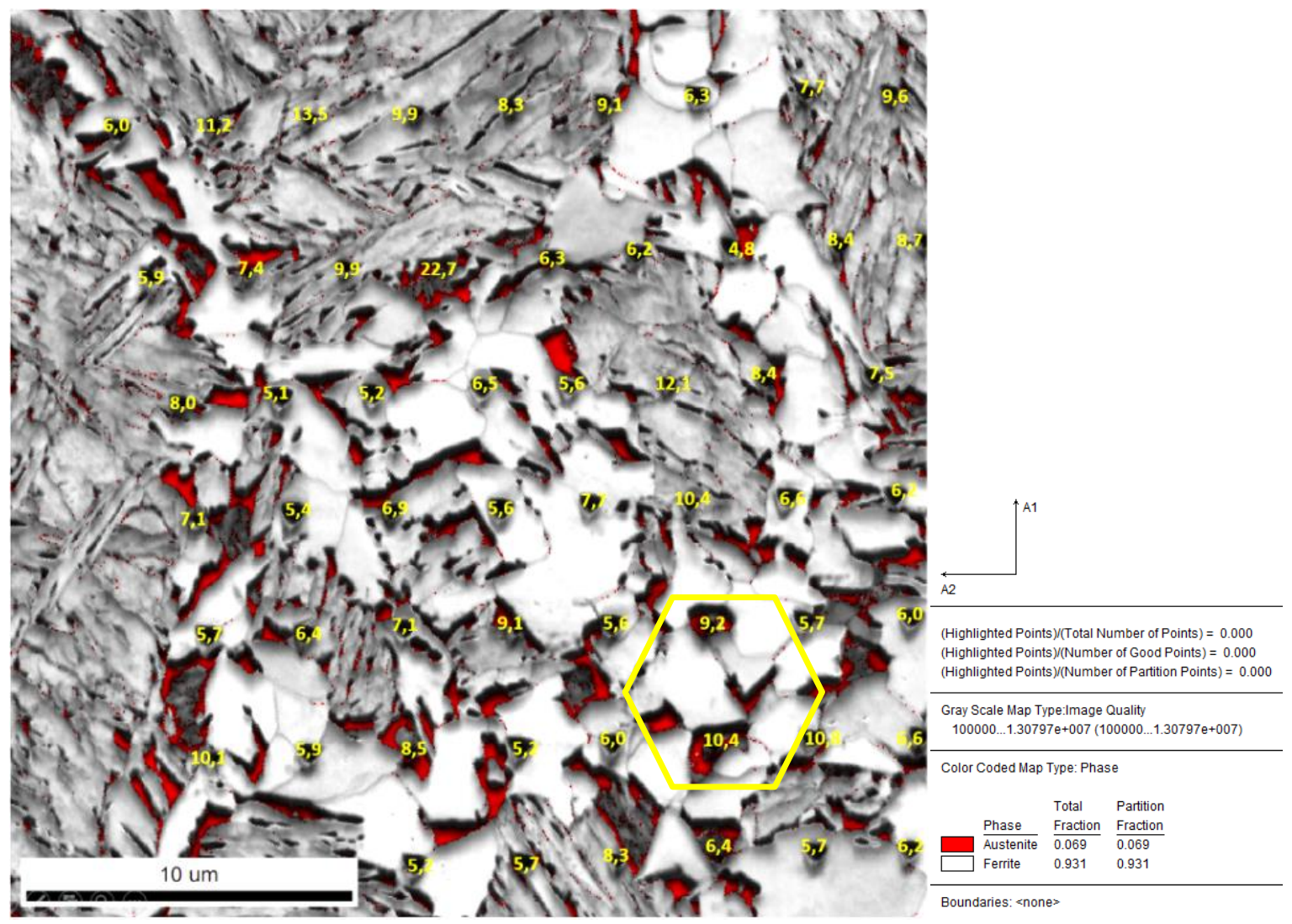

Figura 7-31. Mapa de identificação das fases (austenita em vermelho) e resultados de nanodureza. Amostra HSQ\&P, austenitizada intercriticamente a $800{ }^{\circ} \mathrm{C}$, deformada a $800{ }^{\circ} \mathrm{C} \mathrm{em} 30 \%$, temperada a $318{ }^{\circ} \mathrm{C}$ e particionada a $400{ }^{\circ} \mathrm{C}$ por $100 \mathrm{~s}$.

A região delimitada pelo hexágono na Figura 7-31 apresenta duas regiões de martensita fresca indentadas. Essa região junto às curvas de nanoindentação são apresentados na Figura 7-32. Nessa figura observa-se claramente o comportamento dos pop-ins durante o estágio do carregamento, associados à nucleação de discordâncias em grande escala no início da deformação plástica [171], à ativação de discordâncias pré-existentes [234], ao efeito TRIP da austenita presente dentro do grão [175], ou como já foi comentado, como resultado de um amolecimento geométrico quando uma tensão externa é aplicada e, uma variante específica da martensita é selecionada [235]. No caso da primeira hipótese, o início da nucleação de discordâncias nos grãos de austenita pode ser observado com base no desvio da solução hertziana $^{13}$ (curva azul pontilhada) indicado pela seta vermelha na Figura 7-32. Antes do início dos pop-ins, isto é, antes de $\approx 40 \mathrm{~nm}$ de profundidade de penetração, é provável que o indentador não encontre discordâncias e o primeiro pop-in observado durante o carregamento é provável que seja uma consequência do início da nucleação de discordâncias [235]. Os subsequentes

\footnotetext{
${ }^{13}$ A deformação da parte elástica na curva de carregamento $(P)$ vs. profundidade $(h)$ no teste de nanoindentação pode ser descrita, segundo a solução elástica hertziana, como: $P=\frac{4}{3} E^{*} R_{i}^{1 / 2} h^{3 / 2}$, em que $E^{*}$ é o modulo reduzido da indentação e $R_{i}$ é o raio na ponta do indentador $(\approx 450 \mathrm{~nm})$.
} 
pop-ins observados na curva de carregamento-deslocamento durante a nanoindentação de grãos de austenita metaestável correspondem ao início da transformação martensítica induzida pela deformação [170]. Portanto, uma vez que o primeiro pop-in representa a transição da deformação elástica para elasto-plástica durante a indentação [234], as tensões nos pop-ins durante a indentação podem ser estimadas a partir da mecânica do contato elástico Hertziano [234]. Cabe destacar que esses pop-ins foram observados principalmente nas regiões contendo blocos de austenita o que poderia indicar menor estabilidade neste tipo de austenita retida. Entretanto, os resultados da indentação 2 na Figura 7-32 não apresentaram o comportamento de pop-ins. Isto pode ser devido à alta densidade de discordâncias pré-existentes [238] no volume indentado da martensita fresca.

O tamanho (profundidade e largura) das impressões feitas pelo nanoindentador com cargas menores pareceram apropriadas para avaliação da nanodureza de fases individuais, uma vez que as indentações estiveram claramente localizadas em áreas de martensita e ferrita, evitando assim, as contribuições dos contornos de grão entre as fases.
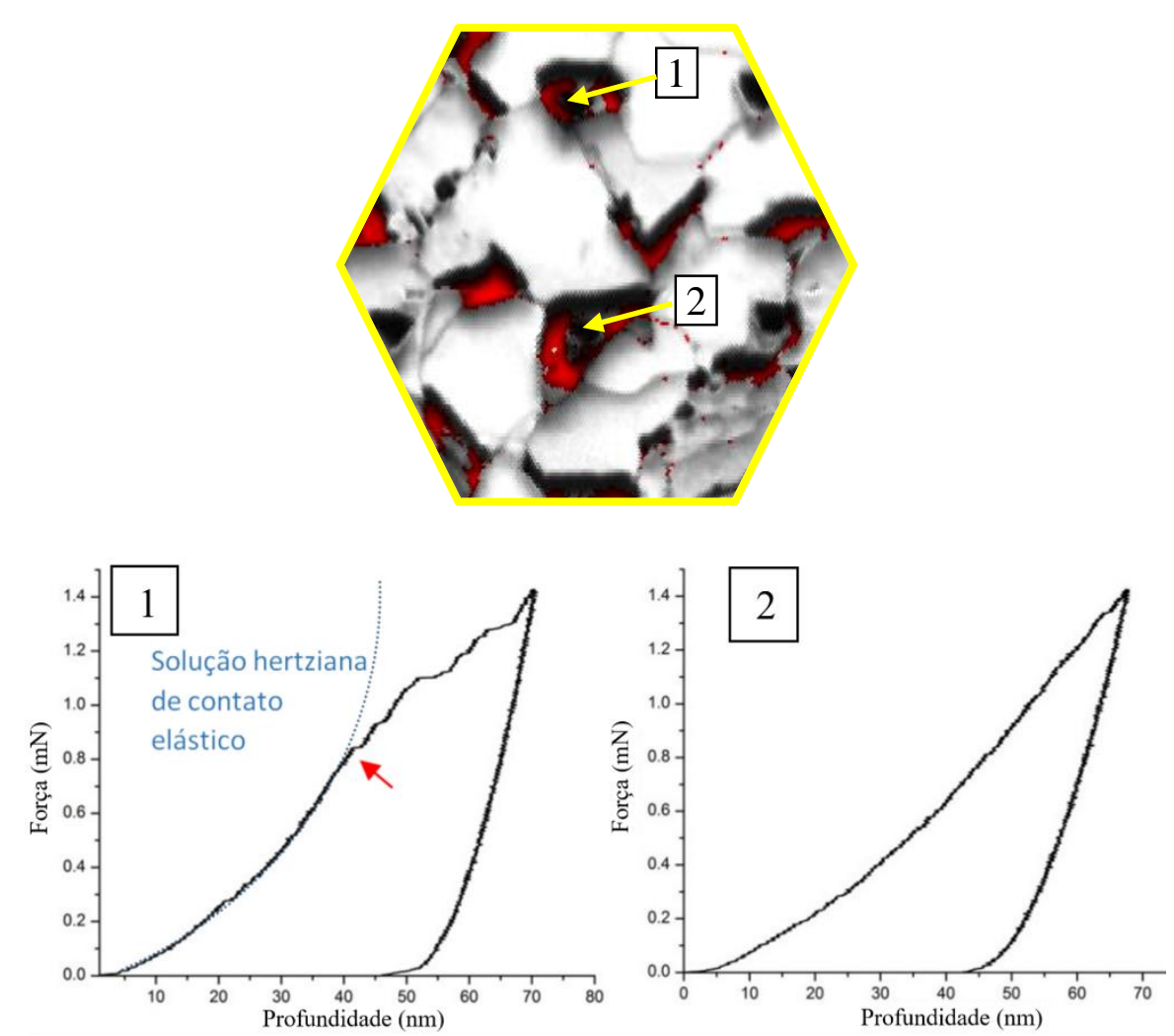

Figura 7-32. Hexágono sinalizado na Figura 7-31 e curvas de nanoindentação para regiões identificadas como martensita fresca.

Na Figura 7-33 são apresentados os resultados das nanoindentações superpostas aos resultados de EBSD combinando a imagem de qualidade, o mapa de orientações de grãos 
(Figura 7-33(a)) e o fator de Schmid (Figuras 7-33(b) e 7-33(c)) para a amostra HSQ\&P austenitizada intercriticamente a $800{ }^{\circ} \mathrm{C}$, deformada a $800{ }^{\circ} \mathrm{C}$ em $30 \%$, temperada a $318{ }^{\circ} \mathrm{C}$ e particionada a $400{ }^{\circ} \mathrm{C}$ por $100 \mathrm{~s}$. O fator de Schmid [120] foi calculado uma vez que esse critério oferece uma indicação da resistência à deformação de uma região particular para um certo estado de tensões.

Nos resultados da Figura 7-33 é observado, de forma similar ao que foi observado na Figura 7-30, que os grãos de ferrita e martensita com tendência à orientação [111] possuem maiores valores de nanodureza, que os grãos que tendem a estar orientados nas direções [001] e [101] ${ }^{14}$. Nos resultados das Figura 7-33(b) e 7-33(c) os grãos que têm maior fator de Schmid são indicados em vermelho, enquanto os grãos com menor fator de Schmid são indicados em azul. Comparando os resultados dos fatores de Schmid se observa que a grande maioria dos grãos de ferrita próximos à orientação [111] apresentam um fator de Schmid menor que os grãos com outros tipos de orientação. Isso significa que para essa orientação é necessária uma força (ou tensão ${ }^{15}$ ) maior para que ocorra a deformação plástica por deslizamento das discordâncias no sistema de escorregamento de máxima densidade atômica (110) para a estrutura CCC. Já no caso dos grãos orientados nas direções [001] e [101] os fatores de Schmid são similares, e possuem os maiores fatores de Schmid da microestrutura.

Segundo a teoria de Schmid, grãos com maior fator de Schmid estão prestes a deformar, ou sofrem transformação de fase induzida mecanicamente mais rapidamente sendo, portanto, menos estáveis [120], já que a tensão (cisalhante) crítica projetada, para a ocorrência da deformação plástica ou transformação martensítica, é atingida mais rapidamente. Isso ocorre devido a que os planos de deslizamento nesses grãos não precisam sofrer muita rotação antes que a tensão de cisalhamento projetada (ou resolvida) atinja um valor crítico [226], uma vez que as discordâncias estão distribuídas de forma muito mais homogênea entre os planos de deslizamento [239]. Dentro de cada grão (ou estrutura do cristal) as diferentes densidades atômicas dos planos, dependentes da direção de deslizamento, podem estar relacionadas à ativação de um maior ou menor número de sistemas de deslizamento. Desta forma, nas estruturas cúbicas o deslizamento ocorre predominantemente nos planos de maior densidade atômica e na direção de maior empacotamento, o que representa a menor distância entre os átomos ou a direção de menor energia. Assim, os grãos orientados nas direções [001] ou [101]

\footnotetext{
${ }^{14}$ Essa afirmação está baseada não só nos resultados apresentados aqui, mas também em outros resultados de EBSD e nanoindentação realizados na presente pesquisa em amostras Q\&P e HSQ\&P.

${ }^{15}$ A tensão necessária para provocar a deformação é conhecida como tensão de cisalhamento projetada ou tensão de cisalhamento crítica projetada (chamada em inglês: resolved shear stress).
} 
podem ativar mais facilmente um maior número de sistemas de deslizamento e, portanto, precisariam valores menores de tensão para escoar plasticamente, o que explicaria a menor resistência à deformação plástica durante a nanoindentação e os menores valores de nanodureza nessas direções (comparar as indentações delimitadas pelo retângulos e quadrados amarelos nas Figuras 7-33(b) e 7.33(c)), como mostrado na Figura 7-34.

Na Figura 7-33(c) é apresentada a relação do fator de Schmid para as regiões identificadas como austenita (CFC). É interessante observar que os grãos de austenita que estão embebidos dentro dos grãos de ferrita possuem um maior fator de Schmid e, portanto, poderiam atingir mais rapidamente a tensão critica projetada (lei de Schmid) tendo, por conseguinte, maior possibilidade de deformar plasticamente do que os grãos que estão nos contornos entre a ferrita e a martensita. Em outras palavras, os grãos de austenita identificados com o menor fator de Schmid (grãos em cor amarelo claro, verde ou azul) poderiam ser muito mais estáveis (neste caso, seria uma estabilidade dependente da orientação cristalográfica). De acordo com Tirumalasetty et al. [226], durante a deformação ocorre rotação, preferencialmente, nos grãos de austenita (pudendo causar variação na orientação dos planos e direções de deslizamento) que têm os maiores fatores de Schmid. Na medida em que avança a deformação pode ocorrer a redução dos fatores de Schmid nesses grãos e, portanto, ocasionar o decréscimo da tensão crítica projetada para que ocorra a transformação martensítica. Por conseguinte, a rotação dos grãos de austenita, que são transformados em martensita nos últimos estágios da deformação, é um fator adicional na contribuição da estabilidade mecânica da austenita para aços TRIP de baixo carbono [226].

No entanto, cabe ressaltar que as propriedades mecânicas (e a estabilidade dos grãos) de planos cristalográficos individuais também dependem, além do fator de Schmid (ou seja, da orientação cristalográfica), da composição química (principalmente do teor de carbono), do tamanho do volume do grão e das restrições impostas pelos microconstituintes circundantes. Por outro lado, nessas análises as profundidades das áreas indentadas e dos tamanhos subsuperficiais dos grãos são desconhecidos, de modo que os resultados das medidas de nanodureza podem ter sido afetados pela presença de fases moles ou duras que se encontram embaixo da região indentada. Uma forma de esclarecer a profundidade da indentação e o comportamento subsuperficial dos grãos (incluindo a análise na densidade de discordâncias e o alcance da deformação plástica) seria realizando a preparação transversal por FIB do perfil da indentação e fazer a análise posterior por microscopia eletrônica de transmissão. 


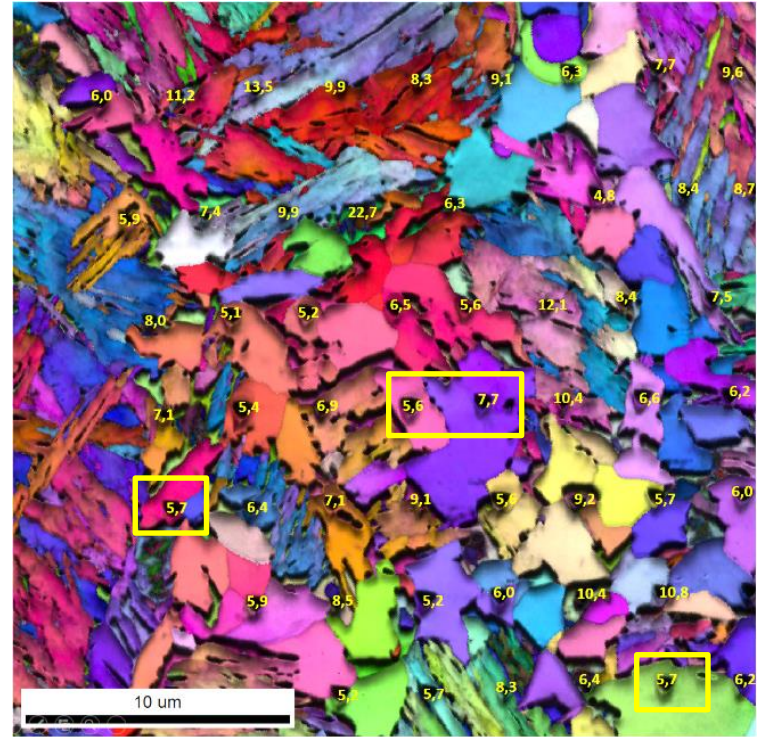

Color Coded Map Type: Inverse Pole Figure [001]

Fernte
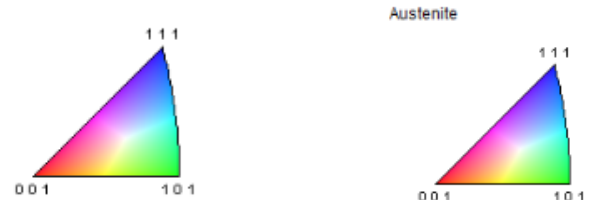

a)

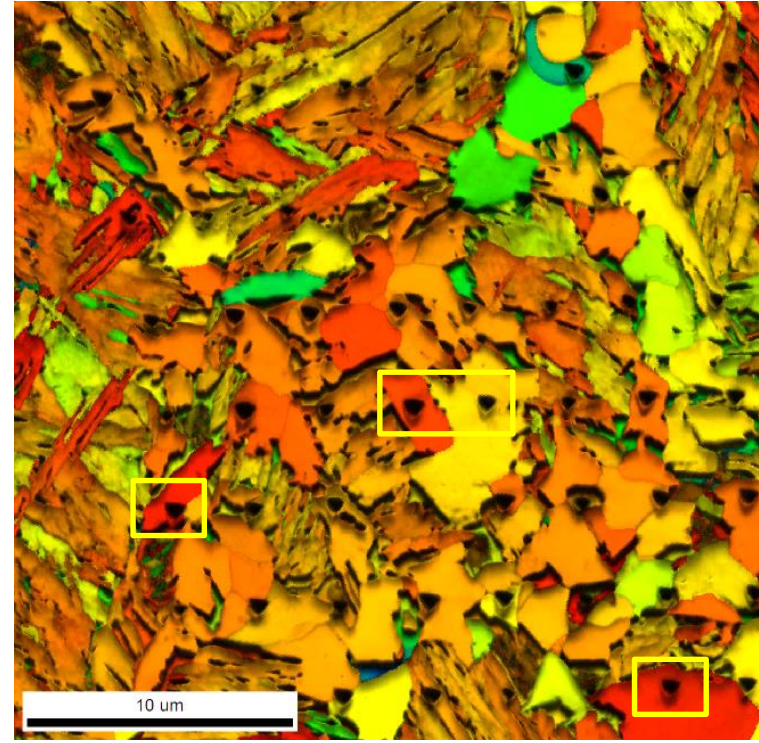

Color Coded Map Type: Schmid Factor

Sigma Values:
$\begin{array}{ccc}1.0 & 0.0 & 0.0\end{array}$

$\begin{array}{lll}0.0 & 0.0 & 0.0 \\ 0.0 & 0.0 & 0.0\end{array}$

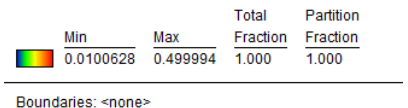

(b)

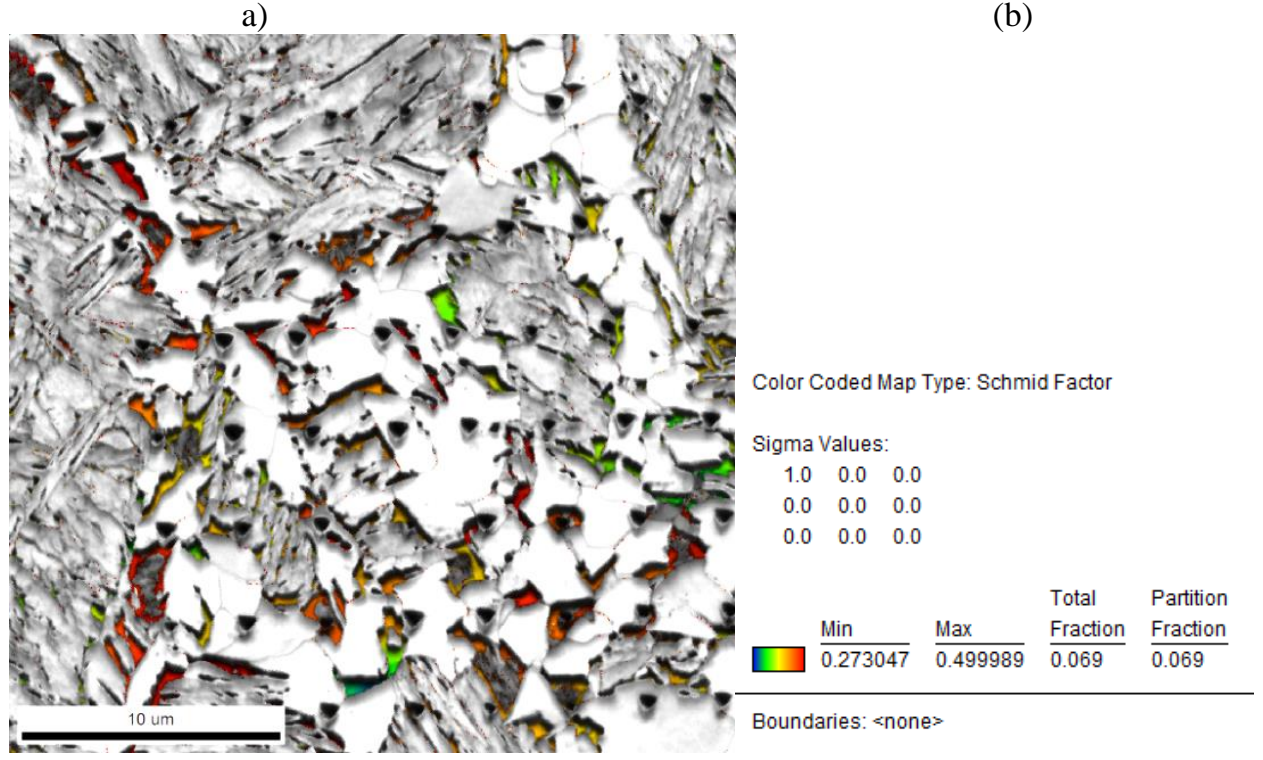

(c)

Figura 7-33. Superposição das nanoindentações aos resultados de EBSD da amostra HSQ\&P, austenitizada intercriticamente a $800{ }^{\circ} \mathrm{C}$, deformada a $800^{\circ} \mathrm{C}$ em $30 \%$, temperada a $318^{\circ} \mathrm{C}$ e particionada a $400{ }^{\circ} \mathrm{C}$ por $100 \mathrm{~s}$. (a) Mapa de orientações de grãos combinada com a imagem de qualidade (IQ); (b) fator de Schmid combinado com IQ para as fases CFC e CCC; (c) fator de Schmid combinado com IQ para a fase CFC. 


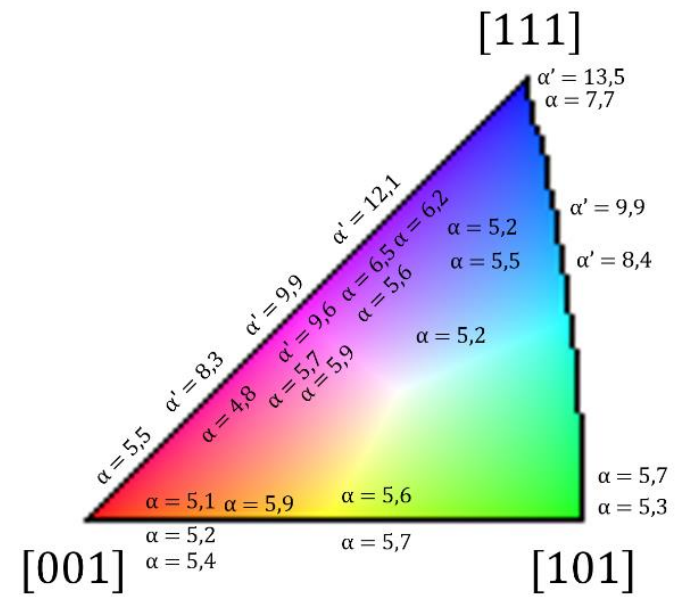

Figura 7-34. Valores de nanodureza superpostos sobre o triângulo unitário de referência para as orientações da fase CCC, indicando os planos [111], [001] e [101] pelas cores azul, vermelha e verde, respectivamente. $\alpha$ e $\alpha^{\prime}$ representam ferrita e martensita, respectivamente. Valores em GPa. Valor da carga nas nanoindentações: 1,5 $\mathrm{mN}$.

\subsubsection{Estereologia e dureza}

A partir de observações por MEV a ferrita foi quantificada por estereologia em pelo menos três micrografias para cada tratamento, usando uma malha de 391 pontos. Nas Tabelas 7-2 e 7-3 os resultados dessa quantificação são relacionados junto aos da austenita retida obtida por difração de raios X e os da microdureza. Na Tabela 7-2 são apresentados os resultados das amostras tratadas por têmpera e partição (Q\&P), enquanto na Tabela 7-3 os das amostras que incluem prévia deformação, tanto a frio (CS) como a quente (HS).

Tabela 7-2. Resultados de microdureza $\left(\mathrm{HV}_{0,5}\right)$, porcentagens de ferrita $(\alpha)$ e de austenita $(\gamma)$ para as amostras tratadas por têmpera e partição (Q\&P), para temperaturas de austenitização intercrítica (IT) de $800^{\circ} \mathrm{C}$ e $820^{\circ} \mathrm{C}$.

\begin{tabular}{cccccc}
\hline Tratamento térmico & $\mathrm{QT}\left({ }^{\circ} \mathrm{C}\right)$ & $\mathrm{Pt}(\mathrm{s})$ & $\mathrm{HV}_{0,5}$ & $\alpha(\%)$ & $\gamma(\%)$ \\
\hline & 308 & 100 & $380 \pm 13$ & 18,3 & 5,7 \\
$\mathrm{Q} \& \mathrm{P}$ & 308 & 500 & $355 \pm 17$ & 23,7 & 3,7 \\
$\left(\mathrm{IT}=800^{\circ} \mathrm{C}\right)$ & 318 & 100 & $373 \pm 13$ & 21,4 & 8,1 \\
& 318 & 500 & $352 \pm 10$ & 25,1 & 5,6 \\
& 328 & 100 & $348 \pm 11$ & 30,4 & 6,7 \\
\hline $\mathrm{Q} \& \mathrm{P}$ & 328 & 500 & $338 \pm 14$ & 32,3 & 4,3 \\
\hline$\left(\mathrm{IT}=820^{\circ} \mathrm{C}\right)$ & 328 & 100 & $321 \pm 15$ & 30,9 & 7,7 \\
\hline
\end{tabular}

$\overline{\mathrm{QT}}$, Pt, $\mathrm{HV}_{0,5}, \alpha$ e $\gamma$ representam a temperatura de têmpera, tempo de partição, dureza Vickers $(0,5 \mathrm{kgf})$, ferrita $\mathrm{e}$ austenita, respectivamente. 
Tabela 7-3. Resultados de microdureza $\left(\mathrm{HV}_{0,5}\right)$, porcentagens de ferrita $(\alpha)$ e de austenita $(\gamma)$ para as amostras tratadas por têmpera e partição (Q\&P) com prévia deformação a frio (CSQ\&P) ou a quente (HSQ\&P), e temperaturas de austenitização intercrítica (IT) de $800{ }^{\circ} \mathrm{C}$ e $820^{\circ} \mathrm{C}$.

\begin{tabular}{|c|c|c|c|c|c|c|c|c|c|c|c|}
\hline \multirow{2}{*}{$\begin{array}{l}\text { Tratamento } \\
\text { termomecânico }\end{array}$} & \multirow{2}{*}{$\mathrm{QT}\left({ }^{\circ} \mathrm{C}\right)$} & \multirow{2}{*}{$\mathrm{Pt}(\mathrm{s})$} & \multicolumn{3}{|c|}{$\varepsilon=10 \%$} & \multicolumn{3}{|c|}{$\varepsilon=30 \%$} & \multicolumn{3}{|c|}{$\varepsilon=50 \%$} \\
\hline & & & $\mathrm{HV}_{0,5}$ & $\alpha(\%)$ & $\gamma(\%)$ & $\mathrm{HV}_{0,5}$ & $\alpha(\%)$ & $\gamma(\%)$ & $\mathrm{HV}_{0,5}$ & $\alpha(\%)$ & $\gamma(\%)$ \\
\hline \multirow{6}{*}{$\begin{array}{c}\text { HSQ\&P; } \\
\text { IT = } 800^{\circ} \mathrm{C} \\
\mathrm{T} \varepsilon=750{ }^{\circ} \mathrm{C}\end{array}$} & 308 & 100 & $310 \pm 7$ & 41,6 & 8,6 & $296 \pm 8$ & 43,8 & 10,3 & $329 \pm 5$ & 35,7 & 10,1 \\
\hline & 308 & 500 & & & & $287 \pm 10$ & 31,2 & & $309 \pm 5$ & 37,3 & \\
\hline & 318 & 100 & $315 \pm 7$ & 37,2 & 10,3 & $306 \pm 9$ & 41,3 & 10,4 & $361 \pm 7$ & 38,6 & 8,8 \\
\hline & 318 & 500 & & & & $298 \pm 7$ & 31,8 & & $304 \pm 13$ & 38,6 & 12,1 \\
\hline & 328 & 100 & $324 \pm 20$ & 31,0 & 9,1 & $303 \pm 8$ & 41,9 & 12,1 & $333 \pm 12$ & 42,3 & 9,8 \\
\hline & 328 & 500 & & & & $282 \pm 8$ & 35,7 & 10,3 & $310 \pm 4$ & 48,9 & \\
\hline \multirow{5}{*}{$\begin{array}{c}\text { HSQ\&P; } \\
\mathrm{IT}=800^{\circ} \mathrm{C} ; \\
\mathrm{T} \varepsilon=800^{\circ} \mathrm{C}\end{array}$} & 308 & 100 & $336 \pm 13$ & 41,3 & 6,4 & $324 \pm 7$ & 26,9 & 10,1 & $310 \pm 9$ & 35,8 & 10,9 \\
\hline & 318 & 100 & $314 \pm 7$ & 41,4 & 7,5 & $341 \pm 11$ & 22,1 & 13,3 & $302 \pm 9$ & 41,5 & 10,3 \\
\hline & 318 & 500 & & & & $336 \pm 19$ & 22,4 & & $304 \pm 9$ & 25,9 & \\
\hline & 328 & 100 & $320 \pm 13$ & 35,6 & 7,0 & $340 \pm 14$ & 33,8 & 10,0 & $300 \pm 9$ & 33,2 & 10,8 \\
\hline & 328 & 500 & & & & $334 \pm 10$ & 21,9 & & $305 \pm 15$ & 29,9 & \\
\hline $\begin{array}{c}\text { HSQ\&P; } \\
\text { IT }=820^{\circ} \mathrm{C} ; \\
\mathrm{T} \varepsilon=750^{\circ} \mathrm{C}\end{array}$ & 328 & 100 & $319 \pm 11$ & 48,4 & 9,7 & $322 \pm 15$ & 50,4 & 17,5 & & & \\
\hline CSQ\&P; & 318 & 100 & $339 \pm 10$ & 28,7 & 8,2 & & & & & & \\
\hline $\begin{array}{c}\mathrm{IT}=800^{\circ} \mathrm{C} \\
\mathrm{T} \varepsilon=20^{\circ} \mathrm{C}\end{array}$ & 328 & 100 & $313 \pm 11$ & 33,5 & 8,4 & & & & & & \\
\hline
\end{tabular}

QT, $\mathrm{Pt}, \mathrm{HV}_{0,5}, \alpha$ e $\gamma$ representam a temperatura de têmpera, tempo de partição, dureza Vickers $(0,5$ kgf), ferrita e austenita, respectivamente. $\varepsilon$ e T $\varepsilon$ representam as porcentagens e temperaturas de deformação, respectivamente.

Comparando os resultados dos tratamentos Q\&P (Tabela 7-2) se observa que com o aumento do tempo de partição houve um aumento da porcentagem de ferrita $(\approx 18 \%, \bar{\alpha})$ e diminuição tanto da porcentagem de austenita como dos valores de dureza. A diminuição da porcentagem de austenita foi observada durante o estágio de partição nas análises realizadas in situ por radiação síncrotron e foi associada à decomposição da austenita, possivelmente pela formação de ferrita-bainítica. O aumento da dureza para tempos menores de partição pode estar associado à menor formação de ferrita e, também à maior presença de martensita fresca (fase mais dura, devido ao seu alto teor de carbono) originada na têmpera final pela austenita que não foi estabilizada o suficiente durante o estágio de partição. Nesses resultados, também se observa claramente que, tanto para os tempos de partição de $100 \mathrm{~s}$ como os de $500 \mathrm{~s}$, houve diminuição da dureza com o aumento da temperatura de têmpera (QT), o que estaria relacionado com a menor formação de martensita na medida em que QT aumenta. Por sua vez, a porcentagem de austenita retida apresentou os maiores valores para a temperatura prevista pelo modelo CCE (QT de $318^{\circ} \mathrm{C}$ ), independentemente do tempo de partição (100 ou 500 s). Isso sugere que o cálculo da temperatura ótima de têmpera usando o modelo de equilibrio constrito do carbono (CCE) pode ser utilizado como parâmetro inicial para obter os maiores valores de austenita retida na temperatura ambiente. No entanto, seriam necessárias análises adicionais, principalmente com temperaturas maiores de têmpera, para afirmar essa premissa. Por outro lado, observa-se que com o aumento da QT houve um aparente aumento da porcentagem de 
ferrita. A quantificação de ferrita por estereologia, incluiu tanto as ferritas formadas em alta temperatura (intercritica e DIFT) quanto a ferrita-bainítica que se forma durante o estágio de partição. Desse modo, o incremento da fração de ferrita com o aumento da QT nas amostras $\mathrm{Q} \& \mathrm{P}$, pode ser explicado devido ao fato de que em temperaturas de têmpera mais altas é formada uma menor porcentagem de martensita e, portanto, há uma maior porcentagem de austenita para ser estabilizada no estágio de partição. Dessa forma, o enriquecimento em carbono da austenita pela partição de carbono a partir da martensita é menor, compromentendo a estabilidade da austenita. Esses fatores favorecem a transformação da austenita em ferritabainítica durante o estágio de partição, explicando o aumento da fração volumétrica de ferrita com o aumento da temperatura de têmpera.

No caso das amostras que sofreram tratamento de partição com deformação prévia em alta temperatura (HSQ\&P) ou na temperatura ambiente (CSQ\&P) observa-se que, dependendo das condições (QT e porcentagens e temperaturas de deformação) do tratamento termomecânico, houve variações consideráveis tanto nos resultados de microdureza, quanto nos resultados das porcentagens das fases ( $\alpha$ e $\gamma$ ). Quando foi realizado o planejamento experimental, decidiu-se variar a temperatura ótima de têmpera em $\pm 10^{\circ} \mathrm{C}$, com a finalidade de contemplar possíveis mudanças promovidas pela deformação prévia. De fato, esperava-se que por causa da deformação em alta temperatura a temperatura ótima de têmpera fosse deslocada para valores menores, uma vez que a maior formação de ferrita causada pela deformação implicaria em mais carbono na austenita e, em consequência, menores temperaturas $M_{S}$. No entanto, a variação da temperatura QT não causou aumentos significativos na porcentagem de $\gamma$, optando-se, portanto, por não apresentar e analisar esses resultados no trabalho.

Além disso, observa-se que, tanto para a deformação a $750^{\circ} \mathrm{C}$ como a $800^{\circ} \mathrm{C}$, a porcentagem de austenita retida na temperatura ambiente aumenta quando a deformação aumenta de $10 \%$ para $30 \%$. Já no caso do aumento de $30 \%$ para $50 \%$ no caso da deformação a $750{ }^{\circ} \mathrm{C}$ diminuiu a porcentagem de austenita, enquanto a $800^{\circ} \mathrm{C}$ não se nota a mesma tendência, sendo que só se observa essa diminuição para a QT de $318^{\circ} \mathrm{C}$. Por outro lado, o comportamento da porcentagem de ferrita no caso dos tratamentos HSQ\&P não teve a mesma tendência que as amostras Q\&P (aumento da porcentagem de $\alpha$, com o aumento de QT). Nesse caso, observa-se que com uma deformação prévia de $10 \%$, em alta temperatura, houve diminuição da porcentagem de $\alpha$, na medida em que aumenta a QT, tanto para a deformação a $750{ }^{\circ} \mathrm{C}$ como a $800{ }^{\circ} \mathrm{C}$, enquanto para as deformações de $30 \%$ e $50 \%$ essa variação não é significativa. Nos resultados de dilatometria (Figura 6-4) observou-se que durante os ensaios de Q\&P há uma expansão do volume da amostra durante o estágio de partição, associado possivelmente à formação de bainita. Por sua 
vez, os resultados para as amostras HSQ\&P mostraram uma considerável redução nessa expansão. Portanto, a diminuição das porcentagens de ferrita com o aumento de QT para a deformação de $10 \%$, permite inferir que devido à deformação há uma estabilização mecânica da austenita que dificulta o crescimento da bainita [158] durante o estágio de partição. Como discutido, a formação de florestas de discordâncias durante a etapa de partição justifica esta estabilização. Em consequência, a mudança da porcentagem da ferrita poderia estar relacionada, principalmente, ao crescimento da fase causado pelo maior alcance da difusão do carbono, o que estaria sendo dependente da temperatura de têmpera. A mesma mudança não foi tão evidente para porcentagens de deformação de 30\% ou 50\% (na temperatura de deformação de $\left.750{ }^{\circ} \mathrm{C}\right)$, onde a ferrita não apresentou mudanças significativas $(1,2 \%$ e $8,4 \%$, respectivamente). Igualmente para temperaturas de deformação em $750{ }^{\circ} \mathrm{C}$ observa-se que quando a temperatura muda de $308{ }^{\circ} \mathrm{C}$ para $318{ }^{\circ} \mathrm{C}$, há um aumento dos resultados da microdureza de aproximadamente $2 \%, 4 \%$ e $10 \%$ para as deformações de $10 \%, 30 \%$ e $50 \%$, respectivamente. Adicionalmente, observa-se que quando a deformação aumentou de $10 \%$ para $30 \%$ a $750{ }^{\circ} \mathrm{C}$ houve um aumento da porcentagem de ferrita $\left(5,3 \%, 11,0 \%\right.$, e $32,5 \%$, para as QT de $308{ }^{\circ} \mathrm{C}$, $318^{\circ} \mathrm{C}$ e $328^{\circ} \mathrm{C}$, respectivamente), enquanto para a deformação a $800^{\circ} \mathrm{C}$ houve uma diminuição $\left(34,9 \%, 46,9 \%\right.$, e $5,1 \%$, para as QT de $308{ }^{\circ} \mathrm{C}, 318^{\circ} \mathrm{C}$ e $328^{\circ} \mathrm{C}$, respectivamente). Já no caso do aumento da deformação de $30 \%$ para $50 \%$, para a temperatura de deformação de $750{ }^{\circ} \mathrm{C}$ houve uma diminuição da ferrita em $18,5 \%$ e de $6,5 \%$ para as QT de $308{ }^{\circ} \mathrm{C}$ e $318{ }^{\circ} \mathrm{C}$, respectivamente; enquanto, para a temperatura de deformação de $800{ }^{\circ} \mathrm{C}$ observa-se um aumento da porcentagem de ferrita de $33 \%$ e $88 \%$ para as QT de $308{ }^{\circ} \mathrm{C}$ e $318{ }^{\circ} \mathrm{C}$, respectivamente.

De forma geral, observa-se que as amostras deformadas a $750{ }^{\circ} \mathrm{C}$ formaram maiores porcentagens de ferrita, o que poderia estar relacionado, como apontam Ghosh et al. [221], à diminuição da força motriz para que ocorra transformação $\gamma \rightarrow \alpha$ com o aumento da temperatura de deformação. No caso da temperatura de têmpera de $328{ }^{\circ} \mathrm{C}$ as mudanças de ferrita não são significativas $(\approx 2 \%)$. Em geral, os resultados de dureza para ambas as temperaturas de deformação mostram-se compatíveis com as tendências das porcentagens de martensita e ferrita. Isto é, nas amostras que apresentaram as maiores porcentagens de ferrita se observaram os menores valores de dureza, e vice-versa. Nos resultados da amostra HSQ\&P austenitizada intercriticamente a $820^{\circ} \mathrm{C}$ e deformada em $10 \%$ e $30 \%$, a dureza e as porcentagens de ferrita e austenita aumentaram em $1 \%, 4 \%$ e $80 \%$, respectivamente. Todavia, é evidente que a dureza não depende apenas da porcentagem de ferrita, mas também pode variar com o refinamento dos grãos, a presença de carbonetos [240, 241] (devido a sua influência na diminuição da 
supersaturação em carbono da martensita), a porcentagem de austenita ou pela densidade de discordâncias presentes na microestrutura.

No capítulo 2, na Figura 2-4, foram apresentadas as relações de resistência mecânica e ductilidade obtidas por Matlock e Speer [28] usando modelamento numérico para misturas hipotéticas de ferrita-martensita, correspondentes aos aços AHSS da primeira geração, e a predição das propriedades mecânicas de aços com variações hipotéticas de austenita-martensita localizados na região determinada como aços da terceira geração. Essa curva sugere, que as propriedades intermediárias entre os aços da primeira e da segunda geração sejam preenchidos por combinações microestruturais complexas entre fases de alta resistência (martensita, ferrita com grãos refinados ou bainita) e fases endurecíveis por deformação (como a austenita), e consequentemente, essa combinação resultar em maior energia de deformação que aços consistindo de combinações de ferrita e martensita. As curvas apresentadas nessa figura foram obtidas a partir das propriedades atribuídas na Tabela 7-4 [28]:

Tabela 7-4. Dados das propriedades mecânicas para os constituintes considerados como entrada no modelo de Mileiko [242] para prever relações de resistência mecânica e ductilidade de aços AHSS.

\begin{tabular}{ccc}
\hline Constituinte & UTS (MPa) & $\begin{array}{c}\text { Deformação de Engenharia } \\
\text { Uniforme }(\%)\end{array}$ \\
\hline Ferrita & 300 & 0,3 \\
Austenita & 640 & 0,6 \\
Martensita & 2000 & 0,008 \\
\hline
\end{tabular}

Os valores apresentados na Tabela 7-4 mostraram-se razoáveis para estimar as propriedades mecânicas da ferrita e martensita [243, 244] e para a austenita estabilizada em um aço TWIP [245]. Relacionando os valores do modelo proposto por Mileiko [242] (Tabela 7-4) com as diversas porcentagens das fases obtidas experimentalmente (Tabelas 7-2 e 7-3) foi possível construir, usando a regra das misturas, um diagrama alongamento contra resistência mecânica, como mostrado na Figura 7-35. Mesmo sabendo que a regra das misturas é uma aproximação muito simplificada para a predição das propriedades mecânicas, o interesse esteve em comparar os valores experimentais da presente pesquisa com a predição numérica proposta por Matlock e Speer [25, 28] para preencher a lacuna dos aços da terceira geração. Adicionalmente, essa regra é utilizada frequentemente por pesquisadores interessados no desenvolvimento dos aços AHSS, inclusive em aços TRIP [246, 247], como uma abordagem inicial para predizer as propriedades de resistência e ductilidade de microestruturas multifásicas. A aproximação de Mileiko [242] tem sido utilizada com sucesso para descrever as combinações de resistênciaductilidade em aços bifásicos (DP) [243, 244, 248] e em aços inoxidáveis austeníticos [249]. Não obstante, como será observado no capítulo 8, para o limite de resistência essa previsão 
mostrou-se superior $(\approx 35 \%)$, em relação aos resultados experimentais, enquanto o alongamento mostrou um melhor ajuste.

Como se observa nessa figura, os maiores valores de resistência mecânica estão associados aos tratamentos Q\&P, enquanto o maior alongamento uniforme e menor resistência mecânica aos HSQ\&P. Esse comportamento está relacionado, como vem sendo discutido, às maiores frações volumétricas de austenita retida e de ferrita induzida pela deformação nas amostras HSQ\&P. Comparando os resultados de HSQ\&P se observa que as deformações isotérmicas em temperaturas mais altas $\left(800^{\circ} \mathrm{C}\right)$ são mais vantajosas para elevar a resistência mecânica, enquanto as deformações não isotérmicas (iniciando em $750{ }^{\circ} \mathrm{C}$ ) são sugeridas caso o objetivo seja o aumento da ductilidade, sacrificando a resistência mecânica.
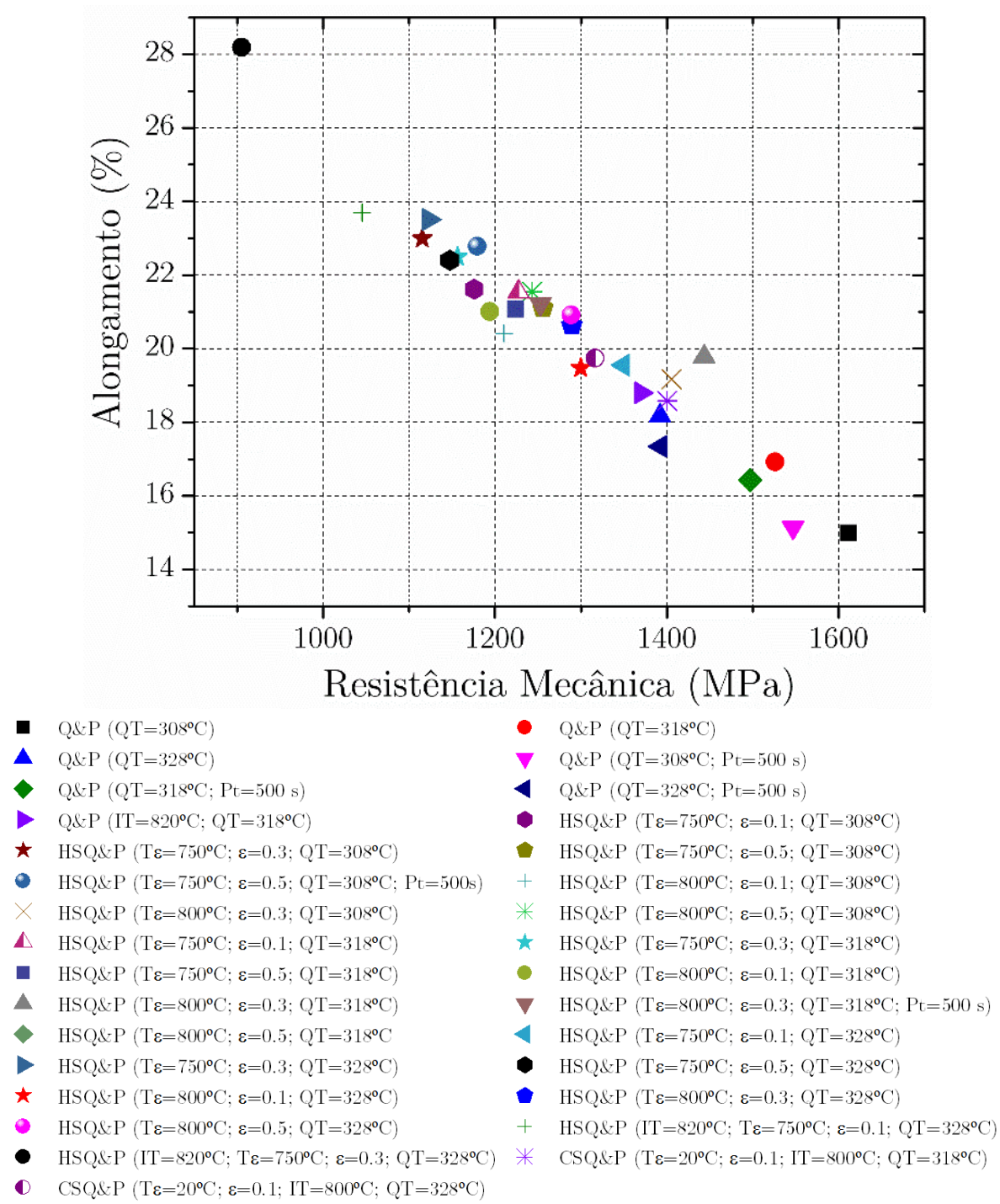

Figura 7-35. Combinações de ductilidade e resistência mecânica obtidas por regra das misturas a partir dos resultados das frações volumétricas calculadas experimentalmente para os diversos tratamentos realizados: têmpera e partição (Q\&P), deformação a quente seguido por têmpera e partição (HSQ\&P) e deformação a frio seguido por têmpera e partição (CSQ\&P). T $\varepsilon, \varepsilon$, QT e Pt representam a temperatura de deformação, a porcentagem de deformação, a temperatura de têmpera e o tempo de partição, respectivamente. 
Uma vez que um dos objetivos da presente pesquisa é estudar a expansão do espectro de aços de alta resistência, com particular interesse nos aços de uma "terceira geração", que melhorem o compromisso entre resistência mecânica e alongamento, e a redução do peso da estrutura do veículo, os resultados das propriedades mecânicas calculadas pela lei das misturas, foram superpostos à curva "banana" como mostrado na região intermediária da Figura 7-36. Esses resultados, mostram que os diversos tratamento térmicos realizados são promissores para preencher parte da lacuna dos aços da terceira geração, como foi previsto pelo modelo numérico criado por Matlock e Speer [28].

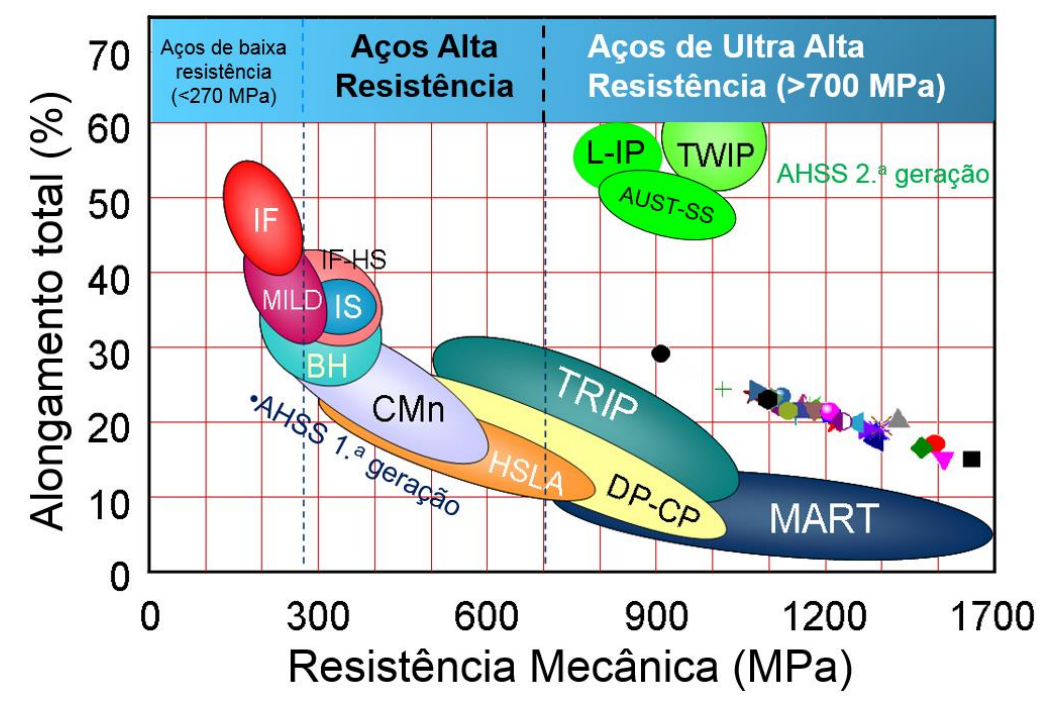

Figura 7-36. Superposição dos resultados obtidos na presente pesquisa na curva alongamento-resistência mecânica para a região dos aços de ultra alta resistência correspondentes aos da terceira geração. Adaptado de Matlock et al. [16].

\subsection{Conclusões}

No presente capítulo foram investigados vários tratamentos térmicos e termomecânicos aplicados a um aço TRIP consistindo em têmpera (Q), têmpera e partição (Q\&P), estampagem a quente (HS), e o processo combinado de estampagem a quente com posterior têmpera e partição (HSQ\&P). A finalidade principal foi investigar e discutir os efeitos das variáveis que envolvem os tratamentos, isto é, a temperatura de austenitização intercrítica, a temperatura e quantidade de deformação, a temperatura de têmpera e a temperatura e o tempo de partição, e analisar sua influência nas respostas microestruturais e mecânicas. A avaliação foi feita tanto durante os tratamentos (in situ) como também após os tratamentos térmicos e termomecânicos aplicados. A realização e análise desses tratamentos térmicos e termomecânicos permitiram a obtenção dos seguintes resultados e conclusões: 
- A metodologia descrita para calcular a temperatura ótima de têmpera, incluindo austenitização intercrítica, permitiu estimar a temperatura de têmpera para os processos de Q\&P e de HSQ\&P a fim de obter uma quantidade substancial de austenita retida na temperatura ambiente. Essa previsão mostrou-se útil na obtenção das maiores porcentagens de austenita retida, mesmo considerando as restrições impostas pelo modelo de equilíbrio constrito de carbono.

- Os resultados da mudança do parâmetro de rede usando difração de raios X in situ com luz síncrotron mostraram o efeito evidente do enriquecimento em carbono da austenita durante o estágio de partição. Adicionalmente, observou-se que em todos os casos o aumento da deformação promove a redução do enriquecimento em carbono da austenita e que a deformação a $800{ }^{\circ} \mathrm{C}$ favorece um maior enriquecimento, quando comparado com as amostras deformadas a $750{ }^{\circ} \mathrm{C}$. Portanto, o enriquecimento em carbono durante o estágio de partição não depende unicamente dos parâmetros do tratamento térmico de Q\&P, mas também das condições criadas na microestrutura em alta temperatura pelas deformações isotérmica ou não isotérmica.

- Os resultados de radiação síncrotron usando detector 2D permitiram observar a textura presente no material, antes do tratamento térmico e no início e fim da etapa de partição. Essas análises permitem concluir que a textura está presente no material desde antes do tratamento e se mantém até o fim do estágio de partição, o que confirma que a textura cristalográfica não surge como consequência dos parâmetros do tratamento Q\&P.

- Constatou-se a partir dos resultados das análises de variância (ANOVA), que para as amostras HSQ\&P a influência da temperatura de deformação é mais significativa na temperatura $M_{S}$ do que a porcentagem de deformação. No entanto, quando a ANOVA foi feita considerando a porcentagem de deformação, observou-se que existe uma diferença estatisticamente significativa na variável-resposta $M_{s}$, sendo que a influência na temperatura $M_{s}$ é maior quando a amostra é previamente deformada a $750{ }^{\circ} \mathrm{C}$.

- Os resultados de dilatometria, difração de raios $\mathrm{X}$ e microestruturais sugerem que a deformação da austenita promove a transformação de fase difusional $\left(\alpha_{D I F T}\right)$, o que resulta na redistribuição de carbono entre a ferrita supersaturada e a austenita previamente à transformação martensítica, levando ao enriquecimento da austenita não transformada e, consequentemente, à diminuição da temperatura $M_{s}$. Esse fenômeno parece ser o predominante para porcentagens de deformação de até $30 \%$. No entanto, propõe-se que para deformações maiores o aumento da energia livre total pela criação de uma força motriz mecânica causada pela deformação é o fenômeno preponderante. 
- A partir dos resultados de EBSD foi possível distinguir claramente as diferentes morfologias da austenita retida que se apresentou na forma de: blocos equiaxiais (grãos pré-existentes de austenita) distribuídos ao longo dos pacotes de martensita e próximos aos contornos da ferrita; filmes entre as ripas de martensita e entre as placas de ferrita-bainítica; e embebida nos grãos de ferrita.

- A combinação do mapa qualidade com o mapa de orientações permitiu observar que as ilhas de austenita pertencentes ao mesmo grão possuem a mesma orientação cristalográfica, indicando que essa austenita retida se originou do mesmo grão prévio de austenita.

- Para a amostra Q\&P temperada a $318^{\circ} \mathrm{C}$ e particionada a $400{ }^{\circ} \mathrm{C}$ por 100 s o valor médio do tamanho do grão foi de $28 \mu^{2}$, enquanto as amostras HSQ\&P deformadas em $30 \%$, temperada a $318^{\circ} \mathrm{C}$ e particionadas a $400^{\circ} \mathrm{C}$ por $100 \mathrm{~s}$ mostraram valores médios em torno aos $16 \mu^{2}$. Isso sugere que tanto a transformação de austenita em ferrita produzida pela deformação como a recristalização dinâmica seriam os principais mecanismos que contribuem na formação de grãos refinados de ferrita.

- Foi possível distinguir a martensita da ferrita pelas regiões de menor índice de qualidade, resultado da alta densidade de discordâncias da martensita. A partir dos resultados da desorientação ponto à origem de kernel observou-se que a desorientação é menor que $2^{\circ}$ para a ferrita, entre $10^{\circ}$ e $20^{\circ}$ para a ferrita-bainítica e acima dos $20^{\circ}$ para as martensitas revenida e fresca. O que representa uma nova abordagem para identificação dos microconstituintes usando a desorientação de kernel a partir dos resultados de EBSD.

- Nas amostras HSQ\&P foram analisadas algumas interfaces ferrita/ferrita usando mapas de distribuição de desorientação Kernel (KAM). Devido à variação nos resultados da desorientação para esse tipo de interface, propõe-se a formação e identificação de dois tipos de ferrita: a ferrita gerada pelo efeito DIFT, que apresenta menores valores de KAM, e a ferrita formada durante a etapa intercrítica, que foi deformada principalmente nos contornos de grão e que apresenta maiores valores de KAM.

- Foi proposta uma abordagem de caracterização microestrutural e mecânica em escala local, baseada na combinação do EBSD e da nanoindentação instrumentada. Esse tipo de abordagem mostrou-se útil para relacionar, além das fases às nanoindentações, a dependência da nanodureza com a orientação cristalográfica e com a distribuição e tamanho dos grãos.

- De acordo com os resultados combinando a nanoindentação e o EBSD, as faixas de nanodureza, para o tratamento de Q\&P, estão entre 5,0 e 5,9 GPa para martensita, entre 2,6 e 4,0 GPa para a ferrita, e entre os 3,1 e 5,0 GPa para a ferrita-bainítica. A superposição dos 
valores de nanodureza para a ferrita e a ferrita-bainítica entre aproximadamente os 3 e os $4 \mathrm{GPa}$ foi atribuído à influência na nanodureza de fatores como: tamanho de grão, orientação cristalográfica, aumento ou diminuição na densidade de discordâncias ou tensões geradas pelas fases circundantes.

- $\mathrm{Na}$ amostra HSQ\&P deformada a $800{ }^{\circ} \mathrm{C}$ em $30 \%$ a martensita apresentou resultados de nanodureza entre 4,9 e 6,8 GPa, enquanto os grãos de ferrita teve valores de nanodureza entre 2,8 e 3,9 GPa. Comparando esses resultados com os da amostra Q\&P observou-se um aumento de $\approx 15 \%$ na nanodureza da martensita. Esse aumento foi relacionado ao aumento na densidade de defeitos, como discordâncias ou maclas, ou à diminuição do tamanho dos grãos causados pela deformação em alta temperatura.

- A nanodureza foi levemente maior nos grãos com tendência à orientação [111], do que nos grãos que tendem a estar orientados nas direções [001] e [101]. Esse resultado foi compatível com os resultados dos fatores de Schmid em que se observou que a grande maioria dos grãos de ferrita próximos à orientação [111] apresentaram um fator de Schmid menor que os grãos com outros tipos de orientação, o que poderia estar associado a um maior esforço requerido para ativar e deslizar as discordâncias nessa direção.

- Nas amostras Q\&P e HSQ\&P foi observado que os grãos de austenita que estão embebidos dentro dos grãos de ferrita possuem um maior fator de Schmid e, portanto, poderiam atingir mais rapidamente a tensão critica projetada, tendo, por conseguinte, maior possibilidade de deformar plasticamente do que os grãos que estão nos contornos entre a ferrita e a martensita.

- Os resultados de estereologia e microdureza dos tratamentos Q\&P permitiram observar que com o aumento do tempo de partição houve um aumento da porcentagem de ferrita e uma diminuição tanto da porcentagem de austenita como dos valores de dureza, o que poderia estar associado ao consumo da fase austenítica pela formação de uma maior porcentagem de ferritabainítica.

- Usando a regra das misturas foi possível construir um diagrama alongamento-resistência mecânica, identificar e relacionar as condições de tratamento térmico ou termomecânico que levam ao aumento da ductilidade ou da resistência de acordo com as frações volumétricas das fases resultantes. Comparando os resultados para os tratamentos de HSQ\&P observou-se que as deformações isotérmicas em temperaturas mais altas $\left(800^{\circ} \mathrm{C}\right)$ são mais vantajosas para elevar a resistência mecânica, enquanto as deformações não isotérmicas (iniciando em $750{ }^{\circ} \mathrm{C}$ ) são sugeridas, caso o objetivo seja o aumento da ductilidade, sendo sacrificada a resistência mecânica. 


\section{AVALIAÇÃo DA PARTIÇÃo dO CARBONO NA NOVA GERAÇÃO DE AÇOS DE ALTA RESISTÊNCIA Q\&P E HSQ\&P}

\section{Resumo}

Considerando que a estabilidade da austenita retida e a distribuição do carbono especialmente sua concentração local nas fases, nos contornos de grão ou nos contornos das interfaces - influenciam as transformações de fase e as propriedades mecânicas, decorre a importância da caracterização e da compreensão dos mecanismos de enriquecimento em carbono da austenita retida [230, 250]. Por conseguinte, com o objetivo de avaliar o efeito da deformação em alta temperatura no enriquecimento em carbono da austenita, escolheu-se estudar um subgrupo dos experimentos descritos no capítulo 7, que incluem um tratamento térmico de Q\&P e dois de HSQ\&P (representados na Figura 0-1). Os três tratamentos correspondem à condição em que foi aplicada a temperatura ótima de têmpera $\left(\mathrm{QT}=318^{\circ} \mathrm{C}\right)$, calculada de acordo com o modelo de equilíbrio constrito do carbono [1]. As condições de Q\&P estudadas, nos três tratamentos, obedecem às mesmas condições de temperatura, tempos de permanência e velocidades de aquecimento e resfriamento. No caso dos dois tratamentos em que se aplica a deformação em alta temperatura (HSQ\&P), são analisadas duas temperaturas de deformação diferentes, uma aplicada isotermicamente na zona intercrítica a $800{ }^{\circ} \mathrm{C}$, e a outra aplicada durante o resfriamento (não isotérmica), com início em $750{ }^{\circ} \mathrm{C}$. Os resultados estão baseados nas técnicas de caracterização descritas na metodologia nas seções 5.1 a 5.7, que incluem: microscopia eletrônica de varredura (MEV) e de transmissão (STEM, Scanning Transmission Electron Microscopy), difração de elétrons retroespalhados (EBSD, Electron BackScatter Diffraction), nanoindentação, tomografia de sonda atômica (APT, Atom Probe Tomography), ensaios micromecânicos em corpos de prova sub-size e correlação de imagem digital (DIC, Digital Image Correlation). O EBSD é usado a fim de observar as mudanças microestruturais após os tratamentos de Q\&P e HSQ\&P e obter orientações úteis para a compreensão da evolução microestrutural a partir da: identificação das fases e sua morfologia (austenita, ferrita/martensita, ferrita bainítica), quantificação e localização da austenita retida, e a identificação dos dois tipos de martensita: a não revenida, conhecida também como martensita fresca (martensita criada na têmpera final até a temperatura ambiente) e a martensita particionada ou revenida (a martensita que particiona o carbono para austenita na etapa de partição). O EBSD combinado com os experimentos de nanoindentação instrumentada permite a caracterização micromecânica das fases individuais, e possibilita a identificação das regiões 
de interesse para posterior análise por APT e STEM. A combinação das técnicas de EBSD e nanoindentação para identificação das fases e das regiões para extração das agulhas por FIB para os posteriores ensaios de APT não tem sido explorada na literatura até o momento e mostrou-se útil na caracterização de aços multifásicos com microestrutura complexa. Como um dos principais objetivos deste capítulo é compreender o papel do estágio de partição na distribuição (ou segregação) do soluto (carbono e elementos substitucionais) na austenita retida, na ferrita, na martensita e nas reações do revenido que possam ocorrer (como precipitação de carbonetos ou "clustering" dos átomos de carbono nas discordâncias ou nas interfaces), as amostras foram analisadas por APT em regiões identificadas como austenita (tanto na forma de blocos como de filmes), na ferrita, na martensita, nas interfaces e nos carbonetos. Os resultados de APT fornecem resultados essenciais para a melhor compreensão das mudanças microestruturais, incluindo a precipitação de carbonetos na martensita durante os tratamentos de Q\&P e HSQ\&P. A partir dos dados adquiridos utilizando a técnica APT foi feita uma discussão detalhada em relação aos mecanismos de enriquecimento de austenita, para condições onde ocorre deformação em alta temperatura. Os resultados de nanoindentação foram correlacionados com as características microestruturais.

Os experimentos de APT foram realizados no CNMS (Center for Nanophase Materials Science) pertencente ao Laboratório Nacional de OAK Ridge em Tennessee nos Estados Unidos, sob a proposta de pesquisa CNMS2015-301 - Evaluation of Carbon Partitioning in New Generation of Quenching and Partitioning (Q\&P) Steels. 


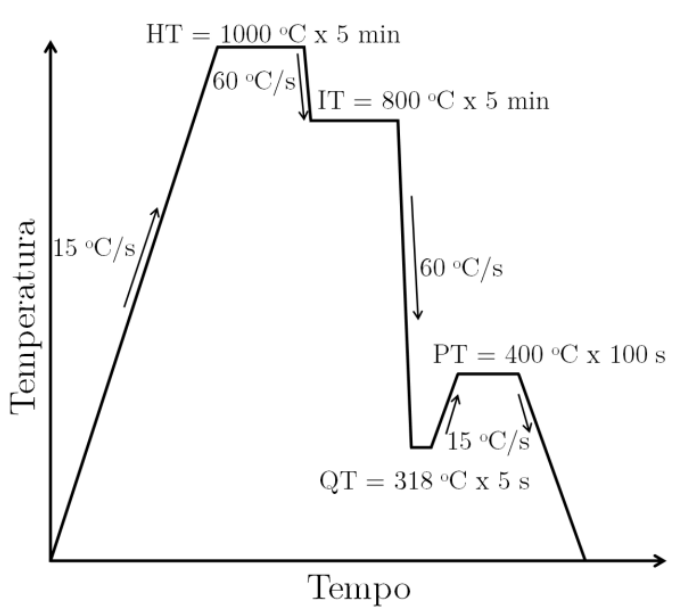

(a)

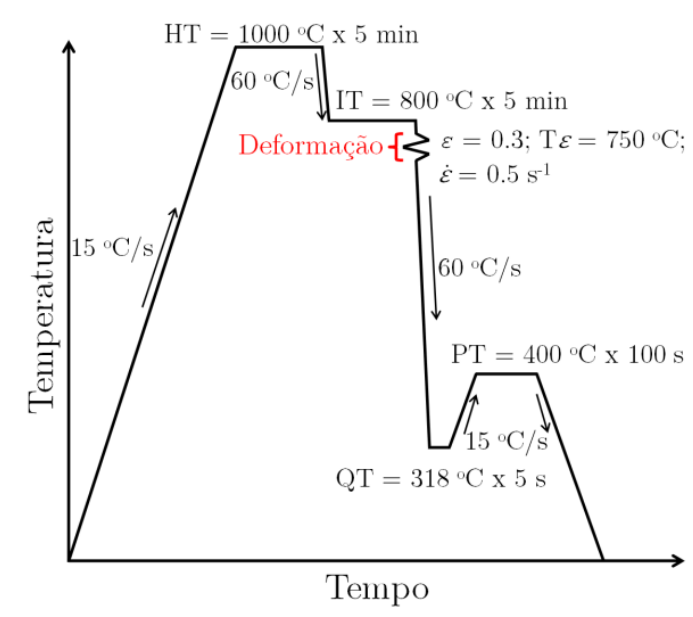

(b)

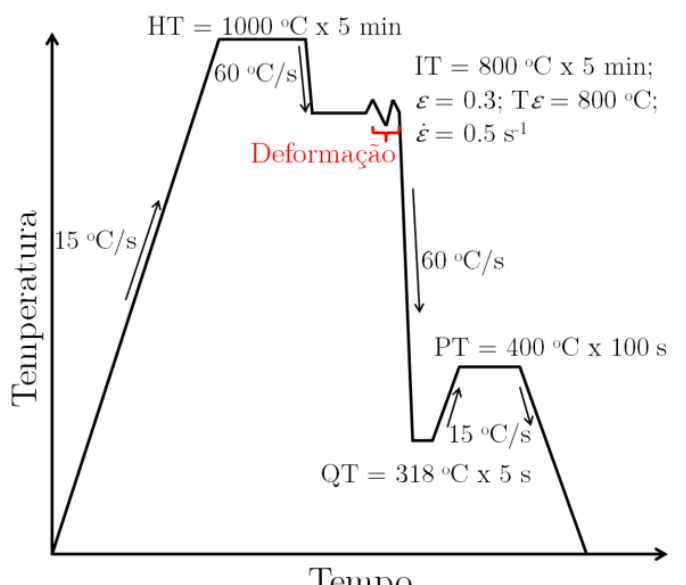

(c)

Figura 0-1. Representação esquemática dos tratamentos termomecânicos de (a) Q\&P, (b) e (c) HSQ\&P, com temperaturas iniciais de deformação de $750^{\circ} \mathrm{C}$ e $800^{\circ} \mathrm{C}$, respectivamente. HT, IT, QT e PT representam as temperaturas de homogeneização, intercrítica, têmpera e partição, respectivamente. 


\subsection{Introdução}

A influência dos elementos de liga na formação microestrutural e nas propriedades mecânicas dos aços continuam sendo assuntos de pesquisa em constante evolução. Em vista disso, para a ampliação do espectro dos aços com propriedades avançadas (alta resistência e maior ductilidade) é relevante a compreensão quantitativa da distribuição das porcentagens atômicas dos elementos de liga, dos precipitados e da segregação nos contornos de grão ou nas interfaces, durante e depois da transformação da austenita. Desse modo, a caracterização dos aços multifásicos, como é o caso dos aços TRIP, é uma tarefa científica e tecnológica importante, uma vez que as propriedades mecânicas são determinadas pelas características microestruturais e estas, por sua vez, pela movimentação atômica de solutos substitucionais e intersticiais. No caso dos aços submetidos aos tratamentos de Q\&P, a compreensão quantitativa mais importante está no que concerne ao papel da distribuição do soluto (segregação) entre as fases, a austenita retida, as interfaces e os carbonetos (como cementita e carbonetos de transição), com especial interesse no carbono, manganês e silício. O teor de carbono na austenita retida é considerado o elemento químico controlador de sua estabilidade na temperatura ambiente (uma vez que determina sua força motriz química) e, portanto, também controla a ductilidade do material, principalmente nos aços de baixa liga [251]. Entretanto, nos aços TRIP, pesquisas experimentais têm mostrado que a estabilidade da austenita retida é afetada não só pelo teor de carbono [191, 252] ou do manganês [187, 253], mas também pela distribuição e tamanho do volume dos grãos de austenita [254, 255] (causados pela redução da temperatura de início da transformação martensítica e pelo aumento da energia de deformação elástica), pelas características (morfologia) e interações (ou restrições) impostas pelas fases que circundam a austenita [256], e pela orientação cristalográfica (fator de Schmid) da austenita em relação à direção de carregamento [44, 120, 257]. Em relação à dependência da morfologia do grão no teor de carbono da austenita retida, na literatura existe uma notável discrepância. Alguns afirmam que os grãos de austenita na forma de filmes apresentam maior teor de carbono [51-54, 258, 259], enquanto outros asseveram o contrário, que a austenita na forma de blocos possui maior teor de carbono $[177,260]$. No entanto, todos os autores coincidem em afirmar que a austenita retida na forma de filmes é mais estável frente a uma deformação mecânica, mesmo apresentando um menor teor de carbono. Este comportamento é associado principalmente ao maior número de defeitos, como falhas de empilhamento ou discordâncias, presentes na austenita na forma de blocos [52], os quais atuam como sítios de nucleação da martensita [56], mesmo em baixas deformações. Além disso, filmes de austenita retida estão 
geralmente circundados por microconstituintes com maior dureza e resistência ao escoamento plástico, como martensita e bainita. Dessa forma, a austenita é estabilizada pela alta pressão hidrostática exercida por essas fases, que restringe a expansão volumétrica e a deformação cisalhante associada à transformação martensítica [52, 57].

No capítulo anterior a cinética da transformação e a evolução do parâmetro de rede foram investigadas por difração de raios $\mathrm{X}$ usando radiação síncrotron a fim de determinar $\mathrm{o}$ enriquecimento em carbono da austenita durante o estágio de partição. No entanto, esses resultados não fornecem informação em relação ao teor de carbono dentro dos grãos de austenita. Portanto, foram realizadas análises complementares por tomografia de sonda atômica, uma vez que a extensão da partição do carbono não é conhecida. Além disso, o método tradicional para determinação do teor de carbono usando as mudanças do parâmetro de rede pode ser impreciso devido ao uso de equações empíricas para calcular essa relação, às tensões presentes na estrutura e à influência de outros elementos de liga na variação do parâmetro de rede (solutos substitucionais). Indo além, o carbono pode estar presente tanto na forma de solução sólida, quanto na forma de carbonetos na martensita. Como os teores de carbono na austenita e na martensita e a presença de carbonetos afetam significativamente as propriedades mecânicas dos aços, é importante estudar quantitativamente a distribuição do carbono entre as distintas fases formadas nos processos de Q\&P e de HSQ\&P.

Alguns pesquisadores têm usado a tomografia por sonda atômica para obter informação sobre a quantidade e localização do carbono nas microestruturas Q\&P [71, 111, 261-266]. No entanto, até o momento não há informação sobre o enriquecimento em carbono da austenita em tratamentos realizados por $\mathrm{Q} \& \mathrm{P}$, após deformação prévia em alta temperatura (tratamentos de HSQ\&P). Desta forma, a técnica de APT permite esclarecer se o efeito DIFT [86, 267] (Deformation Induced Ferrite Transformation) ou de transformação dinâmica [221] contribui para o enriquecimento em carbono da austenita e para sua estabilização e se a precipitação de carbonetos concomitante com a precipitação de ferrita dificulta a difusão do carbono para a austenita vizinha. 


\subsection{Resultados e discussão}

\subsubsection{Caracterização da amostra Q\&P}

O principal objetivo de realizar medições de APT foi medir a distribuição dos átomos de carbono e o acúmulo de carbono nas diferentes fases e interfaces. Para isso, realizou-se a preparação das amostras por FIB das regiões contendo as fases e interfaces almejadas para estudo, i.e., austenita retida, ferrita-bainítica e martensita. Devido à complexidade microestrutural das amostras após os tratamentos de Q\&P e HSQ\&P, os resultados obtidos por EBSD e nanoindentação foram utilizados para a identificação das fases, microconstituintes e contornos de grão de interesse para posterior análise por APT, como se observa na Figura 0-2 para a amostra Q\&P temperada a $318^{\circ} \mathrm{C}$ e particionada a $400{ }^{\circ} \mathrm{C}$ por $100 \mathrm{~s}$. Essa metodologia para localização de regiões ou microconstituintes mostrou-se útil para ser aplicada em microestruturas complexas que serão posteriormente analisadas por APT ou STEM. Na Figura 0-2(a) pode-se observar as três regiões identificadas para extração das lâminas para análise por APT. Na região 1 o interesse esteve em estudar a concentração de carbono numa interface ferrita/austenita ( $\alpha / \gamma$, austenita em cor vermelho), enquanto na região 2 foi avaliado um grão de ferrita $(\alpha)$. Na região 3 o objetivo foi quantificar o teor de carbono de um filme de austenita retida $(\gamma)$ entre as placas de martensita $\left(\alpha^{\prime}\right)$. A Figura 0-2(b) apresenta as regiões de onde foram extraídas as pontas M26 (correspondente a um grão de ferrita) e M28 (interface $\alpha / \gamma$ ), para análise por APT, previamente identificadas por EBSD. A Figura 0-2(c) apresenta a ponta extraída da região martensítica (identificada com o número 3 na Figura 0-2(a)) após preparação usando feixe de íons localizado (FIB), pronta para ser analisada no tomógrafo por sonda atômica.

A Figura 0-3 apresenta os resultados por APT das regiões identificadas com os números 1, 2 e 3 na Figura 0-2(a). A Figura 0-3(a) apresenta o mapa dos átomos de carbono de uma austenita na forma de bloco, contendo $\approx 6.00$ at.\%C, extraída de uma região que se encontra entre um grão de ferrita e uma região de martensita $\left(\alpha / \gamma_{\mathrm{b}} / \alpha^{\prime}\right)$. O teor de carbono dessa austenita é consideravelmente superior ao teor de carbono nominal do material (1,06 at.\%C). Esse resultado é próximo ao determinado recentemente por Poling et al. [268] ( $\approx 5,7$ at.\%), obtido também para uma austenita na forma de bloco em um aço submetido ao processo Q\&P. Em seu trabalho, Poling et al. [268] comentam que fizeram várias tentativas a fim de analisar outras regiões que incluíssem austenita na forma de filmes, porém não tiveram sucesso. 


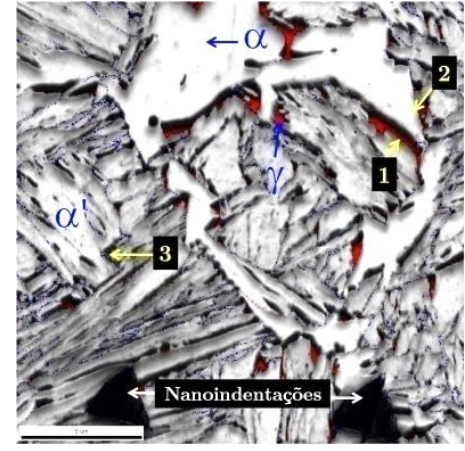

(a)

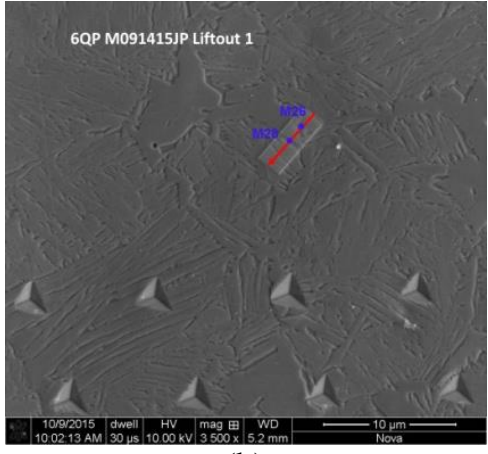

(b)

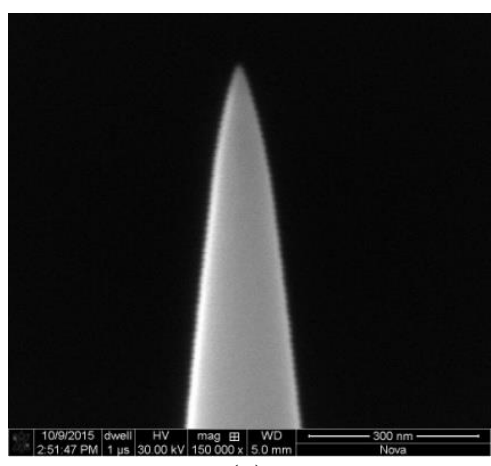

(c)

Figura 0-2. (a) Mapa de EBSD e nanoindentações da amostra Q\&P, austenitizada intercriticamente a $800{ }^{\circ} \mathrm{C}$, temperada a $318{ }^{\circ} \mathrm{C}$, particionada a $400{ }^{\circ} \mathrm{C}$ por $100 \mathrm{~s}$; (b) regiões da localização das agulhas a serem extraías por FIB para os experimentos de APT; (c) agulha nanométrica extraída por FIB para posterior evaporação por APT.

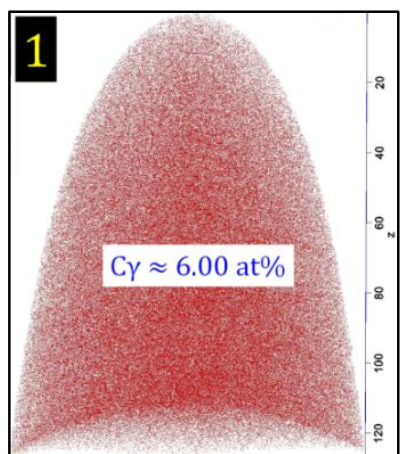

(a)

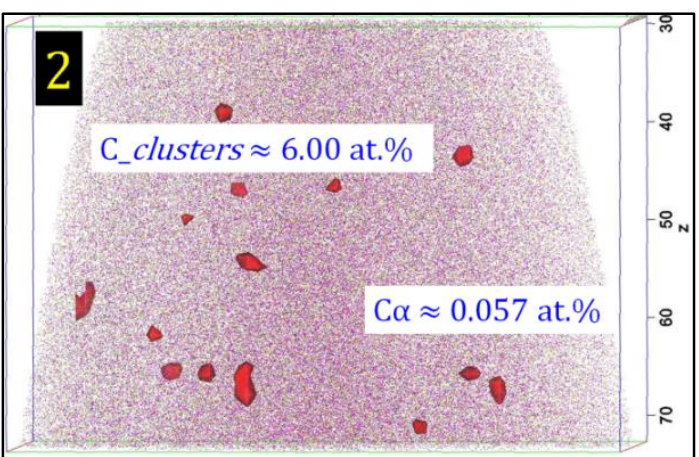

(b)

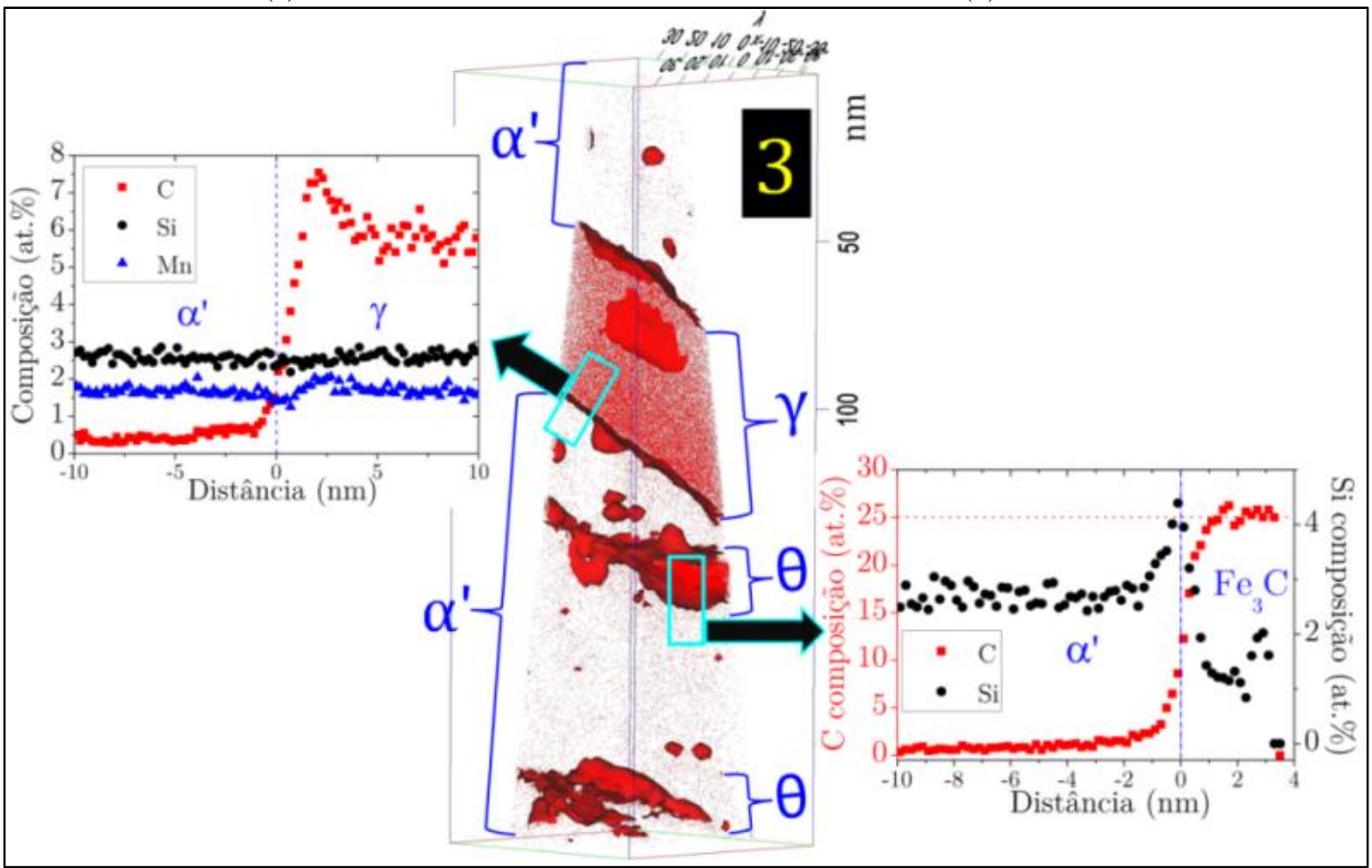

(c)

Figura 0-3. (a) Mapa dos átomos de carbono de uma austenita na forma de bloco contendo $\approx 6.00$ at. $\% \mathrm{C}$ extraída da região identificada com o número 1 na Figura 0-2a. (b) Distribuição dos átomos de carbono da ferrita extraída da região identificada como o número 2 na Figura 0-2a, (c) Superfície de isoconcentração de 2 at.\%C para uma interface de martensita $\left(\alpha^{\prime}\right)$ e austenita $(\gamma)$ extraída da região 3 em referência à Figura 0 -2a sobreposta a um mapa de átomos de carbono e histogramas de proximidade obtidos através de uma interface cementita $(\theta$,

$\left.\mathrm{Fe}_{3} \mathrm{C}\right) / \alpha^{\prime}$ e de uma interface $\alpha^{\prime} / \gamma$. 
Na Figura 0-3(b) são mostrados os resultados de APT correspondentes à ferrita extraída da região 2 , adjacente à austenita obtida na região 1 . O baixo teor de carbono medido na ferrita $(\approx$ 0,06 at.\%) reflete a baixa solubilidade do carbono na ferrita formada durante a etapa intercrítica. No entanto, são observadas pequenas aglomerações de carbono ao longo da fase. O teor de carbono desses clusters $(\approx 6$ at.\%) é baixo para que sejam identificados como carbonetos, mas é consistente com a segregação de carbono para defeitos cristalinos, notavelmente discordâncias.

Na Figura 0-3(c) são mostrados os resultados de APT da amostra extraída da região 3. É possível distinguir martensita com teor de carbono de $\approx 0,23$ at.\%, um filme de austenita $\left(\gamma_{f}\right)$ com $\approx 5,51$ at. $\% \mathrm{C}$ e precipitados na martensita com $\approx 25$ at.\% $\mathrm{C}$, estequiometricamente compatíveis com a cementita $\left(\theta, \mathrm{Fe}_{3} \mathrm{C}\right)$. Esses precipitados foram provavelmente formados durante o revenido da martensita a $400{ }^{\circ} \mathrm{C}$. As frações atômicas de carbono, manganês e silício usando proxigramas (histogramas de proximidade) foram estimadas por meio de superfícies de isoconcentração de 2 at.\%. Os perfis de concentração dos elementos substitucionais indicam que não houve partição do manganês e do silício entre a martensita e a austenita, de modo que apenas a partição de carbono ocorreu durante a etapa de partição a $400{ }^{\circ} \mathrm{C}$ por $100 \mathrm{~s}$. Por sua vez, o comportamento do silício no perfil composicional do precipitado $\theta$ (mostrado à direita na Figura 0-3(c)) é compatível com a formação de cementita, pois é sabido que, devido à baixa solubilidade do silício na cementita, seu crescimento deve ser acompanhado da rejeição desse elemento. O conceito de equilíbrio constrito de carbono assume que todo o carbono da martensita deve se difundir para a austenita durante a partição. Dessa forma, a formação de carbonetos de revenido é um dos mecanismos que causam um desvio significativo do modelo, diminuindo o potencial para o enriquecimento em carbono da austenita. A presença de cementita na martensita evidenciada nas medidas de APT indica claramente que a hipótese de supressão completa de precipitação de carbonetos considerada no modelo CCE não é necessariamente verdadeira, mesmo para um aço contendo silício (1,23 wt.\%). No entanto, a reação é retardada o suficiente para permitir um significativo enriquecimento em carbono na austenita durante o processo de partição.

A partição de carbono evidenciada nos proxigramas (histogramas dos perfis de composição) permite a identificação de fases e contornos de grão. Os quadros verdes na Figura 0-3(c) indicam os volumes ao longo dos quais os perfis de concentração foram medidos. No proxigrama à esquerda da Figura 0-3(c) são apresentados os perfis de concentração dos átomos de carbono, manganês e silício, iniciando na martensita e finalizando na austenita. A partir desse resultado é possível observar que a austenita é significativamente enriquecida em carbono $\left(\mathrm{C}_{\gamma_{\mathrm{f}}} \approx\right.$ 5,51 at.\%C) e que a martensita é empobrecida em carbono $\left(\mathrm{C}_{\alpha} \approx 0,23\right.$ at.\%) em relação ao teor 
nominal em carbono do aço $\left(1,06\right.$ at.\%C). Além disso, na interface $\alpha^{\prime} / \gamma$ há um acúmulo de carbono de aproximadamente 7,6 at.\%C, implicando em um gradiente negativo de carbono na austenita. Esses resultados são uma forte evidência da partição do carbono da martensita para austenita durante o estágio de partição. Esse fenômeno ocorre porque na interface o potencial químico do carbono na ferrita supersaturada $\left(\alpha^{\prime}\right)$ é maior do que na austenita e as duas fases possuem diferente solubilidades. Durante o estágio de partição, o sistema busca equilibrar o potencial químico do carbono, dando origem a um fluxo difusivo de carbono da martensita para austenita $[1,65,263]$. De acordo com o modelo CCE a partição finaliza quando o equilíbrio metaestável entre a ferrita $\left(\alpha^{\prime}\right)$ e a austenita é alcançado, isto é, quando a redistribuição do carbono (partição) atinge o ponto em que o potencial químico do carbono é igualado através da interface. Dessa forma, a evidência de um gradiente de carbono na interface indica que a partição de carbono ainda não atingiu o estado de equilíbrio [208].

Os resultados de difração de raios $\mathrm{X}$ in situ durante o estágio de partição para tempos de partição de $500 \mathrm{~s}$ mostraram que após $180 \mathrm{~s}$ houve uma aparente estabilização no enriquecimento em carbono da austenita (Figura 7-6). Esse comportamento justifica porque o carbono na austenita não é homogêneo após $100 \mathrm{~s}$ de partição. No entanto, usar tempos prolongados pode aumentar a possibilidade de que ocorra maior precipitação de carbonetos e transformação bainítica.

Uma estimativa do tempo médio requerido $(t)$ para a homogeneização completa de carbono na austenita retida a partir da migração do carbono da martensita pode ser obtida usando a equação 8.1:

$$
t=\frac{\bar{x}^{2}}{6 D}
$$

em que $\bar{x}$ é a distância média de difusão e $D$ é a difusividade do carbono na austenita, que pode ser expressa como:

$$
D=D_{o} \exp (Q / R T)
$$

em que $D_{o}$ é a constante pré-exponencial $\left(1,00 \times 10^{-5} \mathrm{~m}^{2} / \mathrm{s}\right), Q$ é a energia de ativação para difusão do carbono na austenita $(135,7 \mathrm{~kJ} / \mathrm{mol}), R$ é constante universal dos gases $(8,314$ $\mathrm{J} / \mathrm{Kmol}$ ), e $T$ é a temperatura absoluta em K. Para o cálculo do tempo de homogeneização assume-se que a distância média de difusão é equivalente à espessura do filme de austenita, ou seja, aproximadamente $50 \mathrm{~nm}$, de acordo com a Figura 0-3(c). A aplicação da equação 8.1 leva a um tempo de homogeneização na temperatura de têmpera $\left(318^{\circ} \mathrm{C}\right)$ de $41,4 \mathrm{~s}$, enquanto o 
tempo de manutenção a essa temperatura foi de apenas 5 s. De Knijf et al. [152] sugerem o tempo de manutenção isotérmico na temperatura de têmpera deve ser mantido curto o suficiente para evitar produtos de transformação isotérmica, formados abaixo da temperatura de início da transformação martensítica $\left(M_{S}\right)$. O mesmo cálculo aplicado para a temperatura de partição $\left(400^{\circ} \mathrm{C}\right)$ leva a um tempo de partição necessário para homogeneização do carbono da austenita de $\approx 1,43$ s. No entanto como observado nas Figuras 8-2(a) e 8-3(a) existem regiões de austenita de até $0,5 \mu \mathrm{m}$ de espessura, para as quais seria necessário um tempo de homogeneização de 142,9 s durante o estágio de partição.

Em relação ao efeito da morfologia da austenita no teor de carbono, a austenita retida na forma de bloco $\left(\mathrm{C} \gamma_{\mathrm{b}}\right)$ apresenta maior concentração de carbono em relação à austenita em forma de filme $\left(\mathrm{C} \gamma_{\mathrm{f}}\right): \mathrm{C} \gamma_{\mathrm{b}} \approx 6,00 \pm 0,01$ at.\% e $\mathrm{C} \gamma_{\mathrm{f}} \approx 5,51 \pm 0,02$ at.\%. Esse resultado pode ser explicado pela contribuição no enriquecimento em carbono produzido (na austenita em forma de bloco) pela ferrita e a martensita. Além disso, a formação de cementita observada na martensita nas vizinhanças da austenita na forma de filme tem uma influência direta no carbono disponível para ser particionado desde a martensita.

\subsubsection{Caracterização da amostra HSQ\&P deformada a $750{ }^{\circ} \mathrm{C}$}

Na Figura 0-4 são apresentados os resultados de APT para a amostra HSQ\&P (relacionada ao tratamento esquematizado na Figura 0-1(b)) deformada a $750{ }^{\circ} \mathrm{C}$ em $30 \%$ (deformação real) a uma taxa $(\dot{\varepsilon})$ de $0,5 \mathrm{~s}^{-1}$, temperada a $318^{\circ} \mathrm{C}$ e particionada a $400{ }^{\circ} \mathrm{C}$ por $100 \mathrm{~s}$. As Figuras 84(a) e 8-4(c) mostram a imagem obtida por EBSD identificando as regiões de martensita $\left(\alpha^{\prime}\right)$, martensita fresca $\left(\alpha_{\mathrm{f}}^{\prime}\right)$, ferrita $(\alpha)$ e austenita $(\gamma)$. Os retângulos em amarelo indicam as regiões de onde foram extraídas as agulhas por FIB para posterior análise no APT. Comparando o EBSD desta figura com o da figura da amostra submetida ao tratamento Q\&P (Figura 0-2(a)) é possível observar como a deformação em alta temperatura promove a diminuição do tamanho de grão tanto da ferrita como da martensita, o que poderia contribuir para melhorar o compromisso resistência-ductilidade do aço TRIP estudado. A diminuição do tamanho de grão pode estar associada provavelmente à recuperação dinâmica, na qual, no mesmo plano de deslizamento, a densidade de discordâncias decresce através da aniquilação mútua das discordâncias de sinal oposto. Isto acontece devido ao fato das discordâncias tenderem a tomar posições energeticamente mais favoráveis, o que também causa a formação de redes espacialmente mais fechadas com contornos de ângulo muito pequenos (conduzindo à 
poligonização do grão). Cabe esclarecer, que a recuperação dinâmica é o fenômeno metalúrgico que permite entender a redução do retorno elástico (springback) no processo de hot stamping uma vez que diminui as tensões residuais de forma tal que um estado estacionário (ou steady state, no qual a quantidade de defeitos gerados é compensada pela quantidade de defeitos eliminados, pelo que permanece constante a quantidade de defeitos) de tensões dentro do componente pode ser, eventualmente, alcançado [269].

A identificação dos valores de nanoindentação no EBSD permitiu relacionar os valores de nanodureza com as regiões analisadas e desta forma identificar os grãos de ferrita, a martensita e a austenita presentes no volume analisado. O mapa dos átomos de carbono de uma interface $\alpha / \gamma$ e seu perfil de composição atômica (histograma de proximidade) para o carbono, o silício e o manganês são apresentados na Figura 0-4(b). Os resultados do perfil de composição evidenciam um significativo enriquecimento em carbono na austenita $(\mathrm{C} \gamma \approx 6,63 \pm 0,01$ at.\%), enquanto os resultados para o silício e o manganês não apresentam uma evidente partição nesta região. Nesta figura se observa também um acumulo de carbono na interface $\alpha / \gamma$ de $\approx 9,45$ at. $\%$. Com o intuito de analisar se houve precipitação de carbonetos na martensita sob as condições de tratamento estudadas, uma medida de APT foi conduzida em uma agulha extraída da região delimitada claramente como martensita pelo contorno pontilhado em cor azul na Figura 0-4(c), especificamente da região delimitada pelo retângulo amarelo. Na Figura 0-4(d) é apresentado o perfil de composição para o silício, o carbono e o manganês na interface do aglomerado indicado pela seta azul na parte superior dessa figura. Esse resultado revela que a concentração do silício é homogênea tanto na martensita como no aglomerado, indicando que este, provavelmente, é uma aglomeração (cluster) de carbono ao invés de uma partícula de cementita. Além disso, o cluster apresenta um teor de carbono inferior $(\approx 15$ at.\%) ao esperado para um precipitado estável como a cementita $(\approx 25$ at.\%) ou de transição (metaestável), como o carboneto $\varepsilon\left(\approx 33\right.$ at.\%), $\mathrm{Fe}_{2,4} \mathrm{C}$ (hexagonal) ou o carboneto eta $(\eta \approx 29$ at.\%). Timokhina et al. $[270,271]$ identificaram carbonetos de baixa temperatura que possuem teores de carbono entre 10 e 20 at.\%, como o $\mathrm{Fe}_{32} \mathrm{C}_{4}$ ou $\mathrm{Fe}_{4} \mathrm{C}_{0.63}$. Esses carbonetos foram associados à formação de ferrita bainítica durante transformação isotérmica em baixas temperaturas $\left(\approx 200^{\circ} \mathrm{C}\right)$ por longos períodos de manutenção (10 dias) e à ferrita em aço dual phase após o processo de bake hardening com pré-deformação $\left(\varepsilon=5 \%\right.$, tratado a $175^{\circ} \mathrm{C}$ por $\left.30 \mathrm{~min}\right)$. Contudo, no presente trabalho a região onde foram identificados esses aglomerados foi claramente identificada, por EBSD e nanoindentação, como martensita. Ademais, as martensitas de baixo carbono consistem de ripas, separadas por contornos de baixo ou alto ângulo, mas contendo uma alta densidade de discordâncias entre elas [272]. Sabe-se que os contornos de grão e as discordâncias servem 
como sumidouros para os átomos de carbono devido à redução do potencial químico do carbono nos defeitos [273], o que resulta em um enriquecimento local em carbono nestas regiões. Portanto, os aglomerados observados na Figura 0-4(d) correspondem, mais provavelmente, à segregação de carbono nos contornos das interfaces das ripas de martensita. É importante destacar que os clusters de carbono apresentam características de distribuição linear alinhados entre si em um único plano de hábito, ou planos preferenciais invariantes da interface, ao longo dos quais se formam as ripas de martensita. As características das placas paralelas poderiam ser correspondentes à segregação do carbono nas falhas ou nas micromaclas da martensita, observadas por microscopia de transmissão (Figuras 8-6 e 8-7). Outra explicação é que esse alinhamento poderia ter sido causado pelas tensões aplicadas, as quais favorecem a formação de variantes cristalográficas preferenciais acerca dos planos de tensão máxima cisalhante [190]. Portanto, devido ao fato de que existem muitas variantes cristalográficas disponíveis por grão de austenita há uma alta probabilidade que a orientação de uma placa se encontre próxima da orientação preferencial para que ocorra o alinhamento com respeito às tensões [39]. Cabe destacar, que a presença desses aglomerados ou a formação de precipitados na martensita reduzem os níveis de carbono disponíveis para enriquecer a austenita e estabilizá-la na temperatura ambiente.

Comparando os teores de carbono da austenita na forma de bloco (em uma interface $\alpha / \gamma_{\mathrm{b}}$ ) das amostras HSQ\&P deformada a $750{ }^{\circ} \mathrm{C}\left(\mathrm{C} \gamma_{\mathrm{b}} \approx 6,63 \pm 0,01\right.$ at.\%) e Q\&P $\left(\mathrm{C} \gamma_{\mathrm{b}} \approx 6,00 \pm 0,01\right.$ at.\%), ambas temperadas a $318^{\circ} \mathrm{C}$ e particionadas a $400{ }^{\circ} \mathrm{C}$ por $100 \mathrm{~s}$, observa-se que houve um incremento em $\approx 10 \%$ no teor de carbono para a amostra HSQ\&P. Esse resultado pode ser explicado pela contribuição adicional (além da parcela produzida pela martensita no estágio de partição) no enriquecimento em carbono na austenita produzido pela partição em carbono a partir da ferrita que foi formada durante a deformação em alta temperatura, i.e., formada pelo efeito DIFT [86, 267]. Este é um efeito combinado dos aumentos tanto da força motriz produzida pela energia de deformação armazenada na austenita (deformada) para gerar a transformação ferrítica, como do número de sítios de nucleação produzidos pelo aumento na densidade de discordâncias induzidos pela deformação. Portanto, a quantidade, a taxa e a temperatura de deformação podem ter um efeito nesse tipo de transformação. Dessa forma, observa-se que a deformação da austenita em alta temperatura promove uma transformação de fase difusional (comprovada também pela maior quantidade de ferrita na amostra HSQ\&P quando comparada com a Q\&P), o que leva a um maior enriquecimento na austenita não transformada e na redução do início da temperatura da transformação martensítica (MsQ\&P = $390{ }^{\circ} \mathrm{C}, \operatorname{Ms}$ HSQ\&P $\left.(\varepsilon=750)=372{ }^{\circ} \mathrm{C}\right)$. 


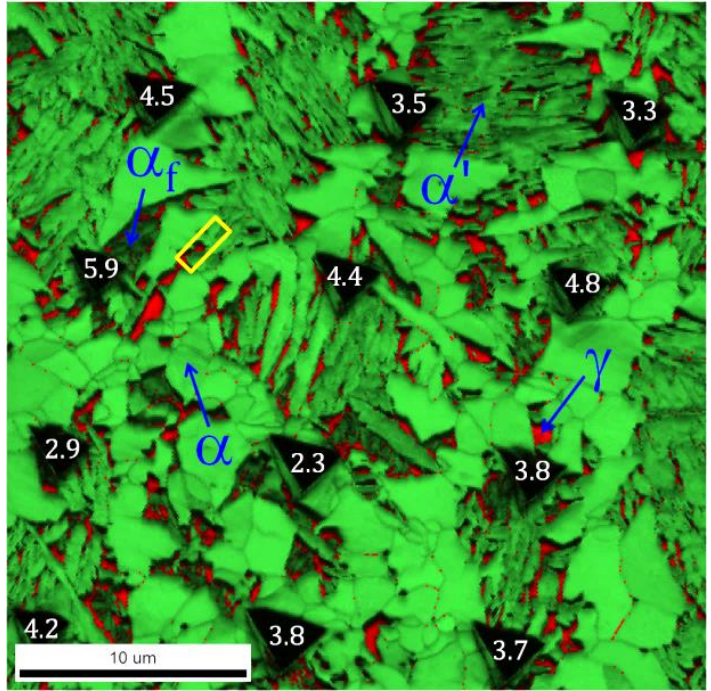

(a)

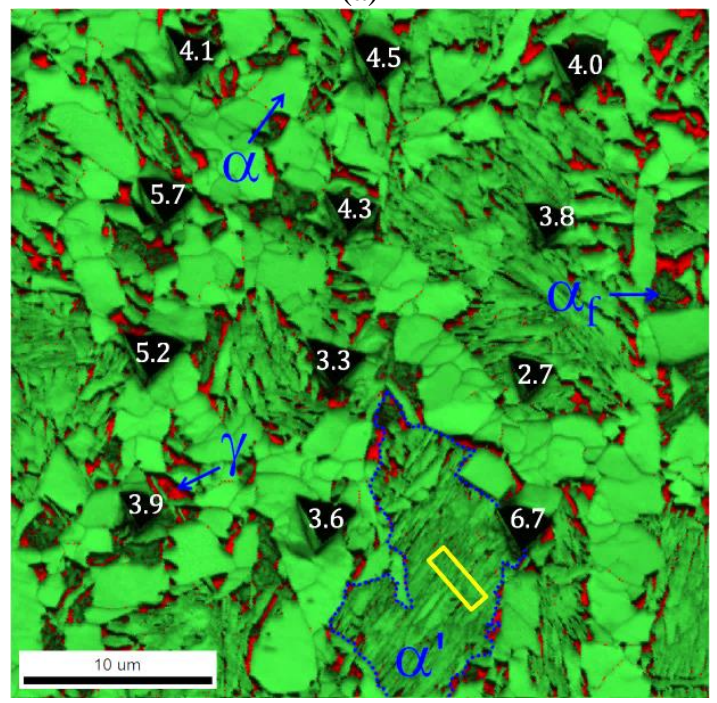

(c)
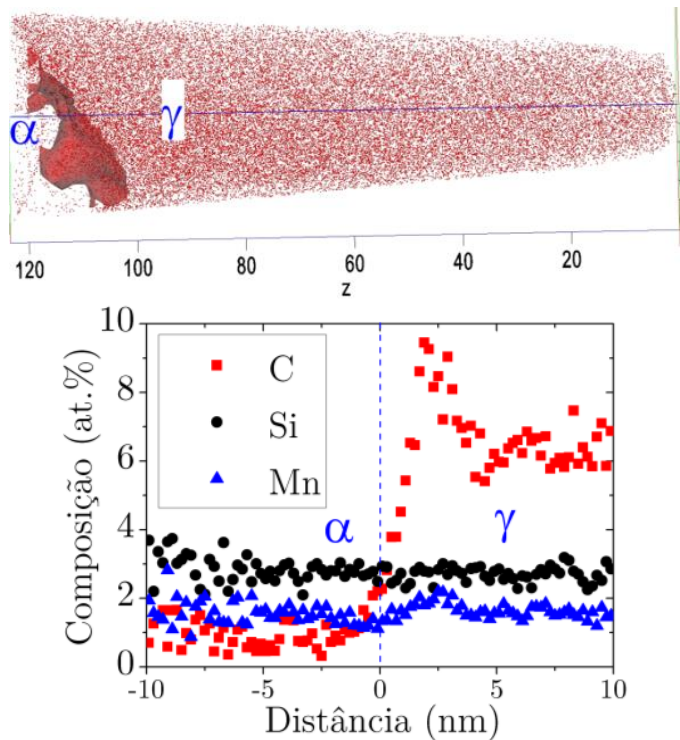

(b)
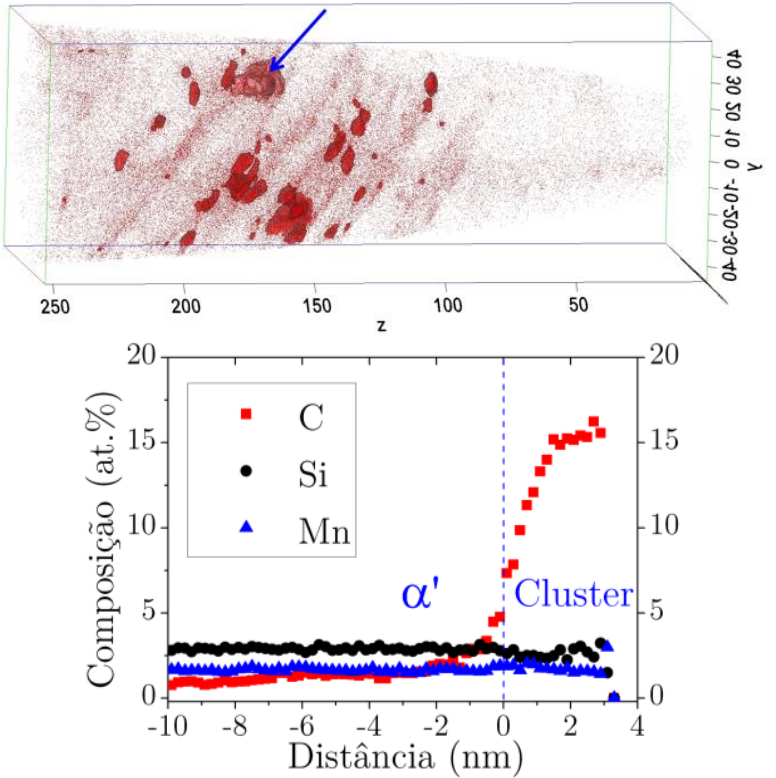

(d)

Figura 0-4. Amostra HSQ\&P deformada a $750{ }^{\circ} \mathrm{C}$ em $30 \%$ a uma taxa de $0,5 \mathrm{~s}^{-1}$, temperada a $318^{\circ} \mathrm{C}$ e particionada a $400{ }^{\circ} \mathrm{C}$ por $100 \mathrm{~s}$. (a) e (c) mapas de EBSD e nanoindentações da amostra HSQ\& $\mathrm{P}_{750}$, (b) mapa da superfície de isoconcentração de 3 at.\%C, para uma interface de martensita $(\alpha)$ e austenita $(\gamma)$, extraída da região

indicada no retângulo amarelo em (a), e proxigramas obtidos através da interface $\alpha / \gamma$ (d) superfície de isoconcentração de 7 at.\%C, na região de martensita identificada no retângulo amarelo em (c) e histograma de proximidade obtidos através da interface $\alpha$ /cluster de carbono.

A Figura 0-5 mostra a sequência de etapas para extração de amostras por FIB para caracterização por microscopia eletrônica de transmissão (STEM) a partir da amostra HSQ\&P deformada em $30 \%$ a $750{ }^{\circ} \mathrm{C}$, temperada a $318^{\circ} \mathrm{C}$ e particionada a $400{ }^{\circ} \mathrm{C}$ por $100 \mathrm{~s}$. As áreas para observação foram selecionadas a partir do mapa de fases obtido por EBSD (Figura 0-5(a)). Na Figura 0-5(a) o mapa de EBSD permite identificar as regiões correspondentes a ferrita $(\alpha)$, martensita $\left(\alpha^{\prime}\right)$, martensita fresca $\left(\alpha_{\mathrm{f}}^{\prime}\right)$ e austenita retida $(\gamma)$. Na mesma figura à direita é mostrada imagem por microscopia eletrônica de varredura das duas regiões selecionadas para análise com deposição de platina. O recobrimento de platina é utilizado para delimitar a região 
de interesse e, principalmente, para proteger a superfície de possíveis danos que possam ser causados durante o corte pelo feixe de íons de gálio $\left(\mathrm{Ga}^{+}\right)$, além de evitar implantação iônica. As Figura 0-5(b) e 8.5(c) mostram etapas intermediárias da preparação da amostra nas quais são observados cortes feitos com os íons de $\mathrm{Ga}^{+}$antes da extração da lâmina e a amostra soldada no porta-amostra após polimento final, podendo ser identificados alguns grãos sub-superficiais. Os resultados de microscopia eletrônica de transmissão das regiões identificadas com os números 1 e 2 na Figura 0-5(a) são apresentados nas Figuras 8-6 e 8-7, respectivamente.

A parte superior da Figura 0-6 da imagem obtida por transmissão corresponde à superfície assinalada pelo retângulo amarelo na Figura 0-5(a) onde se identifica uma interface $\alpha / \alpha_{f}^{\prime}$. A região identificada como martensita fresca $\left(\alpha_{f}^{\prime}\right)$ apresenta uma alta densidade de discordâncias, o que causa um acúmulo maior de carbono nessa região, como se observa no mapa de composição do carbono obtido por espectroscopia de raios X por dispersão de energia (EDS) mostrado na parte esquerda superior da figura. Como resultado da grande distorção causada pela supersaturação em carbono no parâmetro de rede da martensita, existe uma atração entre os átomos de carbono e os campos de tensões das discordâncias e, dessa forma, o carbono tende a difundir em locais próximos das discordâncias a fim de reduzir seu potencial químico [274].

$\mathrm{Na}$ parte central dessa figura foi identificado um grão de martensita embebido entre grãos de ferrita. A ampliação de uma das regiões centrais da microestrutura apresenta características típicas de martensita maclada, relacionada com a transformação que ocorre em aços com alta concentração de carbono. A austenita transforma em martensita maclada durante a têmpera final (i.e., durante o resfriamento final até a temperatura ambiente) quando a concentração de carbono na austenita não excede certo valor crítico para estabilizá-la à temperatura ambiente [275]. Isto mostra que após o estágio de partição, uma parte da austenita possui o carbono suficiente para ser estabilizada na temperatura ambiente, enquanto outra parte da austenita que possui um teor de carbono razoavelmente alto não é completamente estabilizada, transformando-se em martensita maclada não revenida. 

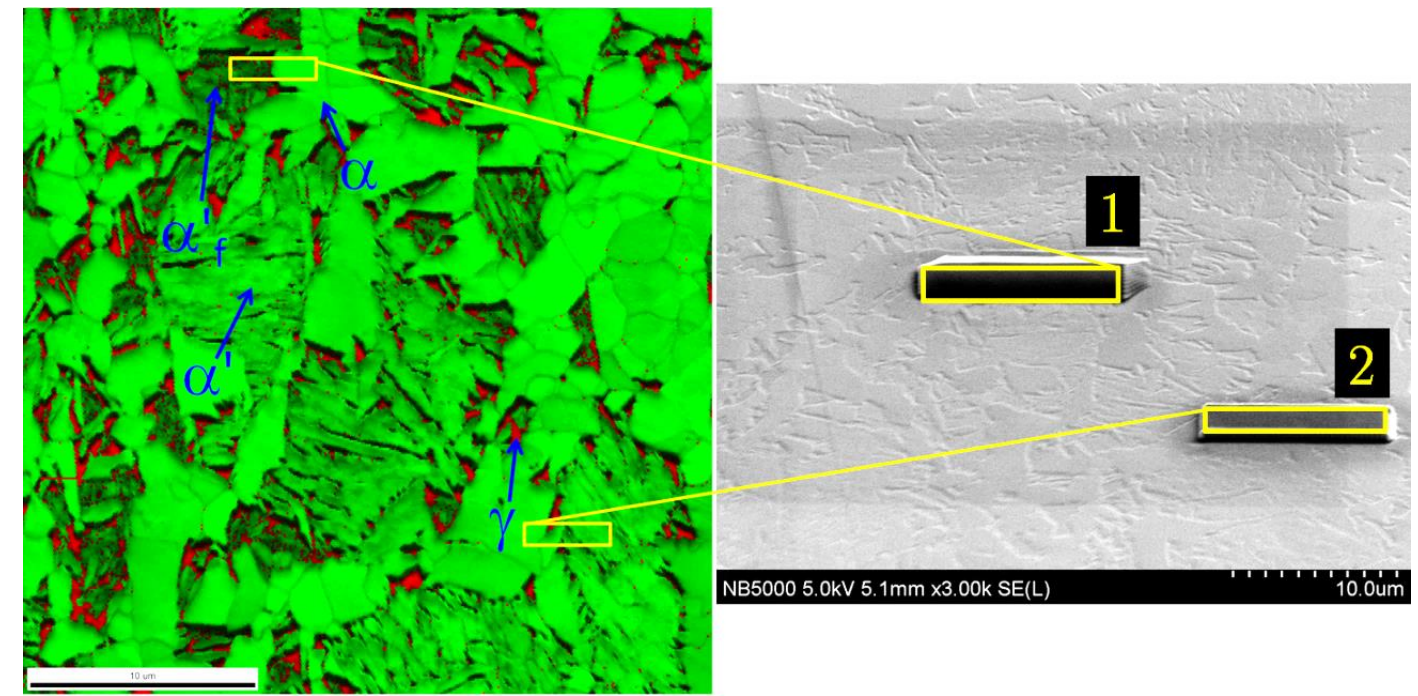

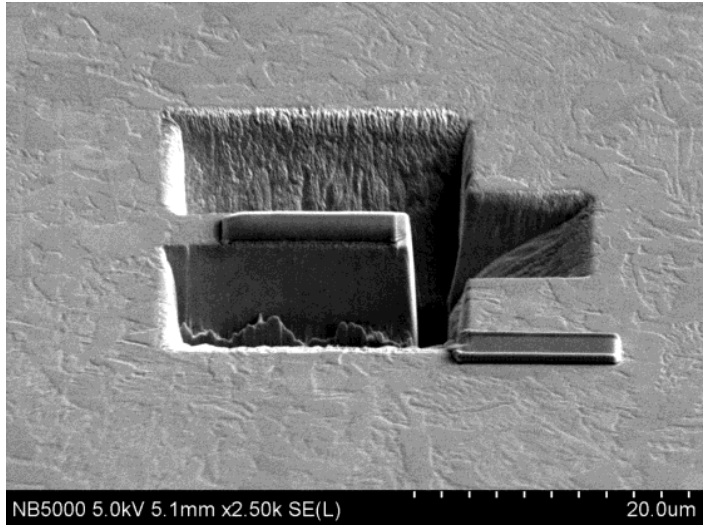

(b) (a)

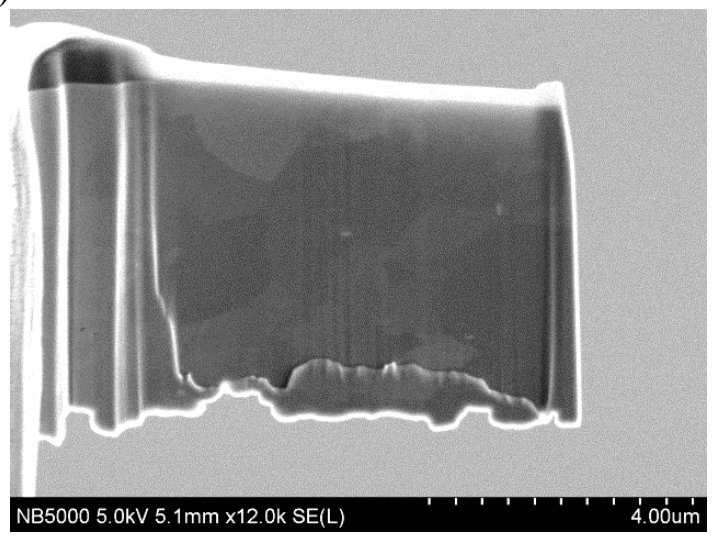

(c)

Figura 0-5. Amostra HSQ\&P deformada a $750{ }^{\circ} \mathrm{C}$ em $30 \%$ a uma taxa de $0,5 \mathrm{~s}^{-1}$, temperada a $318^{\circ} \mathrm{C}$ e particionada a $400{ }^{\circ} \mathrm{C}$ por 100 s.(a) EBSD identificando as regiões correspondentes a ferrita $(\alpha)$, martensita $\left(\alpha^{\prime}\right)$, martensita fresca $\left(\alpha_{\mathrm{f}}^{\prime}\right)$ e austenita retida $(\gamma)$, (b) e (c) corte por íons de gálio e lamela após polimento final por FIB, da região identificada na figura (a).

Na Figura 0-7 são mostradas as imagens obtidas por STEM da amostra extraída da região 2, na qual são analisadas interfaces $\alpha^{\prime} / \gamma, \alpha / \gamma$ e $\alpha / \alpha^{\prime}$ (antigas interfaces $\alpha / \gamma$ ). As regiões identificadas como austenita apresentam uma elevada densidade de discordâncias, como pode ser constatado pelo tom escurecido das respectivas regiões. A presença adjacente de martensita (cuja formação induz defeitos na austenita circundante) e a etapa de deformação do processo HSQ\&P justificam esse resultado. Na mesma figura são mostrados mapas de composição obtidos por EDS do carbono e do manganês. É possível observar que os filmes de austenita que se intercalam entre as ripas de martensita são enriquecidos em carbono, evidenciado a partição de carbono. Adicionalmente, observa-se que a austenita enriquecida em carbono possui uma morfologia de dentes de serra, de modo que nas proximidades da interface com a ferrita o enriquecimento em carbono é maior. Esse resultado mostra que a presença de ferrita possui algum papel no enriquecimento em carbono da austenita. Uma possível explicação para esse 
fenômeno é a pré-existência de um acúmulo de carbono nas proximidades da interface ferrita/austenita original. A existência de tal acúmulo é possível caso a formação da ferrita não tenha atingido o equilíbrio ou caso não houvesse tempo suficiente para que o carbono se homogeneizasse na austenita. Como a formação de ferrita DIFT ocorre rapidamente durante a etapa de deformação (0,6 s de duração), ambas as considerações são compatíveis com os resultados experimentais. Em relação à distribuição de manganês na região analisada é observado um acúmulo significativo de Mn ao longo da interface ferrita/martensita (austenita original). Não obstante, não é possível observar significativa diferença no teor de Mn no volume (longe da interface) entre martensita (austenita) e a ferrita, embora a partição de Mn seja prevista termodinamicamente. Essa partição limitada à interface pode ser associada a dois fenômenos: a ocorrência de arraste de soluto na interface durante o crescimento da ferrita, ou o regime de controle cinético conhecido como equilíbrio local com partição desprezível de soluto (LENP). O regime LENP é discutido adiante junto com a discussão dos resultados de APT da amostra HSQ\&P deformada a $800{ }^{\circ} \mathrm{C}$.
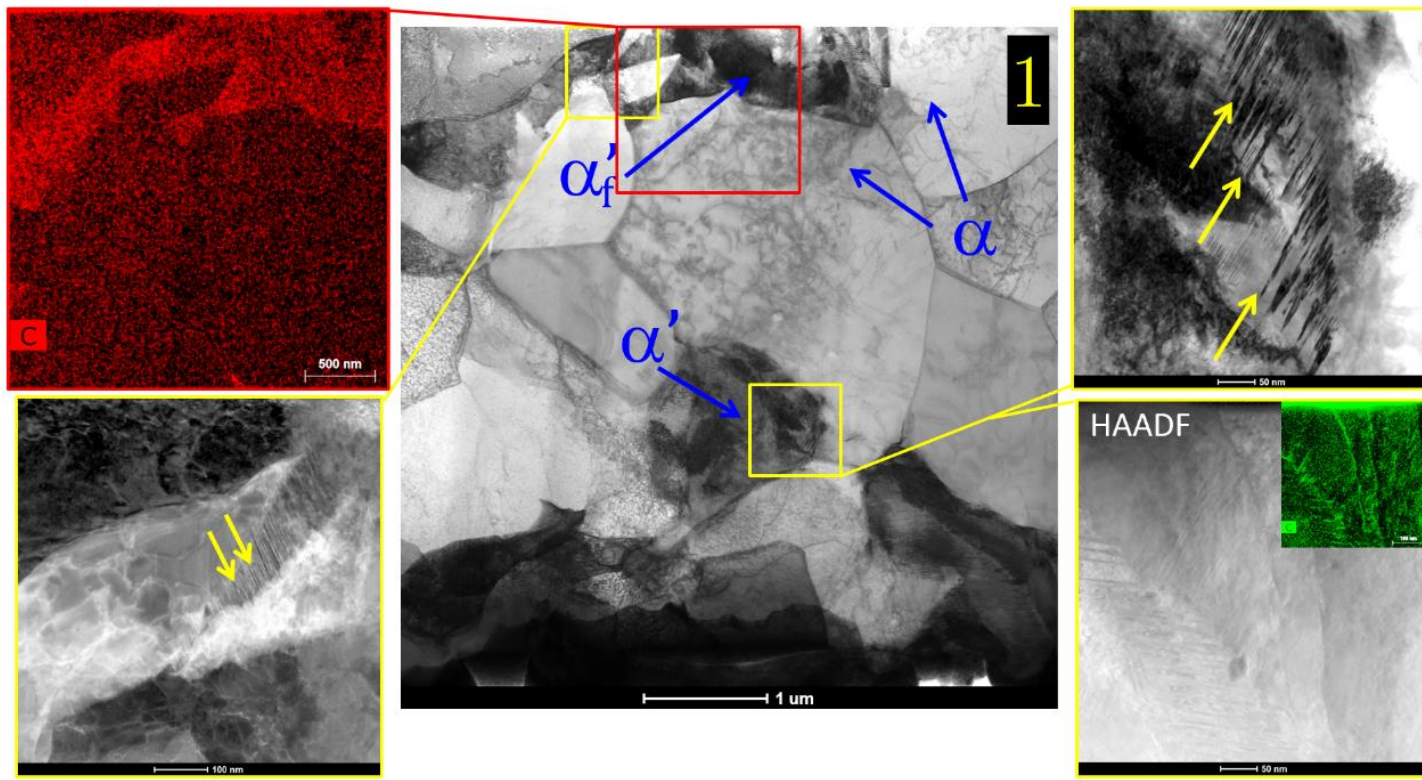

HAADF

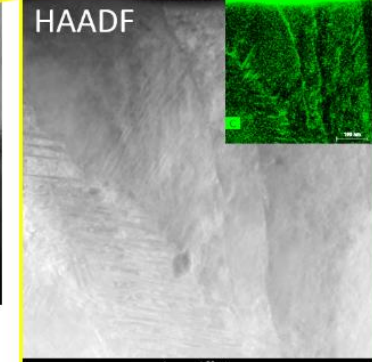

Figura 0-6. Imagem obtida por microscopia eletrônica de transmissão em campo claro da região 1 identificada na Figura 0-5 (a) da amostra HSQ\&P deformada a $750{ }^{\circ} \mathrm{C}$ em $30 \%$ a uma taxa de $0,5 \mathrm{~s}^{-1}$, temperada a $318^{\circ} \mathrm{C}$ e particionada a $400^{\circ} \mathrm{C}$ por $100 \mathrm{~s}$. À esquerda se observam o mapa de carbono obtido por espectroscopia de raios X por dispersão em energia (EDS). Nas imagens com contorno amarelo são identificadas, pelas setas amarelas, regiões com maclação. Na parte inferior direita, imagem obtida com detector de campo escuro anular (HAADF) e mapa de carbono por EDS dessa região. 

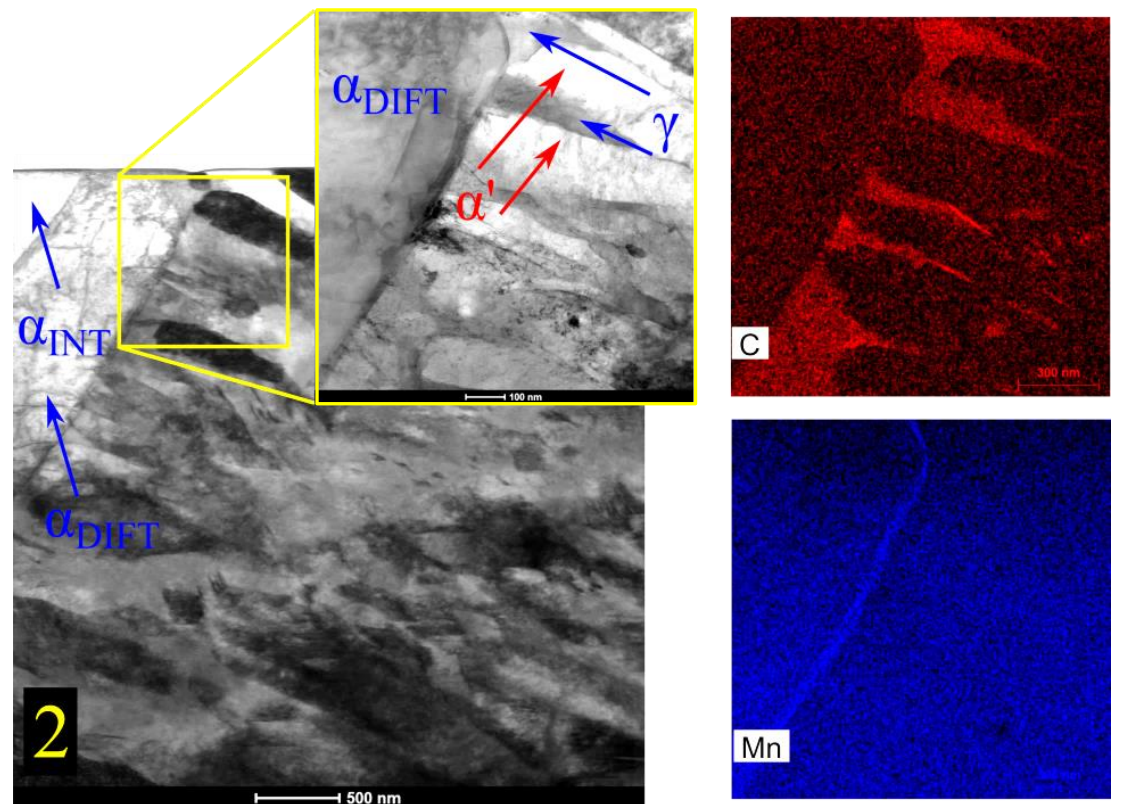

Figura 0-7. Imagem de microscopia eletrônica de transmissão da região 2 identificada na Figura 0-5(a) para amostra HSQ\&P deformada a $750{ }^{\circ} \mathrm{C}$ em $30 \%$ a uma taxa de $0,5 \mathrm{~s}^{-1}$, temperada a $318^{\circ} \mathrm{C}$ e particionada a $400{ }^{\circ} \mathrm{C}$ por $100 \mathrm{~s}$. À direita se observam os mapas de carbono (C, em vermelho) e manganês (Mn, em azul) obtidos por espectroscopia de raios $\mathrm{X}$ por dispersão em energia (EDS).

\subsubsection{Caracterização da amostra HSQ\&P deformada a $800{ }^{\circ} \mathrm{C}$}

Na Figura 0-8 são apresentados os resultados da amostra HSQ\&P deformada a $800{ }^{\circ} \mathrm{C} \mathrm{em}$ $30 \%$ a uma taxa de $0,5 \mathrm{~s}^{-1}$, temperada a $318^{\circ} \mathrm{C}$ e particionada a $400{ }^{\circ} \mathrm{C}$ por $100 \mathrm{~s}$. Na Figura 0-8(a) é apresentada a imagem de EBSD identificando as indentações que permitiram localizar três regiões de interesse ( $\alpha$, ferrita; $\alpha^{\prime}$, martensita e $\gamma$, austenita retida) para análise por APT. Como se observa nas Figuras 8-8(a) e 8-8(b), a austenita avaliada na região 1, obtida em uma interface $\alpha^{\prime} / \gamma$ nas proximidades de um grão de ferrita, é significativamente enriquecida em carbono $(\mathrm{C} \gamma \approx 7,3$ at.\%), indicando a partição de carbono desde a martensita. Como pontuado anteriormente, o acúmulo de carbono durante a formação de ferrita DIFT também pode contribuir para o enriquecimento em carbono da austenita.

$\mathrm{Na}$ interface $\alpha^{\prime} / \gamma$ obtida na região 3 (Figura 0-8(d)), longe da influência do grão de ferrita, também se observa acúmulo de carbono na interface $\left(\mathrm{C}_{\alpha^{\prime} / \gamma} \approx 7,3\right.$ at.\%), porém menor do que o observado na interface obtida na região $1\left(\mathrm{C}_{\alpha^{\prime} / \gamma} \approx 11 \mathrm{at} . \%\right)$. Em complemento à caracterização da região 1 , esse resultado indica fortemente que a presença de ferrita nas redondezas afeta 0 teor de carbono da austenita retida $(C \gamma)$. Já que $C \gamma$ na interface $\alpha^{\prime} / \gamma / \alpha$ foi de 7,3 at.\%, enquanto na interface $\alpha^{\prime} / \gamma$ esse valor foi de 5,9 at.\%. Nessa figura também é apresentado o histograma de proximidade obtido através de uma interface $\theta / \alpha^{\prime}$. O teor de carbono determinado em $\theta$ foi de $\approx 23$ at.\%, abaixo da composição nominal da cementita (25 at.\%). Todavia, a rejeição de silício 
observada na cementita sugere que a fase identificada seja de fato cementita. Devido à elevada força motriz para precipitação de carbonetos a partir da martensita supersaturada em carbono, a precipitação de carbonetos é praticamente inevitável. Desse modo, a partição do carbono da martensita para austenita e o fenômeno de revenido ocorrem simultaneamente, não sendo, todavia, mutuamente exclusivos sob os tratamentos termomecânicos realizados. Consequentemente, uma das principais considerações do modelo CCE — ausência de terceiras fases durante a etapa de partição — é violada.

Na Figura 0-8(c) são apresentados os resultados da análise da interface $\alpha / \gamma$ obtida na região 2. Os teores medidos de carbono no volume em $\gamma$ e em $\alpha$ nessa região apresentaram valores de $\approx 5,22 \pm 0,01$ at. $\%$ e de $\approx 0,02 \pm 0,00$ at.\%, respectivamente, enquanto um acúmulo de $\approx 6,09$ $\pm 0,1$ at. $\%$ foi observado na interface. No entanto, embora seja observada a mesma concentração de manganês na ferrita e na austenita no volume, na interface é observado um alto enriquecimento em Mn. Como reportado anteriormente, tal comportamento pode ser associado ou ao arraste de soluto ou ao crescimento da ferrita sob condições de equilíbrio local com partição desprezível do soluto (LENP) [276]. De forma a avaliar se a largura do pico de Mn é compatível com o regime LENP, aplica-se a equação 8.1 para se estimar o tempo necessário para que tal pico se desenvolva. Sun e Pugh [277] sugerem que a difusividade do manganês na austenita pode ser calculado pela expressão (avaliada $\mathrm{em}^{2} / \mathrm{s}$ ):

$$
D_{M n}^{\gamma}=0,16 \exp \left(-\frac{261700}{R T}\right)
$$

Aplicando a difusividade calculada a $800{ }^{\circ} \mathrm{C}$ e a largura do pico de $\mathrm{Mn}$ estimada em $3 \mathrm{~nm}$ na equação 8.1 , obtém-se $0,51 \mathrm{~s}$, valor próximo ao intervalo de tempo da etapa de deformação, na qual a ferrita DIFT é formada.

O enriquecimento em carbono nas interfaces observado por APT foi igualmente evidenciado a partir dos resultados de nanoindentação. O contorno azul da Figura 8-9(a), para a amostra Q\&P, inclui duas nanoindentações, uma no centro de um grão de martensita como uma nanodureza de 4,18 GPa e uma outra em uma interface ferrita/martensita, com um valor de nanodureza de 4,71 GPa. O aumento da dureza perto da interface pode ser explicado pelo aumento do teor de carbono nessa região. O resultado foi igualmente observado na amostra HSQ\&P deformada a $750{ }^{\circ} \mathrm{C}$ onde se obteve o maior valor de dureza $(6,17 \mathrm{GPa})$ na microestrutura ao redor da interface. De fato, o resultado da maior nanodureza para a interface da amostra HSQ\&P, quando comparada com a amostra Q\&P, é condizente com os resultados 
de APT onde se observou que os maiores enriquecimentos em carbono foram obtidos para amostra deformada.
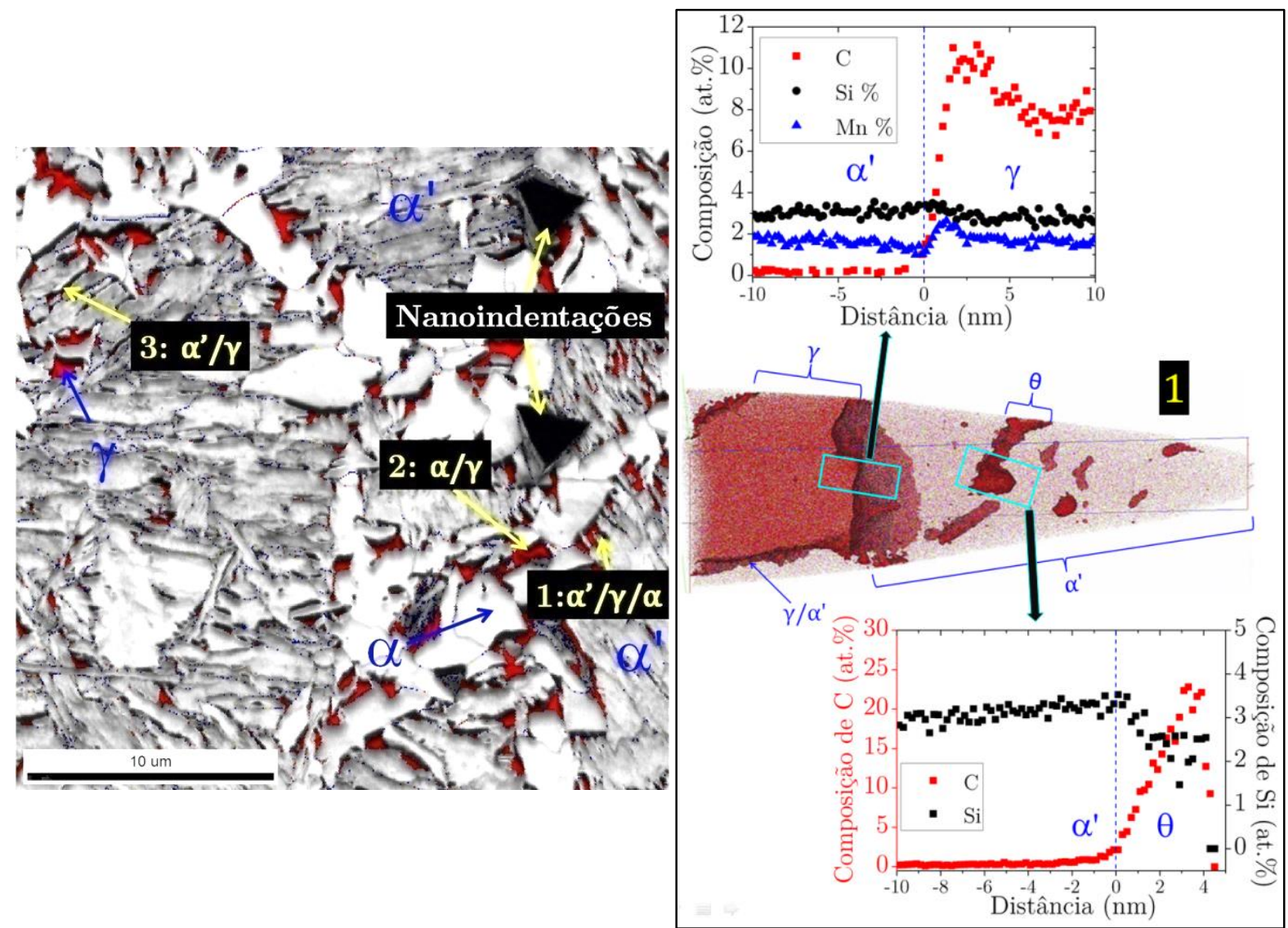

(a)

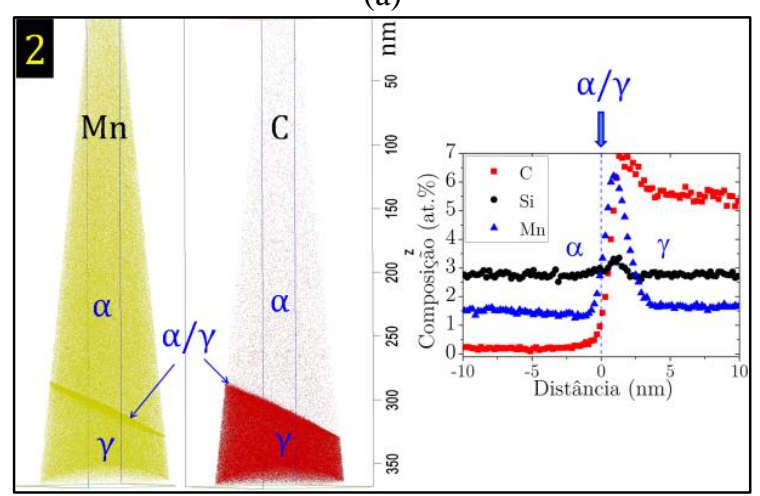

(c)

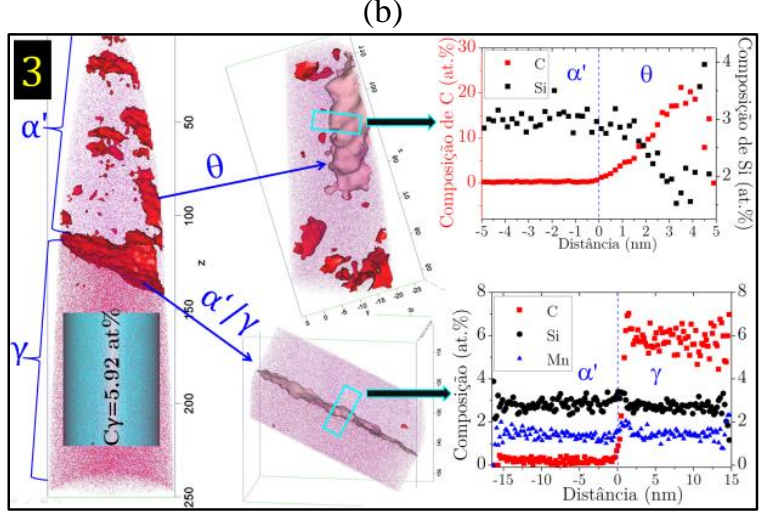

(d)

Figura 0-8. Amostra HSQ\&P deformada a $800{ }^{\circ} \mathrm{C}$ em $30 \%$ a uma taxa de $0,5 \mathrm{~s}^{-1}$, temperada a $318^{\circ} \mathrm{Ce}$ particionada a $400^{\circ} \mathrm{C}$ por $100 \mathrm{~s}$. (a) EBSD identificando as indentações que permitiram localizar as regiões de interesse correspondentes a ferrita $(\alpha)$, martensita $\left(\alpha^{\prime}\right)$ e austenita retida $(\gamma)$; (b) Mapa dos átomos de carbono de uma interface $\alpha^{\prime} / \gamma$ extraída da região identificada com o número 1 na imagem (a); (c) APT dos átomos de

carbono e de manganês de uma interface $\alpha / \gamma$ da região identificada como o número 2 na imagem (a); (d) Superfície de isoconcentração de 3 at.\%C, para uma interface de martensita $\left(\alpha^{\prime}\right)$ e austenita $(\gamma)$, identificada com o número 3 na imagem (a), sobreposta a um mapa de átomos de carbono e histogramas de proximidade obtidos através de uma interface cementita $(\theta) / \alpha^{\prime}$ e de uma interface $\alpha^{\prime} / \gamma$. 


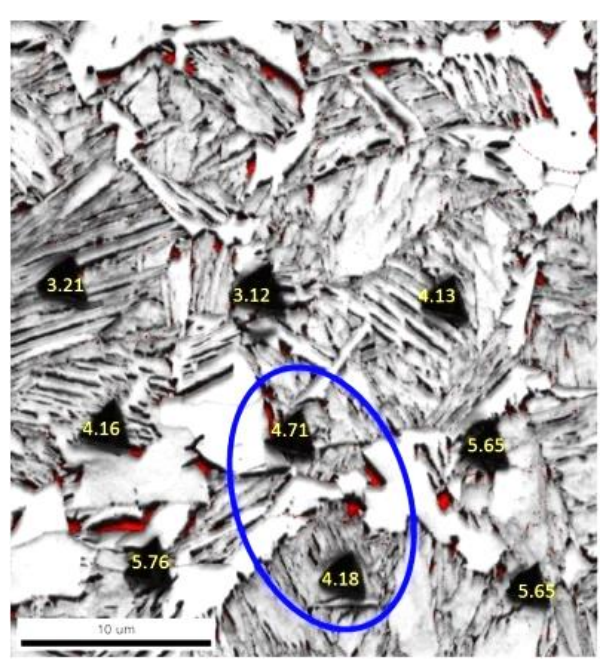

(a)

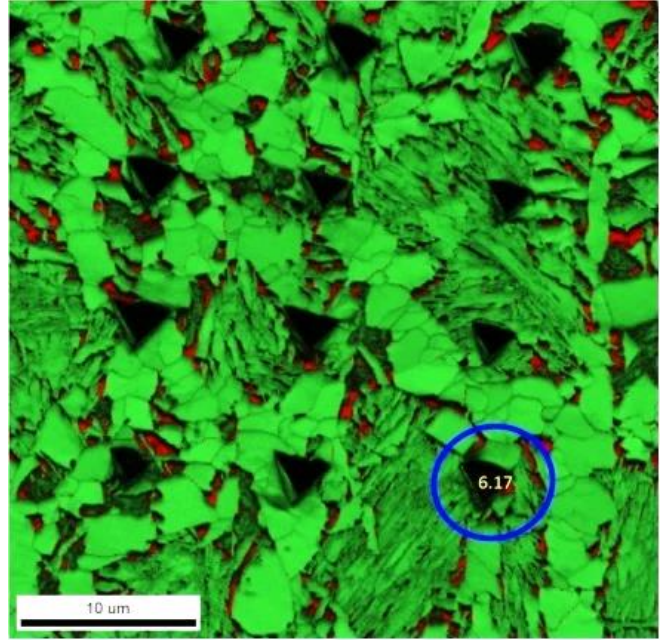

(b)

Figura 0-9. Mapas de EBSD e nanoindentações das amostras Q\&P e HSQ\&P, austenitizadas intercriticamente a $800{ }^{\circ} \mathrm{C}$, temperadas a $318{ }^{\circ} \mathrm{C}$, particionadas a $400{ }^{\circ} \mathrm{C}$ por $100 \mathrm{~s}$. A amostra HSQ\&P foi deformada a $750{ }^{\circ} \mathrm{C} \mathrm{em}$ $30 \%$ a $0,5 \mathrm{~s}^{-1}$.

O resultado que indica uma maior nanodureza para a interface da amostra HSQ\&P, com deformação a $750{ }^{\circ} \mathrm{C}$, associada ao maior teor de carbono observado por APT é explicado usando o diagrama da Figura 0-10. Na parte superior da Figura 0-10(a) se observa esquematicamente o comportamento do carbono em uma interface $\alpha / \gamma$ para uma amostra Q\&P e na parte inferior o que acontece na mesma interface para uma amostra que foi submetida ao processo de HSQ\&P. O enriquecimento em carbono da austenita na interface $\alpha / \gamma$ é produzido, principalmente pela migração do carbono que provem do crescimento da ferrita, e nas zonas distantes da interface, onde não existe uma zona enriquecida difusionalmente pelo crescimento da fase, o teor de carbono da austenita é consequência da condição de austenitização intercrítica imposta nos tratamentos térmicos. Na amostra que foi submetida ao processo de HSQ\&P foi observado, por estereologia, um aumento do teor de ferrita de $\approx 10 \%$. Esse aumento da ferrita DIFT $\left(\alpha_{\text {DIFT }}\right)$, atribuído à aceleração das taxas de nucleação e crescimento da ferrita após a deformação intercrítica ${ }^{16}$, leva a um maior teor de carbono disponível para se difundir (por causa da diferença na solubilidade nas duas fases) na austenita. Esse aumento do teor de carbono na interface causa uma diminuição da temperatura de início de transformação martensítica $\left(M_{S}\right)$ nessa região, como esquematizado na Figura 0-10(b), o que por sua vez produz um aumento da estabilidade da austenita. Esse comportamento da redistribuição do carbono também permite entender a presença na amostra deformada da subestrutura maclada (principalmente nas

\footnotetext{
${ }^{16}$ Quando a transformação de fase $\gamma \rightarrow \alpha$, ocorre desde uma austenita deformada a austenita se forma, não só nos contornos do grão, mas também em sítios de nucleação dentro dos grãos de austenita como bandas de deformação ou seus contornos, o que explica o aumento da taxa de nucleação da ferrita.
} 
interfaces) observada por microscopia de transmissão e indicadas pelas setas amarelas na Figura $0-6$.
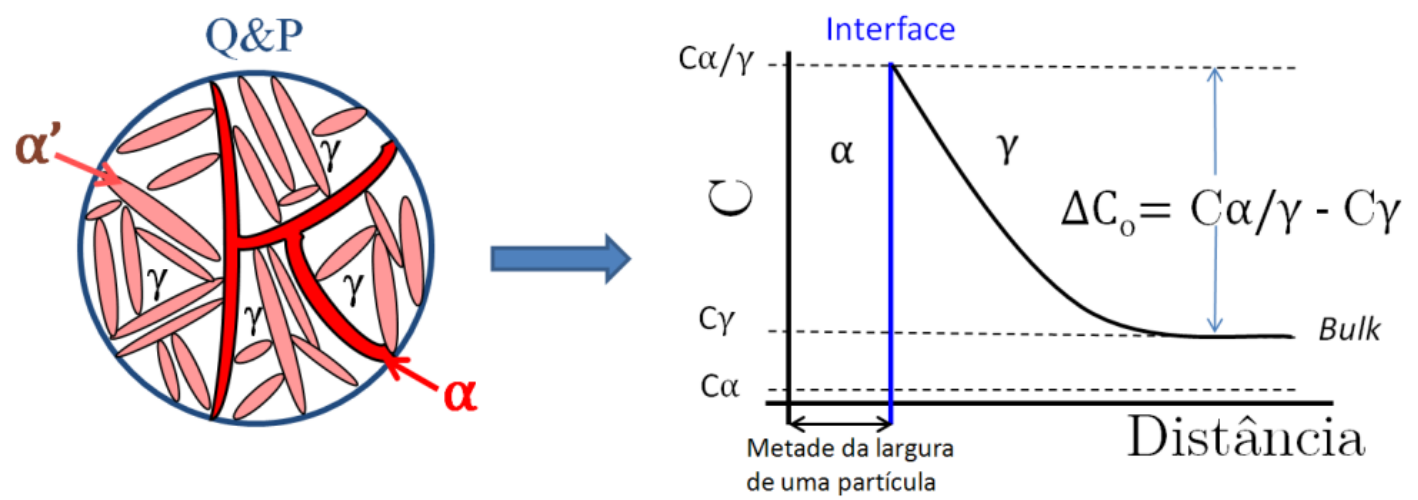

HSQ\&P; $\varepsilon=30 \%$ a $750^{\circ} \mathrm{C}$
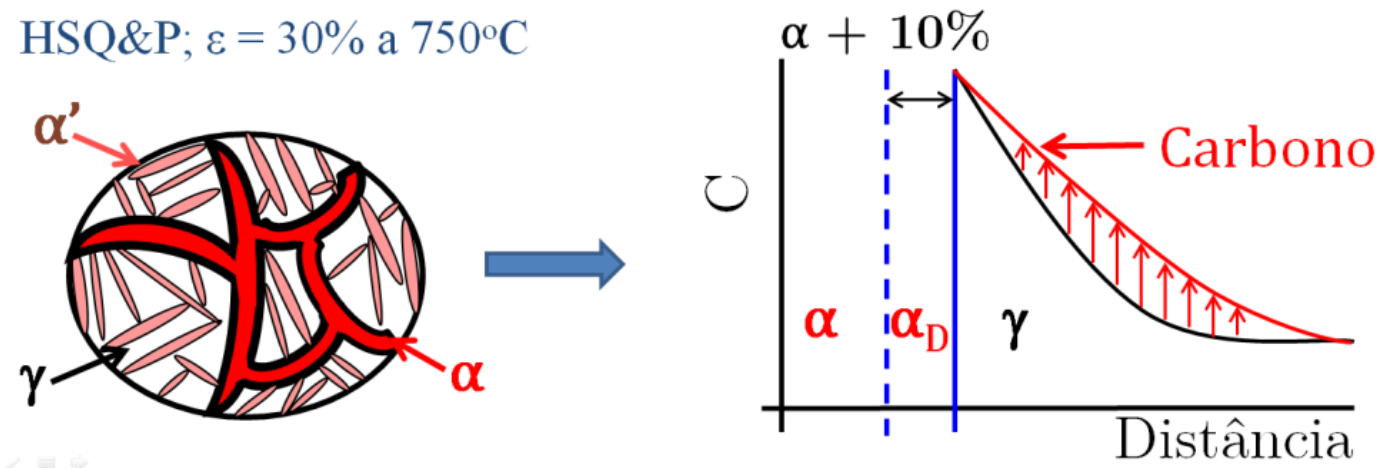

(a)

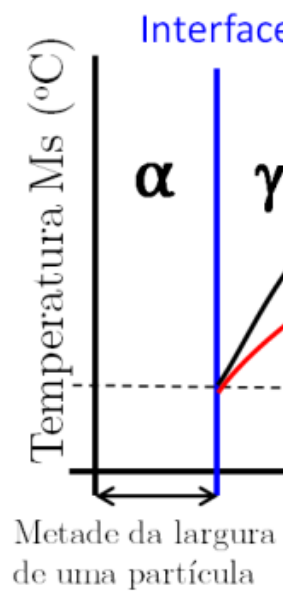


resultados de difração de raios X (DRX) apresentados no capítulo anterior. Na Figura 0-11 são apresentados os resultados dos difratogramas e da fração volumétrica da austenita retida $(\mathrm{V} \gamma)$ para os tratamentos apresentados neste capítulo. Os resultados de $V \gamma$ foram de $8,1 \pm 0,1 \%, 10,4$ $\pm 0,1 \%$ e $13,3 \pm 0,1 \%$ para os tratamentos de Q\&P, HSQ\&P deformada a $750{ }^{\circ} \mathrm{C}$ e HSQ\&P deformada a $800{ }^{\circ} \mathrm{C}$, respectivamente. Como mostrado nos resultados de APT, os maiores valores de enriquecimento em carbono da austenita foram observados para amostra HSQ\&P deformada a $800^{\circ} \mathrm{C}$ e os menores para amostra tratada por Q\&P, o que é condizente com os resultados da fração volumétrica da austenita retida obtidos por DRX. Isso significa que um maior aumento no teor em carbono da austenita pode contribuir com sua maior estabilização na temperatura ambiente.

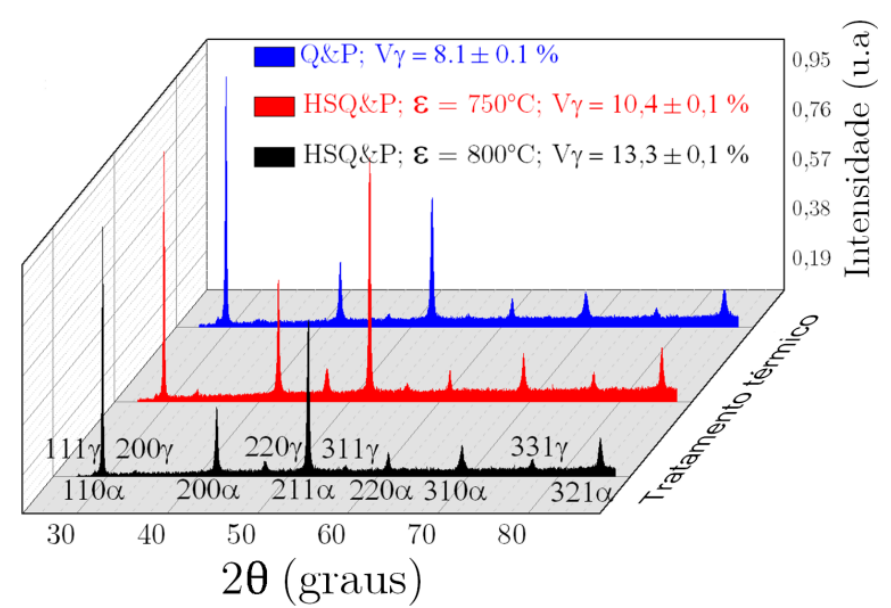

Figura 0-11. Difratogramas e frações de austenita retida das amostras de aço TRIP tratadas por tratamento têmpera e partição (Q\&P), e de processo combinado de estampagem a quente e têmpera e partição (HSQ\&P) com deformações a $750{ }^{\circ} \mathrm{C}$ e $800{ }^{\circ} \mathrm{C}$.

Por outro lado, os resultados das concentrações de carbono na austenita obtidos por DRX, calculados a partir da mudança no parâmetro de rede da austenita, usando uma relação [278] que inclui além do carbono outros elementos de liga como manganês, níquel, alumínio, cromo e molibdênio, mostraram que o teor de carbono da austenita para os tratamentos de Q\&P, HSQ\&P deformada a $750{ }^{\circ} \mathrm{C}$ e HSQ\&P deformada a $800{ }^{\circ} \mathrm{C}$ são de 1,02 wt.\% (4,6 at.\%), 0,89 wt.\% (4,0 at.\%) e 0,98 wt.\% (4,4 at.\%), respectivamente. Os teores de carbono obtidos por DRX diferem dos resultados obtidos por APT onde os menores enriquecimentos foram observados para amostra Q\&P e os maiores para amostra HSQ\&P deformada a $800^{\circ} \mathrm{C}$. Essa discrepância nos resultados de APT e de DRX pode ter ocorrido e ser explicada pela falta de homogeneidade do carbono nos grãos de austenita. Além disso, a concentração de carbono obtida por APT fornece informação local, enquanto os resultados por DRX fornecem uma informação estatística (a partir da relação volumétrica maior) [71]. Por outro lado, o aumento do parâmetro 
de rede da austenita pela partição pode ser causado não só pelo enriquecimento em carbono, mas também pelo alívio das tensões causado pelas transformações de fase que acontecem durante o processo, em especial pela transformação martensítica. Na literatura existe uma grande quantidade de trabalhos publicados sobre a correlação da concentração do carbono da austenita com o parâmetro de rede [167,279-283] e os cálculos realizados para medir a variação do teor de carbono usando essas relações (todas empíricas) levam a resultados que variam de 0,5 a 1,4 wt.\%, para o mesmo tratamento térmico. Isso é uma dificuldade na escolha da relação que melhor represente o teor de carbono na austenita, e evidencia a necessidade de pesquisas adicionais para determinar a relação que possibilite o melhor cálculo do teor de carbono na austenita deformada e não deformada. Alguns pesquisadores justificam a escolha da relação parâmetro de rede/teor de carbono, simplesmente pelo fato de ser a mais comumente utilizada ou pelo fato de incluir um maior número de elementos de liga. Assim sendo, as premissas (valores dos fatores multiplicadores que acompanham cada elemento e dos sinais para calcular as proporções desses elementos) das relações empíricas que convertem os parâmetros de rede da austenita em teores de carbono podem influenciar as diferenças nos resultados de APT e de DRX.

Embora o tratamento de Q\&P tenha mostrado o maior enriquecimento em carbono da austenita durante o estágio de partição (Figura 0-12), essa amostra apresentou as menores porcentagens de austenita retida na temperatura ambiente (Figura 0-11). Como se observa na Figura 0-13(a), correspondente ao início do estágio de partição a $400{ }^{\circ} \mathrm{C}$, para o processo de Q\&P existe mais austenita disponível para receber carbono por partição que para o processo HSQ\&P. Isto acontece porque no processo de HSQ\&P parte da austenita formada intercriticamente foi consumida pela formação da ferrita $\left(\alpha_{D I F T}\right)$ resultante da deformação em alta temperatura. Pela lei de Bragg sabe-se que a redução dos valores de $2 \theta$ indicam um aumento das distâncias interplanares e, consequentemente, maiores parâmetros de rede, o que, por sua vez, é associado ao enriquecimento em carbono da fase. Portanto, mesmo que o processo de Q\&P possua maior quantidade de austenita no início da partição e apresente os maiores enriquecimentos em carbono durante a etapa de partição, essa austenita é menos estável (fator de estabilidade da austenita entre o final da partição e a temperatura ambiente calculado em $0,71^{17}$ ) do que a austenita do processo HSQ\&P (fator de estabilidade calculado em 0,86 ), o que

\footnotetext{
${ }^{17}$ Embora a descarbonetação durante os ensaios in-situ afetem a medição da fração volumétrica da austenita em alta temperatura, pela diminuição da intensidade dos picos, para um mesmo tratamento térmico é possível estimar por radiação síncrotron a fração volumétrica ao final do estágio de partição e ao final do resfriamento, o que permite ter uma estimativa do fator de estabilidade. Uma análise futura importante usando radiação síncrotron in
} 
faz com que parte dela se transforme em martensita fresca durante o resfriamento final até a temperatura ambiente.

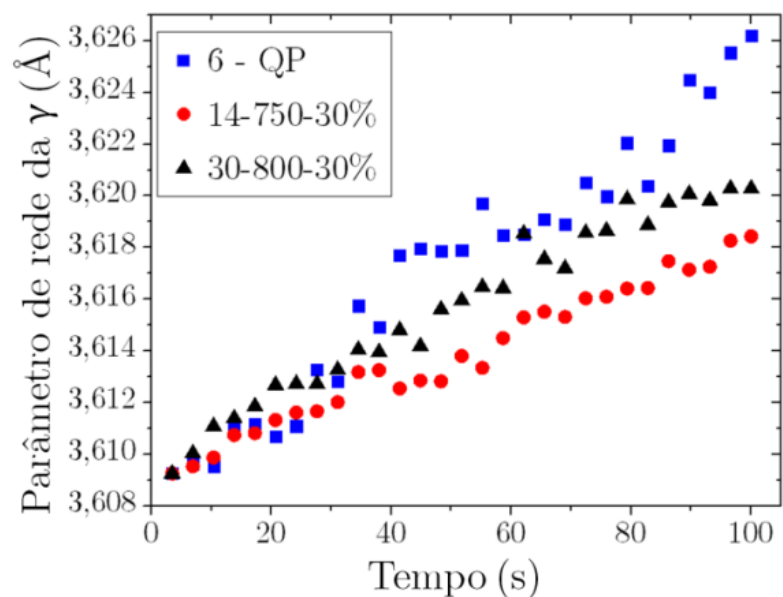

Figura 0-12. Variação do parâmetro de rede em função do tempo durante o estágio de partição a $400{ }^{\circ} \mathrm{C}$. Resultados obtidos por difração de raios X usando fonte radiação síncrotron.

Como se observa na Figura 0-13(b) na amostra Q\&P formou-se martensita fresca na microestrutura (círculo amarelo) após o resfriamento final, enquanto na amostra HSQ\&P deformada a $800{ }^{\circ} \mathrm{C}$ não se observam ilhas de martensita fresca, e, além disso, se observam maiores porcentagens de austenita retida (em vermelho) principalmente nos contornos da ferrita, o que justificaria a hipótese de maior estabilidade da austenita retida na amostra HSQ\&P. Ademais, se durante o processo de Q\&P ocorre reação bainítica durante o estágio de partição, esse processo se manifesta como um mecanismo adicional no enriquecimento em carbono, mas também, estaria consumindo parte da austenita disponível o qual como consequência reduz a porcentagem de austenita retida na temperatura ambiente. Por outro lado, na amostra HSQ \&P a formação de bainita durante o estágio de partição pode ter sido suprimida pela estabilização mecânica da austenita produzida pela formação de florestas de discordâncias devidas à deformação.

Portanto, a comparação das concentrações em carbono obtidas por difração de raios X e por APT não é comparável qualitativamente, no entanto, ambas são complementares para demonstrar que ocorrem fenômenos de partição do carbono nos tratamentos térmicos e termomecânicos realizados.

A Figura 0-14 e a Tabela 0-1 apresentam os resultados da curva tensão $(\sigma)$ deformação $(\varepsilon)$, os mapas de deformação para um instante antes ( 2 s) da ruptura final, obtidos por correlação de

situ, depois de melhorar as condições de vazio do sistema Gleeble, é a quantificação volumétrica da austenita durante o estágio de partição. 
imagem digital (DIC), e os resultados do comportamento mecânico das amostras Q\&P e HSQ\&P, discutidas neste capítulo. Como se observa os maiores limites de escoamento e de resistência mecânica foram obtidos para amostra Q\&P, enquanto os maiores níveis de alongamento uniforme e total foram para amostra HSQ\&P deformada a $800{ }^{\circ} \mathrm{C}$. A elevada resistência do material Q\&P está relacionada à formação de maiores porcentagens de martensita e bainita, enquanto os maiores níveis de ductilidade nas amostras HSQ\&P estão associados às maiores porcentagens de ferrita e de austenita retida formadas neste material. Portanto, nos aços HSQ\&P, a relação entre a porcentagem de austenita retida e o maior alongamento poderia estar vinculada à estabilidade da austenita durante a deformação, causada pelo maior enriquecimento em carbono discutido ao longo deste capítulo. Se a austenita não fosse estável o suficiente ela transformaria para martensita nos primeiros estágios da deformação, diminuindo assim a habilidade do material em sofrer transformação induzida por plasticidade (efeito TRIP). Mas, por outro lado, uma excessiva estabilidade da austenita também poderia dimunir a capacidade do material em sofrer transformação martensítica induzida por deformação o que reduziria o alongamento do material [284].

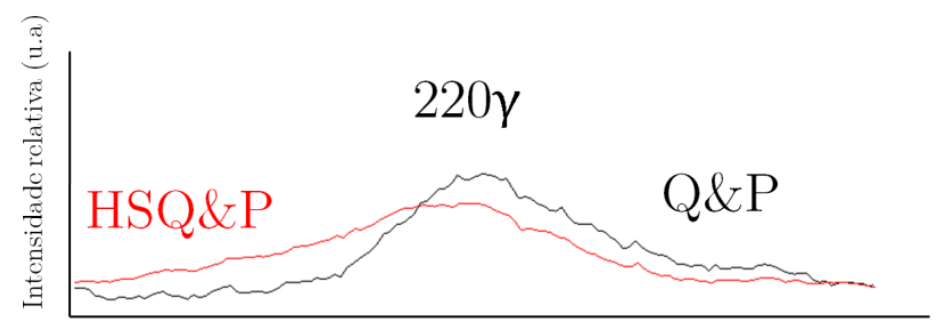

$2 \theta$

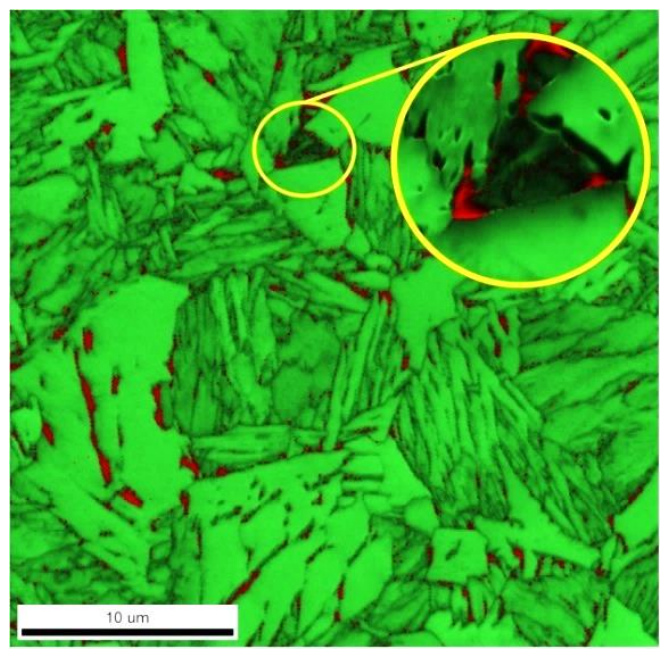

(b)

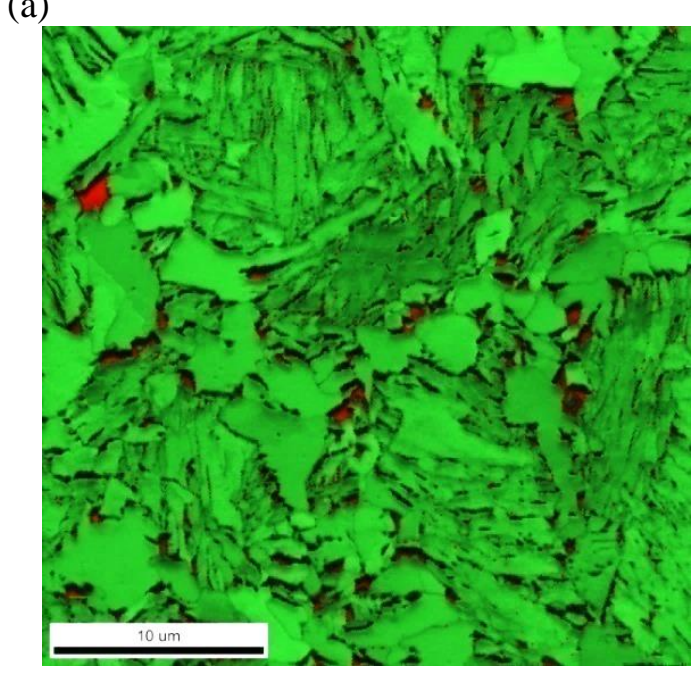

(c)

Figura 0-13. (a) Difratogramas das amostras Q\&P e HSQ\&P (deformada a $800{ }^{\circ} \mathrm{C}$ ) da região do pico da

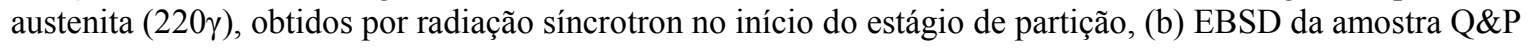
identificando uma região de martensita fresca (círculo amarelo), e (c) EBSD da amostra HSQ\&P deformada a $800{ }^{\circ} \mathrm{C}$. As regiões em vermelho identificam as fases CFC (austenita) e em verde as CCC. 
A Tabela 0-1 apresenta os resultados do alongamento uniforme $\left(\varepsilon_{u}\right)$, o alongamento total $\left(\varepsilon_{T}\right)$, do limite de escoamento $\left(\sigma_{\mathrm{y}}\right)$ e do limite de resistência $(L R)$ após os ensaios mecânicos realizados nas amostras Q\&P e HSQ\&P com deformação a $750{ }^{\circ} \mathrm{C}$ e $800^{\circ} \mathrm{C}$. Além disso, contém os resultados do produto $(\delta)$ entre a resistência mecânica (LR ou UTS - ultimate tensile strenght) e o alongamento total $\left(\varepsilon_{T}\right)$, o qual reflete diretamente a capacidade de absorção de energia do material $(\delta)$. Nesses resultados, observa-se que o maior nível de absorção de energia (melhor combinação de resistência e ductilidade) poderia ser obtido para um material submetido ao processo HSQ\&P com deformação a $800{ }^{\circ} \mathrm{C}$, chegando a resultados superiores aos obtidos pelo processo convencional de têmpera e revenido [285], aos aços que sofreram só o processo de hot stamping [79, 286, 287], e a outros estudos onde foi aplicado o processo de Q\&P [176, 288, 289]. Isto demonstra a importância para o aumento da ductilidade o teor, distribuição e estabilidade da austenita retida para favorecer o efeito TRIP ou o bloqueio efetivo da propagação de microtrincas [290] no processo de HSQ\&P. Por outro lado, vários estudos têm mostrado que há uma evidente redução da fração volumétrica de austentia com o aumento da deformação. Por exemplo, Poling et al. [268] em seu estudo em aços Q\&P mostraram que a fração volumétrica de austenita retida foi reduzida em $50 \%$ quando foi aplicada uma deformação plástica de $\approx 10 \%$ e Zhou et al [291] mostraram que com 5\% de deformação quase toda a austenita retida (25\%) foi transformada em martensita. Pelo que o processo de HSQ\&P representa a vantagem adicional que ao final do processo tem-se o produto já conformado e ainda há quantidades razoáveis de austenita retida disponiveis (entre 15 e 20\%), com a estabilidade suficiente para favorecer o efeito TRIP. Quando se pensa em projetos para aplicações em componentes de carroceria, as amostras HSQ\&P permitiriam a produção de peças de alta resistência com boa ductilidade, e a redução do peso do veículo pela possibilidade de produzir chapas com espessuras mais finas. Adicionalmente, a maior estabilização da austenita é desejada nas aplicações de aços da indústria automotiva já que vai favorecer o efeito TRIP durante o impacto, aumentando a segurança dos passageiros. 


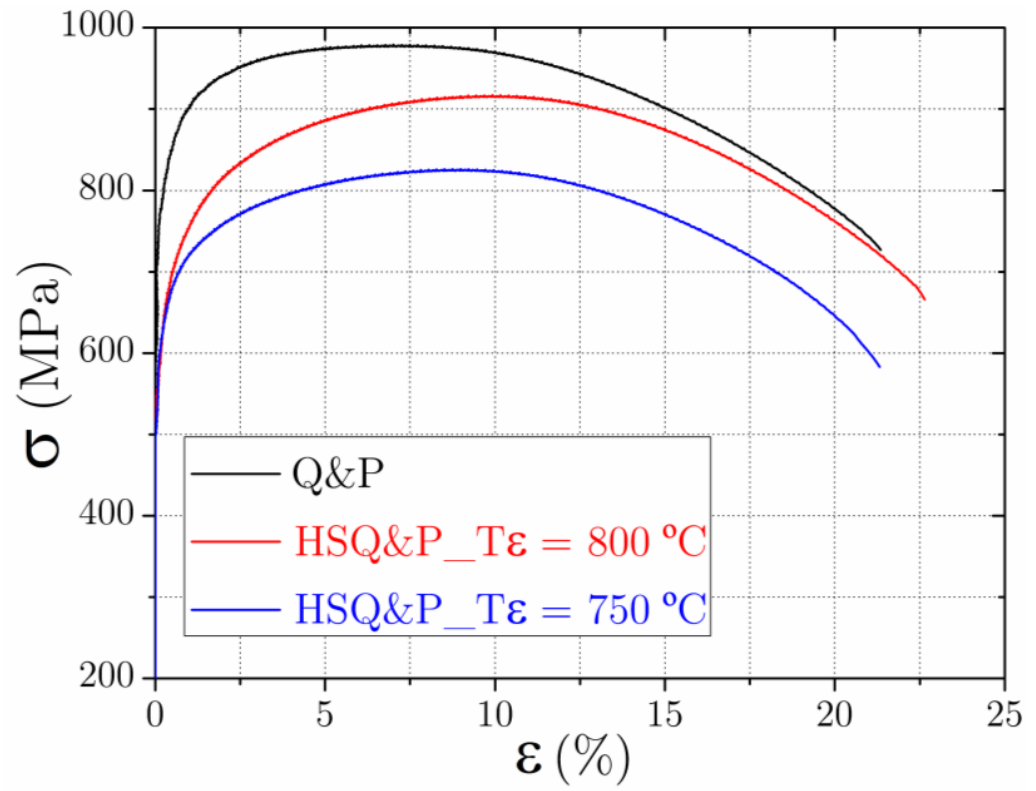

(a)

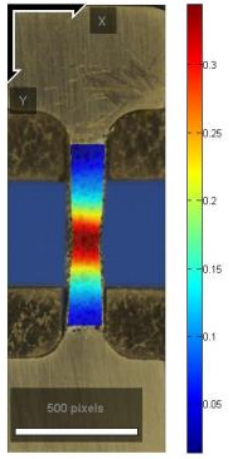

Q\&P

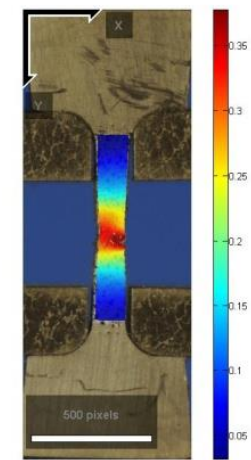

HSQ\&P $\varepsilon=800^{\circ} \mathrm{C}$

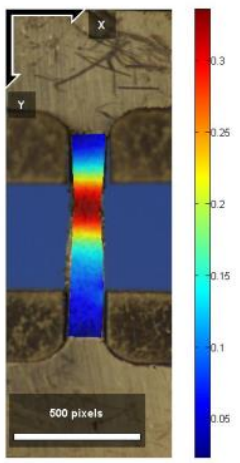

HSQ\&P $\varepsilon=750^{\circ} \mathrm{C}$

(b)

Figura 0-14. (a) Curvas tensão $(\sigma)$ vs. deformação $(\varepsilon)$ obtidas usando corpos de prova sub-size, após tratamentos termomecânicos de Q\&P e HSQ\&P, com deformação a $750{ }^{\circ} \mathrm{C}$ e $800^{\circ} \mathrm{C}$. (b) Mapas de deformação calculados usando correlação de imagem digital para um estágio prévio à deformação nas amostras submetidas aos tratamentos de Q\&P e HSQ\&P.

Tabela 0-1. Alongamento uniforme $\left(\varepsilon_{u}\right)$, alongamento total $\left(\varepsilon_{T}\right)$, limite de escoamento $\left(\sigma_{\mathrm{y}}\right)$, limite de resistência $(L R)$, e absorção de energia $(\delta)$ após os processos de Q\&P e HSQ\&P.

\begin{tabular}{c|c|c|c|c|c}
\hline Condição & $\varepsilon_{U}(\%)$ & $\varepsilon_{T}(\%)$ & $\sigma_{y}(\mathrm{MPa})$ & $L R(\mathrm{MPa})$ & $\delta(\mathrm{GPa} . \%)$ \\
\hline Q\&P & 9,5 & 21 & 941 & 978 & 20 \\
HSQ\&P, $\varepsilon=750^{\circ} \mathrm{C}$ & 10,5 & 22 & 760 & 821 & 18 \\
HSQ\&P, $\varepsilon=800^{\circ} \mathrm{C}$ & 11,5 & 24 & 820 & 912 & 22 \\
\hline
\end{tabular}




\subsection{Conclusões}

- Devido à complexidade microestrutural das amostras após os processos de Q\&P e de HSQ\&P, o uso combinado do EBSD e da nanoindentação para a identificação e caracterização das regiões de interesse para posteriores análises por APT e STEM mostrou-se bastante útil.

- Foi possível confirmar o enriquecimento significativo em carbono da austenita após os processos de Q\&P e de HSQ\&P, e o empobrecimento do carbono na martensita, o que confirma o fenômeno de partição do carbono durante o estágio de partição.

- Os resultados da amostra Q\&P para um filme de austenita retida indicaram uma porcentagem de carbono de 5,51 $\pm 0,02$ at.\% e de $0,23 \pm 0,00$ at.\% na martensita, com um considerável acúmulo de carbono na interface $\alpha^{\prime} / \gamma(7,6 \pm 0,1$ at.\%). Nesta região também foi observada a precipitação de carbonetos identificados como cementita ( $\theta$, Fe3C) pela estequiometria do carbono e pela redução do silício nesta região. A formação dos carbonetos durante a partição (revenimento da martensita) é um dos mecanismos que diminuem o enriquecimento em carbono da austenita sob o pressuposto de completa partição do carbono nos processo Q\&P. Portanto, a hipótese de supressão de precipitação de carbonetos adotada no modelo CCE, mesmo para teor de silício elevado (1,23 wt.\%), não é verdadeira. No entanto, os resultados mostram que a reação é suficientemente atrasada para permitir o enriquecimento em carbono da austenita durante a etapa de partição.

- A austenita na forma de bloco da amostra Q\&P apresentou um teor de carbono de $\approx 6,00 \pm$ 0,01 at.\%. A comparação entre o teor de carbono entre uma austenita na forma de bloco e os filmes presentes entre as ripas de martensita permite afirmar que o aumento do teor de carbono na austenita na forma de blocos se deve à contribuição no enriquecimento em carbono tanto da ferrita como da martensita durante o estágio da partição. Além disso, a precipitação de carbonetos observada na martensita próxima aos filmes de austenita consome grande parte do carbono disponível na martensita para se difundir para austenita durante o estágio de partição. No entanto, são necessários mais estudos comparativos que permitam fazer uma relação estatística mais acurada.

- Tanto nas amostras Q\&P como nas HSQ\&P foram observados grandes enriquecimentos em carbono nas interfaces, o que pode ser explicado devido ao fato de que os contornos de grão e as discordâncias funcionam como sumidouros de carbono (o carbono é aprisionado nas discordâncias presentes na interface) devido à redução do potencial químico do carbono nos defeitos (segregação de carbono nas falhas de empilhamento) ou às tensões induzidas pela diferença na distância interplanar produzida por uma interface com alto grau de incoerência. $\mathrm{O}$ 
enriquecimento em carbono nas interfaces, em ambos os tratamentos, pode ser também explicado pela Lei de Fick, em que o fluxo de difusão é orientado no sentido de um gradiente de composição química. De tal forma, se não existisse esse gradiente de composição e diferença na solubilidade das fases (na martensita a solubilidade do carbono é muito menor e taxa de difusão é relativamente maior), a partição observada não seria possível.

- Nas amostras HSQ\&P foram observados os maiores enriquecimentos em carbono na fase austenítica, quando comparada com a austenita nas amostras Q\&P. Isto pode estar associado à contribuição no enriquecimento em carbono, nas amostras HSQ\&P, da ferrita proeutetóide e à migração de carbono pela formação de ferrita-DIFT e pela partição de carbono desde a martensita supersaturada em carbono, durante o estágio de partição. Por sua vez, a austenita na amostra Q\&P só recebe contribuição em carbono da ferrita proeutetóide e da martensita durante o estágio de partição. Uma consequência do maior enriquecimento nas amostras HSQ\&P é que essa austenita retida se torna mais estável quimicamente, devido à redução da temperatura de início da transformação martensítica, o que aumenta a habilidade do material para sofrer plasticidade induzida por transformação.

- Além da partição do carbono, também foi observado um pico (spike) de concentração de manganês nas proximidades de interfaces ferrita/austenita. No perfil de carbono na austenita também foi observado um pequeno gradiente de composição. Isto poderia ser um indicativo de que o crescimento da ferrita ocorre sob condições de equilíbrio local com partição desprezível de soluto (LENP).

- A compreensão da redistribuição do carbono durante o processo de Q\&P e de HSQ\&P é importante para o desenvolvimento de microestruturas complexas em aços avançados de alta resistência.

- A comparação das curvas tensão-deformação e da estabilidade da austenita retida para favorecer o efeito TRIP permite compreender o papel do teor de carbono, e da distribuição e quantidade percentual das fases no comportamento mecânico do material. 


\section{REFERÊNCIAS}

1. SPEER, J. et al. Carbon partitioning into austenite after martensite transformation. Acta Materialia, v. 51, n. 9, p. 2611-2622, maio 2003.

2. MAHMOUD Y. DEMERI. Evolving Advanced High-Strength Steel Grades. In: MAHMOUD Y. DEMERI (Ed.). . Advanced High-Strength Steels: Science, Technology, and Applications. Ohio: ASM International, 2013. p. 263-274.

3. BLECK, W.; PHIOU-ON, K. Effects of Microalloying in Multi Phase Steels for Car Body Manufacture. In: Microstructure and Texture in Steels and Other Materials. India: Springer, 2009. p. 145-163.

4. INTERNATIONAL IRON \& STEEL INSTITUTE. Advanced High Strength Steel (AHSS) Application Guidelines. 3. ed. [s.l: s.n.].

5. GORNI, A. A. Novas tendências para o processo de estampagem a quente. Corte $\&$ Conformação de Metais, p. 62-77, 2010.

6. ULTRALIGHT STEEL AUTO BODY CONSORTIUM. ULSAB-AVC - Advanced Vehicle Concepts Overview Report. [s.l: s.n.].

7. FONSTEIN, N. Advanced High Strength Sheet Steels. Chicago, IN, USA: Springer, 2015.

8. WORLDAUTOSTEEL. Future steel vehicle - Final engineering report. Disponível em: <http://www.autosteel.org/Programs/Future Steel Vehicle.aspx>. Acesso em: 02 dez. 2016.

9. GORNI, A. A. Aços avançados de alta resistência: microestrutura e propriedades mecânicas. Corte \& Conformaçao de Metais, p. 26-57, 2008.

10. PLA-FERRANDO, R. et al. Advanced high strength steel (AHSS) TWIP: A door to the future in metal forming2012Disponível em: $<$ http://scitation.aip.org/content/aip/proceeding/aipcp/10.1063/1.4707551>. Acesso em: 02 dez. 2016

11. NANDA, T.; SINGH, V.; SINGH, V. Third generation of advanced high-strength steels : Processing routes and properties. Materials: Design and Applications, v. 0, n. 0, p. 130, 2016.

12. HU, X. et al. Determining Individual Phase Flow Properties in a Quench and Partitioning Steel with In Situ High-Energy X-Ray Diffraction and Multiphase Elasto-Plastic SelfConsistent Method. Metallurgical and Materials Transactions A, 2016.

13. MOOR, E. DE et al. Strategies for Third-Generation Advanced High-Strength Steel Development. v. 7, n. AIST Transactions, p. 133-144, 2010.

14. LOLLA, T. et al. Development of rapid heating and cooling (flash processing) process to produce advanced high strength steel microstructures. Materials Science and Technology, v. 27, n. 5, p. 863-875, 2011.

15. BLECK, W.; PHIU-ON, K. Microalloying of Cold-Formable Multi Phase Steel Grades. Materials Science Forum, v. 500-501, p. 97-114, 2005.

16. MATLOCK, D. K. et al. Recent developments in Advanced High Strength Sheet Steels for automotive applications: an overview. Jestech, v. 15, n. 1, p. 1-12, 2012.

17. LU, J. et al. Strengthening mechanisms and their relative contributions to the yield strength of microalloyed steels. Metallurgical and Materials Transactions A: Physical Metallurgy and Materials Science, v. 43, n. 9, p. 3043-3061, 2012.

18. KUZIAK, R.; KAWALLA, R.; WAENGLER, S. Advanced high strength steels for automotive industry. ARCHIVES OF CIVIL AND MECHANICAL ENGINEERING, v. VIII, n. 2, p. 103-117, 2008.

19. BRASIL.ELPAIS.COM. https://goo.gl/45EP3j. Acesso em: 02 dez. 2016.

20. HTTPS://GOO.GL/LYQP27. car-emissions.com. Acesso em: 02 dez. 2016. 
21. INTERNATIONAL ENERGY AGENCY. Key world energy statistics. Paris, France: [s.n.]. Disponível em: <www.iea.org>. Acesso em: 02 dez. 2016

22. http://www.energiaeambiente.org.br/. Acesso em: 02 dez. 2016

23. LORA, F. . et al. Press Hardening Technology: Current Challenges and Potential for Expansion in the Brazilian Industrial Sector.SENAFOR 35th. Anais...Porto Alegre: 2015

24. WANG, X. et al. Research on Holding Pressure and Cooling Process During Hot Forming of Ultra-High Strength Steel 22MnB5Proceedings of the FISITA 2012 World Automotive Congress. Anais...Springer Berlin Heidelberg, 2013

25. MATLOCK, D. K. et al. Recent developments in Advanced High Strength Sheet Steels for automotive applications: an overview. Jestech, v. 15, n. I, p. 1-12, 2012.

26. BILluR, E.; ALTAN, P. D. T. Challenges in Forming Advanced High Strength SteelsAdvanced high strength steels for automotive industry. Anais...Genova: 2011

27. PLACIDI, F. et al. An efficient approach to springback compensation for Ultra High Strength Steel structural components for the automotive field New Developments on Metallurgy and Applications of High Strength Steels. Anais...Buenos Aires: 2008

28. MATLOCK, D.; SPEER, J. Design Considerations for the Next Generation of Advanced High Strength Sheet Steels (H. C. Lee, Ed.)3rd Int. Conf. on Structural Steels. Anais...Seoul, Korea: 2006

29. ZACKAY, V. et al. Enhancement of ductility in high-strength steels. ASTM Trans Q, v. 60, n. 2, p. 252-259, 1967.

30. MARK, A. Microstructural effects on the stability of retained austenite in transformation induced plasticity steels. [s.1.] Queen's University, 2007.

31. SIERRA, R.; NEMES, J. A. Investigation of the mechanical behaviour of multi-phase TRIP steels using finite element methods. International Journal of Mechanical Sciences, v. 50, n. 4, p. 649-665, abr. 2008.

32. MAHMOUD Y. DEMERI. Transformation-Induced Plasticity Steels. In: MAHMOUD Y. DEMERI (Ed.). . Advanced High-Strength Steels: Science, Technology, and Applications. Ohio: ASM Interational, 2013. p. 115-125.

33. GALÁN, J. et al. Advanced high strength steels for automotive industry. Revista de Metalurgia, v. 48, n. 2, p. 118-131, 2012.

34. OLSON, G.; COHEN, M. A mechanism for the strain-induced martensitic transformations* nucleation of. Journal of the Less-Common Metals, v. 28, p. 107-118, 1972.

35. JUNG, J.; KIM, H.; DE COOMAN, B. C. Yielding Behavior of Nb Micro-alloyed CMn-Si TRIP Steel Studied by In-situ Synchrotron X-ray Diffraction. ISIJ International, v. 50, n. 4, p. 620-629, 2010.

36. BOLLING, G.; RICHMAN, R. The plastic deformation-transformation of paramagnetic f.c.c. Fe-Ni-C alloys. Acta Metallurgica, v. 18, n. 6, p. 673-681, 1970.

37. MARTINS, A. R. Têmpera e Partição em Aços de Alta Resistência contendo Ni: Modelagem Cinética, Microestrutura e Propriedades Mecânicas. [s.l.] Pontifícia Universidade Católica do Rio de Janeiro, 2007.

38. CHATTERJEE, S. Transformations in TRIP-assisted Steels: Microstructure and Properties. [s.1.] University of Cambridge, 2006.

39. BHADESHIA, H. K. D. H. Stress and Strain Effects. In: Bainite in Steels. 2nd. ed. London: [s.n.]. p. 201-224.

40. REZA, T.; ABBAS, N.; REZA, S. Drawing of CCCT diagrams by static deformation and consideration deformation effect on martensite and bainite transformation in NiCrMoV steel. Journal of Materials Processing Technology, v. 196, n. 1-3, p. 321-331, 2008.

41. CURTZE, S. et al. Deformation behavior of TRIP and DP steels in tension at different 
temperatures over a wide range of strain rates. Materials Science and Engineering A, v. 507, p. 124-131, 2009.

42. PAPATRIANTAFIlloU, I. . TRIP Steels: Constitutive modeling and computational issues. [s.1.] University of Thessaly, 2005.

43. VANDIJK, N. et al. Thermal stability of retained austenite in TRIP steels studied by synchrotron X-ray diffraction during cooling. Acta Materialia, v. 53, n. 20, p. 5439-5447, dez. 2005.

44. BLONDÉ, R. et al. High-energy X-ray diffraction study on the temperature-dependent mechanical stability of retained austenite in low-alloyed TRIP steels. Acta Materialia, v. 60, n. 2, p. 565-577, jan. 2012.

45. MIN, J. et al. Elevated-temperature mechanical stability and transformation behavior of retained austenite in a quenching and partitioning steel. Materials Science and Engineering: A, v. 673, p. 423-429, 2016.

46. BAI, D. Q.; DI CHIRO, A.; YUE, S. Stability of Retained Austenite in a Nb Microalloyed Mn-Si TRIP Steel. Materials Science Forum, v. 284-286, p. 253-262, 1998.

47. CHIANG, J. et al. Effect of microstructure on retained austenite stability and work hardening of TRIP steels. Materials Science and Engineering: A, v. 528, n. 13-14, p. 45164521, maio 2011.

48. WANG, J.; VAN DER ZWAAG, S. Stabilization Mechanisms of Retained Austenite in Transformation-Induced Plasticity Steel. Metallurgical and Materials Transactions A, v. 32A, n. 6, p. 1527-1539, 2001.

49. MARK, A. F. et al. Development and characterisation of model TRIP steel microstructures. Materials Science and Engineering A, v. 576, p. 108-117, 2013.

50. CHIANG, J.; BOYD, J. D.; PILKEY, A. K. Effect of microstructure on retained austenite stability and work hardening of TRIP steels. Materials Science and Engineering A, v. 638 , p. 132-142, 2015.

51. YI, H. L.; CHEN, P.; BHADESHIA, H. K. D. H. Optimizing the Morphology and Stability of Retained Austenite in a $\delta$-TRIP Steel. Metallurgical and Materials Transactions A, v. 45, n. 8, p. 3512-3518, 25 mar. 2014.

52. PARK, H. S. et al. Nano-scale observation on the transformation behavior and mechanical stability of individual retained austenite in CMnSiAl TRIP steels. Materials Science and Engineering A, v. 627, p. 262-269, 2015.

53. DING, R. et al. A New Type of Quenching and Partitioning Processing Developed from Martensitic Pre-microstructure. Materials and Manufacturing Processes, v. 29, n. 6, p. 704 709, 3 jun. 2014.

54. GAO, G. et al. Enhanced ductility and toughness in an ultrahigh-strength Mn-Si-Cr-C steel: The great potential of ultrafine filmy retained austenite. Acta Materialia, v. 76, p. 425433, 2014.

55. MANG, T. et al. Friction, Wear and Wear Protection Thixoforming Applied Tribology Nanolubricants. [s.l: s.n.].

56. OLSON, G. B.; COHEN, M. Kinetics of Strain-Induced Martensitic NucleationMetallurgical Transactions A, 1975.

57. NAKADA, N. et al. Self-stabilization of untransformed austenite by hydrostatic pressure via martensitic transformation. Acta Materialia, v. 110, p. 95-102, 2016.

58. SAKAKI, T.; SUGIMOTO, K.; FUKUZATO, T. Role of Internal Stress for Continuous Yielding of Dual-Phase Steels. Acta Metallurgica, v. 31, n. 10, p. 1737-1746, 1983.

59. PARISH, C. . Fundamental study of phase transformations in Si-Al TRIP steels. [s.1.] University of Pittsburgh, 2003.

60. PYSHMINTSEV, I. Y. et al. The influence of the stress state on the plasticity of transformation induced plasticity-aided steel. Metallurgical and Materials Transactions A, 
v. 33A, n. 6, p. 1659-1667, 2002.

61. SAMANTA, S. et al. Development of multiphase microstructure with bainite, martensite, and retained austenite in a Co-containing steel through quenching and partitioning (Q\&P) treatment. Metallurgical and Materials Transactions A: Physical Metallurgy and Materials Science, v. 44, n. 13, p. 5653-5664, 2013.

62. MATLOCK, D. K.; SPEER, J. G. Processing Opportunities for New Advanced HighStrength Sheet Steels. Materials and Manufacturing Processes, v. 25, n. 1-3, p. 7-13, 22 mar. 2010.

63. SPEER, J. G. et al. Partitioning of carbon from supersaturated plates of ferrite, with application to steel processing and fundamentals of the bainite transformation. Current Opinion in Solid State and Materials Science, v. 8, n. 3-4, p. 219-237, jun. 2004.

64. MATLOCK, D. K.; BRÄUTIGAM, V. E.; SPEER, J. G. Application of the Quenching and Partitioning (Q\&P) Process to a Medium-Carbon, High-Si Microalloyed Bar Steel. Materials Science Forum, v. 426-432, p. 1089-1094, 2003.

65. HILLERT, M.; ÅGREN, J. On the definitions of paraequilibrium and orthoequilibrium. Scripta Materialia, v. 50, n. 5, p. 697-699, mar. 2004.

66. SPEER, J. G. et al. Comments on "On the definitions of paraequilibrium and orthoequilibrium" by M. Hillert and J. Ågren, Scripta Materialia, 50, 697-9 (2004). Scripta Materialia, v. 52, n. 1, p. 83-85, jan. 2005.

67. HILLERT, M.; ÅGREN, J. Reply to comments on "On the definition of paraequilibrium and orthoequilibrium”. Scripta Materialia, v. 52, n. 1, p. 87-88, jan. 2005.

68. HULTGREN, A. Isothermal transformation of austenite. Transactions of the American Institute for Metals, v. 39, p. 915-1005, 1947.

69. MALAKHOV, D. V.; PURDY, G. R. Some fundamental and computational aspects of paraequilibrium. Canadian Metallurgical Quarterly, v. 41, n. 2, p. 231-241, 2002.

70. QU, H.; MICHAL, G. M.; HEUER, A. H. Third Generation 0.3C-4.0Mn Advanced High Strength Steels Through a Dual Stabilization Heat Treatment: Austenite Stabilization Through Paraequilibrium Carbon Partitioning. Metallurgical and Materials Transactions A, v. 45, n. 6, p. 2741-2749, 27 fev. 2014.

71. TOJI, Y. et al. Atomic-scale analysis of carbon partitioning between martensite and austenite by atom probe tomography and correlative transmission electron microscopy. Acta Materialia, v. 65, p. 215-228, fev. 2014.

72. ARIZA, E. A. et al. Characterization and methodology for calculating the mechanical properties of a TRIP-steel submitted to hot stamping and quenching and partitioning (Q\&P). Materials Science and Engineering A, v. 671, p. 54-69, 2016.

73. SANTOFIMIA, M. J. et al. Microstructural development during the quenching and partitioning process in a newly designed low-carbon steel. Acta Materialia, v. 59, n. 15, p. 6059-6068, 2011.

74. SETO, K.; MATSUDA, H. Application of nanoengineering to research and development and production of high strength steel sheets. Materials Science and Technology, v. 29 , n. 10, p. 1158-1165, 2013.

75. LOBO, J. A.; GEIGER, G. H. Thermodynamics and solubility of carbon in ferrite and ferritic Fe-Mo alloys. Metallurgical Transactions A, v. 7, n. 8, p. 1347-1357, 1976.

76. LOBO, J. A.; GEIGER, G. H. Thermodynamics of carbon in austenite and Fe-Mo austenite. Metallurgical Transactions A, v. 7, n. 8, p. 1359-1364, 1976.

77. KARBASIAN, H.; TEKKAYA, A. E. A review on hot stamping. Journal of Materials Processing Technology, v. 210, n. 15, p. 2103-2118, nov. 2010.

78. BERGLUND, G. The history of hardening of boron steel in northern swedenInternational conference on hot sheet metal forming of high-performance steel. Anais...Kassel, Germany: 2008 
79. NADERI, M. et al. Analysis of Microstructure and Mechanical Properties of Different Hot Stamped B-bearing Steels. Steel Research International, v. 81, n. 3, p. 216-223, mar. 2010.

80. TURETTA, A. Investigation of Thermal, Mechanical and Microstructural Properties of Quenchable High Strength Steels in Hot Stamping Operations. [s.1.] Padova, 2008.

81. CARLSSON, B.; OLSSON, L. Improved formability of ultra high strength steels through local heat treatmentInternational Conference on Steels in Cars and Trucks. Anais...Sweeden: SAAB Tunnplat AB, 2006

82. NAGANATHAN, A.; PENTER, L. Hot Stamping. In: ALTAN, T.; TEKKAYA, A. E. (Eds.). . Sheet Metal Forming - Processes and Applications. [s.l.] ASM International, 2012. p. $133-156$.

83. ENGELS, H.; SCHALMIN, O.; MÜLLER-BOLLENHAGEN, C. Controlling and Monitoring of the Hot-Stamping Process of Boron-Alloyed Heat-Treated SteelsThe International Conference "New Development in Sheet Metal Forming Technology. Anais...Stuttgart, Germany: 2006

84. HU, P. et al. Hot Forming Process. In: Theories, Methods and Numerical Technology of Sheet Metal Cold and Hot Forming SE - 3. Springer Series in Advanced Manufacturing. [s.1.] Springer London, 2013. p. 35-45.

85. PRIESTNER, R.; DE LOS RIOS, E. Ferrite grain refinement by controlled rolling of low-carbon and microalloyed steel. Metals Technology, v. 7, n. August, p. 309-316, 1980.

86. DONG, H.; SUN, X. Deformation induced ferrite transformation in low carbon steels. Current Opinion in Solid State and Materials Science, v. 9, n. 6, p. 269-276, 2005.

87. LUO, H. Thermodynamic and kinetic analysis of dynamic strain-induced transformation during hot deformation in plain carbon steels. Materials Science and Engineering A, v. 528, n. 28, p. 8259-8262, 2011.

88. ZHENG, C. et al. On the ferrite refinement during the dynamic strain-induced transformation: A cellular automaton modeling. Scripta Materialia, v. 58, n. 10, p. 838-841, 2008.

89. GHOSH, C.; BASABE, V. V.; JONAS, J. J. Thermodynamics of dynamic transformation of hot deformed austenite in four steels of increasing carbon contents. Materials Science and Engineering: A, v. 591, p. 173-182, jan. 2014.

90. MATSUMARA, Y.; YADA, H. Evolution Deformation of Ultrafine-grained Ferrite in Hot Successive Deformation. ISIJ International, v. 27, p. 492-498, 1987.

91. HONG, S. C. et al. Effect of Undercooling of Austenite on Strain Induced Ferrite Transformation Behavior. ISIJ International, v. 43, n. 3, p. 394-399, 2003.

92. CHOI, J. et al. Formation of Ultrafine Ferrite by Strain-induced Dynamic Transformation in Plain Low Carbon Steel. IS, v. 43, n. 5, p. 746-754, 2003.

93. HURLEY, P. J.; HODGSON, P. D. Effect of process variables on formation of dynamic strain induced ultrafine ferrite during hot torsion testing. Materials Science and Technology, v. 17, n. November, p. 1360-1368, 2001.

94. SIETSMA, J. Nucleation and growth during the austenite-to-ferrite phase transformation in steels after plastic deformation. In: PERELOMA, E.; EDMONDS, D. (Eds.).

. Phase Transformations in steels. Philadelphia: Woodhead Publishing in Materials, 2012. p. 505-554.

95. MIN, J.; LIN, J.; MIN, Y. Effect of thermo-mechanical process on the microstructure and secondary-deformation behavior of 22MnB5 steels. Journal of Materials Processing Technology, v. 213, n. 6, p. 818-825, jun. 2013.

96. MIN, J. et al. On the ferrite and bainite transformation in isothermally deformed 22MnB5 steels. Materials Science and Engineering: A, v. 550, p. 375-387, jul. 2012. 
97. WANG, W. et al. Non-isothermal deformation behavior and FE simulation of ultrahigh strength BR1500HS steel in hot stamping process. The International Journal of Advanced Manufacturing Technology, 2016.

98. ZHENG, C. et al. Numerical simulation of dynamic strain-induced austenite-ferrite transformation in a low carbon steel. Acta Materialia, v. 57, n. 10, p. 2956-2968, 2009.

99. LI, Z. D. et al. Influence of austenite deformation on ferrite growth in a Fe-C-Mn alloy. Materials Science and Engineering A, v. 527, n. 16-17, p. 4406-4411, 2010.

100. TONG, M. et al. Monte carlo-method simulation of the deformation-induced ferrite transformation in the Fe-C system. Metallurgical and Materials Transactions A, v. 35, n. 5, p. 1565-1577, 2004.

101. GHOSH, C.; ARANAS, C.; JONAS, J. J. Dynamic transformation of deformed austenite at temperatures above the Ae3. Progress in Materials Science, v. 82, p. 151-233, 2016.

102. CAHN, J. W. The Kinetics of Grain Boundary Nucleated Reactions. Acta Metallurgica, v. 4, p. 449-459, 1956.

103. WENG, Y. Ultra-Fine Grained Steels. Beijing: Springer Berlin Heidelberg, 2009.

104. LIU, H. et al. An ultrahigh strength steel with ultrafine-grained microstructure produced through intercritical deformation and partitioning process. Materials and Design, v. 83, p. 760-767, 2015.

105. ESSADIQI, E.; JONAS, J. J. Effect of deformation on the austenite-to-ferrite transformation in a plain carbon and two microalloyed steels. Metallurgical Transactions A, v. 19 , n. 3, p. 417-426, 1988.

106. HODGSON, P. D.; BELADI, H. Dynamic strain-induced ferrite transformation (DSIT) in steels. In: PERELOMA, E. V.; MATLOCK, D. (Eds.). . Phase Transformations in steels. Philadelphia: Woodhead Publishing in Materials, 2012. p. 527-554.

107. GORELIK, S. . Recrystallization in Metals and Alloys. Cleveland, OH: MIR, 1981.

108. ROSOCHOWSKY, A.; OLEJNIK, L. Severe plastic deformation for grain refinement and enhancement of properties. In: LIN, J.; BALING, D.; PIETRZYK, M. (Eds.). . Microstructure Evolution in Metal Forming Processes. [s.1.] Woodhead Publishing in Materials, 2012. p. 114-141.

109. GORNI, A. A. Aços ferríticos com alta resistência mecânica e boa conformabilidadeCorte \& Conformaçao de Metais. Anais...São Paulo: 2009

110. BARDELCIK, A.; WORSWICK, M. J.; WELLS, M. A. The influence of martensite , bainite and ferrite on the as-quenched constitutive response of simultaneously quenched and deformed boron steel - Experiments and model. v. 55, p. 509-525, 2014.

111. CLARKE, A. J. et al. Carbon partitioning to austenite from martensite or bainite during the quench and partition (Q\&P) process: A critical assessment. Acta Materialia, v. 56, n. 1, p. 16-22, jan. 2008.

112. FULTZ, B.; HOWE, J. Diffraction and the X-Ray Powder Diffractometer. In: Transmission Electron Microscopy and Diffractometry of Materials. Graduate Texts in Physics. Berlin, Heidelberg: Springer Berlin Heidelberg, 2013. p. 1-57.

113. ASTM 975-03. Standard Practice for X-Ray Determination of Retained Austenite in Steel with Near Random Crystallographic Orientation. ASTM International, 2008.

114. GNÄUPEL-HEROLD, T.; CREUZIGER, A. Diffraction study of the retained austenite content in TRIP steels. Materials Science and Engineering: A, v. 528, n. 10-11, p. 3594-3600, abr. 2011.

115. CULLITY, B. . Elements of X-ray Diffraction. Massachusetts: Addison-Wesley, 1956.

116. DYSON, D. J.; HOLMES, B. Effect of alloying additions on the lattice parameter of austenite. J Iron Steel Inst, v. 208, n. 5, p. 469-474, 1970. 
117. VAN BOHEMEN, S. M. C. The nonlinear lattice expansion of iron alloys in the range 100-1600 K. Scripta Materialia, v. 69, n. 4, p. 315-318, 2013.

118. ASTM E3-01. Standard Guide for Preparation of Metallographic Specimens. ASTM, 2007.

119. OIM user Manual Orientation Imaging Microscopy. Data Analysis version 6.2. Draper, UT.TexSem Laboratories, , 2014.

120. BLONDE, R. et al. High-resolution X-ray diffraction investigation on the evolution of the substructure of individual austenite grains in TRIP steels during tensile deformation. Materials Science \& Engineering A, v. 47, n. 3, p. 965-973, 2014.

121. LARSON, D. et al. Local electrode atom probe tomography. New York: [s.n.].

122. 562-02, A. Standard Test Method for Determining Volume Fraction by Systematic Manual Point Count. ASTM, 2002.

123. OLIVER, W. C.; PHARR, G. M. Measurement of hardness and elastic modulus by instrumented indentation: Advances in understanding and refinements to methodology. Journal of Materials Research, v. 19, n. 1, p. 3-20, 3 mar. 2011.

124. THO, K. K. et al. Simulation of instrumented indentation and material characterization. Materials Science and Engineering A, v. 390, n. 1-2, p. 202-209, 2005.

125. PUlECIO, S. A. R.; FARIAS, M. C. M.; SOUZA, R. M. Finite element and dimensional analysis algorithm for the prediction of mechanical properties of bulk materials and thin films. Surface and Coatings Technology, v. 205, n. 5, p. 1386-1392, nov. 2010.

126. MA, Z. S. et al. Characterization of stress-strain relationships of elastoplastic materials: An improved method with conical and pyramidal indenters. Mechanics of Materials, v. 54, p. 113-123, 2012.

127. DAO, M. et al. Computational modeling of the forward and reverse problems in instrumented sharp indentation. Acta Materialia, v. 49, n. 19, p. 3899-3918, nov. 2001.

128. RODRÍGUEZ, R.; GUTIERREZ, I. Correlation between nanoindentation and tensile properties influence of the indentation size effect. Materials Science and Engineering A, v. 361, n. 1-2, p. 377-384, 2003.

129. MATA, M.; ANGLADA, M.; ALCALÁ, J. Contact Deformation Regimes Around Sharp Indentations and the Concept of the Characteristic Strain. Journal of Materials Research, v. 17, n. 5, p. 964-976, 2002.

130. KNIJF, D. DE et al. Effect of fresh martensite on the stability of retained austenite in quenching and partitioning steel. Materials Science \& Engineering A, v. 615, p. 107-115, 2014.

131. BLABER, J.; ADAIR, B.; ANTONIOU, A. Ncorr: Open-Source 2D Digital Image Correlation Matlab Software. Experimental Mechanics, p. 1105-1122, 2015.

132. HILD, F.; ROUX, S. Digital Image Correlation: from Displacement Measurement to Identification of Elastic Properties - a Review. Strain, v. 42, p. 69-80, 2006.

133. www.ncorr.com. Acesso em: 02 dez. 2016

134. HAJY AKBARY, F.; SANTOFIMIA, M. J.; SIETSMA, J. Elastic Strain Measurement of Miniature Tensile Specimens. Experimental Mechanics, v. 54, p. 165-173, 2014.

135. NIST. Http://www.ctcms.nist.gov/oof/oof2/. Acesso em: 02 dez. 2016

136. CHAWLA, N. et al. Microstructure-based simulation of thermomechanical behavior of composite materials by object-oriented finite element analysis. Materials Characterization, v. 49, n. 5, p. 395-407, dez. 2002.

137. LANGER, S. .; FULLER, E. R.; CARTER, W. . OOF: An Image-Based Finite-Element Analysis of Material Microstructures. Computing in Science \& Engineering, v. 3, n. 3, p. 1523, 2001.

138. NYGARDS, M. Microstructural Finite Element Modeling of Metals. [s.1.] KTH Royal Institute of Technology, 2003. 
139. HOSSEINI-TOUDESHKY, $\mathrm{H}$. et al. Microstructural deformation pattern and mechanical behavior analyses of DP600 dual phase steel. Materials Science and Engineering A, v. 600, p. 108-121, 2014.

140. UTHAISANGSUK, V.; PRAHL, U.; BLECK, W. Modelling of damage and failure in multiphase high strength DP and TRIP steels. Engineering Fracture Mechanics, v. 78, n. 3, p. 469-486, 2011.

141. SCHNEIDER, Y. et al. Plastic deformation behaviour of $\mathrm{Fe}-\mathrm{Cu}$ composites predicted by 3D finite element simulations. Computational Materials Science, v. 48, n. 3, p. 456-465, 2010.

142. SINGH, H. et al. Application of digital image processing for implementation of complex realistic particle shapes/morphologies in computer simulated heterogeneous microstructures. Modelling And Simulation In Materials Science And Engineering, v. 14, n. 3, p. 351-363, 2006.

143. CHOI, K. S. et al. Influence of various material design parameters on deformation behaviors of TRIP steels. Computational Materials Science, v. 50, n. 2, p. 720-730, 2010.

144. SODJIT, S.; UTHAISANGSUK, V. Microstructure based prediction of strain hardening behavior of dual phase steels. Materials and Design, v. 41, p. 370-379, 2012.

145. THOMAS, G. A.; SPEER, J. G.; MATLOCK, D. K. Quenched and Partitioned Microstructures Produced via Gleeble Simulations of Hot-Strip Mill Cooling Practices. Metallurgical and Materials Transactions A, v. 42, n. 12, p. 3652-3659, 9 mar. 2011.

146. MERKLEIN, M.; LECHLER, J.; GEIGER, M. Characterisation of the Flow Properties of the Quenchenable Ultra High Strength Steel 22MnB5. CIRP Annals - Manufacturing Technology, v. 55, n. 1, p. 229-232, jan. 2006.

147. LIU, H. et al. An ultrahigh strength steel with ultrafine-grained microstructure produced through intercritical deformation and partitioning process. Materials \& Design, v. 83, p. 760-767, 2015.

148. KARAM-ABIAN, M. et al. Micro and macro-mechanical behavior of a transformation-induced plasticity steel developed by thermomechanical processing followed by quenching and partitioning. Materials Science and Engineering: A, v. 651, p. 233-240, 2016.

149. CHANG, Y. et al. Effect of Quenching and Partitioning with Hot Stamping on Martensite Transformation and Mechanical Properties of AHSS. Journal of Materials Engineering and Performance, v. 24, p. 3194-3200, 2015.

150. LIU, H. et al. Enhanced mechanical properties of a hot stamped advanced high-strength steel treated by quenching and partitioning process. Scripta Materialia, v. 64, n. 8, p. 749$752,2011$.

151. LIU, H. et al. Martensitic microstructural transformations from the hot stamping, quenching and partitioning process. Materials Characterization, v. 62, n. 2, p. 223-227, fev. 2011.

152. DE KNIJF, D. et al. Effect of fresh martensite on the stability of retained austenite in quenching and partitioning steel. Materials Science and Engineering A, v. 615, p. 107-115, 2014.

153. SANTOFIMIA, M. J. et al. New low carbon Q\&P steels containing film-like intercritical ferrite. Materials Science and Engineering: A, v. 527, n. 23, p. 6429-6439, set. 2010.

154. KIM, D. H. et al. Observation of an Isothermal Transformation during Quenching and Partitioning Processing. Metallurgical and Materials Transactions A, v. 40, n. 9, p. 20482060, 8 jul. 2009.

155. SANTOFIMIA, M. J.; ZHAO, L.; SIETSMA, J. Model for the interaction between interface migration and carbon diffusion during annealing of martensite-austenite microstructures in steels. Scripta Materialia, v. 59, n. 2, p. 159-162, jul. 2008. 
156. ZHONG, N. et al. Interface Migration between Martensite and Austenite. Journal of Materials Science \& Technology, v. 22, n. 6, p. 751-754, 2006.

157. LI, H. Y. et al. Microstructure and Mechanical Properties of an Ultrahigh-Strength 40SiMnNiCr Steel during the One-Step Quenching and Partitioning Process. Metallurgical and Materials Transactions A, v. 41, n. 5, p. 1284-1300, 12 fev. 2010.

158. BHADESHIA, H. K. D. H. Stress and Strain Effects. In: Bainite in Steels. 2nd. ed. London: IOM Communications, 2001. p. 201-224.

159. NIKRAVESH, M. et al. Phase transformations in a simulated hot stamping process of the boron bearing steel. Materials \& Design, v. 84, p. 18-24, 2015.

160. SINGH, S. B. Mechanisms of bainite transformation in steels. In: Phase Transformations in steels. Cambridge: [s.n.]. p. 385-416.

161. SALARI, S. et al. Martensitic Transformation Behavior of B-Bearing Steel During Isothermal Deformation. Steel Research International, v. 83, n. 8, p. 733-742, 4 ago. 2012.

162. SANTOFIMIA, M. J.; ZHAO, L.; SIETSMA, J. Microstructural Evolution of a LowCarbon Steel during Application of Quenching and Partitioning Heat Treatments after Partial Austenitization. Metallurgical and Materials Transactions A, v. 40, n. 1, p. 46-57, 14 nov. 2008.

163. DING, R.; TANG, D.; ZHAO, A. A novel design to enhance the amount of retained austenite and mechanical properties in low-alloyed steel. Scripta Materialia, v. 88, n. July, p. 21-24, out. 2014.

164. GAO, G. et al. Enhanced ductility and toughness in an ultrahigh-strength $\mathrm{Mn}-\mathrm{Si}-\mathrm{Cr}-$ $\mathrm{C}$ steel: The great potential of ultrafine filmy retained austenite. Acta Materialia, v. 76, p. 425433, set. 2014.

165. WU, J. et al. Image quality analysis: A new method of characterizing microstructures. ISIJ international, v. 45, n. 2, p. 254-262, 2005.

166. DE KNIJF, D. et al. Study of heat treatment parameters and kinetics of quenching and partitioning cycles. Materials Science and Technology, v. 0, n. 0, p. 1743284714Y.000, 11 nov. 2014.

167. ZHANG, M. et al. Characteristics of retained austenite in TRIP steels with bainitic ferrite matrix. Journal of Wuhan University of Technology-Mater. Sci. Ed., v. 26, n. 6, p. 1148-1151, 20 dez. 2011.

168. TAN, X. et al. Effect of partitioning procedure on microstructure and mechanical properties of a hot-rolled directly quenched and partitioned steel. Materials Science and Engineering: A, v. 594, p. 149-160, jan. 2014.

169. GHASSEMI-ARMAKI, H. et al. Deformation response of ferrite and martensite in a dual-phase steel. Acta Materialia, v. 62, p. 197-211, 2014.

170. GADELRAB, K. R. et al. Local characterization of austenite and ferrite phases in duplex stainless steel using MFM and nanoindentation. Journal of Materials Research, v. 27, n. 12, p. 1573-1579, 17 abr. 2012.

171. BALTAZAR HERNANDEZ, V. H. et al. Nanoindentation and microstructure analysis of resistance spot welded dual phase steel. Materials Letters, v. 64, n. 2, p. 207-210, jan. 2010.

172. HAN, Q. et al. Suppression of M s temperature by carbon partitioning from carbonsupersaturated ferrite to metastable austenite during intercritical annealing. Materials and Design, v. 51, p. 409-414, 2013.

173. DE DIEGO-CALDERÓN, I. et al. Deformation behavior of a high strength multiphase steel at macro- and micro-scales. Materials Science and Engineering: A, v. 611, p. 201-211, ago. 2014.

174. DE DIEGO-CALDERÓN, I. et al. Global and local deformation behavior and mechanical properties of individual phases in a quenched and partitioned steel. Materials Science and Engineering: A, v. 630, p. 27-35, 2015. 
175. SEOK, H. et al. Nano-scale observation on the transformation behavior and mechanical stability of individual retained austenite in CMnSiAl TRIP steels. Materials Science \& Engineering A, v. 627, p. 262-269, 2015.

176. MAHESWARI, N. et al. Influence of alloying elements on the microstructure evolution and mechanical properties in quenched and partitioned steels. Materials Science and Engineering: A, v. 600, p. 12-20, abr. 2014.

177. XIONG, X. C. et al. The effect of morphology on the stability of retained austenite in a quenched and partitioned steel. Scripta Materialia, v. 68, n. 5, p. 321-324, 2013.

178. HTTP://WWW.R-PROJECT.ORG/. R version 3.1.1. Acesso em: 02 dez. 2016

179. FEREIDUNI, E.; GHASEMI BANADKOUKI, S. S. Improvement of mechanical properties in a dual-phase ferrite-martensite AISI4140 steel under tough-strong ferrite formation. Materials and Design, v. 56, p. 232-240, 2014.

180. MAZAHERI, Y.; KERMANPUR, A.; NAJAFIZADEH, A. Nanoindentation study of ferrite-martensite dual phase steels developed by a new thermomechanical processing. Materials Science and Engineering: A, v. 639, n. 0, p. 8-14, 2015.

181. FEREIDUNI, E.; GHASEMI BANADKOUKI, S. S. Ferrite hardening response in a low alloy ferrite-martensite dual phase steel. Journal of Alloys and Compounds, v. 589, p. 288-294, 2014.

182. HAN, X. et al. Research on one-step quenching and partitioning treatment and its application in hot stamping process. Journal of Engineering Manufacture, p. 1-11, 2015.

183. OKITSU, Y.; TAKATA, N.; TSUJI, N. Mechanical properties of ultrafine grained ferritic steel sheets fabricated by rolling and annealing of duplex microstructure. Journal of Materials Science, v. 43, n. 23-24, p. 7391-7396, 2008.

184. KARMAKAR, A. et al. Development of Ultra-Fine Grained Dual-Phase Steels: Mechanism of Grain Refinement during Inter-Critical Deformation. Materials Science Forum, v. 783-786, p. 674-678, 2014.

185. MATSUMARA, O. et al. Etfect of Retained Austenite on Formability of High Strength Sheet Steels. ISIJ International, v. 32, n. 10, p. 1110-1116, 1992.

186. YIN, H. XIANG et al. Influence of original microstructure on the transformation behavior and mechanical properties of ultra-high-strength TRIP-aided steel. International Journal of Minerals, Metallurgy and Materials, v. 22, n. 3, p. 262-271, 2015.

187. GIBBS, P. J. et al. Austenite Stability Effects on Tensile Behavior of ManganeseEnriched-Austenite Transformation-Induced Plasticity Steel. Metallurgical and Materials Transactions A, v. 42, n. 12, p. 3691-3702, 27 abr. 2011.

188. HAN, H. N. et al. Design method for TRIP-aided multiphase steel based on a microstructure-based modelling for transformation-induced plasticity and mechanically induced martensitic transformation. Materials Science and Engineering A, v. 499, n. 1-2, p. 462-468, 2009.

189. YOUNG, C. H.; BHADESHIA, H. K. D. H. Strength of mixtures of bainite and martensite. Materials Science and Technology, v. 10, n. 3, p. 209-214, 1994.

190. HASE, K.; GARCIA-MATEO, C.; BHADESHIA, H. K. D. H. Bainite formation influenced by large stress. Materials Science and Technology, v. 20, n. 12, p. 1499-1505, 2004.

191. HELL, J.-C. et al. Microstructure - Properties Relationships in Carbide-free Bainitic Steels. ISIJ International, v. 51, n. 10, p. 1724-1732, 2011.

192. CORNIDE, J. et al. Distribution of Dislocations in Nanostructured Bainite. Solid State Phenomena, v. 172-174, p. 117-122, 2011.

193. GONG, W. et al. Effect of prior martensite on bainite transformation in nanobainite steel. Acta Materialia, v. 85, p. 243-249, 2015.

194. CABAllerO, F. G.; GARCIA-MATEO, C.; MILLER, M. K. Design of novel 
bainitic steels: Moving from ultrafine to nanoscale structures. Jom, v. 66, n. 5, p. 747-755, 2014.

195. SANTOFIMIA, M. J.; ZHAO, L.; SIETSMA, J. Microstructural evolution of a lowcarbon steel during application of quenching and partitioning heat treatments after partial austenitization. Metallurgical and Materials Transactions A: Physical Metallurgy and Materials Science, v. 40, n. 1, p. 46-57, 2009.

196. SANTOFIMIA, M. J. et al. Microstructural development during the quenching and partitioning process in a newly designed low-carbon steel. Acta Materialia, v. 59, n. 15, p. 6059-6068, 2011.

197. STEINEDER, K. et al. Comparative Investigation of Phase Transformation Behavior as a Function of Annealing Temperature and Cooling Rate of Two Medium-Mn Steels. Steel Research International, v. 86, n. 10, p. 1179-1186, 2015.

198. GRAJCAR, A. et al. Microstructural Features of Strain-Induced Martensitic Transformation in Medium-Mn Steels with Metastable Retained Austenite. Archives of Metallurgy and Materials, v. 59, n. 4, p. 12-14, 2014.

199. AYDIN, H. et al. Development of 3rd generation AHSS with medium Mn content alloying compositions. Materials Science and Engineering: A, v. 564, p. 501-508, mar. 2013.

200. BARDELCIK, A.; WORSWICK, M. J.; WELLS, M. A. The influence of martensite, bainite and ferrite on the as-quenched constitutive response of simultaneously quenched and deformed boron steel - Experiments and model. Materials \& Design, v. 55, p. 509-525, mar. 2014.

201. KOISTINEN, D. P.; MARBURGER, R. E. A general equation prescribing the extent of the austenite-martensite transformation in pure iron-carbon alloys and plain carbon steels. Acta Metallurgica, v. 7, p. 59-60, 1959.

202. VAN BOHEMEN, S. M. C. Bainite and martensite start temperature calculated with exponential carbon dependence. Materials Science and Technology, v. 28, n. 4, p. 487-495, 2012.

203. ANDREWS, K. . Empirical Formulae for the Calculation of Some Transformation Temperatures. Journal of the Iron and Steel Institute, v. 203, p. 721-727, 1965.

204. RIZZO, F. C. et al. Quenching and Partitioning of Ni-Added High Strength Steels. Materials Science Forum, v. 539-543, p. 4476-4481, 2007.

205. CLARKE, A. J. et al. Influence of carbon partitioning kinetics on final austenite fraction during quenching and partitioning. Scripta Materialia, v. 61, n. 2, p. 149-152, jul. 2009.

206. DE KNIJF, D. et al. Orientation dependence of the martensite transformation in a quenched and partitioned steel subjected to uniaxial tension. Journal of Applied Crystallography, v. 47, n. 4, p. 1261-1266, 19 jul. 2014.

207. DIEGO-CALDERÓN, I. DE et al. Effect of Q\&P parameters on microstructure development and mechanical behaviour of Q\&P steels. Revista de Metalurgia, v. 51, n. 1, p. $1-12,2015$.

208. DE KNIJF, D. et al. Effect of fresh martensite on the stability of retained austenite in quenching and partitioning steel. Materials Science and Engineering A, v. 615, p. 107-115, 2014.

209. DICKSON, M. J. Signific\%Ance of Texture Parameters in Phase Analysis By X-Ray Diffraction. Journal of Applied Crystallography, v. 2, p. 176-180, 1969.

210. FIELDING, L. C. D. et al. Synchrotron analysis of toughness anomalies in nanostructured bainite. Acta Materialia, v. 105, p. 52-58, 2016.

211. NIKRAVESH, M.; NADERI, M.; AKBARI, G. H. Influence of hot plastic deformation and cooling rate on martensite and bainite start temperatures in 22MnB5 steel. Materials Science and Engineering: A, v. 540, p. 24-29, abr. 2012. 
212. WANG, H.-Z. et al. Effect of hot deformation of austenite on martensitic transformation in high manganese steel. Journal of Alloys and Compounds, v. 558, p. 26-33, maio 2013.

213. HE, B. B.; XU, W.; HUANG, M. X. Increase of martensite start temperature after small deformation of austenite. Materials Science and Engineering A, v. 609, p. 141-146, 2014.

214. HAN, Q. et al. Suppression of Ms temperature by carbon partitioning from carbonsupersaturated ferrite to metastable austenite during intercritical annealing. Materials and Design, v. 51, p. 409-414, 2013.

215. ZHANG, M. et al. Author's Accepted Manuscript Austenite deformation behaviour and effect of ausforming process on starting martensite microstructure in medium-carbon $\mathrm{Si}-$ Al-rich alloy steel. 2013.

216. LUO, H. et al. Effect of Intercritical Deformation on Bainite Formation in Alcontaining TRIP Steel. ISIJ International, v. 43, n. 8, p. 1219-1227, 2003.

217. GARCIA-MATEO, C. et al. Estimation of dislocation density in bainitic microstructures using high-resolution dilatometry. Scripta Materialia, v. 61, n. 9, p. 855-858, nov. 2009.

218. FAN, D. W. et al. Influence of Isothermal Deformation Conditions on The Mechanical Properties of 22MnB5 HPF Steel. Steel Research International, v. 81, n. 4, p. 292-298, abr. 2010.

219. YI, H. L.; LEE, K. Y.; BHADESHIA, H. K. D. H. Mechanical stabilisation of retained austenite in $\delta$-TRIP steel. Materials Science and Engineering A, v. 528, n. 18, p. 5900-5903, 2011.

220. HE, B. B.; HUANG, M. X. On the Mechanical Stability of Austenite Matrix After Martensite Formation in a Medium Mn Steel. Metallurgical and Materials Transactions A, v. 47, n. 7, p. 3346-3353, 2016.

221. GHOSH, C. et al. The dynamic transformation of deformed austenite at temperatures above the Ae3. Acta Materialia, v. 61, n. 7, p. 2348-2362, 2013.

222. HURLEY, P. J.; MUDDLE, B. C.; HODGSON, P. D. The production of ultrafine ferrite during hot torsion testing of a $0.11 \mathrm{wt}$ pct $\mathrm{C}$ steel. Metallurgical and Materials Transactions A, v. 33, n. 9, p. 2985-2993, 2002.

223. HSU (XU ZUYAO), T. Y. Additivity hypothesis and effects of stress on phase transformations in steel. Current Opinion in Solid State and Materials Science, v. 9, n. 6, p. 256-268, 2005.

224. SHI, Z. et al. Effect of non-isothermal deformation of austenite on phase transformation and microstructure of 22SiMn2TiB steel. Materials Science and Engineering: A, v. 535, p. 290-296, fev. 2012.

225. SOMANI, M. C. et al. Designing a Novel DQ\&P Process through Physical Simulation Studies. Materials Science Forum, v. 762, p. 83-88, jul. 2013.

226. TIRUMALASETTY, G. K. et al. Deformation-induced austenite grain rotation and transformation in TRIP-assisted steel. Acta Materialia, v. 60, n. 3, p. 1311-1321, 2012.

227. THOMAS, G. et al. Application of electron backscatter diffraction techniques to quenched and partitioned steels. Microscopy and microanalysis, v. 17, n. 3, p. 368-373, 2011.

228. SEOL, J. B. et al. Atomic scale effects of alloying, partitioning, solute drag and austempering on the mechanical properties of high-carbon bainitic-austenitic TRIP steels. Acta Materialia, v. 60, n. 17, p. 6183-6199, 2012.

229. HIDAKA, K.; TAKEMOTO, Y.; SENUMA, T. Microstructural Evolution of Carbon Steels in Hot Stamping Processes. ISIJ International, v. 52, n. 4, p. 688-696, 2012.

230. SHEN, Y. F. et al. Effects of retained austenite volume fraction, morphology, and carbon content on strength and ductility of nanostructured TRIP-assisted steels. Materials Science and Engineering: A, v. 636, p. 551-564, 2015. 
231. RASOULI, D. et al. Effect of cooling rate on the microstructure and mechanical properties of microalloyed forging steel. Journal of Materials Processing Technology, v. 206, n. 1-3, p. 92-98, set. 2008.

232. SANTOFIMIA, M. J. et al. Microstructural analysis of martensite constituents in quenching and partitioning steels. Materials Characterization, v. 92, p. 91-95, jun. 2014.

233. SUN, J. et al. Study of microstructural evolution, microstructure-mechanical properties correlation and collaborative deformation-transformation behavior of quenching and partitioning (Q\&P) steel. Materials Science \& Engineering A, v. 596, p. 89-97, 2014.

234. DE DIEGO-CALDERÓN, I. et al. Global and local deformation behavior and mechanical properties of individual phases in a quenched and partitioned steel. Materials Science and Engineering: A, v. 630, p. 27-35, abr. 2015.

235. MISRA, R. D. K. et al. Ultrahigh strength martensite-austenite dual-phase steels with ultrafine structure: The response to indentation experiments. Materials Science and Engineering: A, v. 560, p. 693-699, jan. 2013.

236. FURNÉMONT, Q. et al. On the measurement of the nanohardness of the constitutive phases of TRIP-assisted multiphase steels. Materials Science and Engineering A, v. 328, p. 3-20, 2002.

237. RIOS, P. R.; PADILHA, A. F. Transformações de fase. São Paulo: Artliber Editora Ltda, 2007.

238. HE, B. B.; HUANG, M. X. Revealing the Intrinsic Nanohardness of Lath Martensite in Low Carbon Steel. Metallurgical and Materials Transactions A, v. 46, n. 2, p. 688-694, 4 dez. 2014.

239. BERNIER, N. et al. Crystallographic Reconstruction Study of the Effects of Finish Rolling Temperature on the Variant Selection During Bainite Transformation in C-Mn HighStrength Steels. Metallurgical and Materials Transactions A, v. 45, n. 13, p. 5937-5955, 2014.

240. CHAOUCH, D.; GUESSASMA, S.; SADOK, A. Finite Element simulation coupled to optimisation stochastic process to assess the effect of heat treatment on the mechanical properties of 42CrMo4 steel. Materials \& Design, v. 34, p. 679-684, fev. 2012.

241. NAYAK, S. S. et al. Microstructure-hardness relationship in quenched and partitioned medium-carbon and high-carbon steels containing silicon. Materials Science and Engineering: A, v. 498, n. 1-2, p. 442-456, dez. 2008.

242. MILEIKO, S. The Tensile Strength and Ductility of Continuous Fibre Composites. Journal of Materials Science, v. 4, p. 974-977, 1969.

243. DAVIES, R. G. Influence of martensite composition and content on the properties of dual phase steels. Metallurgical Transactions A, v. 9, n. 5, p. 671-679, 1978.

244. DAVIES, R. The mechanical properties of zero-carbon ferrite-plus-martensite structures. Metallurgical Transactions A, v. 9, n. March, p. 451-455, 1978.

245. FROMMEYER, G.; BRÜX, U.; NEUMANN, P. Supra-Ductile and High-Strength Manganese-TRIP/TWIP Steels for High Energy Absorption Purposes. ISIJ International, v. 43, n. 3, p. 438-446, 2003.

246. LI, Z. C. et al. Microstructural evolution and deformation behavior in the Fe-(6, 8.5)Mn-3Al-0.2C TRIP steels. Materials Science and Engineering A, v. 672, p. 161-169, 2016.

247. LI, Z. C. et al. Mechanical properties and deformation behavior in hot-rolled 0.2C1.5/3Al-8.5Mn-Fe TRIP steel: The discontinuous TRIP effect. Materials Science and Engineering A, v. 673, p. 63-72, 2016.

248. DAVIES, R. G. The deformation behavior of a vanadium-strengthened dual phase steel. Metallurgical and Materials Transactions A, v. 9, n. 1, p. 41-52, 1978.

249. OLSON, G. B. Transformation Plasticity and the Stability of Plastic Flow. In: 
KRAUSS, G. (Ed.). . Deformation, Processing and Structure. Ohio: ASM International, 1984. p. 391-424.

250. CHOI, K. S. et al. Influence of various material design parameters on deformation behaviors of TRIP steels. Computational Materials Science, v. 50, n. 2, p. 720-730, 2010.

251. WANG, C. et al. Multi-phase microstructure design of a novel high strength TRIP steel through experimental methodology. Materials Science and Engineering: A, v. 610, p. 436$444,2014$.

252. BLONDÉ, R. et al. The mechanical stability of retained austenite in low-alloyed TRIP steel under shear loading. Materials Science and Engineering A, v. 594, p. 125-134, 2014.

253. CAI, Z. H. et al. Austenite stability and deformation behavior in a cold-rolled transformation-induced plasticity steel with medium manganese content. Acta Materialia, v. 84, p. 229-236, 2015.

254. JIMENEZ-MELERO, E. et al. Characterization of individual retained austenite grains and their stability in low-alloyed TRIP steels. Acta Materialia, v. 55, n. 20, p. 6713-6723, dez. 2007.

255. MATSUOKA, Y. et al. Effect of Grain Size on Thermal and Mechanical Stability of Austenite in Metastable Austenitic Stainless Steel. ISIJ International, v. 53, n. 7, p. 12241230, 2013.

256. TIMOKHINA, I. B.; HODGSON, P. D.; PERELOMA, E. V. Effect of microstructure on the stability of retained austenite in transformation-induced-plasticity steels. Metallurgical and Materials Transactions A, v. 35, n. August, p. 2331-2341, 2004.

257. KRUIJVER, S. et al. In situ observations on the austenite stability in TRIP-steel during tensile testing. International Conference on TRIP-Aided High Strenght Ferrous Alloys, p. 25-30, 2002.

258. BLONDÉ, R. et al. Mechanical stability of individual austenite grains in TRIP steel studied by synchrotron X-ray diffraction during tensile loading. Materials Science and Engineering: A, v. 618, p. 280-287, nov. 2014.

259. MATSUDA, H. et al. Effect of Retained Austenite Stability on Mechanical Properties of 590MPa Grade TRIP Sheet Steels. Materials Science Forum, v. 638-642, p. 3374-3379, jan. 2010.

260. SHEN, Y. F. et al. Improved ductility of a transformation-induced-plasticity steel by nanoscale austenite lamellae. Materials Science and Engineering: A, v. 583, p. 1-10, out. 2013.

261. GOUNÉ, M. et al. Unambiguous carbon partitioning from martensite to austenite in $\mathrm{Fe}-\mathrm{C}-\mathrm{Ni}$ alloys during quenching and partitioning. Scripta Materialia, v. 68, n. 12, p. 1004 1007, jun. 2013.

262. JIANG, H. et al. Element distribution and diffusion behavior in Q\&P steel during partitioning. International Journal of Minerals, Metallurgy, and Materials, v. 20, n. 11, p. 1050-1059, 20 nov. 2013.

263. SEO, E. J.; CHO, L.; COOMAN, B. C. DE. Kinetics of the partitioning of carbon and substitutional alloying elements during quenching and partitioning ( Q \& P ) processing of medium Mn steel. Acta Materialia, v. 107, p. 354-365, 2016.

264. THOMAS, G. A. et al. Carbon Atom Re-Distribution during Quenching and Partitioning. v. 54, n. 12, p. 2900-2906, 2014.

265. TOJI, Y.; MIYAMOTO, G.; RAABE, D. Carbon partitioning during quenching and partitioning heat treatment accompanied by carbide precipitation. Acta Materialia, v. 86, p. 137-147, mar. 2015.

266. CLARKE, A. J. et al. Atomic and nanoscale chemical and structural changes in quenched and tempered 4340 steel. Acta Materialia, v. 77, p. 17-27, 2014.

267. MOHAMADIZADEH, A. et al. The effect of strain induced ferrite transformation on 
the microstructural evolutions and mechanical properties of a TRIP-assisted steel. Materials Science and Engineering: A, v. 607, n. 0, p. 621-629, 2014.

268. W. POLING, V. SAVIC, L.G. HECTOR, JR., A.K. SACHDEV, X. HU, A. DEVARAJ, X. SUN, F. A.-F. Combined Synchrotron X-Ray Diffraction and Digital Image Correlation Technique for Measurement of Austenite Transformation with Strain in TRIPAssisted Steels. SAE International, p. 1-5, 2016.

269. ZHANG, L.-Q.; TAN, W.-F.; LI, L.-X. Experimental Investigation of Hot Stamping of Ultra High Strength Steel. Steel Research International, v. 85, n. 10, p. 1459-1464, 7 out. 2014.

270. TIMOKHINA, I. B. et al. Nanoscale microstructural characterization of a nanobainitic steel. Acta Materialia, v. 59, n. 14, p. 5511-5522, 2011.

271. TIMOKHINA, I. B. et al. Characterization of the Bake-hardening Behavior of Transformation Induced Plasticity and Dual-phase Steels Using Advanced Analytical Techniques. ISIJ International, v. 50, n. 4, p. 574-582, 2010.

272. HUTCHINSON, B. et al. Microstructures and hardness of as-quenched martensites (0.1-0.5\%C). Acta Materialia, v. 59, n. 14, p. 5845-5858, 2011.

273. QU, H. Advanced High Strength Steel through Paraequilibrium Carbon Partitioning and Austenite Stabilization. [s.1.] Case Western Reserve University, 2013.

274. CABAllERO, F. G.; GARCIA-MATEO, C.; MILLER, M. K. Modern steels at atomic and nanometre scales. Materials Science and Technology, v. 31, n. 7, p. 764-772, 2015.

275. CHEN, J. et al. Transmission Electron Microscopy and Nanoindentation Study of the Weld Zone Microstructure of Diode-Laser-Joined Automotive Transformation-Induced Plasticity Steel. Metallurgical and Materials Transactions A, v. 39, n. 3, p. 593-603, 5 fev. 2008.

276. GOUNÉ, M. et al. Overview of the current issues in austenite to ferrite transformation and the role of migrating interfaces therein for low alloyed steels. Materials Science and Engineering: R: Reports, v. 92, p. 1-38, 2015.

277. SUN, S.; PUGH, M. Manganese Partitioning in Dual-Phase Steel During Annealing. Materials Science and Engineering: A, v. 276, p. 167-174, 2000.

278. BABU, S. S. et al. In-situ observations of lattice parameter fluctuations in austenite and transformation to bainite. Metallurgical and Materials Transactions A, v. 36, n. 12, p. 3281-3289, 2005.

279. RUHL, R. .; COHEN, M. Splat Quenching of Iron-Carbon Alloys. Transactions of The Metallurgical Society of AIME, v. 245, p. 241-251, 1969.

280. SUGIMOTO, K. . et al. Effects of Volume Fraction and Stability of TRIP-aided of Retained Austenite on Ductility Dual-phase Steels mm mm. ISIJ International, v. 32, n. 12, p. 1311-1318, 1992.

281. BELLHOUSE, E. M.; MCDERMID, J. R. Effect of Continuous Galvanizing Heat Treatments on the Microstructure and Mechanical Properties of High Al-Low Si Transformation Induced Plasticity Steels. Metallurgical and Materials Transactions A, v. 41, n. 6, p. 1460-1473, 19 fev. 2010.

282. LEE, S.-J.; LEE, Y.-K. Quantitative analyses of ferrite lattice parameter and solute $\mathrm{Nb}$ content in low carbon microalloyed steels. Scripta Materialia, v. 52, n. 10, p. 973-976, maio 2005.

283. ONINK, M. et al. The Lattice Parameters of Austenite and Ferrite in Fe-C Alloys as Functions of Carbon Concentration and Temperature. Scripta Metallurgica et Materialia, v. 29, p. 1011-1016, 1993.

284. XU, Y. et al. Microstructure evolution and mechanical properties of a hot-rolled directly quenched and partitioned steel containing proeutectoid ferrite. Materials Science and 
Engineering: A, v. 607, p. 460-475, jun. 2014.

285. HUANG, X. et al. Effect of a quenching - long partitioning treatment on the microstructure and mechanical properties of a $0.2 \mathrm{C} \%$ bainitic steel. Journal of Materials Processing Technology, v. 222, p. 181-187, 2015.

286. NADERI, M. et al. Analysis of microstructure and mechanical properties of different high strength carbon steels after hot stamping. Journal of Materials Processing Technology, v. 211, n. 6, p. 1117-1125, jun. 2011.

287. NADERI, M. et al. A Numerical and Experimental Investigation into Hot Stamping of Boron Alloyed Heat Treated Steels. p. 77-84, 2008.

288. LIU, G. et al. Fast-heating for intercritical annealing of cold-rolled quenching and partitioning steel. Materials Science and Engineering: A, v. 669, p. 387-395, 2016.

289. YAN, S. et al. Microstructural evolution and mechanical properties of low-carbon steel treated by a two-step quenching and partitioning process. Materials Science and Engineering: A, v. 640, p. 137-146, 2015.

290. ZHANG, K. et al. A new effect of retained austenite on ductility enhancement in highstrength quenching-partitioning-tempering martensitic steel. Materials Science and Engineering: A, v. 528, n. 29-30, p. 8486-8491, nov. 2011.

291. ZOU, Y. et al. Austenite stability and its effect on the toughness of a high strength ultra-low carbon medium manganese steel plate. Materials Science and Engineering: A, v. 675, p. 153-163, 2016.

292. SEOL, J. B. et al. Atomic scale effects of alloying, partitioning, solute drag and austempering on the mechanical properties of high-carbon bainitic-austenitic TRIP steels. Acta Materialia, v. 60, n. 17, p. 6183-6199, 2012.

293. TAMURA, I. Deformation-induced martensitic transformation and transformationinduced plasticity in steels. Metal Science, v. 16, n. 5, p. 245-253, 1982.

294. FALLEIROS, I. G.; CAMPOS, M. Nucleação da recristalização. In: Textura e Relações de Orientação. São Paulo: EPUSP, 2001. p. 39-48.

295. Oxford Instruments Analytical - technical briefing. Electron Backscattered Diffraction Explained. http://www.ebsd.com. Acesso em: 02 dez. 2016 